\title{
Emergency Preparedness Source Term Development for the Office of Nuclear Material Safety and Safeguards-Licensed Facilities
}

Manuscript Completed: July 1984

Date Published: August 1984

Prepared by

S. L. Sutter, J. Mishima, M. Y. Ballinger, C. G. Lindsey

Pacific Northwest Laboratory

Richland, WA 99352

Prepared for

Division of Fuel Cycle and Material Safety

Office of Nuclear Material Safety and Safeguards

U.S. Nuclear Regulatory Commission

Washington, D.C. 20555

NRC FIN B2218

\section{DISCLAIMER}

This report was prepared as an account of work sponsored by an agency of the United States Government. Neither the United States Government nor any agency thereof, nor any of their employees, makes any warranty, express or implied, or assumes any legal liability or responsibility for the accuracy, completeness, or usefulness of any information, apparatus, product, or process disclosed, or represents that its use would not infringe privately owned rights. Reference herein to any specific commercial product, process, or service by trade name, trademark, manufacturer, or otherwise does not necessarily constitute or imply its endorsement, recommendation, or favoring by the United States Government or any agency thereof. The views and opinions of authors expressed herein do noi necessarily state or reflect those of the United States Government or any agency thereof.

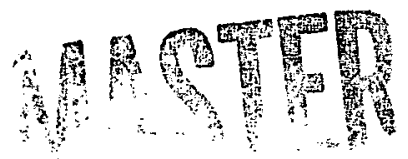




\section{DISCLAIMER}

This report was prepared as an account of work sponsored by an agency of the United States Government. Neither the United States Government nor any agency Thereof, nor any of their employees, makes any warranty, express or implied, or assumes any legal liability or responsibility for the accuracy, completeness, or usefulness of any information, apparatus, product, or process disclosed, or represents that its use would not infringe privately owned rights. Reference herein to any specific commercial product, process, or service by trade name, trademark, manufacturer, or otherwise does not necessarily constitute or imply its endorsement, recommendation, or favoring by the United States Government or any agency thereof. The views and opinions of authors expressed herein do not necessarily state or reflect those of the United States Government or any agency thereof. 


\section{DISCLAIMER}

Portions of this document may be illegible in electronic image products. Images are produced from the best available original document. 
○

$\ominus$

. 
In order to es ablish requirements for emergency preparedness plans at facilities licensed by the Office of Nuclear Materials Safety and Safeguards, the Nuclear Regulatory Commission (NRC) needs to develop source terms (the amount of material made airborne) in accidents. These source terms are used to estimate the potential public doses from the events, which, in turn, will be used to judge whether emergency preparedness plans are needed for a particular type of facility. Pacific Northwest Laboratory is providing the NRC with source terms by developing several accident scenarios for eleven types of fuel cycle and by-product operations. Several scenarios are developed for each operation, leading to the identification of the maximum release considered for emergency preparedness planning (MREPP) scenario.

The MREPP scenarios postulated were of three types: fire, tornado, and criticality. Fire was significant at oxide fuel fabrication, UF 6 production, radiopharmaceutical manufacturing, radiopharmacy, sealed source manufacturing, waste warehousing, and university research and development facilities. Tornadoes were MREPP events for uranium mills and plutonium contaminated facilities, and criticalities were significant at nonoxide fuel fabrication and nuclear research and development facilities. Techniques for adjusting the MREPP release to different facilities are also described. 


\section{CONTENTS}

ABSTRACT

ABBREVIATIONS, ACRONYMS, AND INITIALISMS $\ldots \ldots \ldots \ldots \ldots \ldots \ldots \ldots \ldots \ldots \ldots \ldots$

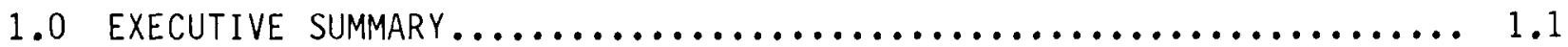

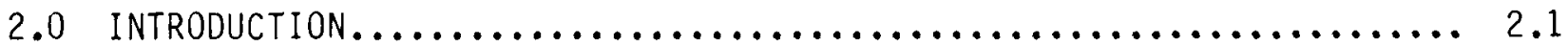

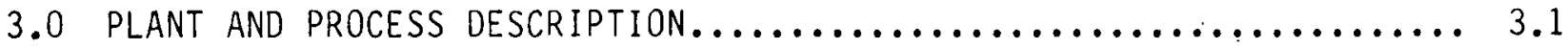

3.1 URANIUM FUEL FABRICATION PLANTS $($ OXIDE FUEL) $\ldots \ldots \ldots \ldots \ldots \ldots \ldots . . . . .$.

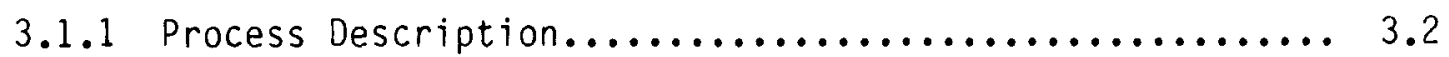

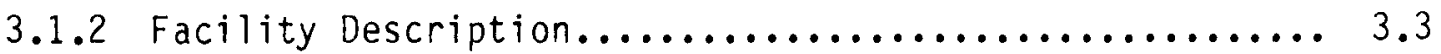

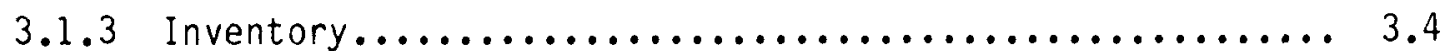

3.2 URANIUM FUEL FABRICATION PLANTS (NONOXIDE FUEL) $\ldots \ldots \ldots \ldots \ldots \ldots$

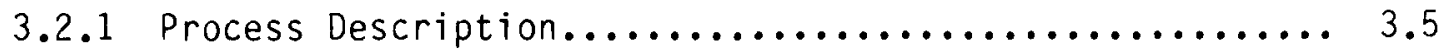

3.2 .2 Facility Description......................... 3.6

3.2 .3 Inventory $\ldots \ldots \ldots \ldots \ldots \ldots \ldots \ldots \ldots \ldots \ldots \ldots \ldots \ldots \ldots \ldots \ldots$

3.3 URANIUM HEXAFLUORIDE PRODUCTION PLANTS $\ldots \ldots \ldots \ldots \ldots \ldots \ldots \ldots \ldots . \ldots$

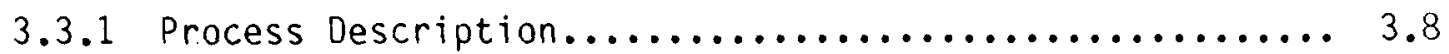

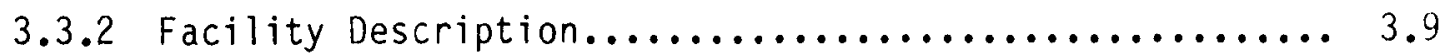

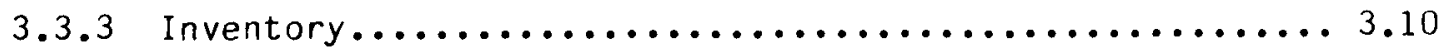

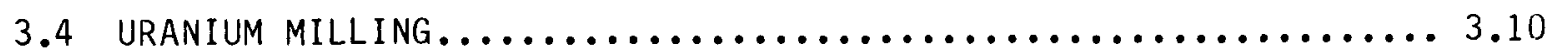

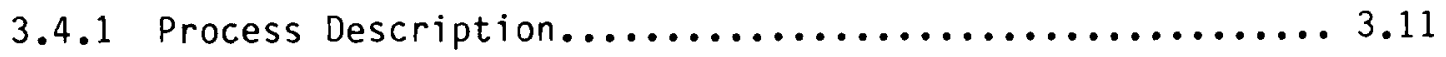

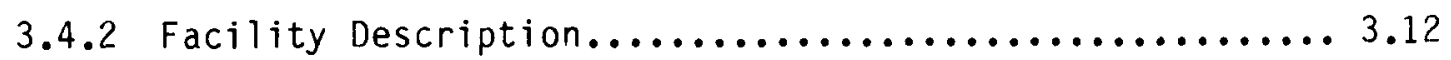

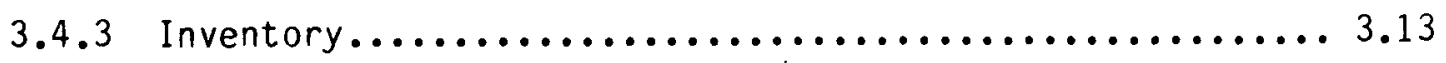

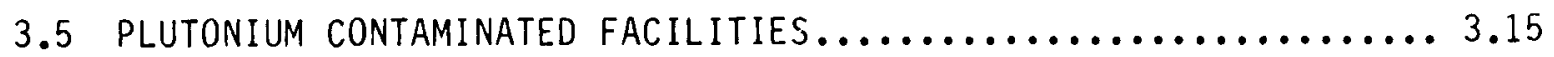

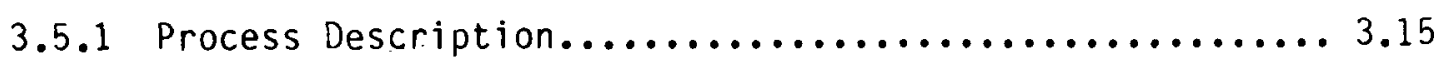

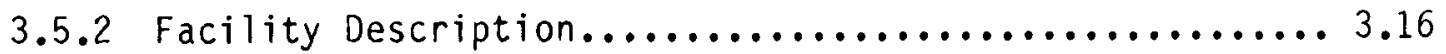




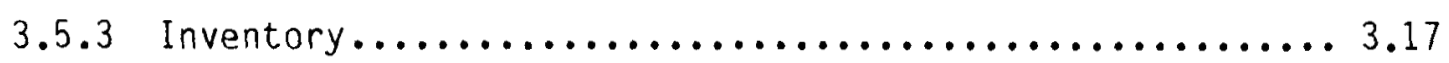

3.6 RADIOPHARMACEUTICAL MANUFACTURING $\ldots \ldots \ldots \ldots \ldots \ldots \ldots \ldots \ldots \ldots \ldots \ldots$

3.6.1 Process Description............................ 3.18

3.6.2 Facility Description............................. 3.19

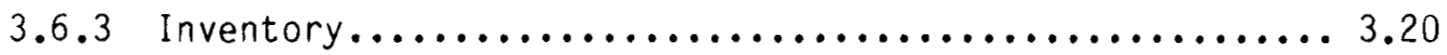

3.7 RADIOPHARMACY................................... 3.22

3.7.1 Process Description........................... 3.22

3.7.2 Facility Description........................... 3.23

3.7 .3 Inventory $\ldots \ldots \ldots \ldots \ldots \ldots \ldots \ldots \ldots \ldots \ldots \ldots \ldots \ldots \ldots \ldots \ldots \ldots \ldots \ldots \ldots, 23$

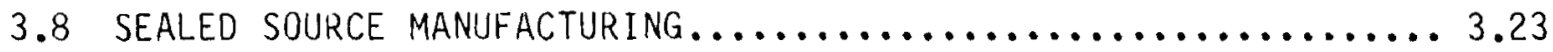

3.8 .1 Process Description............................. 3.25

3.8.2 Facility Description................................. 3.26

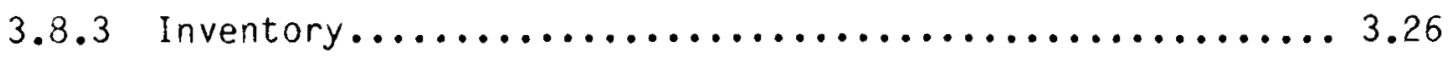

3.9 RESEARCH AND DEVELOPMENT OF NUCLEAR rUELS $\ldots \ldots \ldots \ldots \ldots \ldots \ldots, 3.27$

3.9.1 Process Description........................... 3.27

3.9.2 Facility Description.............................. 3.28

3.9 .3 Inventory.................................... 3.29

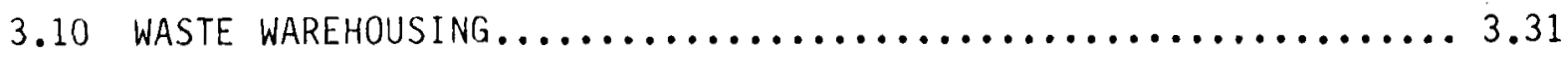

3.10 .1 Process Description........................... 3.31

3.10 .2 Facility Description........................ 3.32

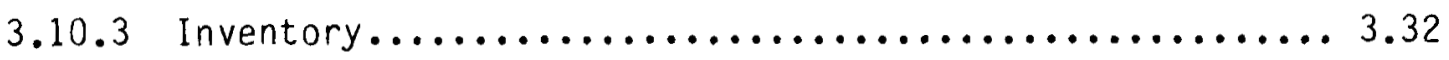

3.11 UNIVERSITY RESEARCH AND DEVELOPMENT $\ldots \ldots \ldots \ldots \ldots \ldots \ldots \ldots \ldots . . \ldots \ldots$

3.11.1 Process Description........................... 3.33

3.11 .2 Facility Description............................ 3.35

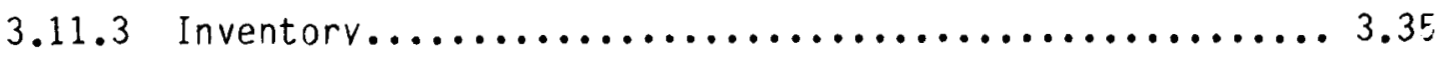


4.0 ACCIDEnT SCEnARI0................................... 4

4.1 URANIUM FUEL FABRICATION PLANTS (OXIDE FUEL) $\ldots \ldots \ldots \ldots \ldots \ldots, 4.1$

4.1.1 Potential Accident Scenarios...................... 4.1

4.1.2 Uraniuim Fuel Fabrication Plants MREPP Scenario........ 4.8

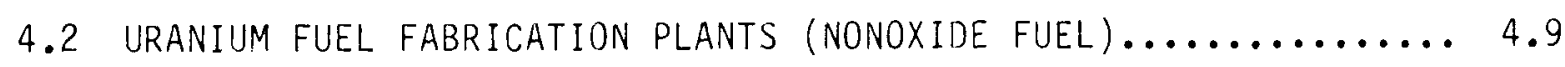

4.2.1 Potential Accident Scenarios..................... 4.9

4.2.2 Uranium Fuel Fabrication Plants MREPP Scenario......... 4.14

4.3 URANiUM HEXAFLUORIDE PRODUCTION...................... 4.15

4.3.1 Potential Accident Scenarios.................... 4.15

4.3.2 Uranium Hexafluoride Production MREPP Scenario........ 4.20

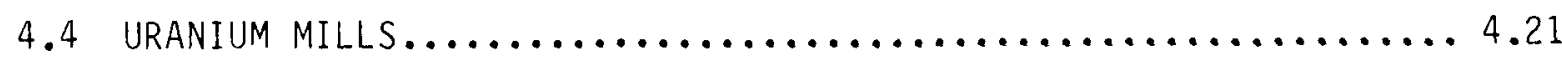

4.4.1 Potential Accident Scenarios.................... 4.21

4.4.2 Uranium Mil1 MREPP Scenario...................... 4.23

4.5 Plutonium contaminated facilities $\ldots \ldots \ldots \ldots \ldots \ldots \ldots \ldots \ldots . .24 .24$

4.5.1 Potential Accident Scenarios..................... 4.24

4.5.2 Plutonium Contaminated Facility MREPP Scenario......... 4.26

4.6 RADIOPHARMACEUTICAL MANUFACTURING $\ldots \ldots \ldots \ldots \ldots \ldots \ldots \ldots \ldots . . \ldots \ldots$

4.6.1 Potential Accident Scenarios..................... 4.28

4.6.2 Radiopharmaceutical Manufacturing MREPP Scenario....... 4.36

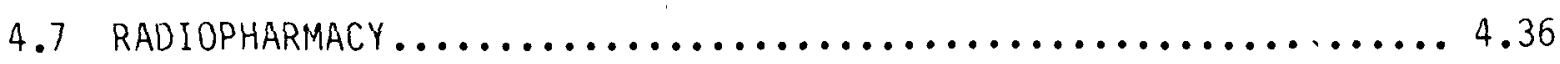

4.7.1 Potential Accident Scenarios..................... 4.37

4.7.2 Radiopharmacy MREPP Scenario.................... 4.39

4.8 SEAled SOURCE ManUfacturing $\ldots \ldots \ldots \ldots \ldots \ldots \ldots \ldots \ldots \ldots \ldots . . \ldots \ldots$

4.8.1 Potential Accident Scenarios.................... 4.40

4.8.2 Sealed Source Manufacturing MREPP Scenario........... 4.48

4.9 RESEARCh AND DEVELOPMENT OF NUCLEAR FUELS $\ldots \ldots \ldots \ldots \ldots \ldots \ldots .4 .48$ 
4.9.1 Potential Accident Scenarios..................... 4.48

4.9.2 Research and Development of Nuclear Fuels

MREPP Scenario............................... 4.53

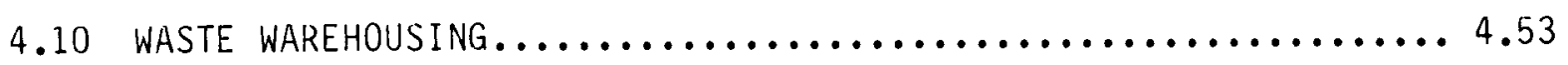

4.10.1 Potential Accident Scenarios................... 4.54

4.10 .2 Waste Warehousing MREPP Scenario................ 4.56

4.11 UNIVERSitY RESEARCH AND DEVELOPMENT $\ldots \ldots \ldots \ldots \ldots \ldots \ldots \ldots . .56$

4.11.1 Potential Accident Scenarios..................... 4.57

4.11.2 University Research and Development MREPP Scenario.... 4.61

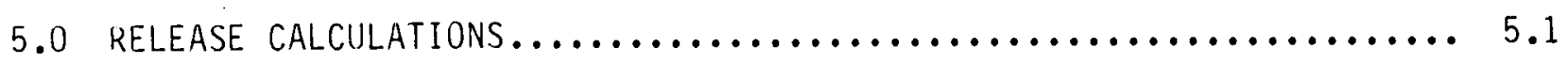

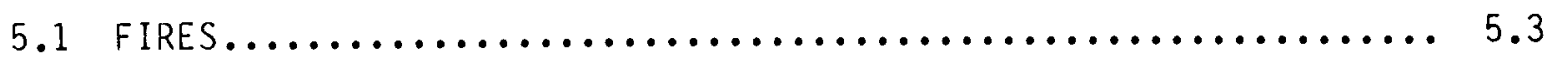

5.1 .1 Facility Fire.............................. 5.3

5.1 .2 Loading Dock Fire........................... 5.17

5.2 TORNADO......................................... 5.22

5.2 .1 Uranium Milling............................ 5.28

5.2 .2 Plutonium Contaminated Facilities................ 5.31

5.3 CRITICALITY........................................ 53

5.3 .1 Uranium Fuel Fabrication....................... 5.33

5.3.2 Research and Development of Nuclear Fuel............ 5.35

6.0 BIOBLIOGRAPHY $\ldots \ldots \ldots \ldots \ldots \ldots \ldots \ldots \ldots \ldots \ldots \ldots \ldots \ldots \ldots \ldots \ldots \ldots \ldots \ldots \ldots$

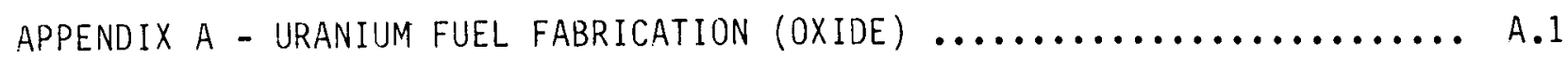

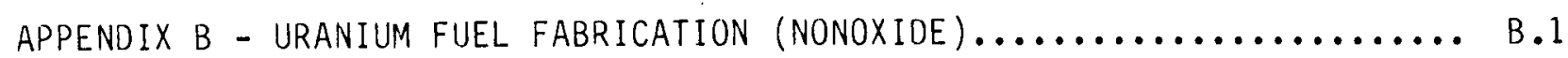

APPENDIX $C$ - URANIUUM HEXAFLUORIDE PRODUCTION..................... C. 1

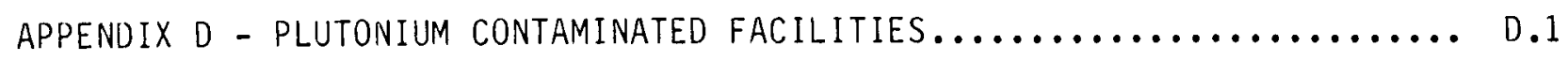

APPENDIX E - RADIOPHARMACEUTICAL MANUFACTURING................... E.I

APPENDIX F - RADIOPHARMACY................................ F.1 


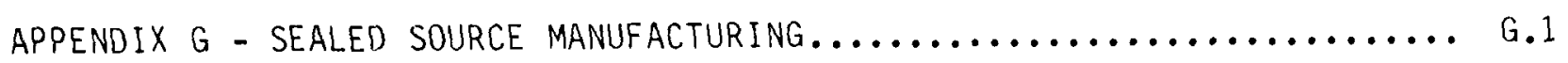
APPENDIX $H$ - RESEARCH ANO DEVELOPMENT OF NUCLEAR FUELS .............. H.1

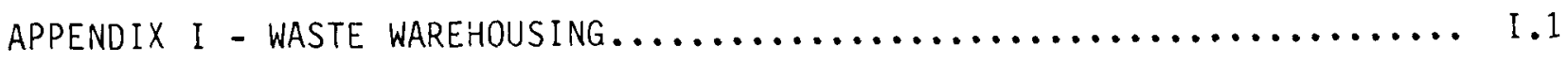
APPENDIX $J$ - UNIVERSITY RESEARCH AND DEVELOPMENT ................. J.1

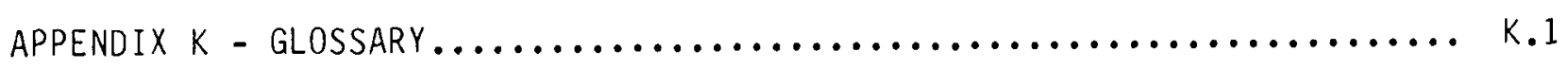


○

$\bullet$ 
5.1 Scaled Explosion Yields................................. 5.7

5.2 The Basic Relationship Between Overpressure and Scaled Range...... 5.8

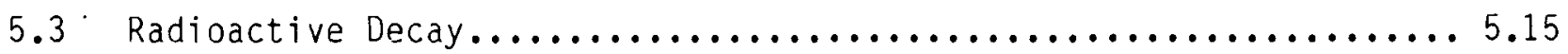

5.4 Flux Incident on Unit Area from Various Fires................. 5.19

5.5 Distribution of Tornadoes in the United States, Total Tornadoes $1955-1967 \ldots \ldots \ldots \ldots \ldots \ldots \ldots \ldots \ldots \ldots \ldots \ldots \ldots \ldots \ldots . .23$

A.1 Babcock and Wilcox Commercial Nuclear Fuel Plant

Facility Diagram......................................... A.2

A.2 Location of Buildings and Facilities on Combustion

Engineering Hematite Plant Site......................... A.8

A.3 Combustion Engineering Windsor Site Facility Diagram...............12

A.4 Exxon Nuclear $U 0_{2}$ Building Diagram.........................16

A.5 Diagram of General Electric Wilmington Fuel

Manufacturing Building.................................. A.20

A.6 Detailed Site Plan for Westinghouse Electric Columbia Facility..... A.25

B.1 General Atomic Fuel Manufacturing Facility.................. B.3

B.2 General Atomic TRIGA Fuel Fabrication Building................ B.4

B.3 Fuel Fabrication Area of Rockwell International

Fuel Manufacturing Building................................ B

C.1 Site Plan for Allied Chemical UF 6 Plant, Metropolis, Illinois.................................... c.3

C.2 Facility Diagram of Kerr-McGee Sequoyah $U_{6}$ Plant.............. C.8

D.1 Babcock and Wilcox Parks Township Site Plutonium Plant........... D.2

D.2 Diagram of the Building 102 Main Floor, General Electric

Nuclear Center........................................... D.6

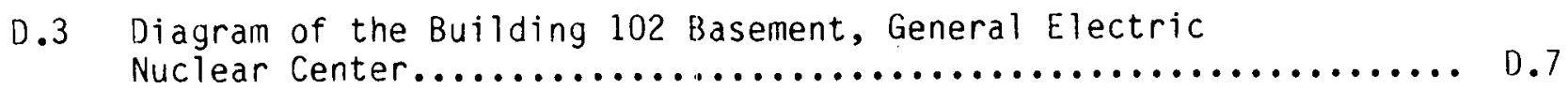

D.4 Floor Plans of Kerr-McGee Cirimarron Plant

Plutonium Storage Facility.................................. D.11 
D.5 Westinghouse Plutonium Fuel Development Facility -

General Plan........................................ D.14

E.1 Abbott Park Site Plan.................................. E.2

E.2 A Typical Iodination Laboratory at Abbott Laboratories............ E.3

E.3 New England Nuclear Buildings.......................... E.5

E.4 Plan of Fifth Floor at New England Nuclear Building............. E.6

E.5 New England Nuclear North Billerica Site Diagram................ E.12

E.6 Plan of the E. R. Squibb and Sons Site..................... E. 8

F.1 Facility Diagram of Nuclear Pharmacy at

G.1 575 Building at the $3 M$ Site............................ G.5

G.2 . Monsanto Site Plan.........................................15

G.3 Safety Light Site Plan....................................20

H.1 Building A of the Lynchburg Research Center................. H.4

H.2 Building B of the Lynchburg Research Center................... H.5

H.3 Building $C$ of the Lynchburg Research Center................. H.6

H.4 Building 020 Floor Plan, Rockwell NDFL.......................1

H.5 Building 055 Floor Plan, Rockwell NDFL.....................12

H.6 Waltz Mill Transfer Building Floor Plan........................15

H.7 Reactor Service Waltz Mill Building Floor Plan.................. H.17

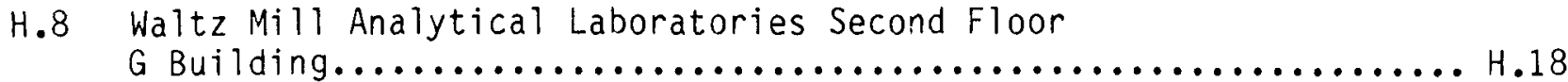

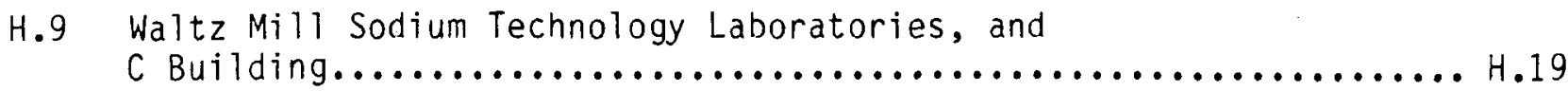

I.1 Atomic Disposal Waste Storage Facility.................... I.2

I.2 Interex Waste Storage Building......................... I.5

. J.1 MSU Clinical Center - Radiology Section...................... J.5 


\section{TABLES}

1.1 Summary Table of Releases from Accident Scenarios.............. 1.2

2.1 Directory of the Office of Nuclear Materials Safety and

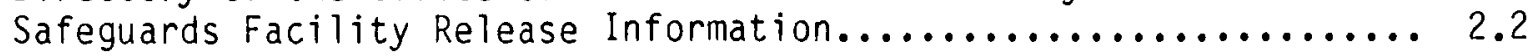

3.1 Chemical and Fuel Materials Found at UF 6 Production

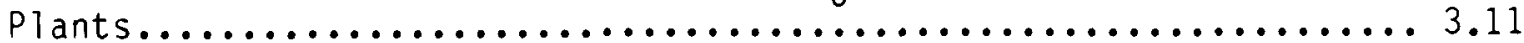

3.2 Information on Typical Uranium Mill Operations...................

3.3 Materials Used in Uranium Ore Processing.......................... 35

3.4 Typical Combustibles in Mixed 0xide Plants........................ 3.

3.5 Significant Inventories of Isotopes Licensed for

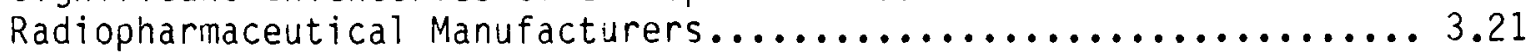

3.6 Representative Radiopharmacy Inventories......................... 34

3.7 Significant Maximum License Inventories at Sealed

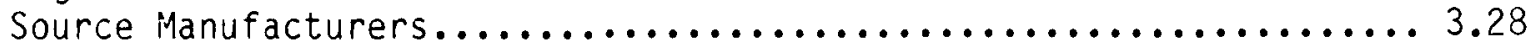

3.8 Radioactive Material Found as Sealed Sources or Analytical

Quantities at Nuclear Fuel Development Laboratories.............3.30

3.9 License Limits of Radioactive Material at University

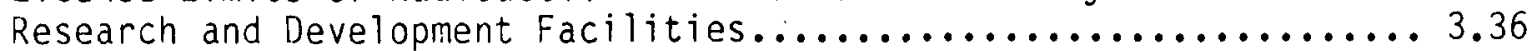

4.1 Radioactivity of Important Nuclides Released from a

Criticality Accident in a Uranium Fuel Fabrication

Plant.......................................... 4.7

4.2 Selected Isotopes Found in Radiopharmaceutical Manufaciuring

Facilities Grouped by Health Concern Based on Permissible

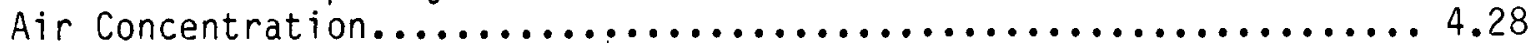

4.3 Suggested Fire Release Factors for Selected Isotopes Found

in Radiopharmaceutical Manufacturing Facilities................4.32

4.4. Selected Isotopes Found in Sẹaled Source Manufacturing

Facilities Grouped by Health Concern Based on Permissible

Air Concentrations..................................4.40

4.5 Fire Release Factors Developed for Selected Isotopes Found

in Sealed Source Manufacturing Facilities.................... 4.42

4.6 Release from Dropping a Heavy Item in Fuel Storage Pool........4.53 
4.7 Radioisotopes Associated with and Released from

Representative Drummed Waste in a Combustion/Explosion

Event.......................................... 4.57

4.8 Potential MREPP of Isotopes Potentially Involved in a

Major Fire at the Shipping/Receiving Department at a

University Research and Development Laboratory..............4.61

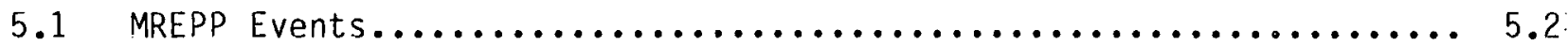

5.2 Potential Releases of Radionuclides Found in Significant

Amounts in Sealed Sources Manufacturing Plants............... 5.12

5.3 Half-Lives of Radioisotopes Potentially Available for

Accidental Fire Release of Drummed Waste.........................

5.4 F Scale and Corresponding Weighted Average Maximum

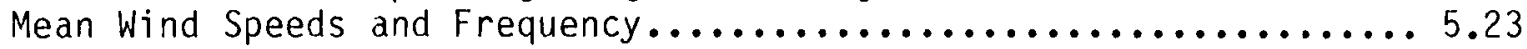

5.5 F2 Scale Tornado Damage for Several Structure Types............. 5.24

5.6 Fractional Airborne Release Factors.................... 5.26

5.7 Fujita Scale of Tornado Wind Intensity and Related

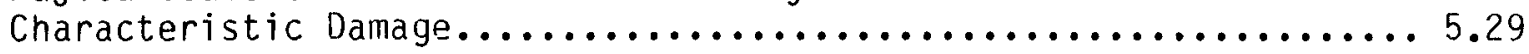

A.1 Ventilation Capacities of the Powder/Pellet and Assembly

Facility, Babcock and Wilcox Commercial Nuclear Fuel Plant........ A.4

A.2 Inventories of Radioactive Materials at the Babcock and

Wil cox CNFP.

A.3 Chemical Storage at Babcock and Wilcox CNFP...................

A.4 Possession Limits for the Combustion Engineering

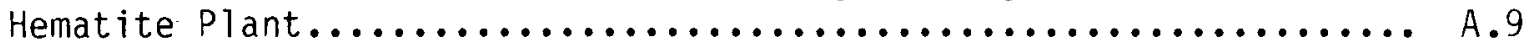

A.5 Chemicals Used at Combustion Engineering Hematite Plant.......... A.10

A.6 Airflow in Combustion Engineering Windsor Plant..................11

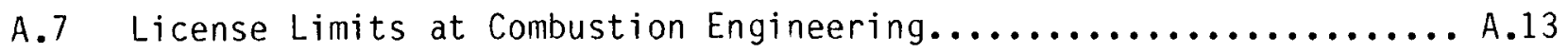

A.8 Inventory of Chemicals Combustion Engineering Windsor Plant....... A.14

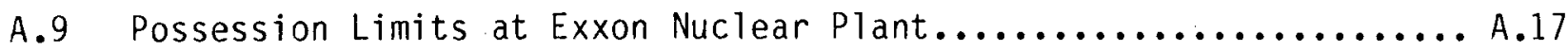

A.10 Storage Locations of Chemicals at Exxon Nuclear Plant..............18

A.11 Air Circulation in General Electric Wilmington Plant...............21 
A.12 Radioactive Materials Inventory at General Electric

Wilmington.......................................... A.22

A.13 Possession Limits at General Electric Wilmington................ A.22

A.14 Chemicals and Flammable Materials Inventory at

General Electric Wilmington Plant.............................23

A.15 Radioactive Materials Inventory at Westinghouse

Columbia Plant............................................ A.26

A.16 License Limits at Westinghouse Columbia Plant...................27

A.17 Chemicals Used in the Westinghouse Fuel Fabrication Plant......... A.27

B.1 License Limits for General. Atomic Facility................... B.5

B.2 Fuel Production Station Inventory Limits...................... B.7

B.3 Nuclear Materials Allowed at Rockwell International

Canoga Park Facility Under Special Nuclear Materials

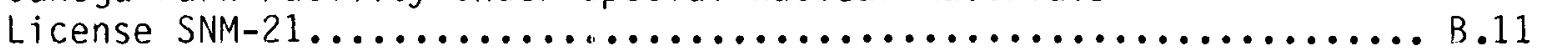

B.4 Mass Limits of ${ }^{235} U$ at Fuel Fabrication Stations................ B.11

C.1 Areas Containing Amounts of Nuclear Materials at

Allied Chemical IJF 6 Plant.................................. C.4

C.2 Typical Plant Radioactive Inventory at Allied Chemical

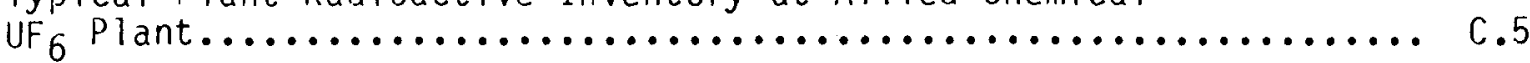

C.3 Chemicals, Hazardous, and Combustible Materials Used

at Allied Chemical........................................ C.6

C.4 Building Areas at the Sequoyah $U_{6}$ Facility $\ldots \ldots \ldots \ldots \ldots \ldots \ldots \ldots$. .9

C.5 Storage Capacity of Radioactive Materials at the

Sequoyah Facility....................................... C.10

C.6 Chemicals, Hazardous, and Combustible Materials at the

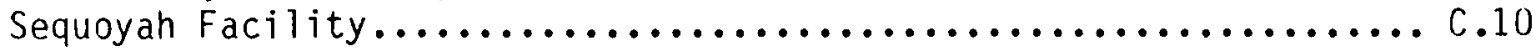

0.1 Floor Area of Potentially Contaminated Rooms.................. D.3

D.2 License Limits of Special Nuclear Materials During

Operations at Babcock and Wilcox Plutonium Plant................ D.4

D.3 Process Areas in General Electric Vallecitos Plant............... D.5

D.4 Floor Area of Potentially Contaminated Rooms at Kerr-McGee

Plutonium Storage Facility................................. D.10 
D.5 Areas Holding Contaminated Materials at Westinghouse,

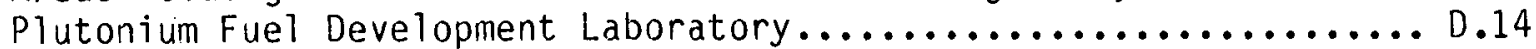

D.6 Possession Limits for Westinghouse PFOL................... D.16

D.7 Chemicals Used at the Cheswick Site...................... 0.17

E.1 Radioactive Inventory at NEN Boston........................ E

E.2 Hazardous and Combustible Materials in

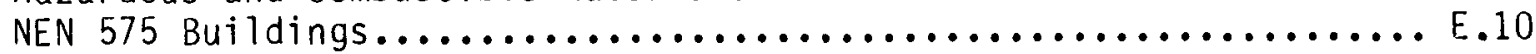

E.3 License Quantities for the North Billerica Nuclides

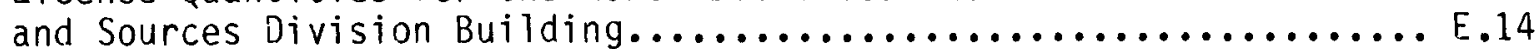

E.4 License Quantities for the North Billerica Medical

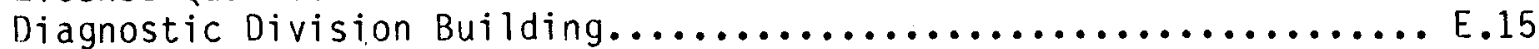

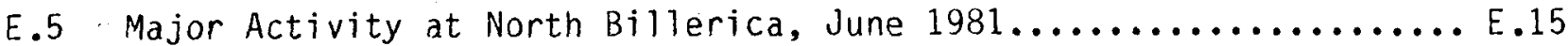

E.6 Isotope Movement During a Typical Week at

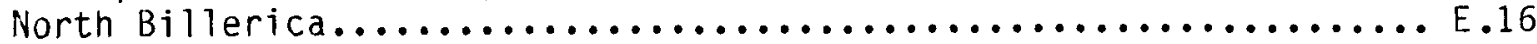

E.7 Radioactive Waste Inventory at North Billerica

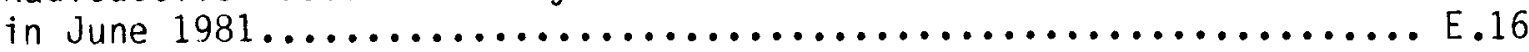

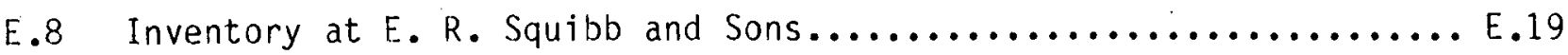

F.1 Material and Activities Ordered by Ohio State University

Pharmacy During One Year.................................. 3

G.1 Radioisotope Possession Limits at Amersham Facility............ G.3

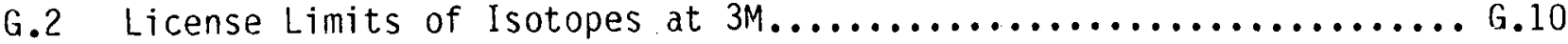

G.3 Typical Radioactive Inventory in 575 Building Modules...............11

G.4 Maximum Anounts of Nuclear Medical Isotopes Present

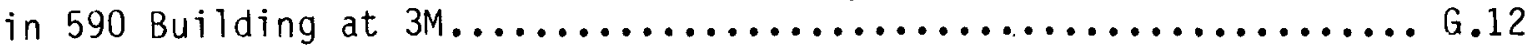

G.5 Maximum Amounts of Isotopes Present in Processes in

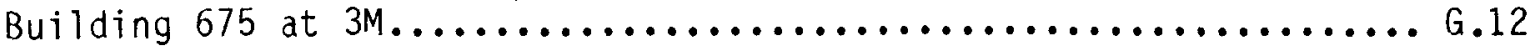

G.6 Maximum Inventory of Waste in Storage in 573 Building...............13

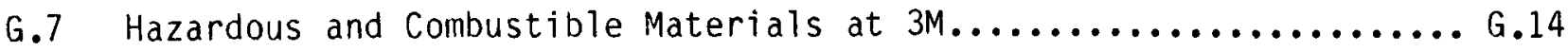

G.8 Possession Limits of Isotopes at Monsanto Research

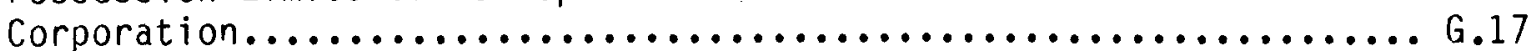

G.9 Possession Limits for Pan American World Airways...................19 
G.10 Possession Limits of Princifal Isotopes at

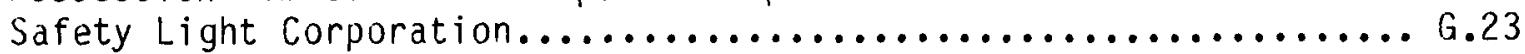

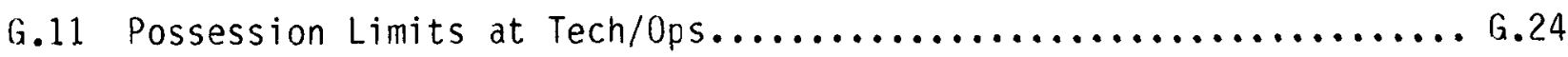

H.1 License Limits at Lynchburg Research Center.................. H.8

H.2 Mass Limits for Nuclear Materials at Lynchburg

Research Center................................... H.9

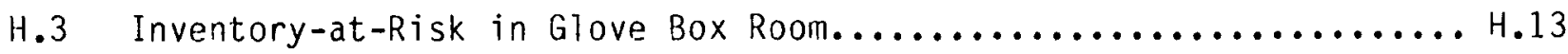

H.4 Amounts of Combustible Materials in Glove Box Room.............. H.14

H.5 Limits on Amounts of Radioactive Materials at the

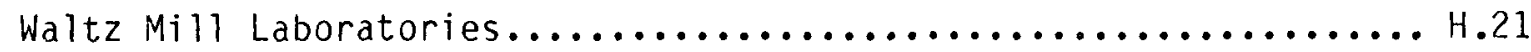

I.l Typical Inventory at Atomic Disposal.................... I.3

I.2 Drumned Inventory at Atomic Disposal....................... I.

I.3 Possession Limits at Interex Corporation................. I.6

I.4 Possession Limits at Teledyne Isotopes, Inc............... I.8

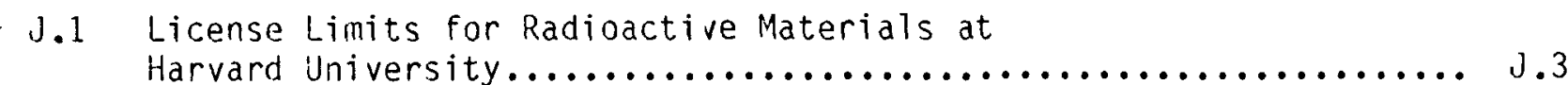

J.2 Radioactive Materials at Michigan State University..............6

J.3 Room Dimensions of Labs at Ohio State University ................ J.7

J.4 License Limits at Ohio State University.................. J.8

J.5 License Limits at Oral Rober:s University.......................

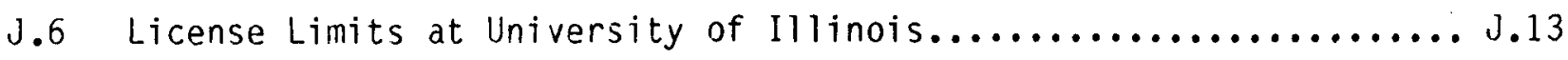

J.7 Maximum Concentration of Radioactive Isotopes Allowed

in Liquid Waste Incinerated at the University of Illinois

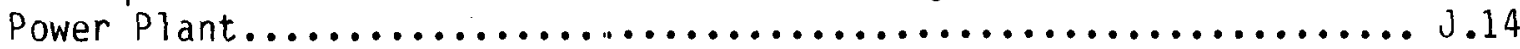

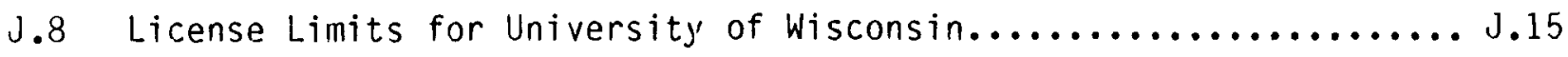

J.9 Inventory of Major Isotopes at University of Wyoming.............17

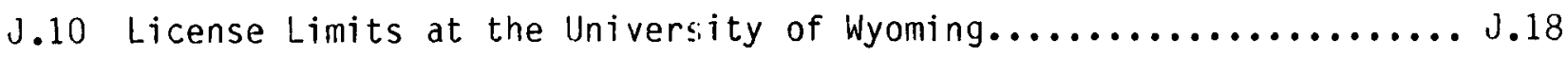


$\vartheta$

$\ominus$ 


\section{ABBREVIATIONS, ACRONYMS, AND INITIALISMS}

ADU

ammonium diuranate

AED

aerodynamic equivalent diameter

AFL

Advanced Fuels Láboratory

ATR

Advanced Test Reactor

AUC

ammonium uranyl carbonate

CNFP

Commercial Nuclećr Fuel Plant

$\mathrm{cpm}$

counts per minute:

DOT

(U.S.) Department of Transportation

EBR-II Experimental Breeder Reactor

FFTF

Fast Flux Test Facility

HEPA

high-efficiency farticulate air (filter)

HEU

highly enriched uranium

HSA

human serum albumin

HTGR

high-temperature gas-cooled reactor

HVAC

heating, ventilating, and air conditioning (system)

IX

ion exchange

LCD

liquid crystal display

LEU

low enriched uranium

$1 \mathrm{fm}$

linear foot per minute

LPG

liquid petroleum gas

$L P R$

Lynchburg Pool Reactor

MFP

mixed fission products

MOX

mixed (uranium and plutonium) oxide fuel

MPC

maximum permissible concentration 
maximum release considered for emergency preparedness planning

MT

metric ton

MTU

metric tons of uranium

NEN

New England Nuclear

NMSS

(Office of) Nuclear Materials Safety and Safeguards

NRC

(U.S.) Nuclear Regulatory Commission

PAL

Plutonium Analytical Laboratory

PFDL

Plutonium Fuels Development Laboratory

PMMA

polymethylmethacrylate

PNL

Pacific Northwest Laboratory

PVC

polyvinyl chloride

RCP

Radiological Contingency Plan

RIBD

radioisotope buildup and decay

SNM

special nuclear material

TBP

tributyl phosphate

TCAAP

Twin City Army Ammunition Plant

TIG

tungsten inert gas

TRIGA

Training Reactor, Isotopes Production, General Atomic 


\subsection{EXECUTIVE SUMMARY}

During the past year, Pacific Northwest Laboratory conducted studies to provide the Nuclear Regulatory Commission (NRC) with source terms (fractional releases) for accident conditions. This was accomplished by developing several accident scenarios for each operation category, leading to the identification of the maximum release considered for emergency preparedness planning (MREPP) scenario. This research will aid individuals charged with evaluating safety reviews and emergency preparedness plans at facilities licensed by the office of Nuclear Materials Safety and Safeguards (NMSS).

Eleven different types of NMSS-licensed operations were investigated and accident-generated radioactive airborne release source terms developed. These operations categories are as follons:

1. uranium fuel fabrication (oxide fuel)

2. uranium fuel fabrication (nonoxide fuel)

3. uranium hexafluoride $\left(U_{6}\right)$ production from yellowcake

4. uranium milling

5. plutonium (Pu) contaminated facility

6. radiopharmaceutical manufacturing

7. radiopharmacy

8. sealed source manufacturing

9. research and development of n:clear fuels

10. waste warehousing

11. university research and development.

Individual facilities within a category were identified for investigation by the NRC. These were located in nonagreement states and include licensees ordered on February 11, 1981, to submit radiological contingency plans.

Estimated releases from the potential accident scenarios are summarized in Table 1.1. The maximum radionuclide release events were of three types: fire, tornado, and criticality. The corresponding facility types are as follows:

- Fire - radiopharmaceutical manufacturing, radiopharmacy, waste warehousing, sealed source manufacturing, university research and development, uranium fuel fabrication (oxide), and UF 6 production.

- Tornado - uranium mill and plutonium contaminated facility.

- Criticality - uranium fuel fabrication (nonoxide) and research and development of nuclear fuels.

With a fire, the maximum postulated releases were in the form of gaseous ${ }^{3} \mathrm{H}$, which is dispersed as water vapor, or as UF 6 , which converts to particulate $\mathrm{UO}_{2} \mathrm{~F}_{2}$. While these may be the maximum releases in terms of curies, significant amounts of isotopes of radiological concern, such as ${ }^{131}$, can become airborne in a fire. These isotopes are disisussed and fire-generated release factors were developed for a range of those prepared as radiopharmaceutical and sealed sources. 
TABLE 1.1. Summary Table of Releases from Accident Scenarios

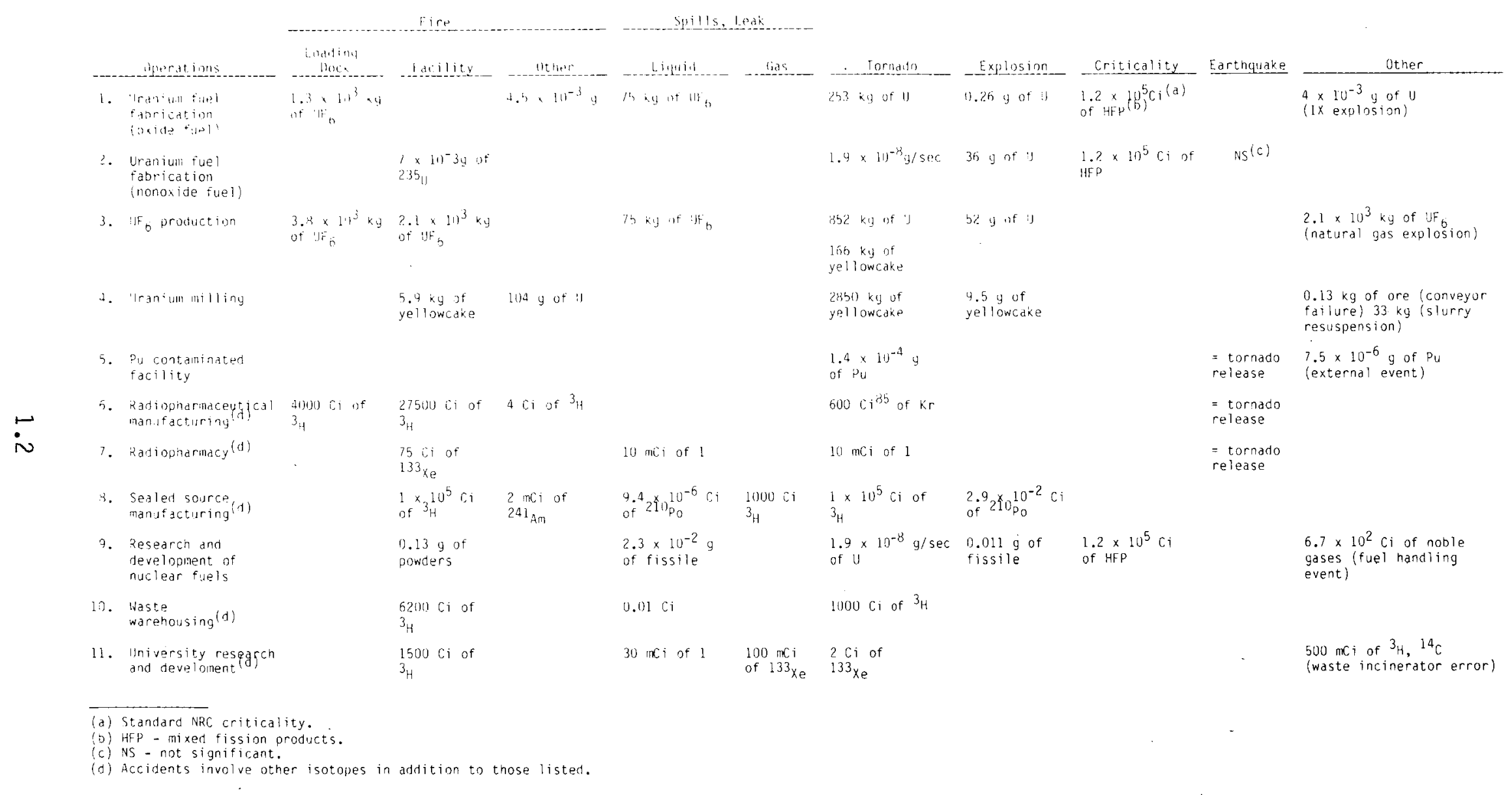


Tornado releases were particulate yellowcake or resuspended plutonium surface contamination. The probajility that these releases would occur is dependent on the tornado region where a facility is located. Tornado dispersion of the release reduces the inmediate radiological concern to an individual.

Criticality releases are prinarily fission product gases. The NRC staff has developed methods for analyzing criticality events. These NRC guides (USNRC, 1977a, 1979a) are the standard reference that should be used when estimating criticality releases. 


\subsection{INTRODUCTION}

The NRC is examining the possibility of radiological accidents occurring in NMSS-licensed operations that could result in serious radiation doses of $f$ site. Pacific Northwest Laboratory has developed source terms for potential accident scenarios to aid in the examination. They will be used for safety reviews and for assessing the needed scope and extent of emergency preparedness at NMSS-licensed facilities. This work is sponsored by the NRC, Uranium Fuel Licensing Branch, Division of Fuel Cycle and Material Safety. This report provides technical assistance to its staff in developing and implementing the emergency preparedness program.

The objective of this study is to develop source terms for accidentgenerated airborne releases for various generic types of NMSS-licensed activities. Realistic maximized standard accidents for each operation type are identified and the airborne release fractions are estimated. Facilities considered are uranium fuel fabrication (both oxide and nonoxide), uranium hexafluoride (UF ${ }_{6}$ ) production from yellowcake, uranium milling, plutonium (Pu) contaminated facilities, radiopharmaceutical manufacturing, radiopharmacy, sealed source manufacturing, waste warehousing, and research and development (nuclear fuel and university). The specific facilities considered were identified by the NRC and include some of the licensees that were ordered on February 11, 1981, to submit radiological contingency plans. Elements making up the source terms are described and developed. These consist of an initial dispersing event, maximum quantities and characteristics of potential airborne releases, and possible specific mitigating actions. Generic source terms are developed and can be modified for use in a range of circumstances.

A diverse range of operations are covered in this report; however, a user may be interested in only one. This document, therefore, has been constructed to help the user in finding pertinent information. The summary section (Section 1) contains a table of calculated releases and a listing of MREPP scenarios for each facility type. A directory, Table 2.1, lists the operation type and refers the user to the report section where relevant information for that category is found.

A mix of both metric and English units have been included in this report. The most common unit of measure was selected in each case to further assist engineers and scientists in using this report.

Accident scenarios are developed by studying the plant and processes, and by identifying radioactive material holdings, operational procedures, room dimensions, HVAC system, etc. This leads to the identification of specific potential accident scenarios that would involve significant radionuclide releases. Section 3 discusses typical plant and processes for each facility category, and Section 4, presents a range of potential accidents leading to the selection of a MREPP scenario. These two sections have been numbered to aid the user; the second digit of the heading identifies a facility type. For 


\section{TABLE 2.1. Directory of the Office of Nuclear Materials Safety and Safeguards}

Facility Release Information

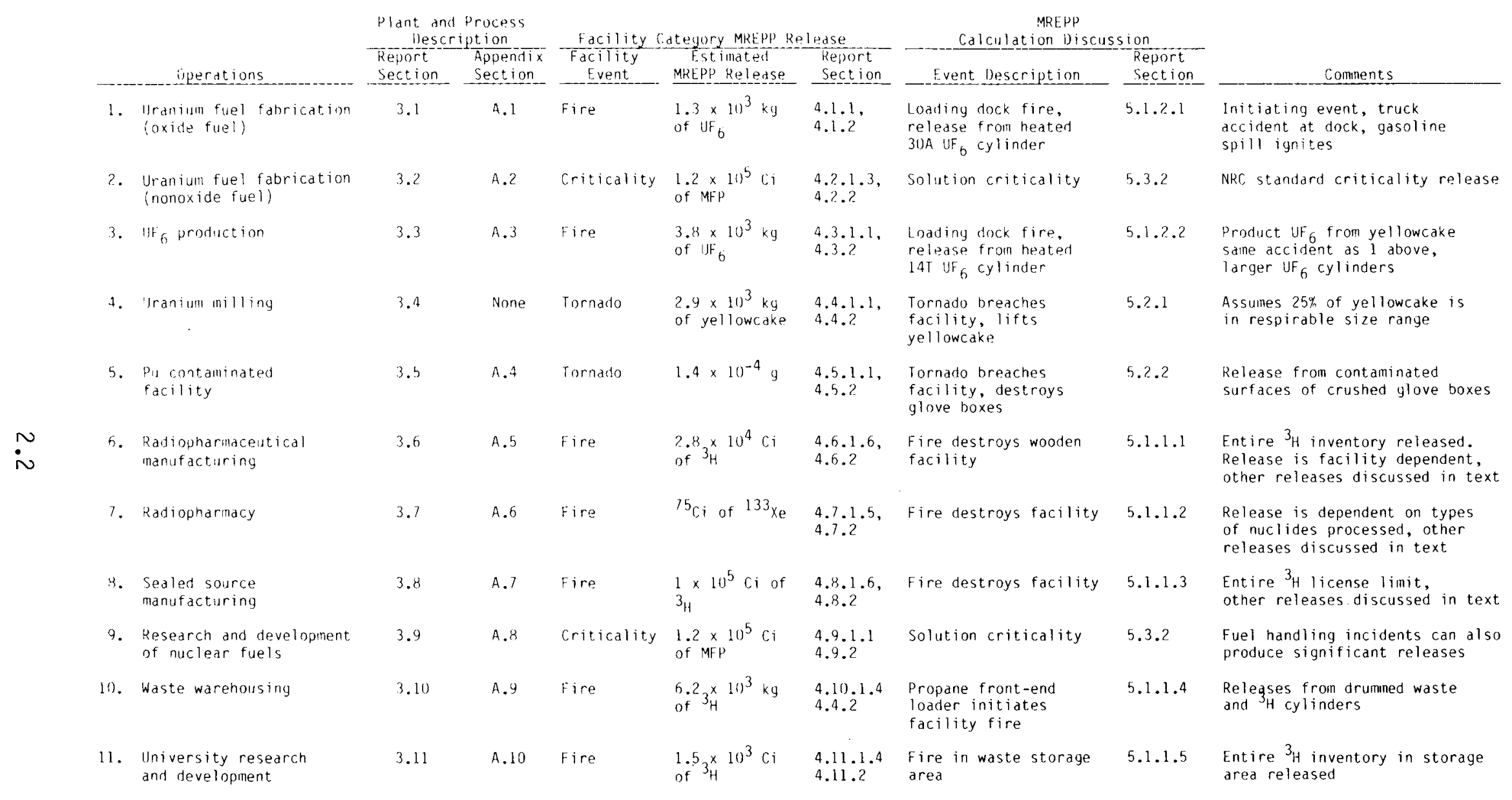


example, Section 3.3 is the discussion of UF 6 plants and processes; Section 4.3 is the corresponding section that discusses accident scenarios.

The MREPP calculations are found in Section 5. One of three general scenarios--fire, tornado, or criticality--was the MREPP accident for all facilities considered. Therefore, this section presents information on the accident type, followed by details relating to the specific facility category where it was the MREPP event.

The NRC identified specific facilities to be used for our release calculation development. Details on plant and process descriptions for these facilities are in Appendices A through $\mathrm{J}$.

Information in this report was developed using a literature review and plant visits. The literature review included NRC docket information, safety assessinents, journal articles, environmental reports, standard accident criteria, research reports, experimental data, and symposia proceedings. Plant visits were made when possible.

Because a large range of facility types is covered, the information available is not at the same level of detail and completeness for all categories. Therefore, the number of descriptive subsections describing the plants and processes varies with facility type. 


\subsection{PLANT AND PROCESS DESCRIPTION}

This section describes the plants and processes for the 11 operations categories of NMSS-licensed facilities. Specific facilities within the categories were identified by the NRC for study. A general description of each facility type has been developed and is presented in this section. Details on specific facilities are found in Appendices A through $J$.

Because of the wide range of categories, the same level of information was not available for all operations. For example, fuel manufacturing plants have had detailed public safety assessments and there is voluminous docket material available to use. On the other hand, little information is available in the literature on radiopharmacies. Docket material on radiopharmacies is sparse. This leads to different levels of information available for inclusion in this report.

For all operations categories, we have tried to include plants studied; process descriptions; building description including strength of materials, HVAC, and engineered safety systems; and inventories of radioactive and hazardous materials. Our sources include docket material, environmental impact statements, journal articles, safety assessments, reports on accident scenarios, and standard references. We visited one representative facility for some categories or several, in the case of radiopharmaceutical manufacturing. Pictures, observations, and discussions with facility staff, therefore, augmented our information.

The numbering system used for the text pertaining to the operation and the related accident is designed to help the user find each one easily. For example, Section 3.1 is a facility description, and Section 4.1 is the corresponding accident scenario. The appendices do not follow this sequence because there is no detailed plant description for uranium mills, since no specific plant was designated in this study.

\subsection{URANIUM FUEL FABRICATION PLANTS (OXIDE FUEL)}

The six facilities listed below were studied to develop information to characterize the uranium oxide fuel fabrication plants.

1. Babcock and Wilcox, Lynchburg, Virginia (commercial nuclear fuel plant)

2. Combustion Engineering, Hematite, Missouri

3. Combustion Engineering, Windsor, Connecticut

4. Exxon Nuclear, Richland, Washington

5. General Electric, Wilmington, North Carolina

6. Westinghouse, Columbia, South Carolina. 


\subsubsection{Process Description}

\subsubsection{Operation}

Most uranium fuel fabrication plants use the ammonium diuranate (ADU$\left.\left(\mathrm{NH}_{4}\right)_{2} \mathrm{U}_{2} \mathrm{O}_{7}\right)$ process $\xi_{0}$ convert $U_{6}$ to $\mathrm{UO}_{2}$ powder. The UF 6 , at an enrichment of less than $5 \%$ of ${ }^{235} \mathrm{U}$, is transported in cylinders of 2.5-ton capacity and placed in a steam chest. The UF 6 is vaporized in a steam or electric heat chest and is hydrolyzed with deionized water to form an uranyl fluoride solution. Ammonium hydroxide is added to the solution to precipitate ammonium diuranate, which is filtered or centrifuged. The precipitate is reduced to $\mathrm{UO}_{2}$ in a calciner operating at high temperatures in a hydrogen-reducing atmosphere.

A variation on the conversion process is the dry process in which UF $_{6}$ is vaporized in a steam chest and is then sent through a series of fluidized bed reactors operating under a reducing atmosphere to complete the conversion to $\mathrm{UO}_{2}$ powder.

In the pelletizing process, $\mathrm{UO}_{2}$ powder is blended to form a uniform composition. The powder is compacted into wafers, then granulated to form a uniform size. An organic lubricant may be added, and the powder is pressed into pellets.

Pellets are sintered in furnaces at high temperatures in a reducing atmosphere to give them high density. The sintered pellets are ground down to a specified diameter, inspected for cracks, and loaded into metal tubes. The tubes are seal welded and inspected before being bundled into fuel elements.

\subsubsection{Waste Disposa?}

Combustible contaminated wastes are frequently burned in incinerators in batch quantities. The ashes are sent to scrap recovery operations. Low-level noncombustible waste such os filter elements, metal, and glass scrap is compressed when possible for shipment off site to a licensed disposal site. Liquid wastes may be treated by many methods such as filtration, flocculation, lime addition, distillation: or precipitation in holding ponds to remove contaminants prior to disposal in a waterway.

\subsubsection{Scrap Recover:}

Many of the plants have solvent extraction systems to recover uranium from scrap materials. The scrap is dissolved in nitric acid and fed through extraction columns counter-currerit to an organic solvent. The solvent extracts uranium from the feed; then it is stripped of uranium by dilute nitric acid in a stripping column. The product, uranium nitrate, is concentrated by evaporation. The ADU is precipitared, filtered, dried, and reduced to $\mathrm{UO}_{2}$ feedstock material. 
In some plants the solvent extraction purification step is deleted. Scrap is dissolved in nitric acid, and the ADU is precipitated with the addition of ammonia. The ADU is separated from solution with a filter or centrifuge and calcined to $\mathrm{UO}_{2}$ or $\mathrm{U}_{3} \mathrm{O}_{8}$.

Some plants may have an ion exchange column to separate uranium from waste streams containing small quantities of uranium.

Clean scrap may be recovered by oxidation to $\mathrm{U}_{3} \mathrm{O}_{8}$ in a furnace. It is then recycled back to the manufacturing area.

\subsubsection{Facility Description}

\subsubsection{Buildings}

Most fuel fabrication plants are located on large parcels of land. The fabrication building sizes range from under 20,000 to several hundred thousand square feet, and operations may be held on one or several floors. Processing operations are generally divided. Ceiling heights range from 25 to $35 \mathrm{ft}$ high; an average height is about $30 \mathrm{ft}$.

Some of the buildings have cast concrete or concrete walls, concrete floors, and a gypsum roof deck. Steel beams may be usejd for support. Most buildings are designed to withstand earthquakes and wind loadings according to local building codes.

\subsubsection{Heating, Ventilating, and Air Conditioning Systems}

Fuel fabrication plants use scrubbers and/or high-efficiency particulate air (HEPA) filters to reduce release of airborne particles to the atmosphere. Scrubbers are commonly used in the $U_{6} 6$ conversion and scrap recovery operations. Prefilters may be employed prior to final filters in areas of heavy dust. Process areas are kept at negative pressure. Airflow is provided to give 7 to 24 air changes per hour. Air may be recirculated through process areas.

\subsubsection{Engineered Safety Systems}

Fire protection systems consist mainly of manual dry-type fire extinguishers in areas where criticality might be possible. Overhead sprinklers may be provided in some areas of the plant that have a high combustible loading.

Potential hazards such as hydrogen or propane gas lines are equipped with interlocking controls and automatic shutoff capabilities to prevent buildup of the gases. Excess hydrogen is burned off at areas where it is released to the air. Radiation alarms are located throughout the plants. 


\subsubsection{Surrounding Area}

Most of the uranium fuel fabrication plants are located in a rural setting, away from heavy industry. Operations other than fuel manufacturing at some of the plants include research facilities, chemical recovery operations, and fuel component manufacture.

\section{1 .3 Inventory}

\subsubsection{Radioactive Inventory}

The licensed possession limits for the operations studied range from 10,000 to $50,000 \mathrm{~kg}$ of $235 \mathrm{U}$. However, the maximum amount of material inventory at the plant is usually well below the license limit and may be as little as half of the limit. The major part of the inventory is stored as completed fuel assemblies, which may compose 25 to $35 \%$ of the total. Other forms can comprise up to this fraction of the total inventory: fuel rods, $30 \%$; $\mathrm{UO}_{2}$ powder, $15 \%$; $U_{6}, 29 \%$; contaminated waste, $5 \% ; U_{3} \mathrm{O}_{8}, 3 \%$; and UNH, less than $1 \%$.

\subsubsection{Hazardous and Combustible Inventory}

Chemicals are usually stored in tanks and cylinders in some central location outside of the process buildings and piped into various locations in the plant. Ammonium hydroxide, liquid anhdyrous ammonia, and hydrofluoric acid are used in conversion of $\mathrm{UF}_{6}$ to $\mathrm{UO}_{2}$ and are stored in 5000- to 20,000-gal tanks in an outside storage area. Nitric acid may be used in the solvent extraction recovery system or as a cleaning or pickling agent. Nitric acid is stored outside in large-capacity tanks.

Small quantities of polyvinyl alcohol may be used as a binder before the pelletizing operation. A lubricant such as zinc stearate is used to ensure that pellets slip out of the mold. Small quantities (100 gal) may be stored in the plant. Hydraulic fluid is used in the plant to operate presses. Fifty-galion quantities of this material may be stored in the plant also.

The scrap recovery system generally involves flammable or potentially explosive organics. Solvent extraction systems use tributyl phosphate (TBP) as an extraction agent with an organic solvent such as kerosene or perchlorethylene. Ion exchange columns contain an organic resin.

Nonreactive gases such as nitrogen and argon are used in potentially hazardous operations. Helium is used in leak testing of finished fuel rods. Gases are stored as a liquid in 500- to 10,000-gal insulated tanks or as compressed gases in $35,000-$ to $220,000-\mathrm{ft}^{3}$ quantities in an outside storage area and piped into the plant.

Hydrogen is used as a reducing gas in process equipment such as furnaces, calciners, and fluidized bed reactors. Excess hydrogen is burned off at 
locations where it enters or exits a system to prevent buildup of the potentially explosive gas. Hydrogen gas may be stored outside or may be provided by cracking ammonia.

Chemicals such as acetone, isopropyl alcohol, trichloroethylene used for cleaning, and detergent are stored in small quantities ( 50 to 100 gal) within the plant. These chemicals may also be found in l-gal dispensers in various locations in the plant.

Hydrogen peroxide, calcium oxide, and potassium hydroxide are used for effluent treatment and may be stored outside the facility. Hydrochloric acid and caustic are used to regenerate resins for demineralizing water for UF 6 hydrolysis. These two chemicals may be stored in 100- to 7000-gal tanks.

\subsection{URANIUM FUEL FABRICATION PLANTS (NONOXIDE FUEL)}

These uranium fuel fabrication plants make fuel for test reactors. To develop a description of nonoxide fuel fabrication plants, environmental reports, license applications, radiological contingency plans, and other docket material was obtained for the following plants:

1. General Atomic, San Diego, California

2. Rockwell International, Canoga Park, California.

\subsubsection{Process Description}

\subsubsection{Operation}

Metal and mixed carbide fuels are made for research reactors. The nonoxide fuel fabrication process starts with highly enriched uranium metal which may be mixed with an alloying metal in an induction furnace. The metal may be rolled, punched, drilled, or crushed and compacted. The fuel is machined and shaped, then enclosed in a metal such as aluminum or stainless steel. The enclosing process may include placing the fuel in a frame, covering it with side plates and rolling the metals together, or the fuel may be injection cast into metal tubes or loaded into a can or mold. Fuel elements may be inspected, cleaned; and pickled in a $\mathrm{HNO}_{3}-\mathrm{HF}$ mixture before being combined into fuel assemblies.

Mixed carbide fuel is made by mixing highly enriched $\mathrm{UO}_{2}-\mathrm{ThO}_{2}$ with graphite flour and heating the mixture to form $\mathrm{UC}_{2}-\mathrm{ThC}_{2}$ kernels. These kernels are shaped into spheres by heating to a temperature in excess of the kernel melting temperature, then coating with carbon and silicon layers in fluidizing furnaces. Coated kernels are injected into a hot mold with a matrix material to form a rod. Rods are inserted into a graphite block.

\subsubsection{Waste Disposal}

Contaminated solid waste is usually packaged for disposal at a licensed burial ground. Some combustible waste may be incinerated on site. Liquid waste is generally treated and retained on site before release. 


\subsubsection{Scrap Recovery}

Scrap recovery operations usually involve dissolution of the scrap in acid followed by filtration and purification of uranium by solvent extraction. Uranium is then precipitated and calcined.

\subsubsection{Facility Description}

\subsubsection{Buildings}

Manufacturing buildings range from less than 7,000 to over $20,000 \mathrm{ft}^{2}$. Room sizes range from 300 to $2500 \mathrm{ft}^{2}$. Fabrication areas are separated from other areas of the plant by concrete or double-wall construction.

Manufacturing areas are generally of substantial construction. Floors are made of poured concrete. Walls are concrete or concrete block with structural steel supports. The roof may be prestressed concrete. Storage vaults of much more substantial construction may be provided for the storage of nuclear materials.

\subsubsection{Heating, Ventilating, and Air Conditioning Systems}

Pickling operations may be equipped with fume scrubbers to remove airborne contaminants. Most areas have HEPA filters to reduce radioactive emissions to the atmosphere. Process areas are kept at negative pressure and airflow is generally from areas of least to greatest potential contamination. Minimum airflow is usually six changes per hour from each room.

Metal machining equipment or other process equipment generating dusts and powders are operated in inert atmospheres that may use fireproof fume hoods to prevent fire or explosion hazards.

\subsubsection{Engineered Safety Systems}

Manual fire extinguishers are usually provided in various locations throughout the plant. Automatic detection systems and sprinklers may be pro-: vided in critically safe areas. Welding operations and process steps generating pyrophoric metal dusts are performed in an inert atmosphere. Explosive gas detectors are located in areas where flammable solvents may be used. Combustible waste is kept in covered containers.

\subsubsection{Surrounding Area}

The plants are located in light industrial areas. Many sites also contain research facilities and test reactors as well as the fuel fabrication process. 


\subsubsection{Inventory}

\subsubsection{Radioactive Inventory}

Less uranium is possessed in nonoxide fuel plants than in oxide plants. License limits range from 1,500 to $2,500 \mathrm{~kg}$ of $235 \mathrm{U}$.

Nuclear materials can be found in the form of $\mathrm{UO}_{2}$ or $\mathrm{ThO}_{2}$ powder; uranium metal ingots, chips, or buttons; ADU and UNH solutions; and uranium encased in aluminum, zirconium, stainless steel, or carbon and silicon spheres. Each station may handle from $350 \mathrm{~g}$ to $13 \mathrm{~kg}$ of nuclear material while vault storage may contain over $1000 \mathrm{~kg}$ of $23 \mathrm{JU}_{\mathrm{U}}$ in various forms.

\subsubsection{Hazardous and Combustible Inventory}

Uranium and zirconium metal chips and fines are pyrophoric; therefore, machining operations using these materials are frequently performed in inert atmospheres. Zirconium chips and fines may be limited to 1 1b or less at each machine. Materials may be collected in 5-1b cans, sealed with inert gas, then stored in concrete storage areas. Pickling operations require $\mathrm{HNO}_{3}$ and $\mathrm{HF}$ solutions, which may be stored in large tanks.

Scrap recovery operations use nitric acid, formic acid, polyvinyl alcohol, or tetrafurfural alcohol for dissolution of materials. An organic solvent is used as a purifying agent in solvent extraction systems. The organic solvent used in metal uranium fuel fabrication plants is not identified in the open literature.

Natural gas, fuel 0 il, and propane may be used as heating fuels in the plant. Fuel 011 and propane may be stored in large tanks both under- and aboveground. Natural gas may be piped in from outside the plant. Fuel is used to provide power and space heat via steam plants, and to heat calciners, furnaces, and incinerators.

Cleaning chemicals such as detergent, trichloroethylene, and solvents are used in the plant. These chemicals may be stored in 55-gal drums but are limited to 1-gal or less safety cans around process equipment.

Lab coats, plastic shoe covers, and other protective clothing may be found at entrances to contaminated areas. These combustibles contribute to the fuel loading of an area.

Compressed or liquified gases such as nitrogen and argon are used to provide inert atmospheres for processes involving pyrophoric metals.

\subsection{URANIUM HEXAFLOURIDE PRODUCTION PLANTS}

Uranium hexafluoride production plants designated for inclusion in this study produce $U_{6}$ from yellowcake. This can be done using either wet or dry processes. 
The two plants in the United States producing UF 6 from yellowcake were used to characterize this type of facility. They are:

1. Allied Chemical Corporation, Metropolis, Illinois

2. Kerr-McGee Nuclear Corporation, Gore, Oklahoma.

Unit operations for both plants include sampling, feed preparation, conversion, purification, condensation, and packaging. However, the Kerr-McGee plant uses the "wet" process to purify uranium prior to conversion to UF 6 while the Allied plant uses a "dry" process and has the purification process after the conversion step.

\subsubsection{Process Description}

\subsubsection{Dperations}

Yellowcake received in 55-gal drums is emptied into a hopper or falling stream unit, weighed, and sampled in a sampling system. The yellowcake is checked for sodium and other impurities.

In the dry process, feed with a high-sodium content goes through a sodiumremoval process consisting of a four-stage counter-current decantation system using ammonium sulfate solution. Feed is then calcined to $U_{3} \mathrm{O}_{8}$, blended, agglomerated, dried, crushed, and sized to a uniform-particle size. Feed preparation in the wet process consists of digesting yellowcake in nitric acid to form uranyl nitrate.

In the wet process, uranyl nitrate solution is purified in a solvent extraction process using tributyl phosphate in hexane as the solvent. The uranium-loaded solvent is washed with dilute solutions of ammonium sulfate and sodium hydroxide to remove impurities, then stripped of uranium in a pulsed stripping column. Product solution is evaporated and denitrated in a stirred reactor to $\mathrm{UO}_{3}$, which is milled to a a uniform size.

Conversion to $\mathrm{UF}_{6}$ for both the wet and dry processes takes place in a series of fluidized bed reactors. The first reactor uses reducing gases from dissociated ammonia to convert $\mathrm{UO}_{3}$ and $\mathrm{U}_{3} \mathrm{O}_{8}$ to $\mathrm{UO}_{2}$ powder. The next two reactors use HF as the fluidizing gas to convert $60_{2}$ to $\mathrm{UF}_{4}$. Fluorine provided by the electrolysis of $\mathrm{HF}$ is the fluidizing gas in the fluorinator that converts $U_{4}$ to $U_{6}$.

The dry process now goes through purification with high- and low-boiling distillation columns removing impurities such as molybdenum and vanadium.

Purified gaseous UF 6 is condensed in cold traps. Condensed solid is reheated intermittently so, that liquid $U F_{6}$ is drained off into cylinders. 


\subsubsection{Waste Disposal}

Liquid wastes may be treated with lime in settling ponds and held prior to release to a waterway. Combustible wastes may be incinerated or drummed for burial at a licensed burial site.

The Allied plant has a scrap recovery system that uses sodium carbonate solution to leach uranium from finely ground scrap. The leached material is drummed as low-level waste, and the recovered uranium is precipitated with the addition of sodium hydroxide and sent to the sodium removal facility.

\subsubsection{Other Operations}

Both plants have an electrolysis system that supplies fluorine to plant operations. The Allied plant also produces sulfur hexafluoride, iodine pentafluoride, and antimony pentafluoride.

\subsubsection{Facility Description}

\subsubsection{Buildings}

The plants are located within a 54- to 75 -acre fenced-in area in an 860to 2100-agre tract of land. The main process areas may cover 12,000 to $26,000 \mathrm{ft}^{2}$. The Allied plant's main process building is six stories high. Uranium hexafluoride cylinder storage areas cover from 25,000 to $200,000 \mathrm{ft}^{2}$.

Most of the Allied plant buildings are concrete block, except for the main processing building, which is steel framed with sheet metal siding. The Kerr-McGee plant structures are all steel framed with some walls constructed to obtain a 4-h fire rating.

\subsubsection{Heating, Ventilating, and Air Conditioning Systems}

Dust collectors are used in dust-generating areas, such as the sampling area.

Scrubbers process gases from the digestion and solvent extraction areas of the Kerr-McGee plant and from various parts of the conversion operation in both plants. Less care is taken to contain airborne particles from UF 6 plants than from uranium fuel fabrication plants because the materials handled have less radioactivity.

\subsubsection{Surrounding Area}

Both plants are located in rural areas with low population densities. No obvious impacts can be seen that might impact on the facilities from outside sources. 


\subsubsection{Engineered Safety Systems}

Fire protection is provided with manual fire extinguishers and water hoses. Automatic extinguishing systems are provided in extremely hazardous areas such as the solvent extraction area and substations.

Alarms that detect abnormal operations in the plant signal are located in the operating rooms. A manual alarm activated by personnel can be set off to alert the plant to releases.

\subsubsection{Inventory}

\subsubsection{Radioactive Inventory}

Plant capacities range from 10,000 to 14,000 tons of $U_{6}$ per year. Uranium at these facilities can be found as:

- Uranium hexafluoride stored outdoors in 10- and 14-ton cylinders may total 1000 to 11,000 tons of uranium.

- Yellowcake in 55-gal drums with 700 lb of uranium drum totals 1000 to 7000 tons of uranium.

- Uranium in other forms in the plant may total 100 to 250 tons of uranium.

\subsubsection{Hazardous and Combustible Inventory}

The chemical, hazardous, and combustible materials that might be found at a $\mathrm{UF}_{6}$ production plant are listed in Table 3.1.

\subsection{URANIUM MILLING}

Uranium mills extract and partially refine uranium from uranium ore, and the material is then prepared for shipment to a $\mathrm{UF}_{6}$ or $\mathrm{UO}_{2}$ facility for additional front-end fuel cycle processing. The uranium is shipped as a solid in powder form $g_{3}$ lled yellowcake, which contains the isotopes ${ }^{234} \mathrm{U},{ }^{235} \mathrm{U}$, and predominately ${ }^{238} \mathrm{U}$ (Geffen, 1981).

No specific mills were identified by the NRC for inclusion in this study. Therefore, this report is derived from information obtained from Environmental Impact Statements (USAEC, 1974; USNRC, 1977b, 1980) and from documents describing reference uranium mills (Schneider and Kabele, 1979; Schneider, 1982). No site visits were conducted, nor was specific information available from radiological contingency plans. 
TABLE 3.1. Chemical and Fuel Materials Found at UF 6 Production Plants

\section{Material}

Ammonia

Ammonium sulfate

Ethylene glycol

Fluorspar

Fuels

Hydrofluoric acid

Lime

Nitric acid

Potassium hydroxide

Sodium carbonate

Sodium hydroxide

Sulfuric acid

\section{Description}

Stored in 15,000- to 25,000-gal tanks and used to provide reducing gases to various processes.

Used to pretreat impure feed.

May be used to cool the cold traps in the condensation process.

May be used as the bed material in the fluidized bed reactors.

Natural gas, fuel oil, and liquid petroleum gas (LPG) are used in the plants for : ect or backup heating and to operate process solipment. Natural gas may be piped in from city lines:- e fuel $0 i l$ and LPG are usually stored outside in tanks or $\$ 0,000-$ to 30,000 -gal capacity.

Stored in 30,000-gal tanks and used as a fluidizing gas and to produce fluoride for the fluorinators in the conversion process.

Used to treat liquid wasie.

Used to dissolved feed in the wet process and stored in a 15,000-gal tank.

Used in the scrubbing system.

May be used to wash empty uranium cylinders and used in the uranium recovery process.

Used in scrap recovery.

May be used in chemical manufacture and to treat liquid waste.

\subsubsection{Process Description}

\subsubsection{Operations}

Ore is shipped by truck from the mines to uranium mills. The majority of uranium mills use an acid leach process to extract uranium from the ore; however, a few mills use an alkaline leach system. 
The mills receive the ore from nearby mines via truck on a daily basis, and the ore is stored on pads awaiting processing. Most mills operate on a 365 day/yr continual basis, and throughput may vary from 1000 to 2000 tons of ore per day, producing 400 to 7000 MT of yellowcake per year. The ore is fed by conveyor into a building where a crushing and wet-grinding operation is performed. In an acid leach, the slurry from the process is treated with sulfuric acid to leach uranium. In the alkaline system, sodium carbonate is mixed with sodium chlorate and steam in leaching tanks. In either process, the leach solution is then passed to a counter-current decantation operation using a series of washing tanks where the sand and slimes are removed and transferred to the tailings impoundment. The resultant clarified solution is then usually passed to a solvent extraction process where the uranium is concentrated and purified in a series of reactor and settling vessels using kerosene-carrying amine-type organic solvents. The aqueous raffinate from this process is transferred to the tailings retention area. The concentrated uranium remaining in solution is precipitated as ammonium diuranate by addition of ammonia. The precipitate is concentrated and washed in thickeners and dried in a dryer at up to $1200^{\circ} \mathrm{F}$. The dried concentrate is then crushed to sizes less than $6 \mathrm{~mm}$ and packed in 55-gal steel drums for storage and shipment.

\subsubsection{Waste Disposal}

The primary forms of radioactive waste from the milling operation consist of the solid and liquid effluents from the decantation circuit, the solvent extraction process, and the uranium precipitation step. These wastes are pumped into the tailings area at a rate of approximately 1 ton of solid waste per ton of ore processed. The solids, liquids, and slimes remain in the tailings pond and are held in place by an earthen and clay dam. Tailings ponds may cover several hundred acres and stand 100 to $200 \mathrm{ft} \mathrm{high.}$

A secondary source of radioactive waste is the ore dust and yellowcake dust generated throughout the milling operation. Most of the yellowcake dust is removed by the wet scrubber systems in the process buildings.

Nonradioactive wastes consist of miscellaneous solids, such as chemical containers, cardboard containers, and other paper trash. Liquid effluents other than those discharged to the tailings area, are organic solutions used during the solvent extraction phase and removed periodically.

\subsubsection{Facility Description}

\subsubsection{Buildings}

Information on typical uranium mill operations is shown in Table 3.2 .

The crushing building houses the ore-crushing devices and has a fairly open interior. The main mill building contains the grinding and acid leach operations, as well as the yellowcake drying and packaging areas. The countercurrent decantation pump house contains the pumps used to transfer solutions and slurries to and from the thickener tanks. The solvent extraction building houses the settling tanks and precipitation equipment. 
TABLE 3.2. Information on Typical Uranium Mill Operations

\begin{tabular}{|c|c|c|c|}
\hline Area & Dimension, $m$ & Construction & Feature \\
\hline Crushing & $16 \times 12 \times 20$ & Steel & $\begin{array}{l}\text { Insulated walls, } \\
\text { concrete floor }\end{array}$ \\
\hline Conveyor & $41 \times 9 \times 18$ & Steel & Wood floor \\
\hline Ore bins & $25 \times 9 \times 26$ & Steel & \\
\hline Mill building & $54 \times 42 \times 15$ & Steel & Concrete floor \\
\hline $\begin{array}{l}\text { Counter-current } \\
\text { decantation }\end{array}$ & $40 \times 15 \times 10$ & Steel, concrete & Concrete floor \\
\hline $\begin{array}{l}\text { Solvent extraction } \\
\text { building }\end{array}$ & $62 \times 27 \times 13$ & Steel & \\
\hline Thickener tanks & $34 \times 4.3$ & Wood & \\
\hline Maintenance & $30 \times 18 \times 8$ & Steel & \\
\hline Change house & $30 \times 18 \times 8$ & Steel & \\
\hline Offices & $38 \times 15 \times 3$ & Steel & \\
\hline
\end{tabular}

\subsubsection{Heating, Ventilating, and Air Conditioning System}

Dust from crushing, grinding, drying, and storage operations is collected by wet scrubbers. Fumes generated by leaching and solvent extraction systems may be discharged to the air without treatment.

\subsubsection{Engineered Safety Systems}

Most process areas at uranium mills have fire alarms and sprinklers. Water or foam suppression is stored on site for the fire-suppression system.

\subsubsection{Surrounding Area}

Uranium mills tend to be located in very rural areas within convenient distances of the uranium mines. Most mills are located in the western United States in Wyoming, Colorado, Utah, New Mexico, and Texas. No other facilities that might pose a threat from an accident standpoint are located near the mills.

\subsubsection{Inventory}

\subsubsection{Radioactive Inventory}

Radioactive inventories at uranium mills consist of ${ }^{238} U$ and $23+5$ daughter products (primarily thorium, radium, and radon). The amounts of $235 \mathrm{U}$ are small. 
A typical mill will process 1000 to 2000 tons of ore per day containing approximately $0.2 \%$ of $\mathrm{U}_{3} \mathrm{O}_{8}$ per ton, or 2 tons of $\mathrm{U}_{3} \mathrm{O}_{8}$ /day. Assuming an activity level of $515 \mu \mathrm{Ci}$ per ton of ore, and conthpuous turnover of the ore, 2000 tons of ore represents approximately $1 \mathrm{Ci}$ of $238 \mathrm{U}$ throughput per day. Assuming further that $95 \%$ of the uranium is recovered as yellowcake, roughly 3.8 tons of yellowcake are produced per day for a 2000-ton throughput of ore. Because as much as 200 tons of yellowcake may be stored prior to shipment, total $l^{\circ}$ activity in stored $\mathrm{U}_{3} \mathrm{O}_{8}$ may be $5 \mathrm{Ci}$.

A conservative estimate of radioactivity levels in the tailings pond area would be as follows:

- $328 \mathrm{~J}: 0.1 \mathrm{mCi} / \mathrm{ton}$

- 234u: $0.0 \mathrm{mCi} / \mathrm{ton}$

- ${ }^{230}$ Th: $0.036 \mathrm{mCi} /$ ton

- ${ }^{226} \mathrm{Ra}: 0.38 \mathrm{mCi} / \mathrm{ton}$.

A typical tailings pile might contain roughly $1.5 \times 10^{7}$ tons of tailings, yielding the following levels of activity:

- 238 U: $150 \mathrm{Ci}$

- 234 U: $150 \mathrm{Ci}$

- 230 Th: $5400 \mathrm{Cj}$

- ${ }^{226} \mathrm{Ra}: 5700 \mathrm{Ci}$.

\subsubsection{Hazardous and Combustible Inventory.}

Potentially hazardous materials used during the uranium ore process steps are shown in Table 3.3.

Miscellaneous combustibles would include paper, cardboard, and wooden furniture. The acid leach tanks (six 18-ft-diam x 18-ft-high tanks) may be constructed of wood, as well as the clarifier tank (65-ft diam) and the thickener tanks (five 105-ft-diam $\times 17-f t-h i g h$ tanks).

Propane (or natural gas) is used to generate process heat. The uranium precipitate dryers use propane or natural gas also and may contain 1600 lb or more yellowcake at any one time.

Emergency power is frequently provided by a diesel generator using fuel oil stored in an underground tank (3000 gal). Additionally, the fuel oil may be burned in steam boilers to provide building heat and/or hot water used in various stages of the ore processing. 
TABLE 3.3. Materials Used in Uranium Ore Processing

\begin{tabular}{lc} 
Material & Quantity \\
\hline Amines (organics) & 62 lb/day \\
Ammonium sulfate & $250 \mathrm{lb} /$ day \\
Anhydrous ammonia & $10,000 \mathrm{lb} /$ day \\
Fuel oil & $3000 \mathrm{gal}$ in storage \\
Kerosene & $170,000 \mathrm{gal} /$ day \\
Liquid glue & $320 \mathrm{gal} /$ day \\
Organics storage & 600 gal/storage tanks \\
Polymeric flocculants & quantity unknown \\
Propane (natural gas) & $2000 \mathrm{lb} /$ day \\
Sodium chlorate & $2600 \mathrm{gal} /$ day \\
Sulfuric acid &
\end{tabular}

\subsection{PLUTONIUM CONTAMINATED FACILITIES}

The plutonium contaminated facilities are plants formerly used as mixed oxide or mixed carbide fuel fabrication plants, which are now being decontaminated and decommissioned.

Four plants are used to characterize this type of facility:

1. Babcock and Wilcox Plutonium Facility, Parks Township, Pennsylvania

2. General Electric Nuclear Center, Vallecitos, California

3. Kerr-McGee Plutonium Fuel Plant, Cimarron, Oklahoma

4. Westinghouse Plutonium Fuel Development Laboratory, Cheswick, Pennsylvania.

\subsubsection{Process Description}

\subsubsection{Operation}

During plant operation, the facilities made mixed oxide or mixed carbide fuel using the process discussed below.

Blending was done by mixing $\mathrm{PuO}_{2}$ and $\mathrm{UO}_{2}$ powders, or mixing $\mathrm{PuO}_{2}, \mathrm{UO}_{2}$, and $C$ powders in a reducing atmosphere in high temperatures and milling the resultant product, or mixing plutonium and uranium nitrate solutions and coprecipitating the mixture from solution with the addition of ammonia and drying and calcining the precipitate to form mixed oxide. The powder was then compacted, broken into granules, pressed into pellets, and sintered in a reducing atmosphere. Sintered pellets were ground to a specified size in a centerless grinder and loaded into tubes. 


\subsubsection{Scrap Recovery}

Scrap recovery operations involved solvent extraction and/or ion exchange systems. Scrap was dissolved in nitric acid; uranium and plutonium were separated out onto the organic solvent or resin; then uranium and plutonium were recovered from the organic state and converted to a usable form.

During decontamination, process equipment is taken apart, cleaned, and prepared for shipment to a licensed burial site.

\subsubsection{Facility Description}

\subsubsection{Buildings}

Plutonium contaminated facilities are located on 60-to over 1000-acre sites of which about 60 acres is used to house process buildings. The fabrication plant itself may range from 10,000 to $100,000 \mathrm{ft}^{2}$ in floor space. Operations are usually located on the ground floor, although a basement may also contain radioactive material. If the facility has a second floor, it is usually used for heating, ventilating, and air conditioning (HVAC) equipment.

Individual room sizes range from 200 to $3500 \mathrm{ft}^{2}$ in area with ceiling heights of 12 to over 30 feet. Operations are contained within glove boxes. An average room has about $1400 \mathrm{ft}^{2}$ with 17 glove boxes.

Construction materials are generally concrete and steel. The basement, if provided, is reinforced concrete like the floor slabs. Walls are usually reinforced concrete block, although one of the plants has corrugated steel siding exterior walls and cement plaster interior walls with steel studs. The roof may be metal decking supported by structural steel columns, or steel decking with concrete slab.

Plants may contain a vault and/or a hot cell area, which are built of much more substantial construction than the rest of the plant. Hot cells may have 2- to 3-ft-thick high-density concrete walls.

\subsubsection{Heating, Ventilating, and Air Conditioning Systems}

Plutonium contaminated facilities use from one to three stages of HEPA filters to filter exhaust air. Airflow is always toward areas of greater potential contamination and glove boxes are generally kept at negative pressure with respect to the room. Room air may be recycled.

\subsubsection{Engineered Safety Systems}

Plutonium contaminated plants have automatic fire detection systems that alarm at various locations in the plant. Manual dry chemical fire extinguishers are provided in most locations. Some areas may have automatic dry chemical extinguishing systems or automatic sprinklers. Backup power is provided as well as redundant ventilation systems to protect the final filters from fire. 


\subsubsection{Surrounding Area}

Most plutonium contaminated facilities are located in rural areas outside of small towns. The Kerr-McGee plant is in an oil-producing area; the Westinghouse plant has several gas stations located nearby. Other than that, no potential accident impacts are seen on the plants from their surroundings.

\subsubsection{Inventory}

\subsubsection{Radioactive Inventory}

Mixed oxide fuel plants may have had from 5 to $100 \mathrm{~kg}$ of plutonium and mixed oxide in jeopardy during plant operations. However, very little remains after decontamination.

To provide a reference point for the source term, facilities are assumed to have been emptied of their inventory and initially cleaned so that only ground-in contamination of glove boxes, building surfaces, and ductwork remains. Measurement of maximum residual groynd-in contamination at a fuel cycle facility was $5 \times 10^{-9} \mathrm{~g}$ of plutonium $/ \mathrm{cm}^{2}$ (Mishima and Ayer, 1981). Because of uncertainty about the level of contamination as a conservative value, $1 \times 10^{-4} \mathrm{~g}$ of plutonium $/ \mathrm{m}^{2}$ was used to estimate ground-in contamination (Mishima and Ayer, 1981). This value has been selected for use here.

Plants contain from 50 to 80 glove boxes. At an average, glove box size of $7 \mathrm{ft} \times 3 \mathrm{ft}$, total contaminated areas in the plants (inside of glove boxes) ranges from 570 to $760 \mathrm{~m}^{2}$. Therefore, about 47 to $76 \mathrm{mg}$ of plutonium are present as materials at risk in the facility.

\subsubsection{Hazardous and Combustible Inventory}

During plant operations, chemicals such as nitric acid, ammonia, acetone, hydraulic fluid, tributyl phosphate, and organic solvents were used for various processes. Reducing gases, commonly hydrogen, were required for sintering and calcining steps.

Six basic groups of combustible materials were commonly used in mixed oxide (MOX) plants. An estimate was made of the quantity of each type of material based on the number of glove boxes and glove box construction and use. Table 3.4 lists these materials along with their use and the range of quantities found.

During decontamination and decommissioning operations, the plants may contain more cellulosics and some solvents for cleaning. After decontamination, only the glove boxes themselves are assumed to be left. Viewing windows, rubber gasketing, and plastic covers remain. 
TABLE 3.4. Typical Combustibles in Mixed Oxide Plants

\begin{tabular}{llc}
\multicolumn{1}{c}{ Material } & \multicolumn{1}{c}{ Form } & Quantity, 1b \\
\cline { 3 - 4 } Cellulosics & Papers, rags, wipes & $1600-2250$ \\
Elastomers & Rubber gloves, gaskets & $900-12,175$ \\
Hydraulic fluid & Lubricants & $16-70$ \\
Polymethyl methacrylate & Glove box viewing windows & $4800-6900$ \\
Polystyrene & Ion exchange resin & $50-225$ \\
Polyvinyl chloride & Wrapping, bagging, covers. & $650-920$
\end{tabular}

\subsection{RADIOPHARMACEUTICAL MANUFACTURING}

Radiopharmaceutical manufacturing plants produce radionuclide labeled compounds for medical diagnostics and tracers. They can produce many or only a few isotopes. Four radiopharmaceutical manufacturing facilities were investigated in this study:

1. Abbott Laboratory, North Chicago, 111 inois

2. New England Nuclear (NEN), Boston, Massachusetts

3. New England Nuclear (NEN), North Billerica, Massachusetts

4. E. R. Squibb and Sons, New Brunswick, New Jersey.

Each site was visited during this investigation.

\subsubsection{Process Description}

\subsubsection{Operation}

All four plants label organic compounds with radioisotopes for use by hospitals and reseagch fagilities for patient diagnosis and treatment. Two plants manufacture ${ }^{9}{ }_{M o}{ }^{99}$ TC generators (NEN-Billerica and Squibb) and two perform radioiodination (Squibb and Abbott) of diagnostic substances. At present, the only work at the Abbott facility is radioiodination. Squibb production is about equally divided between radioiodination and generator production. Both NEN sites are involved with a variety of processes.

At the NEN-Boston site, ${ }^{3} H,{ }^{14} \mathrm{C},{ }^{32} \mathrm{p}$, and ${ }^{35} \mathrm{~S}$ constitute the bulk of isotopes handled; it is the only façility of the four handling ${ }^{14} \mathrm{C},{ }^{32} \mathrm{P}$, and ${ }^{35}$. Large quantities of tritium, ${ }_{H}$, are also handled at this site. Production, precursor, and synthesis labs for tritium products represent a sizable portion of the operation. I3zaddition to gegerators, Billerica produces pharmaceuticals containing $\mathrm{Xe}, \mathrm{Ga}$, and ${ }^{2} \mathrm{Tl}$. Billerica also operates a source division, which handles a variety of isotopes, many produced by their own cyclotrons. 
Labeling organic products is usually a wet chemistry process conducted in fume hoods or glove boxes. Abbott and Squibb have small laboratories containing one or two hoods or glove boxes for labeling operations. New England Nuclear uses large areas containing many hoods and glove boxes. Packaging and shipping is generally an assembly line operation at all sites except Abbott, whose small size precludes this approach. All of the plants have quality control labs.

Generators are groduced in an assembly line type of operation. Billerica and Squibb load the ${ }^{9}$ Mo generators in a remote cell. Generators are transferred by conveyors.

Radiopharmaceutical manufacturers can purchase isotopes from vendors. At all sites, radioactive materials arrive by truck to a warehouse/loading dock type area. The largest concentration of activity in these areas is usually on receiving days, which may be one to three times a week. At Billerica and Squibb shipments leave through this area.

Curie amounts of isotopes may be received in bulk shipments and are dispensed for production. The radiopharmaceuticals produced by these plants are generally in the microcurie to millicurie range. Generators may each contain a maximum of about 2 Ci.

\subsubsection{Waste Disposal}

Al1 sites produce similar waste products, although both quantities and activity levels of wastes vary. Lab trash--paper, glassware, and clothing--is a common waste form. Rejected products, generators, and vials of compounds, for example, are disposed of as radioactive waste. Liquid waste can be solidified and drummed (NEN) or held for decay and discharge after sludge removal (Squibb and Abbott). New England Nuclear-Boston ships its waste to Billerica. The other three facilities have separate waste warehouse areas. Forklifts fueled by LPG or electricity can be used to move drums.

\subsubsection{Facility Description}

\subsubsection{Buildings}

Facilities usually have buildings specifically designed for radiopharmaceutical operations. Concrete, concrete block, brick, and steel are used in construction. Radioactive areas are isolated from nonradioactive areas and buildings can be isolated to minimize the risk of spreading contamination. However, the NEN-Boston production building is a converted wood and brick warehouse that was constructed about 1890. This building is adjacent to another production building designed for handling radioactivity, and because they are close, a major fire in one could spread quickly to the other.

Waste warehouses associated with these facilities are concrete and steel buildings with concrete floors. 


\subsubsection{Heating, Ventilating, and Air Conditioning Systems}

All sites have central heating and air conditioning. High-efficiency particulate air and charcoal filters are commonly used for air cleaning. Ductwork is sheet metal except at NEN-Boston, which has some polyvinyl chloride (PVC) ducting. Warehouse areas are usually heated with gas or electric space heaters.

\subsubsection{Engineered Safety Systems}

Sprinklers, fire alarms, exhaust air monitors, and radiation detectors are used at all the facilities. Construction materials at the Billerica, Squibb, and Abbott buildings promote fire suppression.

\subsubsection{Surroundings}

New England Nuclear-Boston is located in downtown South Boston in a commercial district. The other sites are in rural or sparsely populated residential areas. Squibb and Abbott radiopharmaceutical labs are a small part of larger facilities.

\subsubsection{Inventory}

\subsubsection{Radioactive Inventory}

Table 3.5 lists the license inventory range of some of the more significant isotopes found at radiopharmaceutical manufacturers.

Of the four plants, both NEN facilities handle by far the greatest levels of activity. The largest permissibleactivity level is $1.0 \times 10^{5} \mathrm{Ci}$ of tritium at NEN. Abbott's limit of $75 \mathrm{Ci}$ of ${ }^{25}{ }_{1}$ is one of the smaller holdings.

Although all the licenses permit possession of isotopes with atomic numbers in the range of 3 to 83 , only NEN possesses a wide variety, 1 and these are primarily at the sougge djgision at Billerica. Abbott handles ${ }^{125}$ I only; squibb handles ${ }^{3}$ and ${ }^{99} \mathrm{Mo} /{ }^{99 \mathrm{~m}} \mathrm{TC}$ on $7 \mathrm{y}$.

Waste inventories range from 1 to $10 \mathrm{Ci}$ at all sites except Billerica where $10^{4} \mathrm{Ci}$ of tritium waste may be stored.

\subsubsection{Hazardous and Combustible Inventory}

Organic chemistry operations require the use of hazardous combustible liquid solvents. All facilities use these materials, although again the amount on hand varies with the size of the operation. Solvents and other chenicals are generally stored in glass bottles with a capacity of 1 gal or less.

Lab paper, cardboard shipping containers, plastic containers, PVC piping, acoustic tiles, and similar materials are found at all sites. Glove boxes can 
TABLE 3.5. Significant Inventories of Isotopes Licensed for Radiopharmaceutical Manufacturers

\begin{tabular}{|c|c|c|c|}
\hline Element & I sotope & Possible Form & $\begin{array}{l}\text { Inventory or } \\
\text { Range, } \mathrm{Ci}\end{array}$ \\
\hline Americium & $241_{A m}$ & Sealed source & 350 \\
\hline Carbon & ${ }^{14} \mathrm{C}$ & $\begin{array}{l}\text { Gas, labeled barium } \\
\text { carbonate, lab trash }\end{array}$ & 500 \\
\hline Cesium & ${ }^{137} \mathrm{Cs}$ & $\begin{array}{l}\text { Lab trash, } \mathrm{HCl} \\
\text { solution }\end{array}$ & 1 to 500 \\
\hline Chromium & ${ }^{51} \mathrm{Cr}$ & $\mathrm{HCl}$ solution & 0.001 to 100 \\
\hline Hydrogen & $3_{H}$ & Gas in cylinders & 10 to $1 \times 10^{5}$ \\
\hline Gold & ${ }^{198} \mathrm{Au}$ & $\mathrm{HCl}-\mathrm{HNO}_{3}$ solution & 200 \\
\hline Iodine & $\begin{array}{l}125 \\
131 \\
13\end{array}$ & $\begin{array}{l}\text { Lab trash, NaI } \\
\text { Lab trash, liquid }\end{array}$ & $\begin{array}{l}2 \text { to } 100 \\
10 \text { to } 150\end{array}$ \\
\hline Iron & $55_{\mathrm{Fe}}$ & $\mathrm{HCl}$ solution & 200 \\
\hline Krypton & $85_{k r}$ & Gas & $1 \times 10^{4}$ \\
\hline Molybdenum & ${ }^{99}$ Mo & $\begin{array}{l}\text { Generator, } \mathrm{NH}_{4} \mathrm{OH} \\
\text { solution }\end{array}$ & $2 \times 10^{3}$ \\
\hline Nickel & ${ }^{63} \mathrm{Ni}$ & Solid, $\mathrm{HCl}$ solution & $1 \times 10^{3}$ \\
\hline Phosphorous & $32 p$ & $\mathrm{H}_{3} \mathrm{PO}_{4}$, lab trash & 50 to 500 \\
\hline Selenium & ${ }^{75} \mathrm{Se}$ & $\mathrm{HCl}$ solution & 5 to 100 \\
\hline Strontium & ${ }^{90} \mathrm{Sr}$ & $\begin{array}{l}\text { Solid, encapsulated, } \\
\mathrm{HCl} \text { solution }\end{array}$ & 100 to 500 \\
\hline Sulfur & $35_{S}$ & $\begin{array}{l}\mathrm{H}_{2} \mathrm{SO}_{4} \text {, sodium } \\
\text { sulfate, elemental } \\
\text { sulfur, in benzene }\end{array}$ & 100 to $1 \times 10^{3}$ \\
\hline Xenon & $133 \mathrm{xe}$ & Gas in vials. & $1 \times 10^{3}$ \\
\hline
\end{tabular}


be Plexiglass, as used at NEN. Some or all of the following combustibles are used at all but the Abbott lab: oxygen, hydrogen, propane, and natural gas.

Billerica has a small surface tank farm for storing diesel and gasoline fuel for vehicles. Squibb and NEN-Boston have underground diesel fuel tanks to store fuel for emergency generators.

\subsection{RADIOPHARMACY}

Radiopharmacies receive radiopharmaceuticals and distribute them for use by hospitals and medical research facilities. They are not production facilities and thus do minimal handling of the isotopes. A hospital will either have its own radiopharmacy or, as is becoming common in large metropolitan areas, order radiopharmaceuticals from one or more private radiopharmacy firms serving as central distribution points for all hospitals and research facilities in the area. In the latter case, centralizing the firms increases the transportation requirements because a single firm serving a number of clients must provide for distribution of the required material.

Information in this section was taken from the Ohio State University Radiological Contingency Plan for its hospital and nuclear pharmacy, and from a site visit to a private radiopharmacy in Seattle, Washington. Data on radioactive inventories were developed from a number of NRC licenses for private radiopharmacies.

\subsubsection{Process Description}

3.7.1.1 Operation

A radiopharmacy receives shipments of radiopharmaceuticals from vendors either in bulk quantities or as prepackaged diagnostic kits. In the latter case, the pharmacy merely holds the material until it is required for use by the hospital. Bulk material can be ${ }^{99} \mathrm{Mo} /{ }^{99 m_{T}}$ generators. The radiopharmacy prepares individual doses by loading the required activity into a syringe, a process usually conducted in a fume hood. If other bulk materials are handled (e.g., iodine-labeled compounds), they may be dispensed in glove boxes. After individual doses are prepared, they are transported elsewhere for use.

\subsubsection{Waste Disposal}

Waste generated at a radiopharmacy can include used generators and storage packs and miscellaneous laboratory equipment such as paper, glassware, and used syringes. These materials are collected in a central area and held for shipment to a disposal site or stored until decayed sufficiently for disposal with nonradioactive materials. Material can be uncontained (generators) or contained in cardboard boxes or in drums.

\footnotetext{
(3) Plexiglas is a trademark of Rohm and Haas, Philadelphia, PA 19105
} 


\subsubsection{Facility Description}

\subsubsection{Buildings}

Building design and construction is not standardized. A firm in Seattle, Washington, occupies a concretg-block building consisting of a small labora-

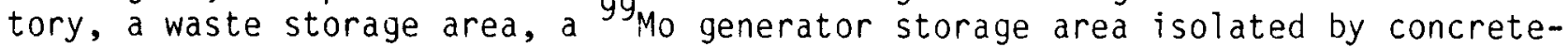
block cubicles, offices, and a shipping and receiving area. The Ohio State University nuclear pharmacy is located in a hospital building and is a single large room housing a fume hood, glove box, concrete and lead isotope storage area, and work space. A separate room adjacent to the pharinacy houses the waste storage.

\subsubsection{Heating, Ventilating, and Air Conditioning Systems}

Radiopharmacies usually have standard heating and ventilating systems found in business locations. Electric baseboard heating or centrally supplied heating and air conditioning are both identified for radiopharmacies. Fume hoods and glove boxes have their own air discharge systems, and special filtration is not identified.

\subsubsection{Engineered Safety Systems}

Fire extinguishers and/or sprinkler systems are used at radiopharmacies. Exhaust air discharge from hoods or glove boxes may be monitored and alarmed to notify personnel of an emergency.

\subsubsection{Inventory}

\subsubsection{Radioactive Inventory}

Typical radiopharmacy inventories age gixgn in Table 3.6. Not all firms

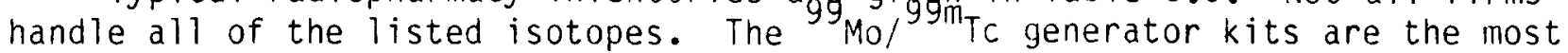
common, followed by iodine-labeled compounds. Actual inventories on hand may be lower than the tabulated values. Short half-lives of many of the isotopes indicated that there is either a fairly rapid turn around of inventories, or isotopes are ordered only as needed on an intermittent basis.

\subsubsection{Hazardous and Combustible Inventory}

Radiopharmacies may use limited amounts of solvents such as methanol for cleaning equipment. Combustibles include builging materials and miscellaneous paper and cardboard shipping containers. The ${ }^{99} \mathrm{Mo} /{ }^{99 \mathrm{~m}} \mathrm{TC}$ generators can be shielded by a 10-1b cask filled with depleted uranium.

\subsection{SEALED SOURCE MANUFACTURING}

Facilities in this category produce sealed sources and self-lumirious devices. The types of processes, radioactive material inventories and businesses vary widely. Nine sealed source manufacturing facilities were investigated in this study: 
TABLE 3.6. Representative Radiopharmacy Inventories

\begin{tabular}{|c|c|c|c|}
\hline Element & Isotope & Possible Form & $\begin{array}{c}\text { Inventory or } \\
\text { Range, } \mathrm{Ci}\end{array}$ \\
\hline Barium & $133_{\mathrm{Ba}}$ & Sealed source & $3 \times 10^{-3}$ \\
\hline Carbon & ${ }^{14} \mathrm{C}$ & In vitro test kits & $5 \times 10^{-3}$ \\
\hline Chromium & ${ }^{51} \mathrm{Cr}$ & $\begin{array}{l}\text { Sodium chromate } \\
\text { labeled serum }\end{array}$ & 0.013 to 0.02 \\
\hline Cesium & ${ }^{137} \mathrm{Cs}$ & Sealed source & $\begin{array}{l}2.0 \text { to } 10^{-4} \text { to } \\
1 \times 10^{-3}\end{array}$ \\
\hline \multirow[t]{3}{*}{ Cobalt } & ${ }^{57} \mathrm{Co}$ & $\begin{array}{l}\text { Cyanocobalamin } \\
\text { (vitamin B12) }\end{array}$ & $1.4 \times 10^{-4}$ \\
\hline & ${ }^{58} \mathrm{Co}$ & Labeled cyanocobalamin & $5 \times 10^{-3}$ \\
\hline & ${ }^{60} \mathrm{Co}$ & Sealed source & 2 to 3 \\
\hline Gallium & ${ }^{67} \mathrm{Ga}$ & Gallium & 1.2 \\
\hline Gold & ${ }^{198} \mathrm{Au}$ & Colloidal & 0.5 \\
\hline Hydrogen & ${ }^{3} \mathrm{H}$ & In vitro test kits & 0.01 to 0.5 \\
\hline \multirow[t]{2}{*}{ Indium } & $111_{\text {In }}$ & Indium & 0.049 \\
\hline & ${ }^{113} \mathrm{In}$ & Indium chloride & 0.5 \\
\hline \multirow[t]{3}{*}{ Iodine } & ${ }^{123} \mathrm{I}$ & Sodium iodide & 0.19 \\
\hline & ${ }^{125} \mathrm{I}$ & $\begin{array}{l}\text { Sodium iodide, fibrogen } \\
\text { diagnostic kits }\end{array}$ & $\begin{array}{l}2.5 \times 10^{-4} \\
\text { to } 0.1\end{array}$ \\
\hline & $131_{I}$ & $\begin{array}{l}\text { Sodium iodide, labeled } \\
\text { organic compounds }\end{array}$ & 0.1 to 4.5 \\
\hline Iron & $59 \mathrm{Fe}$ & & 0.01 to 0.02 \\
\hline Molybdenum & ${ }^{99} \mathrm{Mo} /{ }^{99 \mathrm{~m}_{\mathrm{TC}}}$ & Generators (1iquid) & 20 to 426 \\
\hline Selenium & ${ }^{75} \mathrm{Se}$ & Labeled compound & 0.05 \\
\hline Strontium & ${ }^{90} \mathrm{Sr}$ & Nitrate or chloride & 0.01 to 0.5 \\
\hline Thallium & ${ }^{201} T 1$ & Thallium & 2.1 \\
\hline Tin & ${ }^{113} \mathrm{Sn}$ & ${ }^{113} \mathrm{Sn} /{ }^{113 \mathrm{~m}_{\mathrm{In}}}$ generators & 0.06 to 0.5 \\
\hline Uranium & $238_{U}$ & Shielding for generators & $91 \mathrm{~kg}$ \\
\hline Xenon & ${ }^{133} \times e$ & Gas or saline & 0.5 to 75 \\
\hline
\end{tabular}


1. Amersham Corporation, Arlington Heights, Illinois

2. Automation Industries, Phoenixville, Pennsylvania

3. Micro Display Systems, Inc., Norristown, Pennsylvania

4. Minnesota Mining and Manufacturing (3M), New Brighton, Minnesota

5. Monsanto Research Corporation, Dayton, Ohio

6. Pan American World Airways, Kennedy Space Center, Florida

7. Safety Light Corporation, Bloomsburg, Pennsylvania

8. Stocker and Yale, Inc., Beverly, Massachusetts

9. Technical Operations, Burlington, Massachusetts.

Information used for descriptions of sealed source manufacturers was developed from NRC dockets for all firms and Radiological Contingency Plans for $3 \mathrm{M}$, Monsanto, and the Safety Light Corporation.

\subsubsection{Process Description}

\subsubsection{Operation}

Sealed-source production may be divided into two areas: 1) production of doubly encapsulated alpha, beta, and gamma radiation sources; and 2) production of self-luminous devices for use in watches, compasses, and aircraft instrumentation. Although within the first category not all sources will be doubly encapsulated, this is the most prevalent means to ensure safe handiing of the isotopes. Such sources may be used in instruments, as reference sources, as calibration sources, or in smoke detectors. Self-luminous devices usually are gaseous tritium sealed in a phosphor-coated glass ampule.

Sealed-source production methods vary, but in general consist of receiving the bulk isotope in an approved shipping container, dispensing the material in the required amounts in an appropriate containment, placing the material in an inner capsule that is welded or brazed, then sealing the inner capsule in an outer capsule that is also welded or brazed closed. Thus little actual chemical processing occurs; rather, the operations are more a repackaging and redistribution process. The $3 M$ facility goes through a series of steps to convert the raw isotope to microspheres prior to encapsulation, and this operation involves some chemical processing. Tritium light source production usually requires that the gaseous tritium be transferred to a glass ampule, although in some cases a tritiated paint is produced for application to watch or compass dials.

\subsubsection{Waste Disposal}

Solid waste is usually produced by these firms. Liquid waste may be held for decay before discharge to sewer systems, but more frequently is solidified and then treated as solid waste. Most facilities have a special waste storage area where 55-gal steel drums are held awaiting disposal at an approved site. Because much of the waste can have a high specific activity, it is frequently collected inside a hot cell or glove box and stored there in special containers. The waste is removed from the containment periodically and transferred to the waste storage area for final packaging and disposal. 


\subsubsection{Facility Description}

\subsubsection{Buildings}

Building design and materials show some consistency. Most radiation areas are separated from other buildings, or, if in a main building, are separated by special walls. Work areas tend to be divided into smaller modules for labs, glove box areas, hot cells, storage, and services. Construction materials are most often reinforced concrete or concrete block on a concrete slab. Roofing materials are frequently metal paneling with an asphalt (tar) surface. Interior walls are usually standard dry wall. A few facilities have wood paneling for outside walls. Sometimes work areas or storage areas for sources are in concrete below grade sheltered areas or bunkers.

\subsubsection{Heating, Ventilating, and Air Conditioning Systems}

Ventilation in radiation areas almost always consists of air inflow from a central system exhausting through fume hoods or glove boxes operating at negative pressure. Hot cells usually have their own nonrecirculatory ventilation systems. Discharge is usually through two high-efficiency filters in series: one at the containment exhaust port and the other at the discharge stack.

\subsubsection{Engineered Safety System}

Buildings can be made of reinforced concrete construction to provide a strong facility. Sites may have below grade bunkers for storage of large radioactive inventories.

Ventilation and other services can be monitored using alarmed systems to warn of contamination spread. Buildings have sprinkler systems, and fire extinguishers can be provided.

\subsubsection{Surrounding Area}

Most sites are located in urban industrialized areas. A number of potential problem areas are located near the 3M site: propane storage, fuel oil storage, ammunition, and gun powder storage.

\subsubsection{Inventory}

\subsubsection{Radioactive Inventory}

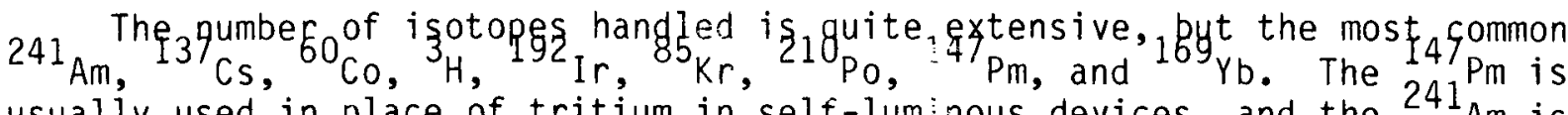
usualiy used in place of tritium in self-luminous devices, and the ${ }^{241} \mathrm{Am}$ is most often used in smoke detectors. The other isotopes are used to produce alpha, beta, and gamma double encapsulated sources. Isotopes frequently require handling in hot cells. Other isotopes are handled only in glove boxes.

Most of the radioactive materials watie in solid forms: gauzes, metallic wafers or foils, or powders. Tritium is handled as a gas. 
Radioactive inventories vary widely among the licensees. Some are permitted only millicurie amounts of a particular isotope, usually as a purchased sealed source for reference calibrations, while others may be permitted to possess several thousands of gyries of that isotope. For example, $3 M$ is allowed to possess $200 \mathrm{Ci}$ of ${ }^{\mathrm{C}} \mathrm{C}$, while Tech/Ops, Inc. is permitted $15,000 \mathrm{Ci}$. The largest single possession limit is $100,000 \mathrm{Ci}$ of ${ }_{H}$ by the Safety Light Corporation. Significant maximum license inventories at sealed source manufacturers are listed in Table 3.7 .

\subsubsection{Hazardous and Combustible Material}

Hazardous materials are generally kept to a minimum in any areas where isotopes are handled. Some solvents such as isopropyl alcohol may be used to clean encapsulated sources. Minnesota Mining and Manufacturing uses some $\mathrm{HNO}_{3}$, $\mathrm{NaOH}$ solutions, and other potentially hazardous materials during microsphere production, but quantities are limited. Because most capsules are welded or brazed, tungsten or acetylene welders are used inside glove boxes or hot cells.

\subsection{RESEARCH AND DEVELOPMENT OF NUCLEAR FUELS}

Plants in this category develop methods of fuel preparation and perform analysis of radioactive materials, particularly those materials used as fuel. Four facilities were included in this category:

1. Isotopic Analysis, Inc., Tulsa, Oklahoma

2. Lynchburg Research Center, Lynchburg, Virginia

3. Rockwell Nuclear Development Fuel Laboratory, Santa Susana, California

4. Westinghouse Electric Corporation, Waltz Mill, Pennsylvania.

\subsubsection{Process Description}

\subsubsection{Operation}

Research and development activities may include transfer of irradiated fuel elements into hot cells where the elements are declad and fuel is tested and examined. Fuel elements may be stored temporarily on site in pools designed for their storage.

Development of fuel manufacturing processes takes place in laboratories and glove box trains. Operations such as blending, crushing, milling, sintering, and grinding may take place depending on the process undergoing study. Samples are taken at different points in the process and studied in a number of labs. Analytical chemistry, radiochemistry, and other types of labs are used to analyze samples.

The larger research and development facilities, Lynchburg Research Center and Rockwell, are part of a larger complex devoted to the development of nuclear energy. 
TABLE 3.7. Significant $(a)$ Maximum License Inventories at Sealed Source Manufacturers

\begin{tabular}{|c|c|c|c|}
\hline Element & Isotope & Manufacturer & $\begin{array}{c}\text { Maximum } \\
\text { Inventory, } \mathrm{Ci}\end{array}$ \\
\hline Americium & $241_{A m}$ & Monsanto & $6 \times 10^{3}$ \\
\hline Cesium & ${ }^{137} \mathrm{Cs}$ & $3 M$ & $8 \times 10^{4}$ \\
\hline Cobalt & ${ }^{60} \mathrm{Co}$ & Automation Industries & $2 \times 10^{4}$ \\
\hline Hydrogen & $3_{H}$ & Safety Light & $1 \times 10^{5}$ \\
\hline Iridium & ${ }^{192}$ Ir & Automation Industries & $2.5 \times 10^{4}$ \\
\hline Krypton & $85_{K r}$ & $3 M$ & $1.5 \times 10^{3}$ \\
\hline Polonium & $210_{\mathrm{Po}}$ & $3 M$ & $4 \times 10^{3}$ \\
\hline Promethium & $147 \mathrm{Pm}$ & $3 M$ & $3.5 \times 10^{3}$ \\
\hline Strontium & ${ }^{90} \mathrm{Sr}$ & $3 M$ & $3 \times 10^{3}$ \\
\hline Tantalum & ${ }^{183} \mathrm{Ta}$ & Tech/Ops & $2 \times 10^{3}$ \\
\hline Thulium & ${ }^{170} \mathrm{Tm}$ & Tech/Ops & $5 \times 10^{3}$ \\
\hline Plutonium $(b)$ & $\begin{array}{c}236,239,240 \\
241,242 \mathrm{pu}\end{array}$ & Monsanto & $199 \mathrm{~g}$ \\
\hline Uranium (b) & Depleted U & $\begin{array}{l}\text { Pan American World } \\
\text { Airways }\end{array}$ & $15,000 \mathrm{~kg}$ \\
\hline
\end{tabular}

(a) Inventories over $1 \times 10^{3} \mathrm{Ci}$

(b) Not a sealed source

\subsubsection{Waste Disposal}

Solid radioactive waste is packaged in approved shipping containers and stored on site prior to shipment to a licensed waste disposal facility. The smaller facilities may ship unused materials back to the customer.

Liquid radioactive waste is handled on site in waste processing facilities. Liquid waste may be retained in large basins or combined with liquid radioactive waste generated from other facilities nearby. Treatment systems may include activated charcoal, ion exchange columns, or various chemical treatment systems.

\subsubsection{Facility Description}

\subsubsection{Buildings}

Laboratories may be constructed of concrete and steel, brick and cement, or cinder block. Vaults are usually provided within the laboratories for 
storage of nuclear materials. Vault walls usually withstand greater stresses than the buildings in which they are contained and may be 12-in.-thick concrete. Hot cells are provided for larger facilities in which examination or testing of fuel rods takes place. Hot cell walls may be 11- to 13-in. lead or $42-$ in. concrete.

\subsubsection{Heating, Ventilating, and Air Conditioning Systems}

Hot cells, glove boxes, fume hoods, and other types of containment generally operate under separate exhaust systems from the rest of the plant. Exhaust from areas containing radioactive materials is filtered through a prefilter and a HEPA filter before being exhausted to the atmosphere.

Airflow is toward areas of greater potential contamination. Except for special materials such as sodium, which is highly reactive with air, glove boxes, and hot cells are kept at negative pressure to ensure this condition. Sodium is kept under an inert atmosphere at positive pressure.

Hot cells and other glove boxes may also be provided with an inert gas purge system. This prevents potential reactions and acts as a fire extinguishing system.

\subsubsection{Engineered Safety Systems}

Monitors for radiation levels, smoke detection, heat detection, and potential criticality situations are located in most facilities. Alarms are provided that trigger at specified levels. Hot cells usually have some form of automatic fire extinguishing system. Inert gas may be used to flood the cell and smother the fire. Manual fire extinguishers, both water and dry chemical, may be found throughout the facilities.

\subsubsection{Surroundings}

Plants are generally located in low population areas with the nearest town several miles away. Other nuclear facilities such as fuel manufacturing or test reactors may share the site, but operate under separate licenses.

\subsubsection{Inventory}

\subsubsection{Radioactive Inventory}

Nuclear Fuel Research and Development facilities may be licensed to hold as many as three irradiated fuel assemblies and 40 irradiated Lynchburg Pool Reactor (LPR) fuel elements. These materials are stored and handled in the storage pool and hot cell areas of the plant. The Rockwell plant has a license limit of $3.5 \mathrm{~kg}$ of plutonium in the hot cell building, although only 600 to $805 \mathrm{~g}$ of plutonium (the amount in three fuel rods) are in process at one time.

In larger plants where glove box trains are used for development of fuel manufacturing processes, license limits may restrict plutonium inventory to 1 
to $2 \mathrm{~kg}, 235 \mathrm{U}$ to 900 to $1500 \mathrm{~kg}$, and $232 \mathrm{U}$ to $1 \mathrm{tg} 5 \mathrm{~kg}$. A glove box may contain as much as $225 \mathrm{~g}$ of plutonium and $540 \mathrm{~g}$ of $235_{\mathrm{U}}$.

Analytical labs handle much smaller samples of radioactive materials. The amount of uranium and plutonium per sample may be hundredths of a gram. The maximum quantity of these materials in process in the lab at one time may be $5 \mathrm{~g}$ of plutonium, and $334 \mathrm{~g}$ of uranium. Other radioactive materials are also analyzed in the labs. These elements and elements used as sealed sources are listed in Table 3.8 .

TABLE 3.8. Radioactive Material Found as Sealed Sources or Analytical Quantities at Nuclear Fuel Development Laboratories

\begin{tabular}{|c|c|c|}
\hline Element & Isotope & $\begin{array}{l}\text { Licensed } \\
\text { Quantity }\end{array}$ \\
\hline Americium & ${ }^{24} 1_{\mathrm{Am}}$ & $30 \mathrm{Ci}$ \\
\hline Barium & ${ }^{133} \mathrm{Ba}$ & $0.1 \mathrm{Ci}$ \\
\hline Californium & ${ }^{252} \mathrm{Cf}$ & $4 \mathrm{mg}$ \\
\hline Cesium & ${ }^{134} \mathrm{Cs}$ & $0.1 \mathrm{Ci}$ \\
\hline Cesium & ${ }^{137} \mathrm{Cs}$ & $0.1 \mathrm{Ci}$ \\
\hline Cobalt & & $0.1 \mathrm{Ci}$ \\
\hline Cobalt & ${ }^{60} \mathrm{Co}$ & $0.1 \mathrm{Ci}$ \\
\hline Hydrogen & $3_{H}$ & $100 \mathrm{Ci}$ \\
\hline Krypton & ${ }^{85} \mathrm{Kr}$ & $0.1 \mathrm{Ci}$ \\
\hline Manganese & ${ }^{54} \mathrm{Mn}$ & $0.1 \mathrm{Ci}$ \\
\hline Neptunium & ${ }^{237} \mathrm{~Np}$ & $0.1 \mathrm{Ci}$ \\
\hline Plutonium & ${ }^{239} \mathrm{Pu}$ & $1 \mathrm{~kg}$ \\
\hline Plutonium & & $0.5 \mathrm{~kg}$ \\
\hline Sodium & ${ }^{22} \mathrm{Na}$ & $0.1 \mathrm{Ci}$ \\
\hline Strontium & & $0.1 \mathrm{Ci}$ \\
\hline Xenon & ${ }^{135} \mathrm{xe}$ & $0.1 \mathrm{Ci}$ \\
\hline
\end{tabular}

\subsubsection{Hazardous and Combustible Inventory} plants:

Various types of hazardous and combustible materials are found at the

- When decladding operations take place in hot cells, pyrophoric zircaloy metal grindings may be produced. These are normally kept in a medium designed to inhibit combustion. 
- Solvents and other flammable liquids used in the hot cells in the decladding process or in the labs are kept in special storage cabinets away from radioactive materials. Smaller quantities, generally limited to $1 \mathrm{~L}$, or in some cases 5-gal containers are brought out as needed.

- Bagging material, needed to transfer nuclear material into and out of containment, is another common combustible waste.

- Glove boxes with rubber gloves are used in process development. Some glove boxes have Plexiglas ${ }^{\circledR}$ windows.

- Natural gas may be used for heating.

- Diesel oil is generally stored away from the plant for use in emergency power generation.

- Ion exchange resins may be used in liquid waste purification systems. These are also located away from the plant.

\subsection{WASTE WAREHOUSING}

Waste warehouses receive and store radioactive waste temporarily awaiting shipment to a licensed burial ground for disposal. The description of waste warehousing facilities was based on docket information on the three following companies:

1. Atomic Disposal, Inc., Tinley Park, Illinois

2. Interex Corporation, Natick, Massachussets

3. Teledyne Isotopes, Inc., Westwood, New Jersey.

A site visit to the waste storage facility of New England Nuclear Radiopharmaceutical Manufacturing Plant in Billerica, Massachusetts, also provided us with information.

\subsubsection{Process Description}

\subsubsection{Operations}

Radioactive waste in 5-, 30-, and 55-gal drums is transported to the waste storage facility. The waste is monitored and a smear test is taken to determine the radioactive contamination level. Containers must not exceed $200 \mathrm{mR} / \mathrm{h}$ at the surface. Drums are marked as to contents and radioactivity and stored for not more than 6 months before being transported to a licensed radioactive burial ground. Drums are not allowed to be opened while in transport to and from storage and while in storage in the Teledyne and Interex faciliies. The Atomic Disposal facility is planning an opening and repackaging area in the warehouse. 


\subsubsection{Facility Description}

\subsubsection{Buildings}

Waste may be stored in a trailer or a warehouse type of building. Sizes ranges from 600 to $2045 \mathrm{ft}^{2}$ with ceiling heights of 10 to $20 \mathrm{ft}$. If windows are provided, they are protected by steel mesh. A rollup door may be provided in a warehouse to allow movement of drums into and out of the facility.

\subsubsection{Heating, Ventilating, and Air Conditioning Systems}

Not much information is available on the ventilation systems in the waste warehousing facilities studied. The assumption is made that no active ventilation system is in operation. No HEPA filters are in place to filter air. The rollup doors provide open circulation to the facility.

The Atomic Disposal site has four fume absorbers in the proposed drum handling room where opening and repackaging of drums is planned. The system provides seven air changes per hour and flow through $98 \%$-efficient charcoal filters.

\subsubsection{Engineered Safety Systems}

Waste warehousing storage areas may be provided with sprinklers or $\mathrm{CO}_{2}$ automatic fire extinguishers. Radiation surveys of the facility are done routinely.

\subsubsection{Surrounding Area}

Storage buildings may be located next to office buildings or radiochemical laboratories. The Billerica site has two gas tanks located near the warehouse.

\subsubsection{Inventory}

\subsubsection{Radioactive Inventory}

Drums may contain animal carcasses preserved in a chemical and packed in plastic bays; scintillation vials containing 10 to $12 \mathrm{~cm}^{3}$ of fluid each and packed in an absorbent; contaminated combustibles such as gloves, rags, wipes, plastic lab equipment; small amounts of liquid radioactive waste in absorbent and double drummed; or other types of waste generated from a hospital, clinical lab, or radiochemistry lab.

The Atomic Disposal site has an inventory of $24 \mathrm{Ci}$ in about 2200 drums. A listing of the radionuclides in the inventory is given in the individual description of the plant in Appendix I.

License limits range from 25 to $2000 \mathrm{Ci}$ of by-product materials other than $3_{\mathrm{H}}$ and 2000 to $5000 \mathrm{Ci}$ of $3 \mathrm{H}$. From 220 to $12,500 \mathrm{lb}$ of source material is permitted, and from 75 to $200 \mathrm{~g}$ of special nuclear material such as $233 \mathrm{U}$ and $235 \mathrm{U}$ are allowed. 


\subsubsection{Hazardous and Combustible Inventory}

Much of the waste in the druns is combustible. Gloves, cellulosic materials, plastic lab equipment, and contaminated clothing may be in the drums, as well as combustible solvents in scintillation vials.

The transport vehicle (a forklift in the Billerica Storage Building) may be fueled with a flammable liquid. Gas heaters may also be located in the waste storage facility.

\subsection{UNIVERSITY RESEARCH AND DEVELOPMENT}

University research and development facilities receive radioactive materials at a central receiving point and distribute them to various laboratories where research projects take place. Diagnosis and therapy using nuclear materials at the universities are also covered in the licenses.

Information characterizing university research and development operations was gathered from docket materials on the following seven facilities and from a site visit to a representative facility in an agreement state:

1. Harvard University, Cambridge, Massachusetts

2. Michigan State University, East Lansing, Michigan

3. Ohio State University, Columbus, Ohio

4. Oral Roberts University, Tulsa, Oklahoma

5. University of Illinois, Urbana, Illinois

6. University of Wisconsin, Madison, Wisconsin

7. University of Wyoming, Laramie, Wyoming.

\subsubsection{Process Description}

\subsubsection{Operation}

Radioactive materials are shipped into a central receiving area. Packages contain millicurie amounts of isotopes double or triple packaged to prevent puncture or breakage during shipping. A typical example is a few cubic centimeters of radioactive liquid in a plastic container surrounded by styrofoam in a cardboard box. Lead pigs are used as shipping containers for those isotopes requiring shielding.

Packages may be checked at a central office for leakage or distributed to the individual labs and checked. Facilities may have from 30 to 500 laboratories where radioactive materials may be handled.

In the labs, millicurie amounts of radioactive materials are used to label compounds for reseagch şfudies. 35 abs may contain up to 10 to $25 \mathrm{Ci}$ of isotopes such as ${ }_{\mathrm{H},}{ }^{14} \mathrm{C}$, ${ }^{2} 5_{\mathrm{I}},{ }^{32} \mathrm{P}$, and ${ }^{35} \mathrm{~S}$. Lab coats, protective clothing, rubber or plastic gloves, wipes, paper towels, and other combustibles may be used in the process as well as solvents or organic liquids in liter quantities or less. Special hot laboratories may handle as much as $50 \mathrm{mC} i$ of material. 
In some universities animals are injected or implanted with microcurie to millicurie amounts of radioisotopes in various forms such as solutions, capsules, or wire. The animals are isolated while under study. Animal wastes and carcasses are monitored and disposed of through radioactive waste disposal.

Sealed sources containing hundreds of millicurie to $1 \mathrm{Ci}$ per source are used for training programs, measurement devices, and assays. The sources are checked periodically for leakage and are contained within instruments. Some sources may be taken off site if specified in the license.

As much as $100 \mathrm{mCi}$ amounts of some isotopes may be used off campus for field experiments. The location, amount, and type of isotope is specified in the license along with descriptions of the application and monitoring procedure for its use. These materials are divided in smaller units of microcurie to millicurie amounts before being implanted or injected into plants or animais for various studies. Carbon-14, ${ }^{35} \mathrm{~S},{ }^{32} \mathrm{P}$, and ${ }^{3} \mathrm{H}$ are commonly used isotopes for these studies.

Diagnosis and therapy involving radioactive material can be performed in a hospital. Common diagnosis and therapy operations are injections or oral administration of 10 to $30 \mathrm{mC} i$ amounts of $131 \mathrm{I}$; implant of $40 \mathrm{mC} i$ amounts of ${ }^{125}$ I seedş; injection of $10 \mathrm{mCi}{ }^{99 \mathrm{~m}} \mathrm{TF}{ }^{90} \mathrm{Sr}$ eye application; injection of up or ${ }^{192}$ Ir as wires or seeds. Patients are hospitalized until the residual,

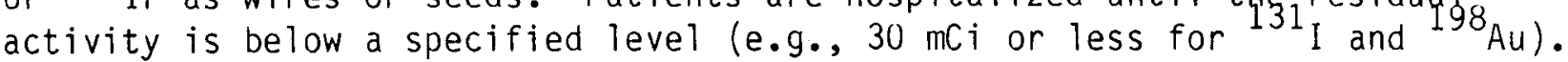

\subsubsection{Waste Disposal}

Solid radioactive waste is usually stored in 5-, 30-, or 55-gal drums at a central location prior to shipping to a licensed burial ground. Combustible waste may be incinerated either at the university or metered in with fuel at a nearby power plant. Incineration processes and procedures are specified in the license and are monitored closely. Ash and gases from incineration are monitored to assure escaping radioactivity is within the specified limit. Radioactive ash is disposed of at a licensed burial site.

Liquid waste is neutralized and stored in 1- to 5-gal nonbreakable (polyethylene) bottles or metal cans, which are then put in 30-gal steel barrels prior to burial at a licensed disposal ground. At some universities the liquid waste is combined with fuel oil and fed to an incinerator. Concentrations must be $3 \mathrm{mCi} / 5 \mathrm{gal}$ of fuel or less for this application. Combustible liquid waste may be 60 to $70 \%$ toluene, 30 to $40 \%$ xylene, 4 to $5 \%$ dioxane, and 1 to $10 \%$ water and miscellaneous compounds with ${ }^{3} \mathrm{H}$ and ${ }^{14} \mathrm{C}$ as the major isotopes.

The waste storage area might hold up to 40 drums of solid and liquid waste. Solid waste may contain animal carcasses, glassware, rubber or plastic gloves, paper towels, wipes, and plastic bags. 


\subsubsection{Facility Description}

\subsubsection{Buildings}

From 30 to 500 laboratories under one license may handle radioactive materials. Several of these labs may be located in one building, although the distribution covers the entire campus. Each lab is usually equipped with a sink, hood, hung ceilings with fluorescent lights, tile floors, and a nonporous counter top. The receiving area for radioactive materials may be a loading dock with a storage room set aside for a temporary storage of incoming material. The storage room may also contain a desk, chair, and metal cart and is similar in construction to laboratories.

Hot laboratories that store or handle greater quantities of radioactive materials have special shielding for storage considerations. They may be equipped with caves for added protection.

The waste storage area is usually separated from other campus buildings. It may be a trailer or a store room and may be equipped with a separate heating system.

Buildings are usually made of concrete block with tile-covered floors and hung ceilings. Laboratory walls may be sheetrock. Hot laboratories or specially designed storage rooms may have masonry walls. Storage vaults and bins may be concrete or lead.

\subsubsection{Heating, Ventilating, and Air Conditioning Systems}

Most laboratories have hoods with a flow rate of 600 to $1300 \mathrm{ft}^{3} / \mathrm{min}$ and a face velocity of 100 to $200 \mathrm{ft} / \mathrm{min}$. Air is exhausted through a duct work system above the hung ceilings. This system combines with other room exhausts and releases to the atmosphere. Charcoal filters may be used in some iodination labs, although generally no filtration is applied. Waste storage areas do not usually have an active ventilation system.

\subsubsection{Engineered Safety Systems}

Manual fire extinguishers are located in laboratories and in most areas of the university.

\subsubsection{Inventory}

\subsubsection{Radioactive Inventory}

License limits restrict university research and development operations to the quantities of isotopes listed in Table 3.9 .

Sealed sources may contajp $3.5 \mathrm{mC}$ to $1 \mathrm{Ci}$ per source. Iodinations in the labs handle 19 to $25 \mathrm{mCi}$ of ${ }^{125}$ I ata time. Diagnosis and therapy doses use up to $30 \mathrm{mC} i$ of $13 I^{2}$, up to $5 \mathrm{mC} ;$ of ${ }^{32} \mathrm{p}$, up to $30 \mathrm{mC} i$ of ${ }^{133} \mathrm{Xe}$, and millicurie 
TABLE 3.9. License Limits of Radioactive Material at University Research and Development Facilities

\begin{tabular}{|c|c|c|}
\hline Element & Isotope & $\begin{array}{l}\text { Inventory, } \\
\mathrm{Ci} \text { (range) }\end{array}$ \\
\hline $\begin{array}{l}\text { By-product material } \\
\text { atomic no. } 3-83\end{array}$ & & $\begin{array}{l}1 \text { to } 25 \text { each } \\
10 \text { to } 500 \text { total }\end{array}$ \\
\hline Americium & $241_{A m}$ & $5 \times 10^{-4}$ to 5 \\
\hline Cadinium & ${ }^{109} \mathrm{Cd}$ & $2 \times 10^{-2}$ \\
\hline Calcium & ${ }^{45} \mathrm{Ca}$ & 0.1 \\
\hline Cal ifornium & ${ }^{252} \mathrm{Cf}$ & $5.6 \times 10^{-3}$ to 0.1 \\
\hline Carbon & ${ }^{14} \mathrm{C}$ & $5 \times 10^{-3}$ to 10 \\
\hline Cerium & ${ }^{141} \mathrm{Ce}$ & $2 \times 10^{-2}$ \\
\hline Cesium & ${ }^{137} \mathrm{Cs}$ & $1 \times 10^{-3}$ to 45 \\
\hline Chlorine & ${ }^{36} \mathrm{Cl}$ & $1 \times 10^{-2}$ \\
\hline Chromium & ${ }^{51} \mathrm{Cr}$ & $5 \times 10^{-3}$ to 1 \\
\hline Cobalt & ${ }^{60} \mathrm{Co}$ & $3 \times 10^{-2}$ to 20 \\
\hline Curium & & $1 \times 10^{-5}$ to $5.1 \times 10^{-2}$ \\
\hline Gadolinium & ${ }^{153} \mathrm{Gd}$ & $\quad 12$ \\
\hline Hydrogen & $3_{H}$ & 9.3 to 3000 \\
\hline Iodine & ${ }^{125} \mathrm{I}$ & 2 to 8 \\
\hline Iron & ${ }^{59} \mathrm{Fe}$ & 0.1 \\
\hline Krypton & $85 \mathrm{Kr}$ & 10 \\
\hline Mercury & $203 \mathrm{Hg}$ & $1 \times 10^{-2}$ \\
\hline Molybdenum/Technetium & ${ }^{99} \mathrm{Mo}{ }^{99 \mathrm{~m}_{\mathrm{TC}}}$ & $5 \times 10^{-2}$ to 10 \\
\hline Neptunium & $23 / \mathrm{NP}$ & $5 \times 10^{-4}$ to 0.1 \\
\hline Nickel & ${ }^{63} \mathrm{Ni}$ & $8 \times 10^{-3}$ to 1 \\
\hline Phosphorous & $\begin{array}{l}32_{p} \\
33_{p}\end{array}$ & $\begin{array}{c}2 \times 10^{-3} \text { to } 5 \\
2.5\end{array}$ \\
\hline Platinum & $195 \mathrm{~m}_{\mathrm{Pt}}$ & $\quad 0.1$ \\
\hline Polonium & 210 Po & $2 \times 10^{-2}$ to 125 \\
\hline Potassium & $4 C_{K}$ & $1 \times 10^{-2}$ \\
\hline Protactinium & ${ }^{231} \mathrm{~Pa}$ & $5 \times 10^{-4}$ \\
\hline Rubidium & ${ }^{86} \mathrm{Rb}$ & $1 \times 10^{-2}$ \\
\hline
\end{tabular}


TABLE 3.9. (contd)

\begin{tabular}{llcc}
\multicolumn{1}{c}{ Element } & Isotope & \multicolumn{2}{c}{$\begin{array}{c}\text { Inventory } \\
\text { Ci (range) }\end{array}$} \\
\cline { 1 - 1 } Scandium & ${ }^{46} \mathrm{Sc}$ & & $2 \times 10^{-3}$ \\
Strontium & ${ }^{90} \mathrm{Sr}$ & & $2 \times 10^{-3}$ to 500 \\
Sulfur & ${ }^{35} \mathrm{~S}$ & & $2 \times 10^{-3}$ to 5 \\
Tantalum & ${ }^{182} \mathrm{Ta}$ & $1 \times 10^{-2}$ \\
Thorium & ${ }^{228} \mathrm{Th}$ & $1.5 \times 10^{-2}$ \\
Tin & $113_{\mathrm{Sn}}$ & $2 \times 10^{-2}$ \\
Uranium (depleted) & & $500 \mathrm{~kg}$ \\
Xenon & $133_{\mathrm{Xe}}$ & 10 to 2000 \\
Ytterbium & $169 \mathrm{Yb}$ & 100 \\
Zinc & ${ }^{65} \mathrm{Zn}$ & 0.2
\end{tabular}

amounts of ${ }^{99 m} \mathrm{Tc}$. Other isotopes are handled in millicurie amounts except ${ }^{3} \mathrm{H}$, which may be stored in one location in a quantity of $1500 \mathrm{Ci}$ in the form of shipping containers holding 100 to $25 \mathrm{mCi}$ each.

Radioactive waste is main $1 y_{5}$ composed of ${ }^{14} \mathrm{C},{ }^{3} \mathrm{H},{ }^{32} \mathrm{P}$, and ${ }^{125} \mathrm{I}$ isotopes. The major activity comes from ${ }^{125}$.

\subsubsection{Hazardous and Combustible Inventory}

Isotopes are packaged in plastic, styrofoam, and cardboard, all of which may be consumed in a fire. Shipping docks where the materials are received may also contain combustible liquids in drums. Transport vehicles run on combustible liquids.

Laboratories use solvents and organic materials up to liter quantities. Wipes, paper towels, and other cellulosics may be found in the lab. Protective clothing and plastic or rubber gloves may be worn. Laboratories contain a radioactive waste can or box that may contain contaminated combustibles.

Medical facilities are generally not allowed to accumulate combustibles. However, disposable materials--plastic syringes, paper towels, absorbent paper, and clothing--are commonly used and may be a source of fuel for a fire. Waste compacting and storage areas contain combustible solid and liquid waste in barrels. 


\subsection{ACCIDENT SCENARIOS}

A range of potential accidents are discussed in this section for the 11 operations categories of NMSS-licensed facilities, leading to the selection of a MREPP scenario for each. The selected accident scenarios focus on those that are considered to have potentially significant radiological consequences. In the context of emergency preparedness, a release to the atmosphere outside a facility that would impact the public has the most significant consequences. Therefore, accidents that occur either outside the facility or breach the facility's integrity providing a pathway to the atmosphere are generally the MREPP scenarios. Exposures of onsite personnel are excluded from this study.

Several steps are required to assess releases from accidents. First we list the radioactive materials and consider the quantity and the ease of dispersal of these materials. These listings are in Section 3. The force and conditions generated by the event are then evaluated. These events can be facility or process related or externally generated (i.e., by natural phenomena or impact of vehicles). In nuclear facilities, the materials are sometimes fine powders that move with airflow, so flow direction and filtration are examined.

The level and type of deagglomeration and dispersal forces that impact on radioactive material are determined (i.e., identify stresses on the source). once airborne, particulate materials obey physical laws of behavior and can be transported from the facility. The pathway from the facility can be formed by the events or can exist as doorways, filters, etc.

The above steps were used when defining the postulated accidents and estimating the quantities of radioactive materials that might be released. No consequence assessments were made in this study. Significant digits have been retained in this work to allow a user to easily reproduce the calculation. A user can round them off as appropriate for a specific facility.

\subsection{URANIUM FUEL FABRICATION PLANTS (OXIDE FUEL)}

In this plant category, accidents will involve uranium powders and solutions, UF 6 , and hazardous chemicals.

\subsubsection{Potential Accident Scenarios}

Potential accidents discussed for the uranium oxide fuel fabrication category are $U_{6}{ }_{6}$ cylinder rupture (loading dock fire), leak of UF 6 liquid, tornado impact, chemical explosion, criticality, ion exchange explosion, fire, and natural gas explosion.

\subsubsection{Uranium Hexafluoride Cylinder Rupture (Loading Dock Fire)}

Uranium hexafluoride cylinders might be ruptured accidentally in a variety of situations: puncture, dropping, or a natural or operational event. The 
consequence depends on variables involved: number of cylinders, heat generated by the event, location of the accident, mitigation, etc. An accident is postulated in which a truck delivering supplies strikes the cyclone fence and ruptures two cylinders in a UF 6 storage area. The truck fuel tank is torn open by metal debris and the entire 100 gal of gasoline in the fuel tank spills to the ground and is ignited by sparks created by metal contact with the concrete.

Calculating the release requires an estimate of the fire size and duration, the $U_{6}$ cylinder surface area exposed to the fire heat, heat flux to the cylinder, and finally, the UF 6 release. Section 5.1 .2 gives a stepwise procedure and a detailed illustration as well as a discussion of the parameters.

Fire size and duration are determined by the amount and geometry of the pool and its burning rate. It is assumed that the $100\left(13 \mathrm{ft}^{3}\right)$ gal of gasoline forms a 20-ft-diam circular area and reaches a depth of 0.5 in. (volume $13 \mathrm{ft}^{3}$ ). Steady-state burning velocities of 1 (Khitrin, 1962) to $5 \mathrm{~mm} / \mathrm{min}$ (Tryon, 1962) have been reported for gasoline. The fuel could be consumed in 2.5 to 12.5 min at these rates.

Cylinders of $U_{6}$ can be stored in the loading dock area. Two are assumed to be located near the fire. Fire completely engulfing the cylinders would provide the maximum heat flux. In this fire, however, it is reasonable to assume the fire centers around the truck, with the flame height equivalent to the fire diameter. The cylinders are assumed about $10 \mathrm{ft}$ from the fire and oriented so that the entire curved side is exposed to the fire.

The principal heat transfer mechanism from a fuel-rich fire is radiation. According to Clarke et al. (1974), the convective heat flux can be neglected, assuming that the fire radiates as a black body compensates for this omission. A radiative heat transfer coefficient of $32.4 \mathrm{Btu} / \mathrm{hr}-\mathrm{ft}{ }^{\circ}{ }^{\circ} \mathrm{F}$ for a $2000^{\circ} \mathrm{F}$ fire and $80^{\circ} \mathrm{F}$ container has been calculated (Clarke et al., 1974). The radiative heat transfer coefficient is a function of distance from the source and must be estimated. In the semicircular fire profile postulated, at a distance of $10 \mathrm{ft}$, the flux is 0.25 of the radiative heat transfer coefficient.

Since half the curved wall of the $30 \mathrm{~A}$ cylinder is the heat-absorbing surface, at a temperature difference of $1780^{\circ} \mathrm{F}$, approximately $6420 \mathrm{Btu} / \mathrm{min}$ could be absorbed by the cylinder. The heat of sublimation for UF $6\left(147^{\circ} \mathrm{F}\right)$ is $58.2 \mathrm{Btu} / 1 \mathrm{~b}$.

Disregarding the heat used to raise the temperature of the cylinder and $U_{6}, 1101 \mathrm{~b}$ of $\mathrm{UF}_{6} / \mathrm{min}$ from each ruptured cylinder could be made airborne. Thus, 550 to $2,7501 \mathrm{~b}(250$ to $1,249 \mathrm{~kg})$ of $\mathrm{UF}_{6}$ from the two cylinders could be made airborne during the course of the fire if no remedial action is taken. Some UF $_{6}$ would also be continuously vaporized from the ruptured cylinders at the temperature of the cylindor and its contents after the fire.

Undamaged cylinders in the immediate vicinity of the ruptured cylinders could also be heated. Under the assumptions stated above, the radiative heat transfer is sufficient to raise the temperature of the cylinder and its 
contents from $20^{\circ}$ to $101^{\circ} \mathrm{F}$, increasing the vapor pressure of the UF 6 inside the cylinder by only 3.5 to $33 \mathrm{lb} / \mathrm{in} .^{2}$ (well within the operating pressure of the cylinders).

Uranium hexafluoride reacts very readily with water to form particulate $\mathrm{UO}_{2} \mathrm{~F}_{2}$ and $\mathrm{HF}$ gas recording to the reaction:

$$
\mathrm{UF}_{6}+2 \mathrm{H}_{2} \mathrm{O}+\mathrm{UO}_{2} \mathrm{~F}_{2}+4 \mathrm{HF}
$$

Water is formed during the complete combustion of the ${ }_{3}$ gasoline. The gasoline involved in the fire can have a density of $0.703 \mathrm{~g} / \mathrm{cm}^{3}$ for a total mass of $2.66 \times 10^{5} \mathrm{~g}$. Assuming that gasoline is $15.5 \%$ hydrogen by weight, $3.78 \times 10^{5} \mathrm{~g}$ of water are formed by the complete combustion of 100 gal. This amount of water could react with up to $3.7 \times 10^{3} \mathrm{~kg}$ of $\mathrm{UF}_{6}$ to produce particulate $\mathrm{UO}_{2} \mathrm{~F}_{2}$. Consequently, the $1,249 \mathrm{~kg}$ of $\mathrm{UF}_{6}$ assumed to be airborne from this accident could be considered completely converted to $\mathrm{UO}_{2} \mathrm{~F}_{2}$ particulate.

The number of these particles that can persist in air depends somewhat on the size distribution and mass of the particles as well as the conditions. To make an estimate of the concentration of these particles, a stirred settling model (Koontz et al., 1970) was used. Because it was developed for a 10-m-high container, it was considered sufficiently similar to the outdoor 3 plume situation here. The persistent airborne mass calculated to $0.237 \mathrm{~g} / \mathrm{m}$. All the mass is considered associated with particles less than $10 \mu \mathrm{m}$ aerodynamic equivalent diameter (AED). This is equivalent to a $3.1-\mu \mathrm{m} \mathrm{UO}_{2} \mathrm{~F}_{2}$ sphere with a density of 10.5. To estimate dose, the model assumes all mass reaching an individual is associated with particles 1-um AED, which are respirable and deposit in the deep lung. A significant fraction of particles as large as $5 \mu m$ AED can enter the respiratory system. A 1.54- $\mu \mathrm{m}$ particle of $\mathrm{U}_{2} \mathrm{~F}_{2}$ is equiva-

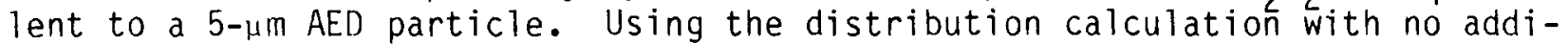
tional agglomeration, $70 \%$ of the mass is associated with particles less than $1.54 \mathrm{\mu m}\left(0.17 \mathrm{~g} / \mathrm{m}^{3}\right)$. This is the maximum concentration of the UF 6 particulate.

\subsubsection{Leak of Uranium Hexafluoride}

Leaks of $U F_{6}$ within the facility can occur during processing. Some events that have initiated $U_{6}$ release within a gaseous diffusion production facility (Tabor, 1974) are gasket failure, refrigeration failure, valving error, open valves on a heated cylinder, and leaking pigtails. A leak in a transfer line connecting the $U_{F}$ evaporator to the precipitator is postulated in an oxide fuel fabrication facility where uranium hexafluoride flows from the transfer line at the operational rate of $3 \mathrm{~kg}$ of $\mathrm{UF}_{6} / \mathrm{min}$ ( $2 \mathrm{~kg}$ of uranium/min). It is assumed that about 15 to $25 \mathrm{~min}$ is required for the operation to cease and for the cylinder to cool sufficiently for the UF 6 flow to stop. The maximum release is thus $75 \mathrm{~kg}$ of $U F_{6}$ gas $(50 \mathrm{~kg}$ of uranium). Uranium hexafluoride tends to condense and react with water producing $\mathrm{HF}$ gas and $\mathrm{UO}_{2} \mathrm{~F}_{2}$ particles. This would enable $\mathrm{UO}_{2} \mathrm{~F}_{2}$ removal by deposition. The conservative assumption is that all the $75 \mathrm{~kg}$ of $\mathrm{UF}_{6}$ is released to the environment as gas. 
4.1.1.3 Tornado Impact

It is postulated that a design basis tornado strikes a fully operational uranium oxide fuel facility. The assumed consequences are as follows:

- Complete loss of part of walls and roof

- Missiles are generated

- Massive equipment such as UF 6 vaporizer and precipitator remain

- A line from the UF 6 vaporizer is sheared by a missile.

Some airborne release of uranium could occur from the damage of the process piping sheared by the missile and from other uranium materials in that area. Three locations in the process with the largest inventory in jeopardy from an airborne release viewpoint are the UF 6 vaporizer, the ADU (ammonium diuranate) filter, and the scrap recovery area. The potential releases may be uranium from the vaporizer, $297 \mathrm{~kg}$ of uranium on the filter, and 2,000 $\mathrm{kg}$ of in-process scrap.

The $\mathrm{UF}_{6}$ is assumed released from the evaporator at its operational vaporization rate of $3 \mathrm{~kg} / \mathrm{min}$ ( $2 \mathrm{~kg}$ of uranium/min). Some remedial action such as stopping the steam flow to the evaporator could be instituted promptly, or the steam flow could be disrupted by damage from the tornado. Both of these events could limit the releases to less than the time required for cooling, or about $25 \mathrm{~min}$.

The release of ADU from the filter and in-process scrap are assumed to be simultaneous. The quantity of in-process scrap that is present as a dispersible powder or other form varies continuously. For the purposes of this calculation it is assumed that as much as $10 \%$ or $200 \mathrm{~kg}$ of uranium is in the form of powder and these particles are assumed in the respirable size range.

The ADU on the filter is a moist powder containing at 1east $5 \%$ moisture. When dry, ADU could have a particle size ranging from 10 to $150 \mu \mathrm{m}$. The average particle size would be approximately $100 \mu \mathrm{m}$ AED. For a powder with a $10 \mathrm{~g}$ normal particle-size distribution, a calculated AED of $100 \mu \mathrm{m}$ and a geometric standard deviation of 2 ; less than $0.1 \%$ would have a particle size less than $10 \mu \mathrm{m}$. Therefore, it is conservatively postulated that $1 \%$ or $3 \mathrm{~kg}$ of the $297 \mathrm{~kg}$ of uranium is released as respirable particles.

The total airborne release as a result of the tornado is thus postulated to be $203 \mathrm{~kg}$ of uranium as $\mathrm{UO}_{2}$ and $\mathrm{U}_{3} \mathrm{O}_{8}$ powders instantaneous released and $2 \mathrm{~kg} / \mathrm{min}$ as $\mathrm{UF}_{6}$ while heating is retained. If the leak continues for $25 \mathrm{~min}$, the total release is $253 \mathrm{~kg}$.

\subsubsection{Chemical Explosion}

Propane is used as auxiliary fuel in some of the plants and could present an explosion hazard. However, the storage facilities are located apart from the other plant facilities. If an explosion occurs, this would mean it would 
not effect the plant or jeopardize radioactive materials. Combustion within propane containers can occur in applications where it is used in conjunction with oxygen; however, such use does not occur in this facility.

Hydrogen explosions could occur in equipment such as the sintering furnace. The fluid bed reactor in the dry UF 6 production process is a potential hydrogen-air explosion site. However, to cause this explosion simultaneous failures in several different systems are required. These include failure to close the ball valve from the feed hopper; failure of the $\mathrm{CO}_{2}$ purge supply; and reduction of the operating pressure in the reactor from 2 atmospheres to atmospheric pressure. This is judged unlikely and no release postulated.

\subsubsection{Criticality}

A criticality accident releases energy as a result of accidentally producing a self-sustaining or divergent neutron chain reaction (American Nuclear Society, 1975). One might be initiated by 1) inadvertent transfer or leakage of a solution of fissile material from a geometrically safe vessel into an area or vessel not so designed, 2) introduction of excess fissile material to a vessel, 3) introduction of excess fissile material to a solution, 4) overconcentration, 5) failure to maintain sufficient neutron absorbing materials in a vessel, 6) precipitation of fissile solids from a solution and their retention in a vessel, 7) introduction of neutron moderators or reflectors, 8) deformation of or failure to maintain safe storage arrays, or 9) similar actions that can lead to increases in the reactivity of fissile systems (USNRC, 1979a).

Six incidents of unplanned excursions were recorded to occur behind heavy shielding in processing or production facilities (USAEC, 1971). None occurred in a powder system; they generally occur in solution systems with material accumulation in the tank and a surge to unsafe geometry. There appear to be no vessels of unsafe geometry in this facility where materials could accumulate during processing. The only tanks of unsafe geometry exist in the waste treatment facility. For any significant quantity of fissile material to reach the tanks, it would have to pass several alarmed radioactivity monitors and fail to be discovered by routine sampling analysis. No criticality accidents have been associated with low-enriched fuel fabrication operations (Exxon, 1974). No environmental impacts resulted from four criticality accidents that have occurred in other fuel fabrication and/or scrap recovery operations. Some small fission gas releases have occurred, and while they are thus of very low probability, they are covered as part of the required accidents for a safety analysis.

The regulatory guide (USNRC, 1979a) for evaluating criticality in uranium fuel fabrication plants recommends assuming simultaneous breakdown of at least two independent controls throughout all elements of the operation. The standard criticality accident is assumed applicable for the purpose of assessing this accident. However criticality is highly unlikely for this process. 
An excursion is assumed to occur in a vented vessel of ynfavorable geometry containing a solution of $400 \mathrm{~g} / \mathrm{L}$ of uranium enriched in $235 \mathrm{U}$. The excursion produces an initial burst of $1 \mathrm{E}+18$ fissions in $0.5 \mathrm{~s}$ followed successively at 10 -min intervals by 47 bursts of $1.9 E+17$ fissions for a total of $1 \mathrm{E}+19 \mathrm{fissions}$ in $8 \mathrm{~h}$. The excursion is assumed to be terminated by evaporation of $100 \mathrm{~L}$ of the solution.

It is assumed that all of the noble gas fission products and $25 \%$ of the iodine radionuclides resulting from the excursion are released directly to a ventilated room atmosphere. It is also assumed that an aerosol, which is generated from the evaporation of solution during the excursion is released directly to the room atmosphere. The aerosol is assumed to comprise $0.05 \%$ of the salt contept of the solution that is evaporated. This is $20 \mathrm{~g}$ of uranium enriched in $235 \mathrm{U}$.

A reduction in the amount of radioactive material available for release to the environment may be taken into account but evaluated on an individual case basis. The iodine depletion allowance is $75 \%$.

The USNRC regulatory guide allows a reduction in the amount of radioactive material available for release through filtration in the plant exhaust. Therefore, the amount of particulate released from the plant is mitigated by the HEPA filtration system. A decontamination factor of $2.5 \times 10^{-y}$ is considered applicable to two HEPAs in series so the atmospheric release is $5 \times 10^{-6} \mathrm{~g}$ of enriched uranium.

In addition to the particulate release, fission product gaseous releases have been estimated (USNRC, 1979a) and are shown in Table 4.1. The last column shows the iodine release retention allowance included.

\subsubsection{Ion Exchange Explosion}

One plant has an ion exchange column used for removal of small amounts of uraniuin from waste streams. Ion exchange explosion incidents can occur due to thermal transients from radiolytic heating, oxidation due to nitration under uncontrolled conditions, excessive applied heat, or heating by strong oxidants (Selby et al., 1975). This waste stream column does not appear to be a likely candidate for an ion exchange explosion. However, the magnitude of a release is estimated to illustrate the consequence.

After an actual ion exchange column explosion the fractional release to the ${ }_{6}$ atmosphere down stream of HEPA filters (the filters were not damaged) was $10^{-6}$ to $10^{-7}$ of the column radioactive inventory (ERDA, 1976). The contamination level of the waste stream is $300 \mu \mathrm{g} / \mathrm{cm}$ of uranium. The column capacity is $17 \mathrm{~L}$; $13 \mathrm{~L}$ of this capacity, is resin where the uranium is concentrated by a factor of $1 \times 10^{3}$. 
TABLE 4.1. Radioactivity of Important Nuclides Released

from a Criticality Accident in a Uranium Fuel

Fabrication Plant

\begin{tabular}{|c|c|c|c|c|c|}
\hline \multirow{3}{*}{$\frac{\text { Nuclide }}{83 m_{k r}}$} & \multirow[b]{2}{*}{ Half-life } & \multicolumn{3}{|c|}{ Radioactivity, Ci } & \multirow{2}{*}{$\begin{array}{c}\text { Iodine } \\
\text { Retention }\end{array}$} \\
\hline & & 0 to $0.5 \mathrm{~h}$ & 0.5 to $8 \mathrm{~h}$ & Total & \\
\hline & $1.8 \mathrm{~h}$ & $2.2 \times 10^{1}$ & $1.4 \times 10^{2}$ & $1.6 \times 10^{2}$ & \\
\hline $85 m_{k r}$ & $4.5 \mathrm{~h}$ & $2.1 \times 10^{1}$ & $1.3 \times 10^{2}$ & $1.5 \times 10^{2}$ & \\
\hline $85_{K r}$ & $10.7 \mathrm{yr}$ & $2.2 \times 10^{-4}$ & $1.4 \times 10^{-3}$ & $1.6 \times 10^{-3}$ & \\
\hline${ }^{87} \mathrm{Kr}$ & $76.3 \mathrm{~min}$ & $1.4 \times 10^{2}$ & $8.5 \times 10^{2}$ & $9.9 \times 10^{2}$ & \\
\hline $88 \mathrm{Kr}$ & $2.8 \mathrm{~h}$ & $9.1 \times 10^{1}$ & $5.6 \times 10^{2}$ & $6.5 \times 10^{2}$ & \\
\hline $89 \mathrm{Kr}$ & $3.2 \mathrm{~min}$ & $5.9 \times 10^{3}$ & $3.6 \times 10^{4}$ & $4.2 \times 10^{4}$ & \\
\hline $131 m_{X e}$ & 11.9 day & $1.1 \times 10^{-2}$ & $7.0 \times 10^{-2}$ & $8.2 \times 10^{-2}$ & \\
\hline $133 m_{x e}$ & 2.0 day & $2.5 \times 10^{-1}$ & 1.6 & 1.8 & \\
\hline $133 x e$ & 5.2 day & 3.8 & $2.3 \times 10^{1}$ & $2.7 \times 10^{1}$ & \\
\hline $135 m_{X e}$ & $15.6 \min$ & $3.1 \times 10^{2}$ & $1.9 \times 10^{3}$ & $2.2 \times 10^{3}$ & \\
\hline${ }^{135} \mathrm{xe}$ & $9.1 \mathrm{~h}$ & $5.0 \times 10^{1}$ & $3.1 \times 10^{2}$ & $3.6 \times 10^{2}$ & \\
\hline${ }^{137} \mathrm{Xe}$ & $3.8 \mathrm{~min}$ & $6.9 \times 10^{3}$ & $4.2 \times 10^{4}$ & $4.9 \times 10^{4}$ & \\
\hline $138 x \mathrm{x}$ & $14.2 \mathrm{~min}$ & $1.8 \times 10^{3}$ & $1.1 \times 10^{4}$ & $1.3 \times 10^{4}$ & \\
\hline${ }^{131} 1_{I}$ & 8.0 day & 1.2 & 7.5 & 8.7 & 2.2 \\
\hline 132 I & $2.3 \mathrm{~h}$ & $1.5 \times 10^{2}$ & $9.5 \times 10^{2}$ & $1.1 \times 10^{3}$ & $2.8 \times 10^{2}$ \\
\hline${ }^{133} \mathrm{I}$ & $20.8 \mathrm{~h}$ & $2.2 \times 10^{1}$ & $1.4 \times 10^{2}$ & $1.6 \times 10^{2}$ & $4.0 \times 10^{1}$ \\
\hline${ }^{134} \mathrm{I}$ & $52.6 \min$ & $6.3 \times 10^{2}$ & $3.9 \times 10^{3}$ & $4.5 \times 10^{3}$ & $1.1 \times 10^{3}$ \\
\hline${ }^{135} \mathrm{I}$ & $6.6 \mathrm{n}$ & $6.6 \times 10^{1}$ & $4.0 \times 10^{2}$ & $4.7 \times 10^{2}$ & $1.2 \times 10^{2}$ \\
\hline
\end{tabular}

An estimated column uranium inventory is as follows:

- $1.3 \times 10^{4} \mathrm{~cm}^{3}$ reşin with conģentrated $(300 \mu \mathrm{g}) \times\left(1 \times 10^{3}\right)$ uranium level of $3 \times 10^{5} \mathrm{\mu g} / \mathrm{cm}^{3}=3.9 \times 10^{3}$ uranium on resin.

- $4 \times 10^{3} \mathrm{~cm}^{3}$ liquid with a uranium level of $300 \mu \mathrm{g} / \mathrm{cm}^{3}=1.2 \mathrm{~g}$ of uranium in solution.

If the total inventory is subject to release, $3.9 \times 10^{3} \mathrm{~g}$ of uranium could be subject to stress with a resulting maximum release of $4 \times 10^{-3} \mathrm{~g}$ of uranium using a $10^{-6}$ atmospheric release fraction. The release from the solution is negligible. If the waste processing area is not equipped with HEPA filters, the release level could be higher. 


\subsubsection{Fire}

Combustible materials such as polyvinyl alcohol, hydraulic fluid, lubricants, and kerosene are used during the fabrication operations. Flammable materials (e.g., acetone) used for cleaning could present a fire hazard during the process. However, only small amounts in containers, such as gallon dispensers, are in the plant and large quantities are stored outside. Therefore, fires could occur at various locations within the plant.

Kerosene is used in the solvent extraction process for both high- and lowenriched processes, making this the potential site of a fire accident scenario. The minimum flammability limit of kerosene in air is $0.6 \%$ (Burger, 1956). Solvents other than kerosene are used in scrap recovery and a similar scenario could also apply to them.

The quantities and configurations of in-process scrap that are present as dispersible powder varies continuously. In this scenario, it is assumed that $2000 \mathrm{~kg}$ of scrap is in process, $10 \%$ powder and $90 \%$ with the solvent. All of the solvent-associated uranium is subject to airborne release as a result of fire.

Fire behavior of uranium in kerosene has been investigated experimentally (Mishima and Schwendiman, 1973c) and less than $1 \%$ would be the conservative fire release value for a solvent fire. The maximum release is $18 \mathrm{~kg}$ of uranium, if all of the solvent burns. The release is in the facility and is not anticipated to have a significant environmental release. Since the fire is some distance from the filters, they should retain their integrity. The release through the HEPA filters would be $18 \mathrm{~kg} \times 2.5 \times 10^{-9}=4.5 \times 10^{-6} \mathrm{~kg}$ or $4.5 \times 10^{-3} \mathrm{~g}$.

Fires can volatilize UF $_{6}$, as discussed in the cylinder rupture scenario. However, this scrap recovery fire would not be near the cylinders and thus would not provide heat to volatilize $U_{6}$. Uranium hexafluoride gases, if volatilized, would react with room air and precipitate on equipment and building surfaces, and be filtered out by any HEPA filtration system.

\subsubsection{Natural Gas Explosion}

Natural gas explosions are discussed in detail in Section 4.3.1.6 of this report. It has been hypothesized (Rockwell, 1976) that a complete rupture of a 1-in. gas line operating at a pressure of 8 in. of $\mathrm{H}_{2} \mathrm{O}$ would release approximately $750 \mathrm{ft}^{3} / \mathrm{h}$ of gas. In these facilities minimum airflows of 7 to 24 changes per hour ensure that natural gas could not build up to an explosive concentration in event of a line rupture.

\subsubsection{Uranium Fuel Fabrication Plants (0xide Fuel) MREPP Scenario}

Because a criticality accident is considered highly unlikely in this process, the UF 6 cylinder rupture is selected as the MREPP scenario. The tornado and fire releases were in the same range. Several considerations in selecting the MREPP were as follows: 
- The event occurs outside a facility.

- The event is common to all facilities (not just tornado-prone areas).

- High inventory is in jeopardy.

- Release levels are high.

- The energy input/release can be estimated.

It is postulated that a truck delivering supplies and equipment strikes the UF 6 storage area with sufficient force to rupture two cylinders. The truck fuel tank is torn open by the metal debris generated in the crash and the entire capacity of $100 \mathrm{gal}$ spills to the ground and is ignited by sparks created by contact of the metal and concrete.

\subsubsection{Material Release}

- Twelve cylinders each containing $2247 \mathrm{~kg}$ (Oak Ridge Operations Office 1972) of UF 6 -enriched gas are located in outside storage. Two are involved in a fire and 1249 of $\mathrm{UF}_{6}$ becomes airborne and is complętely converted to $\mathrm{UO}_{2} \mathrm{~F}_{2}$ particulate with a maximum concentration of $0.17 \mathrm{~g} / \mathrm{m}^{3}$.

\subsubsection{Factors Affecting Releases}

The following factors affect release at uranium fuel fabrication plants (oxide fuel):

- Truck fuel tank capacity

- Fill of fuel tank

- Number of cylinders involved

- Fill of cylinders

- Gasoline distribution in spill

- Fire suppression techniques

- Burning velocity

- Weather conditions.

\subsection{URANIUM FUEL FABRICATION PLANTS (NONOXIDE FUEL)}

These facilities produce nonoxide reactor fuel. Inventory linits required for criticality control define the inventory available for the other accidental releases.

\subsubsection{Potential Accident Scenarios}

Potential accidents discussed are earthquake, tornado, criticality, fire, explosion, and flooding. Releases are fine particles or gaseous fission products.

\subsubsection{Earthquake}

The uranium fuel fabrication facilities identified in this study are located in California. These uranium fuel fabrication plants could experience earthquakes. These plants are built to comply with standards of the uniform building code applicable to that area and, therefore, should be constructed to 
withstand earthquakes anticipated in that area. Damage scenarios would be a function of ground acceleration. Some examples of earthquake damage at different ranges are as follows (Mishima et al., 1979a, 1979b):

- <0.09 g, no significant damage

- 0.09 to $0.18 \mathrm{~g}$, toppling of gas cylinder

- 0.18 to $0.25 \mathrm{~g}$, process vessel or equipment overturned

- >0.39.g, transfer lines fail

- $0.49 \mathrm{~g}$, building collapses.

Another study indicated facilities did not sustain structural damage below 0.4 $\mathrm{g}$, and buildings will collapse above $0.5 \mathrm{~g}$ (Tokarz et al., 1975).

Based on the above analysis, there would be no structural damage in an earthquake, but some spills and process vessels would be overturned in a facility. In some cases, process equipment is bolted to the floor to prevent upset. Because the integrity of the facility is not breached, an earthquake should not cause significant releases of fuel material to the atmosphere.

Equipment failures may result as a consequence of earthquake, which could in turn cause fires or pressurized releases. These releases are discussed in the sections on fire and explosions.

\subsubsection{Tornado}

These buildings have been substantially constructed. Some minor damage may occur in a tornado (e.g., a door blown from the alloy shop) and this could result in minor amounts of surface contamination or uncontained powder being blown from the building. However, the powders are usually contained, so their release is unlikely.

Waste storage and liquid retention basins could be vulnerable when located away from the main process building. These are not common to all facilities. At one site, 5000 gal of dilute, $0.005-\mathrm{g} / \mathrm{L}$ waste is held in a retention basin. The basin is stainless steel set in concrete, so it is unlikely that more than minor spillage would occur in a tornado strike. A portion of the spill, perhaps $10 \%$ could be subject to aerodynamic entrainment by translational tornado wind forces and $25 \%$ is assumed entrained. A spill would be followed by resuspension of the surface contamination, winds will be lower after the event, so a long-term fractional rate of $10^{-8} / \mathrm{sec}$ (Sehmel and Lloyd, 1974a) is used. If $100 \mathrm{gal}$ (about $380 \mathrm{~L}$ ) is spilled, $9.5 \mathrm{~L}$ containing $0.05 \mathrm{~g}$ is immediately airborne, $1.9 \mathrm{~g}$ can be subject to resuspension, and the release is $1.9 \times 10^{-8} \mathrm{~g} / \mathrm{sec}$.

\subsubsection{Criticality}

Criticalities are infrequent events and those that have occurred have had no significant environmental impact (UNC, 1980). In Section 4.1.1.5 of this report, events that could initiate a criticality were discussed. Specific causes can be equipment failure, inadequate control of complex systems, and human error. 
In the context of this study, we are concerned with the public safety assessment and thus the amount of radioactive material released from the facility is of importance. Noble gases and vapors can be released from the facility through the filter system; if the building retains its integrity, particle releases are mitigated by HEPA filtration. Therefore, breaching the filters or facility greatly increases the downwind hazard. Consequently, we try to estimate the energy produced by an event to see if building damage could result from the event.

It has been estimated that $10^{18}$ fissions produce approximately $6 \times 10^{6}$ calories of heat (UNC, 1973). This falculates to $2.4 \times 10^{4}$ Btu. The TNT equivalent is $1800 \mathrm{Btu} / \mathrm{lb}$, so the $10^{18}$ fissions are equivalent to $13 \mathrm{lb}$ of TNT. However, only a fraction of the energy proguced causes damage, approximately $1.4 \%$ (Stratton, 1967). Therefore the $10^{18}$ fissions are equal to about 0.2 lb of TNT in terms of building damage. An event of this magnitude would not breach the facility. Energy not expended producing building damage is expended as heat.

Stratton (1967) compiled a comprehensive review of criticality events. He suggested that the frequency of accidents might be related to the frequency of producing an unfamiliar critical configuration. The criticality incidents he cited for solution systems and metal systems in air produced total fissions ranging from about $10^{15}$ to $10^{19}$. Usually no physical damage ensued, but in some cases minor damage such as warping occurred.

He suggested using the Godiva model (Wimmet, 1956) for information in this area. If the reactivity insertion rate is known, and a neutron source is present that is sufficiently strong to guarantee that a continuing fission chain starts at above prompt critical, the burst yield can be calculated.

Wogk done by woodcock (1966) suggested that a maximum of $3 \times 10^{18}$ and $3 \times 10^{19^{2}}$ fissions could occur in solution systems of 100 gal or less, and more than 100 gal, respectively. Other empirical models give the same magnitude of estimated fissions product yield as Woodcock.

Scenarios for criticality events are uranium accumulation in pickling solutions, unencapsulated moderated sludges or solutions, or an unsafe geometry accumulated in storage (IJNC, 1973).

One potential criticality (Babcock and Wilcox, 1974) suggested a release of $0.35 \mathrm{Ci}$ of fission gases from a boiling solution producing a $1 \times 10^{17}$ fission criticality. They estimated that $50 \%$ of the release was contained by the building, and the atmosphere release was $0.175 \mathrm{Ci}$. The release could be carried from the building by the ventilation system.

For evalugting these accidents it appears the the standard criticality event, $1 \times 10^{19}$ fissions, is representative of an accident in the pickling operations. It is assumed the solution is overconcentrated to allow criticality. Releases discussed in Section 4.1.1.5 were $20 \mathrm{~g}$ of enriched uranium through a single HEPA filter and fission product gases produced by the event as listed in Table 4.1. These are all assumed released to the atmosphere for a 
total of $1.2 \times 10^{5} \mathrm{Ci}$. Iodine could be absorbed on filters or deposited in the building. The standard criticality will allow credit of $75 \%$ of the iodine removed by retention.

\subsubsection{Fire}

Because uranium and zirconium metals are both pyrophoric, there are many opportunities for fires in the metal working operations. For example, loss of coolant to a drill press could lead to spontaneous ignition of the chips. In machining operations, small fires would result, but they would be limited in size because of the amount of metal present, which could be about $11 \mathrm{~b}$.

Several areas of the facility could be the site of metal fires: incinerators, laboratories, alloy shop, pickle area, filler press box line, and scrap recovery operations. The amount and form of uranium present and the opportunity for airborne release define the fire impact. Some larger fires could result in deflagrations and will be discussed in the section on explosions.

Uranium is pyrophoric, and the form can be a controlling variable. Rockwell (1976) compiled the following information on burning characteristics of various uranium forms. Large pieces of metal do not generally burn at room temperature unless exposed to water; turnings ignite during machining; uranium metal powders ignite at room temperature, and aluminum powder increases pyrophoricity. The powder appears to be the form most likely to be involved in a fire, and the ignition could be caused by friction of the operation, static spark, or spark from equipment.

Some fires have been hypothesized in environmental reports. A zirconium fines fire augmented by flammable solvent (UNC, 1973) could blow out a hood window allowing 100 to $300 \mathrm{~g}$ of a $1-\mathrm{kg}$ source to be blown from the hood into the plant, the maximum airborne release was $2 \times 10^{-2} \mathrm{Ci}$. Because combustible wastes are burned using propane, an uncontrolled incinerator fire is possible (Babcock and Wilgox, 1974). The fractional airborne release of the source would be $5 \times 10^{-4}$ (Mishima and Schwendiman, 1973b), and it could be assumed ejected from the system However, contamination levels in the waste could be low, abput $2,13 \mathrm{~g}$ of $235 \mathrm{U}$ per drum of waste. In this uncontrolled fire, about $7 \times 10^{-5} \mathrm{~g} 235 \mathrm{U}$ could become airborne if all of the material is expelled from the drum. It could be anticipated that the release will be contained by the HEPA filters and that only about $3.5 \times 10^{-8} \mathrm{~g}$ would pass through a single HEPA filter. The incinerator location is such that this fire would not involve other building components.

Uranium feed materials for the metal fuel fabrication process can be mixed with alloying metal in operations involving crushing, grinding, sieving, and blending. A fire could be initiated during these operations by a spark from equipment after loss of the protective inert gas atmosphere due to human error. The maximum inventory in these work stations could be $3.5 \mathrm{~kg}$ of ${ }^{235} \mathrm{U}$ (Rockwell, 1976). It is assumed that a glove box fire occurs and $1 \%$ of the powder becomes airborne in the enclosure. Some of the material is ejected into the room after the gloves are destroyed, and this fraction is estimated at $10 \%$. Calculation of the release is $3.5 \times 10^{3} \mathrm{~g} \times 0.01=35 \mathrm{~g}$ airborne in the enclosure, and 
$3.5 \mathrm{~g}$ is transported to the room. If the entire release reaches the HEPA filters, $1.8 \times 10^{-3} \mathrm{~g} 235 \mathrm{U}$ will pass to the atmosphere, assuming one filter and no deposition in the facility.

These processes could be conducted in a glove box train. If so, there is the opportunity for a fire to pass to crushing, weighing, recycling, and blending operations in a domino effect. This would result in a total release of $7 \times 10^{-3} \mathrm{~g}$ to the atmosphere from four units.

\subsubsection{Explosion}

Fires could initiate explosions when flammable vapors ignite in an enclosure. The enclosure pressurizes, leading to component failure and explosive releases.

An explosion resulting in dispersion of $U_{2}$ from a press line could be suggested. A box line containing $\mathrm{UO}_{2}$, zirconium, and alcohol loses its inert gas atmosphere allowing an explosive mixture to accumulate in the boxline. An ignition source (static charge, for example) detonates the mixture, destroying the boxline and opening a hole in the building roof. One percent of the $3.6 \mathrm{~kg}$ $\mathrm{UO}_{2}$ in the line is ejected through the hole in the roof, and a release of $36 \mathrm{~g}$ $\mathrm{UO}_{2}^{2}$ is postulated.

Explosions in retention tanks caused by inadvertent addition of acid could cause some liquid spills. Contamination levels in these tanks are low and, consequently, so are any potential airborne releases.

A uranium aluminide powder explosion in a glove box was hypothesized (Rockive11, 1976) to produce $19.6 \mathrm{~kg}$ of mixed $\mathrm{UO}_{2}$ and $\mathrm{Al}_{2} \mathrm{O}_{3}$ airborne, $10.4 \mathrm{~kg}$ of which was $93 \%$ enriched uranium. It was assumed that $1 \%{ }^{2}$ of the mass was transported to the filters, and the release through one HEPA filter would be $0.048 \mathrm{~g}$ of enriched uranium.

An explosion in the induction furnace could release material from five trays containing a total $3.6 \mathrm{~kg}$ or less of uranium powders (General Atomic, 1971). Uranium carbide or uranium-thorium carbide are oxidized in an oxygenair atmosphere, then reduced in a hydrogen atmosphere. Malfunction of the dilution gas system valve and airflow detector allows $\mathrm{H}_{2}$ to accumulate to levels above the $4 \%$ flammability limit to about $15 \%$. This event could be assumed to have $1 \%(36 \mathrm{~g})$ of the materials ejected from the furnace. The energy of the explosion would not breach the facility. Therefore, the release challenges the single HEPA filter for a release of $5 \times 10^{-4} \times 36=1.8 \times 10^{-2} \mathrm{~g}$ released.

Natural gas explosions discussed in detail in Section 4.3.1.6 of this report, are another potential release situation. It has been hypothesized (Rockwell, 1976) that a complete rupture of a 1-in. gas ling operating at a pressure of $8 \mathrm{in}$. of $\mathrm{H}_{2} \mathrm{O}$ would release approximately $750 \mathrm{ft}^{3} / \mathrm{h}$ of natural gas. Minimum airflows of six changes per hour for each room mean that a natural gas explosion is not likely to occur. 


\subsubsection{Flooding}

Flooding itself will not produce airborne release. It is of concern in regard to producing an environment where criticality could occur and produce airborne releases. Water flooding is not considered credible because there is no internal water source with capacity sufficient to produce flood levels. Water entering the facility must flood to a depth of $3 \mathrm{ft}$ to reach a level of concern.

\subsubsection{Uranium Fuel Fabrication Plants (Nonoxide Fuel) MREPP Scenario}

Two events had significant releases from this facility category, the standard criticality accident and the boxline explosion.

The criticality release is particulate material from the evaporation of $100 \mathrm{~L}$ of $400 \mathrm{~g} / \mathrm{L}$ solution. The aerosol is $0.05 \%$ of the salt content of the solution, or $20 \mathrm{~g}$. Fission product radionuclide releases are listed in Table 4.1 (USNRC, 1979). The energy produced by the event would not be sufficient to breach the integrity of the facility. Therefore, the HEPA filters 35 would remove a portion of the airborne particulate material, reducing the $235 \mathrm{U}$ release to $1 \mathrm{~g}$. Gaseous fission product release totals $1.2 \times 10^{5} \mathrm{Ci}$. The $8.7 \mathrm{Ci}$ of $131 \mathrm{I}$, however, is the fission product release of most concern because of radiological health effects.

The boxline explosion event ejects about $36 \mathrm{~g}$ of $\mathrm{UO}_{2}$ to the atmosphere through an opening in the building roof. To compare this to the criticality it can be converted to curies using the follgwing equation (Bureau of Radiological Health, 1970) and a half-life of $7.1 \times 10^{8}$ y (Weast, 1973):

$$
\mathrm{Ci} / \mathrm{g}\left(\text { specific activity) }=\frac{3.578 \times 10^{5}}{\left(T_{1 / 2} \mathrm{yr}\right)(\text { atomic mass })}\right. \text {. }
$$

For $235_{U}$ the calculation is:

$$
\mathrm{Ci} / \mathrm{g}=\frac{3.578 \times 10^{5}}{\left(7.1 \times 10^{8}\right)(235)}=2.1 \times 10^{-6} \mathrm{Ci} / \mathrm{g} \text {. }
$$

Assuming the $36 \mathrm{~g}$ atmospheric release is all ${ }^{235} \mathrm{U}, 7.6 \times 10^{-5} \mathrm{Ci}$ is released. This is much lower than the gaseous fission product release in terms of curies. The fission product nuclides with the higher specific activity are more of a radiological concern; enriched $235 U$ is of concern in radiation damage to the lungs or the kidney (Eisenbud, 1973). Gaseous releases are an immersion hazard, and the particulate uranium is an inhalation hazard since the particles $10 \mu \mathrm{m}$ and less can be deposited in the lung.

A review of dose commitment factors (Hoenes and Soldat, 1977) would suggest that $235_{U}$ constitutes the greatest hazard on a unit (per curies) 
basis. However, the actual curie level associated with the $235 \mathrm{U}$ is at a signifjcantly lower level, and a comparison of dose from the actual releases shows ${ }^{131}$ I the greater hazard.

In the uranium oxide fabrication plants with powder processes, criticality accidents were considered unlikely and another accident was selected as the MREPP event. However, in these metal plants there are liquid operations that could provide opportunity for criticality: pickling operations, liquid wastes, and scrap recovery.

Based on the opportunity of occurrence and radiological hazard associated with I3I I, criticality is selected as the MREPP event for uranium nonoxide fuel fabrication plants.

\subsubsection{Material Release}

The total atmospheric release from this criticality accident is $1.2 x$ $10^{5} \mathrm{C} 3 \mathrm{f}_{\mathrm{f}}$ mixed krypton, xenon, and iodine isotopes and $1 \times 10^{-2} \mathrm{~g}$ of particulate $235 \mathrm{U}$. These releases are listed in Table 4.1 , which also shows the iodine retention allowances.

\subsubsection{Factors Affecting Releases}

The following factors affect release at uranium metal fuel fabrication plants:

- Effectiveness of automatic control devices

- Containinent

- Deposition in facility

- Filtration

- Decay in facility

- Ventilation flow.

\subsection{URANIUM HEXAFLUORIDE PRODUCTION}

At the $U_{6}$ production plants, natural uranium (yellowcake) is processed to UF 6 . Accidents will involve natural uranium in powder or liquid form, or as gaseous $\mathrm{UF}_{6} \cdot$

\subsubsection{Potential Accident Scenarios}

Potential accident scenarios discussed include UF 6 cylinder rupture, liquid $\mathrm{JF}_{6}$ leak, tornado strike, solvent fire, facility fire, chemical explosion, and natural gas combustion explosion.

\subsubsection{Uranium Hexafluoride Cylinder Rupture (Loading Dock Fire)}

Cylinder ruptures were discussed in Section 4.1.1.1. Similar events can occur in UF 6 production facilities, but, since the cylinders used are 10 and 14 ton capacity, more $\mathrm{JF}_{6}$ is available to enter the atmosphere. However, the 
natural uranium will have a low specific activity. Cylinders are stored outside so there is a potential of a truck-type event similar to that described in. Section 4.1.1.1. The $1.9 \times 10^{4} \mathrm{Btu} / \mathrm{min}$ absorbed by the exposed cylinder surface could release $326 \mathrm{lb} /$ min for a total release of UF 6 of 815 to $4.1 \times 10^{3} \mathrm{lb}$ (368 to $1.9 \times 10^{3} \mathrm{~kg}$ ) from one cylinder. If two cylinders are involved, the release is $3.8 \times 10^{3} \mathrm{~kg}$. (Calculations are the same as in Section 4.1.1.1.) A pool fire centered around a cylinder rather than a truck was considered unlikely but woyld have higher UF 6 release levels: $1365 \mathrm{~kg} / \mathrm{min}$, totaling $3.4 \times 10^{3}$ to $1.7 \times 10^{4} \mathrm{~kg}$ of $\mathrm{UF}_{6}$.

A second postulated outdoor release scenario occurs during handling or transfer where a valve failure is assumed to occur (USAEC, 1974). The estimated releaşe over a period of $1 \mathrm{~h}$ is $9.2 \times 10^{3} 1 \mathrm{~b}\left(4.2 \times 10^{3} \mathrm{~kg}\right)$ natural UF 6 , or $2.8 \times 10^{3} \mathrm{~kg}$ of uranium.

Another variation of the cylinder rupture or valve failure estimated that 4550 ib of UF $6\left(2.1 \times 10^{3} \mathrm{~kg}\right.$ of $\mathrm{UF}_{6}$ or $1.4 \times 10^{3} \mathrm{~kg}$ of uranium $)$ is released in a 40-min leak through a 1.5-in.-diam hole in the wall above the UF 6 liquid level (Kerr-McGee, 1975). Heat supplied by the steam cabinet would vaporize

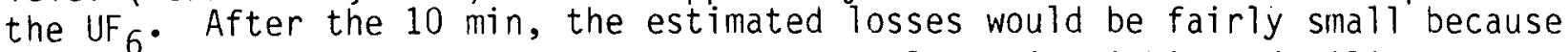
the $\mathrm{UF}_{6}{ }_{6}$ should be solidified. Because the release is within a facility, there would be opportunity for $U_{6}$ or $\mathrm{UO}_{2} \mathrm{~F}_{2}$ deposition, thus lowering the release.

\subsubsection{Liquid Uranium Hexafluoride Leak}

As discussed in 4.1.1.2, leaks of the heated $\mathrm{UF}_{6}$ in liquid form can occur within the facility from a variety of initiating events. In one occurrence (Allied Chemical, 1975), a valve failure in the distillation section led to a 95-1b UF 6 release. No offsite elevated uranium concentrations were detected.

Uranium hexafluoride releases are independent of the uranium enrichment, so the maximum $60-\mathrm{kg}$ release postulated in Section 4.1 .1 .2 would be applicable in this situation. This release is based on the flow rate of $150 \mathrm{~kg} / \mathrm{h}$ of heated $U_{6}\left(100^{\circ} \mathrm{C}\right)$ through a $1-i n$. transfer line and a half-hour leak.

\subsubsection{Tornado}

A tornado strike could involve uranium materials stored outside a facility, either drums of yellowcake primary feed or the cylinders of UF 6 . Potential building damage could also occur causing loss of containment.

\subsection{Primary Feed Release}

Primary feed is stored in 55-gal drums on a pad outside the building in a location vulnerable to tornado damage. About 3000 yellowcake-filled drums are stored in stacks three or four deep on pallets. Drums are $0.61 \mathrm{~m}$ in height, and it is assumed that they are stacked three high; total height is approximately $2.5 \mathrm{~m}$, allowing for pallet spacing. The top layer is assumed to be impacted by tornado forces to the point of failure. Specification $17 \mathrm{H}$ drums, can survive an impact equivalent to a drop onto an unyielding surface from a height of $1.2 \mathrm{~m}$ (Geffen, 1981) as required for Department of Transportation 
(DOT) requirements so drums in lower layers are assumed intact. This would mean 1000 drums in the top stack layer each holding about $360 \mathrm{~kg}$ of yellowcake could be lifted by the tornado and impacted on the ground. It is assumed that $30 \%$ of the contents are spilled from the drum as it impacts on the ground. In this type of bulk flow incident, only a fraction of this (10\%) material can be mixed with the air sufficiently to induce dispersion, and a fraction of this becomes airborne. Sutter (1980) developed relationships between wind speed and the fraction of source airborne. At a tornado translational velocity of $40 \mathrm{mi} / \mathrm{h}, 25 \%$ of the source becomes airborne.

Yellowcake can have various particle size distributions in different lots depending on the source. During a site visit, it was indicated that only $5 \%$ was less than 325 mesh $(44 \mu \mathrm{m})$. This calculates to an aerodynamic diameter greater than $100 \mu \mathrm{m}$, an order of magnitude above the respirable size range. However, Geffen (1981) reported aerodynamically measured yellowcake diameters and used an estimate of $25 \%$ in the respirable range for safety assessments.

The immediate airborne release is 1000 drums $\times 360 \mathrm{~kg} \times 30 \%$ falling to the ground $\times 10 \%$ mixed with air $\times 25 \%$ fraction airborne $\times 25 \%$ fraction respirable $=$ $675 \mathrm{~kg}$ airborne. This is the release in the hazardous range that becomes airborne.

Wind forces following the event could resuspend the yellowcake on the ground, at a fractional rate of $10^{-8} / \mathrm{sec}$ (Mishima, 1976). This calculates to $3.9 \mathrm{~kg} / \mathrm{h}$ for an additional $31 \mathrm{~kg}$ release in the $8 \mathrm{~h}$ following the event. All resuspended material is assumed in the respirable range for a total release of $706 \mathrm{~kg}$ yellowcake.

\subsection{Uranium Hexafluoride Cylinder Impact}

Experimental work with the 10 ton $U_{6} 6$ cylinders indicates they will retain their integrity for most hypothetical accident conditions (Richardson and Bernstein, 1971). After as much as a 30-ft drop, there was no visible evidence of rupture, only a slight leak that could be self sealing. Therefore, no release from the cylinders is estimated.

\subsection{Building Impact}

The building damage would be similar to tornado damage postulated in Section 4.1 .1 .3 , and the postulated $U F_{6}$ release is $2 \mathrm{~kg} / \mathrm{min}$ of UF 6 for $8 \mathrm{~h}$ totaling $960 \mathrm{~kg}$ of UF 6 (640 kg of uranium). About $200 \mathrm{~kg}$ of uranium in process is airborne in the initiating event plus $3 \mathrm{~kg}$ associated with the filter. Total uranium in the release is $852 \mathrm{~kg}$ of $\mathrm{U}$.

\subsubsection{Fire}

A fire in the solvent rework section has been postulated (Kerr-McGee, 1975; USAEC, 1974). A fire in the solvent extraction stream could involve 2500 gal of solvent containing as much as $817 \mathrm{~kg}$ of low specific-activity uraniun and daughter products. All of this uranium is subject to becoming airborne at a $1 \%$ fraction release (Section 4.1 .1 .7 ). The release is thus about 
$8 \mathrm{~kg}$. Because the solvent extraction operations are conducted in a separate building, the fire damage will be restricted to that area.

If a fire occurs within a facility, $U F_{6}$ in cylinders could be volatilized, or the integrity of $\mathrm{UF}_{6}$ vessels and transport lines could be jeopardized. Combustion sources in the facility are cellulosics, lubricants, and fuel oil. They could be involved in fire with ethylene glycol or propane. Bulk storage of these flammable materials is located outside the main process facility, reducing the potential for a massive facility fire. However, in the facility an inadvertent event might initiate a fire that could involve these materials.

It is assumed that a fire is initiated by spontaneous ignition of a lubricant soaked rag and could involve:

- Propane. This material would not be used close to UF 6 and, therefore, when burning it is less likely to cause heating and subsequent release.

- Ethylene glycol. A leak from a cooling mantle could allow ethylene glycol to burn in the fire. It could contribute to the fire because it has an ignition temperature of $385^{\circ} \mathrm{C}$ and a lower flammable limit in air of $3.2 \%$. Because it is used close to $\mathrm{UF}_{6}$, there is an opportunity for interaction.

It is assumed that ethylene glycol leaks from a malfunctioning valve and becomes involved in the fire. With the loss of cooling from the mantle in addition to the elevated fire temperatures, UF 6 expands and subsequently breaks the container, and gases enter the facility. The total UF 6 vaporizing is, equivalent to that from a UF 6 cylinder, $2.1 \times 10^{3} \mathrm{~kg}$ of $U_{6} 6$ in $40 \mathrm{~min}$. Even with loss of ventilation, it can be assumed that all of the releases are assumed carried upwards by convection from the fire and out open ventilation ports in upper portions of the building.

\subsubsection{Chemical Explosion}

A "red oil" explosion in the UNH evaporator can be a suggested event, but the possibility is considered remote because temperatures are held below the $266^{\circ} \mathrm{F}$ required for this type of explosion. "Red oil" is a term applied to nitrated organic materials formed by the degradation of process liquids.

Degraded process solvents or organic decontaminating agents inadvertently included in a stream with excess heat could trigger a "red oil" explosion. The blast effects of such an explosion have been estimated at 3 lb of TNT, with a shock wave of $800 \mathrm{lb} / \mathrm{in}^{2}$ and an energy of $230 \mathrm{ft} 1 \mathrm{~b} / \mathrm{ft}^{2}$ at a distance of $15 \mathrm{ft}$ (Battelle, 1975). The evaporator is ruptured and all the liquid ejected. Releases from equipment damage in this explosion are shown below:

\begin{tabular}{lc} 
Source & $\begin{array}{c}\text { Quantity } \\
\text { (gallons of UNH) }\end{array}$ \\
\hline Evaporator & 1000 \\
UNH surge tank (half full) & 1000 \\
RAC storage (Half full) & $\frac{500}{4500}$ \\
Sx seal & Maximum release source term $=$
\end{tabular}


At a specific gravity of $1.66 \mathrm{~g} / \mathrm{cm}^{3}$, this calculates to about $2.8 \times 10^{7} \mathrm{~g}$ of UNH. The processing area, estimated at $40,000 \mathrm{ft}^{3}$, is filled with a mist concentration of $0.1 \mathrm{~g} / \mathrm{m}^{3}$ UNH. This release, is carried with the airflow from the building for a total release of $1.1 \times 10^{2} \mathrm{~g}$ UNH (52 g of uranium).

No further damage is foreseen.

\subsubsection{Natural Gas Combustion Explosion}

Natural gas used as a building heat source could pose an explosion hazard. The lower flammability limit for natural gas is 4\% (Mckinnon, 1976). A gas explosion can occur with a fraction of a room, 0.25 or less, filled with gas.

The open structure of the process building would seem to ensure safety from natural gas explosions. Fans can provide for continual removal of contaminated air. If the building airflow rate of one room change every 5 min is maintained, it is unlikely that an explosive mixture could be reached in a room. However, the natural gas is carried through lines in the center of the building where airflow could be restricted. Loss or reduction of airflow in conjunction with a natural gas line rupture with gas flow continuing could initiate an explosion, or the leak could occur in a "dead" air space allowing opportunity for an explosion when the gas accumulates.

To illustrate this release, it is hypothesized that a natural 3 gas leak occurs, and gas accumulated to the $4 \%$ explosive level in a $1000 \mathrm{ft}^{3}$ volume, approximately the size of a small room. The gas mixed with air ignites, the heated air expands, pressure rises, and an explosion follows.

One natural gas composition is $75 \%$ methane, $21 \%$ ethąne, and $4 \%$ propane. The heat of ${ }_{3}$ combustion for this mixture is $1120.3 \mathrm{Btu} / \mathrm{ft}^{3}$ at a gas density of $0.055 \mathrm{lb} / \mathrm{ft}^{3}$. This is $1120 / 0.055=2 \times 10^{4} \mathrm{Btu} / \mathrm{lb}$. 1976):

The explosion equivalent yield can be calculated (Strehlow and Baker,

$$
W_{T N T}=\frac{\Delta H_{C} \times W_{C}}{1800}
$$

where

$$
\begin{aligned}
& W_{T N T}=\text { equivalent TNT wt/lb } \\
& \Delta_{C}=\text { heat of combustion of hydrocarbon, Btu/1b } \\
& W_{C}=\text { weight available as explosive source, Ib } \\
& 1800=\text { heat of explosion of TNT Btu/lb. }
\end{aligned}
$$

For the illustrated explosion these parameters are

$$
\begin{aligned}
\Delta H_{C} & =2 \times 10^{4} \mathrm{Btu} / 1 \mathrm{~b} \\
W_{C} & =\left(1000 \mathrm{ft}^{3} \times 0.04\right) \times 0.055 \mathrm{lb} / \mathrm{ft}^{3}=2.2 \mathrm{lb} .
\end{aligned}
$$


Calculations are

$$
\begin{gathered}
W_{\text {TNT }}=\frac{2 \times 10^{4} \mathrm{Btu} / 1 \mathrm{~b} \times 2.2}{1800 \mathrm{Btu} / 1 \mathrm{~b}} \\
W_{\text {TNT }}=24.4 .
\end{gathered}
$$

However, not all of the heat of combustion energy is released in an explosion. Brasie and Simpson (1968) investigated explosions of vapors in confined but ventilated operating structures and found the probable yield from these events was a very small fraction of the predicted value. Relative yields were one twentieth, and he suggested that they may typically range from one fortieth to one tenth. For illustration here, the one tenth or $10 \%$ value is used, so it is the equivalent of $2.4 \mathrm{lb}$ TNT.

This illustrated explosion would be anticipated to cause damage, with overpressures in a range that could cause glass breakage (1 to $2 \mathrm{lb} / \mathrm{in}$. ${ }^{2}$ at $20 \mathrm{ft})$. It is hypothesized that one of the two distillation columns is located sufficiently close to the explosion center to sustain damage. Overpressures generated by the incident are postulated damaging the valving. Ethylene glycol, hexane, and other solvents in the vicinity would sustain a fire initiated by the explosion.

The heat produced by the event would cause UF $_{6}$ to vaporize from the ruptured container. Total UF 6 airborne assumes the distillation column contains the equivalent of a UF 6 cylinder and would, therefore, release $4550 \mathrm{lb}$

$\left(2.1 \times 10^{3} \mathrm{~kg}\right)$ of UF 6 in $40 \mathrm{~min}$. The entire release would leave the building through penetrations formed by the accident. This release would be increased if more than one container were involved in the event.

\subsubsection{Uranium Hexafluoride Production MREPP Scenario}

Scenarios where UF 6 can be volatilized and released in the gaseous form have maximum impact for emergency preparedness, because the release is in a form that can be transported downwind. Three events leading to this UF 6 release were discussed: 1) the cylinder rupture outside the facility, 2) facility fire, and 3) a natural gas explosion and associated fire. The latter two events expel vaporized UF 6 from the facility. Although we did not take credit for mitigation by deposition in a facility in the accident scenarios this can occur. Therefore, a UF 6 leak from cylinders located outside a facility would be considered the most serious event.

\subsubsection{Material Release}

Cylinder ruptures outside the facility as a loading dock fire scenario were discussed in Section 4.1.1.1. Larger cylinders used for the natural uranium $\mathrm{UF}_{6}$ mean that a larger sourçe is in jeopardy. The release from two cylinders was estimated as $3.8 \times 10^{3} \mathrm{~kg}$ of $U_{6}$, with the fire centered around the truck. A fire centered around a cylinder could give even higher releases. 
The mechanisms driving the release are the same force: heating a damaged $\mathrm{UF}_{6}$ cylinder to vaporize $\mathrm{UF}_{6}$.

\subsubsection{Factors Affecting Releases}

The same factors affecting $U_{6}$ releases (Section 4.1 .2 ) from a $U_{6}$ cylinder outside a facility apply in this scenario and will not be repeated here.

\subsection{URANIUM MILLS}

Uranium mills extract and partially refine uranium ore. Releases of uranium and uranium daughter products $\left({ }^{230} \mathrm{Th}\right.$ and $\left.226 \mathrm{Ra}\right)$ can come from ore piles, the tailing retention system, ore crushing, and others. However, the scope of this study emphasizes the particulate releases. The mill operation is the primary focus of our work; tailing releases have been well documented in other studies.

\subsubsection{Potential Accident Scenarios}

The potential aerosol-generating accidents discussed are waste retention, pond slurry release, tornado strike, fires, dryer explosion, and equipment failure in the ore-handling system.

\subsubsection{Tornado}

Tornadoes can inflict building damage and disperse uranium material. For this event, it has been assumed in the generic uranium mill environmental impact statement (USNRC, 1979b) that 1) 2 days production is free and not packaged in containers, 2) the maximum inventory of 45 MT of yellowcake is on site when the tornado strikes, and 3 ) $15 \%$ of the contained material is released. It was assumed that the tornado lifts $11,400 \mathrm{~kg}$ of yellowcake. The most conservative model assumes all of the yellowcake is in respirable form. However, Geffen (1981) reported that two yellowcake samples were sized aerodynamically to determine the respirable fraction. This fraction was 18 and 32 wt\% less than $10 \mu \mathrm{m} \mathrm{AED}$, and she used the average value of $25 \%$ in her studies. Using this $25 \%$ respirable fraction value for this release means that $2850 \mathrm{~kg}$ of respirable yellowcake becomes airborne.

\subsubsection{Waste Retention Pond Slurry Release}

Inadvertent discharge of the liquid held in the tailing ponds as a result of dam failure would, of itself, not lead to airborne releases. However, the exposed pond bed would become subject to wind stresses and result in airpgrne resuspension releases. Fractional airborne release rates of $10^{-8}$ to $10^{-10} / \mathrm{sec}$ (Sehmel and Lloyd, 1974a) could apply to estimating this release.

Dam failure could occur as a result of an earthquake or flooding; equipment failure, such as rupture of a tailings distribution pipeline; or operating errors. Tailings dike failures have occurred in the past; however, new mills are required to use new construction methods that could reduce this risk. 
It is not likely that the entire volume is released. Based on historical data, about $8 \times 10^{6}$. 1b of solids would be an average release from a pond. It is assumed this release occurred, but did not reach a waterway. The material is assumed to form a 1-in.-thick cover over an area approximatgly $4000 \times 250 \mathrm{ft}$ (USNRC, 1977b). This would provide an exposed area $1 \times 10^{6} \mathrm{ft}^{2}$ subject to resuspension, or a tgtal volume of $2.4 \times 10^{9} \mathrm{~cm}^{3}$. At a density of $1.6 \mathrm{~g} / \mathrm{cm}^{3}$, this totals $3.8 \times 10^{9} \mathrm{~g}$.

Sludge and slime material would be wet and not prone to resuspension so the fractional rate of $10^{-10} / \mathrm{sec}$ would apply. The release would be $0.38 \mathrm{~g} / \mathrm{sec}$. The release would be dependent on wind stresses and weather conditions. Some bank surfaces could contribute additional resuspension, but releases would be low. Total release could be $33 \mathrm{~kg} / 24 \mathrm{~h}$ day. Because the ore was originally $0.2 \%$ of $\mathrm{U}_{3} \mathrm{O}_{8}$, and about $7 \%$ remains in the tailings, this is about $5 \mathrm{~g}$ of uranium. It might be assumed that prompt administrative action would be taken and the released material covered to prevent resuspension.

\subsubsection{Fire}

A fire in the solvent extraction system could be initiated if kerosene fumes reach the flammability limit and an ignition source is introduced (e.g., a spark from machinery). There could be cellulosics present to continue to fuel the fire. Thirteen hundred pounds of yellowcake can be involved in the process and based on experimentally measured releases (Mishima and Schwendiman, 1973c), not more than $1 \%$ becomes airborne. In these experiments, $1 \%$ or less of the uranium in solution was released during combustion even when the vessel was heated externally after a self-sustaining heating period. The release in the solvent extraction fire is calculated to be $131 \mathrm{~b}$. The solvent extraction operation is located in a building separate from other processes so they would not be impacted. The building should retain its integrity, but for a maximum event it is assumed that the entire release passes to the atmosphere through windows and the ventilation system.

In two large solvent fires in uranium mills that have been reported (USAEC, 1974), 2000 to 3000 lb of uranium were present. There was no appreciable release to the atmosphere in either case.

The acid leach tanks contain sulfuric acid, which, if spilled on cellulosic material, can initiate a fire by spontaneous combustion. It is assumed that a leak in the tank occurs, resulting in spilled sulfuric acid contacting rags and a fire.

Because sulfuric acid is not flammable (Industrial Health and Safety Office, 1980) the fire release is limited. However, if the leach tank integrity is breached, it can be assumed that the building is filled with sulfuric acid mists, droplets, and vaporized salts as a quasi-stable aerosol with a concentration of $0.01 \mathrm{~g} / \mathrm{m}^{3}$ (ORNL, 1970).

These droplets could be assumed to have a uranium concentration similar to that of the leach solution, which could be $85 \%$ uranium. The density of the leach solution is about $1.2 \mathrm{~g} / \mathrm{cm}^{3}$, so the $0.01 \mathrm{~g} / \mathrm{m}^{3}$ airborne represents about 
$0.008 \mathrm{~cm}^{3}$ At a solution concentration of $0.85 \mathrm{~g} / \mathrm{cm}^{3}$, the $0.008 \mathrm{~cm}^{3}$ or $6.8 \times 10^{-3} \mathrm{~g} / \mathrm{m}^{3}$ is the calculated uranjum airborne concentration. The total mill building volume is about $3.4 \times 10^{4} \mathrm{~m}^{3}$, and this volume is reduced to $1.7 \times 10^{4} \mathrm{~m}^{3}$, if it is assumed that half of the building volume is filled with equipment. Therefore, $58 \mathrm{~g}$ of uranium would be airborne in the counter current decantation room and later discharged to the atmosphere.

A fire in the drying and packaging area could be initiated accidentally with a cutting tool. This fire would be small, and releases would pass through a filter, reducing the impact.

\subsubsection{Explosion}

Propane or natural gas fired dryers containing 1600 lb of yellowcake could be the site of a deflagration explosion. The free air space in the building following an explosion could be filled with a yellowcake dust. Although the instantaneous mass airborne can be high, the total quantities present will decrease with time. After $80 \mathrm{~min}$, less than $10 \%$ of the initial mass might remain airborne (Steindler and Seefeldt, 1981).3 It is assumed that the aerosol reaches a quasi-stable concentration of $0.1 \mathrm{~g} / \mathrm{m}^{3}$ (Selby et al., 1975) for a time fol fowing the explosion. The room volume where the dryer is located is $3.8 \times 10^{4} \mathrm{~m}^{3}$; it is aşsumed to be half full of yellowcake for a total of $1.9 \times 10^{3} \mathrm{~g}\left(1.6 \times 10^{3} \mathrm{~g}\right.$ of uranium) and $25 \%$ of this material could be $10 \mu \mathrm{m}$ AED or less (in the respirable range). Dust collectors for yellowcake are $98 \%$ efficient (USNRC, 1979b), and it is assumed they are undamaged. The atmospheric release is then $9.5 \mathrm{~g}$ of yellowcake in the respirable range.

\subsubsection{Conveyor Failure}

Equipment failure, specifically failure (rupture) of an ore conveyor to the building could lead to airborne releases. When the conveyor breaks, ore spills from the conveyor continuing until corrective action (stopping ore flow) is taken, perhaps $10 \mathrm{~min}$. At a mill throughput of $1800 \mathrm{MT} / 24-\mathrm{h}$ day, 12.5 MT $\left(1.25 \times 10^{4} \mathrm{~kg}\right)$ of ore is spilled. The ore can be assumed fairly dry since drying is used to reduce the moisture content (USNRC, 1980). The ore mass moving on the conveyor is $95 \%$ in pieces larger than $100 \mu \mathrm{m}$ in diameter, only $1 \%$ are less than $5 \mu \mathrm{m}$ (USNRC, 1979b). Therefore about $125 \mathrm{~kg}$ is assumed in the respirable size range and only a portion of that, perhaps $0.1 \%$ (Sutter et a)., 1981 ) would become airborne for a release of $0.125 \mathrm{~kg}$ of ore $(0.25 \mathrm{~g}$ of uranium).

\subsubsection{Uranium Mill MREPP Scenario}

Several levels of release values have been calculated for the uranium-mill accident scenarios. These are natural uranium releases, presenting a toxicity hazard.

\subsubsection{Material Release}

Atmospheric releases were $2850 \mathrm{~kg}$ of yellowcake for a tornado, $5 \mathrm{~g}$ of uranium/day resuspended from a tailing pond release, fire releases of $5.9 \mathrm{~kg}$ to 
$116 \mathrm{~g}$, about $10 \mathrm{~g}$ of yellowcake from an explosion, and $0.125 \mathrm{~kg}$ of ore dust from equipment failure. The tornado impact, therefore, was the MREPP event for uranium mills.

\subsubsection{Factors Affecting Release}

The following factors affect release at uranium mills:

- Quantity of material unconfined in the facility

- Onsite inventory

- Retention of filtration

- Particle size of material

- Size of facility breach.

\subsection{PLUTONIUM CONTAMINATED FACILITY}

Plutonium contaminated facilities are plants fomerly used as mixed oxide or mixed carbide fuel fabrication plants now being decontaminated and decommissioned. Decontamination and decommissioning operational releases are not within the scope of this study; Jenkins et al. (1979) covers them. Rather, we are currently looking at the plant licensed as a contaminated facility, referring to the residual plutonium stored as surface contamination. The inventogy of concern is this fixed contamination estimated conservatively as $1 \times 10^{-4} \mathrm{~g}$ of plutonium $/ \mathrm{m}^{2}$ (Mishima and Ayer, 1981). The total plutonium at risk in this type of facility can range from 46 to $76 \mathrm{mg}$.

\subsubsection{Potential Accident Scenarios}

For fixed plutonium surface contamination, there will be little opportunity for airborne release. The inventory is not in a dispersible form and will require mechanical or aerodynamic stresses sufficient to dislodge it. Events that are discussed are tornado, earthquake, fire, explosion, external event, and criticality.

\subsubsection{Tornado}

Damage resulting from a tornado could include crushing of glove boxes by failure of building interior partitions. The number of glove boxes damaged in the event would be dependent on the magnitude of the tornado windspeeds. Crushing the glove boxes would result in stresses sufficient to suspend fixed surface contamination.

Surface contamination is conservatively estimated using a resuspension factor $(\mathrm{a})$ of $10^{-2} / \mathrm{m}$ (Mishima and Ayer, 1981). The maximum dimensions of a glove box are $7 \mathrm{ft} \times 3 \mathrm{ft} \times 3 \mathrm{ft}$ and the volume is about $1.8 \mathrm{~m}$. Ising the

(a) Resuspension factor: $\mathrm{k} / \mathrm{m}=\frac{\text { airborne concentration (units } / \mathrm{m}^{3} \text { ) }}{\text { contamination level (units } / \mathrm{m}^{2} \text { ) }}$ 
$10^{-4} \mathrm{~g}$ of plutonium $/ \mathrm{m}^{2}$ surface contamination levels, assuming the glove box volume is the affected volume, the instantaneous release per glove box is:

$$
\left(10^{-2} / \mathrm{m}\right)\left(10^{-4} \mathrm{~g} \mathrm{Pu} / \mathrm{m}^{2}\right)\left(1.8 \mathrm{~m}^{3}\right)=1.8 \times 10^{-6} \mathrm{~g} \mathrm{Pu} \text {. }
$$

This calculates to $1.4 \times 10^{-4} \mathrm{~g}$ of plutonium if all $80 \mathrm{glove}$ boxes are involved. This is the maximum number of glove boxes in a facility.

Plutonium material could be embedded in the glove box filters and shaken loose in this event. However, it can be assumed that new HEPA filters were emplaced at the implementation of the storage mode. Since the glove boxes are not used during storage, there would be negligible plutonium carried to the filters by minimal airflow, so no release is estimated from this source.

All plutonium not instantaneously suspended could become airborne if contaminated surfaces are exposed to the existing wind field. Breached glove boxes could be assumed buried under rubble and debris generated by the event so only a small portion, less than an estimated $10 \%$ could be subject to suspension. An appropriate resuspension rate to use could be $10^{-10} / \mathrm{sec}$ for the fixed contamination, since the most readily removed material was released instantaneously. The contaminated area inside a glove $b 0 x$ can range frem 9.4 to $15.2 \mathrm{~m}^{2}$. The release could range from $9.4 \times 10^{-14}$ to $1.52 \times 10^{-13} \mathrm{~g}$ of $\mathrm{plu}-\overline{8}$ tonium/sec dependent on glove box size. Maximum release would be $1.3 \times 10^{-8} \mathrm{~g}$ of plutonium from each glove box in $24 \mathrm{~h}$ following the event, for a total resuspension release of $1 \times 10^{-6} \mathrm{~g}$.

\subsubsection{Earthquake}

Collapse of the exterior walls and roof could lead to glove box damage similar to that described for a tornado. To estimate the maximum event, the instantaneous and time-dependent release are assumed the same as for the tornado release.

\subsubsection{Criticality}

Plutonium-rich, silica-like sludges tend to accumulate in significant quantities in chemical plants that have been in operation over a period of years. These deposits can be created with a low hydrogen/plutonium atomic ratio raising the possibility of an autocatalytic nuclear excursion (Stratton, 1967). In contaminated facility status, equipment will have been removed. However, drain pipes might not have been replaced, and could conceivably contain sludge deposits. If such a sludge inadvertently exists in the cleaned out storage facility, addition of water (e.g., a flood) to a mass of this material could force it to the critical state. Stratton concluded that even for such an apparently dangerous situation it is difficult to imagine an explosive reaction. Based on his conclusions and the unlikelihood of inadvertent sludge accumulation to a level where criticality is possible, it does not seem that a criticality accident is feasible. 


\subsubsection{Fire}

These buildings are generally concrete and steel. Walls are usually reinforced concrete block, although the Westinghouse plant has corrugated steel siding exterior walls and cement plaster interior walls with steel studs. The roof may be metal decking supported by structural steel columns or steel decking with a concrete slab. Therefore, there would be little to sustain a fire in the event one started, and no release from the facility is anticipated as a result of fires.

\subsubsection{Explosion}

Only empty glove boxes are left in the cleaned out facility, so there are no process-related materials to initiate an explosion. The only potential explosion initiator could be the heating plant. An explosion from this source would probably not impact the glove boxes, and no release is identified.

\subsubsection{External Event}

The only fire/explosion-type event that could be envisioned generating an airborne release would be an airplane or truck crash puncturing the building walls, dumping fuel in the facility. A large pool fire is assumed ignited and could involve contaminated plastic surfaces, thereby aerosolizing some of the plutonium. Plutonium is not considered volatile so suspension would require that it be attached to a burning material. Because metal surfaces will not burn, only plastic material is involved.

It is assumed that the airborne release from burning cellulosic materials would apply to plastic, so the appropriate fractional release is $5 \times 10^{-4}$ (Mishima and Schwendiman, 1973b). These would be releases from the plastic glove box surfaces, estimated at about one-fifth of the glove box surface area.

If all the glove boxes in the building were involved, the total source would range from 9.2 to $15 \mathrm{mg}$, resulting in a maximum of $7.5 \times 10^{-6} \mathrm{~g}$ airborne in the facility.

This scenario seems highly improbable and is included for illustration only.

\subsubsection{Plutonium Contaminated Facility MREPP Scenario}

The MREPP scenario for plutonium contaminated facilities is the tornado accident. Mechanical and aerodynamic stresses from the tornado resuspend plutonium surface contamination.

\subsubsection{Material Release}

In the unlikely event that all of the maximum 80 glove boxes in a facility were crushed, the total release is estimated to be $1.4 \times 10^{-4} \mathrm{~g}$. It is all assumed released to the atmosphere. 


\subsubsection{Factors Affecting Release}

The following factors affect release at plutonium contaminated facilities:

- Probability of the event is $10^{-7} / \mathrm{yr}$ (Mishima and Ayer, 1981)

- Plutonium surface contamination inventory

- Wind speed

- Glove boxes breached

- Number and size of glove boxes

- Residual contamination level.

\subsection{RADIOPHARMACEUTICAL MANUFACTURING}

Radiopharmaceutical manufacturing facilities produce a wide range of radionuclides and the individual licenses cover products with atomic numbers in a range from 3 to 83 as well as specific identified amounts of other radionuclides. Physical forms can include solids, liqujgs, colloids, gaseş or microspheres (Grotenhuis 1966 ). Examples are ${ }^{190} \mathrm{Au}$ as a colloid, ${ }^{32} \mathrm{P}$ as chromic phosphate, and ${ }^{13}$ Xe gas. Each form responds differently to accident stresses: gases will become immediately airborne if a container is breached; tritium is volatile forming water vapor; radioiodides are volatile; cesium and strontium are semivolatile depending on temperature (Junkins et al., 1964). Thus dispersibility is a function of form plus physical properties.

Some facilities produce only one or two radionuclides, others many. Quantities of these inventories cogver a wide range of values from millicurie amounts of ${ }^{5} \mathrm{Cr}$ to $10^{5} \mathrm{Ci}$ of ${ }_{\mathrm{H}}$. Thus the isotopes of concern will vary with the site. Radionuclides with potential inyentories in curie amounts were

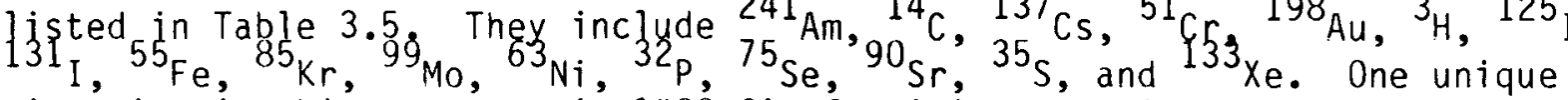
situation in this category is $1000 \mathrm{Ci}$ of tritium associated with waste stored at the Billerica facility. This quantity could not be considered a generic situation. However, because ${ }_{H}$ is the largest inventory at risk, it will determine the MREPP from this operation. However, other radionuclides can contribute more significantly to the radiological consequences of the release and will also be discussed. The maxiqum alloggble concentration in air (USCFR,

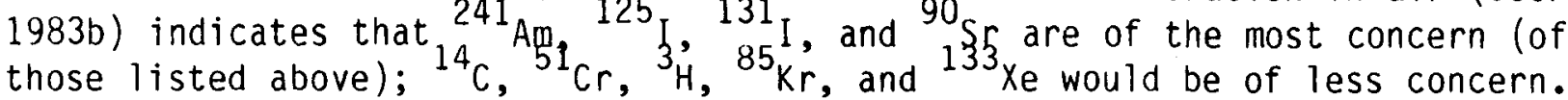
Table 4.2 lists the isotopes at the different levels of concern based on permissible air concentrations. In another listing, the National Institute of Health (1972) classified isotopes according to relative radiotoxicity per unit activity. The above radiopharmaceuticals listed in those classes are the following:

- Class 1 (very high toxicity): ${ }^{241} \mathrm{Am},{ }^{90} \mathrm{Sr}$

- Class 2 (high toxicity): ${ }^{125}$ I, $131_{\text {I }}$

- Class 3 (moderate toxicity): ${ }^{137} \mathrm{Cs},{ }^{198} \mathrm{Au},{ }^{55} \mathrm{Fe},{ }^{85} \mathrm{Kr},{ }^{99} \mathrm{Mo},{ }^{32} \mathrm{P}$, ${ }^{35} \mathrm{~S}, 133_{\mathrm{Xe}}$

- Class 4 (slight toxicity): ${ }^{14} \mathrm{C},{ }^{51} \mathrm{Cr},{ }^{3} \mathrm{H}$. 
TABLE 4.2. Selected Isotopes Found in Radiopharmaceutical

Manufacturing Facilities Grouped by Health

Concern Based on Permissible Air Concentration

\begin{tabular}{|c|c|c|c|}
\hline \multicolumn{4}{|c|}{ Intermediate } \\
\hline $\mathrm{High}$ & Concern & Ranges & Low \\
\hline Concern & Upper & Lower & Concern \\
\hline$\overline{241_{A m}}$ & $\overline{137 \mathrm{Cs}}$ & $\overline{198 \mathrm{Au}}$ & ${ }^{14} \mathrm{C}$ \\
\hline $125_{I}$ & ${ }^{63} \mathrm{Ni}$ & ${ }^{55} \mathrm{Fe}$ & 51 \\
\hline $131_{I}$ & $32 p$ & $9_{M}$ & \\
\hline${ }^{90} \mathrm{Sr}$ & ${ }^{35} \mathrm{~s}$ & ${ }^{75} \mathrm{Se}$ & ${ }^{85} \mathrm{Kr}$ \\
\hline & & & $133 \times \mathrm{e}$ \\
\hline
\end{tabular}

Isotopic half-life could be considered in evaluating events involving the short-lived isgtopes. Of the isotopes in the significant quantity category listed above, ${ }^{9}$ Mo has the shortest halfilife at $66.79 \mathrm{~h}$. Other half-lives range from several days to $5730 \mathrm{yr}$ for ${ }^{14} \mathrm{C}$. All, therefore, have a lifetime long enough to be of concern in an emergency preparedness accident scenario and the impact could be dependent on the process phase. For example, when associated with process waste, the shorter lived ones might be assumed expended since after 10 half-lives have passed they would have decayed to background levels (Sodee and Early, 1981). Thus Mo associated with waste could be assumed expended after $668 \mathrm{~h}$ or 28 days.

\subsubsection{Potential Accident Scenarios}

Two portions of the radiopharmaceutical operation will sometimes contain relatively larger amounts of radionuclides and, therefore, be the site of accidents with potentially higher releases. These are the shipping/receiving and waste storage areas. During processing, the isotopes are commonly 3 used in small amounts in hoods, caves, or glove boxes. In one operation, ${ }^{H}$ processes were concentrated in one general area.

Events that have been considered for this category are loading dock fire, explosion (including natural gas), facility fire/deflagration, tornado, earthquake, leaks and spills, cyclotron accident, and fire incidents involving waste.

Because fires are significant accidents for facilities, the potential behavior of important nuclides in response to fire stresses will be discussed before the accidents are postulated. Fractional releases of some of the nuclides have been developed in experimental work; however, this type of information is limited at present and usually covers isotopes that would have the largest health effects. Separation techniques and other information developed for chemical analysis is used to give clues as to the volatility of other isotopes. Vapor pressure, boiling point, and behavior of nonradioactive elements will be used to suggest release potential if no experimental measurements 
were available. However, this is not considered conclusive evidence of their behavior. Nonvolatile nuclides associated with waste materials such as paper and rags are assumed to have a fractional release similar to that experimentally megsured from burning contaminated waste (Mishima and Schwendiman 1973b), $5 \times 10^{-4}$.

The suggested volatilities for selected isotopes found in radiopharmaceutical material facilaities are as follows:

- Americium-241 can be volatile at extremely high temperatures. This conclusion is based on americium purification work in which trace amounts separated by volatilization gave a yield on the order of $50 \%$ (Penneman and Keenhan, 1960). Americium is separated from lanthanum based on volatility (Schulz, 1976), and the vapor pressure of the americium metal can be calculated:

$$
\log p(\mathrm{~atm})=(6.578 \pm 0.045)-(14,315 \pm 55) / T\left(990-1358^{\circ} \mathrm{K}\right)
$$

Based on vapor pressure studies ${ }^{241}$ Am can be volatile above $1727^{\circ} \mathrm{C}$ (Ward et a1., 1976). Americium is a decay product of plutonium (Weast, 1973). If the properties are similar, the release factors for burning plutonium contaminated liquids and powders might be appropriate to use at lower temperatures $\left(1000^{\circ} \mathrm{C}\right)$. Heated plutonium powder had a maximum release rate of $0.82 \%$ (Mishima et a1., 1968a) and plutonium solution $0.3 \%$ (Mishima et a1., 1968b). Therefore, $1 \%$ is selected as the conservative upper limit release for americium since the material can be found as either a powder or in solution.

- Carbon-14 can be found as gaseous $\mathrm{CO}_{2}$ or as labeled barium carbonate crystalline solid (NEN, 1976). The gas would all be released if its containment is breached in the fire. This could possibly occur due to pressurization of the container from heating in the fire. It has been considered easily volatilized (Durkosh, 1980). Therefore it is suggested that ${ }^{14} \mathrm{C}$ be considered completely airborne in a fire.

- Cesium-137 exhibits volatility on heating as found in experimental studies of potential heat-generated releases. These studies show that volatility is a function of increasing temperature. Releases at $1000^{\circ} \mathrm{C}$ in percent per hour were found to be: 1 (Albrethsen and Schwendiman, 1967), 1 or less (Mishima and Schwendiman, 1973c), 1.5 (Gray, 1981), and 4.2 (Walmsley et al., 1969). Some of the volatile release could be removed by filter retention and condensation ( 35 to $93 \%$ ), and an additional $30 \%$ by deposition (Hilliard, 1959). Based on this information, $1 \%$ per hour is the suggested conservative release fraction for ${ }^{137} \mathrm{Cs}$, assuming there will be some mitigation of the release.

- Chromium-51 forms can include chromic chloride solutions, sodium chromate, or EDTA complexes (NEN, 1976). Its volatility is not available. However, it has a high boiling point, $2672^{\circ} \mathrm{C}$ (Weast, 1973), and does not seem to be a candidate for high fire generated release levels. During chemical separation by distillation, chromyl chloride was found to be the only 
volatile form of chromium (Pijck, 1964). Typical distillation of other chromium forms yielded $0.03 \%$. Based on this information, a $3 \times 10^{-4}$ fractional release is suggested for ${ }^{51} \mathrm{Cr}$.

- Gold-198 could be in an acid solution. Gold melts at $1064^{\circ} \mathrm{C}$ and boils at $2807^{\circ} \mathrm{C}$ (Weast, 1973) suggesting that it could be considered a semivolatile. Gold can be volatilized from rapidly evaporating aqua regia $\left(\mathrm{HCl}-\mathrm{HNO}_{3}\right)$ solutions or if evaporated from $\mathrm{H}_{2} \mathrm{SO}_{4}$. Solutions containing gold lost about 1 to $3 \%$ on evaporation (Emery and Leddicotte, 1961). Because the gold can be in an aqua regia solution it is assumed semivolatile, and the conservative fractional release estimate would be $3 \times 10^{-2}$.

- Hydrogen-3 (tritium) is volatile and could be released from breached containers. One study of breached ${ }^{3}$ containers estimated that $98 \%$ of the total inventory was released in the first hour after the event (Niemyer, 1970), and heat woyld not be required for volatilization. In this work, Niemyer noted the ${ }^{H}$ could be released at $25^{\circ} \mathrm{C}$. Therefore, the entire ${ }^{3} \mathrm{H}$ inventory could be assumed airborne even at ambient temperatures. The release to the environment would usually be converted to the oxide form quite rapidly and dispersed like ordinary water (Jacobs, 1968).

- Iodine-125 and -131 are of concern because they are considered volatile isotopes (Kristensen, 1979). Iodine solutions are volatile (Gandsman et al., 1980). At ambient temperature, $\mathrm{NaI}$ solutions generate volatile iodides and achieve a steady-state vaporization rate (Pollock and Myser, 1979; Quinn, 1980). Volatilization can be a function of increasing temperature (Rimshaw and Case, 1981), and iodine has been found to be almost completely volatile during combustion and has compounds that are volatile at room temperature (Alexander et al., 1981). Mishima and Schwendiman (1973c) found that $65 \%$ of the iodine in a TBP solution was released during liquid burning, and further heating of the residue resulted in a total iodine release of $83 \%$. Using a conservative approach, it is considered $100 \%$ volatile in a fire.

- Iron-55 may be assumed similar to nonradioactive iron, which melts at $1535^{\circ} \mathrm{C}$ and boils at $2750^{\circ} \mathrm{C}$ (Weast, 1973). Vapor pressure measurements (Nesmeyanov, 1963) suggest the solid material is nonvolatile. Iron oxide decomposes at $1300^{\circ} \mathrm{C}$ and temperatures less than about $1100^{\circ} \mathrm{C}$ are recommended during analytical procedures. Iron-55 can be in acid solutions (NEN, 1976). A separation technique for iron in a mixed acid solution evaporates the solution to dryness. This method yielded $99 \%$ indicating a maximum loss of $1 \%$ (Nielsen, 1960). While all of this loss might not be caused by volatility during evaporation, the value might be used to suggest a conservative upper limit release factor of $1 \%$.

- Krypton-85 is a gas and would become airborne in a fire.

- Molybdenum-99 is stable in air and it is, therefore, assumed that negligible amounts would become airborne in a fire. The melting point of molybdenum is $2617^{\circ} \mathrm{C}$ and the boiling point is $4612^{\circ} \mathrm{C}$. 
- Nickel-63 has been assumed stable (Wang, 1969) and is, therefore, not airborne in a fire. Separation techniques that include boiling nickel solutions had 100\% recovery of nickel (Kirby, 1961). This behavior suggests that ${ }^{63} \mathrm{Ni}$ is nonvolatile in a fire environment.

- Phosphorus-32 could be considered to resemble other forms of phosphorous (Wang, 1969), which are volatile and therefore would all be airborne in a fire. This assumption is substantiated since phosphorous can be separated from acid solutions based on phosphorous volatility (Mullins and Leddicotte, 1962).

- Selenium-75 is found as acid solutions. Selenium has a boiling point of $685^{\circ} \mathrm{C}$ (Weast, 1973). The solid melts at $221^{\circ} \mathrm{C}$ and boils at $685^{\circ} \mathrm{C}$ forming a yellow vapor (Bagnal1, 1966). It is very reactive forming the dioxide on burning. It could be considered volatile in a fire environment, and this is confirmed by the fact that selenium is separated from other metals on the basis of volatility. In the chemical behavior of selenium, studies showed that selenium is lost from samples due to volatilization. It is volatilized from dilute $\mathrm{HCl}$ solutions above $100^{\circ} \mathrm{C}$ (Molinski and Leddicote, 1965 ).

- Strontium-90 releases have been studied experimentally, and ${ }^{90}$ Sr was found to semivolatile. Releases were three orders of magnitude less than those for ${ }^{137} \mathrm{Cs}$ (Albrethsen and Schwendiman, 1967). In another study, $0.2 \%$ of the strontium was released from burning contaminated tributyl phosphate in a kerosene-type diluent (Sutter et al., 1974). Therefore, this value may be used as the fire release fraction.

- Sulfur-35 can be found as a sodium sulfate solution, as sulfuric acid, as elemental sulfur in benzene solution, or as labeled compounds such as $\mathrm{SO}_{2}$. Sulfur is low boiling ranging from $113^{\circ} \mathrm{C}$ to $445^{\circ} \mathrm{C}$ (Weast, 1973), and also has a gaseous form. It is an easily ignitable combustible solid with an ignition temperature of $450^{\circ} \mathrm{C}$ (NFPA, 1978). Sulfur dioxide is the main incineration product of sulfur (USEPA, 1977) and coyld be considered volatile in a fire environment. Sulfur, including ${ }^{35}$, is analytically separated on the basis of hydrogen sulfide (a colorless gas) volatility (Leddicotte, 1962). This supports the conclusion that ${ }^{35} \mathrm{~S}$ would be completely volatile in a fire.

- Xenon-133 is a gas and is therefore considered volatile.

The suggested volatilities discussed above are shown as release factors in Table 4.3.

\subsubsection{Loading Dock Fire}

Raw by-product material is delivered to the radiopharmaceutical manufacturers by truck. The largest inventories of nuclides are usually found in these areas on shipping days. 
TABLE 4.3. Suggested Fire Release Factors for Selected Isotopes Found in Radiopharmaceutical Manufacturing Facilities

\begin{tabular}{|c|c|c|c|}
\hline Element & Isotope & $\begin{array}{c}\text { Suggested } \\
\text { Release Factor } \\
\end{array}$ & Comments \\
\hline Americium & $241_{A m}$ & 0.01 & Volatile above $1727^{\circ} \mathrm{C}$ \\
\hline Carbon & ${ }^{14} \mathrm{C}$ & 1.0 & Depends on form \\
\hline Cesium & ${ }^{137} \mathrm{Cs}$ & 0.01 & $\begin{array}{l}\text { Release per hour of } \\
\text { burning }\end{array}$ \\
\hline Chromium & ${ }^{51} \mathrm{Cr}$ & -- & Nonvolatile \\
\hline Gold & ${ }^{198} \mathrm{Au}$ & $3 \times 10^{-4}$ & \\
\hline Hydrogen & $3_{H}$ & 1 & Gas \\
\hline \multirow[t]{2}{*}{ Iodine } & $125_{\mathrm{I}}$ & 1 & \multirow{2}{*}{$\begin{array}{l}\text { Volatility can be a } \\
\text { function of increas- } \\
\text { ing temperature }\end{array}$} \\
\hline & $131_{I}$ & 1 & \\
\hline Iron & ${ }^{55} \mathrm{Fe}$ & 0.01 & $\begin{array}{l}\text { Essentially } \\
\text { Nonvolatile }\end{array}$ \\
\hline Krypton & $85 \mathrm{Kr}$ & 1 & Gas \\
\hline Molybdenum & ${ }^{99}$ Mo & --- & Nonvolatile \\
\hline Nickel & ${ }^{63} \mathrm{Ni}$ & -- & Nonvolatile \\
\hline Phosphorous & $32_{p}$ & 1 & \\
\hline Selenium & $75 \mathrm{Se}$ & 1 & $\begin{array}{l}\text { Solution completely } \\
\text { volatile above } 100^{\circ} \mathrm{C}\end{array}$ \\
\hline Strontium & ${ }^{90} \mathrm{Sr}$ & $2 \times 10^{-3}$ & \\
\hline Sulfur & ${ }^{55} \mathrm{~S}$ & 1 & Forms a gas \\
\hline Xenon & $133 \times \mathrm{e}$ & 1 & Gas \\
\hline
\end{tabular}

It is postulated that a truck delivering supplies and equipment strikes the delivery dock as described in the generic truck/receiving dock fire scenario in Section 4.1.1.1. The truck fuel tank is torn open by the metal debris generated by the crash and the entire $100 \mathrm{gal}$ of gasoline in the tank spills to the ground and is ignited by sparks created by the contact of metal and concrete. The fire following this event would last a maximum of $12.5 \mathrm{~min}$.

The accident is assumed to occur on a receiving day, and thus curie amounts of isotopes in the bulk shipment could be in jeopardy in the fire. The largest inventory at risk could be $2000 \mathrm{Ci}$ of $3_{\mathrm{H}}$ in two pressurized cylinders. The integrity of these cylinders could be breached by the impact damaging valves, or heating and subsequent pressurization could cause cylinder failure. The entire inventory of ${ }^{H}$ is assumed airborne. 
Other radioactive materials could be on a shipping dock and releases of these isotopes could be of concern. Shipments of 125 I are approximately $4 \mathrm{Ci}$ each, and this entire inventory is assumed airborne. Other isotopes potenfjally involved ang assumed completely airborne are $5 \mathrm{Ci}$ of $32 \mathrm{P}$ and $10 \mathrm{Ci}$ of $14 \mathrm{C}$. As gases, $133 \mathrm{Xe}$ and $85 \mathrm{Kr}$ would all be released if the shipping containers are greached. Releases are 450 and $200 \mathrm{Ci}$, respectively. Negligible amounts of ${ }^{99}$ Mo would be released from canisters containing $800 \mathrm{Ci}$ of solution. Shipping regulations allow packages containing $10 \mathrm{Ci}$ of ${ }^{13} \mathrm{Cs}$ and $0.4 \mathrm{Ci}$ of $90 \mathrm{Sr}$ in normal form (USCFR, 1983a). (Normal form is a form other than special form such as encapsulated sources.) Cesium-137 and $90 \mathrm{Sr}$ exhibit volatility and, since the fire is assumed to last $12.5 \mathrm{~min}$, the release would be about $20 \%$ of the releage for $19 \mathrm{~b}$. This results in releases of $2 \times 10^{-2} \mathrm{Ci}$ of ${ }^{13} \mathrm{Cs}$ and $1.6 \times 10^{-4} \mathrm{Ci}$ of $\mathrm{Sr}$ per package of the normal form.

Amounts in shipments will vary. The amounts that are suggested are typical amounts that might be found on the loading dock and are included for illustration only. Also, the isotopes would not all necessarily be on the loading dock at the same time.

In some facilities radioactive waste is stored in the shipping/receiving area and, therefore, could potentially become involved in the fire. Because the 20-ft fire is centered around the truck, it would seem that the waste would be stored at a distance where it would not necessarily become involved unless other events intervened. For example, the waste storage area could be heated using natural gas heaters and use propane fueled front-loaders to move the waste. Involvement of either or both of these combustible fuels in the fire could mean additional releases from the drummed waste.

It is therefore assumed that the fire spreads to the waste area where it heats and ruptures drums containing lab trash. A fraction of the stored waste, perhaps $10 \%$, is expelled from the drums and contributes to the fire. Volatile nuclides associated with this expelled waste become airborne. The nonvolatiles associated with the cellulosics in the drums become airborne with a fractional release of $5 \times 10^{-4}$ and the volatiles are all airbogne. The expelled lab trash could contain $200 \mathrm{Ci}$ of ${ }^{3} \mathrm{H}, 5 \mathrm{Ci}$ of ${ }^{14} \mathrm{C}, 1_{3} \mathrm{Ci}$ of ${ }^{125} \mathrm{I}$, and $0.5 \mathrm{Ci}$ of $32_{\mathrm{P}}$. These are all assumed volatilized. Since ${ }^{32} p$ has a 14.3 -day half-life, it could be assumed decayed at the time of the fire.

\subsubsection{Tornado}

Radiopharmaceutical manufacturing facilities are built according to specifications of the uniform building code and are not constructed to withstand tornado damage. It is assumed that a tornado could strike an operational radiopharmaceutical manufacturing facility. The results could be:

- Wall damage and loss of roof

- Missile generation

- Caves remain intact

- Fume hood and glove box damage. 
Several hoods or glove boxes could be in use at the same time, and $100 \mathrm{Ci}$ of $13 \mathrm{I}_{\mathrm{I}}$ or $500 \mathrm{Ci}$ of $3_{\mathrm{H}} \mathrm{might}$ be the total maximum inventory in process. This inventory would not all be in jeopardy, since it is distributed in smaller vials within the hood or glove box. A portion of these vials could be assumed damaged so that some of the material is spilled, and released in the hood. The spilled portion is assumed as $1 \%$, to $1 \mathrm{Ci}$ of ${ }^{131} \mathrm{I}$ or $5 \mathrm{Ci}$ tritiated water per enclosure. The exhaust system filters are assumed to fail, and all the release will be carried to the atmosphere.

If alternately, the HVAC system is damaged, the material may be ejected into the room. Because there would be no ventilation flow to transport the release, it would leave the facility by diffusion, a slow process.

Xenon-133 gas is dispensed from a cylinder in a plexiglass hood. Damage to this hood accompanied by cylinder damage would allow it to become airborne. If this cylinder was full at the time of the tornado, $350 \mathrm{Ci}$ would become airborne and would be subsequently released to the atmosphere.

Krypton-85, $200 \mathrm{Ci}$ per cylinder, could also be in jeopardy. About $1100 \mathrm{Ci}$ could be in processing at the time of the event, and it is assumed that half of the cylinders are damaged and $600 \mathrm{Ci}$ become airborne.

\subsubsection{Earthquake}

Maximum ground acceleration from seismic events can cause damage at different ranges as discussed in Section 4.2.1.1. The degree of severity and likelihood of the event is dependent on the geographical location of the manufacturer. The collapse of an entire facility might be anticipated at a linear acceleration of $0.25 \mathrm{~g}$.

Lesser levels would not produce significant structural damage. Overturning process vessels and equipment, and rupturing glass vessels would be anticipated. Amounts of material in the process could spill or leak. Generally there is no powder (a dispersible form) in process. Gases are the most dispersible form, and a broken valve could allow the same gaseous releases produced by a tornado.

\subsubsection{Spills and Leaks}

Spills can occur in gaseous and liquid processes. The environment in which this accident occurs is similar to a chemistry laboratory. This means that there would not be sufficient material involved in any single event to lead to a significant atmospheric release.

\subsubsection{Explosions}

Use of solvents in the process provides the opportunity for explosions. As in the case of leaks and spills, because the operations are scattered, a single event of this type would be unlikely to lead to a significant atmospheric release. 
Natural gas explosions were discussed in Section 4.3.1.6. It is assumed that a similar event occurs in the radiopharmaceutical manufacturing plant, yielding a 2.4-ib TNT equivalent. This event could subsequently lead to a major facility fire and will be discussed under that heading.

\subsubsection{Facility Fire}

A flammable vapor leak (i.e., natural gas) accumulates and subsequently deflagrates (Section 4.3.1.6). Oxygen lines located at each glove box are breached by the initial explosion and could accelerate burning of solvents, paper, and wood furniture. In a steel- and concrete-reinforced structure, the damage would be limited. In a wood structure, a full-scale facility fire could ensue. In an older wooden building, it would be possible to envision the ȩntire building becoming engulfed in fire and eventually gutted. The entire ${ }^{3}$ inventory in the building could be released in this accident, $3 \times 10^{4} \mathrm{Ci}$, the maximum amount at the facility.

In addition to ${ }^{3} H$, other isotopes of concern could be released in significant amounts in a facility fire. Releases of other isgtopes from that structure could be $59 \mathrm{Ci}$ of ${ }^{14} \mathrm{C}, 1 \mathrm{Ci}$ of ${ }^{32} \mathrm{P}$, and $10 \mathrm{Ci}$ of ${ }^{35} \mathrm{~S}$. Iodine isotopes were not listed in the inventory for the specific wooden structure, but if present, would be completely volatilized. The wooden structure seems to be the only one likely to have a major facility fire.

\subsubsection{Cyclotron Accident}

Cyclotrons in radiopharmaceutical manufacturing operations are enclosed in caves with 6- or 7-ft-thick concrete walls and 4-ft-thick concrete ceilings. This would contain any releases from an unplanned event.

\subsubsection{Waste-Incident Fire}

Waste is gathered together in a facility and either solidified and drummed 86 held for decay. "Decay in storage" is used for the shorter-lived " $p$ or $99 \mathrm{~m}$ Tc isotopes.

Drummed waste commonly contains lab trash such as paper, glassware, and clothing. This type of waste can also be stored in cardboard containers. Gaseous waste is stored in cylinders.

A Targe ${ }^{85} \mathrm{Kr}$ inventory of $1000 \mathrm{Ci}$ is stored in Matheson $3-\mathrm{L}$ stainless steel units (cylinders) or equal, with 100 to $150 \mathrm{Ci}$ per container. The pressure is less than atmospheric. These, in turn, are stored in a shipping overpack (Devlin, 1978). This stringent packaging means that the container integrity is of sufficient strength, so an accident is unlikely to occur. Two thousand curies of $\mathrm{H}$ could be contained in type $17 \mathrm{H} 55$-gal steel drums with 6 in. of concrete surrounding each container. This matrix is not conducive to accidents. A large fire involving waste was discussed as part of the loading dock accident and will not be repeated here, a smaller event may occur. 
It is postulated that a glass container of acid is inadvertently included in the waste and broken during compacting. The spilled acid saturated cellulosics and consequently the cellulosics ignite spontaneously. Heat from the fire pressurizes the drum and ruptures it.

125 Lab trash is pgstulated to contain $50 \mathrm{Ci}$ of ${ }^{14} \mathrm{C}, 2000 \mathrm{Ci}$ of ${ }^{3} \mathrm{H}, 10 \mathrm{Ci}$ of ${ }^{125} \mathrm{I}$, and $5 \mathrm{Ci}$ of ${ }^{32} \mathrm{P}$. An estimate of the number of drums stored in the building is about 580 drums. This assumes ten stacks of pallets four wide and four high with four drums per pallet. Therefore one drum of lab trash would contain $0.1 \mathrm{Ci}$ of ${ }^{14} \mathrm{C}, 4 \mathrm{Ci}$ of ${ }^{3} \mathrm{H}, 2 \times 10^{-2} \mathrm{Ci}$ of $125 \mathrm{I}$, and $1 \times 10^{-2} \mathrm{Ci}$ of ${ }^{32} \mathrm{p}$. All of this inventory in the grum would become airborne. Again, because of decay, it is unlikely that the ${ }^{32} \mathrm{p}$ would be available for release.

If the fire involves all of the waste, spreading by igniting the pallets, the entire inventory could become airborne. This fire is considered unlikely if fire suppression systems operate effectively.

\subsubsection{Radiopharmaceutical Manufacturing MREPP Scenario}

The quantities of ${ }^{3} \mathrm{H}$ used, coupled with its volatility, make it the contaminant with the largest release potential at radiopharmaceutical manufacturing operations. However, releases of the isotopes of more concern with regard to health effects have also been suggested.

\subsubsection{Material Release}

The MREPP event for this category would be facility dependent. For a wooden structure, there is a potential for a major facility fire. Concrete and steel building construction would reduce this potential and a loading dock fire would become the MREPP event.

$3_{3}$ Calculated maximum releases $\mathrm{f}, 32$ the wooden strugture fire were $3 \times 10^{4} \mathrm{Ci}$ of ${ }^{3} \mathrm{H}$, plus $59 \mathrm{Ci}$ of ${ }^{14} \mathrm{C}, 1 \mathrm{Ci}$ of ${ }^{32} \mathrm{P}$ and $10 \mathrm{Ci}$ of ${ }^{35} \mathrm{~S} .24$ Fires at other facilities could release other isotopes (e.g., example ${ }^{241}$ Am and ${ }^{131} \mathrm{I}$ ). Using the maximum inventory in Table 3.5 and the suggested release factors, releases of these isotopes could be 3.5 and $150 \mathrm{Ci}$, respectively.

\subsubsection{Factors Affecting Release}

The following factors affect release at radiopharmeceutical manufacturing facilities:

- Facility construction

- Effectiveness of fire safety systems

- Inventory in process

- Container integrity.

\subsection{RADIOPHARMACY}

At a radiopharmacy, isotopes are received from a radiopharmaceutical manufacturer and repackaged in dose-size amounts as administered in hospitals. 
Generators preparing ${ }^{99} \mathrm{~m}_{\mathrm{T}} \mathrm{c}$ from ${ }^{99}$ Mo are another segment of the work. The operations resemble those of a chemical laboratory, and work is performed on lab benches or in hoods in a few small rooms. Typical work is pipetting dosesize aliquots of an isotope solution into a syringe and individually packingi them in lead carriers ready for hospital use.

The isotopes used are similar to those in radiopharmaceutical manufacturing, but in very small quantities. License limit ranges were listed in Table 3.6 and show ${ }^{9}$ Mo with the maximum potentjal inventgry, $426 \mathrm{Ci}$. Isotopes of mare concern with regard to health effects, $13 I_{\mathrm{I}}$ and $90 \mathrm{Sr}$, would have maximum potential inventories of 4.5 and $0.5 \mathrm{Ci}$, respectively. Depleted uranium enclosed in a stainless steel casing can be used as shielding, and the maximum license allows $91 \mathrm{~kg}$.

\subsubsection{Potential Accident Scenarios}

The small scale of the operations, low license limits, and small individual packages reduce the risks associated with a radiopharmacy. Accidents discussed are spills and leaks, tornado, earthquake, fire, and explosion.

\subsubsection{Spil1s and Leaks}

Airborne releases from spills would be at a low level because of the small amounts used and quantities in contajners. Typical amounts involved in a spill could be a container of $10 \mathrm{mC} i$ of ${ }^{2}$ I as a NaI solution (NEN, 1976). It is assumed that due to operator error, a $_{1}$ full container of $\mathrm{NaI}$ is overturned, spilling the entire contents. The ${ }^{13}$ I spill is volatile and will be released at a steady-state rate. Therefore, it is estimated that the entire $10 \mathrm{mC}$ becomes airborne. Because the operation does not typically use charcoal filters in the ventilation system, this entire release, even when spilled in a hood, would be carried to the atmosphere outside the facility.

\subsubsection{Tornado}

These facilities would not generally be constructed to withstand tornado damage. Therefore, if a tornado strikes a radiopharmacy, severe damage and breaching of the facility could be anticipated. The isotopes in process at the time of the event could be considered at risk. Packaged isotopes (e.g., lead shjelded syringes) should not breach as a result of the tornado. Amounts of 131 actually in process would be in jeopardy since they would be in open containers, and the release would be similar to the spill release or $10 \mathrm{mC}$ per containers in process. It is not conceivable that the entire maximum inventory, $4.5 \mathrm{Ci}$, could be in jeopardy at one time.

\subsubsection{Earthquake}

Earthquake damage to a radiopharmacy could be anticipated to be similar to tornado damage. Spilled material could be carried to the atmosphere by building airflow resulting in releases similar to the tornado event. If the 
ventilation system fails, materials would be slowly released by diffusion. Again, rigorous packaging and small inventories would prevent large releases.

\subsubsection{Explosions}

Potential explosions in the process seem limited due to the small-scale operations. Solvents and hazardous materials are used in small quantities that are unlikely to cause explosions.

Natural gas used for heating could be the source of a potential explosion leading to a deflagration. This event is discussed in detail in Section 4.3.1.6 of this report. In this facility, small rooms could enable an explosive amount of gas from a leak to build up. It is hypothesized that a deflagration occurs in the radiopharmacy. Combustible building material ignites and a full-scale facility fire follows. Releases from this scenario will be quantified as a facility fire.

\subsubsection{Fire}

A major facility fire is suggested as a consequence of a natural gas explosion. It is possible to envision such an event consuming the entire building and fire fighters breaching the roof in attempts to fight the fire. Or, alternately, the roof could have been breached in the initiating event. This would provide a direct path to the atmosphere for airborne contamination.

on 135 ire temperatures reaching $328^{\circ} \mathrm{C}$ could melt lead shielding (Weast, 1973) entire inventory could become airborne in the fire, a value that could range from $10 \mathrm{mC} i$ to $4.5 \mathrm{Ci}$.

Cylinders containing ${ }^{13}$ Xe would sustain damage and the entire maximum inventory 8 f $75 \mathrm{Ci}$ of gas could become airborne. The maximum license limit of $75 \mathrm{Ci}$ of ${ }^{9} \mathrm{~m} \mathrm{Tc}$ could contribute to the release, since technetium is about $1 \%$ volatile at $600^{\circ} \mathrm{C}$ (Rimshaw et al., 1980; Rimshaw and Case, 1981).

A fraction of the $0.596 j$ of ${ }^{90} \mathrm{Sr}$ inventory ${ }_{3}$ could become airborne. The fire release fraction for $90 \mathrm{Sr}$ could be $2 \times 10^{-3}$ (Sutter et al., 1974) so a release of $1 \times 10^{-3} \mathrm{Ci}$ of ${ }^{90} \mathrm{Sr}$ is calculated.

Stainless steel casing on the generators could be anticipated to withstand temperatures in the range of $2220^{\circ} \mathrm{F}\left(1200^{\circ} \mathrm{C}\right)$ (Perry, 1973). If temperatures reach above this level, the steel casing could conceivably be melted, exposing the enclosed depleted uranium to the fire stress then subsequently become airborne. A 1\% fraction (Mishima and Schwendiman, 1973a) is assumed airborne. Assuming the maximum license limit of $91 \mathrm{~kg}$ present in the facility, the release would be $910 \mathrm{~g}$ of uranium.

Fire could engulf the waste in decay in the storage room. Radionuclides associated with the waste could become airborne. Some additional release could occur here, but they have been included in the numbers suggested already, since those figures were based on total license limits. 


\subsubsection{Radiopharmacy MREPP Scenario}

The facility fire is the accident with the MREPP potential at a radiopharmacy.

4.7.2.1 Material Release

Release of radioisotopes from a facility fire based on inventory limits will be from material in process and associated with contaminated waste. These potential releases are $4.5 \mathrm{Ci}$ of $131 \mathrm{I}, 2 \times 10^{-3} \mathrm{Ci}$ of ${ }^{90} \mathrm{Sr}, 1 \mathrm{Ci}$ of $99 \mathrm{~m} \mathrm{Tc}$, $75 \mathrm{Ci}$ of $133 \mathrm{xe}$, and $910 \mathrm{~g}$ of uranium. Actual releases would depend on the inventory on hand at the time of the fire.

\subsubsection{Factors Affecting Release}

The following factors affect release at a radiopharmacy:

- Inventory on hand

- Effectiveness of fire suppression systems

- Building construction.

\subsection{SEALED SOURCE MANUFACTURING}

Facilities licensed in this category produce sealed sources or selfluminous devices or are distribution centers for these devices. The latter procedure is generally receiving the isotope and repackaging it in the desired configuration. In other operations some chemical processing occurs.

Some facilities handle using radiopharmaceutical isotopes. Rather than cover these again within this category, the user is referred to sections 4.6 and 4.7 , radiopharmaceutical manufacturing or radiopharmacy when appropriate to do so for a safety analysis. Waste warehousing is another function performed and that section of this report can be used when applicable for a safety assessment.. In this category, warehousing can include storage of bulk shipments as received or manufactured sources before disbursement.

License limits can range from a few millicuries to a maximum $281 \times 1 \times 10^{5} \mathrm{Ci}$ for ${ }^{3} \mathrm{H}_{3}$ and $192 \mathrm{clude}$ a varjety of $\mathrm{j}$ sotopes. The most common are: ${ }^{241} \mathrm{Am},{ }^{137} \mathrm{Cs}$,

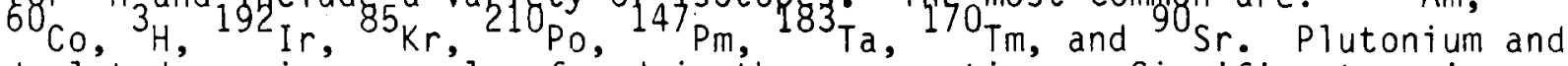
depleted uranium are also found in these operations. Significant maximum inventories of these materials are listed in Table 3.7 .

The majority of the time, the isotopes are in a form not susceptible to airborne release. These could be for example, pellets, metallic. wafers or foils, or platinum gauzes. Plastic microspheres of controlled particle size encase some of the isotopes. These are generally spherical and range from 10 to $250 \mathrm{\mu m}$ in diameter (Grotenhuis, 1966). Tritium and ${ }^{85} \mathrm{Kr}$ are gaseous and would disperse if their containment is breached. Isotopes are particularly vulnerable to dispersal when they are in the process flow. When they are being processed they could be in open containers that could be spilled in an 
accident. The quantity of ${ }^{3} H$ would make it the MREPP, but there are large inventories of radionuclides with significant biological effects, and their releases are also discussed. The relative hazard of these isotopes as reflected in the allowable air concentrations (USCFR, 1983b) is listed in Table 4.4 for the isotopes commonly found in sealed source manufacturing facilities.

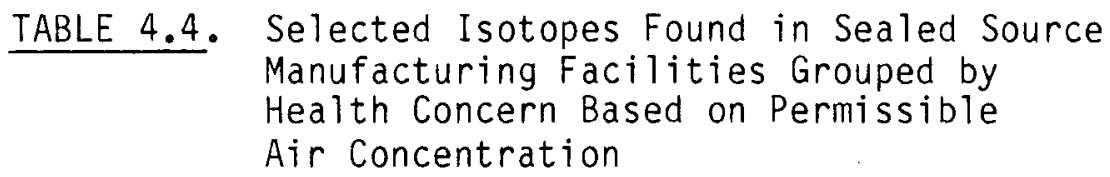

\begin{tabular}{|c|c|c|c|}
\hline & \multicolumn{2}{|c|}{ Intermediate } & \multirow{3}{*}{$\begin{array}{c}\text { Low } \\
\text { Concern }\end{array}$} \\
\hline $\mathrm{High}$ & Concern & Ranges & \\
\hline Concern & Upper & Lower & \\
\hline$\overline{241_{A m}}$ & $\overline{137} \mathrm{Cs}$ & $\overline{60} \mathrm{Co}_{\mathrm{O}}$ & $3_{\mathrm{H}}$ \\
\hline $210_{P_{0}}$ & $192 \mathrm{Ir}$ & & $85_{K r}$ \\
\hline${ }^{90} \mathrm{Sr}$ & ${ }^{147} \mathrm{Pm}$ & & \\
\hline & ${ }^{170} \mathrm{Tm}$ & & \\
\hline $\mathrm{Pu}$ & & & \\
\hline U & & & \\
\hline
\end{tabular}

The National Institute of Health (1972) classified these isotopes as follows:

- Class 1 (very high toxicity): ${ }^{90} \mathrm{Sr},{ }^{241} \mathrm{Am},{ }^{210} \mathrm{Po},{ }^{239} \mathrm{Pu}$

- Class 2 (high toxicity): ${ }^{170}$ Tm, natural uranium

- Class 3 (moderate toxicity): ${ }^{60} \mathrm{Co},{ }^{85} \mathrm{Kr},{ }^{137} \mathrm{Cs},{ }^{147} \mathrm{Pm},{ }^{192} \mathrm{Ir}$

- Class 4 (slight toxicity): ${ }^{3} \mathrm{H}$.

No information on ${ }^{183}$ Ta toxicity was suggested in either source.

\subsubsection{Potential Accident Scenarios}

Potential accidents are similar to those postulated for radiopharmaceutical manufacturing facilities. Events that are discussed include: fire during process operations, tornado, earthquake, leaks of both liquids and gas, spills, explosion, and facility fire.

Fires are an important accident type and the potential isotope releases are discussed first. These facilities use many of the same isotopes as the radiopharmaceutical manufacturing facilities, plus some additional isotopes. Only the potential release of these additional isotopes is discussed. The user is referred to Section 4.6.1 for the discussion of isotopes common to both 
operations with release factors suggested in Table 4.3 , Release factors are developed here for ${ }^{6} \mathrm{Co}$, ${ }^{192} \mathrm{Ir},{ }^{210} \mathrm{Po}, 147 \mathrm{Pm}, 18{ }^{1} \mathrm{Ta}, 190 \mathrm{Tm}$, plutonium, and uranium and are listed in Table 4.5.

- Cobalt-60 is used as a sealed source. The melting point of cobalt is $1495^{\circ} \mathrm{C}$, boiling point, $2870^{\circ} \mathrm{C}$ (Weast, 1973). Analytical determinations include sample ignition (Bate and Leddicotte, 1961) suggesting low volatility. In studies of contaminated waste incineration, ${ }^{60}$ Co was suggested as slightly less volatile than ${ }^{13} \mathrm{Cs}$ (Alexander et al., 1981). Based on the distrjbytion of both nuclides, the ${ }^{C}$ o volatility would be about $20 \%$ that of ${ }^{137} \mathrm{Cs}$. The volatility of ${ }^{137} \mathrm{Cs}$ was suggested at $1 \%$ per hour. Based on this information, ${ }^{60} \mathrm{Co}$ is suggested to have a fractional release of $2 \times 10^{-3} / \mathrm{h}$.

- Iridium-192 has been classified as a nonvolatile (Leddicotte, 1961) and impurities are removed from it by distillation. It is therefore considered nonvolatile in a fire.

- Polonium-210 is found as a liquid, in sealed sources, and microspheres. Polonium is a low-melting fairly volatile metal, $50 \%$ of which is vaporized in air in $45 \mathrm{~h}$ at $55^{\circ} \mathrm{C}$ (Weast, 1973 ). The melting point is $254^{\circ} \mathrm{C}$; the

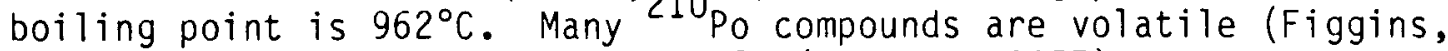
1961 ), show $10 \%$ weight loss at $300^{\circ} \mathrm{C}$ (Bagnall, 1957), and are considered somewhat volatile (Moyer, 1956). In air, polonium begins to sublime (convert to a vapor) at $700^{\circ} \mathrm{C}$ and is completely volatile at $900^{\circ} \mathrm{C}$. One chemical separation procedure warned against flaming the sample and losing the polonium. Vaporization of polonium deposited on platinum begins, $350^{\circ} \mathrm{C}$ (Haissinsky and Tuck, 1964). Based on all this information, 21 Po is considered volatile in a fire environment.

- Promethium-147 in encapsulated form is used for sealed source production. With a melting point of about. $1080^{\circ} \mathrm{C}$ and boiling point about $2460^{\circ} \mathrm{C}$ (Weast, 1973), it could have some degree of volatility. Wheelwright (1973) reported $\mathrm{a}_{3} 0.1 \%$ processing loss at $1100^{\circ} \mathrm{C}$. This value is used to suggest a $1 \times 10^{-3}$ release factor for ${ }^{14 \%} \mathrm{Pm}$.

- Tantalum-183 can be found as metal or sealed sources. Tantalum has a high boiling point, $5425^{\circ} \mathrm{C}$, and melting point, $2996^{\circ} \mathrm{C}$ (Weast, 1973). The vapor pressure at $1737^{\circ} \mathrm{C}$ is $9.510^{-11} \mathrm{~mm}$ of $\mathrm{Hg}$ (Moshier, 1964). Therefore, it is considered nonvolatile.

- Thulium-170 is found as a sealed source. Thulium is reasonably stable in air with a melting point of $1545^{\circ} \mathrm{C}$ and a boiling point of $1947^{\circ} \mathrm{C}$ (Weast, 1973). It would not appear to be volatile until extremely high temperatures are reached, over $1500^{\circ} \mathrm{C}$. Therefore, ${ }^{1} \mathrm{Tm}$ is considered nonvolatile in a fire. 
TABLE 4.5. Fire Release Factors Developed for Selected Isotopes Found in Sealed Source Manufacturing Facilities

\begin{tabular}{|c|c|c|c|}
\hline Element & Isotope & $\begin{array}{c}\text { Suggested } \\
\text { Release Factor }\end{array}$ & Comments \\
\hline Cobalt & ${ }^{60} \mathrm{Co}$ & $2 \times 10^{-3} / \mathrm{h}$ & $\begin{array}{l}\text { Slightlyy less volatile } \\
\text { than }{ }^{3} \mathrm{Cs}\end{array}$ \\
\hline Iridium & ${ }^{192} \mathrm{Ir}$ & --- & Nonvolatile \\
\hline Plutonium & & $1 \times 10^{-2}$ & \\
\hline Polonium & $210_{\mathrm{Po}}$ & 1 & \\
\hline Promethium & ${ }^{147} \mathrm{Pm}_{\mathrm{m}}$ & $1 \times 10^{-3}$ & Based on processing loss \\
\hline Tantalum & ${ }^{183} \mathrm{Ta}$ & -- & Very high boiling point \\
\hline Thulium & $1 / 0 \mathrm{Tm}$ & --- & $\begin{array}{l}\text { Reasonably stable, but } \\
\text { could be volatile at } \\
\text { high temperature }\end{array}$ \\
\hline Uranium & & $1 \times 10^{-2}$ & \\
\hline
\end{tabular}

- Plutonium and uranium fire releases from solutions and powders have been measured experimentally at the Pacific Northwest Laboratory (Mishima et al., 1968a, 1968b; Mishima and Schwendiman, 1973a). The weight percent of these materials released from boiling solutions was 0.2 to 0.3 ; when external heating is added, total releases were $1 \%$ or less. Mishima and Schwendiman (1970) reported a maximum release from a plutonium powder as $0.9 \%$. Heated powders had a maximum release rate of $0.82 \%$ per hour. Based on this work and considering experimental variability (Mishima et al., $1968 \mathrm{a}), 1 \%$ is selected as the conservative upper limit for plutonium and uranium releases in a fire.

\subsubsection{Process Related Fire}

Fires could occur at several points in the operation, but would probably be of limited size because of small amounts of combustibles available.

A fire could occur in a glove box where ${ }^{238} \mathrm{Pu}$ and ${ }^{241}$ Am powders are used for manufacturing neutron sources. They are ball milled to mix with beryllium in one phase. As the first step, acetone is used to degrease the equipment. Acetone is a potential fire initiator because it is easily ignited: many acetone fires have been started by static electricity (Industrial Health and Safety office, 1980). Ball milling is a contained operation, so the times when powder would be in jeopardy are during filling or unloading operations. It is assumed that a beaker of degreasing solvent (acetone) is left in the glove box after degreasing and is inadvertently spilled during filling of the ball mill. A static charge ignites the spilled acetone and a fire follows. For this solvent fire, the combustion source is limited since few cellulosics are in the glove box to contribute to the fire. Therefore, the fire would burn out when 
the acetone is expended and the rubber gloves are burned. The burning rate of actone is $2.41 \mathrm{~mm} / \mathrm{min}$ (Khitrin, 1962), so a 5 -mm-deep spill would burn about 2 min.

Flash fires can cause pressurization of the glove box and subsequent glove ruptures (USDOE, 1980), allowing material to be ejected into the room. Only a fraction of the powder in the glove box can be assumed at risk (i.e., loose so that it is subject to dispersal mechanisms). This is estimated as $10 \%$ of the ipyentory It appears that the maximum inventory is $6 \times 10^{3} \mathrm{Ci}$ of $24 \mathrm{I}_{\mathrm{Am}}$ and $250 \mathrm{Ci}$ of $238 \mathrm{Pu}$. Because ${ }^{241} \mathrm{Am}$ is the isotope with the largest inventory, it is assumed involved in the accident. Six hundred curies are loose and at risk, and a fraction would be ejected into the room through the breach. The size of breach and amount of powder ejected would be a function of the explosive magnitude as well as other variables. Sutter (1983) measured aerosols generated by releases of powders from a pressurized chamber. Releases were a function of source mass and chamber pressure. At $250 \mathrm{lb} / \mathrm{in} .{ }^{2}$ gage, the average release was about $10 \%$ of the sources mass. The pressure generated here would probably rupture the containment at a lower level, but this value suggests a conservative upper limit release. Therefore, $10 \%$ of ${ }^{60} \mathrm{C} i$ is estimated to be ejected into the room. Much of the release would remain in the room, but for a conservative estimate, it is assumed that the release reaches the building exhaust HEPA filters. About $2 \times 10^{-5} \mathrm{Ci}$ is released to the atmosphere, assuming transmission of a $2.5 \times 10^{-7}$ fraction. The pressure is expended during breaching the containment and ejecting the powder, and increased levels of pressure should not impact the building filters.

Another potential fire location is in the 210 po extraction process where solvents in a sonic bath are used to clean the bismuth slug target. It is postulated that the sonic bath is left on after use, the solvent overheats, vaporizes and burns; a possible ignition source is a faulty electrical circuit. Material in the containment is not in a dispersible form so there would be no release from this glove box. The box is in a glove box train, but it is unlikely that the fire would be carried to the other units because of the low combustible loading of the fire.

Other small fires could occur in hoods or glove box units where welding or brazing using propane or oxyacetylene operations are conducted. These operations usually involve small radioactive inventory units in operations such as sealing individual sources. Therefore, it can be assumed that the atmospheric release would be negligible from this fire.

Promethium-147 microspheres are mixed with dry phosphorous in preparation of sources. White (yellow) phosphorous ignites spontaneously in air, and other forms can expibit different degrees of ignition and reaction behavior. A fire involving ${ }^{14} \mathrm{Pm}$ would result in less than $0.1 \%$ volatilizing. The maximum inventory in the containment could be $500 \mathrm{Ci}$, so $0.5 \mathrm{Ci}$ might be airborne to challenge the filters resulting in a $1.3 \times 10^{-9} \mathrm{Ci}$ release.

\subsubsection{Leaks}

The potential exists for both gas and liquid leaks in this facility: 
- Gas Leak. Krypton-85 in a shielded container holding a maximum of $100 \mathrm{Ci}$ is connected to a filling system and sealed source capsules are filled through a filling tube to a maximum of $1.5 \mathrm{Ci}$ per source. The filled tube is then sealed in an operation using a portable $L P G$ source. The operation is contained in a fume hood. Small amounts of $85 \mathrm{Kr}$ are routinely exhausted during filling operations. The maximum accidental release that can be envisioned is one where the contents of an entire container leak, possibly due to human error, and $100 \mathrm{Ci}$ of $85 \mathrm{Kr}$ are carried to the ventilation exhaust and released to the atmosphere.

Another potential gas leak could be ${ }^{3} \mathrm{H}$ during transfer initiated by faulty equipment or human error. One ${ }^{H}$ cylinder contains $1000 \mathrm{C}$. The entire cylinder inventory is assumed released in a leak so that it reaches the atmosphere.

- Liquid Leak. The ${ }^{210}$ Po operation appears to provide opportunity for liquid leaks. A leak in the Po transfer line could allow molten $\mathrm{NaOH}$ and bismuth to spill. However, because the line is within the containment, there would be little airborne release to the atmosphere. A factor to consider in evaluating the accident is the operator response, since turning off heating results in cooling and solidification of the slag, and this, in turn, results in loss of flow and consequently the release source.

Another potential leak situation is ${ }^{210} \mathrm{P}_{0}$ in liquid storage in the containment. A maximum of $40 \mathrm{~L}$ containing $2300 \mathrm{Ci}$ are held here until required for use in the process. In the event of a leak, droplets could become airborne in the enclosure to a level of $10 \mathrm{mg} / \mathrm{m}^{3}$, the value suggested for a quasi-stable aerosol (ORNL, 1970), The gloxe box dimensions are $2.5 \times 4 \times 5 \mathrm{ft}$, calculating to a volume of $50 \mathrm{ft}^{3}$ or $1.4 \mathrm{~m}^{3}$. Assuming a solution density of $1 \mathrm{~g} / \mathrm{m}^{3}$, $0.01 \mathrm{~cm}^{3}$ of liquid becomes airborne in the $1.4 \mathrm{~m}_{-2}$ enclosure. There are $2300 \mathrm{C}^{i}$ in the $40 \mathrm{~L}$ of solution, calculating to $5.8 \times 10^{-2} \mathrm{Ci} / \mathrm{cm}^{3}$. Thus the $0.014 \mathrm{~cm}^{3}$ airbornge in the glove box contains $8.1 \times 10^{-4} \mathrm{Ci}$. The exhaust flow is $300 \mathrm{ft} / \mathrm{min}$ or approximately $8 \mathrm{~m} / \mathrm{min}$, and $6.5 \times 10^{-3} \mathrm{Ci} / \mathrm{min}$ is carried with the flow. This airflow is cleaned by absolute filters assumed at $99.9 \%$ for this sitguation, and two sets would have a decontamination efficiency of $1 \times 10^{-6}=6$ The facility release is calculated as $6.5 \times 10^{-9} \mathrm{Ci} / \mathrm{min}$, or $9.4 \times 10^{-6} \mathrm{Ci}$ per $24-h$ day. The release is dependent on the time elapsed before remedial measures are taken.

The ${ }^{3} \mathrm{H}$ gas leak situation appears to be the largest potential release from a leak for sealed source manufacturers.

\subsubsection{Spills}

During sealed source processing, isotopes are usually contained or are, in a form such as microspheres so they are not in a dispersible form when spilied. Liquids are handled in containments, such as hoods. Spills at these locations would be a low release event and the maximum release from a spill would be similar to that from a leak. This assumes that droplets from the spilled liquid fill the containment with an aerosol concentration of $10 \mathrm{mg} / \mathrm{m}^{3}$. 
One operation (3M) transfers material between modules in sepagate buildjhgs as part of the processing operations. Microspheres of ${ }^{60} \mathrm{Co}, 90 \mathrm{Sr}$, and ${ }^{13} \mathrm{Cs}$ are placed in brass cylinders with screw caps and then placed in a lead pig for transfer to the storage module. Transfers are made on a specially shielded cart to minimize the opportunity for dropping containers. This, in addition to the rigid packaging specifications, ensures that no microspheres of these isotopes are spilled.

Polonium-210 and $147 \mathrm{Pm}$ are doubly contained in sealed containers and placed in an approved Type B shipping container to transfer by truck between modules. Transportation is within a fenced area where trucks travel at low speeds, precluding consideration of a high speed collision and overturn. Lowspeed accidents would not result in airborne releases because packages built to rigid specifications would retain their integrity. However, a shipment of improperly packzged microspheres could allow a low level of release. A release fraction of $10^{-8}$, similar to that suggested for a spill of improperly packaged waste (PNL, 1979) might be appropriate to use estimating the release. It is assumed quantities can be based on special form shipping regulations 2 fHSCFR, 1983a). The 4 ackage could therefore contain a maximum of $200 \mathrm{Ci}$ of $2 \mathrm{P}_{\mathrm{P}_{5}}$ or $1000 \mathrm{Cj}$ of $14 \mathrm{Pm}$, and this calculates to releases of $2 \times 10^{-6}$ and $3 \times 10^{-5} \mathrm{Ci}$, respectively.

\subsubsection{Explosion}

Solvents such as benzene and acetone as well as gases such as acetylene and hydrogen used in the process present the opportunity for explosive mixtures to develop. Some specific incidents are discussed in this section.

Gas line ruptures during the brazing and sealing of sources could result in small releases, since the radioactive material is in containers and is used in small amounts. If a fire results, there could be overheating of a container leading to a material jetting from a pressurized container. Expelling microspheres, which range in size from 10 to $250 \mu \mathrm{m}$, would mean low-airborne release hazards because they are above the size that can be inhaled and retained in the lung.

Natural gas heating has not been indicated in the processing areas, so this is not a source of potential explosive releases.

Argon, pjtrogen, and $\mathrm{He}-\mathrm{H}_{2}(96$ to $4 \%$ ) are used to transfer extraction products of 210 Po between containment modules. It is postulated that a valving error allows excess hydrogen to enter the transfer line and build up, exceeding the explosive limit. Static electricity in the metal line causes an explosion rupturing the transfer line at the point of exit from a containment spewing the extractant into the room. There is no release after this instant, assuming flow ceases. At this operational step, the ${ }_{-2} \mathrm{Po}_{\mathrm{s}}$ in a clear liquid with an

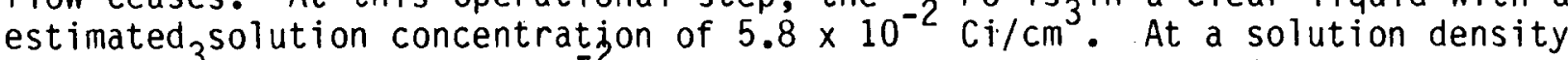
of $1 \mathrm{~g} / \mathrm{cm}^{3}$, this is $5.8 \times 10^{-2} \mathrm{Ci} / \mathrm{g}$. This explosive release is estimated to reach a quasi-stable level in a portion of the room near the release. This portion is estimated to fill about $5 \mathrm{~m}^{3}$ with a concentration of $0.1 \mathrm{~g} / \mathrm{m}^{3}$; 
thesefore, a total of $0.5 \mathrm{~g}$ of the solution is airborne, calculating to $2.9 \times$ $10^{-2} \mathrm{Ci}$. Because these operations are apparently not filtered, this is an atmospheric release.

\subsubsection{Tornado}

It is postulated that a tornado strikes a sealed source manufacturing operation resulting in building damage similar to that discussed in

Section 4.1.1.3. This results in the following:

- Loss of part of the walls and the complete loss of the roof

- Missiles generated

- Significant damage so that only massive equipment such as caves and below grade bunkers remain

- Damage to all hoods and glove boxes.

Potential isotopic releases from the various process modules in sealed source manufacturing facilities are discussed:

- Strontium-90 and ${ }^{137} \mathrm{Cs}$ in liqujid solutions containing $1000 \mathrm{Ci}$ of ${ }^{90} \mathrm{Sr}$ in $0.1 \mathrm{~L}$ of $\mathrm{HCl}$ and $2000 \mathrm{Ci}$ of ${ }^{3} \mathrm{Cs}$ in $0.2 \mathrm{~L}$ of $\mathrm{HCl}$ are used in the hot cells. A hot cell is a massive piece of equipment and should not sustain tornado damage. The filter system could sustain damage, and solutions might be spilled in the cell. However, the ventilation system could be destroyed in the event so the vapors would only move to the atmosphere by diffusion. This is a slow process and releases are not considered significant.

- Krypton-85 is in process as $100 \mathrm{Ci}$ in cylinders and $100 \mathrm{Ci}$ contained in sealed sources. The sealed sources would be dispersed, but are not considered an airborne release, since they are assumed to be greater than $10 \mu \mathrm{m}$ in size. Cylinders containing the gas would be damaged and the entire $100 \mathrm{Ci}$ inventory released in the event.

- Polonium-210 in liquid storage in a containment is vulnerable, assuming the containment is crushed in the event. Liquids airborne in this type of event have been estimated at $500 \mathrm{mg} / \mathrm{m}^{3}$ of the enclosure volume (Mishima and Ayer, 1980). This is the $5.8 \times 10^{-2} \mathrm{Ci} / \mathrm{g}$ disgussed in the section on liquid leaks. At $500 \mathrm{mg} / \mathrm{m}_{2}$ airborne in the $1.4 \mathrm{~m}^{3}$.glove box, the instantaneous release is $4 \times 10^{-2} \mathrm{Ci}$. Resuspension of releases of spilled material will continue because of aerodynamic wind stresses. The estimated rate is $10^{-9} / \mathrm{se} \xi$ for winds greater than $5 \mathrm{mi} / \mathrm{h}$ (Mishima and Ayer, 1980). This is $8 \times 10^{-3} \mathrm{Ci} / \mathrm{h}$ assuming a $2300 \mathrm{Ci}$ source. After $6 \mathrm{~h}$, the release is $0.048 \mathrm{Ci}$; after $16 \mathrm{~h}$, it is $0.13 \mathrm{Ci}$. Releases are dependent on how quickly remedial action is taken.

- Hydrogen-3 (tritium), based on a limited understanding of the ${ }^{3} \mathrm{H}$ storage system in depleted uranium beds, can be assumed ${ }_{5}$ released: The entire inventory contained in the damaged beds, $1 \times 10^{5} \mathrm{Ci}$, is released. 
- Iridium-192 is encapsulated as metallic pellets. This should not be a significant inhalation hazard if dispersed.

- Promethium-147 microspheres could be dispersed but could be assumed of a size greater than $10 \mu \mathrm{m}$ that should not be a significant inhalation hazard.

\subsubsection{Facility Fire}

Limited information was available on areas surrounding the facilities except for one that noted potential problem areas: propane and fuel oil storage, and ammunition and gun powder storage. However, these areas are segregated from the sealed source operations, so they should not jeopardize the sealed source operations. Other sites are located in urban industrialized areas, so it is conceivable that a fire could occur outside the facility and spread to the facility.

While construction was most often reinforced concrete or concrete block on a concrete slab, the roof could be constructed from material that could burn. Roofing materials were frequently metal paneling with an asphalt (tar) surface. This type of roofing is considered combustible (Mckinnon, 1976). It is assumed that the roofing ignites and burns, spreading to interior wooden walls, which are used in many of the facilities. Combustible loading of the facilities will vary and, therefore, the potential fire magnitude.

Fire response of the radionuclides will vary, and releases from fires for the individual isotopes were discussed in Sections 4.6.1 and 4.8.1.

Cesium-137, ${ }^{90} \mathrm{Sr}$, and ${ }^{210}$ Po liquid solutions are found in hot cells, either in process or in storage. Fire engulfing the building could cause heat generation in the hot cells and melting HEPA filters. This could lead to releases of these isotopes. At the release rate of $-3 \times 10^{-2} / \mathrm{h}, 20 \mathrm{Ci}$ of the $2000 \mathrm{Ci}$ of ${ }^{137} \mathrm{Cs}$ source becomes airborne; at $2 \times 10^{-3} / \mathrm{h}, 2 \mathrm{Ci}$ of the $1000 \mathrm{Ci}$ of ${ }^{9} \mathrm{Sr}$ source becomes airborne. The entire $210 \mathrm{Po}_{\mathrm{O}} \mathrm{inventory,} \mathrm{which} \mathrm{could} \mathrm{be} \mathrm{as}$ much as $2300 \mathrm{Ci}$, in liquid storage becomes airborne. All of these materials are released to the atmosphere, since filters are assumed to fail.

Gaseous ${ }^{85} \mathrm{Kr}$ is in process as $100 \mathrm{Ci}$ in cylinders and $100 \mathrm{Ci}$ as sealed sources. Heating the cylinders could cause the gas to expand, pressurize, and damage the cylinder or valving resulting in an atmospheric release. If the microspheres melt, an additional inventory could also be vulnerable and the entire $200 \mathrm{Ci}$ from cylinders plus sealed source released.

The ${ }^{3} H$ inventory in the storage system is assumed released when the beds are heated and damaged. The entire $1 \times 10^{5} \mathrm{C} i$ inventory is released.

Waste is solidified, compacted and stored in drums. The drums are stored in metal or approved fire-resistant containers. Therefore, releases in a fire would be by heating and subsequent container rupture due to pressure buildup. 
Small additional releases could occur, but because the releases already discussed are based on maximized inventories, releases from waste are considered to be included in them.

\subsubsection{Sealed Source Manufacturing MREPP Scenario}

A large-scale facility fire is the MREPP event postulated at sealed source manufacturing facilities. The magnitude of the release will vary according to the facility since not all isotopes are used at all facilities.

\subsubsection{Material Release}

The MREPP hypothesized was $1 \times 10^{5} \mathrm{Ci} ;{ }^{3} \mathrm{H}$ and other isotope releases were discussed. This represented the maximum license limit. Releases will vary with the specific inventory in a facility and can be calculated using the fractional releases suggested in Tables 4.3 and 4.5 .

\subsubsection{Factors Affecting Release}

The following factors affect release at sealed source manufacturing facilities:

- Safety system

- Inventory distribution in facility, among buildings

- Combustible materials present

- Deposition in facility.

\subsection{RESEARCH AND DEVELOPMENT OF NUCLEAR FUELS}

These facilities perform research and development related to reactor fuel manufacturing and testing. They use special nuclear materials (SNM) in forms ranging from powders to solutions, although larger quantities are usually in the form of fuel pellets.

A facility can include a test reactor and/or criticality experiments. These areas are not included under the SNM license of concern in our study and are, therefore, not included in our accident scenarios. Some work can use expended commercial nuclear fuel. Fuel handling is therefore covered using established nuclear safety assessments to estimate releases.

\subsubsection{Potential Accident Scenarios}

Potential accidents discussed include criticality, spills and leaks, tornado, earthquake, fire outside facility, fire, explosion (including natural gas), and fuel-handling accidents.

\subsubsection{Criticality}

Criticalities were discussed in Sections 4.1.1.5 and 4.2.1.3 and the discussion will not be repeated here. The mere existence of fissile material in quantities greater than a minimum critical mass creates some finite risk 
that criticality can occur (Carter et al., 1968). Criticality is prevented by using favorable geometries, fixed poisons, limitations of mass or concentration, or soluble poisons. Larger quantities of fissile material at nuclear research and development facilities are powders or other forms not likely to sustain a criticality. As discussed in Section 4.1.1.5, criticality is more likely in a liquid system. However, nuclear safety and the potential for criticality can be considered in all operations at these facilities. These operations include fissile material receipt and transport, alloy preparation, powder preparation, fuel billet fabrication, fuel plate fabrication, fuel element assembly, machining operations, and process fuel storage and scrap. Administrative procedures and fissile material restrictions provide criticality safety in these facilities.

The glove box train is one area likely to have quantities of fissile material sufficient for a criticality if water is added to the powder preparation operation. The glove box train area is provided with an automatic sprinkler system. An accident that breaks the glove box window and damages the sprinkler system could allow water to penetrate the glove box, resulting in full water reflection. An earthquake could precipitate the above damage.

As discussed in Section 4.2.1.3, the kinetic energy released at $10^{18} \mathrm{fis}-$ sions would probably be at a level where building damage would not be caused by the criticality. Damage to the high-efficiency particles air filter could have occurred because of the earthquake, and therefore the $20 \mathrm{~g}$ of uranium (see Section 4.1.1.5, the standard criticality event) released is assumed to go difectly to the atmosphere. The fission product gas release totals $1.2 \mathrm{x}$ $10^{5} \mathrm{Ci}$; see Table 4.1 for tabulated releases of individual isotopes.

\subsubsection{Spills and Leaks}

While radioactive materials can be found in any form in these facilities, from powder to solutions, it appears that contaminated liquids are the primary radioactive waste. These would be relatively low level. For example, at one site, waste is controlled to ensure that no more than $230 \mathrm{~g}$ of fissile material are contained therein. The liquid waste is ${ }_{3}$ collected in a 3000-gal waste tank so the concentration would be $2 \times 10^{-5} \mathrm{~g} / \mathrm{cm}^{3}$. Even in the unlikely event that the contents of the entire tank spilled, the contamination present should not produce significant airborne releases. Maximum airborne material from a liquid spill in static air could be $0.01 \%$ of the squrce (Sutter et al., 1981) so the airborne release is calculated at $2.3 \times 10^{-2} \mathrm{~g}$.

\subsubsection{Tornado}

The buildings are built to withstand a tornado strike. There could be minor damage and equipment overturned. If a door is blown out, minor amounts of surface contamination or uncontained powder can be blown from the building. The powders are usually contained so these releases would be insignificant.

Low-level liquid radioactive waste may be retained in large basins. This type of basin and the airborne release are discussed in Section 4.2.1.2. 
Because the basin was set in concrete and unlikely to have more than minor spillage in a tornado, the anticipated spillage results in $0.05 \mathrm{~g}$ of uranium immediately airborne and $1.9 \mathrm{~g}$ of uranium subject to resuspension fractional release. This resuspension occurs after the tornado has passed and is at a rate of $10^{-8} / \mathrm{sec}$.

\subsubsection{Earthquake}

Research facilities are built according to the Uniform Building Code and should be capable of withstanding a linear acceleration appropriate to the region. It is assumed there would be little or no structural damage as a result of earthquake acceleration. Some spills and process vessels could overturn in a facility, and process equipment could be upset. The integrity of the facility should not be breached; therefore, an earthquake should cause insignificant releases of fuel material to the atmosphere. Additionally, any spilled material could be covered with debris, making resuspension unlikely.

Fires or pressurized releases resulting from equipment failure as a result of the earthquake could contribute to releases. These are discussed in the section on fire and explosion.

\subsubsection{Fire Outside Facility}

One of the facilities, Rockwell Nuclear Fuel Development Laboratory, is in a location where range fires could be considered a potential hazard. The structure is built of fire resistant materials, concrete, and steel. There is some distance from the facility to large vegetation growth. However, sparks can be carried from range fires by strong, hot winds. It can be assumed that, while not specifically identified as to material, the roof is fire resistant and any sparks reaching the roof would not ignite it. Therefore an external range fire should not damage the facility.

\subsubsection{Fires}

The use of solvents and flammable liquids, such as methanol, during sample preparation could lead to small fires. These would occur in a glove box, and the ignition source could be an overheated sonic bath. Because glove box operations are normally conducted in an inert atmosphere, combustion would not be supported. However, glove failure could allow air to enter, enabling a fire to start. The amount of material in the glove box during sample preparation would limit the release, since the source would be perhaps $46 \mathrm{~g}$ of plutonium and $189 \mathrm{~g}$ of $235 \mathrm{U}$. Based on releases measured in experimental fires and discussed earlier in this report (Mishima et al., 1968a, 1968b; Mishima and Schwendiman, 1973a), $1 \%$ is the selected maximum release factor. The glove box filter is destroyed, and the release is expelled from the glove box, $0.46 \mathrm{~g}$ of plutonium and $1.89 \mathrm{~g}$ of ${ }^{-4} \mathrm{U}$. reach the final. HEPA ( $5 \times 10^{-4}$ decontamination) for a release of $2.3 \times 10^{-4} \mathrm{~g}$ of plutonium and $9.5 \times 10^{-4} \mathrm{~g}$ of $235 \mathrm{U}$.

A major fire could occur during milling operations in a glove box train. Material in the glove box can be in any form from powders to pellets. Powders and zircaloy metal used in the processes are pyrophoric, so to maximize the 
release, it is assumed that the entire glove box inventory is in powder form, perhaps in blending and sieving operations. The inventory per work station is limited, using for example, about $2 \mathrm{~kg}$ of mixed pyrophoric powders.

Because it is a glove box train, it can be assumed the air and thus the fire spreads through the transfer space until all 13 glove boxes are involved in the fire. Thus at $2 \mathrm{~kg} /$ work station, the source is $26 \mathrm{~kg}, 1 \%$ is assumed airborne, calculating to $260 \mathrm{~g}$ airborne. The glove box HEPA filters are destroyed but the building HEPA filter remains. The atmospheric release is $0.13 \mathrm{~g}$ mixed pyrophoric powders.

\subsubsection{Explosions}

Solvents used for cleaning could generate vapors in sufficient quantity to be explosive in air. Due to the small amounts of solvents involved, an explosive ignition of the vapors would have negligible releases.

A powder explosion could occur in a glove box during blending and sieving, with $1 \%$ of the mass becoming dispersed into the room through a breached glove. since $2.2 \mathrm{~kg}$ is the glove box inventory, $22 \mathrm{~g}$ become airborne and transported to the ventilation HEPA filter. The explosive force of the overpressure should be expended before reaching this final filter, so the atmospheric release is $0.011 \mathrm{~g}$ of fissile material.

Sintering furnace explosions could release airborne material. A release of this type was discussed in Section 4.2 .1 .5 , where $1 \%$ of the material was estimated ejected from a furnace. Inventory restrictions would limit the release (as in the powder explosion) to $0.011 \mathrm{~g}$.

Natural gas explosions are discussed in detail in Section 4.3.1.6 of this report and could potentially release fissile material. It has been hypothesized (Rockwel1, 1976) that a complete rupture of a 1-in. gas line operating at a pressure of $8 \mathrm{in}$. of $\mathrm{H}_{2} \mathrm{O}$ would release $\sim 750 \mathrm{ft}^{3} / \mathrm{h}$ of natural gas into the room. The room volume and ventilation rate limit the potential of the gas reaching an explosive limit in the room. Therefore, for this facility, an airborne release from a natural gas explosion was not foreseen.

\subsubsection{Fuel Handling Accident}

In a research and development facility, irradiated fuel assemblies can be used in investigations. The assemblies are transferred into hot cells where they are declad and the fuel is tested and examined. Fuel elements may be stored on site temporarily in pools designed for their storage. A license limit would be three fuel elements from commercial nuclear power reactors.

The NRC has established a guide for evaluating the potential consequences of a fuel handling accident in a fuel handling and storage facility (USNRC, 1972). The illustrative accident sequence consists of the dropping of a fuel assembly resulting in breaching of the fuel rod cladding, release of a portion of the volatile fission gases from the damaged fuel rods, absorption of water 
soluble gases in and transport of soluble and insoluble gases through the water, air filtration (if provided) prior to release into the environment, and dispersion of the released fission products into the atmosphere.

This accident occurs at a time identified as the earliest time fuel handling operations may begin. Radioactive decay of the fission product inventory is taken into consideration. All of the gap inventory is asssumed released. This is $10 \%$ of the noble gases other than $85 \mathrm{Kr}, 30 \%$ of the $85 \mathrm{Kr}$ and $10 \%$ of the iodine in the rods at the time of the accident. The iodine gap inventory is composed of inorganic species $(99.75 \%)$ and organic species $(0.25 \%)$.

The pool decontamination factors for the inorganic and organic species are 133 and 1 , respectively, giving an overall effective decontamination factor of 100 (i.e., 99\% of the total iodine released from the damaged rods is retained by the pool water). This difference in decontamination factors for inorganic and organic iodine species results in the iodine above the fuel pool being composed of $75 \%$ inorganic and $25 \%$ organic species. The retention of noble gases in the pool is negligible (i.e., decontamination factor of 1 ).

The radioactive material that escapes from the pool to the building is released from the building over a $2-h$ time period.

If it can be shown that the building atmosphere is exhausted through absorbers designed to remove iodine, the removal efficiency is $90 \%$ for inorganic species and $70 \%$ for organic species.

Decay times for the fuel assemblies and the radioactive inventories have not been estimated for these research and development facilities in the docket information available. Therefore, another base for estimating the release must be used.

Fuel handling accidents have been described in detail and in the Reactor Safety Study (USNRC, 1975, Appendix I, p. I-96), which will be used as a basis for our safety assessment and nominal releases are back calculated. This will give a conservative estimate of releases because at a reactor there has been little opportunity for the fuel to decay. Shipping regulations mean fuel must be held at a reactor at least 150 days before transport, and thus the isotopes with shorter half-lives would be further decayed when used in a nulf cear fuel research and development facility. This is particularly true of I3I I with an 8-day half-life. The fraction remaining at the shipment time after 150 days storage can be calculated usjog the universal decay tables (Bureau of Radiological Health, 1970). For ${ }^{2}$, for example, the fraction remaining is much less than 0.0001 , an insignificant fraction.

Dropping a heavy item in the spent fuel pool as a result of crane failure could damage one or more fuel assemblies. The average inventory in the fuel pool is one-half a core loading, one-third with 60 days decay and one-sixth with 150 days decay, and releases are estimated as listed in Table 4.6. Seven pressurized water reactor (PWR) fuel assemblies represent approximately $4.5 \%$ of a core loading; therefore, 156 fuel assemblies are the entire loading, and thus 78 fuel assemblies produced the total release listed as calculated in the 
Reactor Safety Study (USNRC, 1975). The release per assembly is then calculated, and multiplied by three to estimate release from this event at a research and development facility, assuming three assemblies are damaged.

These releases are through HEPA and charcoal filters and it was assumed that these will reduce the elemental iodides, organic iodides, and particulates by $99 \%$. Since the ${ }^{13 I_{I}}$ will be decayed, levels will be significantly lower than those listed in Table 4.6 .

\section{TABLE 4.6. Release (Ci) from Dropping a Heavy Item in Fuel Storage Pool}

\begin{tabular}{|c|c|c|c|}
\hline Elements & $\begin{array}{c}\text { One-Half } \\
\text { Core Loading } \\
\text { Release }\end{array}$ & $\begin{array}{c}\text { Release } \\
\text { per } \\
\text { Assembly }\end{array}$ & $\begin{array}{l}R \text { and } D^{(a)} \text { Release } \\
(3 \text { Assemblies })\end{array}$ \\
\hline Noble gas & $1.74 \times 10^{4}$ & $2.2 \times 10^{2}$ & $6.6 \times 10^{2}$ \\
\hline Halogens & $1.18 \times 10^{-2}$ & $1.5 \times 10^{-4}$ & $4.5 \times 10^{-4}$ \\
\hline
\end{tabular}

(a) Research and Development

\subsubsection{Research and Development of Nuclear Fuels MREPP Scenario}

Work with irradiated commercial fuel elements presents a high noble gas release of $6.6 \times 10^{2} \mathrm{Ci}$. This could be much lower, depending on the age and decay status of the fuel elements. For example, 2 years after discharge from a reactor the total curies in a fuel assembly is less than $1 \%$ of the discharge level (Alexander et ${ }_{5}$ al., 1977). However, a criticality event with a total release of $1.2 \times 10^{5} \mathrm{Ci}$ of fission product gases is the MREPP in this facility category. The total curie release and the release of ${ }^{131} \mathrm{I}$, the isotope of most concern, are the largest for this event.

\subsubsection{Factors Affecting Release}

The following factors affect release at facilities for the research and development of nuclear fuels:

- Room volume, air ventilation rate, and retention time

- Radiological decay in fuel

- Filtration systems

- Deposition.

\subsection{WASTE WAREHOUSING}

Radioactive waste in containers (drums) is stored, for a period of not more than 6 months at these facilities. Drums are not opened in the waste warehousing operation: they are stored until transported to a licensed radioactive burial ground. 


\subsubsection{Potential Accident Scenarios}

Because the radioactive material is containerized, the potential for accidental releases is low. An event of sufficient magnitude to breach one or more drums would be required to make material airborne.

Accidents discussed are tornado, earthquake, fire, and facility fire.

\subsubsection{Tornado}

Waste warehousing facilities would probably not be constructed to withstand tornado damage. Therefore, it can be assumed that damage would be inflicted if a tornado strikes the building. It is conceivable that if one or more of the walls collapse and the roof is blown off, the waste drums could be damaged. As discussed in Section 4.3.1.2, only a fraction (estimated at $1 \%$ ) of the drums in a storage area would be involved to the point of failure. A large warehousing operation could have as many as 2200 drums containing $24 \mathrm{Ci}$ of radioactivity, and thus the material in jeopardy is $0.24 \mathrm{Ci}$ from 22 drums.

The inventory is not in a readily dispersible form, as for example, a powder. However, it can be broken up by accident stresses. Drummed waste (i.e., contaminated trash) could be scattered in and about the facility, subject to aerodynamic stresses, and a fraction could be airborne. It will be assumed that the entire $0.24 \mathrm{Ci}$ inventory of the 22 failed drums is subject to aerodynamic stresses for $6 \mathrm{~h}$. The resuspension rate for fixed contamination that could be considered applicable to this situation is $10^{-10} / \mathrm{sec}$. The release is thus $5 \times 10^{-9} \mathrm{Ci}$, and since the building was destroyed, it is released directly to the atmosphere.

One facility stores drummed cylinders of ${ }^{3}$. The maximum license limit is $5000 \mathrm{Ci}, 1000 \mathrm{Ci} / \mathrm{cylinder}$. Assuming one drum is breached, the release is $1000 \mathrm{Ci}$.

\subsubsection{Earthquake}

An earthquake could collapse the warehouse and damage drums of waste. Drums would be buried under debris or some could be scattered. Since much of the waste would be buried, little would be subject to wind resuspension stresses. Releases would not exceed those estimated for a tornado.

\subsubsection{Fire}

Spontaneous ignition of cellulosics contaminated with flammables (oily rags) could lead to a fire in a drum, or a small fire could be caused by inadvertent inclusion of acid in a glass container in a waste drum and breakage of the container allowing the acid to spill on cellulosics, which heat and ignite. In either scenario, the drum is subsequently pressurized and ruptures, allowing a fraction of the contamination associated with the waste to become airborne. 
The inventory could be $24 \mathrm{Ci} / 2200=0.011 \mathrm{Ci} / \mathrm{drum}$ and the release is calculated as $5.5 \times 10^{-6} \mathrm{Ci}$, using $5 \times 10^{-4}$ release factor measured for nonvolatiles associated with burning contaminated waste (Mishima and Schwendiman, 1973b). However, many by-product isotopes are volatile so the release can range from this value to the entire $0.011 \mathrm{Ci}$ inventory assumed airborne from a single drum.

\subsubsection{Facility Fire}

A propane fueled front-end loader is used to. move the waste drums in a warehouse. Fuel leaking from the equipment could conceivably initiate a combustion/explosion event.

Propane flammability limits in air are $2.1 \%$ and $9.5 \%$ (Zabetakis, 1965), with a specific volume of $8.7 \mathrm{ft}^{3} / 1 \mathrm{~b}$ (Linde, 1974), A front-end loader will have a fuel tank capacity of about $10 \mathrm{lb}$ and $87 \mathrm{ft}^{3}$, which, when vaporized, could produce a flammable mixture in $4000 \mathrm{ft}^{3}$. This would be a fraction ${ }_{3}$ of a waste warehouse facility volume. Facilities range in volume from $6 \times 10^{3}$ to $4 \times 10^{4} \mathrm{ft}^{3}$.

The explosion equivalent yield can be calculated using propane heat of combustion $2.1 \times 10^{4}$ Btu/lb (McKinnon, 1976):

$$
W_{T N T}=\frac{\Delta H_{C}+W_{C}}{1800}
$$

where

$W_{T N T}=$ equivalent TNT, $1 \mathrm{~b}$

$$
\begin{aligned}
\Delta H_{C} & =\text { heat of combustion, Btu/lb } \\
W_{C} & =\text { explosive source weight, } 1 \mathrm{~b} \\
1800 & =\text { heat of explosion of TNT, Btu/lb }
\end{aligned}
$$

The calculation is:

$$
W_{T N T}=\frac{2.1 \times 10^{4} \mathrm{Btu} / 1 \mathrm{~b} \times 101 \mathrm{~b}}{1800}=117 \text {. }
$$

Assuming $10 \%$ of the energy is released in the explosion, WTiT is 11.7 . This energy is sufficient to blow the roof off the facility and generate missiles (Brasie and Simpson, 1968).

Because the waste is contained, it will not contribute a large amount of combustible material to permit a fire to engulf the entire facility. However, gas heat in the building, a truck at the loading dock, wooden pallets holding waste, or fuel storage tanks could provide combustibles to fuel the fire. 
It is postulated that missiles generated by the combustion/explosion pass through the open loading dock door and hit gas storage tanks. This event results in gasoline spillage providing fuel sufficient for a fire to engulf the facility.

Wooden pallets support the waste drums. In an alternate scenario these can be assumed ignited, carrying the fire through the facility. Natural gas or propane heaters could provide additional fuel to the fire.

Heat pressyrizing the ${ }^{3} \mathrm{H}$ cylinders could cause the cylinders to rupture and all of the ${ }_{\mathrm{H}}$ would become airborne. A maximum release could be $5000 \mathrm{Ci}$ of $3_{H}$.

Damage to drums, plus heating would cause all the volatile radioisotopes associated with the drummed waste to become airborne. License limits are from 25 to $_{3} 200925$ of 3 py-product material, which will typically include volatiles:

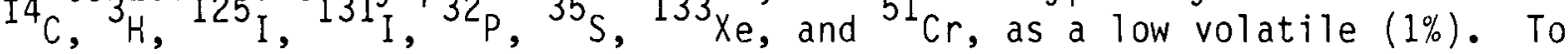
illustrate this release, the isotopic distribution and release from a typical waste mixture (based on the Interex by-product curie limit) are as listed in Table 4.7 .

\subsubsection{Waste Warehousing MREPP Scenario}

A major combustion/explosion resulting in a large facility fire is the MREPP scenario for a waste warehouse.

4.10.2.1 Material Release

The airborne release estimated was $5000 \mathrm{Ci}$ of ${ }^{3} \mathrm{H}$ from the cylinders and $1940.6 \mathrm{Ci}$ of mixed by-product materials associated with the waste. Total ${ }_{\mathrm{H}}$ release is $6200 \mathrm{Ci}$, total release of all nuclides is $6940 \mathrm{Ci}$.

\subsubsection{Factors Affecting Release}

The following factors affect release at waste warehousing facilities:

- Safety systems

- Inventory

- Propane tank volume

- Additional fuel sources.

\subsection{UNIVERSITY RESEARCH AND DEVELOPMENT}

At facilities in this category, radioactive materials are usually received from manufacturers and used in many laboratories covered under one license. They can be received at and distributed from a central receiving area. Solid waste is usually stored at a central location prior to disposal. Thus, the shipping/receiving and waste storage areas have the largest potential radioisotope inventories. License limits are low and actual inventories are usually fractions of the limit. 
TABLE 4.7. Radioisotopes Associated with and Released from

Representative Drumined Waste in a Combustion/

Explosion Event (total source $=2000 \mathrm{Ci}$ )

\begin{tabular}{llll} 
Element & Isotope & $\begin{array}{c}\text { Percent in } \\
\text { Representative } \\
\text { Waste }\end{array}$ & $\begin{array}{c}\text { Airborne } \\
\text { Release, Ci }\end{array}$ \\
\cline { 1 - 1 } Carbon & ${ }^{14} \mathrm{C}$ & 8 & 160 \\
Chromium & ${ }^{5} \mathrm{C}$ & 3 & 0.6 \\
Hydrogen & ${ }^{3}$ & 60 & 1200 \\
Iodine & $125_{\mathrm{I}}$ & 14 & 280 \\
& $131_{\mathrm{I}}$ & 1 & 20 \\
Phosphorous & $32_{\mathrm{P}}$ & 8 & 160 \\
Sulfur & $35_{\mathrm{S}}$ & 6 & 120 \\
& & & 1940.6
\end{tabular}

The laboratories are scattered in different locations on a campus; as many as 500 different locations can handle radioactive materials at one facility. Several laboratories may be located in one building, some are located in rooms in hospitals to provide for use in patients.

Our information does not give details on each of the individual sites. Since the majority of these sites have very low inventories, this would not be cost effective for the safety assessment. Some general incidents are suggested with the major accidents focusing on the high inventory locations: shipping/ receiving and waste storage.

\subsubsection{Potential Accident Scenarios}

Low license limits, small dispensed doses, material forms such as sealed sources, and diffuse operations reduce the risks associated with university research and development facilities. Accidents discussed are spills and leaks, tornado, explosion, fire, waste incinerator error, and a patient-related incident.

\subsubsection{Spills and Leaks}

Small amounts of material, gas or liquid, can become airborne as a consequence of spills and leaks. Some typical events are suggested:

- Gas Leaks. Gaseous ${ }^{133}$ Xe is dispensed using a gas dispensing system. These systems normally use vials containing $20 \mathrm{mC}$; however, they can contain up to $100 \mathrm{mC} / \mathrm{yial}$. Therefore, a valve leak could potentially leak up to $100 \mathrm{mCi}$ of ${ }^{3} \mathrm{Xe}_{3}$ Hospitals can receive multi-dosage vials containing as much as $1 \mathrm{Ci}^{133} \mathrm{Xe}$, in which case a valve could leak as much 
as 1 fij Hospitals can receive multi-dosage vials containing as much as $1 \mathrm{Ci}{ }^{133} \mathrm{Xe}$, in which case a valve could leak as much as $1 \mathrm{Ci}$.

Another potential ${ }^{133} \mathrm{xe}$ release is an accident while administering the xenon to a patient. Since the maximum dosage administered is $20 \mathrm{mC}$, this will be the maximum release.

- Liquid Spills. Iodine-131 and ${ }^{32} \mathrm{p}$ are injected (in the facilities studied) as liquid solutions, with maximum doses of $30 \mathrm{mCi}$ and $5 \mathrm{mCi}$, respectively. It is assumed that due to operator error an entire dose is spilled. Because both $131_{I}$ and $32 p$ are considered volatile, the entire dose becomes aipborne. The maximum release is $30 \mathrm{mCi}$ of $13 \mathrm{I}_{\mathrm{I}}$. Orally administered ${ }^{131}$ I can be $10 \mu \mathrm{Ci}$ in liquid or capsule form, or therapy doses as great as $200 \mathrm{mC} i$ in facilities other than those studied.

\subsubsection{Tornado}

These facilities are not usually constructed to withstand tornado damage. Therefore, if a tornado strikes the facility, severe damage and breaching of the structure are anticipated. Some packaged isotopes (e.g., lead shielded syringes) are not vulnerable to tornado damage.

133 Isotopes in process could be at risk. This could include the $100 \mathrm{mC} i$ of

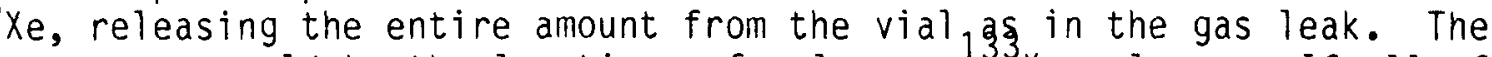
storage area could be the locations of a larger ${ }^{133} \mathrm{Xe}$ release. If all of the units full of ${ }^{133} \mathrm{Xe}$ were in one storage room hit by a tornado, the entire maximum license limit of $10 \mathrm{Ci}$ could be released. It would be extremely unlikely that this inventory level would be in the storage area. Because it has a short ( 5.27 day) half-life, it could be assumed to be moved from the storage area rapidly. Therefore only a fraction of the inventory would be there. If we assume $10 \mathrm{Ci}$ is a week's supply and moved from the storage area daily, $2 \mathrm{Ci}$ would be a more reasonable estimate of the maximum release.

Iodine-131 in use would be released, with a value similar to the spill release. Stringent contajper design would ensure they would not be damaged so they are not a source of ${ }^{2}$ I releases. The total release is dependent on the number of containers actualiy in use when the tornado strikes.

Generators can be damaged spilling $99 \mathrm{~m} T c$. Since technetium is a low volatile (Rimshaw et al., 1980) airborne releases are negligible. Molybdenum-99 is absorbed on an aluminum oxide (Kristensen, 1979), a form not likely to become airborne.

Tritiug in process is vulnerable; however, a significant portion, perhaps $1500 \mathrm{Ci}$ of $\mathrm{H}$, is in waste storage in containers not likely to be breached in a tornado strike.

Because the inventory is dispersed in many small laboratories, it is unlikely that a tornado would damage more than a portion of them. This therefore limits the magnitude of a release. 


\subsubsection{Explosion}

Due to the small scale of the operations, the potential for explosions to produce releases are limited to areas with significant inventories.

Natural gas used for heating could be the source of a potential explosion/ deflagration as discussed in Section 4.3.1.6 of this report. It is hypothesized that a detonation/deflagration occurs in the shipping/receiving or waste storage area. Combustible materials such as wooden pallets fuel the fire, and it is assumed to engulf the area. Releases from this scenario will be quantified as a facility fire.

\subsubsection{Fire}

A major facility fire is suggested as the result of a natural gas explosion. Since the entire license limit is located in several buildings, it would not all be at risk. Two areas are suggested where radionuclides can be found in relatively large amounts: 1) the central shipment receiving and storage area, and 2) radioactive waste storage.

\subsection{Central Receiving/Storage Fire}

This area can be one room in a large building, where radionuclides are received and then distributed to the users. Due to the short half-lives of some of the isotopes, they are ordered and used as required and must be shipped rapidly. Therefore, it is difficult to imagine them accumulating in this area. Perhaps $10 \%$ of the inventory limit are in the area at one time.

Building material, furniture, paper cartons and so on could be available to fuel the fire. Adjacent laboratories could use solvents. These could fuel the fire initiated by the natural gas detonation, and it becomes a major fire.

Volatilities of most of the isotopes potentially involved in the fire were discussed in eastier sectignns and will not be repeated here. Four isotopes, ${ }^{252} \mathrm{Cf},{ }^{244} \mathrm{Cm}$, ${ }^{23} \mathrm{~Np}$, and ${ }^{9} \mathrm{mc}$ were below the amount selected for earlier discussions because they did not represent a significant portion of the inventories in other facilities. Since they are a more significant fraction here, a discussion follows:

- Californium-252 volatility information was not found in the literature review. Because of high radiation danger it should be shielded, even when in use (Hall, 1976). Another source (Subrahmanian et al., 1976) recommended locking ${ }^{252} \mathrm{Cf}$. sources in a fireproof safe when not in use. This would suggest that administrative procedures would minimize the opportunity for airborne: releases. Procedures used during processing indicate that it is not volatile. For example, one step in the operation for producing ${ }^{252} \mathrm{Cf}$ sources includes heating to form $\mathrm{Cf}_{2} \mathrm{O}_{3}$, a stable form (Hall and Rossi, 1974). Based on this information it is assumed that ${ }^{252} \mathrm{Cf}$ will not produce an airborne release in a fire. 
- Curium-244 is appreciably less volatile than americium according to Penneman and Keenhan (1960). However, they do not indicate the volatility level. The melting point of curium is about $1340^{\circ} \mathrm{C}$ (Weast, 1973). A release factor is suggested based on the ratio of the melting points of americium and curium, which is about 0.75 . A 241 Am release factor of 0.01 was suggested for fires about $1000^{\circ} \mathrm{C}$. The ${ }^{244} \mathrm{Cm}$ release factor selected is therefore $7.5 \times 10^{-3}$.

- Neptunium-237 is high boiling at $3902^{\circ} \mathrm{C}$ (Weast, 1973). During preparation it is concentrated by evaporation (Schulz and Benedict, 1972). Based on this information, ${ }^{23} \mathrm{~Np}$ is assumed nonvolatile. However, fluoride com-. pounds can be volatile at $400^{\circ} \mathrm{C}$ as $\mathrm{NpF}_{6}$ (Schulz and Benedict, 1972) so the upper volatility limit would depend on the ${ }^{23} \mathrm{~Np}$ form.

- Technetium-99m is produced by ${ }^{99}$ Mo generators as needed in the university researglangdevelopment facilities. Therefore, airborne releases will be mixed ${ }^{90} /{ }^{99 m_{T C}}$ and dependent on the generation status. Studies of release during 5 gadioactive waste calcining indicated that less than $1 \%$ of the associated ${ }^{9}$ Tc would volatilize (Rimggan et al., 1980). Therefore, a 0.01 release factor is suggested for the ${ }^{99 m} \mathrm{TC}$.

Releases from the major fires are listed in Table 4.8. They are based on the assumptions that $10 \%$ of the maximum inventory is located in this area and the fire lasts $1 \mathrm{~h}$.

\subsection{Radioactive Waste Storage Fire}

Waste from all the laboratories is gathered in a separate facility and held until transported for burial. Only waste in this building is subjected to fire stresses. Wooden pallets holding the barrels of waste can fuel the fire, as well as waste stored in cardboard cartons. With the addition of sufficient heat the drums of waste can rupture and thus this material can be available to fuel the fire.

At one facility (the University of Wisconsin) $1500 \mathrm{Ci}$ of ${ }^{3} \mathrm{H}$ are stored in this area either as a gas or in 55-gal drums absorbed on molecular sieve. It can be assumed that this entire ${ }_{H}$ inventory is vaporized in the fire. Other radionuclides associated with the waste would become airborne with the volatility listed in Table 4.8 .

\subsubsection{Waste Incinerator Error}

Two nuclides, ${ }^{3} \mathrm{H}$ and ${ }^{14} \mathrm{C}$, associated with the liquid waste ( $3 \mathrm{mCi} / 5 \mathrm{gal}$ ) may be released to the atmosphere at a maximum rate of $50 \mathrm{mC} /$ day during waste incineration. They are mixed with fuel oil and pumped into holding tanks before incineration. Operator or clerical error could result in a higher specific activity in the liquid waste. If the waste concentration increased by an order of $10,500 \mathrm{mCi}$ of mixed ${ }^{3} \mathrm{H}$ and ${ }^{14} \mathrm{C}$ could be released to the atmosphere. 
TABLE 4.8. Potential MREPP of Isotopes Potentially Involved in a Major Fire at the Shipping/Receiving Department at a University Research and Development Laboratory

\begin{tabular}{|c|c|c|c|c|}
\hline Element & Isotope & $\begin{array}{c}10 \% \text { of } \\
\text { Maximum } \\
\text { Inventory, } \mathrm{Ci} \\
\end{array}$ & $\begin{array}{c}\text { Suggested } \\
\text { Release } \\
\text { Factor } \\
\end{array}$ & Release, $\mathrm{Ci}$ \\
\hline Americium & $241_{A m}$ & 0.5 & 0.01 & $5 \times 10^{-3}$ \\
\hline Carbon & ${ }^{14} \mathrm{C}$ & 1 & 1 & 1 \\
\hline Californium & ${ }^{252} \mathrm{Cf}$ & 0.01 & --- & --- \\
\hline Cesium & ${ }^{137} \mathrm{Cs}$ & 1.5 & $0.01 / \mathrm{h}$ & $1.5 \times 10^{-2}$ \\
\hline Cobalt & ${ }^{60} \mathrm{Co}$ & 0.5 & $2 \times 10^{-3} / \mathrm{h}$ & $1 \times 10^{-3}$ \\
\hline Curium & ${ }^{244} \mathrm{Cm}$ & 0.01 & $7.5 \times 10^{-3}$ & $7.5 \times 10^{-5}$ \\
\hline Hydrogen & $3_{H}$ & 300 & 1 & 300 \\
\hline \multirow[t]{2}{*}{ Iodine } & ${ }^{129} \mathrm{I}$ & 0.8 & 1 & 0.8 \\
\hline & $131_{I}$ & 0.07 & 1 & $7 \times 10^{-2}$ \\
\hline $\begin{array}{l}\text { Molybdenum( } \\
\text { Technetium }\end{array}$ & ${ }^{99} \mathrm{Mo} /{ }^{99 \mathrm{~m}} \mathrm{Tc}$ & 1 & 0.01 & $1 \times 10^{-2}$ \\
\hline Neptunium & $237 \mathrm{~Np}$ & 0.01 & -- & -- \\
\hline Nickel & ${ }^{63} \mathrm{Ni}$ & 0.1 & $-\cdots$ & -- \\
\hline Phosphorous & $32 p$ & 0.5 & 1 & 0.5 \\
\hline Polonium & $210_{\mathrm{Po}}$ & 10 & 1 & 10 \\
\hline Strontium & ${ }^{90} \mathrm{Sr}$ & 0.05 & $2 \times 10^{-3}$ & $1 \times 10^{-4}$ \\
\hline Sulfur & ${ }^{35} \mathrm{~S}$ & 0.5 & 1 & 0.5 \\
\hline Xenon & $133 \times e$ & 1 & 1 & 1 \\
\hline
\end{tabular}

(a) These are assumed together in generators.

4.11.1.6 Patient Related Incident

Another release mechanism, limited to an administered dose, fguld occur if a patient becomes sick and vomited aftęg treatment. The dose of I3I $I$ can be $30 \mathrm{mCi}$ or as much as $200 \mathrm{mCi}$. Since I can be volatile, the entire dose could become airborne.

\subsubsection{University Research and Development MREPP Scenario}

Two locations were suggested for the MREPP event based on radionuclide inventory level. These were the shipping/receiving and waste storage area. A fire volatilizing radionuclides in the waste storage area is the MREPP because of the large ${ }^{3}$ inventory. 
Other isotopes can be present in the waste. Levels would be low and releases from waste should not exceed those from a fire in the shipping/ receiving area.

\subsubsection{Material Release}

Radionuclides in the shipping area become airborne in the fire depending on volatility. These are listed in Table 4.8. However, the large amount of stored ${ }^{3} \mathrm{H}$ at one facility means that the storage area has the MREPP. The entire $1500 \mathrm{Ci}$ inventory becomes airborne.

\subsubsection{Factors Affecting Release}

The following factors affect release at university research and development facilities:

- Inventory in waste

- Effectiveness of fire safety systems. 


\subsection{RELEASE CALCULATIONS}

While a range of accidental releases have been covered for each of the operations, MREPP events envisioned are limited to the three types listed in Table 5.1. These events are fire, tornado, and criticality accident. The following sections will discuss elements considered when defining each of these accidents and general calculational considerations. The application to the specific facilities where the event was the MREPP is then discussed. This includes calculational techniques and considerations imposed by specific radioactive materials.

Calculating an airborne release after an accident requires several steps leading to a general form:

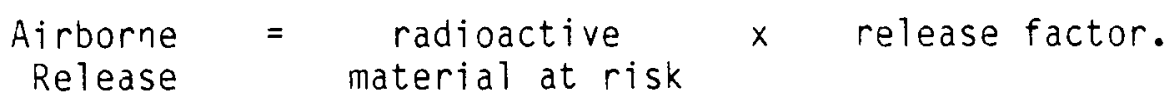

Components of the formulation thus are the material at risk and a release factor made of several elements.

Material at risk is the radioactive inventory that can be in jeopardy from the accident. This is not necessarily and, in fact, usually is not the license limit, but would be some lower value. This value could be, for example, $75 \%$ of the limit. The material at risk will include surface contamination on equipment in a facility. Cellulosic and other radioactively contaminated waste material should be considered in the assessment. Stored materials can be in jeopardy and can often represent a large inventory.

Release factor can include material form, accident stresses, availability, mitigation, time, and particle size. These must be considered and may be included in one release factor or the different parts can be separated. The most straightforward approach is to estimate the amount of material airborne at the site of the event and then relate this to conditions in a specific facility:

- Material form includes whether the inventory is powder, liquid or gas. In some of the facilities studied here the inventory could include microspheres or sealed sources. Surface contamination can be on various materials, and this substrate must also be considered.

- Accident stresses determine the magnitude of the release. These include fire producing high temperature and turbulent stresses, explosions producing high levels of energy, pressurized releases ejecting material forcefully from a container, or impact from spills. Suggested responses of materials are based on empirically determined release factors or known behavior. 


\section{TABLE 5.1. MREPP Events}

\begin{tabular}{|c|c|}
\hline Facility & Event \\
\hline $\begin{array}{l}\text { Uranium fuel fabrication } \\
\text { (oxide) }\end{array}$ & $\begin{array}{l}\text { UF }_{6} \text { cylinder rupture } \\
\text { in loading dock } \\
\text { incident (fire) }\end{array}$ \\
\hline $\begin{array}{l}\text { Uranium fuel fabrication } \\
\text { (metal) }\end{array}$ & Criticality \\
\hline UF $_{6}$ production & $\begin{array}{l}\text { UF }_{6} \text { cylinder rupture } \\
\text { in loading dock } \\
\text { incident (fire) }\end{array}$ \\
\hline Uranium milling & Tornado \\
\hline Waste warehousing & Facility fire \\
\hline Plutonium contaminated & Tornado \\
\hline $\begin{array}{l}\text { Radiopharmaceutical } \\
\text { manufacturing }\end{array}$ & Facility fire \\
\hline Radiopharmacy & Facility fire \\
\hline $\begin{array}{l}\text { Sealed source } \\
\text { manufacturing }\end{array}$ & Facility fire \\
\hline $\begin{array}{l}\text { Research and development } \\
\text { of nuclear fuels }\end{array}$ & Criticality \\
\hline $\begin{array}{l}\text { University research and } \\
\text { development }\end{array}$ & Facility fire \\
\hline
\end{tabular}

- Availability of the material to the accident stresses must be considered next. Packaging of the material (e.g., in DOT-approved containers) precludes releases from all but the most rigorous accident stresses. Even containment within a glove box lowers the potential release, since it adds a barrier to the release path.

- Mitigation can be planned or inadvertent. Filters included in a facility reduce the potential for an atmospheric release, and they must be evaluated to determine if the accident stresses are sufficient to breach them. Deposition, condensation, agglomeration, and other mechanisms can reduce the release. An event outside a facility will have a larger release in the absence of mitigation. 
- Time includes that required for the release or how long the stresses are imposed. Some releases such as from an explosion are essentially instantaneous. However, there will be a period of time after the initial event when the dispersed radioactive materials can become airborne by resuspension due to aerodynamic entrainment. For fires, the burning time will frequently determine the release magnitude. The length of time a fire will burn is dependent on the combustible loading, not just the radioactive component.

- Particle size should be considered in the release analysis because particles with diameters $10 \mu \mathrm{m}$ AED can be inhaled and retained in the lung and represent a health hazard. For many of the materials found in the NMSS facilities, this information is not available, so the release is conservatively estimated all in the respirable range.

In our analysis, we have used the approach of estimating the fraction of the radioactive material airborne at the accident site. Elements contributing to the release have been identified separately rather than using a single release factor. Thus factors such as mitigation by filters can be suggested as they apply to specific conditions.

\subsection{FIRES}

Seven of the facilities reviewed have fires as the MREPP event. Two general fire scenarios were identified: 1) facility fire and 2) loading dock (shipping/receiving area) fire. Each of these is discussed including initiating events, fire ignition and fire development.

Facilities where a facility fire was the suggested MREPP event are radiopharmaceutical manufacturing, radiopharmacy, waste warehousing, sealed source manufacturing, and university research and development. Temperatures resulting from a major facility fire could be 800 to $1000^{\circ} \mathrm{C}$, considered typical of an enclosure fire (Thomas, 1974). A loading dock fire involving UF 6 cylinders was the MREPP event for two facilities, uranium fuel fabrication (oxide) and $U_{6}$ production.

\section{1 .1 Facility Fire}

This fire is considered to be one initiated by an event within the facility or involving the entire facility. These fires include those started by natural gas explosions or fires that spread to an asphalt or flammable roof from an adjacent fire. The Fire Protection Handbook (Mckinnon, 1976) has been used as a basic reference for this fire section.: Fires require both an ignition sequence and a development phase:

- Fire ignition sequence. There must be a heat source, a kindling fuel, and an event (human action or natural act) that gets the heat source and kindling fuel together to start the fire. Human error, failure to recognize and comprehend faults that contribute to the event, is also associated with fires. Initiating events providing an ignition sequence can include: 
- Electrical. Wiring and associated components can cause fires by short-circuit faults or by arcs and sparks from damaged or defective equipment. Heated motors are another fire source.

- Open flames. The use of bunsen burners, welding sparks, and hydrogen burnoff can cause fires.

- Heating equipment. Natural gas and fuel oil are used for space heating. When gas or oil is used there is the hazard of vapors mixing with air and reaching the ignition or explosive level.

- Trash burning. Waste material can be the source of a spontaneously ignited fire. Improper use of incinerators can lead to accidental fires.

- Flammable liquids. Careless handling or storage of flammable or combustible liquids can lead to fires. Ignition can result due to leaking of fuels or spills near a heat source.

- Gas explosion. Gas escaping from piping, storage tanks, or equipment; misuse or faulty operation of equipment can lead to a buildup of gas to an explosive concentration.

- External source. Lightning can initiate a facility fire. Some of these NMSS facilities are in locations where they would be in potential fire jeopardy from sparks from adjacent burning buildings or range fires.

- Fire development. The fire ignition sequence will not of itself lead to a facility fire. This requires the addition of combustible burning material for the fire development. Compartmentation of a building with physical barriers can limit fire spread, as will effective fire suppression systems. Construction deficiencies can be major contributors to fire spread: failure to subdivide large areas, lack of fire doors, absence of fire cutoffs between floors, open stairways and elevator shafts, conveyor and pipe openings, combustible interior materials and finishes.

Improper storage of building contents is a frequent contributor to large fires. Improperly stored liquids can escape from drums, tanks, and processing equipment. Flammable gases escaping from cylinders or piping can contribute to the fire spread. Even if contained, these containers can overpressurize from the initial event.

\subsubsection{Radiopharmaceutical Manufacturing}

The fire ignition sequence for this facility was postulated as a flammable vapor leak with natural gas as the vapor. The gas accumulates and subsequently deflagrates (Section 4.3.1.6). An ignition source is fundamental to a combustion explosion: static electricity is one potential fire ignitor. Since gas is usually used in heat producing equipment, the ignitor can be inherent to the 
system. Solvents used in processes, cellulosics, and wood interior members are available to contribute combustibles to the fire development. This can be accelerated by leakage of oxygen from lines located at each glove box, lines which are assumed broken in the initial deflagration.

To estimate the severity of the event we calculated the overpressure developed as a result of that event. This, in turn leads to an estimate of structural and filter damage. In a wooden building the fire could develop even though the structural integrity is maintained; in a concrete structure, barriers (walls or roof) must fail in order to give opportunity for the fire to spread. Components of the release calculation are fire ignition, damage, radionuclide release, and source term modification:

- Fire ignition. The accident scenario suggests that the gas leaks into a "dead" air space in order to reach a flammable 3 level above $4 \%$. Our illustration uses a $10 \times 10 \times 10 \mathrm{ft}\left(1000 \mathrm{ft}^{3}\right)$ volumę, about the size of a small room, filled with an 0.04 fraction (40 $\mathrm{ft}^{3}$ ) of natural gas. Combustion explosions can occur when only a portion of a room, perhaps $25 \%$, is filled with flammable gas. The ignition sequence is: gas mixes with air, the mixture ignites, heated air expands, and an explosion follows.

- Damage. Estimating potential damage from explosive events is an inexact science at present. Some guidelines have been established that can help relate the overpressure of the event to anticipated damage.

Natural gas is a mixture and can have varying compositions. For our illustration, we selected $75 \%$ methane, $21 \%$ ethane, and $4 \%$ propane (Crane, 1978) and calculaţed a heat of combustion for this specific mixture to be $1120 \mathrm{Btu} / \mathrm{ft}^{3}$ using heat of combustion of the component gases (Pacific Coast Gas Association, 1934). 3 Natural gas heat of combustion can range from 958 to $1124 \mathrm{Btu} / \mathrm{ft}^{3}{ }_{3}$ (McKinnon, 1976). Our specific mixture has a density of $0.055 \mathrm{lb} / \mathrm{ft}^{3}$, which calculated to

$$
\frac{1120 \mathrm{Btu} / \mathrm{ft}^{3}}{0.055 \mathrm{lb} / \mathrm{ft}^{3}}=2 \times 10^{4} \mathrm{Btu} / \mathrm{lb} \text {. }
$$

Use of this heat of combustion value enables us to calculate the energy developed in terms of TNT equivalency, which is then used to estimate damage produced by the deflagration.

The explosion yield can be calculated (Strehlow and Baker, 1976)

$$
\text { - } W_{T N T}=\frac{\Delta H_{C} \times W_{C}}{1800}
$$

where: 


$$
\begin{aligned}
W_{T N T} & =\text { equivalent, TNT wt/lb } \\
\Delta H C & =\text { heat of combustion of hydrocarbon, Btu/lb } \\
W_{C} & =\text { weight available as explosive source, } 1 \mathrm{~b} \\
1800 & =\text { heat of explosion of TNT, Btu/lb. }
\end{aligned}
$$

For the illustrated explosion with a $4 \%$ flammable gas level, these parameters are

$$
\begin{aligned}
\Delta H_{C} & =2 \times 10^{4} \mathrm{Btu} / \mathrm{lb} \\
W_{C} & =\left(1000 \mathrm{ft}^{3} \times 0.04\right) \times 0.055 \mathrm{lb} / \mathrm{ft}^{3}=2.2 \mathrm{lb} .
\end{aligned}
$$

Calculations are

$$
W_{T N T}=\frac{2 \times 10^{4} \mathrm{Btu} / 1 \mathrm{~b} \times 2.21 \mathrm{~b}}{1800 \mathrm{Btu} / 1 \mathrm{~b}}=24.41 \mathrm{~b} .
$$

Not all of the heat of combustion energy is released in the explosion, 10\% (Brasie and Simpson, 1968) is suggested and used in our example. If this value is applied to our example problem, the explosion, therefore, yields the equivalent of 2.4 1b TNT. This yield can be used as a measure of anticipated damage.

The damage is a function of $\left(W_{T N T}\right)^{1 / 3}$ called the scaled yield (Brasie and Simpson, 1968). The scaled explosion yield normalizes the WTNT values to reference values for 1 lb TNT. These values are plotted in Figure 5.1. The yield from our example is estimated at 1.3. Using this scaled value the overpressure at various distances from the event can be calculated and used to estimate damage.

From Figure 5.2 the distance from ground zero to the point where a given overpressure will occur can be estimated using the equation:

$$
\frac{D}{D_{0}}={\frac{W}{W_{0}}}^{1 / 3}
$$

where $D$ is the distance for a given overpressure for a yield of $W$. $D_{0}$ and $W_{0}$ are reference values. 
$\infty$

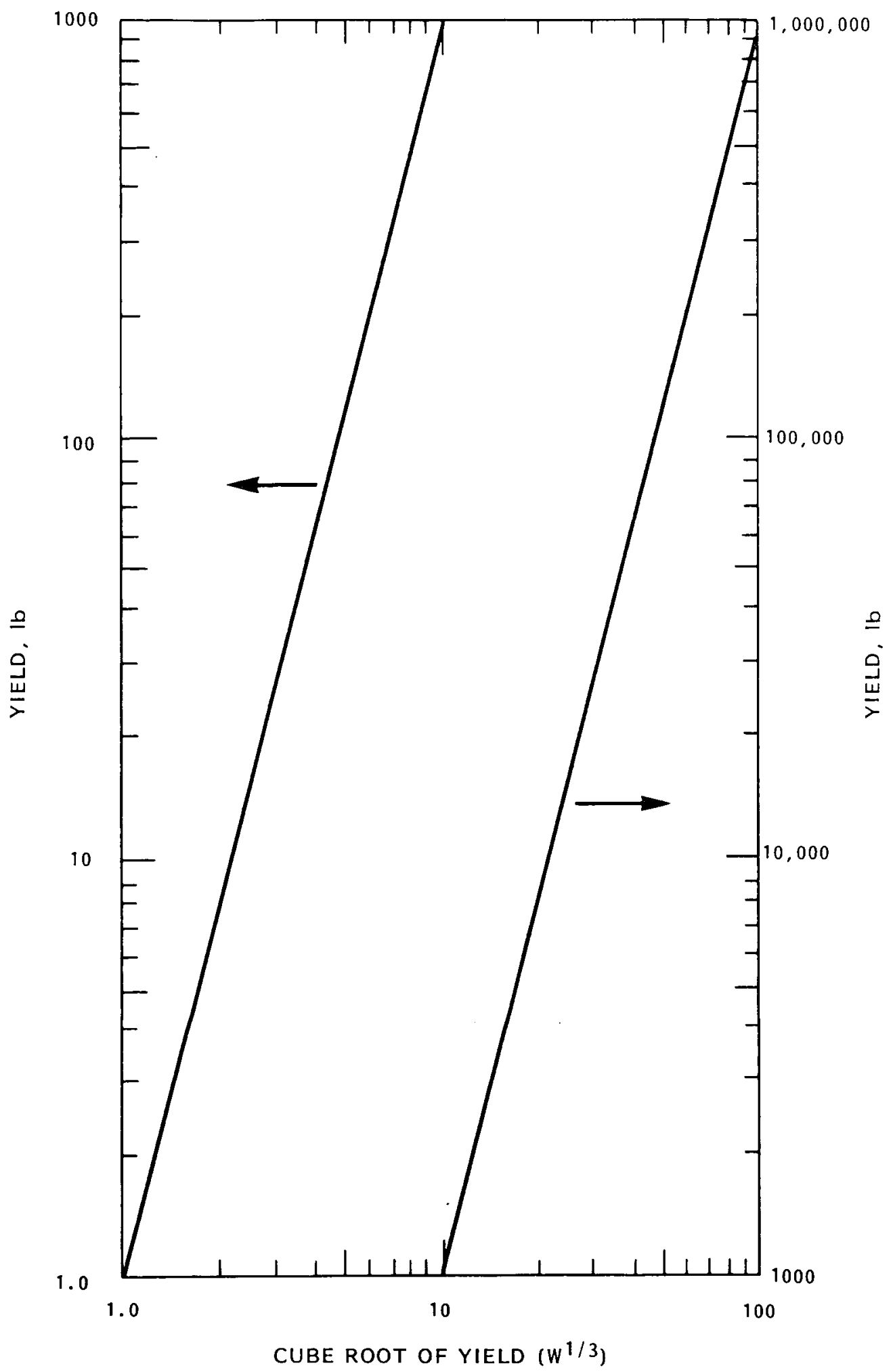

FIGURE 5.1. Scaled Explosion Yields

$$
5.7
$$




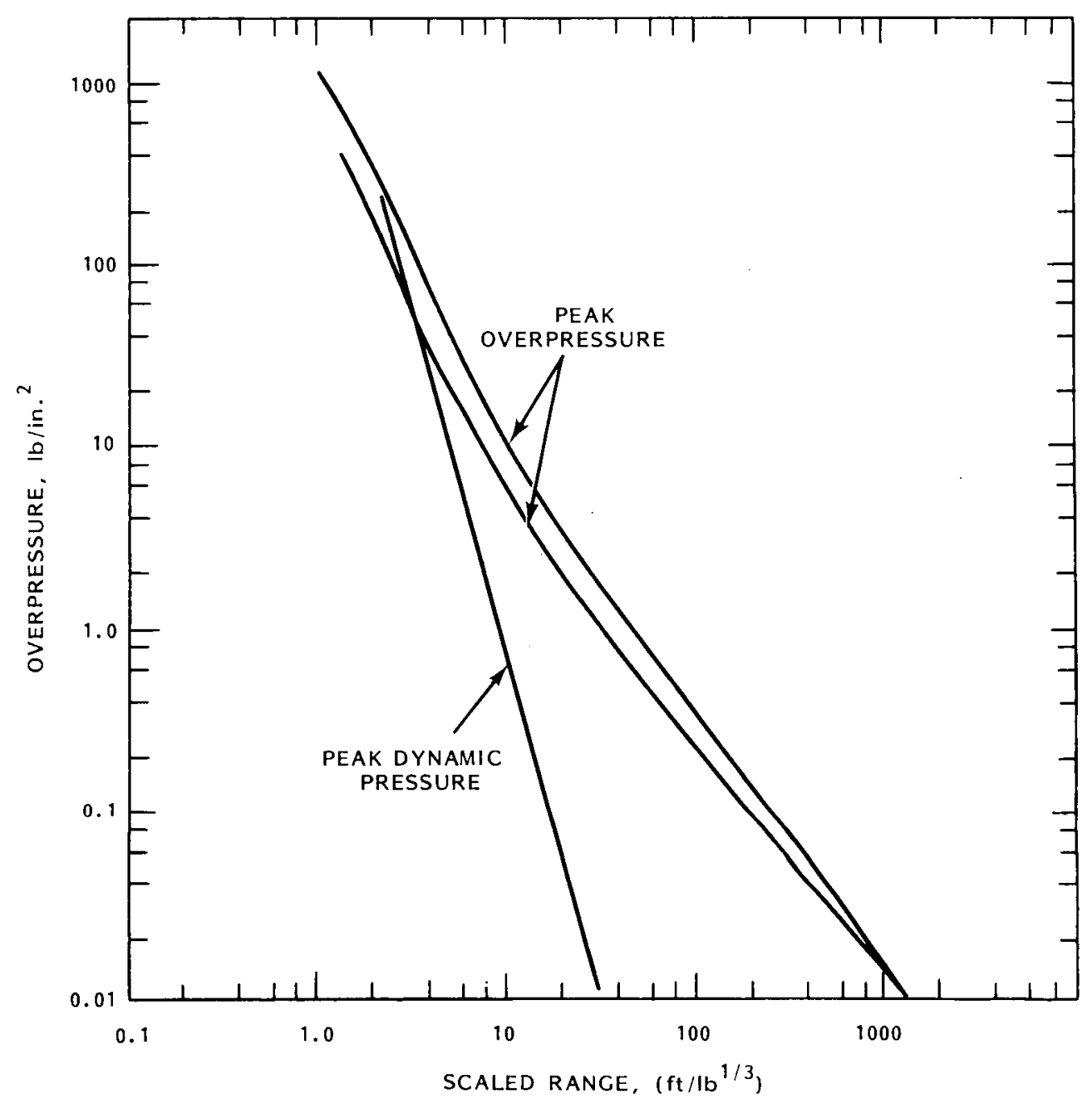

FIGURE 5.2. The Basic Relationship Between Overpressure and Scaled Range

Using the values in our illustration in Eq. 5-2 and using $W_{0}=1$ and $D_{0}$ of $20 \mathrm{ft}$,

$$
\begin{aligned}
\frac{D}{20} & =1.3 \\
D & =26 \mathrm{ft} .
\end{aligned}
$$

Using Figuge 5.2, the overpressure at $D_{0}=20 \mathrm{ft}$ for $1 \mathrm{db}$ TNT is $1.8 \mathrm{lb} / \mathrm{in.}{ }^{2}$. Based on the above calculation $1.8 \mathrm{lb} / \mathrm{in}$. $^{2}$ overpressure is reached at $26 \mathrm{ft}$ for our example. At $130 \mathrm{ft}$ from ground zero the peak overpressure is $0.21 \mathrm{~b} / \mathrm{in}^{2}$. 
Based on this analysis, it is assumed that concrete or cinder blgck panels could sustain damage but are not destroyed (2 to $3 \mathrm{lb} / \mathrm{in}$. $^{2}$ overpressure would be required to destroy them). HEPA filters can fail at 2.2 to 3.2 1b/in.2 overpressure, depending on their depth (Burchsted, 1976). Therefore, the deflagration will be confined to one room in a concrete structure. A wooden structure would be entirely engulfed in fire.

$\rightarrow$ Radionuclide release. The largest inventory in a radiopharmaceutical manufacturing facility is volatile ${ }^{3} \mathrm{H}$; in the wooden interior facility, the entire $27,500 \mathrm{Ci}$ are released by the heat of the fire, since the entire facility is engulfed. In a concrete structure, the release might be the contents of one cylinder or $1000 \mathrm{Ci}$ of $3_{\mathrm{H}}$. While this is the largest release in curies, other releases are of more radiological concern. Table 4.3 suggests release factors for other radioisotopes.

- Modification of the radiopharmaceutical manufacturing source term. Modification of the source term was illustrated in our calculation. The three means of modification are the energy in (or released) and, therefore, the damage produced by the combustion explosion; building structural elements; and inventory at risk.

- Energy. The energy produced by an explosion is calculated in terms of the TNT equivalent and blast overpressure that in turn suggests potential damage. For example, 2 to 4 1b/in. ${ }^{2}$ can collapse a steel panel building or shatter concrete walls (Brasie and Simpson, 1968). The amount and energy available for the explosion depends on the amount and type of explosive involved. If the illustration had postulated a $10 \%$ explosive gas concentration up to above $4 \mathrm{lb} / \mathrm{in}$. 2 pressures could be expected at $75 \mathrm{ft}$ from ground zero.

- Structural elements. Wooden interior walls will burn and add fuel to a fire. Concrete structures must be breached to allow fire spread if combustion sources are available. Overpressures suggested in the illustration should not damage concrete structures. Fire walls and suppression systems were not considered in our generic analysis.

- Inventory. These releases were based on the maximum allowable inventory in the areas affected. Other volatile radionuclides could be present in another situation. Release factors for isotopes found in significant amounts in radiopharmaceutical manufacturing facilities are listed in Table 4.3. Consideration must also be given to physical characteristics, whether they are powders, solids, and liquids. For the generic situation this was not always identified. 


\subsubsection{Radiopharmacy}

These facilities can be either a small building or single room in a large building such as a hospital. Fire initiation scenarios will be facility specific but could potentially be related to the heating system. Natural gas heating could be the source of a deflagration/explosion with the scenario discussed in Section 5.1.1.1. Baseboard electrical heating malfunction igniting combustible material is another fire-initiating scenario. When the radiopharmacy is located in a room in a large facility, the initiating event could be elsewhere in the building. Fire ignition radionuclide release and source term modification follow:

- Fire ignition. For this analysis, a major facility fire was suggested, with the natural gas heating deflagration as the initiating event. Releases to the atmosphere would be maximized by a breach in the facility. Two breaching mechanisms were suggested: the roof could be damaged in the initiating event or fire fighters could chop through the roof in their attempts to fight the fire.

Temperatures resulting from a major fire are high enough to damage containers, which then results in the release of volatile radionuclides. Anticipated releases could be a function of temperature.

- Radionuclide Release. The potential radionuclide release would depend on the inventory in a facility. Table 4.3 listed suggested fire release factors for radiopharmaceutical isotopes, and Table 3.6 gave a range of potential inyentories. Some of the more signifigant

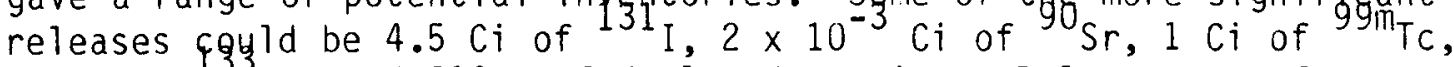
$75 \mathrm{Ci}$ of ${ }^{133} \mathrm{Xe}$, and $910 \mathrm{~g}$ of depleted uranium. Releases are from material in process and radioactivity associated with contaminated waste. The ${ }^{131} \mathrm{I}$ is the most significant release in terms of health effects,
and ${ }^{90} \mathrm{Sr}$ is also of radiological concern.

- Modification of radiopharmacy source term. Because a deflagration initiated by the natural gas heating is the event with MREPP release, the parameters discussed in Section 5.1.1.1 apply here also. Some additional considerations are discussed:

- Location affects the energy and structural elements. For a radiopharmacy located in a hospital or other large building the deflagration source could be there rather than in the pharmacy itself. Therefore, the structural elements and the combustible loading of the larger facility would be important in suggesting the magnitude of the accident.

- Inventory in a radiopharmacy is primarily in a packaged form and is processed rapidly through the facility. This reduces the potential of a large source for the release. 


\subsubsection{Sealed Source Manufacturing}

The facility fire scenario suggested as a MREPP event for the sealed source manufacturing category was hypothesized to involve flammable roofing material. These roofs are frequently constructed using metal paneling with an asphalt (tar) surface. The traditional construction of these roofs has been shown to contribute significant amounts of fuel when exposed to the heat of an intensive interior fire below the deck. Asphalt vaporized by the heat of a fire can help to spread fire under a roof deck (Mckinnon, 1976). The fire ignition scenario, radionuclide release, and source term modification are:

- Fire ignition. Most sealed source manufacturers are located in urban industrialized areas which could provide the source of an external ignition scenario for the fire. The roof could be assumed to ignite and burn, spreading to interior wooden (combustible) walls. Or, conversely, a fire started by malfunction of the building heating system could spread to the interior walls, then to the asphalt roofing. The most dramatic illustration of this type of fire was the General Motors fire at Livonia, Michigan, in 1953, which destroyed that plant (McKinnon, 1976).

- Radionuclide release. Releases for these facilities have been calculated for illustration, using the maximum license inventories listed in Table 3.7 and the suggested release factors in Table 4.3 . Calculated values in Table 5.2 assume the fire lasts for $1 \mathrm{~h}$. These releases are calculated for illustration of potential upper release values and are dependent on variables that are discussed in the section on inventory.

- Modification of sealed source inanufacturing source term. The release is controlled by two parameters:

- Fire magnitude. It was assumed the entire facility burned. Release from a partial burn would be lower. No allowance was taken for safety systems, barriers, or deposition and plateout in the facility. Temperatures reached by the fire woyld also cogtrol fl leases since volatility for some isotopes $\left({ }^{90} \mathrm{Sr}\right.$, ${ }^{\mathrm{CS},}{ }^{24 \mathrm{Im})}$ increases with temperature.

- Inventory. The releases shown in Table 5.2 do not indicate the potential release from single facilities. Sealed source manufacturers specialize in a few isotopes and products. The significant licensed isotopes at the different facilities are listed in Table 3.7. Additionally, the inventory on hand would usually be below the maximum allowable, perhaps $75 \%$.

Even one manufacturer's total inventory would not necessarily be in jeopardy. The inventory could be distributed among different process steps, or on the loading dock or in storage. These different operations often are located in different buildings, and it is a lower likelihood that all the buildings at a site would be involved in the same fire. 
TABLE 5.2. Potential Releases of Radionuclides Found in Significant Amounts in Sealed Sources Manufacturing Plants $(a)$

\begin{tabular}{|c|c|c|c|c|}
\hline Element & Isotope & $\begin{array}{c}\text { Maximum } \\
\text { Inventory, } \mathrm{Ci} \\
\end{array}$ & $\begin{array}{r}\text { Release } \\
\text { Factor }\end{array}$ & $\begin{array}{c}\text { Release, } \\
\mathrm{Ci} \\
\end{array}$ \\
\hline Americium & $241_{A m}$ & $6 \times 10^{3}$ & $1 \times 10^{-2}$ & 60 \\
\hline Cesium & ${ }^{137} \mathrm{Cs}$ & $8 \times 10^{4}$ & $1 \times 10^{-2}$ & 80 \\
\hline Cobalt & ${ }^{60} \mathrm{Co}$ & $2 \times 10^{4}$ & $2 \times 10^{-3}$ & 40 \\
\hline Hydrogen & $3_{H}$ & $1 \times 10^{5}$ & 1 & $1 \times 10^{5}$ \\
\hline Iridium & ${ }^{192} \mathrm{Ir}$ & $2.5 \times 10^{4}$ & --- & --- \\
\hline Krypton & $85 \mathrm{Kr}$ & $1.5 \times 10^{3}$ & 1 & $1.5 \times 10^{3}$ \\
\hline Polonium & & $4 \times 10^{3}$ & 1 & $4 \times 10^{3}$ \\
\hline Promethium & & $3.5 \times 10^{3}$ & $1 \times 10^{-3}$ & 3.5 \\
\hline Strontium & & $3 \times 10^{3}$ & $2 \times 10^{-3}$ & 6 \\
\hline Tantalum & & $2 \times 10^{3}$ & $\ldots$ & --- \\
\hline Thul ium & ${ }^{170} \mathrm{Tm}$ & $5 \times 10^{3}$ & $\cdots$ & -- \\
\hline Plutonium & Mixed & $199 \mathrm{~g}$ & $1 \times 10^{-2}$ & $2 \mathrm{~g}$ \\
\hline Uranium & $\begin{array}{l}\text { Depleted } \\
\text { Uranium }\end{array}$ & $1500 \mathrm{~kg}$ & $1 \times 10^{-2}$ & $150 \mathrm{~kg}$ \\
\hline
\end{tabular}

(a) Calculazted using maximum license inventories greater than $1 \times 10^{3}$ and $1-h$ fire

The physiggl form and packaging will also affect the release. For example, Co can be nonvolatile or semivolatile depending on physical form. Sometimes a large part of the inventory is stored in DOT-approved shipping containers. Their use reduces the potential for isotope releases.

\subsubsection{Waste Warehousing}

The facility fire for the waste warehousing category is a deflagration event of the type described in 5.1.1.1. However, here the initiating scenario involves a propane-fueled front-end loader used to move the waste drums in the warehouse. Fuel leaking from this equipment was ignited by hitting an overheated motor. This ignites and deflagrates. Additional combustible material contributes to fire development when missiles from the detonation hit and breach gas storage tanks or other combustibles. Fire ignition, radionuclides release, and source term modification follow: 
- Fire ignition. Formulations discussed in Section 5.1.1.1 (not repeated here) are used to calculate the explosive equivalent yield. The fuel tank capacity of a front-end Joader is about $10 \mathrm{lb}$, and the propane heat of combustion is $2.1 \times 10^{4}$ Btu/1b. Using these values (and assuming the entire $10 \mathrm{lb}$ of propane is involved), the total energy of the explosion is equivalent to 117 1b TNT. Assuming that only a $10 \%$ fraction of the energy is released, the explosive yield is $W_{T N T}=11.7 \mathrm{lb}$. This energy $\left(2\right.$ to $41 \mathrm{~b} / \mathrm{in} .^{2}$ at $25 \mathrm{ft}$ from the event) is sufficient to blow the roof off the facility and generate missiles (probably from the front-end loader). These missiles might pass through the loading area and could hit gas storage tanks. This was assumed to provide sufficient fuel for a fire with a magnitude sufficient to engulf the facility.

- Radionuclide release. The maximum releases are listed in Table 4.7. A $2000 \mathrm{Ci}$ release assumes all of the volatile inventory associated with the waste becomes airborne.

- Modification of waste warehousing MREPP source term. Several factors contribute to scaling the magnitude of this event: 1) volume of propane in the front-end loader fuel tank, 2) combustible material available to fuel the fire with air available to the fuel, and 3 ) isotopic distribution and decay status of the waste. These are follows:

- Fuel. A completely filled (10 ib) fuel tank was assumed, with TNT equivalent energy released in the event of $11.71 \mathrm{~b}$. One pound of propane would result in a TNT equivalent 1 lb. At $10 \mathrm{ft}$ from the $1-1 \mathrm{~b}$ explosion, the peak pressure would be about $1 \mathrm{lb} / \mathrm{in.}$, a level that should not result in serious damage to the facility, although corrugated siding can show buckling and glass can break.

- Combustibles. If the waste is contained in steel drums, it is not immediately available to contribute to the fire. Structural nembers are steel, concrete blocks, etc. and not combustible. Therefore additional combustible material must be available if burning is to be sustained. These could be flammable roofing material," stored combustible material (in our illustration, gas storage tanks), trucks containing flammable material (gas) at the loading dock as well as the truck fuel tank, or gas heat in the building, wooden pallets, and the waste itself.

- Isotope status. Essentially, this is how much of the contaminated material is still associated with the waste. Since some of the stored isotopes have relatively short half lives, a portion will have decayed away in storage. For our calculations, we used a mixture of representative radionuclides, the majority of which were volatile, and assumed the waste to contain all of the activity inventory present when it was stored. Table 5.3 shows the half-lives of the isotopes 
TABLE 5.3. Half-Lives of Radioisotopes Potentially Available for Accidental Fire Release of Drummed Waste

\begin{tabular}{|c|c|c|c|}
\hline Element & $\begin{array}{l}\text { Waste } \\
\text { Isotope }\end{array}$ & $\begin{array}{l}\text { Half- } \\
\text { Life }\end{array}$ & $\begin{array}{l}10 \text { Half- } \\
\text { Lives, yr (a) }\end{array}$ \\
\hline Carbon & ${ }^{14} \mathrm{C}$ & $5730 \mathrm{yr}$ & 57,300 \\
\hline Chromium & ${ }^{51} \mathrm{Cr}$ & $30.2 \mathrm{yr}$ & 302 \\
\hline Hydrogen & $3_{H}$ & $12.2 \mathrm{yr}$ & 122 \\
\hline \multirow[t]{2}{*}{ lodine } & $125_{I}$ & 60 day & 1.6 \\
\hline & ${ }^{131_{I}}$ & 8.1 day & 0.22 \\
\hline Phosphorous & $32 p$ & 14.3 day & 0.39 \\
\hline Sulfur & ${ }^{35} \mathrm{~s}$ & 88 day & 2.4 \\
\hline
\end{tabular}

(a) Storage period maximum is $0.5 \mathrm{yr}$.

associated with a representative waste storage area. This table illustrates how the inventory can decay with time. For these nuclides, 10 half-lives (listed in the last column) is the point where they are considered to be depleted ${ }_{131}$ For example, about $11 / 3$ months after initial storage, the ${ }^{131}$ I is gone. This isotope and ${ }^{32} \mathrm{p}$ could disappear in the maximum allowable storage period of 6 months. The decay status of the waste can be calculated using the Radioactive Decay Tables (Bureau of Radiological Health, 1970) shown here in Figure 5.3. These tables and the formula are used to calculate the fraction of activity at any time after some zero time. An example is included with the figure.

\subsubsection{University Research and Development}

Fire initiation in this category would be facility specific. In the scenario we suggested that the fire resulted fron a natural gas leak leading to a combustion/explosion event. Other heating systems could also initiate a facility fire as discussed in Section 5.1.1.2. Because many different laboratories in scattered locations are typical for this category, buildings covered under the same license could have different heating systems. The shipping/ receiving and waste storage areas are the suggested fire locations because of the potential for containing a larger inventory. The fire ignition scenario, radionuclide release, and source term modification are:

- Fire ignition. A major facility fire developing after initiation by the heating system is the suggested scenario. Sufficient fuel might be provided by wooden structural members and shelving. Solvents and cellulosics stored in the vicinity of the fire could provide sufficient fuel for fire development. Since some of these operations occur in hospital buildings, it could contribute additional 


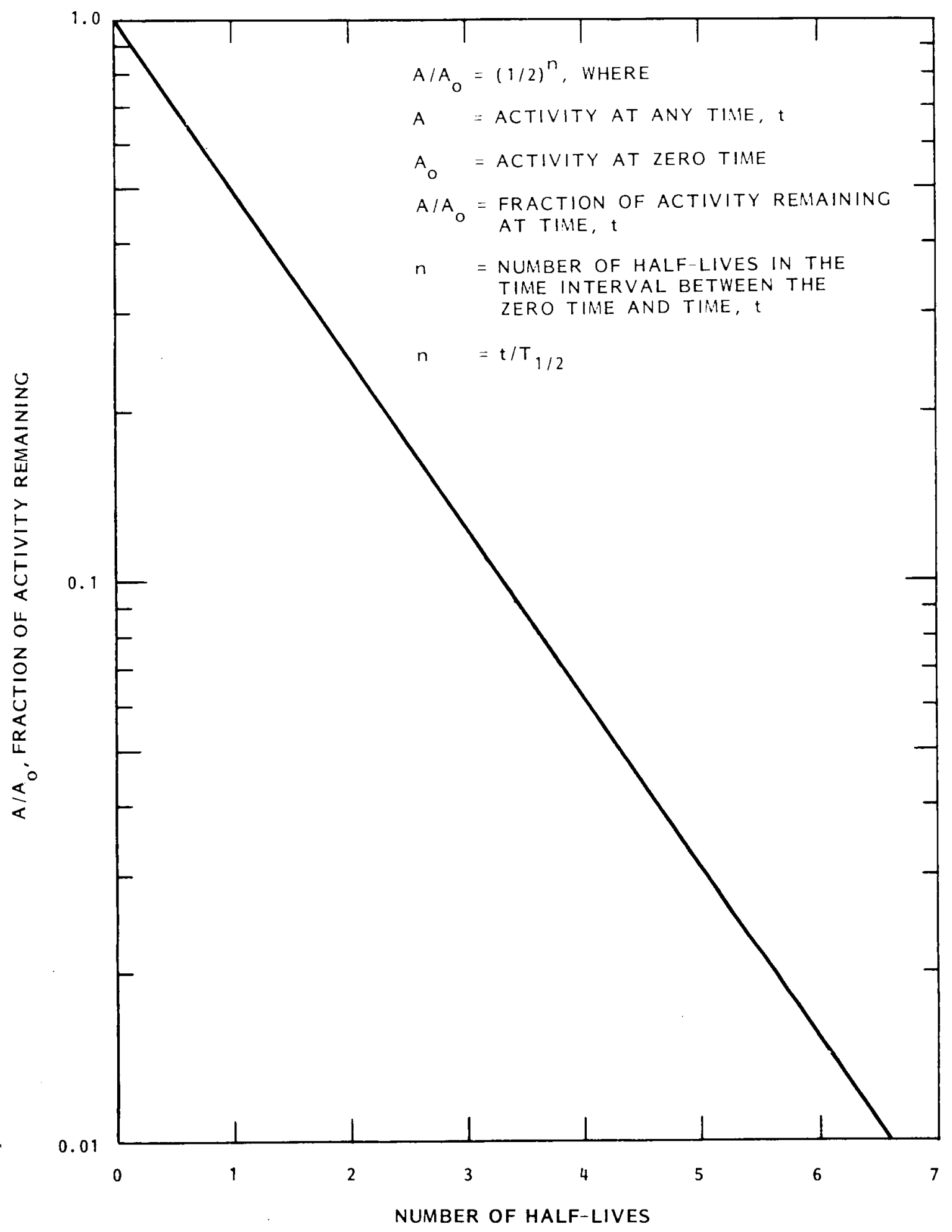

FIGURE 5.3. Radioactive Decay (Bureau of Radiological Health, 1970) 


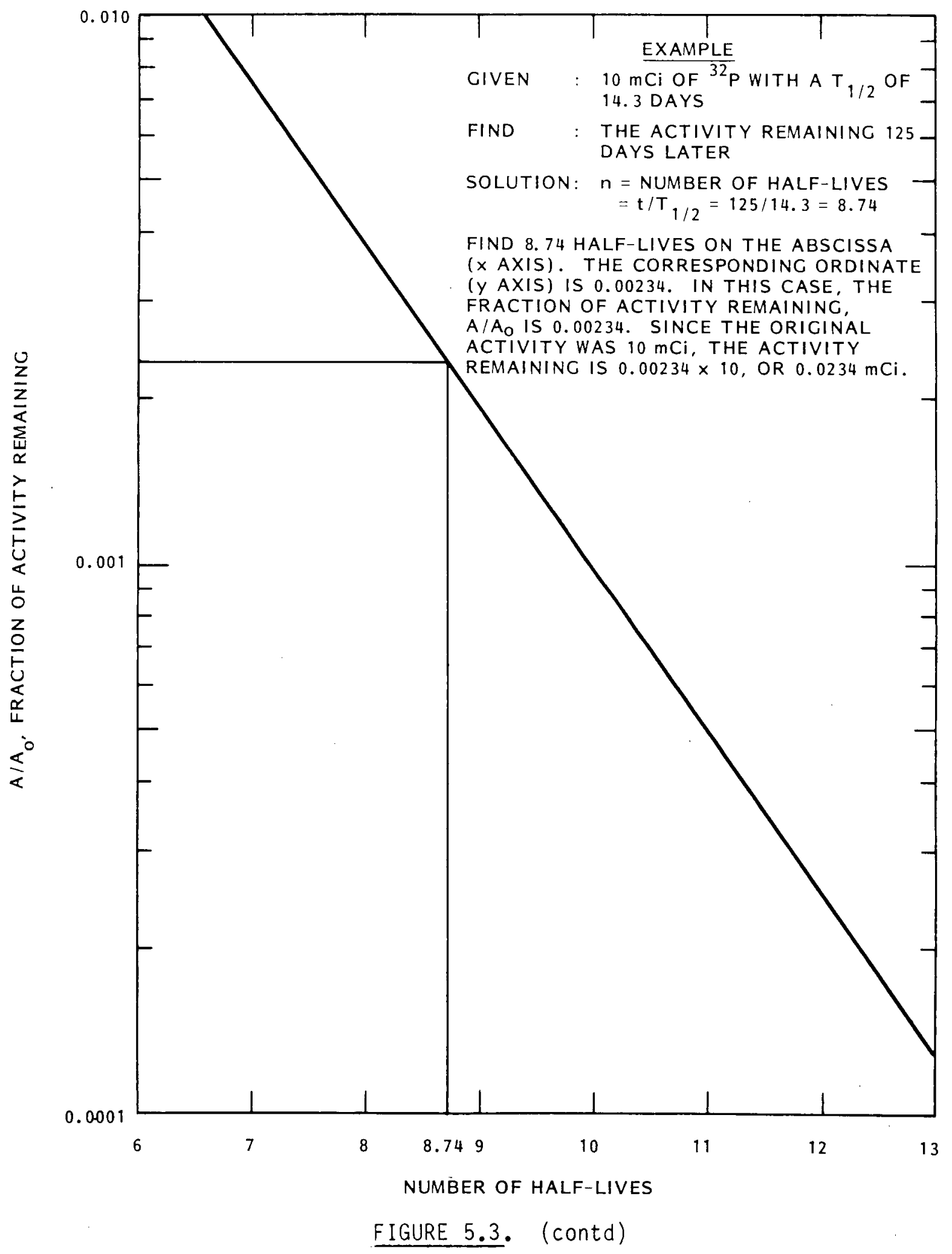

5.16 
combustibles such as solvents. Releases to the atmosphere would be inaximized since the building would not retain integrity.

- Radionuclide release. Two specific locations were suggested for the fire based on the anticipated higher isotope inventory levels:

shipping/receiving and waste storage.

- Shipping/receiving area produces the lower release of the two. This is based on the reasoning that the nuclide residence time in this building or room would be very limited. In order to maintain amounts of some of the rapidly decaying isotopes they must be delivered to a user promptly.

- Waste storage areas will be a collection and holding site where wastes are accumulated. Some of the longer-lived isotopes could be found here. At one facility significant amounts of ${ }_{H}$, $1500 \mathrm{Ci}$, was suggested as vaporized by the fire. A significant 5elease in terms of health effects was the estimated $10 \mathrm{Ci}$ of

- Modification of university research and development source term. The isotope distribution and decay status of the waste are significant variables for this facility category:

- Isotopic distribution of 3 the waste is facility-dependent. There can be large amounts of ${ }_{H}$ associated with the waste fasility. Lower facility license limits--10 $\mathrm{Ci}$ or less--for ${ }^{14} \mathrm{C},{ }^{32} \mathrm{P}$, and I31 I (prominent isotopes in the waste) mean they will be in the waste in fairly small quantities. These can be assumed in shipping/receiving, in use in laboratories, or associated with wastes. Holdings are generally below the license limit so this value can be modified to a lower level. These considerations must be assessed and an estimated activity associated with the waste identified.

- Decay status of the nuclides could lower the inventory.

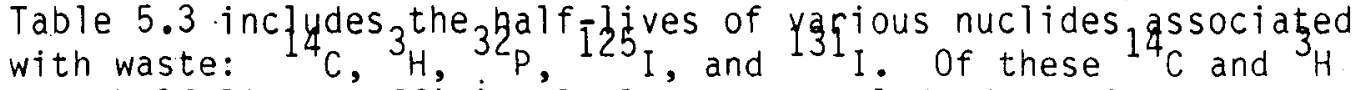
have half-lives sufficiently long to preclude decay in storage. Levels of the others could be reduced after some time in storage. This can be calculated using techniques described in Section 5.1.1.4.

\subsubsection{Loading Dock Fire}

A fire in the loading dock area was the MREPP event for uranium fuel fabrication (oxide) and UF 6 production. The initiating event was a truck accident: a truck delivering supplies or equipment impacts the loading dock. The fuel tank is ruptured in the event, spilling gasoline that is ignited by sparks created by contact of metal and concrete. Uranium hexafluoride was released from cylinders damaged in the initial impact. 


\subsubsection{Uranium Fuel Fabrication (0xide)}

To calculate this $U_{6}$ release requires three steps: (1) the duration and size of the fire is estimated, which is dependent on the rate of burn and depth of the gasoline pool; (2) the heat flux to the cylinder surface is calculated; and (3) the $U_{6} 6$ release is estimated. These are as follows:

- Fire duration and size. Gasoline, being a compound of light and heavy fractions, will burn more rapidly at first when the lighter fractions are burning. Two overall burning rates were cited in Section 4.1.1. The burning rate can vary from 6 to $12 \mathrm{in}$. of depth per hour (McKinnon, 1976). This constant burning rate is proportional to the ratio of the net heat of combustion and the sensible (total) heat of vaporization.

Based on burning rates in petroleum tank fires, an estimate can be made of the extent of area which will be involved in a fire resulting from a gasoline spill. When a spill is burning, the fire area will first be small and then spread to a point of equilibrium where it will burn as fast as it is released. At a burning rate of $0.2 \mathrm{in.} / \mathrm{min}$, a gallon per minute of spillage will reach an equilibrium burning area of about $8 \mathrm{ft}_{2}$. Thus a 10-gal/min spil1 rate will be in equilibrium with $80 \mathrm{ft}^{2}$ of burning area; 100-gal/min, $800 \mathrm{ft}^{2}$ (Mckinnon, 1976).

The example fire we used resulted from an approximate 2.5-min spill covering an area about $20 \mathrm{ft}$ in diameter. The slower the spill time, the smaller the equilibrium area, since it is burned as fast as it is released.

- Heat flux. Uranium hexafluoride is volatile on heating, and the radiative heat generated by the fire provides the energy (Btu) to sublime the $\mathrm{UF}_{6}{ }^{*}$. The radiative heat transfer for our postulated fire is $32.4 \mathrm{Btu} / \mathrm{h}-\mathrm{ft}^{2}$ (Clarke et al., 1974), and this value is used to calculate the heat transferred to the surface of the $U_{F}$ cylinders. This heat flux is a function of distance from the fire and can be estimated from fires of varying magnitude using the information shown in Figure 5.4. For the 10-ft radius fire, we used the suggested fractional heat flux of 0.25 . The calculation of heat transfer is:

$$
h_{\text {rad }}=32.4 \mathrm{Btu} / \mathrm{h} / \mathrm{ft}^{2} \times{ }^{\circ} \mathrm{F}
$$

where:

$$
h_{\text {rad }}=\text { radiative heat transfer }
$$

Our example:

$$
\begin{aligned}
& h_{\text {rad }}=32.4 \mathrm{btu} / \mathrm{h} / \mathrm{ft}^{2} \times 0.25 \times 1780^{\circ} \mathrm{F} \\
& h_{\text {rad }}=1.422 \times 10^{4} \mathrm{Btu} / \mathrm{h} / \mathrm{ft}^{2}
\end{aligned}
$$



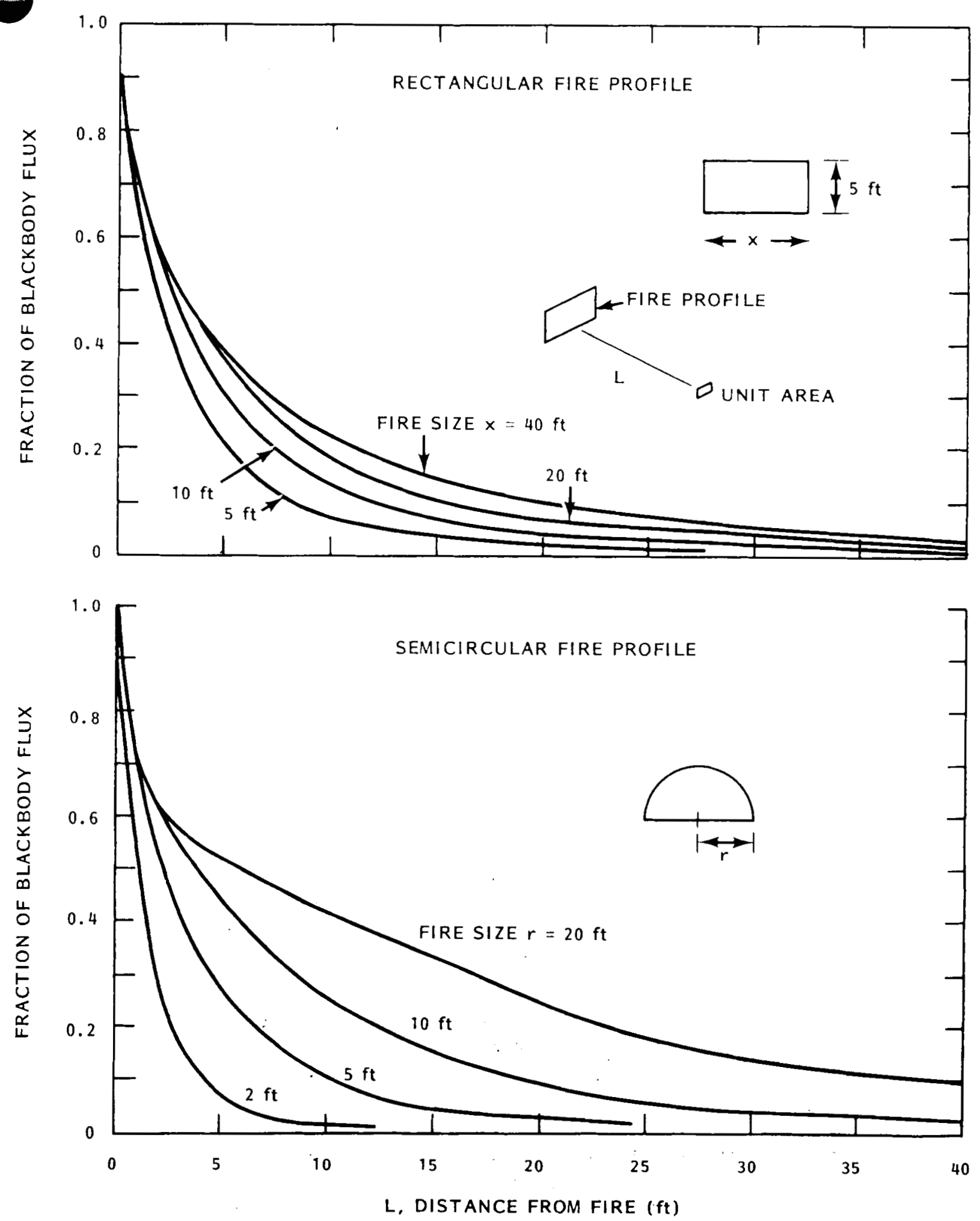

FIGURE 5.4. Flux Incident on Unit Area from Various Fires 
In the unlikely configuration of a fire centered around the cylinders the radiative heat transfer coefficient is 1 and $h_{\text {rad }}$ becomes $5.77 \mathrm{x}$ $10^{4} \mathrm{Btu} / \mathrm{h} / \mathrm{ft}^{2}$.

- Heat absorbed by container. The heat flux is to the cylinder surface directed to the fire. The total cylinder surface area is $53.4 \mathrm{ft}^{2}$ ( $2.5 \mathrm{ft}$ diam $\times 6.8 \mathrm{ft}$ long); therefore, the curved.half exposed to the radiation heat flux is $26.7 \mathrm{ft}^{2}$.

Using the heat flux calculated using Eq. 5-3 the heat absorbed by the container can now be calculated:

$$
\frac{B t u}{\min }=\frac{h^{r a d} \times f t^{2}}{60}
$$

Our example:

$$
\text { Btu/min }=\frac{1.442 \times 10^{4} \mathrm{Btu} / \mathrm{h} / \mathrm{ft}^{2} \times 26.7}{60}=6.42 \times 10^{3}
$$

- Uranium hexafluoride release. Now that the heat absorbed by the cylinder has been established, the UF 6 release can be calculated using the UF 6 heat of sublimation of 58.2 Btu/lb (Oak Ridge Operations office, 1972)

$$
1 \mathrm{~b} / \mathrm{min}=\frac{\text { Btu/min }}{\text { heat of sublimation }}
$$

Our example:

$$
1 \mathrm{~b} / \mathrm{min}=\frac{6.42 \times 10^{3} \mathrm{Btu} / \mathrm{min}}{58.2 \mathrm{Btu} / 1 \mathrm{~b}}
$$

Disregarding the heat required to heat the cylinder and UF 6 to the sublimation temperature, this $U_{6}$ release calculates to a release of 275 and $13751 \mathrm{~b}$ from a single cylinder for a 2.5 or $12.5 \mathrm{~min}$ fire respectively. Total release from our example involving two cylinders is 550 and $2750 \mathrm{lb}(250$ and $1249 \mathrm{~kg})$.

- Modification of uranium fuel fabrication (oxide) MREPP source term. This source term can be easily modified by changing the number or fill of cylinders damaged in the initial impact or by changing the size of the gasoline pool fire:

- Cylinders. This scenario estimated the maximum release from one cylinder, then multiplied by the number involved. This can be extended to any number of cylinders considered appropriate for a specific situation. The amount of surface exposed to radiative 
heat transfer can also be modified as desired using distance from the fire, portion of cylinder exposed to fire stresses, etc. Release increases if a cylinder is in the middle of a pool fire.

- Pool fire. The size, completeness of burning, and duration of the fire determine the British thermal units available to fuel the release. A partially filled fuel tank when ruptured will not provide $100 \mathrm{gal}$ of gasoline. The diameter of a spill of lesser magnitude can be estimated and the heat flux determined.

\subsubsection{Uranium Hexafluoride Production}

This accident scenario is essentially the same as uranium fuel fabrication (oxide); therefore, this release is calculated using the methods described in section 5.1.2.1. The cylinders used in UF 6 production weigh 10 and 14 tons, so more surface is exposed to radiative heat and a larger release per cylinder is calculated. Components discussed include heat absorbed by the container, UF 6 release, and source term modification:

- Heat absorbed by container. The curved surfaçe area of the 14-ton cylinder (4 ft diam $\times 12.5 \mathrm{ft}$ long) is $157 \mathrm{ft}^{2}$, so the exposed half is $78.5 \mathrm{ft}^{2}$. Using $h_{\text {rad }}$ calculated in Eq. 5-3 and 5-4, the Btu/min heat flux to the cylinder is estimated for our example:

$$
\mathrm{Btu} / \mathrm{min}=\frac{1.442 \times 10^{4} \mathrm{Btu} / \mathrm{h} / \mathrm{ft}^{2} \times 78.5}{60}=1.9 \times 10^{4}
$$

If the pool fire is centered around the cylinder rather than the truck, the surface area would more than double. The entire curved surface of the cylinder plus the 2 ends calculate to a total of $182 \mathrm{ft}^{2}$.

- Uranium hexafluoride release. This is calculated using Eq. 5-5 for our example.

$$
1 \mathrm{~b} / \mathrm{min}=\frac{1.9 \times 10^{4} \mathrm{Btu} / \mathrm{min}}{58.2 \mathrm{Btu} / \mathrm{lb}}=326
$$

The total release of UF for 2.5 or $12.5 \mathrm{~min}$ is 815 or $4.1 \times 10^{3} \mathrm{lb}$ respectively $\left(370\right.$ to $\left.1.9 \times 10^{3} \mathrm{~kg}\right)$ from a single cylinder. This is a total release of 740 to $3.8 \times 10^{3} \mathrm{~kg}$ from the two cylinders involved. If it appears possible that the fire could engulf a cylinder, i.e., cylinder in the center of its fire, the $U F_{6}$ release rate is $1365 \mathrm{~kg} / \mathrm{min}$. Total release can be $1.710^{4} \mathrm{~kg}$ of $U F_{6}$ in the longest suggested fire.

- Modification of UF 6 production MREPP source term. The modification factors used in Section 5.1.2.1 would apply here as well and will not be repeated. The source term development illustrated modification of a source term by using a larger container surface area exposed to the 
radiation flux with the analysis used for the uranium fuel fabrication (oxide) fire and also showed the effect of centering the cylinder in the fire. This is essentially the same accident and can be modified using similar methods.

\subsection{TORNADO}

Two of the operations reviewed have tornadoes as the estimated MREPP event: uranium milling and plutonium contaminated. Severe tornado damage can destroy the integrity of a building, damaging the roof and walls. Loose powders in the facility are thus susceptible to direct airborne release, and contaminants on exposed surfaces are subject to resuspension forces. A second release potential could be the result of smashed containers releasing liquids and powders. In an actual event, some of the release would be buried under tornado generated rubble, thus limiting the airborne fraction. However, for our use in making conservative MREPP estimates, this was not assumed.

Some elements that should be considered for tornado release scenarios are tornado frequency, intensity, and damage inflicted on a facility and contained equipment. Once the damage is assessed, the source terms can be estimated. Factors required for this estimate are: quantity and size distribution of the airborne material, and behavior of the airborne material in the time span required for the release (i.e., characteristics and behavior of the source term). The following discussion covers tornado elements and aerosol factors and relates them to types of damage in a facility:

- Frequency. Before considering a tornado as a MREPP event for a specific facility, the likelihood of impact on that facility should be evaluated. While tornadoes have a widespread occurrence, they are more likely to occur in certain parts of the country. About 700 tornadoes a year occur in the United States. The simplified map (Davies-Jones and Kessler, 1974) shown in Figure 5.5 shows the distribution of U.S. tornadoes during a 12-year period (1955-1967).

It can be seen that the central portions of the country have the highest tornado incidence. This is also the area of greatest tornado losses (damage).

- Intensity. Fujita (1978) has prepared a workbook on tornadoes in which he assessed the intensity of tornadoes and used an F scale to relate that intensity to wind speed. Table 5.4 shows the $F$ scale and the corresponding weighted mean maximum wind-speed values that are his suggested representative intensities. (Weighted wind speeds are calculated including a specific weighting function based on the number of tornadoes in an F-scale range.) This speed includes translational and rotational winds plus vortices. A facility would see this wind speed for a maximum of 1 to $3 \mathrm{sec}$. Once the tornado funnel has passed, wind speeds will be lower and contain the translational component only. We have maximized damage and winds by assuming the facility sees the leading edge of the tornado. The third column shows the frequency with which they occur. 


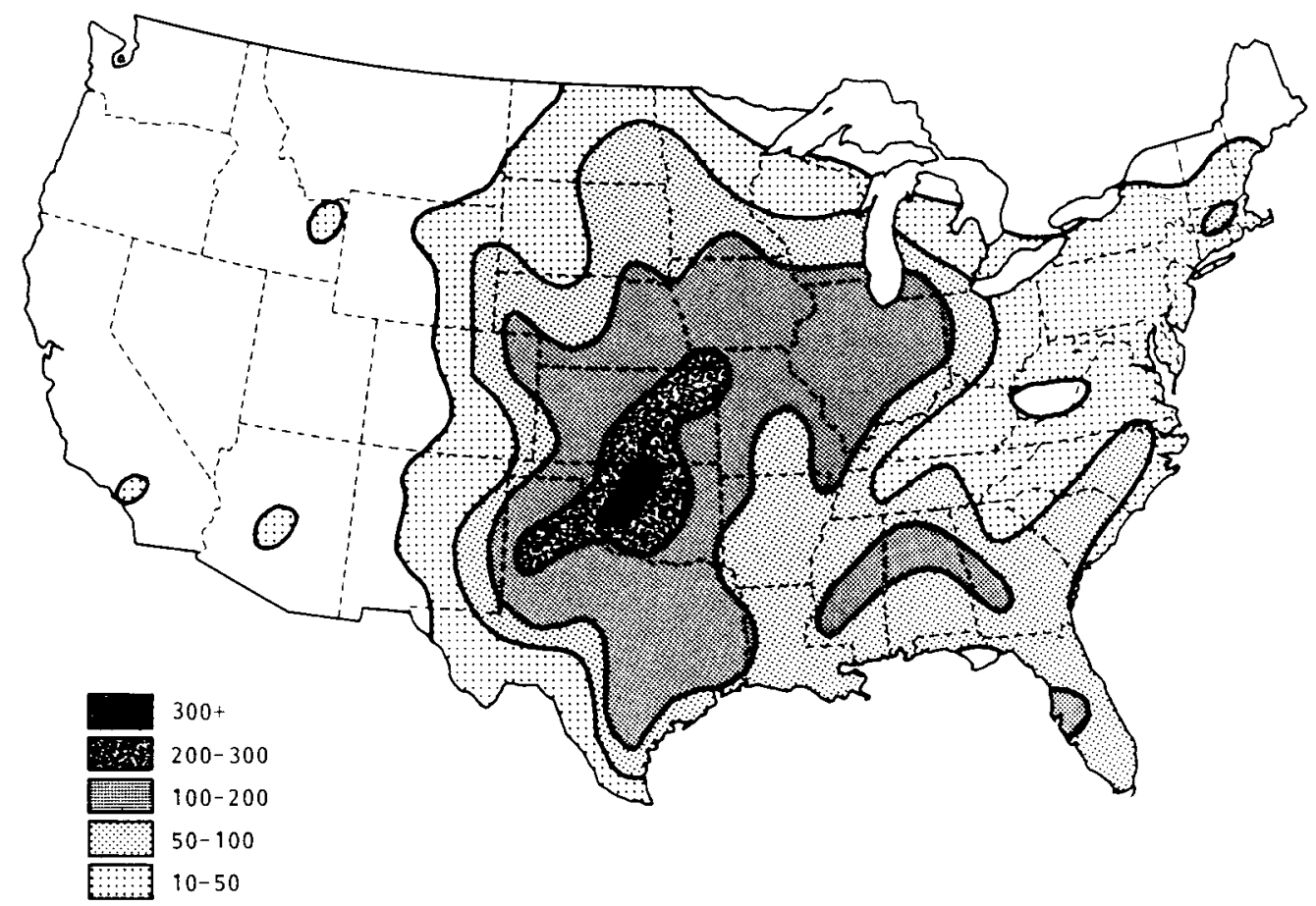

FIGURE 5.5. Distribution of Tornadoes in the United States, Total Tornadoes 1955-1967

TABLE 5.4. F Scale and Corresponding Weighted Average Maximum Mean Wind Speeds and Frequency

\begin{tabular}{|c|c|c|}
\hline F scale & $\begin{array}{l}\text { Mean Wind Speed } \\
\text { (Fujita, 1978) }{ }^{\text {pph }}\end{array}$ & $\begin{array}{c}\text { Frequency, } \% \\
\text { (Fujita, 1976) } \\
\end{array}$ \\
\hline 0 & 59 & 24 \\
\hline 1 & 92 & 42 \\
\hline 2 & 133 & 24 \\
\hline 3 & 176 & 8 \\
\hline 4 & 227 & 2 \\
\hline 5 & 278 & RARE \\
\hline
\end{tabular}

(a) Total mean wind speed, translational + rotational + vortices and is the average weighted mean recommended wind speed. Earlier work gives ranges of wind speeds for $F$ scale. 
It can be seen that $90 \%$ of the tornadoes are at the 133 mph mean wind speed or F2 and below. We will use the F2 tornado to estimate damage. About one-fourth of the tornadoes are F0. Tornadoes also have dimensions of length and width with corresponding frequencies. These have not been included because even the smallest, $0.9 \mathrm{mi}$ long by $51 \mathrm{ft}$ wide, would be of a size sufficient to cause damage if it strikes a facility in a favorable direction.

- Damage. Nuclear plant facilities are the only class of commercial facilities routinely designed to withstand tornado effects (Stevenson, 1976). Other structures will sustain damage that can be related to the Fujita $F$ scale.

One inethod of estimating damage relates the damage for specific structures in terms of percent damage and $F$ scale, where percent damage $=$ repair costs/replacement cost (Hart, 1976). This has been related to the probability of damage for specific structures in a $F 2$ tornado ( $90 \%$ probability) as shown in Table 5.5 .

TABLE 5.5. F2 Scale Tornado Damage for Several Structure Types (Hart, 1976)

\begin{tabular}{|c|c|c|c|c|c|}
\hline \multirow[b]{2}{*}{$\begin{array}{l}\text { Damage } \\
\text { State }\end{array}$} & \multirow[b]{2}{*}{$\begin{array}{l}\text { Percent } \\
\text { Damage }\end{array}$} & \multicolumn{4}{|c|}{ Damage Probability } \\
\hline & & $\begin{array}{l}\text { 1-3 Story (a) } \\
\text { Wood Frame } \\
\text { (commercial) } \\
\end{array}$ & $\begin{array}{l}\text { 1-3 Story } \\
\text { Concrete } \\
\text { or Masonry } \\
\text { (commercial) } \\
\end{array}$ & $\begin{array}{c}\text { 1-3 Story } \\
\text { Metal } \\
\text { (industrial) } \\
\end{array}$ & $\begin{array}{c}4 \text { or } \\
\text { More } \\
\text { Stories } \\
\end{array}$ \\
\hline None & $0-0.05$ & 0.132 & 0.191 & 0.174 & 0.239 \\
\hline Light & $0.05-1.25$ & 0.082 & 0.156 & 0.119 & 0.224 \\
\hline Moderate & $1.25-7.5$ & 0.181 & 0.164 & 0.146 & 0.344 \\
\hline Heavy & $7.5-65$ & 0.379 & 0.275 & 0.411 & 0.180 \\
\hline Very Severe & $65-100$ & 0.104 & 0.104 & 0.114 & 0.012 \\
\hline Collapse & 100 & 0.121 & 0.109 & 0.036 & 0 \\
\hline
\end{tabular}

(a) Further information on structures not given.

It can be seen that there can be several damage level probabilities for all the structure types. Usually heavy damage can occur.

Abbey (1976) suggested some damage for the F2 classification to be tearing the roof from frame houses leaving strong upright walls standing; weak structures or outbuildings demolished; light-object missiles generated; block structures and walls badly damaged. 
Based on our reviews, damage associated with the MREPP scenario includes:

- Wall damage, roof blown off

- Missiles generated (could subsequently cause further damage)

- Massive equipinent (caves, etc.) not damaged

- Hoods and glove boxes damaged.

- Fractional airborne releases of particulate materials. In facilities where radioactive powders are used within containmnts such as hoods or glove boxes, that containment must be damaged before a release can occur. As discussed earlier, loose powders in process could be subject to direct releases.

Mishima and Ayer (1980) assessed high wind damage and related this to fractional releases of particulate materials. Their study is used as a basis for this section. The factors they suggested to estimate airborne releases resulting from postulated damage scenarios are listed in Table 5.6. Considerations influencing the applicability of these factors are discussed in the following section and Mishima and Ayer (1980) is used as a reference.

- Crushing of Glove Box. Crushing is defined as a complete loss of containment such as rupture of the steel shell or loss of one or more of the large glove box viewing windows. The event is assumed to generate sufficient excess force to inject uncontained powders into the air and break glass or thin-wall, rigid plastic containers.

- Glove box containing powder. Vibrating powder resting on a surface does not appear to provide as much dispersion of the powder as tumbling. The mass airborne concentration is indicated by experimental data measuring the value within seconds after tumbling of a powder with a density and size distribution similar to $\mathrm{PuO}_{2}$ (Mishima et al., 1978).

- Glove box containing liquids. Subdivision of liquids during breakage of glass and plastic containers appears to be less effective than forcing a liquid through a small opening such as a larger spray nozzle designed to perform that function. The airborne concentration chosen represents larger sprayy openings $(0.125-i n$. diam) at higher pressures (200 $\mathrm{lb} / \mathrm{in}^{2}$ ) and small openings (0.063-in. diam) at lower pressures $\left(50 \mathrm{lb} / \mathrm{in} .^{2}\right)$ (Mishima et al., 1978).

- Glove box containing surface contamination only. Surface contamination can range from particles settled on the surface to material mixed into the surface. The resuspension factor applied is a value measured for a combination of mechanical and aerodynamic stresses (Mishima et al., 1979b). 
TABLE 5.6. Fractional Airborne Release Factors

Event

Crushing of Glove Box

Containing powder

Containing liquid

Containing surface contamination only

Perforation of Glove Box

Containing powder

Containing liquids

With surface contamination only

Damage to Filters

Crushing

Perforation

Aerodynamic Entrainment

Powder, less than $5 \mathrm{mph}$

Powder, greater than $5 \mathrm{mph}$

Liquids, less than $5 \mathrm{mph}$

Liquids, greater than $5 \mathrm{mph}$
Factor

Volume of glove box $\times 300 \mathrm{mg}$

Volume of gloye box $\times 500 \mathrm{mg}$

$10^{-2} / \mathrm{m}$
Fraction of volume of glove box $x$ $100 \mathrm{mg}$ powder $/ \mathrm{m}^{3}$

Fraction of volume of glove box $x$
$167 \mathrm{mg} \mathrm{liquid/m}$ (b) $10^{-\frac{16}{4} / \mathrm{m}}$

$10^{-1}$ of accumulated material airborne $10^{-2}$ of accumulated material airborne

$10^{-10} / \mathrm{sec}$ of exposed material

$10^{-8}$ / $\mathrm{sec}$ of exposed material

$10^{-11} / \mathrm{sec}$ of exposed material

$10^{-9} / \mathrm{sec}$ of exposed material

(a) Drops $<1003 \mu \mathrm{m}$ in AED. Airborne mass concentration of drops $\leq 10 \mu \mathrm{m}$ is $10 \mathrm{mg} / \mathrm{m}^{3}$.

(b) Drops $>100 \mu \mathrm{m}$ in AED. Airborne mass concentration of drops $\leq 10 \mu \mathrm{m}$ AED is $3.3 \mathrm{mg} / \mathrm{m}^{3}$.

- Perforation of glove box. Perforation is defined as a partial loss of containment (loss of one or more glove ports, loss of a portion of a viewing window, etc.) that allows air to circulate through the glove box. The rate of release from the break will depend on the size of the opening, whether the exhaust system continues to function, and the velocity of air entering the opening. The particulate materials airborne within the volume are released from the glove box with time. If the exhaust flow is zero, the release is exponential with time. Release of greater than $99 \%$ of the airborne material within 30 min is considered instantaneous.

- Glove box containing powders. The force transmitted to the glove box during perforation is assumed to be considerably less than during crushing. Since a finite period of time 
is required to release the airborne particulate material, a mass concentration measured approximately 1 min after tumbling a fine powder and considered quasi-stable, was selected. Furthermore, the disturbance due to perforation can be more localized than in crushing, and it was judged that the powder only occupied a fraction of the volume of the glove box (Mishima et al., 1979a).

- Glove box containing liquids. For the reasons stated above, a reduced mass airborne concentration and volume was selected for the dispersal of liquids held in glass and thin-wall, rigid plastic containers (Mishima et al., 1978).

- Glove box containing surface contamination only. A reduced resuspension factor of $10^{-4} / \mathrm{m}$ was selected to reflect the reduced force and area involved in perforation (Mishima et a)., 1980).

- Damage to exhaust filters. Exhaust filters can also suffer damage, dispersing some airborne material:

- Crushing of filters. Although the filter material (glass fiber mats) is fragile, the fine particulate material accumulated can be embedded in the filter and associated with other materials such as dust, condensed organic vapors, etc. The material may not be readily dispersed in a respirable, transportable size-range. A conservative airborne fractional value of $10 \%$ of the accumulated material released is assumed in the absence of experimental data (Mishima et al., 1979a).

- Perforation of HEPA filters. A reduced fractional airborne release factor of $1 \%$ is applied to reflect the reduced level of stress required for this level of damage (Mishima et al., 1979a).

- Aerodynamic entrainment. Powders and liquids can be entrained in the air passing over their surfaces. Particle suspension results from initiation of movement in larger particles that subsequently transfer momentum to particles in the size range that allows suspension. Under similar conditions of airflow over a liquid film, droplets are much less likely than particles to be airborne because of the higher energy required to break up the film and form droplets. Some suggested entrainment rates are:

- Powder by air velocities greater than $5 \mathrm{mph}(2.2 \mathrm{~m} / \mathrm{sec})$. A conservative suspension rate $\left(10^{-8} / \mathrm{sec}\right.$, measured for a homogeneous bed and with wind velocity variations over a year's duration is applied (Mishima et al., 1978). 
- Powder by air velocities less than $5 \mathrm{mph}(2.2 \mathrm{~m} / \mathrm{sec})$. A suspension rate $\left(10^{-10} / \mathrm{sec}\right)$ measured from a homogeneous bed at these velocities is applied (Sehmel and Lloyd, 1974a).

- Liquids by air velocities greater than $5 \mathrm{mph}(2.2 \mathrm{~m} / \mathrm{sec})$. A conservative measured suspension rate of $10^{-9} / \mathrm{sec}$ is applied. It is consistent with the assumed larger energy input required to disperse liquids (Mishima et al., 1978).

- Liquids by air velocities less than $5 \mathrm{mph}(2.2 \mathrm{~m} / \mathrm{sec})$. The suspension rate applied for higher air velocities was reduced by a factor consjistent with the reductions found for powder yielding $10^{-11} / \mathrm{sec}$.

- Release calculation. Calculation of the release is essentially the material at risk multiplied by the appropriate release factor selected from Table 5.6 .

\subsubsection{Uranium Milling}

In Section 4.4 .2 of this report, a tornado scenario was identified as the MREPP event for uranium mills based on the uraniun mills generic impact statement (USNRC, 1979b). The discussion here will illustrate in greater detail how this release was estimated:

- Material release. It was assumed that two days' yellowcake production was susceptible to wind pickup on breaching the facility. Ore is processed at rates between 1000 and $2000 \mathrm{MT} /$ day; $1800 \mathrm{MT} /$ day was selected as an average value. The ore is $0.16 \% \mathrm{U}_{3} 0_{8}$, and the process is $95 \%$ efficient at producing yellowcake. Therefore, 2.736 MT of yellowcake are produced per day; two days production is roughly 5.47 MT. The remainder of the total 45-MT inventory, 39.5 MT, is in containers. Fifteen percent of these containers rupture (USNRC, 1979b), releasing 5.93 MT of yellowcake subsequently picked up by the wind and becoming airborne. It was assumed that all of the material at risk became airborne in the tornado vortex. The total release is 5.47 MT +5.93 MT $=11.4$ MT $(11,400 \mathrm{~kg})$.

Convective vortices can contain significant amounts of particulate material. Sinclair (1974) estimated loading of $5 \mathrm{~g} / \mathrm{m}^{3}$ for a dust devil; First and Drinker (1952) estimated $10 \mathrm{~g} / \mathrm{m}$ for a duststorm. If the yellowcake airborne concentration is $10 \mathrm{~g} / \mathrm{m}^{3}$, the requiged tornado volume to support the concentration would be $1.14 \times 10^{6} \mathrm{~m}^{3}$. A tornado can have a vortex up to thousands of meters in diameter (Fujita, 1976), so it is not unreasonable to assume that all the yellowcake can be drawn up and dispersed.

We assumed that $25 \%$ of the yellowcake was less than $10 \mu \mathrm{m}$ in diameter based on an aerodynamic sizing reported by Geffen (1981) and, therefore, could be an inhalation hazard. Using the fraction $10 \mu \mathrm{m}$ and 
less in the calculation reduces the release of concern to $2850 \mathrm{~kg}$. Because all of the material was included in the original calculation, no further resuspension release is calculated.

- Modification of uranium mills source term. Two significant controlling parameters are the 1) magnitude of the tornado and 2) amount and characteristics of the material at risk:

- Tornado magnitude in our illustration was of Fujita F2 scale. Ninety percent of United States tornadoes are at this level or below. Each $F$ scale classification has certain damage characteristics. Building damage in turn is the precursor of airborne releases. As discussed in Section 5.2, certain areas of the country are more prone to tornado damage. Most uranium mills are in regions where there are few tornadoes reducing the likelihood of occurrence. In some sections, a tornado in the lower $F$ scale range could be the maximum tornado scenario, ergo, less damage, lower release potential. Table 5.7 (Abbey, 1976) relates $F$ scale to tornado intensity so appropriate damage can be assumed for the relevant portion of the country. Generalized damage descriptions of destruction to be expected in each category are provided. Efforts are continuing to examine the correlation between observed damage and wind speeds necessary to produce that damage.

In the $F 2$ tornado, the roof was assumed torn off the facility, suspending all of the uncontained powder. However, the building is damaged by the maximum intensity and only the latter half of the tornado passage is available to suspend material, thus

TABLE 5.7. Fujita Scale of Tornado Wind Intensity and Related Characteristic Damage

Fujita

Scale

$F-$

F $0 \quad$ Very weak tornado 40-72 mph

F I Weak tornado 73-112 mph
Characteristics of Damage

Little damage is expected.

Some damage to chimneys or TV antennas; breaks branches off trees; pushes over shallow-rooted trees; old trees with hollow inside break or fall; sign boards damaged.

$73 \mathrm{mph}$ is the beginning of hurricane wind speed. Peels surface off roofs; windows broken; trailer houses pushed or overturned; trees on soft ground uprooted; some trees snapped; moving autos pushed off the road. 
TABLE 5.7. (contd)

Fujita

Scale

F 2

Strong tornado
$113-157 \mathrm{mph}$

F 3 Severe tornado 158-206 mph

F 4 Devastating tornado 207-260 mph

F 5 Incredible tornado

261-318 mph
Characteristics of Damage

Roof torn off frame houses leaving strong upright walls standing; weak structure or outbuildings demolished; trailer houses demolished; railroad boxcars pushed over, large trees snapped or uprooted; light-object missiles generated; cars blown off highway; block structures and walls badly damaged.

Roof and some walls torn off well-constructed frame houses; some rural buildings completely demolished or flattened; trains overturned; steel framed hangar-warehouse type structures torn; cars lifted off the ground and may roll some distance; most trees in a forest uprooted, snapped, or leveled; block structures often leveled.

Well-constructed frame houses leveled, leaving piles of debris; structures with foundations lifted, torn, and blown off some distance; trees debarked by small flying debris; sandy soil eroded and gravels fly in high winds; cars thrown some distances or rolled considerable distances finaliy to disintegrate; large missiles generated.

Strong frame houses lifted clear off foundation foundation and carried considerable distance to disintegrate; steel-reinforced concrete structures badly damaged; automobile-sized missiles fly through the distance of 100 yd or more; trees debarked completely; incredible phenomena can occur.

F 6-12 Inconceivable [sic] Should a tornado with the maximum wind speed tornado $319 \mathrm{mph}$ to sonic in excess of $F 6$ occur, the damage may include a number of missiles such as water heaters, storage tanks, automobiles, etc, flying through a long distance, creating serious secondary damage on structures. Assessment of tornadoes in these categories is feasible only through detailed survey involving engineering and aerodynamical calculations as well as meteorological models of tornadoes. 
reducing the release. In a weak tornado, the facility would have some damage such as broken windows leading to wind resuspension of loose powders. The higher entrainment rates in Table 5.6 could be applied to estimate these releases.

- Materials at risk in our example were assumed to be two days' yellowcake production and $15 \%$ of the contained inventory at risk (based on the maximum allowable inventory). Ore throughput can vary from 1000 to 2000 MT per day, hence 1.52 to 3.04 MT yel1owcake is produced per day based on $0.16 \% \mathrm{U}_{3} \mathrm{O}_{8}$ in the ore.

Therefore, loose powder releases can range from 3.04 to $6.08 \mathrm{MT}$.

Contained powder releases were conservatively based on a maximum 45 MT inventory: smaller mills could naturally be assumed to have a lower maximum inventory.

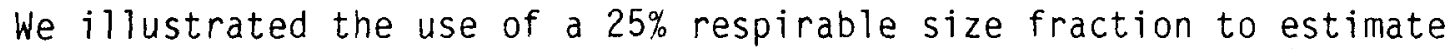
the hazard of the release. This fraction will vary, Geffen (1981) reported two yellowcake samples sized aerodynamically to have 18 and $32 \mathrm{wt} \%$ less than $10 \mu \mathrm{m}$. Use of either of these values in place of the $25 \%$ estimate changes the magnitude of the release.

\subsubsection{Plutonium Contaminated Facility}

Tornado damage in these facilities included crushing of glove boxes by failure of building interior partitions. This results in exposing contaminated surfaces to aerodynamic stresses thereby entraining some of this material. The material release scenario and source term modification follow:

- Material release. In a plutonium contaminated facility, surfaces can be contaminated with residual fixed plutonium. Therefore, the inventory is not in a readily dispersible form.

In estimating the releases, it is assumed that the $10^{-2} / \mathrm{m}$ resuspension factor $(\mathrm{a})$ applicable and that the volume of the glove box $1.8 \mathrm{~m}^{3}$ is the affected volume.

The concentration per $\mathrm{m}^{3}$ is calculated by the following formulation:

Resuspension factor $\times$ contamination level $=$ airborne concentration $/ \mathrm{m}^{3}$

$$
10^{-2} \mathrm{~g} / \mathrm{m} \times 10^{-4} \mathrm{~g} / \mathrm{m}^{2}=1 \times 10^{-6} \mathrm{~g} / \mathrm{m}^{3}
$$

(a) resuspension facator $\mathrm{k} / \mathrm{m}=\frac{\text { airborne concentration (units } / \mathrm{m}^{3} \text { ) }}{\text { surface contamination (units } / \mathrm{m}^{2} \text { ) }}$ 
Affected volume $=1.8 \mathrm{~m}^{3}$

Total release $/ \mathrm{glove}$ box $=1 \times 10^{-6} \mathrm{~g} / \mathrm{m}^{3} \times 1.8 \mathrm{~m}^{3}$

$$
=1.8 \times 10^{-6} \mathrm{~g} \mathrm{Pu} \text {. }
$$

The total release from 80 glove boxes would be $1.4 \times 10^{-4} \mathrm{~g}$ of plutonium. The glove boxes could be assumed buried under debris and only a portion would be subject to continued wind stresses. However our calculations conservatively assume all surfaces are exposed to resuspension. An appropriate resuspension rate to use was selected from Table 5.6 as $10^{-1} / \mathrm{sec}$ for fixed contamination, since most readily removed material was released instantly. Glove box interior surface areas can range from about $9.4 \mathrm{~m}^{2}$ to $15.2 \mathrm{~m}^{2}$, so the maximum resuspension release per glove box is

$$
15.2 \mathrm{~m}^{2} \times 10^{-4} \mathrm{~g} \mathrm{Pu} / \mathrm{m}^{2} \times 10^{-10} / \mathrm{sec}=1.52 \times 10^{-13} \mathrm{~g} \mathrm{Pu} / \mathrm{sec}
$$

If the winds continued for 24 hours, the maximum resuspension release per box is $1.3 \times 10^{-8} \mathrm{~g}$ of plutonium or $1 \times 10^{-6} \mathrm{~g}$ of plutonium if all 80 boxes are breached and all surfaces exposed to resuspension.

- Modification of plutonium contaminated facility source term. As with the uranium mills, the source term can be modified by using 1) the magnitude of the tornado, and 2) the amount of inventory:

- Tornado magnitude. As discussed earlier in this section, the magnitude of the tornado can be estimated leading to evaluation of the damage, here the number of breached glove boxes. Events with a lower characteristic damage would perforate the glove box making the $10^{-4} / \mathrm{m}$ resuspension factor appropriate for use. Correspondingly, few boxes would be damaged.

- Materials at risk. Surface contamination meagurements at a facility indicated a maximum level of $5 \times 10^{-9} \mathrm{~g}$ of plutonium $/ \mathrm{cm}^{2}\left(5 \times 10^{-5} \mathrm{~g}\right.$ of plutonium $\left./ \mathrm{m}^{2}\right)$. The conservative contamination estimate selected for use here is twice that level, $1 \times 10^{-4} \mathrm{~g}$ of plutonium $/ \mathrm{m}^{2}$. This was considered a conservative estimate and contamination levels could be considerably lower.

We estimated that level of contamination on all of the entire interior surface. However, contamination would probably be at lower levels on the walls and ceiling of the glove box.

The maximum tgtal inventory in a facility assuming 80 glove boxes, $15.2 \mathrm{~m}^{2}$ of surface each, and $1 \times 10^{-4} \mathrm{~g}$ of plutonium $/ \mathrm{m}^{2}$ is $0.12 \mathrm{~g}$. No release could therefore exceed this level. Plants containing fewer (e.g., 50 glove boxes) could have 0.047 to $0.076 \mathrm{~g}$ of plutonium depending on their size. 


\subsection{CRITICALITY}

A criticality producing fission product gases is the MREPP for two facilities, the uranium fuel fabrication (nonoxide) and research and development of nuclear fuels. This event releases a total of $1.2 \times 10^{5} \mathrm{Ci}$ as discussed in Section 4.1 and 4.2. The NRC staff has developed methods for analyzing these accidents and these guides (USNRC, 1977a; 1979b) are the standard reference that should be used when estimating criticality releases.

A criticality accident results from an uncontrolled release of energy from an assemblage of fissile material. Three major types of these excursions that have occurred are in solutions of fissile material, metal assemblies in air, and inhomogeneous 1 ight- or heavy-water-mgderated systems (Stratton, 1967). About one-third were water solutions of ${ }^{35} \mathrm{U}$ or ${ }^{239} \mathrm{Pu}$. Accident scenarios for both of these facilities, therefore, assumed water available for the criticality.

The circumstances of a criticality accident are difficult to predict. Criticality depends not only on the quantity of fissile material present, but on the size, shape, and materials of any containment vessel which may be used, on the nature of any solvent or diluents, and on the presence of any adjacent material which may posssibly return neutrons through scattering back into the fissile material (Clayton, 1974).

Excursion characteristics considered for accidents include: (1) maximum number of fissions in a 5-sec interval, (2) duration and total number of fissions from an excursion, and (3) maximum specific fission rate (Tuck, 1974).

Because criticalities were discussed in detail in Sections 4.1 and 4.2 , the discussion here is confined to the specific facilities where they are the MREPP event.

\subsubsection{Uranium Fuel Fabrication (Nonoxide)}

For the uranium fuel fabrication (nonoxide) category, criticality was selected from two potential MREPP scenarios (explosion and criticality) on the basis of the radiological consequences. Krypton, xenon, and iodine fission product gases are the important radionuclides involved.

Several points in the uranium nonoxide process could be the site of a criticality ezyent; especially susceptible are operations using solutions containing 235 . These would be found in metal pickling operations, scrap recovery, and liquid waste. In a uranium nonoxide fuel fabrication plant, the accident could be initiated by leakage of fissile material into an unsafe geometry, introduction of excess fissile material to a solution, overconcentration of a solution, failure to maintain sufficient neutron absorbing materials in a vessel, introduction of neutron moderators or reflectors (e.g., water to a highly undermoderated system), deformation or failure to maintain safe storage arrays, or similar actions that can lead to increases in the activity of fissile systems (USNRC, 1979a). The guides suggest both the radionuclide release level and source term modification as follows: 
- Radionuclide release. The NRC staff suggests calculation of the radioactivity of significant fission products produced in the excursion may be accomplished using the computer code RIBD (Radioisotope Buildup and Decay); or an equivalent calculation can be substituted if justified on an individual case basis.

RIBD analyzes the fission product content of irradiated reactor fue 1 in terms of potential biological hazards and heating effects accompanying decay (Gumprecht, 1968).

If the results of the evaluation using RIBD indicates no criticality exceeding $1 \mathrm{E}+19$ fissions in $8 \mathrm{~h}$ (the NRC standard criticality), it can be assumed adequate for the facility.

In this standard criticality, an excursion is assumed to occur in a vented vessel of unfavorable gegmetry containing a solution of $400 \mathrm{~g} / \mathrm{L}$ of uranium enriched in $235 \mathrm{U}$. The excursion produces an initial burst of $1 E+18$ fissions in $0.5 \mathrm{sec}$ followed successively at 10-min intervals by 47 bursts of $1.9-E+17$ fissions for a total of $1 \mathrm{E}+19$ fissions in $8 \mathrm{~h}$. The excursion is assumed to be terminated by evaporation of $100 \mathrm{~L}$ of the solutions.

It should be assumed that all of the noble gas fission products and $25 \%$ of the iodine radionuclides resulting from the excursion are released directly to a ventilated room atmosphere. It should also be assumed that an aerosol, which is generated from the evaporation of solution during the excursion, is released directly to the room atinosphere. The aerosol should also be assumed to comprise $0.05 \%$ of the salt content of the solution that is evaporated. The rooin volume and air ventilation rate and retention time should be considered on an individual case basis.

Total release are $1.2 \times 10^{5} \mathrm{C} i$ of fission product gases as listed in Table 4.1.

- Modification of the uranium fuel fabrication (nonoxide) source term. This source term can be modified by considering (1) deposition in the facility, (2) radioactive decay, and (3) filtration system effectiveness:

- Deposition can be assumed. The regulatory guide allows a retention allowance for iodine, stating that $25 \%$ of the iodine radionuclides resulting from the excursion are released directly to a ventilated room atmosphere. The room volume and air ventilation rate and retention are considered on an individual basis.

- Radioactive decay reduces the release. The guide states that the effects of radiological decay during transit through the plant can be evaluated on an individual case basis. 
- Filtration of the amount of radioactive material available for release by filtration systems can be taken into account. The amount of the reduction should be evaluated on an individual case basis.

\subsubsection{Research and Development of Nuclear Fuels}

For this facility category, the MREPP criticality accident was assumed to occur from an earthquake that damaged the sprinkler system. The criticality can be postulated to occur when fissile materials are present in a configuration that could be made critical by the addition of water. If a fire is involved, the configuration is likely to be changed by fire such that the addition of water could cause criticality (Carter et al., 1968). Dry chemicals, $\mathrm{CO}_{2}$, inert gases, freon, or high expansion foams are used to fight fissile material fires. An error, human or mechanical, would therefore be required to add water to initiate the criticality. This could be caused by improperly trained or untrained firefighters using water, or by breaching of the facility sprinkler system. An earthquake was assumed to damage the facility, glove boxes, and sprinkler system water entering the glove box train then leads to a criticality event. Radionuclide release and source term modification guides are:

- Radionuclide release. Releases are the same as discussed in Section 4.1 .

- Modification of the research and development of nuclear fuels MREPP source term. The modification of this source term can be accomplished using methods suggested in Section 5.3.1. 


\subsection{BIBLIOGRAPHY}

Abbey, R. F. Jr., "Risk Probabilities Associated with Tornado Windspeeds," in Proceedings of the Symposium on Tornadoes, Assessment of Knowledge and Implications for Man, Texas Tech University, Lubbock, Texas, 1976.

Abbott Laboratories, Radiological Contingency Plan, License No. 12-00621-03, North Chicago, Illinois, 1981.

Albrethsen, A. E. and L. C. Schwendiman, Volatilization of Fission Products From High-Level Wastes, BNWL-338, Pacific Northwest Laboratory, Richland, Washington, 1967 .

Alexander, B. M., R. S. Grimm, and J. W. Doty, Jr., "Incineration of LWR-Type Waste at Mound Facility," in Proceedings of the 16th DOE Nuclear Air Cleaning Conference, San Diego, California, 1981.

Alexander, C.W., C.W. Kee, A. G. Groff, and J. 0. Blomeke, Projections of Spent Fuel to be Discharged by the U.S. Nuclear Power Industry, ONRL/TM-6008, Oak Ridge National Laboratory, Oak Ridge, Tennessee, 1977.

Allied Chemical Corp., Supplemental Report, Docket No. 40-3392, U.S. Nuclear Regulatory Commission, Washington, D.C., 1975.

Allied Chemical Corp., Supplemental Report in Support of Application for Renewal of Source Material License SNM-526, Docket No. 40-3392, U.S. Nuclear Regulatory Commission, Washington, D.C., 1980.

Allied Chemical Corp., Onsite Radiological Contingency Plan, Docket No. 40-3392, U.S. Nuclear Regulatory Commission, Washington, D.C., 1981.

Altman, W., J. Hockert, and E. Quinn, A Safeguards Case Study of the Nuclear Materials and Equipment Corporation Uranium Processing Plant, Apollo, Pennsylvania, NUREG-0627, U.S. Nuclear Regulatory Commission, Washington, D.C., 1980.

American Nuclear Society, American National Standard for Criticality Safety in Operations with Fissionable Materials Outside Reactors, American Nuclear Society, Hindsdale, Illinois, 1975.

Amersham Corporation, Letters from Amersham Corp. to U.S. Nuclear Regulatory Commission, Docket No. 30-4261, U.S. Nuclear Regulatory Commission, Washington, D.C., 1969-1980.

Atomic Disposal Co., Appendix A, Emergency Plan for Atomic Disposal Co.--Tinley Park, IL, Atomic Disposal Co., Tinley Park, Illinois, 1980.

Automation Industries, Inc., Letters from Automation Industries, to U.S. Nuclear Regulatory Commission, Docket No. 30-5998, U.S. Nuclear Regulatory Commission, Washington, D.C., 1966-1980. 
Babcock and Wilcox, Supplement and Revision to Renewal Application J-NFP-212, June 8, 1961 and DAN Ltr July 21, 1961, Revision 2, Docket No. 70-27, U.S. Nuclear Regulatory Cominission, Washington, D.C., 1964.

Babcock and Wilcox, Environmental Report, UF $6-\mathrm{UO}_{2}$ Pellet Plant Addition, Docket No. 70-1201, Babcock and Wilcox, Lynchburg, Virginia, 1972.

Babcock and Wilcox, Revision 2 of Renewal Application for SNM-42, Docket No. 70-27, U.S. Nuclear Regulatory Commission, Washington, D.C., 1974.

Babcock and Wilcox, Demonstration and Conditions for License SNM-778, Docket No. 70-824, U.S. Nuclear Regulatory Commission, Washington, D.C., 1978.

Babcock and Wilcox, Commercial Nuclear Fuel Plant, SNM-1168, Emergency Plan, Docket No. 70-1201, U.S. Nuclear Regulatory Commission, Washington, D.C., 1981a.

Babcock and Wilcox, Lynchburg Research Center, Radiological Contingency Plan, License SNM-778, Docket No. 70-824, U.S. Nuclear Regulatory Commission, Washington, D.C., 1981b.

Babcock and Wilcox, Apollo Site Radiological Contingency Plan, SNM-145, Docket No. 70-135, J.S. Nuclear Regulatory Commission, washington, D.C., 1981C.

Bagnall, K. W., Chemistry of the Rare Radioelements, Academic Press, New York, 1957.

Bagnall, K. W., The Chemistry of Selenium, Tellurium, and Polonium, Elsevier Publishing Company, New York, 1966.

Bate, L. C. and G. W. Leddicote, The Radiochemistry of Cobalt, Oak Ridge National Laboratory, Oak Ridge, Tennessee, 1961.

Battelle, Draft Generic (Light Water Reactor) Chemical Separation Facility Decommissioning Handbook, Vol. 2, Pacific Northwest Laboratory, Richland, Washington, 1975.

Battelle and Hanford Environmental Health Foundation, Occupational Exposures to Uranium: Processes, Hazards and Regulations, PNL-3341, Pacific Northwest Laboratory, Richland, Washington, 1981.

Brasie, W. C. and D. W. Simpson, "Guidelines for Estimating Damage Explosion," Loss Prevention, 2, 91-102, 1968.

Burchsted, D. A., J. E. Kahn, and A. B. Fuller. Nuclear Air Cleaning Handbook, ERDA 76-21, Oak Ridge National Laboratory, Oak Ridge, Tennessee, 1976.

Bureau of Radiological Health, Radiological Health Handbook, U.S. Department of Health, Education, and Welfare, Rockville, Maryland, 1970. 
Burger, L. L., The Flammability of Vapors above Purex Systems, HW-40820, General Electric Company, Richland, Washington, 1956.

Carter, R. D., G. R. Kiel, and K. R. Ridgway, Criticality Handbook Volume 1, ARH-600, Atlantic Richfield Hanford Company, Richland, Washington, 1968.

Clarke, R. K., J. T. Foley, W. F. Hartman, and D. W. Larson, Severities of Transportation Accidents, Volume II - Cargo Aircraft, SLA-74-0001, Sandia Laboratories, Albuquerque, New Mexico, 1974.

Clayton, E. D., "Anomalies of Criticality," Nuclear Technology, 23, 14-27, 1974.

Combustion Engineering Corporation, Combustion Engineering Power Systems Environmental Impact Information, Docket No. 70-36, U.S. Nuclear Regulatory Commission, Washington, D.C., 1975.

Combustion Engineering Corporation, Radiological Assessment of Individual Dose Resulting from Routine Operation--Demonstration of Compliance with

40 CRF 190, Docket No. 70-36, U.S. Nuclear Regulatory Commission, Washington, D.C., 1980a.

Combustion Engineering Corporation, License SNM-1067, C-E NFM-W, Combustion Engineering, Inc., Windsor, Connecticut, 1980b.

Combustion Engineering Corporation, Environmental Impact Information, Combustion Engineering, Inc., Windsor, Connecticut Plant Site, Docket No. 70-1100, U.S. Nuclear Regulatory Commission, Washington, D.C., 1981 .

Combustion Engineering Corporation, Onsite Radiological Contingency Plan, License No. SNM-1067, Docket 70-1100, U.S. Nuclear ReguTatory Commission, Washington, D.C., 1981b.

Combustion Engineering Corporation, Radiological Contingency Plan, License No. SNM-33, Docket 70-36, U.S. Nuclear Regulatory Commission, Washington, D.C., 1982 .

Crane, Flow of Fluids through Valves, Fittings, and Pipes, Technical Paper No. 410, Crane Co., New York, 1978.

Davies-Jones, R. and E. Kessler, "Tornadoes," in weather and Climate Modification, Ed. W. N. Hess, John Wiley and Sons, Inc., New York, 1974.

Devlin, A. L., Letter to F. Combs, Docket No. 30-4581, U.S. Nuclear Regulatory Commission, Washington, D.C., 1978.

Division of Fuel Cycle and Material Safety, Safety Evaluation Report by the Division of Fuel Cycle and Material Safety Related to the License Renewal of the Babcock and Wilcox, Nuclear Materials Division, Parks Township Facility, Leechburg, PA, Docket No. 70-364, U.S. Nuclear Regulatory Commission, Washington, D.C., 1979. 
Durkosh, E. D., Letter to M. A. Lamastra, U.S. Nuclear Regulatory Commission, Washington, D.C., University of Pittsburgh, Pittsburgh, Pennsylvania, 1980.

Eggers, R. F., et al., A Mixed Oxide Fuel Fabrication and Assembly Plant-Example Material Control and Accounting System for Proposed Material Control and Accounting Upgrade Rule, Draft, Pacific Northwest Laboratory, Richland, Washington, 1980.

Eisenbud, M., Environmental Radioactivity, 2nd Ed., Academic Press, New York, 1973.

Emery, J. F. and G. W. Leddicotte, The Radiochemistry of Gold, Oak Ridge National Laboratory, Dak Ridge, Tennessee, 1961.

ERDA, Chemical Explosion of an Ion Exchange Resin Column and Resulting Americium Contamination of Personnel in the 242-Z Building, August 30, 1976, Energy Research and Development Administration, Richland, Washington, 1976.

Exxon Nuclear Company, Environmental Statement Related to Operation of Mixed Oxide Fabrication Plant, Docket No. 70-1257, U.S. Nuclear Regulatory Commission, Washington, D.C., 1974.

Exxon Nuclear Company, Application for Renewal of Special Nuclear Material License No. SNM-1227, XN-2, Exxon Nuclear Company, Richland, Washington, 1979.

Exxon Nuclear Company, Richland Fuel Fabrication Plant, Emergency and Radiological Contingency Plan, Part I, XN-NF-32A, Revision 10, Exxon Nuclear Company, Richland, Washington, 1981.

Figgins, P. E., The Radiochemistry of Polonium, Mound Laboratory, Miamisburg, Ohio, 1961.

First, M. W. and P. Drinker, "Concentrations of Particulates Found in Air," Arch. Ind. Hyg. Occup. Med, 5, 387, 1952.

Fujita, T. T., "Photogrammetric Analysis of Tornadoes," in Proceedings of the Symposium on Tornadoes, Assessment of Knowledge and Implications for Man, Texas Tech University, Lubbock, Texas, 1976.

Fujita, T. T., Workbook of Tornadoes and High Winds for Engineering Applications, SMRP Research Paper 165, University of Chicago, Chicago, Illinois, 1978.

Gandsman, E., D. North and S. C. Spraragen, "Radiation Safety In a Nuclear Medicine Department," Health Physics, 38, 399-407, 1980.

Geffen, C. A., An Analysis of Risk of Transporting Uranium Ore Concentrates by Truck, PNL-34 $\overline{63}$, Pacific Northwest Laboratory, Richland, Washington, 1981. 
General Atomic, Special Nuclear Material Application, Docket No. 70-734, U.S. Nuclear Reguiatory Commission, Washington, D.C., 1965.

General Atomic, Amendment of Special Nuclear License SNM-0696, Docket No. 70-734, U.S. Nuclear Regulatory Commission, Washington, D.C., 1971.

General Atomic, Demonstration Volume SNM 696 Material License Renewal Part I, Docket No. 70-734, U.S. Nuclear Regulatory Commission, Washington, D.C., $1975 \mathrm{a}$.

General Atomic, Environmental Appraisal Report, GAA13033, General Atomic, San Diego, California, 1975b.

General Atomic, Environmental Information Report, Docket No. 70-734, U.S. Nuclear Regulatory Commission, Washington, D.C., 1981 .

General Atomic, Radiological Contingency Plan, Docket No. 70-734, U.S. Nuclear Regulatory Commission, Washington, D.C., 1981b.

General Electric Company, Enviranmental Report, General Electric Nuclear Facility, Wilmington, North Carolina, NED020197 Class 1, Wilmington, North Carolina, 1974.

General Electric Company, Radiological Contingency Plan, Docket No. 70-1113, U.S. Nuclear Regulatory Commission, Washington, D.C., 1982.

Gray, W. J., Volatility of a Zinc Borosilicate Glass Containing Simulated HighLevel Radioactive Waste, BNWL-2111, Pacific Northwest Laboratory, Richland, Washington, 1981 .

Grelecki, C., Fundamentals of Fire and Explosion Hazard Evaluation. American Institute of Chemical Engineers, New York, 1972.

Grotenhuis, I. M., "Properties and Uses of Radiating Microspheres," In Radioactive Pharmaceuticals, U.S. Atomic Energy Commission, Washington, D.C., 1966 .

Gumprecht, R. 0., Mathematical Basis of Computer Code RIBD, DUN-4136, Douglas United Nuclear, Inc., Richland, Washington, 1968.

Haissinsky, M. and D. G. Tuck, Nuclear Chemistry and Its Applications, AddisonWesley Publishing Company, Inc., Reading, Massachusetts, 1964.

Hall, E. J., "The Relative Biological Effectiveness of Californium-252," in Some Physical, Dosimetry, and Biomedical Aspects of Californium-252, International Atomic Energy Agency, Vienna, 1976.

Hall, E. J., and H. H. Rossi, Californium-252 in Teaching and Research, Technical Report Series No. 159, International Atomic Energy Agency, Vienna, 1974. 
Hart, G. C., "Estimation of Structural Damage Due to Tornadoes," in Proceedings of the Symposium on Tornadoes Assessment of Knowledge and Implications for Man, Texas Tech University, Lubbock, Texas, 1976.

Harvard University, License Application Information - Docket No. 30-753, License No. 20-00297-53, U.S. Nuclear Regulatory Commission, Washington, D.C., 1965-1981.

Hilliard, R. K., Fission Product Release from Uranium Heated in Air, HW-60689, Hanford Atomic Products Operation, Richland, Washington, 1959.

Hoenes, G. R. and J. K. Soldat, Age-Specific Radiation Dose Commitment Factors for a One-Year Chronic Intake, NUREG-0172, Pacific Northwest Laboratory, Richland, Washington, 1977.

Industrial Health and Safety Office, Safety Guides, PNL-MA-43, Pacific Northwest Laboratory, Richland, Washington, 1980.

Interex Corporation, License Application Information, Docket No. 30-7725, U.S. Nuclear Regulatory Commission, Washington, D.C., 1971-1977.

Isotopic Analysis, Inc., Letter from Isotopic Analysis, Inc. to U.S. Nuclear Regulatory Commission, Docket No. 70-854, U.S. Nuclear Regulatory Commission, Washington, D.C., 1976.

Jacobs, D. G., Sources of Tritium and Its Behavior on Release to the Environiment, U.S. Atomic Energy Commission, Washington, D.C., 1968.

Jenkins, C. E., E. S. Murphy, and K. J. Schneider, Technology, Safety and Costs of Decommissioning a Reference Small Mixed Oxide Fuel Fabrication Plant, NUREG/CR-0129, Vol. 2, Appendix I, Pacific Northwest Laboratory, Richland, Washington, 1979.

Jersey Nuclear Company, Uranium Oxide Fuel Plant Supplemental Environmental Report, Docket No. 70-1257, Jersey Nuclear Company, Richland, Washington, 1971.

Junkins, R. L., E. C. Watson, D. L. Reid, and L. L. Zahn, The Consequences of Accidental Releases of Radioactive Cerium During Shipment, HW-72163, Rev. 1 , Hanford Atomic Products Operation, Richland, Washington, 1964.

Kerr-McGee Corporation, Applicants Environmental Report, Docket No. 70-1193-3, U.S. Nuclear Regulatory Commission, Washington, D.C., 1971 .

Kerr-McGee Corporation, Cimmarron Plutonium Production Plant, License SNM-1174, Section E, Appendix D, Statement, Revised, Docket No. 70-1193-2, U.S. NucTear Regulatory Commission, Washington, D.C., 1971 b.

Kerr-McGee Corporation, Applicants Environmental Report, Docket No. 40-8027-9, U.S. Nuclear Regulatory Commission, Washington, D.C., 1972 . 
Jerr-McGee Corporation, Sequoyah Uranium Hexafluoride Production Plant, Environmental Report Supplementary, U.S. Nuclear Regulatory Commission, Washington, D.C., 1972 b.

Kerr-McGee Corporation, Applicants Environmental Report Supplement No. 1, Docket No. 70-1193-6, U.S. Nuclear Regulatory Commission, Washington, D.C., 1973.

Kerr-McGee Corporation, Final Environmental Statement Related to the Sequoyah Uranium Hexafluoride Plant, NUREG 75/007, Docket No. 40-8027, U.S. Nuclear Regulatory Commission, Washington, D.C., 1975.

Kerr-McGee Corporation, Radiological Contingency Plan for Sequoyah Conversion Facility, Kerr-McGee Corporation, Gore, Oklahoma, 1981 .

Khitrin, L. N., Physics of Combustion and Explosion, National Science Foundation, Washington, D.C., 1962.

Kirby, L. J., The Radiochemistry of Nickel, Hanford Atomic Products Operation, Richland, Washington, 1961.

Koontz, R. L., L. Baurmash, M. A. Greenfield, C. T. Nelson, D. F. Hausknecht, E. U. Vaughan, M. Silberburg and H. A. Horewitz, Aerosol Modeling of Hypothetical LMFBR Accidents, AI-AEC-12977, Atomics International, Canoga Park, California, 1970.

Kristensen, K., Preparation and Control of Radiopharmaceuticals in Hospitals, International Atomic Energy Agency, Vienna, 1979.

Leddicotte, G. W., The Radiochemistry of Iridium, Oak Ridge National Laboratory, Oak Ridge, Tennessee, 1961.

Leddicotte, G. W., The Radiochemistry of Sulfur, Oak Ridge National Laboratory, Oak Ridge, Tennessee, 1962.

Lichtenberger, H. V., Letter to Mr. W. T. Crow, Combustion Engineering Amendment Application, Docket No. 70-1100, U.S. Nuclear Regulatory Commission, Washington, D.C., 1981 .

Linde, Linde Specialty Gas Catalog, Union Carbide Corporation, Linde Division, New rork, 1974.

McKinnon, G. P., ed., Fire Protection Handbook, Fourteenth Edition, National Fire Protection Association, Boston, Massachusetts, 1976.

McSweeney, T. I., et 3 l. $^{1}$. Improved Material Accounting for Plutonium Processing Facilities and a 235 -HTGR Fuel Fabrication Facility, BNWL-2098, Pacific Northwest Laboratory, Richland, Washington, 1975. 
Metropolis Works, Supplemental Report in Support of Application for Renewal of Source Materials License Sub-526, Docket 40-3392, Allied Chemical

Corporation, Metropolis, Iltinois, 1975.

Michigan State University, License Application Information - Docket No. 30-806,

License No. 21-00021-29, U.S. Nuclear Regulatory Commission, Washington, D.C., 1963-1981.

Micro Display Systems, Inc., License Application Information - Docket No. 3017293 , U.S. Nuclear Regulatory Commission, Washington, D.C., 1980-1981.

Minnesota Mining and Manufacturing, Radiological Contingency Plan, Docket No. 30-4951, U.S. Nuclear Regulatory Commission, Washington, D.C., 1981.

Mishima, J., Plutonium Release Studies II: Release from Ignited, Bulk Metallic Pieces, BNWL-357, Pacific Northwest Laboratory, Richland, Washington, 1966.

Mishima, J., "Potential Aerosol Generation Mechanisms from Damaged Packages," IAEA-SR 10/15, in Transport Packaging for Radioactive Material, Proceedings of a Seminar, Vienna, Austria, 1976.

Mishima, J., and J.E. Ayer, Estimated Airborne Release of Plutonium from the 102 Building at the General Electric Vallecitos Nuclear Center, Villecitos, California, as a Result of Severe Wind and Earthquake Hazard, PNL-3601, Pacific Northwest Laboratory, Richland, Washington, 1980.

Mishima, J., and J.E. Ayer, Estimated Airborne Release of Plutonium from Atomics International's Nuclear Materials Development Facility in the Santa Susana Site, California, as a Result of Severe Wind and Earthquake Hazard, PNL-3935, Pacific Northwest Laboratory, Richland, Washington, 1981.

Mishima, J., R. B. McPherson, L. C. Schwendiman, E. C. Watson, and J. E. Ayer, Source Term and Radiation Dose Estimates for Postulated Damage to the 102 Building at the General Electric Vallecitos Nuclear Center, PNL-2844, Pacific Northwest Laboratory, Richland, Washington, 1979b.

Mishima, J. and L. C. Schwendiman, The Amount and Characteristics of Plutonium Made Airborne Under Thermal Stress, BNWL-SA-3379, Pacific Northwest Laboratory, Richland, Washington, 1970.

Mishima, J. and L. C. Schwendiman, Some Experimental Measurements of Airborne Uranium (Representing Plutonium) in Transportation Accidents, BNWL-1732, Pacific Northwest Laboratory, Richland, Washington, $1973 a$.

Mishima, J., and L. C. Schwendiman, Fractional Airborne Release of Uranium (Representing Plutonium) During the Burning of Contaminated Wastes, BNWL-1730. Pacific Northwest Laboratory, Richland, Washington, 1973b. 
Mishima, J., and L. C. Schwendiman, Interim Report: The Fractional Airborne Release of Dissolved Radioactive Materials During the Combustion of 30 Percent Normal Tributyl Phosphate In a Kerosene-Type Diluent, BNWL-B-274, Pacific Northwest Laboratory, Richland, Washington, 1973c.

Mishima, J., L. C. Schwendiman, and J. E. Ayer, Increment of Analysis: An Estimate of Severe Airborne Release of Plutonium from Babcock and Wilcox Plant as a Result of Wind Hazard and Earthquake, PNL-2812, Pacific Northwest Laboratory, Richland, Washington, 1978.

Mishima, J., L. C. Schwendiman, and J. E. Ayer, An Increment of Analysis: Estimated Airborne Release of Plutonium from Westinghouse Cheswick Site as a Result of Postulated Damage from Severe Wind and Seismic Hazard, PNL-2965, Pacific Northwest Laboratory, Richland, Washington, 1979a.

Mishima, J., L. C. Schwendiman, and J. E. Ayer, Estimated Airborne Release of Plutonium from the Exxon Nuclear Mixed Oxide Fuel Plant at Richland, Washington as a Result of Postulated Damage from Severe Wind and Seismic Hazard, PNL-3340, Pacific Northwest Laboratory, Richland, Washington, 1980.

Mishima, J., L. C. Schwendiman, and C. A. Radasch, Plutonium Release Studies III. Release from Heated Plutonium Bearing Powders, BNWL-786, Pacific Northwest Laboratory, Richland, Washington, 1968a.

Mishima, J., L. C. Schwendiman, and C. A. Radasch, Plutonium Release Studies IV. Fractional Release from Heating Plutonium Nitrate Solutions in a Flowing Air Stream, BNWL-931, Pacific Northwest Laboratory, Richland, Washington, 1968b.

Monsanto Research Corporation, Radiological Contingency Plan, Docket No. 70-572, U.S. Nuclear Regulatory Commission, Washington, D.C., 1981.

Moshier, R. W., Analytical Chemistry of Niobium and Tantalum, Macmillan Company, New York, 1964.

Molinski, V. J. and G. W. Leddicotte, The Radiochemistry of Selenium, NAS-NS-3030, Rev. 1, Subcommittee on Radiochemistry National Academy of Sciences, National Research Council, Washington, D.C., 1965.

Moyer, H. V., Polonium, Oak Ridge, Tennessee, 1956.

Mullins, W. T. and G. W. Leddicote, The Radiochemistry of Phosphorous, Oak Ridge National Laboratory, Oak Ridge, Tennessee, 1962.

Nesmeyanov, An. N., Vapour Pressure of the Elements, Academic Press, New York, 1963.

New England Nuclear (NEN), NEN 1976 Catalog, Boston, Massachusetts, 1976.

New England Nuclear (NEN), Radiological Contingency Plans, License No. 20-00320-98, Boston, Massachusetts, 1981a. 
New England Nuclear (NEN), Radiological Copntingency Plans, License No. 20-00320-13 and 20-11868-01, North Billerica, Massachusetts, 1981b.

NFPA, Fire Protection Guide on Hazardous Materials, National Fire Protection Association, Boston, Massachusetts, 1978.

Nielsen, J. M., The Radiochemistry of Iron, Hanford Laboratories, Hanford Atomic Products Operation, Richland, Washington, 1960.

Niemyer, R. G., "Tritium Loss from Tritium Self-Luminous Aircraft Exit Signs," Isotopes and Radiation Technology, 7(3), 349-352, 1970.

Nuclear Materials and Equipment Corporation, Environmental Report for NUMEC Type II Facility Parks Township Site, SNM-414, Docket 70-364, U.S. Nuclear Regulatory Commission, Washington, D.C., 1973.

Oak Ridge National Laboratory (ORNL), Siting of Fuel Reprocessing and Waste Management Facilities, ORNL-4451, Oak Ridge National Laboratory, Oak Ridge, Tennessee, 1970.

Oak Ridge Operations Office, Uranium Hexafluoride: Handling Procedures and Container Criteria, OR0-651, Oak Ridge, Tennessee, 1972.

Occupational and Environmental Protection Department, Radioactive Materials Shipping Manual, PNL-MA-81, Pacific Northwest Laboratory, Richland, Washington, 1980.

0'Donnel1, F. R. and H. C. Hoy, Occupational Safety Data and Casualty Rates for the Uranium Fuel Cycle, ORNL-5799, Oak Ridge National Laboratory, Oak Ridge, Tennessee, 1981.

Ohio State Universtiy, Materials License, License No. 34-00293-02, U.S. Nuclear Regulatory Commission, Washington, D.C., 1979.

Ohio State University, Radiological Contingency Plan, License No. 34-00293-02, Columbus, Ohio, 1981.

Oral Roberts University, License Application Information - Docket No. 30-14781, License No. 35-18282-01, U.S. Nuclear Regulatory Commission, Washington, D.C., 1979-1981.

Pacific Coast Gas Association, Gas Engineer's Handbook, McGraw Hill Book Company, New York, 1934.

Pacific Northwest Laboratory (PNL), Draft Generic (Light Water Reactor) Chemical Separations Facility Handbook, Vol. 2, Pacific Northwest Laboratory, Richland, Washington, 1975.

Pacific Northwest Laboratory (PNL), Technology for Commercial Radioactive Waste Management, DOE/ET0023, Department of Energy, Richland, Washington, 1979. 
Pan American World Airways, License Application Information, Docket No. 3003974, U.S. Nuclear Regulatory Commission, Washington, D.C., 1977-1979.

Penneman, R. A., and T. K. Keenan, The Radiochemistry of Americium and Curium, University of California, Los Alamos Scientific Laboratory, Los Alamos, New Mexico, 1960.

Perry, R. H., Chemical Engineers' Handbook, 5th Edition, McGraw-Hill Book Company, New York, 1973.

Pijck, J., Radiochemistry of Chromium, Laboratory for Analytical Chemistry, University of Ghent, Ghent, Belgium, 1964.

Pollock, R. W., and R. D. Myser, "Concentrations of I-131 in Air During Thyroid Therapies," Health Physics, 36, 68-69, 1979.

Quinn, J. L., III, The Yearbook of Nuclear Medicine 1980, Yearbook Medical Publishers, Inc., Chicago, Illinois, 1980.

Richardson, E. W. and S. Bernstein, Additional Testing of Ten-Ton Uranium Hexafluoride Cylinders, KY-631, Union Carbide Corporation Nuclear Division, Paducah, Kentucky, 1971 .

Rimshaw, S. J., F. N. Case, and J. A. Tompkins, Volatility of Ruthenium-106, Technetium-99, and Iodine-129 and the Evaluation of Nitrogen Oxide Compounds During the Calcination of High-Level, Radioactive Nitric Acid Waste, ORNL-5562, Oak Ridge National Laboratory, Oak Ridge, Tennessee, 1980.

Rimshaw, S. J., and F. N. Case, "Volatilities of Ruthenium, Iodine, and Technetium on Calcining Fission Product Nitrate Waste," in Proceedings of the 16th DOE Air Cleaning Conference, San Diego, California, $19 \overline{81 .}$

Rockwe11, Environmental Impact Assessment of Operations at Atomics International Under Special Nuclear Materials License No. SNM-21, AI-76-21, Rockwell International, Atomics International Division, Canoga Park, California, 1976.

Rockwell, Technical Information in Support of the Atomics International Application for Broad Nuclear Materials License, A1-75-46, Rockwell International, Atomics International Division, Canoga Park, California, 1977.

Rockwell, Onsite Radiological Contingency Plan for Rockwell International Operations Licensed Under Special Nuclear Material License No. SNM-21, ESG-81-30, Rockwel1 International, Energy Systems Group, Canoga Park, California, 1981.

Safety Light Corporation, Radiological Contingency Plan, U.S. Nuclear Regulatory Commission, Washington, D.C., 1981. 
Schneider, K. J., Nuclear Fuel Cycle Risk Assessment: Descriptions of Representative Non-Reactor Facilities, NUREG/CR-2873, U.S. Nuclear Regulatory Commission, Washington, D.C., 1982.

Schneider, K. J. and T. J. Kabele. 1979. Description of Reference LWR Facilities of Nuclear Fuel Cycles. PNL-2286, Pacific Northwest Laboratory, Richland, Washington.

Schulz, W. W., The Chemistry of Americium, TID-26971, Atlantic Richland Hanford Company, Richland, Washington, 1976.

Schulz, W. W. and G. E. Benedict, Neptunium-237 Production and Recovery. Altantic Richfield Company, Richland, Washington, 1972.

Sehmel, G. A. and F. D. Lloyd, Particle Resuspension Rates, BNWL-SA-5124, Pacific Northwest Laboratory, Richland, Washington, 1974a.

Sehmel, G. A. and F. D. Lloyd, "Particle Suspension Rates," in AtmosphereSurface Exchange of Particulate and Gaseous Pollutants, CONF-740921, ERDATechnical Information Office, 1974b.

Selby, J. M., et al., Considerations in the Assessment of the Consequences of Effluents from Mixed Oxide Fuel Fabrication Plants, BNWL-1697 Rev. 1, Pacific Northwest Laboratory, Richland, Washington, 1975.

Sinclair, P. C., "Vertical Transport of Desert Particulates by Dust Devils and Clear Thermals," in Atmosphere-Surface Exchange of Particulate and Gaseous Pollutants, CONF-740921 and ERDA-Technical Information Office, 1974.

Smith, D. R., R. E. Luna, J. M. Taylor, and A. R. Ducharme, A Risk Assessment for the Transportation of Radioactive Materials in the U.S.A, IAEA-SR-10/20, Sandia Laboratory, Albuquerque, New Mexico, 19--.

Smith, G. H., Letter to Babcock and Wilcox Company, Docket No. 70-135, U.S. Nuclear Regulatory Commission, Washington, D.C., 1980.

Sodee, D. B., and P. J. Early, Mosby's Manual of Nuclear Medicine Procedures, C. V. Mosby Company, St. Louis, Missouri, 1981.

Sorenson, R. J., et a1., Independent Verification of a Material Balance at a LEU Fuel Fabrication PTant, PNL-2418, Pacific Northwest Laboratory, Richland, Washington, 1977.

Squibb, E. R, and Sons, Inc., Radiological Contingency Plan, License No. 29-00139-02, New Brunswick, New Jersey, 1981.

Steindler, M. J., and W. B. Seefeldt, "A Method for Estimating the Challenge to an Air Cleaning System Resulting from an Accidental Explosive Event, in Proceedings of the 16th DOE Air Cleaning Conference, San Diego, California, 1981. 
Stevenson, J. D., "Application of Tornado Technology to the Nuclear Industry," in Proceedings of the Symposium on Tornadoes, Assessment of Knowledge and Implications for Man, Texas Tech University, Lubbock, Texas, 1976.

Stewart, D. C., Handling Radioactivity, John Wiley and Sons, New York, 1981.

Stocker and Yale, Inc., License Application Information, Docket No. 30-11189, U.S. Nuclear Regulatory Commission, Washington, D.C., 1975-1981.

Stratton, W. R., Review of Criticality Accidents, LA-3611, Los Alamos Scientific Laboratory, Los Alamos, New Mexico, 1967.

Strehlow, R. A. and W. E. Baker, "The Characterization and Evaluation of Accidental Explosions," Prog. Energy Combust. Sci., 2, 27-60, 1976.

Subrahmanian, G., G. Venrataraman, and U. Madhvanath, "Radiation Protection Aspects in the Use of Californium-252 Sources," in Some Physical, Dosimetry, and Biomedical Aspects of Californium-252, International Atomic Energy Agency, Vienna, 1976.

Sutter, S. L., Potential Airborne Release from Soil Working in a Contaminanted Area, PNL-3498, Pacific Northwest Laboratory, Richland, Washington, 1980 .

Sutter, S. L., Aerosols Generated by Releases of Pressurized Powders and Solutions in Static Air, NUREG CR/3093, U.S. Nuclear Regulatory Commission, Washington, D.C., 1983.

Sutter, S. L., J. W. Johnston, and J. Mishima, Aerosols Generated by Free Fall Spil1s of Powders and Solutions in Static Air, NUREG/CR-2139, PNL-3786, Pacific Northwest Laboratory, Richland, Washington, 1981.

Sutter, S. L., J. Mishima, and L. C. Schwendiman, Fractional Airborne Release of Strontium During the Combustion of 30 Percent Normal Tributyl Phosphate in a Kerosene-Type Diluent. BNWL-B-358, Pacific Northwest Laboratory, Richland, Washington, 1974.

Tabor, C. D., UF Release Losses 1954-1973, GAT-820-74-7, Goodyear Atomic Corporation, Piketon, Ohio, 1974.

Technical Operations, License Application Information, Docket No. 30-4579, U.S. Nuclear Regulatory Commission, Washington, D.C., 1957-1981.

Teledyne Isotopes, Inc., License Application Information, Docket No. 30-8681, Nuclear Regulatory Commission, Washington, D.C., 1968-1981.

Thomas, P. H., "Fires in Enclosures," in Heat Transfer in Fires: Thermophysics, Social Aspects, Economic Impact, P. L. Blackshear, Ed., John Wiley and Sons, New York, 1974. 
Tokarz, F. J., R. C. Murray, and H. C. Sorenson, Seismic Response and Failure Analysis of a Mixed 0xide Fuel Fabrication Plant, TID-4500, Lawrence Livermore Laboratory, Livermore, California, 1975.

Tuck, G., "Simplified Methods for Estimating the Results of Accidental Solution Excursions," Nuclear Technology, 23, 177-188, 1974.

Tyron, G. H., Fire Protection Handbook, 12th Edition, National Fire Protection Association, Boston, Massachusetts, 1962 .

United Nuclear Corporation (UNC), Environmental Report, Docket-700371-1, United Nuclear Corp., Montville, Connecticut, 1973.

United Nuclear (UNC), SNM License No. 368 Emergency Plan, Docket No. 70-371, U.S. Nuclear Regulatory Commission, Washington, D.C., 1980.

University of Illinois, License Application Information - Docket No. 30-652, License No. 12-00330-050, U.S. Nuclear Regulatory Commission, Washington, D.C., 1957-1981.

University of Wisconsin, License Application Information - Docket No. 30-3405, License No. 48-09843-18, U.S. Nuclear Regulatory Commission, Washington, D.C., 1956-1981.

Iniversity of Wyoming, License Application Information - Docket No. 30-1176, License No. 49-09955-10, U.S. Nuclear Regulatory Commission, Washington, D.C., 1966-1979.

U.S. Atomic Energy Commission (USAEC), Operational Accidents and Radiation Exposure, WASH-1192, Division of Operational Safety, Washington, D.C., 1971.

U.S. Atomic Energy Commission (USAEC), Uranium Hexafluoride: Handling Procedures and Container Criteria, Rev. 3, 0R0-651, U.S. Atomic Energy Commission, Oak Ridge, Tennessee, 1972.

U.S Atomic Energy Commission (USAEC), Environmental Survey of the Uranium Fuel Cycle, WASH-1248, U.S. Atomic Energy Commission, Washington, D.C., 1974 .

U.S. Code of Federal Regulations (USCFR), Hazardous Material Regulations of the Department of Transportation, Title 49, 1983a.

U.S. Code of Federal Regulations (USCFR), Appendix B - Concentrations in Air and Water Above Natural Background, Title 10, Part 20, 1983b.

U.S. Department of Energy (USDOE), Report of the Plutonium Building Incidents at the Lawrence Liverinore National Laboratory on Apri1 8 and 16, 1980, SAN-80-1, San Francisco Operations Office, San Francisco, California, 1980.

U.S. Department of Health, Education, and Welfare, The National Institute of Health Radiation Safety Guide, Public Health Service, 1972. 
Y.S. Environmental Protection Agency, Compilation of Air Pollution Emmission Factors Third Edition, Including Supplements 1-7, PB-275-525, Research Triangle Park, North Carolina, 1977.

U.S. Nuclear Regulatory Commission (USNRC), Assumptions Used for Evaluating the Potential Consequences of a Fuel Handling Accident in the Fuel Handling and Storage Facility for Boiling and Pressurized Water Reactors, Safety Guide 25, Washington, D.C., 1972.

U.S. Nuclear Regulatory Commission (USNRC), Reactor Safety Study: An Assessment of Accident Risks in U.S. Commercial Nuclear Power Plants, Appendix I, WASH-1400, U.S Nuclear ReguTatory Commission, Washington, D.C., 1975.

U.S. Nuclear Regulatory Commission (USNRC), "Assumptions Used for Evaluating the Potential Radiological Consequences of Accidental Nuclear Criticality in a Fuel Reprocessing Plant," Regulatory Guide 3.33, Washington, D.C., 1977 a.

U.S. Nuclear Regulatory Commission (USNRC), Bear Creek Project Environmental Impact Statement, NUREG-0129, Washington, D.C., 1977b.

U.S Nuclear Regulatory Commission (USNRC), Environmental Impact Appraisal, Babcock and Wilcox, Commerical Nuclear Fuel Plant, Docket No. 70-1202, U.S. Nuclear Regulatory Commission, Washington, D.C., 1978a.

U.S. Nuclear Regulatory Commission (USNRC), Environmental Impact Appraisal, Babcock and Wilcox Company, Nuclear Materials Division, Leechburg, Parks Township, Pennsylvania, U.S. Nuclear Regulatory Commission, Washington, D.C., $1978 \mathrm{~b}$.

U.S. Nuclear Regulatory Commission (USNRC), "Assumptions Used for Evaluating the Potential Radiological Consequences of Accidental Nuclear Criticality in a Uranium Fuel Fabrication Plant." Regulatory Guide 3.34, Washington, D.C., 1979a.

U.S. Nuclear Regulatory Commission (USNRC), Draft Generic Environmental Impact Statement on Uranium Milling, NUREG-0511, Washington, D.C., 1979b.

U.S. Nuclear Regulatory Commission (USNRC), Final Generic Environinental Impact Statement on Uranium Milling, NUREG-0706, Washington, D.C., 1980.

Walmsley, D., B. A. Sammons and J. R. Grover, Volatility Studies of Glasses for the Fingal Process, AERE-R-5777, England, 1969.

Wang, Y., Handbook of Radioactive Nuclides, Chemical Rubber Company, Cleveland, Ohio, 1969 .

Ward, J. W., W. Muller, and G. F. Kramer, "The Vapor Pressure of High-Purity Solid Americium," in Transplutonium Elements, Eds. W. Miller and R. Lindner, North Holland Publishing Company, Amersterdam, 1976. 
Weast, R. C., Ed., Handbook of Chemistry and Physics, 54th Edition, CRC Press, Cleveland, Onio, 1973.

Westinghouse Electric Corporation, Application for a Materials License for the Nuclear Fuel Division at the Columbia Site, Docket No. 70-1151, U.S. Nuclear Regulatory Commission, Washington, D.C., 1976.

Westinghouse Electric Corporation, Application for Renewal of SNM-770, Docket No. 70-698, U.S. Nuclear Regulatory Commission, Washington D.C., 1980.

Westinghouse Electric Corporation, Site Emergency Plan, Westinghouse Electric Corporation, Nuclear Fuel Division, Columbia, South Carolina, Docket No. 70-1151, U.S. Nuclear Regulatory Commission, Washington, D.C., 1981.

Westinghouse Nuclear Fuel Division, Westinghouse Cheswick Site Fuel Development Laboratories Environmental Report, Westinghouse Electric Company, 1975.

Westinghouse Nuclear Fuel Division, Plutonium Fuels Development Laboratory, Radiological Contingency Plan, Westinghouse Electric Company, Cheswick, Pennsylvania, 1981.

Wheelwright, E. J., Ed., Promethium Technology, American Nuclear Society, Hinsdale, 11 linois, 1973.

Wimett, T. F., Time Behavior of Godiva Through Prompt Critical, LA-2029, Los Alamos, New Mexico, 1956.

Woodcock, E. R., Potential Magnitude of Criticality Accidents, Safeguards Division, A.H.S.B. Risely, AHSB(RP)-R-14, 1966.

Zabetakis, M. G., Flammability Characteristics of Combustible Gases and Vapors, Bulletin 627 , U.S. Bureau of Mines, Washington, D.C.. 1965. 


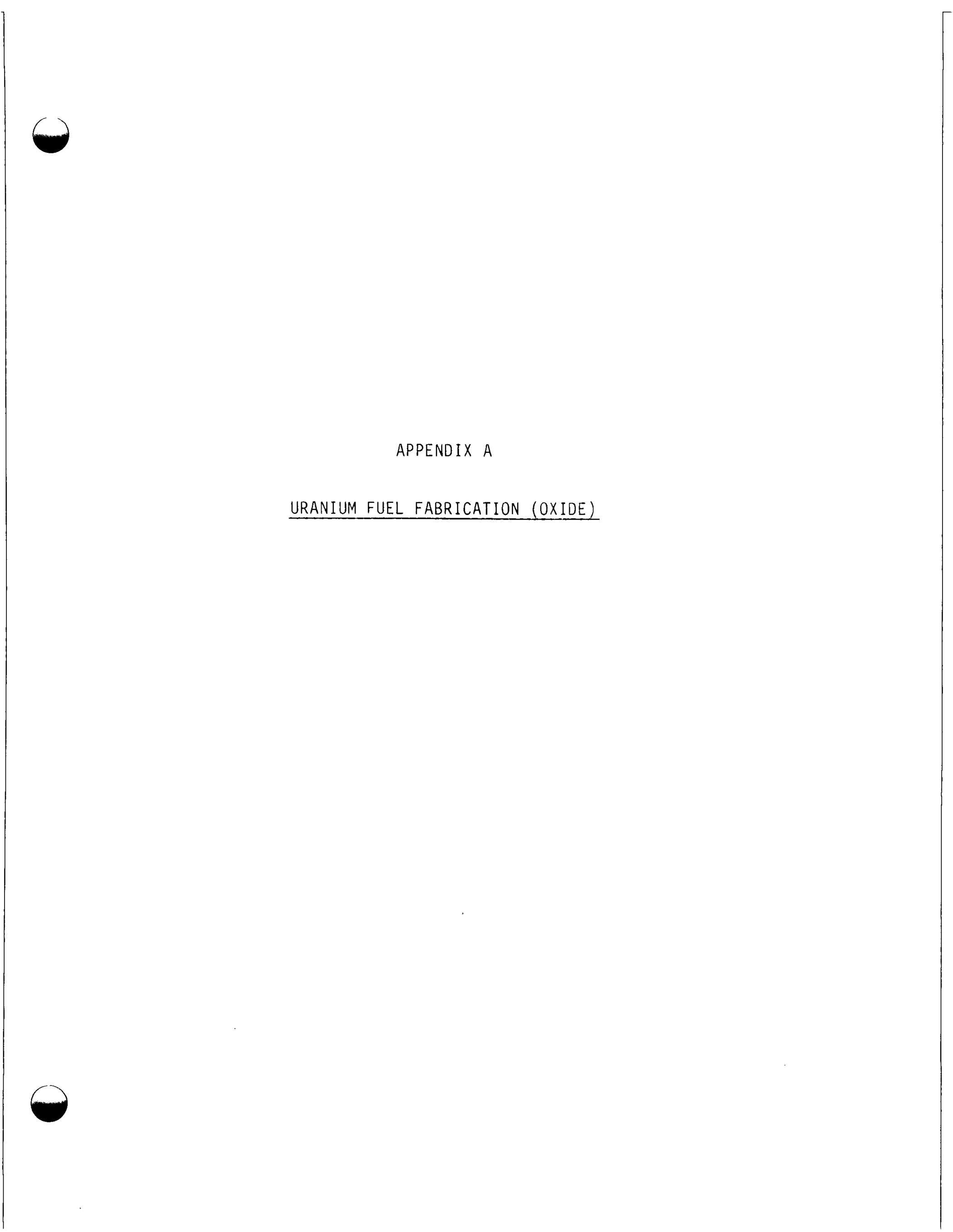


A.1 BABCOCK AND WILCOX, LYNCHBURG, VIRGINIA

The Babcock and Wilcox Commercial Nuclear Fuel Plant (CNFP) at Lynchburg, Virginia, produces fuel assemblies for commercial nuclear power reactors from low-enriched $\mathrm{UO}_{2}$ powder. Information on this plant was obtained from Babcock and Wilcox reports $(1972,1974,1981 \mathrm{a}, 1981 \mathrm{~b})$.

\section{A.1.1 Process Description}

Uranium dioxide is blended, slugged, and granulated, and then is pressed into pellets. The pellets are sintered in reducing furnaces, ground to specified sizes, and loaded into fuel rods. The rods are assembled into fuel bundles and stored before shipping.

\section{Scrap Recovery}

Scrap collection and recycle activities also take place within the plant. Other Operations

Fuel assembly grids are fabricated in the plant and machining operations are performed.

\section{A.1.2 Facility Description}

Buildings

The main building, shown in Figure A.1, is a windowless, metal-paneled structure. Dimensions of the building are $600 \mathrm{ft}$ by $60 \mathrm{ft}$ with a $24-\mathrm{ft}$ average ceiling height. Interior and exterior plant walls are separated by 8 in., including $4 \mathrm{in}$. of insulation. Structural support is provided by steel beams on a 24-ft spacing.

The structure, piping, and all major process equipment are designed to withstand a design basis earthquake of VII on the Modified Mercalli scale. The buildings could not withstand a direct strike from a design basis tornado.

\section{HVAC Systems}

Scrubbers and HEPA filters are used to clean process air. Ten air changes per hour or more are provided for most areas of the plant. Table A.l gives specific ventilation information for the plant. 


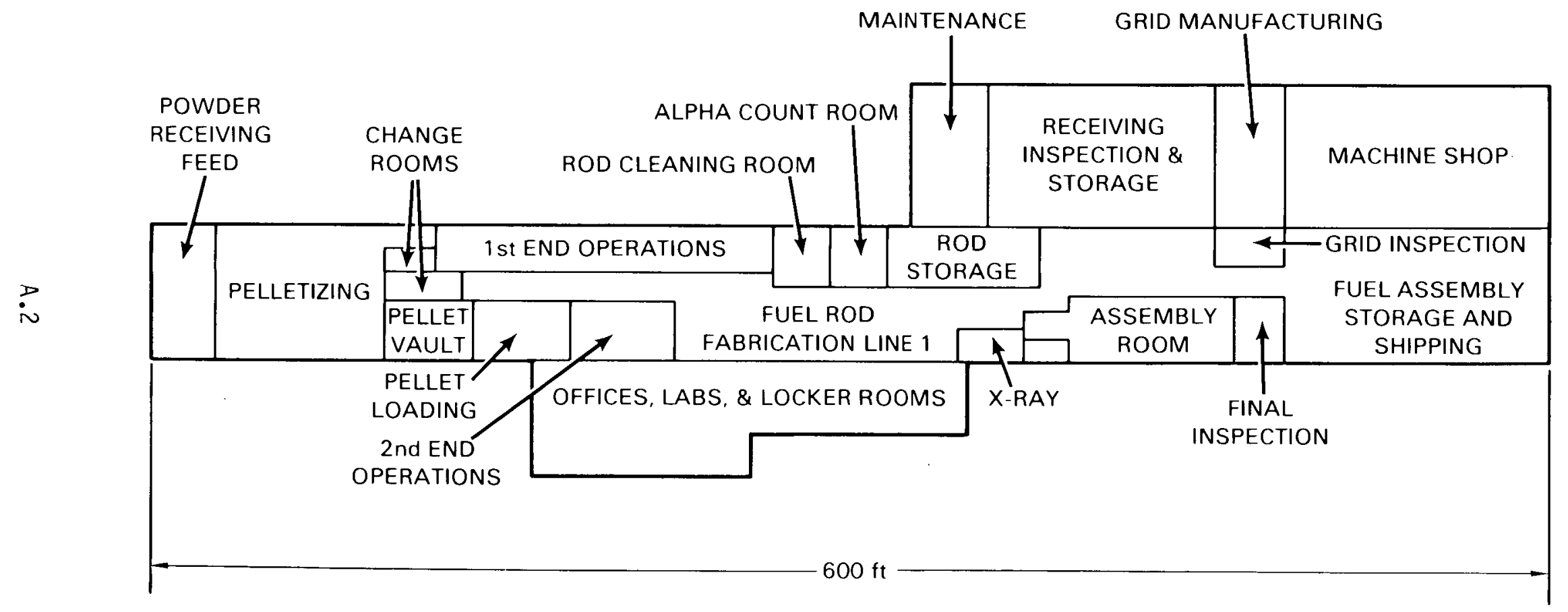

FIGURE A.1. Babcock and Wilcox Commercial Nuclear Fuel Plant Facility Diagram 
Engineered Safety Systems

Manual fire alarms and radiation detectors are located in process areas of the plant.

Surrounding Area

The commercial plant is in a rural area. A naval fuel fabrication plant and a research center are on the same site. Both facilities handle radioactive materials.

\section{A.1.3 Inventory \\ Radioactive Inventory}

Table A.2 gives information on radioactive material inventories in the plant. The plant can process a total of 194 metric tons of uranium (MTIJ) per year.

Hazardous and Combustible Inventory

Some hazardous and combustible chemicals used at the Babcock and Wilcox commercial nuclear fuel plant are listed in Table A.3. The storage capacity and location of these chemicals are also given.

\section{A.2 COMBUSTION ENGINEERING, HEMATITE, MISSOUR I}

The Combustion Engineering uranium oxide fuel fabrication facility produces low-enriched $\mathrm{UO}_{2}$ fuel pellets from $\mathrm{UF}_{6}$ for light water reactor fuel assemblies. The fuel is fabricated into finished elements at the Windsor, Connecticut, plant. Information on this plant was obtained from Combustion Engineering reports (1980a, 1982).

\section{A.2.1 Process Description}

\section{Operation}

Enriched $U F_{6}$ is received as a solid in 2.5-ton cylinders. These cylinders are heated in a steam chest to vaporize the $\mathrm{UF}_{6}$, which then enters the first fluidized bed reactor. Here it is reacted with dry steam to form uranyl fluoride $\left(\mathrm{HO}_{2} \mathrm{~F}_{2}\right)$ and $\mathrm{HF}$ gas.

The gaseous HF and excess steam, "cracked" ammonia or hydrogen exit the reactor through porous metal filters; the $\mathrm{UO}_{2} \mathrm{~F}_{2}$ particles move to a second and third reactor where they are pyrohydrolyzed in a reducing atmosphere of hydrogen to remove residual fluorine and reduce the $\mathrm{UO}_{2} \mathrm{~F}_{2}$ to $\mathrm{UO}_{2}$. Off gases from these reactors are also filtered through porous metal filters, then routed with off gases from the first reactors to scrubbers filled with calcium carbonate. These scrubbers remove most of the HF before the off gas is discharged to the atmosphere. 
TABLE A.1. Ventilation Capacities of the Powder/Pellet and Assembly Facility, Babcock and Wilcox Commercial Nuclear Fuel Plant

\begin{tabular}{|c|c|c|c|c|c|}
\hline Area & $\begin{array}{c}\text { Space } \\
\text { volume, } \\
\mathrm{ft}^{3}\end{array}$ & $\begin{array}{l}\text { Space Air } \\
\text { Supply, } \\
\mathrm{ft}^{3} / \mathrm{min} \\
\end{array}$ & $\begin{array}{c}\text { Recirculated } \\
\mathrm{Ajr}, \\
\mathrm{ft}^{3} / \mathrm{min} \\
\end{array}$ & $\begin{array}{l}\text { Stack } \\
\text { Exhaust, } \\
\mathrm{ft}^{3} / \mathrm{min}\end{array}$ & $\begin{array}{l}\text { No. of Air } \\
\text { Changes/h } \\
\end{array}$ \\
\hline Pelletizing & 438,375 & 64,090 & 60,460 & 12,600 & 10 \\
\hline Vault \& Loading & 30,000 & 4,425 & 4,425 & 575 & 10 \\
\hline Analytical Lab & 40,500 & 10,125 & 0 & 15,000 & 15 \\
\hline \multicolumn{6}{|l|}{ Support: } \\
\hline Toilets & 12,500 & 1,890 & 1,890 & 190 & 10 \\
\hline $\begin{array}{l}\text { Process } \\
\text { Maintenance }\end{array}$ & 10,000 & 1,520 & 1,520 & 150 & 10 \\
\hline Filter Room & 80,000 & 12,120 & 12,120 & 1,210 & 10 \\
\hline Change Room & 36,000 & 5,455 & 5,455 & 545 & 10 \\
\hline Services & 21,400 & 3,240 & 3,240 & 325 & 10 \\
\hline Total Support & & 24,225 & 24,225 & 2,420 & \\
\hline
\end{tabular}

Uranium dioxide $\left(\mathrm{UO}_{2}\right)$ from the third reactor is cooled and pneumatically transferred to storage silos. The powder is withdrawn from the storage silos into a fluid energy mi11, where recycle material may also be added. It is then transferred to blenders and withdrawn for shipment to windsor for use in the pellet plant.

For pelletizing, blending powder is agglomerated using an organic binder and a suitable solvent. The agglomerated powder is then granulated to ensure a consistent press feed, and pressed into pellets. "Green" pellets are processed through a dewaxing furnace to remove the additives and then passed through a sintering furnace where they densify. The sintered pellets are sized using a centerless grinder, dried, inspected, and packed for shipment.

\section{Waste Disposal}

Solid low-level wastes are packaged in 55-gal drums or plastic-lined wooden crates for disposal at a licensed waste facility.

Liquid high-level wastes are chemically processed to recover the uranium. The radioactivity of liquid low-level wastes is determined. It is then either discharged to evaporation ponds or yuarantined in 5b-yal drums until the daughter products decay to acceptable levels.

Cylinder heels are also washed and processed in the waste disposal operations. 
TABLE A.2. Inventories of Radioactive Materials at the Babcock and Wi 1 COX CNFP

\begin{tabular}{|c|c|c|c|c|c|}
\hline Chemical & $\begin{array}{c}\text { Physical } \\
\text { Form } \\
\end{array}$ & Location & $\begin{array}{l}\text { In-Process } \\
\text { Inventory, } \mathrm{kg} \\
\end{array}$ & $\begin{array}{l}\text { In-Storage } \\
\text { Inventory, } \mathrm{kg}\end{array}$ & $\begin{array}{l}\text { Dispersibility } \\
\text { Properties } \\
\end{array}$ \\
\hline $\mathrm{UO}_{2}$ & Powder & Pelletizing & 5,500 & 15,000 & $\begin{array}{l}\text { Insoluble, } \\
0.75-1.0 \mu \mathrm{m} M M D \\
\text { dispersible, } \\
\text { respirables, } \\
2 \text { to } 4 \% 23 \mathrm{~J}\end{array}$ \\
\hline $\mathrm{UO}_{2}$ & Pellets & Pelletizing & 4,000 & -- & $\begin{array}{l}\text { Insoluble, } \\
\text { nonrespirable, } \\
\text { nondispe } 535_{U} \text { le } \\
2 \text { to } 4 \%\end{array}$ \\
\hline $\mathrm{UO}_{2}$ & & Vault &.- & 35,000 & Same \\
\hline $\mathrm{UO}_{2}$ & $\begin{array}{l}\text { Rod pro- } \\
\text { cessing } \\
\text { and } \\
\text { storage }\end{array}$ & & 45, & 000 & Same \\
\hline $\mathrm{UO}_{2}$ & $\begin{array}{l}\text { Finished } \\
\text { fuel } \\
\text { assem- } \\
\text { blies }\end{array}$ & $\begin{array}{l}\text { Fuel } \\
\text { storage }\end{array}$ & -- & 82,300 & Same \\
\hline $\begin{array}{l}\mathrm{IO}_{3} \mathrm{O}_{3}- \\
\mathrm{I}^{-}\end{array}$ & $\begin{array}{l}\text { Powder, } \\
\text { fines } \\
\text { and } \\
\text { grinder } \\
\text { waste }\end{array}$ & Pelletizing & 20 & 000 & $\begin{array}{l}\text { Insoluble, } \\
\text { ranging from } \\
\text { respirable to } \\
\text { nonrespirable, } \\
\text { generally dis- } \\
\text { persible, } 35 \mathrm{y} \\
2 \text { to } 4 \%\end{array}$ \\
\hline
\end{tabular}


TABLE A.3. Chemical Storage at Babcock and Wilcox CNFP

\begin{tabular}{|c|c|c|c|c|}
\hline Chemical & Formula & $\begin{array}{l}\text { Storage } \\
\text { Capacity }\end{array}$ & Container & Location \\
\hline Acetone & $\mathrm{CH}_{3} \mathrm{COCH}_{3}$ & & 55-gal drum & Outside \\
\hline Acetylene & & & Cylinders & Welding shop \\
\hline Ammonia & $\mathrm{NH}_{3}$ & $125,0001 \mathrm{~b}$ & Tanks & Outside \\
\hline $\begin{array}{l}\text { Ammonium } \\
\text { bicarbonate }\end{array}$ & $\mathrm{NH}_{4} \mathrm{HCO}_{3}$ & 1,000 gal & & \\
\hline $\begin{array}{l}\text { Calcium oxide } \\
\text { (lime) }\end{array}$ & $\mathrm{CaO}$ & $30,0001 \mathrm{~b}$ & Tanks & \\
\hline Carbon dioxide & $\mathrm{CO}_{2}$ & $48,0001 \mathrm{~b}$ & Tanks & Outside \\
\hline Caustic & & & 80-gal drum & Outside \\
\hline Cutting $0 i 1$ & & & 50-gal drum & Inside \\
\hline Flocculant & & & Drums & \\
\hline Fuel $0 i 1$ & & $1,500 \mathrm{ga} 1$ & Tank & Outside \\
\hline Helium & $\mathrm{He}$ & $\begin{array}{l}35,000 \\
\text { std. } \mathrm{ft}^{3}\end{array}$ & Cylinders & Outside \\
\hline Hydrochloric acid & $\mathrm{HCl}$ & & Carboys & $\begin{array}{l}\text { Machine equipment } \\
\text { building }\end{array}$ \\
\hline Hydrofluoric acid & $H F$ & & Carboys & Process building \\
\hline Hydraulic fluids & & $50 \mathrm{gal}$ & & Inside \\
\hline Hydrogen peroxide & $\mathrm{H}_{2} \mathrm{O}_{2}$ & & 50-gal drums & \\
\hline Lubricating oil & & $100 \mathrm{gal}$ & & Inside \\
\hline Methanol & $\mathrm{CH}_{3} \mathrm{OH}$ & 8,000 gal & Tanks & Outside \\
\hline Natural gas & & & $\begin{array}{l}\text { Piped (not } \\
\text { stored) }\end{array}$ & \\
\hline Nitric acid & $\mathrm{HNO}_{3}$ & & Carboys & Process building \\
\hline Nitrogen (1 iquid) & $\mathrm{N}_{2}$ & $\begin{array}{l}60,000 \\
\text { std. ft }\end{array}$ & Cylinders & Outside \\
\hline 0xygen & & & Cylinders & Welding shop \\
\hline $\begin{array}{l}\text { Potassium } \\
\text { hydroxide }\end{array}$ & $\mathrm{KOH}$ & $10,0001 \mathrm{lb}$ & Tanks & \\
\hline Propane & & & Tanks & Outside building \\
\hline Trichloroethylene & & & 55-gal drum & Outside \\
\hline Wax & & 50 gal & & Inside \\
\hline
\end{tabular}




\section{A.2.2 Facility Description}

Buildings

Figure A.2 shows the location of buildings at the Combustion Engineering Hematite plant site.

The oxide plant has four levels with dimensions of $31 \mathrm{ft}$ by $36 \mathrm{ft}$ by $50 \mathrm{ft}$ high. The building has a concrete floor, corrugated steel siding, and a metal roof. It opens directly into the pellet plant. Next to the oxide plant is a 31- by 55-ft loading dock with a metal roof and concrete floor.

The pellet plant has dimensions of $83 \mathrm{ft}$ by $161 \mathrm{ft}$ by $17 \mathrm{ft}$ high. The pellet production area occupies an 83- by 83-ft section of the building and the remainder is used for offices and storage. The pellet plant has concrete floors, concrete block walls, and a concrete-on-metal roof.

The recycle/recovery areas and laboratory are in a structure $83 \mathrm{ft}$ by $215 \mathrm{ft}$ by $16 \mathrm{ft}$ high. This building also has concrete floors, exterior concrete block walls with windows and a concrete-on-metal roof. About $6000 \mathrm{ft}^{2}$ are used for uranium recycle and recovery, $2500 \mathrm{ft}^{2}$ for a quality control laboratory, and the rest for offices, change areas, and maintenance.

Process areas of the plant are not designed to withstand an earthquake or tornado.

\section{HVAC Systems}

off gases from UF 6 conversion pass through metal filters and dry scrubbers containing limestone to extract HF. High-efficiency particulate air filters are provided in the exhaust stacks of the oxide building where UF 6 conversion takes place. An unfiltered exhaust is also located in the oxide building to prevent $\mathrm{H}_{2}$ buildup in case of a leak. The $V$-blenders are enclosed in a ventilated hood with a minimum face velocity of $100 \mathrm{ft} / \mathrm{min}$.

The pellet plant has two manifold systems, and each container has two banks of absolute filters and two banks of prefilters. The prefilters protect the final filters.

Ventilation air from the cylinder heel processing equipment is exhausted through a single final filter.

\section{Engineered Safety Systems}

The Hematite plant has a nuclear alarm system consisting of gammasensitive detectors, alarms, and a remote indicator panel at the guard station. A UF 6 vaporizer alarm system is also in place to detect UF 6 leaks. 


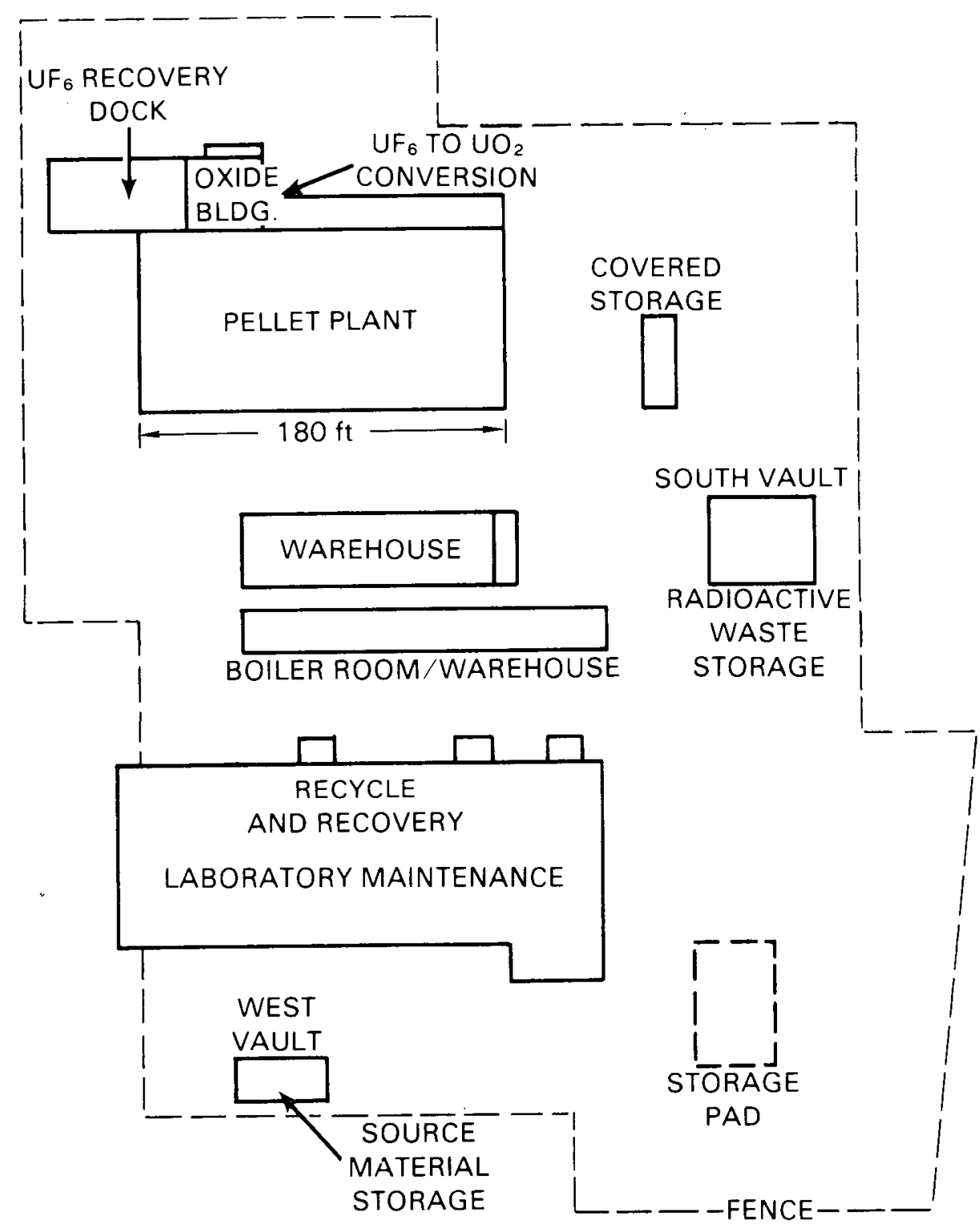

FIGURE A.2. Location of Buildings and Facilities on Combustion Engineering Hematite Plant Site 
Surrounding Area

The nearest residence is 0.5 mile southwest of the plant site. The plant is surrounded by woodlands, water bodies, and open spaces.

\section{A.2.3 Inventory}

Radioactive Inventory

Plant capacity is 225 MTU per year. Possession limits for the plant are given in Table A.4.

TABLE A.4. Possession Limits for the Combustion Engineering Hematite Plant

\begin{tabular}{|c|c|c|}
\hline Material & Form & Quantity \\
\hline $\begin{array}{l}\text { Uranium enriched to } \\
\text { maximum of } 4.1 \text { wt } \% \\
235 \text {. }\end{array}$ & Any & $835_{U} \mathrm{~kg}$ contained \\
\hline $\begin{array}{l}\text { Uranium to any enrichment } \\
\text { in } 235 U\end{array}$ & Any & $350 \mathrm{~g}$ \\
\hline Source material & $\begin{array}{l}\text { Uranium and/or } \\
\text { thoriu!n }\end{array}$ & $20,000 \mathrm{~kg}$ \\
\hline
\end{tabular}

Hazardous and Combustible Inventory

Table A.5 lists some of the chemicals used at the Hematite plant.

A natural-gas-fired heater on the roof of the pellet plant supplies heat to the oxide building. The boiler is also fired with natural gas.

A.3 COMBUSTION ENGINEERING, WINDSOR, CONNECTICUT

The Combustion Engineering uranium oxide fuel fabrication plant at Windsor, Connecticut, produces fuel assemblies from $\mathrm{UO}_{2}$ powder and pellets for reactors. Information on this site was taken from Combustion Engineering reports (1980b, 1981a, 1981b).

\section{A.3.1 Process Description}

\section{Operation}

Uranium dioxide powder from the Hematite plant is transported to the Windsor site. The powder is blended, granulated, pressed into "green" pellets, dewaxed in a reducing furnace and sintered in a reducing atmosphere. Sintered pellets are ground to a specified shape, aligned in a linear array, dried in an 
TABLE A.5. Chemicals Used at Combustion Engineering Hematite Plant

\begin{tabular}{|c|c|c|c|c|}
\hline Chemical & Formula & Use & $\begin{array}{l}\text { Amount, } \\
1 \mathrm{~b} / \mathrm{yr}\end{array}$ & $\begin{array}{l}\text { Storage } \\
\text { Capacity }\end{array}$ \\
\hline Ammonia (anhydrous) & $\mathrm{NH}_{3}$ & Reducing gas & 420,000 & $10,000 \mathrm{gal}$ \\
\hline $\begin{array}{l}\text { Anticorrosion } \\
\text { chemicals }\end{array}$ & & Boiler treatment & 2,600 & \\
\hline Detergent & & Laundry & 400 & \\
\hline Fuel oil & & Backup power & & \\
\hline Hydrochloric acid & $\mathrm{HCl}$ & $\begin{array}{l}\text { Cleaning heat exchanger } \\
\text { tubes in steam boiler }\end{array}$ & 850 & \\
\hline $\begin{array}{l}\text { Hydrogen (compressed } \\
\text { gas) }\end{array}$ & $\mathrm{H}_{2}$ & & & $136,000 \mathrm{ft}^{3}$ \\
\hline Hydrogen peroxide & $\mathrm{H}_{2} \mathrm{O}_{2}$ & $\begin{array}{l}\text { Adjust pH in wet } \\
\text { recovery }\end{array}$ & 20,100 & \\
\hline Hydropholic starch & $\mathrm{C}_{6} \mathrm{H}_{16} \mathrm{O}_{5}$ & $\begin{array}{l}\text { Lubricate pellet } \\
\text { cavities }\end{array}$ & 1,500 & \\
\hline Liquid propane & & $\begin{array}{l}\text { Heat to emergency } \\
\text { center }\end{array}$ & & $\begin{array}{l}300 \mathrm{gal} \text { at } \\
2,200 \mathrm{ib} / \mathrm{in} .^{2},\end{array}$ \\
\hline Natural gas & & Power & & $\begin{array}{l}2,000 \text { gal } \\
\text { underground }\end{array}$ \\
\hline Nitric acid & $\mathrm{HNO}_{3}$ & $\begin{array}{l}\text { Dissolve } \mathrm{U}_{3} \mathrm{O}_{8} \text { in wet } \\
\text { recovery }\end{array}$ & 9,850 & \\
\hline Nitrogen (1 iquid) & $\mathrm{N}_{2}$ & & 500,000 & 1,000 gal \\
\hline Organic binder & & Added to trichloroethane & 900 & \\
\hline Potassium hydroxide & $\mathrm{KOH}$ & Wet scrubber liquid & 3,500 & \\
\hline Sodium chloride & $\mathrm{NaCl}$ & $\begin{array}{l}\text { Regenerate deionizing } \\
\text { resins }\end{array}$ & 7,500 & \\
\hline Sodium hydroxide & $\mathrm{NaOH}$ & $\begin{array}{l}\text { Regenerate resins for } \\
\text { deionizing water }\end{array}$ & 4,500 & \\
\hline Sulfuric acid & $\mathrm{H}_{2} \mathrm{SO}_{4}$ & $\begin{array}{l}\text { Regenerate demineralizer } \\
\text { resins }\end{array}$ & 5,000 & \\
\hline Trichloroethane & $\mathrm{CH}_{3} \mathrm{CCl}_{3}$ & Pellet binder & 9,500 & \\
\hline
\end{tabular}


oven, and loaded into a fuel tube. Caps are welded on the end of the fuel rod, and rods are inspected before being bundled together into assemblies for

shipping to a reactor site.

Waste Disposal

Liquid waste is collected in ten 2,000-gal retention tanks located in a building separate from the process building. The wastes are diluted to $3.0 \times$ $10^{-5} \mu \mathrm{Ci} / \mathrm{ml}$ before being released to the retention tanks. The waste is eventually discharged to an industrial waste line, which carries it to a creek and to the Farmington River.

Solid waste is collected in 55-gal barrels and shipped to a licensed waste disposal contractor.

\section{A.3.2 Facility Information}

Buildings

The Windsor site facility is shown in Figure A.3. The shop section of the fuel manufacturing building has concrete flooring, corrugated asbestos siding, and a poured gypsum roof deck about $30 \mathrm{ft}$ above the floor.

The front section of the fuel manufacturing building has concrete flooring, exterior concrete block with full windows, and a poured gypsum roof.

The warehouse is a prefabricated rigid frame steel structure housing incoming fuel shipping containers, raw materials, and finished components.

The buildings can withstand 100 mph winds and Zone 2 intensity earthquakes on the Mercalli scale.

HVAC Systems

Four systems operate in the fuel manufacturing building area to control airborne releases. They are listed in Table A.6 with their airflow capacity and number of absolute filters.

TABLE A.6. Airflow in Combustion Engineering Windsor Plant

\section{Process Area}

Powder preparation and pressing

Furnace $\mathrm{H}_{2}$ burnoff

Pellet grinding and rod loading

Recycle powder area
Airflow Number of Capacity, $\mathrm{ft}^{3} / \mathrm{min}$ Absolute Filters

$\begin{array}{rr}12,100 & 12 \\ 1,340 & 4 \\ 19,422 & 21 \\ 6,000 & 6\end{array}$

Each system has prefilters and absolute filters. The absolute filters are $99.97 \%$ efficient. 


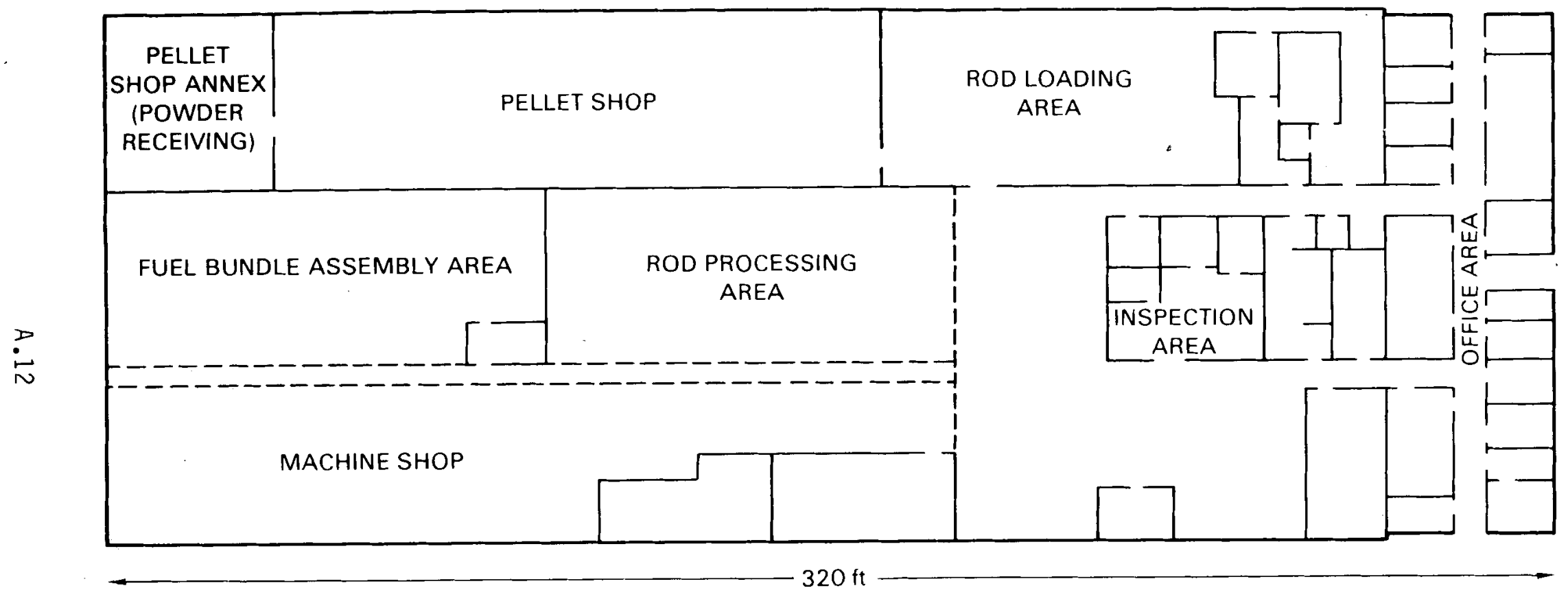

FIGURE A.3. Combustion Engineering Windsor Site Facility Diagram 
An overhead sprinkler system and portable fire extinguishers are located throughout the plant. Only portable dry chemical fire extinguishers are allowed in the unclad fuel-handling area.

Criticality detectors are located throughout the plant.

Surrounding Area

The Windsor site is surrounded by a landfill, the Farmington River, wooded areas and agricultural fields. A government laboratory used for training nava? personnel to operate prototype submarine nuclear reactors is located east of the facility. Onsite is a coal gasification test plant and a nuclear

laboratory. The nearest residence is 700 m east of the manufacturing building.

\section{A.3.3 Inventory}

License limits for the plant are shown in Table A.7.

\section{TABLE A.7. License Limits at Combustion Engineering}

\begin{tabular}{|c|c|c|}
\hline Material & Location & Quantity \\
\hline Uranium $0 x i d e s \leq 4.1 \%{ }^{235} \mathrm{U}$ & Manufacturing Building & $500,000 \mathrm{~kg} \mathrm{U}$ \\
\hline Uranium $\leq 20 \% 2 \overline{3} 5 \mathrm{U}$ & Any Building & $4,800 \mathrm{~g}^{235} \mathrm{U}$ \\
\hline Natural and/or Depleted U & Any Building & $10,000 \mathrm{~kg} \mathrm{U}$ \\
\hline Encapsulated ${ }^{238} \mathrm{Pu}$ & Any Building & 5 sources each $2 \mathrm{~g}{ }^{238} \mathrm{pu}$ \\
\hline Pu Analytical Samples & Any Building & $160 \mu \mathrm{g}$ \\
\hline
\end{tabular}

Hazardous and Combustible Inventory

Table A.8 lists chemicals used at the Combustion Engineering Windsor plant. The amounts stored and used in the plant and yearly consumption are also given.

\section{A.4 EXXON NUCLEAR, RICHLAND, WASHINGTON}

The Exxon Nuclear uranium oxide fuel fabrication facility in Richland, Washington, produces $\mathrm{UO}_{2}$ fuel elements from UF 6 . Information on this facility was taken from Exxon reports $(1979,1981)$ and from a report by Jersey Nuclear Company (1971). 


\section{TABLE A.8. Inventory of Chemicals Combustion Engineering Windsor Plant}

\begin{tabular}{|c|c|c|c|c|}
\hline Chemical & Formula & Storage Contal nment & Use & $\begin{array}{c}\text { Yearly } \\
\text { Consumption } \\
\end{array}$ \\
\hline Acetone & & 1-gal dispenser cans & Cleaning through facllity & $600 \mathrm{gal} / \mathrm{yr}$ \\
\hline A lumi num nitrate & Al $\left(\mathrm{NO}_{3}\right)$ & & $\begin{array}{l}\text { Mixed with process water } \\
\text { to form bath to stop } \\
\text { pickling action }\end{array}$ & $1,200 \mathrm{lb} / \mathrm{yr}$ \\
\hline Anhydrous ammonia & & 2 tanks $(8,000$ and $6,000 \mathrm{gal})$ & Regenerate demineralized resins & $1,800 \mathrm{lb} / \mathrm{yr}$ \\
\hline Caustic & $\mathrm{NaOH}$ & & Pickle Zircaloy components & $1,000 \mathrm{lb} / \mathrm{yr}$ \\
\hline Detergent solution & & & Clean components and assemblies & $800 \mathrm{lb} / \mathrm{yr}$ \\
\hline Diesel & & & & $1,300 \mathrm{lb} / \mathrm{yr}$ \\
\hline Freon & & & $\begin{array}{l}\text { Degreasing materials before } \\
\text { Introduction to process }\end{array}$ & $110 \mathrm{gal} / \mathrm{yr}$ \\
\hline Hydrochlor ic acid & $\mathrm{HCl}$ & & Regenerate demineral lzer resins & $5,000 \mathrm{lb} / \mathrm{yr}$ \\
\hline Hydrofluorlc acid & $\mathrm{HF}$ & & $\begin{array}{l}\text { Mixed with nitric acid and } \\
\text { water for pickling solution }\end{array}$ & $50 \mathrm{gal} / \mathrm{yr}$ \\
\hline |sopropyl alcohol & & 1-gal olspenser cans & Cleanlng & $1,100 \mathrm{gal} / \mathrm{yr}$ \\
\hline $\begin{array}{l}\text { Liquid nitrogen } \\
\text { Liquid propane }\end{array}$ & $\mathrm{N}_{2}$ & $\begin{array}{l}\text { 5000-gal Insulated tank } \\
1500 \text {-gal tank }\end{array}$ & & \\
\hline Machine coolants & & & $\begin{array}{l}\text { Mixed with process water and } \\
\text { used as cooling solution } \\
\text { during machining operations }\end{array}$ & $110 \mathrm{gal} / \mathrm{yr}$ \\
\hline Perchloroethylene & & & $\begin{array}{l}\text { Degrease raw material before } \\
\text { to introduction to process }\end{array}$ & $11,2001 \mathrm{~b} / \mathrm{yr}$ \\
\hline Polyvinyl alcohol & & & $\begin{array}{l}\mathrm{UO}_{2} \text { powder preparation process } \\
\text { to give powder correct flow } \\
\text { quality for pressing }\end{array}$ & $6000 \mathrm{lb} / \mathrm{yr}$ \\
\hline Nitrle acid & $\mathrm{HNO}_{3}$ & $\begin{array}{l}5,000 \text {-gal stainless steel } \\
\text { tank }\end{array}$ & Pickling solution & $800 \mathrm{gal} / \mathrm{yr}$ \\
\hline $\begin{array}{l}\text { Spent pickling } \\
\text { solution }\end{array}$ & & & PIckle ZIrcaloy components & $1000 \mathrm{gal} / \mathrm{yr}$ \\
\hline Vacuum pump oll & & & $\begin{array}{l}\text { Used in vacuum pumps to } \\
\text { achleve low pressure in } \\
\text { process }\end{array}$ & $200 \mathrm{gal} / \mathrm{yr}$ \\
\hline Zinc stearate & & & $\begin{array}{l}\text { Lubricate pellet disc cavities } \\
\text { in backup generators }\end{array}$ & $1,3001 \mathrm{~b} / \mathrm{yr}$ \\
\hline
\end{tabular}




\section{A.4.1 Process Description}

Operation

At the Richland Exxon plant, $U_{6} 6$ is received in cylinders, hydrolyzed to $\mathrm{UO}_{2} \mathrm{~F}_{2}$ and precipitated from solution with the addition of ammonia. The ADU precipitate is then calcined to $\mathrm{UO}_{2}$.

The $\mathrm{UO}_{2}$ is blended and pressed into pellets, which are then sintered and ground to specified diameter. The pellets are stored temporarily and loaded into fuel rods, which are then welded shut. The fuel rods are stored, inspected, etched, and assembled into elements. Elements are stored before shipping.

\section{Waste Disposal}

Liquid waste is stored in lagoons before discharge. Solid contaminated waste is stored in warehouses awaiting treatment or offsite burial.

Scrap Recovery

A solvent extraction system is used to recover uranium from scrap. The process involves dissolution in nitric acid, solvent extraction, stripping, ADU precipitation and calcination. Exxon also has an ion exchange column to separate uranium from low-level contaminated solutions containing 300 ppm uranium.

\section{A.4.2 Facility Description}

Building

Figure A.4 is a diagram of the facility with processing areas identified.

Progess buildings are designed to withstand an average wind loading of $20 \mathrm{lb} / \mathrm{ft}^{2}$ and a design basis earthquake with an acceleration of $0.17 \mathrm{~g}$.

\section{HVAC Systems}

Airflow is from areas of low to high potential contamination. Approximately 7 air changes per hour are supplied to the uranium operations.

Room air is recirculated through HEPA filters. From 1 to 3 stages of HEPA filters are provided to filter process air. Scrubbers are used to clean some process air.

\section{Engineered Safety Systems}

Areas of the plant are labeled to indicate if water may be used to combat fires. Radioactive material storage areas do not have sprinklers; combustibles are kept to a minimum in these areas. Dry powder and carbon dioxide fire extinguishers are located throughout the plant. 


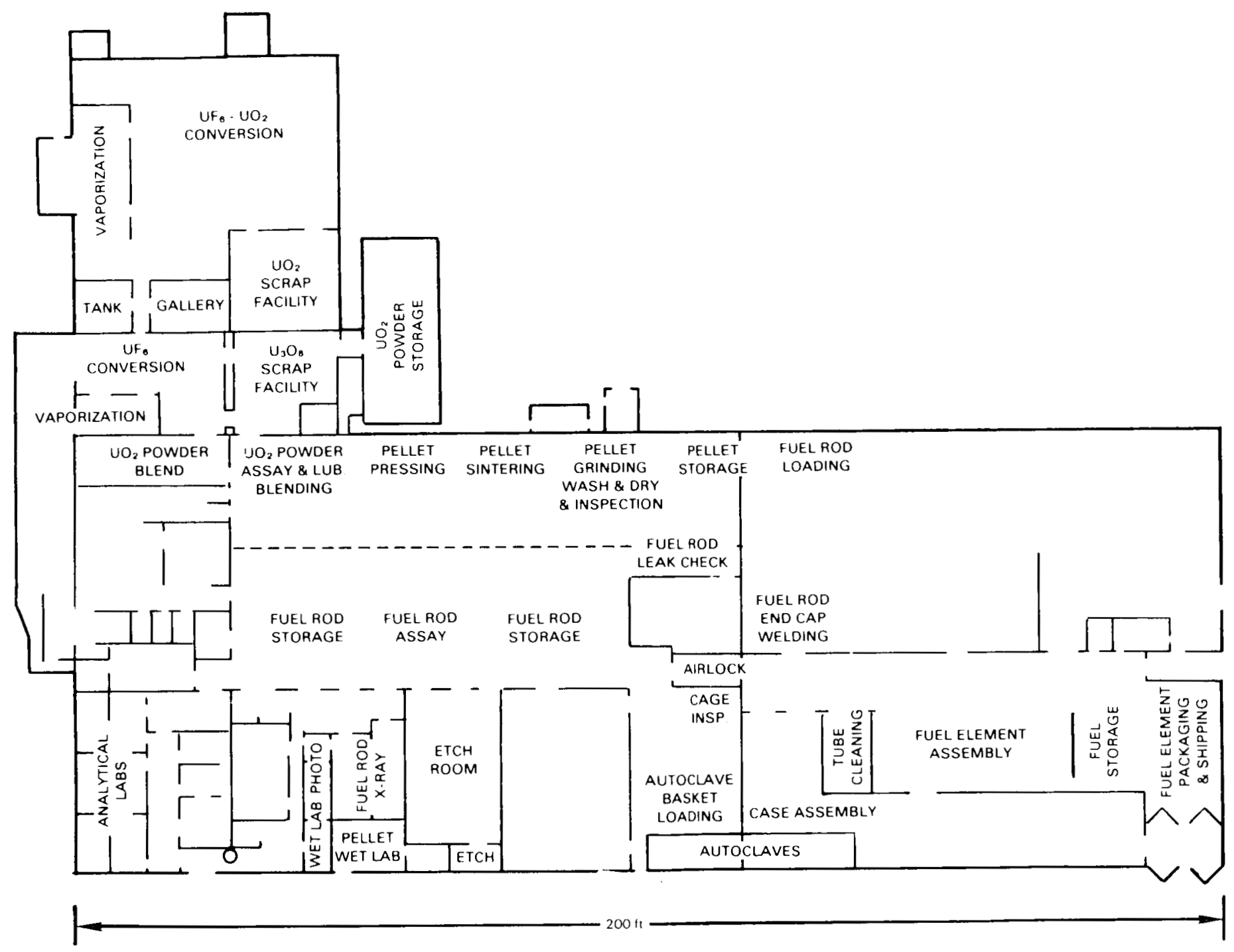

FIGURE A.4. Exxon Nuclear $\mathrm{UO}_{2}$ Building Diagram 
Burning devices and $\mathrm{H}_{2}$ gas detectors are used to prevent buildup of explosive or flammable gases around the sintering furnaces and ovens. Hydrogen is stored outside of the building, and flow of $\mathrm{H}_{2}$ to the furnaces automatically shuts off in case of loss of ventilation.

Neutron detectors are located throughout the plant.

Final HEPA filters are fire resistant and protected from fires by either a liquid scrubber, an automatic sprinkler deluge system, or an automatic cool air injection in the exhaust air upstream of the filters. Rate-of-rise heat detectors as well as automatic and manual alarm systems are provided in the

facility.

Surrounding Area

The facility is located next to a government reservation. Research and production facilities involving nuclear materials are located nearby. The immediate surroundings are mostly sagebrush-covered desert.

A.4.3 Inventory

Radioactive Inventory

Table A.9 gives the possession limits at the Exxon plant.

Hazardous and Combustible Inventory

Table A.10 gives storage locations of various chemicals at the Exxon plant. Combustibles are kept to a minimum in storage areas. Tributyl phosphate in dodecane is used in solvent extraction operations and ion exchange resins (some of wich are combustible) are used in ion exchange columns.

TABLE A.9. Possession Limits at Exxon Nuclear Plant

\begin{tabular}{|c|c|c|c|}
\hline $\begin{array}{l}\text { Radioactive } \\
\text { Material } \\
\end{array}$ & Form & Use & Quantity \\
\hline Uranium-235 & $\begin{array}{rl}19.99 w t \% & 235 \mathrm{UJ} \\
5 \text { wt } \% & 235_{\mathrm{U}}\end{array}$ & Analyses & $\begin{array}{l}25 \mathrm{~g} \\
200 \mathrm{~kg} \\
10,000 \mathrm{~kg}\end{array}$ \\
\hline \multirow[t]{3}{*}{ Plutonium } & $\mathrm{PuO}_{2}$ & $\begin{array}{l}\text { Sealed sources and } \\
\text { standards }\end{array}$ & $1 \mathrm{mg}$ \\
\hline & $\mathrm{PuO}_{2}$ & $\begin{array}{l}\text { Surface contamina- } \\
\text { tion on equipment }\end{array}$ & $500 \mathrm{~g}$ \\
\hline & $\mathrm{PuO}_{2}-\mathrm{UO}_{2}$ & $\begin{array}{l}\text { Encapsulated in fuel } \\
\text { rods or NRC-approved } \\
\text { containers }\end{array}$ & $\sim 100 \mathrm{~kg}$ \\
\hline
\end{tabular}


TABLE A.10. Storage Locations of Chemicals at Exxon Nuclear Plant

$\begin{array}{ll}\frac{c}{\text { Chemical }} & \frac{\text { Location }}{\text { Anhydrous ammonia }} \\ \begin{array}{l}\text { Gases (helium, argon, } \\ \text { oxygen, acetylene) }\end{array} & \text { Cylinders outside of building } \\ \text { Hydrofluoric acid } & \text { Plastic carboys in the etch room } \\ \text { Liquid nitrogen } & \text { Outside manufacturing building } \\ \text { Nitric acid } & \text { Outdoor tanks } \\ \text { Sodium hydroxide } & \text { Outdoor tanks }\end{array}$

\section{A.5 GENERAL ELECTRIC COMPANY, WILMINGTON, NORTH CAROLINA}

The General Electric uranium oxide fuel fabricatigp plant produces fuel rods for nuclear reactors from $U F_{6}$ enriched up to $4 \% 23 \mathrm{U}_{\mathrm{U}}$. The plant is located in Wilmington, North Carolina. Information on this site was taken from General Electric reports $(1974,1982)$.

\section{A.5.1 Process Description}

\section{Operation}

Uranium hexafluoride, up to $4 \%$ enriched $235 U$, is vaporized from 2.5-ton, 30-in.-diameter cylinders. The $U F_{6}$ gas is hydrolyzed with water forming $\mathrm{UO}_{2} \mathrm{~F}_{2}$. Ammonium hydroxide is added to precipitate ADU from solution. The ADU slurry is centrifuged in two stages, then calcined at $1200^{\circ} \mathrm{C}$ in a two-stage calciner to produce $\mathrm{UO}_{2}$.

The $\mathrm{UO}_{23}$ either from powder storage or delivered to the plant as $6 \%$ enriched $235 \mathrm{U}$, is molded into $1 / 2$-in.-diameter pellets $1 / 2 \mathrm{in}$. long. The pellets are sintered in a reducing furnace at $3000^{\circ} \mathrm{F}$, ground down to specified dimensions, inspected, dried, and loaded into Zircaloy tubes. An end cap is fitted onto the tubes and welded into place. Fuel rods are assembled into groups of 49 or 64 and packaged for shipment.

Waste Disposal

Combustible wastes are incinerated. Noncombustible waste is collected in boxes for licensed burial. Liquid wastes are collected in quarantined vessels and classified as nitrate wastes. Lime is added to precipitate fluoride and free ammonia.

Zirconium fines are burned on site under carefully controlled conditions. 
Scrap Recovery

Equipment located in the $\mathrm{UF}_{6}$ to $\mathrm{UO}_{2}$ conversion area recovers uranium scrap to be recycled back into the plant.

Other Operations

Control mechanisms and auxiliary equipment for reactors are manufactured in the plant in facilities separate from the fuel fabrication process. Nonnuclear components of the assemblies are also fabricated.

\section{A.5.2 Facility Description}

Building

The fuel manufacturing building shown in Figure $A .5$ has concrete block walls, and insulated metal siding over a steel framework, and a concrete floor. The roof is metal deck and insulation topped with asphalt and gravel. The roof is designed for $40-1 \mathrm{~b} / \mathrm{ft}^{2}$ live-load in addition to the dead load factor.

\section{HVAC Systems}

A stage of HEPA filters cleans final exhaust air from the manufacturing area. In addition, other air cleaning devices such as prefilters and primary HEPA filters for powder operations and wet scrubbers for chemical processes are in place.

Uranium processing areas are designed to maintain negative pressure with respect to the environment.

Table A.11 lists the air circulation in the fuel manufacturing building.

\section{Engineered Safety Systems}

Sensors and alarms are located throughout the plant to detect high levels of radioactivity.

Sprinkler systems for fire suppression are located in the plant except in the $\mathrm{UO}_{2}$ powder storage area and chemical process control room. A Halon ${ }^{\circledR}$ fire suppression system is used in computer facilities. Smoke detectors are located in exhaust systems and manual fire extinguishers are located throughout the plant.

(B) Halon is a trademark of the Allied Chemical Corp., Morristown, NJ 07960 


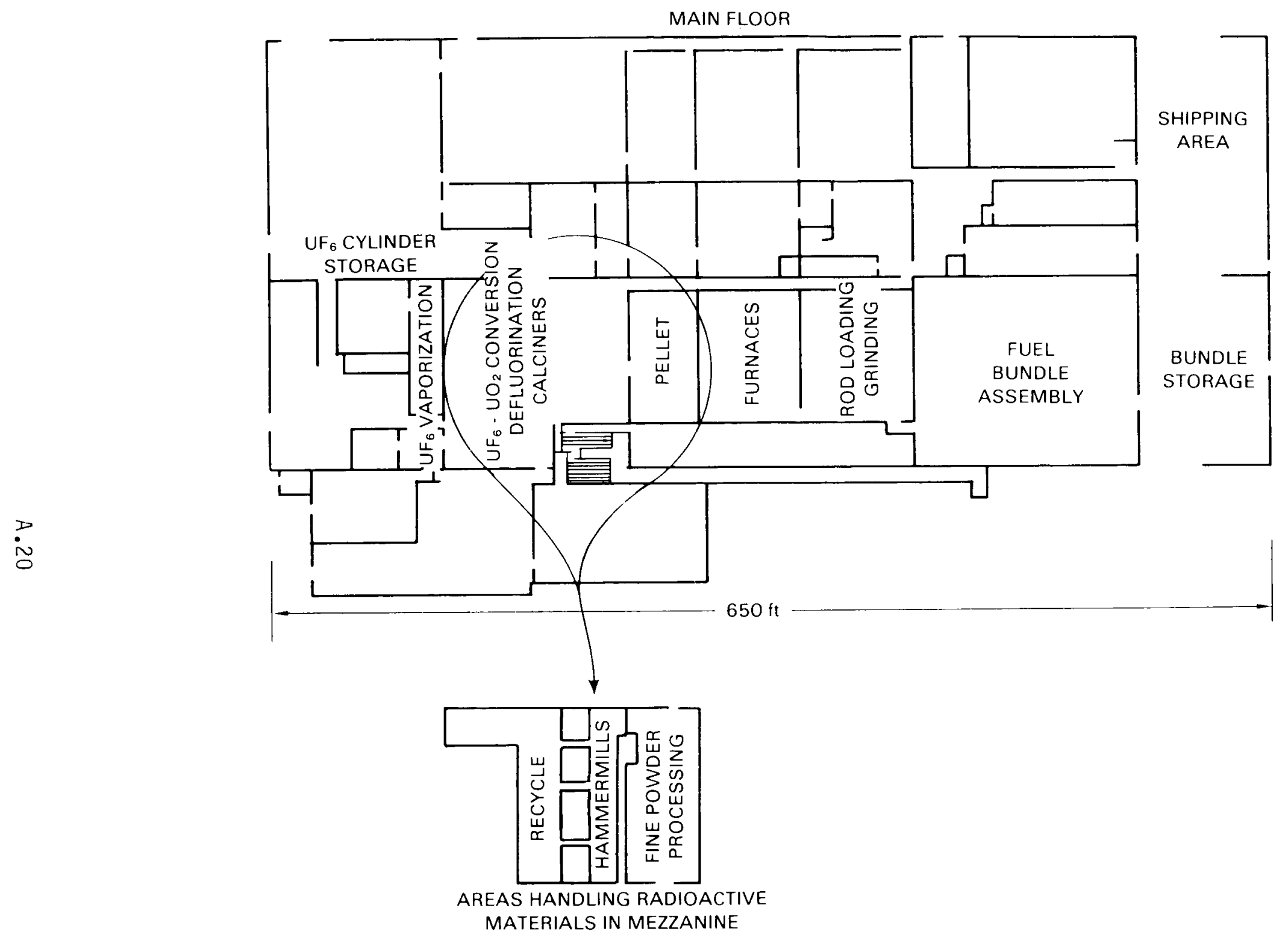

FIGURE A.5. Diagram of General Electric Wilmington Fuel Manufacturing Building 
TABLE A.11. Air Circulation in General Electric Wilmington Plant

\begin{tabular}{|c|c|c|c|c|}
\hline Area & $\begin{array}{l}\text { Volyme, } \\
\mathrm{ft}^{3} \\
\end{array}$ & $\begin{array}{l}\text { Exhaust, } \\
\text { std. } \mathrm{ft}^{3} / \text { min } \\
\end{array}$ & $\begin{array}{l}\text { Recirculation, } \\
\text { std. } \mathrm{ft} / \mathrm{min} \\
\end{array}$ & $\begin{array}{l}\text { No. of Area } \\
\text { Changes } / \mathrm{h}\end{array}$ \\
\hline $\mathrm{UF}_{6}-\mathrm{UO}_{2}$ conversion & 422,900 & 35,570 & 80,400 & 17 \\
\hline Vaporization & 17,000 & 6,000 & 9,000 & 13 \\
\hline North sintering & 160,500 & 12,000 & 53,000 & 24 \\
\hline South sintering & 67,600 & 7,370 & 17,630 & 22 \\
\hline North $\mathrm{UO}_{2}$ powder storage & 78,500 & 5,000 & 7,000 & 9 \\
\hline South $\mathrm{UO}_{2}$ powder storage & 67,700 & 10,000 & 2,000 & 11 \\
\hline North segmentizing & 160,000 & 11,700 & 16,000 & 10 \\
\hline South segmentizing & 74,000 & 11,700 & 16,000 & 10 \\
\hline North pelletizing & 67,620 & 8,600 & 11,300 & 18 \\
\hline South pelletizing & 49,245 & 6,300 & 8,300 & 18 \\
\hline North waste retention & 62,500 & 4,000 & 8,000 & 12 \\
\hline South waste retention & 62,500 & 4,000 & 8,000 & 12 \\
\hline
\end{tabular}

Surrounding Area

Property north of the Wilmington site is wooded and has limited developinent of any kind. South of the site, there is a lightly settled residential area. It is unlikely that an accident could occur at neighboring facilities that would affect the plant site.

\section{A.5.3 Inventory}

\section{Radioactive Inventory}

An inventory of radioactive naterials at the Wilmington plant is given in Table A.12. Table A.13 gives the license limits.

Hazardous and Combustibles Inventory

Table A.14 lists the type, quantity, and location of chemicals at the Wilmington plant.

\section{A.6 WESTINGHOUSE ELECTRIC, COLUMBIA, SOUTH CAROLINA}

The Westinghouse Electric uranium oxide fuel plant produces uranium fuel rods for reactors from UF 6 enriched to a maximum of $4.15 \% 235 \%$. Information on this facility was taken from Westinghouse Electric Corporation reports (1976, 1980, 1981) and from a visit to the plant. 
TABLE A.12. Radioactive Materials Inventory at General Electric Wilmington Radioactive Materials

Uranium nitrate crystals outside of fuel manufacturing building Container Size

Amount, MTU

JF $_{6}$ in cylinders outside of fuel

manufacturing building

$\sim 1.5$ tons/cylinder

23

$\mathrm{JF}_{6}-\mathrm{UO}_{2}$ conversion

$\mathrm{UO}_{2}$ powder storage

Powder/pellets

Intermediate product

Pellets

Fuel rods

Poison pellets

Poison rods

Assemblies

Press scrap

Grinder residue

Grinder residue

Dirty powder

Residue/sludge

Solid waste

20-25 kg units

87

$16 \mathrm{~kg}$ units

2

$20 \mathrm{~kg}$ units 2

$15 \mathrm{~kg}$ units $\quad 16$

$3 \mathrm{~kg} \mathrm{U} / \mathrm{rod}$

41

$11 \mathrm{~kg} \mathrm{U} /$ container 2

$3 \mathrm{~kg} \mathrm{U} / \mathrm{rod} \quad 8$

$3 \mathrm{~kg} \mathrm{U} / \mathrm{rod} \quad 263$

$16 \mathrm{~kg} \mathrm{U} /$ container $\quad 3$

$17 \mathrm{~kg} \mathrm{U} /$ container 3

$17 \mathrm{~kg} \mathrm{U} /$ container 4

$20 \mathrm{~kg} \mathrm{U} /$ container 4

$10 \mathrm{~kg} \mathrm{U} /$ container 4

Samples

$2 \mathrm{~kg} \mathrm{U} /$ container

0.3

Standards

$0.3 \mathrm{~kg} \mathrm{U} / \mathrm{sample}$

$2 \mathrm{~kg} \mathrm{U} /$ units

1

1

TABLE A.13. Possession Limits at General Electric Wilmington

\begin{tabular}{|c|c|c|c|}
\hline Element & Form & $\begin{array}{c}\text { Maximum Engichment } \\
\text { in } 235_{U} \\
\end{array}$ & Quantity \\
\hline Uranium & $\begin{array}{l}\text { Any } \\
\text { Loaded fuel rods } \\
\mathrm{UO}_{2} \text { powder } \\
\text { Any } \\
\text { Any }\end{array}$ & $\begin{array}{l}4 \% \\
4.5 \% \\
6.0 \% \\
\text { Any } \\
15 \%\end{array}$ & $\begin{array}{l}50,000 \mathrm{~kg}^{235} \mathrm{U} \\
350 \mathrm{~g}^{235} \mathrm{U} \\
500 \mathrm{~kg}\end{array}$ \\
\hline Plutonium & $\begin{array}{l}\text { Analytical samples } \\
\text { Standards } \\
\text { Sealed neutron sources }\end{array}$ & & $\begin{array}{l}1.5 \mathrm{mCi} \\
1 \mathrm{mg} \text { and } \leq 65 \mathrm{mCi} \\
7 \mathrm{~g}\end{array}$ \\
\hline
\end{tabular}


TABLE A.14. Chemicals and Flammable Materials Inventory at General Electric Wilmington Plant

Outside of Fuel Manufacturing Building

Acetone

Ammonium hydroxide, $29.4 \%$

Anhydrous ammonia

Argon

Heli ium

Hydrochloric acid, $30 \%$

Hydrochloric acid, $37 \%$

Hydrochloric acid, $72 \%$

Hydrogen

Lime

Nitric acid, $56 \%$

Nitrogen

oxygen

Propane $\left(\mathrm{C}_{3} \mathrm{H}_{8}\right)$

Sodium hydroxide, $50 \%$

Sulfuric acid, $93 \%$

\begin{tabular}{r} 
Amount \\
\hline $550 \mathrm{gal}$ \\
$20,000 \mathrm{gal}$ \\
$15,000 \mathrm{gal}$ \\
$2,400 \mathrm{gal}$ \\
$2,200,000 \mathrm{ft}^{3}$ \\
$7,000 \mathrm{gal}$ \\
$5,000 \mathrm{gal}$ \\
$15,000 \mathrm{gal}$ \\
$65,000 \mathrm{ft}^{3}$ \\
$100,000 \mathrm{gal}$ \\
$5,000 \mathrm{gal}$ \\
$10,500 \mathrm{gal}$ \\
$6,000 \mathrm{gal}$ \\
$143,000 \mathrm{gal}$ \\
$7,000 \mathrm{gal}$ \\
$110 \mathrm{gal}$
\end{tabular}

Inside Fuel Manufacturing Building

Carbon dioxide

Nitrogen

Stearic acid

Outside Equipment Building

Acetone

Anhydrous ammonia

Argon

Helium (inside building)

Hydrochloric acid, $30 \%$

Nitric acid, $67.3 \%$

Nitrogen

Sulfuric acid, $93 \%$

Outside Tubing Manufacturing Building

Argon

Helium

Nitric acid, $56 \%$

Sodium hydroxide, $50 \%$

$$
\begin{array}{r}
1,500 \mathrm{gal}^{3} \\
200,000 \mathrm{ft}^{2} \\
5,000 \mathrm{gal} \\
2,000 \mathrm{gal}
\end{array}
$$




\section{A.6.1 Process Description}

Operation

Uranium received in UF 6 cylinders is stored in a bay and on a storage pad outside the plant. The UF 6 is heated in a steam chest and converted to uranyl fluoride and HF. Twenty-seven percent aqueous ammonia is added to precipitate $A D U$, which is separated in a dual centrifuge. The material is calcined at $1700^{\circ} \mathrm{C}$ in a rotary tube drier in a $\mathrm{H}_{2}$ reducing atmosphere to produce $\mathrm{UO}_{2}$.

The $\mathrm{UO}_{2}$ powder is stored temporarily before being pressed into pellets. Pellets are sintered in a furnace and ground to specified diameter, then inspected, stored, and loaded into fuel rods. The rods are sealed, inspected, and grouped into fuel assemblies.

Waste Disposal

Solid wastes are compressed when possible, baled and loaded into fiberboard boxes or other containers. The containers are gamina scanned and stored before disposal. Solid wastes may be stored outdoors. Contaminated combustibles are incinerated, and noncombustibles are shipped to a licensed burial site.

Liquid wastes may be treated by filtration, flocculation, lime addition, distillation, or precipitation in holding lagoons to remove uranium, ammonia, and fluorides.

\section{Scrap Recovery}

Uranium is recovered from scrap in batch quantities. Clean scrap is crushed to a powder in a mechanical granulator, then screened in a vibratory separator to remove gross impurities. Dirty scrap is dissolved in nitric acid; ADU is precipitated from solution and mechanically separated with a centrifuge, then calcined to $\mathrm{UO}_{2}$ or $\mathrm{U}_{3} \mathrm{O}_{8}$, packaged, and stored.

A solvent extraction system recovers uranium from grease and oil contaminated with $\mathrm{UO}_{2}$, incinerator ash, and oxidation furnace products. The scrap is dissolved in nitric acid and fed countercurrent to a tributyl phosphate solvent mixture. The solvent extracts uranium from solution and then allows the uranium to be stripped in a puised stripping column. A flash evaporator concentrates the UNH product, which is stored before removal and conversion to $\mathrm{UO}_{2}$.

\section{A.6.2 Facility Description}

Buildings

The plant site is shown in Figure A.6, with process areas identified. The process building has a structural steel framework, cast concrete curtain walls, and concrete slab floors. The solvent extraction and chemical process development facility and incinerator system are made of prefabricated, prestressed concrete tee panels. A concrete wall separates the main processes from solvent 


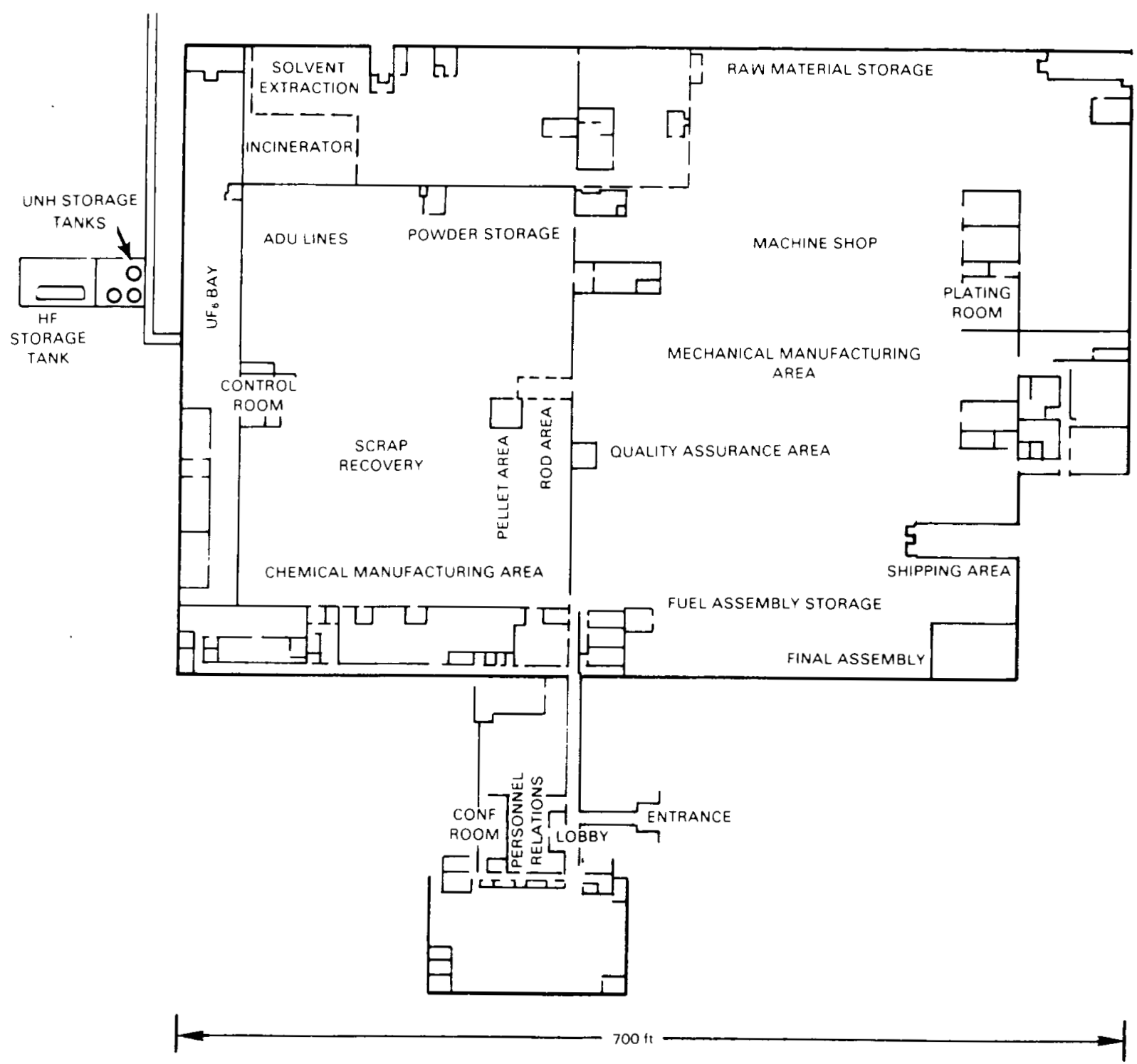

FIGURE A.6. Detailed Site Plan for Westinghouse Electric Columbia Facility

extraction and incineration processes. A partial wall of corrugated metal to excess heat in the sintering area extends from the ceiling to about 6 or $7 \mathrm{ft}$ from the floor. It separates the sintering furnace area from pellet inspection, grinding, and tube-filling processes.

HVAC Systems

Exhaust hoods, HEPA filters, and scrubbers clean the process exhausts. The scrubber cleans air from UF 6 conversion and scrap recovery processes. Building air is recirculated, and pressure is kept negative with respect to the outside. 
Engineered Safety Systems

Hydrogen and propane gas distribution systems have manual and automatic interlock controls to shut off the flow of gas at the source on sensing a pressure loss. Manual extinguishers are provided for fire protection.

Surroundings

The plant is surrounded by farmiand on a site about 8 miles from columbia.

\section{A.6.3 Inventory}

Radioactive Inventory

A typical inventory is $757,000 \mathrm{~kg}$ uranium at 2 to $3 \%$ average enrichment. The inventory breakdown is shown in Table A.15. License limits are shown in Table A.16.

Hazardous and Combustible Inventory

Chemicals in the Westinghouse plant and their uses are given in Table A.17. Propane, fuel oil, anhydrous ammonia, nitric acid, $\mathrm{NaCO}_{3}$, and liquid $\mathrm{H}_{2}, \mathrm{~N}_{2}$, and $\mathrm{Ar}$ are stored in the tank farm.

TABLE A.15. Radioactive Materials Inventory at Westinghouse Columbia Plant

\begin{tabular}{lcr}
\multicolumn{1}{c}{ Material } & $\begin{array}{c}\text { Percent } \\
\text { of Inventory }\end{array}$ & \multicolumn{2}{c}{$\begin{array}{c}\text { Amount, } \\
\text { kg U U }\end{array}$} \\
\cline { 1 - 1 } $\mathrm{UF}_{6}$ & 29 & \\
Assemblies & 220,000 \\
Rods & 29 & 204,000 \\
$\mathrm{UO}_{2}$ & 8 & 220,000 \\
$\mathrm{U}_{3} \mathrm{O}_{8}$ & 3 & 60,500 \\
Pellets & 1 & 22,700 \\
Scrap & 0.6 & 7,600 \\
UNH & 0.2 & 4,500 \\
Hard scrap & 0.4 & 1,500 \\
Hold-up & 0.07 & 3,000 \\
Baled waste & 0.08 & 500 \\
Incinerator ash & 0.16 & 1,200
\end{tabular}


TABLE A.16. License Limits at Westinghouse Columbia Plant

\begin{tabular}{|c|c|c|}
\hline Material & Form & Quantity \\
\hline 235 y & Any form & $350 \mathrm{~g}$ \\
\hline $235 U$ & Any form $\leq 4.15 \mathrm{wt} \%$ & $50,000 \mathrm{~kg}$ \\
\hline $235_{y}$ & Any form $>4.15$ wt $\%$ but $\leq 5$ wt $\%$ & $2,500 \mathrm{~kg}$ \\
\hline $235 y$ & Any form for lab use only & $5 \mathrm{~g}$ \\
\hline${ }^{238} \mathrm{Pu}$ & Sealed sources & $1.5 \mathrm{~g}$ \\
\hline Mixed oxides & $6.6 w t \%$ Pu as sealed fuel rods & $750 \mathrm{~kg} \mathrm{Pu}$ \\
\hline
\end{tabular}

TABLE A.17. Chemicals Used in the Westinghouse Fuel Fabrication Plant

\begin{tabular}{|c|c|}
\hline Chemical & Use \\
\hline Acetone & Sealed rod cleaning \\
\hline Hydraulic fluid & $\begin{array}{l}\text { Used in presses and for tube } \\
\text { loading }\end{array}$ \\
\hline Hydrogen & $\begin{array}{l}\text { Reducing gas for calciner and } \\
\text { sintering furances }\end{array}$ \\
\hline Kerosene & Solvent extraction system \\
\hline Natural gas & Heat calciner \\
\hline Perchlorethylene & Solvent extraction system \\
\hline Tributyl phosphate & Solvent extraction system \\
\hline
\end{tabular}

\section{A.7 REFERENCES}

Babcock and Wilcox, Environmental Report, UF ${ }_{6}-U F_{2}$ Pellet Plant Addition, Docket No. 70-1201, Babcock and Wilson, Lynchburg, Virginia, 1972.

Babcock and Wilcox, Revision 2 of Renewal Application for SNM-42, Docket No. 70-27, U.S. Nuclear Regulatory Commission, Washington, D.C., 1974.

Babcock and Wilcox, Commercial Nuclear Fuel Plant, SNM-1168, Emergency Plan, Docket No. 70-1201, U.S. Nuclear Regulatory Commission, Washington, D.C., $1981 a$.

Babcock and Wilcox, Lynchburg Research Center, Radiological Contingency Plan, License SNM-778, Docket No. 70-824, U.S. Nuclear Regulatory Commission, Washington, D.C, 1981b. 
Combustion Engineering Corporation, Radiological Assessment of Individual Dose Resulting from Routine Operation--Demonstration of Compliance with 40 CFR 190, Docket No. 70-36, U.S. Nuclear Regulatory Commission, Washington, D.C., 1980 a.

Combustion Engineering Corporation, License SNM-1067, C-E NFM-W, Combustion Engineering, Inc., Windsor, Connecticut, 1980b.

Combustion Engineering Corporation, Environinental Impact Information, Combustion Engineering, Inc., Windsor, Connecticut Plant Site, Docket No. 70-1100, U.S. Nuclear Regulatory Commission, Washington, D.C., 1981 .

Combustion Engineering Corporation, Onsite Radiological Contingency Plan License No. SNM-1067, Docket 70-1100, Docket No. 70-1100, U.S. Nuclear Regulatory Cominission, Washington, D.C., $1981 \mathrm{~b}$.

Combustion Engineering Corporation, Radiological Contingency Plan, License No. SNM-33, Docket 70-36, Docket No.70-36, U.S. Nuclear Regulatory Commission, Washington, D.C., 1982.

Exxon Nuclear Company, Application for Renewal of Special Nuclear Material License No. SNM-1227, XN-2, Exxon Nuclear Company, Richland, Washington, 1979.

Exxon Nuclear Company, Richland Fuel Fabrication Plant, Emergency and Radiological Contingency PTan, Part I, XN-NF-32A, Revision 10, Exxon Nuclear Company, Richland, Washington, 1981.

General Electric Company, Environmental Report, General Electric Nuclear Facility, Wilmington, North Carolina, NED020197 CTass I, Wilmington, North Carolina, 1974.

General Electric Company, Environmental Contingency Plan, Docket №. 70-1113, U.S. Nuclear Regulatory Commission, Washington, D.C., 1982.

Jersey Nuclear Company, Uranium Oxide Fuel Plant Supplemental Environmental Report, Docket No. 70-1257, Jersey Nuclear Company, Richland, Washington, 1971.

Westinghouse Electric Corporation, Application for a Materials License for the Nuclear Fuel Division at the Columbia Site, Docket No. 70-1151, U.S. Nuclear Regulatory Commission, Washington, D.C., 1976.

Westinghouse Electric Corporation, Application for Renewal of SNM-770, Docket No. 70-698, U.S. Nuclear Regulatory Commission, Washington D.C., 1980 .

Westinghouse Electric Corporation, Site Emergency Plan, Westinghouse Electric Corporation, Nuclear Fuel Division, Columbia, South Carolina, Docket No. 70-1151, U.S. Nuclear Regulatory Commission, Washington, D.C., 1981. 
APPENDIX B

URANIUM FUEL FABRICATION (NONOXIDE) 
URANIUM FUEL FABRICATION (NONOXIDE)

\section{B.1 GENERAL ATOMIC, SAN DIEGO CALIFORNIA}

General Atomic uranium fuel fabrication facility produces fuel elements for experimental reactors on the General Atomic site. Information on this facility is obtained from docket material on the site, primarily from General Atomic reports (1965, 1971, 1975a, 1975b, 1981a, and 1981b).

\section{B.1.1 Process Description}

Operation

High-temperature gas-cooled reactor (HTGR) fuel is produced from $93 \%$ enriched $\mathrm{UO}_{2}$, and $\mathrm{ThO}_{2}$ material. The fuel is mixed with graphite flour, ethyl cellulose, and an organic solvent in a batch process. The mixture is homogeneously blended, dried, ground, and screened to separate the material into various sizes. Appropriately sized material is loaded into a crucible and heated in a vacuum to form $\mathrm{UC}_{2}-\mathrm{ThC}_{2}$ kernels with by-product gases of $\mathrm{CO}$ and $\mathrm{CO}_{2}$. The kernels are cooled in an inert atmosphere, then transferred in an inert atmosphere to a furnace operating at a temperature in excess of the kernel melting temperature. The particles assume a spherical form in the furnace and are solidified in this form. The $U C_{2}-T_{2} C_{2}$ is unstable in air and may be explosive if not kept in an inert atmosphere.

The fissile particles are coated with carbon and silicon carbide in an inert gas in each of three different furnaces. In the first furnace a hydrocarbon gas such as acetylene, propane, or propylene is added. The hydrocarbon dissociates producing free carbon, which deposits on the kernels as a pyrolytic carbon layer. Methyltrichlorosilane is introduced to the second furnace to deposit a silicon carbon on the particles. In the third furnace a pyrolytic carbon coat is added again.

Coated thorium and uranium-thorium particles are mixed and loaded into molds. A matrix material is injected into the hot mold under high pressure, then allowed to cool. Rods of about $0.5 \mathrm{in}$. in diameter by 2 in. long are formed in this way. The rods are loaded into furnace boats and heated in an inert atmosphere to carbonize the matrix material. The rods are cleaned with $\mathrm{HCl}$ gas to remove contamination, then fired at high temperature to stabilize dimensions.

Rods are loaded into hexagonal graphite blocks $15 \mathrm{in}$. across and $31 \mathrm{in}$. long. After loading, the holds are plugged with graphite plugs and baked to cure the plug cement. Elements are loaded into approved shipping casks and stored before removal off site. 
Training Reactors Isotopes Production, General Atomic (TRIGA) fuel is made of uranium metal (from 20 to 93\% enriched). The uranium is annealed, rolled, reduced to chips, and batched in containers. The uranium chips are mixed with zirconium and other additives such as erbium in an induction crucible, which is then placed in a vacuum induction furnace. The alloy ranges from 8.5 to $12 \%$ uranium. In the furnace, the contents of the crucible are melted, mixed by induction and poured into a mold. When the metal has cooled, the ingots are taken out, machined, and drilled.

Machined pieces are cleaned, heated in a furnace with a hydrogen atmosphere, machined again, and ground down to final size. The finished pieces are inserted into an aluminum, stainless steel, Hastelloy ${ }^{\circledR}$, or Inconel ${ }^{\circledR}$ can, which is then sealed by welding the end caps in place.

\section{Waste Disposal}

Waste material is concentrated, then consigned to a licensed waste disposal contractor for burial.

\section{Scrap Recovery}

Bulky materials are crushed and burned to reduce the volume. Siliconcarbide-coated HTGR fuel particles are ground and then burned to convert the kernel to oxides. The scrap is dissolved in acid, filtered, and purified in a solvent extraction process. The uranium is then precipitated and calcined, converting it to purified $\mathrm{U}_{3} \mathrm{O}_{8}$.

The TRIGA scrap is returned to the U-Zr alloy state and reintroduced to the fabrication process.

Other Operations

Three pool-type TRIGA reactors are also located onsite. Two of the reactors are operating; one is shut down.

\section{B.1.2 Facility Description}

\section{Buildings}

Figure B.l shows the fuel manufacturing facility, and Figure $B .2$ is a diagram of the TRIGA fuel fabrication building.

The fuel manufacturing facility is bounded by two outside walls: a masonry wall and a structural steel wal1, which separate it from other non-fuel operations areas and activities.

\footnotetext{
() Hastelloy is a trademark of the Union Carbide Corp., New York, NY 10017 (Inconel is a trademark of Huntington Alloy Products Div., International Nickel Co., Inc., Huntington, WV 25720
} 


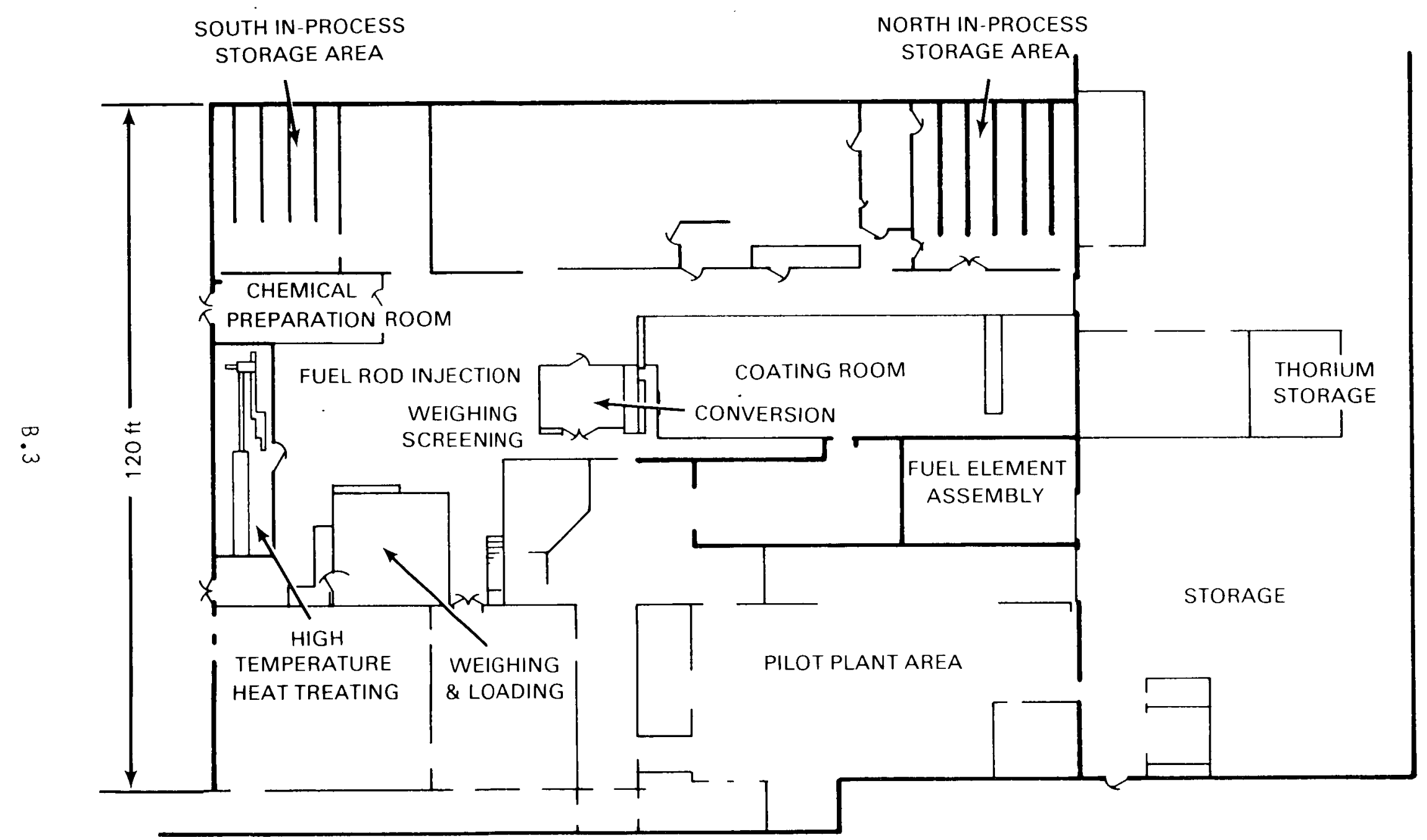

FIGURE B.1. General Atomic Fuel Manufacturing Facility 


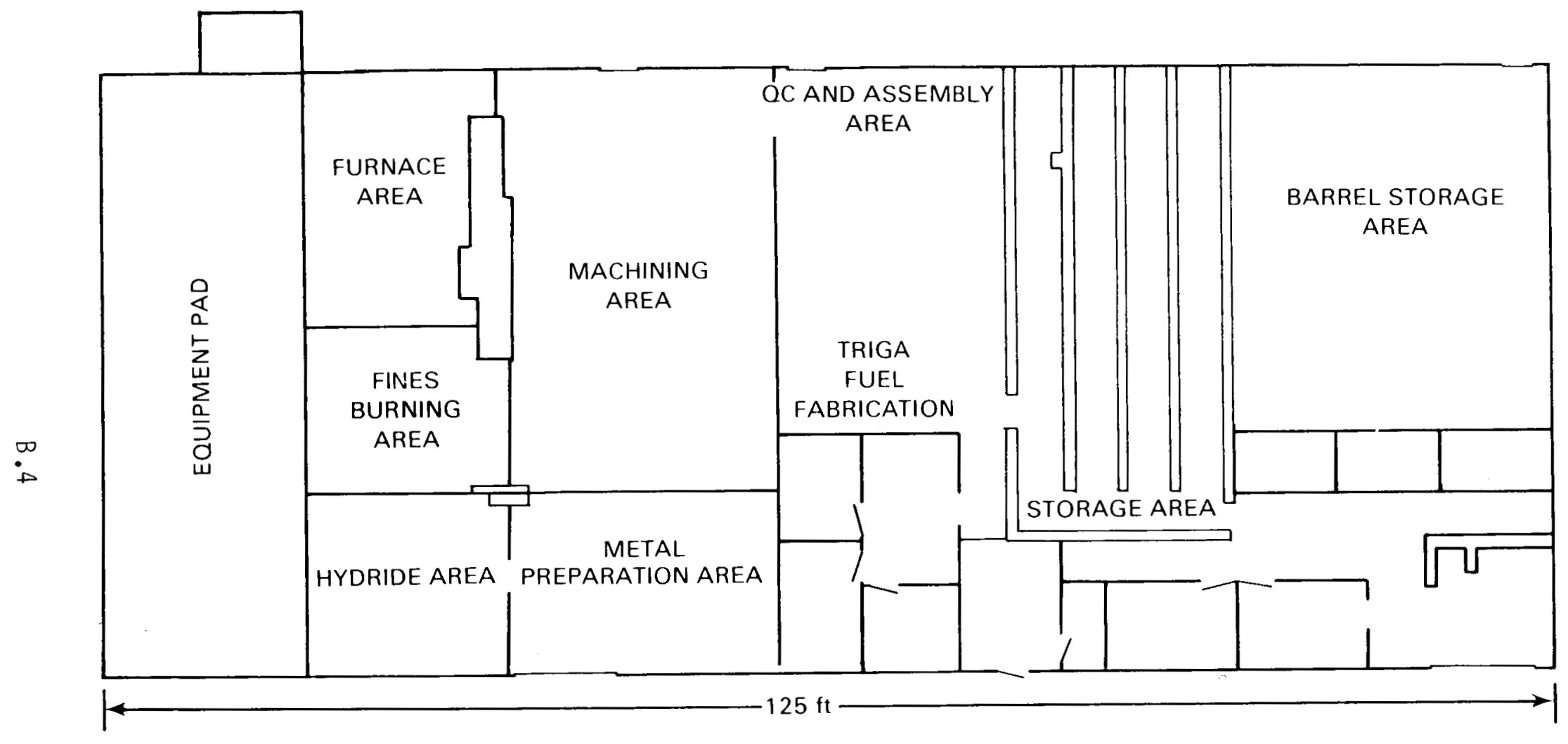

FIGURE B.2. General Atomic TRIGA Fuel Fabrication Building 
The TRIGA fuel fabrication building is constructed of 7.5-in.-thick reinforced concrete prefabricated wall panels. The roof is 4 -in.-thick prestressed concrete.

\section{HVAC Systems}

High-efficiency particulate air filters are used to limit release of radioactive airborne particles to the atmosphere. Process areas are kept at negative pressure. All building equipinent that may generate airborne radioactivity is used within enclosures. The pickling station uses a fume scrubber. Flow direction is towards areas with greater potential contamination.

\section{Engineered Safety Systems}

Radiation alarms are located throughout the plant. Afterburners and massive air dilution coupled with safety interlocks are used to avoid buildup of potentially explosive or flammable gases.

Surrounding Area

Besides the fuel fabrication operations, several laboratories and test reactors are located on site.

\section{B.1.3 Inventory}

\section{Radioactive Inventory}

Table B.1 lists the license limits and inventory locations for the General Atomic facility.

TABLE B.1. License Limits for General Atomic Facility

\begin{tabular}{|c|c|c|c|}
\hline Type & Isotopic Content & Mass Limit & Location \\
\hline Uranium & $\begin{array}{l}\text { Up } 53_{5} \text { fully enriched } \\
\text { in } 23{ }_{U}\end{array}$ & $2500 \mathrm{~kg}$ of $235 \mathrm{U}$ & $\begin{array}{l}\text { Fuel Fabrication } \\
\text { Facility }\end{array}$ \\
\hline $\begin{array}{l}\text { Encapsulated } \\
\text { Uranium }\end{array}$ & $\begin{array}{l}\text { Up } t 8_{\text {fully enriched }} \\
\text { in } 238_{U}\end{array}$ & $10 \mathrm{~g}$ of $238 \mathrm{U}$ & $\begin{array}{l}\text { Fuel Fabrication } \\
\text { Facility }\end{array}$ \\
\hline $\begin{array}{l}\text { Encapsulated } \\
\text { Plutonium }\end{array}$ & $\begin{array}{l}\text { U } \mathrm{B}_{9} \text { to } 100 \%{ }^{238} \mathrm{Pu}, \\
\text { may be in combination } \\
\text { with other isotopes }\end{array}$ & $\begin{array}{l}440 \mathrm{~g} \text { of contained } \\
239 \mathrm{Pu} \text { and } 240 \mathrm{O} 3 \mathrm{gd} 2 \mathrm{~kg} \\
\text { of contained } 23 \mathrm{Pu}^{-}\end{array}$ & $\begin{array}{l}\text { Sorrento Valley } B \\
\text { Building }\end{array}$ \\
\hline
\end{tabular}


Individual stations in the fuel fabrication facility contain from less than 1 to $8 \mathrm{~kg}$ of nuclear material. Table B.2 lists the quantities and types of material that may be found at each station.

Hazardous and Combustible Inventory

A hydrocarbon gas such as acetylene, propane, or propylene is used in the fluid bed furnace. Nitric acid and solvent are used in the scrap recovery operation. Uranium and zirconium metals are pyrophoric. Formic acid, polyvinyl alcohol, and tetrahydrafurfuryl alcohol may be used in UNH dissolution. Ammonium hydroxide and isopropyl alcohol may be used to wash the UNH batch. A propane-fueled engine/generator unit is available onsite for backup power. Acetylene, propylene, and $\mathrm{N}_{2}$ are stored in the area west of the Sorrento Valley B building.

\section{B.2 ROCKWELL INTERNATIONAL, CANOGA PARK, CALIFORNIA}

The Rockwell International uranium fuel fabrication facility produces fuel elements for the Experimental Breeder Reactor (EBR-II) and Advanced Test reactor (ATR). Information on the Rockwell plant is taken primarily from Rockwell International Reports (1977, 1981).

\section{B.2.1 Process Description}

Operation

Uranium in the form of broken metal buttons originally 5 in. in diameter by $1 / 2 \mathrm{in}$. thick is received and stored in the special nuclear material (SNM) vault. The material is weighed, sampled, and stored until release for the fuel fabrication process.

In the fabrication of ATR fuel, the broken buttons, at $93 \mathrm{wt} \%{ }^{235} \mathrm{U}$, and a measured amount of aluminum are blended and melted together to obtain a UAl $x$ blend batch. The batch is crushed and sieved to a uniform size in glove boxes.

Predetermined quantities of $U A I_{X}$ and aluminum powders are combined into glass jars. A maximum of 24 jars is loaded during one time. The jars are moved to the compacting press, loaded into a die and pressed into a fuel compact. Each compact is placed in an aluminum picture frame, vacuum annealed, and assembled into preformed cover plates. The assemblies are hot rolled to obtain a 12:1 reduction in thickness, inspected, and cut to size by removing only excess aluminum picture frame and corresponding picture frame material. These fuel.plates are then formed and assembled into fuel elements.

The productjop of EBR-II fuel involves weighing broken uranium buttons enriched to $67 \%{ }^{235} U$ and alloying the metal with the correct amount of fissium in a sealed induction furnace. Ingots of the uranium-fissium alloy are then injection cast into fuel pins in another induction furnace. The fuel pins are 
TABLE B.2. Fuel Production Station Inventory Limits

Station

Batch weighing
Blending
Blending
Calcining
Cleaning
Coating
Conversion
Crucible loading
Dissolution
Drying
Furnaces
Grinding
Grinding, sizing
Grinding, sizing,
blending
High-level oxidation
HTGR fuel production R\&D
In-process storage
In-process storage
Lab-scale operations

Large batch precipitation

Liquid storage

Load, unload

Material transfer

Rod batching

Rolling

\begin{tabular}{l} 
Material \\
\hline $\mathrm{UO}_{2} \mathrm{ThO}_{2}$ powder \\
$\mathrm{UO}_{2}\left(\mathrm{C}_{2}\right) \mathrm{ThO}_{2}\left(\mathrm{C}_{2}\right)$ graphite particles \\
$\mathrm{and}_{\mathrm{n}}$ powder \\
$\mathrm{UO}_{2} \mathrm{ThO}_{2}$ powder \\
$\mathrm{UO}_{2} \mathrm{ThO}_{2}$ graphite precipitate
\end{tabular}

$U C_{2} \mathrm{ThC}_{2}$ graphite in fuel rods

$U C_{2} \mathrm{ThC}_{2}$ uncoated or partially
coated particles

$\mathrm{UO}_{2} \mathrm{ThO}^{2}$ powder

$\mathrm{UO}_{2} \mathrm{ThO}_{2} \mathrm{C}$ powder

$\mathrm{UO}_{2} \mathrm{ThO}_{2}$ graphite and solution

$\mathrm{UO}_{2} \mathrm{ThO}_{2}$ powder

$\mathrm{UO}_{2}\left(\mathrm{C}_{2}\right) \mathrm{ThO}_{2}\left(\mathrm{C}_{2}\right)$ graphite particles

$\mathrm{UO}_{2}\left(\mathrm{C}_{2}\right) \mathrm{ThO}_{2}\left(\mathrm{C}_{2}\right)$ graphite particles
and powder

$\mathrm{UO}_{2} \mathrm{ThO}_{2}$ powder

$\mathrm{UO}_{2} \mathrm{ThO}_{2}$ graphite powder

$\mathrm{UO}_{2}\left(\mathrm{C}_{2}\right) \mathrm{ThO}_{2}\left(\mathrm{C}_{2}\right)$ graphite particles

$\mathrm{UO}_{2} \mathrm{ThO}_{2}$ graphite

$\mathrm{UO}_{2}\left(\mathrm{C}_{2}\right) \mathrm{ThO}_{2}\left(\mathrm{C}_{2}\right)$ graphite particles

$\mathrm{UO}_{2}\left(\mathrm{C}_{2}\right) \mathrm{ThO}_{2}\left(\mathrm{C}_{2}\right)$ powder and

$\mathrm{UO}_{2} \mathrm{ThO}_{2} \mathrm{C}$ powder, coated particles, uncoated particles

$\mathrm{UO}_{2} \mathrm{ThO}_{2}$ graphite solution

$\mathrm{UO}_{2} \mathrm{ThO}_{2}$ graphite in closed containers

$U C_{2} \mathrm{ThC}_{2}$ powder

$\mathrm{UO}_{2}\left(\mathrm{C}_{2}\right) \mathrm{ThO}_{2}\left(\mathrm{C}_{2}\right)$ graphite particles and powder

$\mathrm{UC}_{2} \mathrm{ThC}_{2}$ graphite coated particles

$\mathrm{UO}_{2} \mathrm{ThO}_{2}$ powder

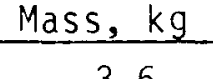

3.6

3.6

$0.79-3.6$

$0.75-3.6$

3.6

3.6

$0.74-3.6$

3.6

3.6

8.0

$0.35-3.6$

3.6

8.5

3.6

$0.75-3.6$

0.35

3.6

3.6

0.35

3.6

3.6

3.6

3.6

$3.6-4.2$

0.79

\section{B.7}


TABLE B.2. (contd)

\begin{tabular}{|c|c|c|}
\hline Station & Material & Mass, $\mathrm{kg}$ \\
\hline Screening & $\mathrm{UC}_{2} \mathrm{ThC}_{2}$ coated particles & 0.79 \\
\hline Screen, weigh, load & $\mathrm{UC}_{2} \mathrm{ThC}_{2}$ coated particles & 3.6 \\
\hline Sizing, weighing & $\mathrm{UO}_{2} \mathrm{ThO}_{2}$ powder & $0.75-3.6$ \\
\hline Size reduction & $\begin{array}{l}\mathrm{UO}_{2}\left(\mathrm{C}_{2}\right) \mathrm{ThO}_{2}\left(\mathrm{C}_{2}\right) \text { graphite particles } \\
\text { and powder }\end{array}$ & 3.6 \\
\hline Splitting & $\begin{array}{l}\mathrm{UC}_{2} \mathrm{ThC}_{2} \text { coated or uncoated } \\
\text { particles }\end{array}$ & 3.6 \\
\hline Unloading, weighing & $\mathrm{UO}_{2} \mathrm{ThO}_{2}$ powder & 3.6 \\
\hline Weigh, screen, load & $\mathrm{UC}_{2} \mathrm{ThC}_{2}$ uncoated particles & 3.6 \\
\hline Weigh, sample & $\begin{array}{l}\mathrm{UO}_{2}\left(\mathrm{C}_{2}\right) \mathrm{ThO}_{2}\left(\mathrm{C}_{2}\right) \text { powder, coated } \\
\text { particles or uncoated particles }\end{array}$ & 3.6 \\
\hline
\end{tabular}

inspected before being inserted into stainless steel jackets along with a measured amount of sodium. The jacket is welded shut and heat-treated so the sodium is bonded to the fuel and jacket.

\section{B.2.2 Facility Description}

\section{Buildings}

The facility shown in Figure $B .3$ is located in the region of the San Andreas fault and is built to withstand an earthquake of 7.3 on the Richter scale without major damage. Process equipment is bolted to the poured concrete floor to prevent upsets.

The manufacturing building is made of precast tilt-up concrete slabs. The fuel fabrication area is enclosed with double-wall construction. A poured concrete floor separates an office area on the second floor from the fabrication area.

The storage vault has walls of 12-in. filled concrete block, a 6-in.-thick concrete floor, a 9-in.-thick reinforced concrete ceiling, and a 1-in.-thick steel door.

HVAC System

Cutting machinery has fireproof fume hoods with high-draft ventilation ducts to remove small chips and dust. Movement of air is always towards areas of greater contamination, and air is not recirculated. Prefilters are provided upstream of all HEPA filters. 


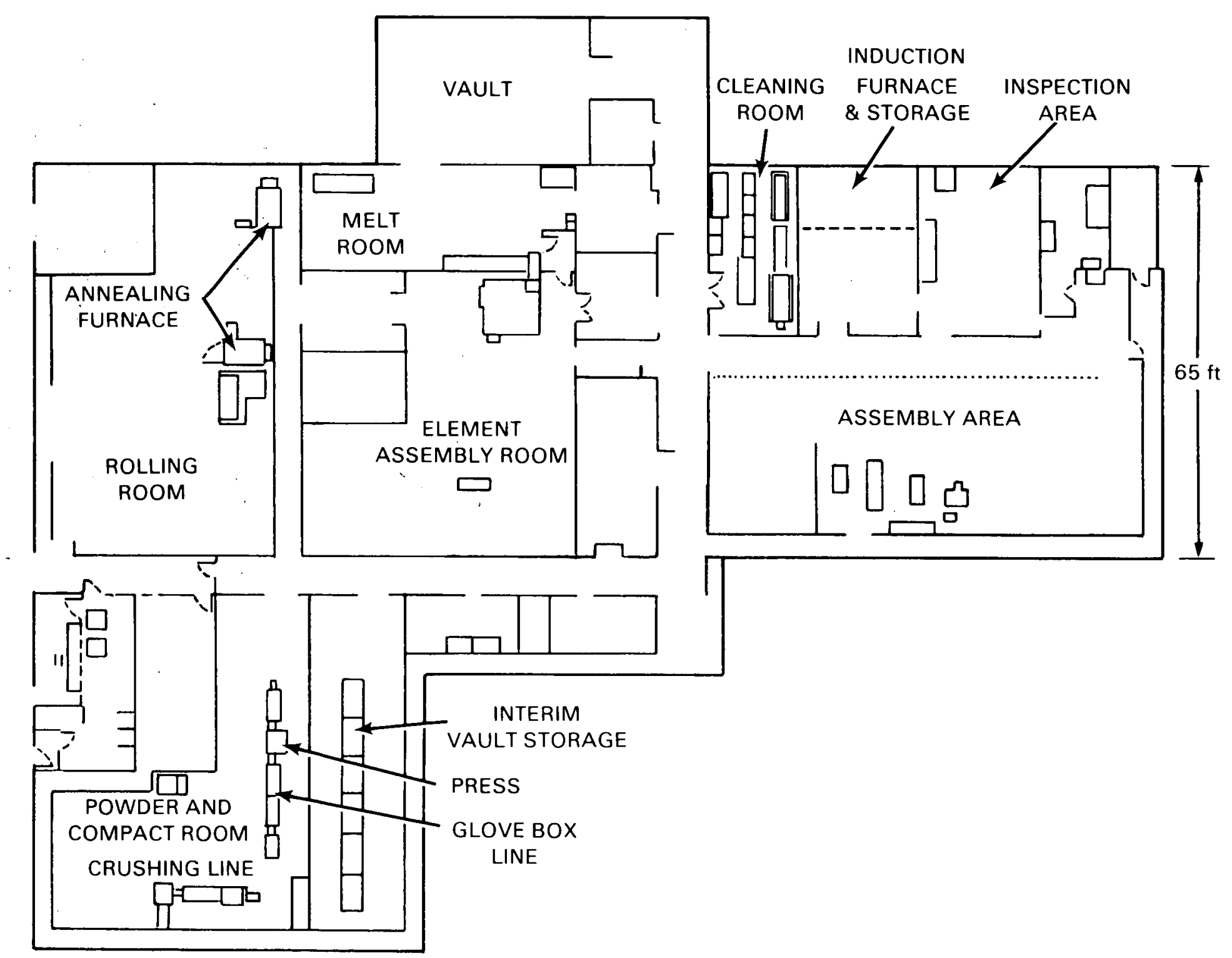

FIGURE B.3. Fuel Fabrication Area of Rockwell International Fuel Manufacturing Building 
A minimum of 6 air changes per hour in each room is provided. Average air duct velocities range from 2000 to $2500 \mathrm{ft} / \mathrm{min}$.

Pulverizing, sieving, and blending operations on UAl $x$ powder are performed in an inert argon atmosphere.

Engineered Safety Systems

Water scrubbers or fiberglass prefilters are provided in the exhaust where cutting operations may generate sparks.

Automatic fire detection and sprinkler systems are provided in all areas of the plant except the vault, which has a manually controlled sprinkler system. Also, sprinkler heads are blocked off in areas containing alkali metals.

Criticality safety is provided by limiting the amount of material handled and by geometry controls.

\section{Surrounding Area}

Several small commercial establishments and an area containing both single- and multiple-family dwellings are located about $275 \mathrm{ft}$ from the manufacturing building on the other side of a public street.

\section{B.2.3 Inventory}

\section{Radioactive Inventory}

License limits for the Rockwell plant at Canoga Park are given in Table B.3. Additional information on mass limits of $235 \mathrm{U}$ at individual stations in the plant is given in Table B.4. Total ATR fuel manufacture may require up to $900 \mathrm{~kg}$ of $235 \mathrm{U}$ in storage and in process. Total EBR-II fuel manufacture may require up to $600 \mathrm{~kg} 235 \mathrm{U}$ in storage and in process.

\section{Hazardous and Combustible Inventory}

Acid and organic solvents are used in the laboratory in quantities of less than a gallon. Solid chemicals in the lab are stored in containers of less than a pound capacity.

Flammable materials within the plant are carefully controlled. Organic cleaning compounds are kept in limited quantities. Paper is used for required record keeping and documentation although most of the clerical work is performed outside of the main fabrication facility. Some office spaces containing wooden desks are walled off from the work areas. Lab coats and plastic shoe covers are provided at the entrance to contaminated areas. Contaminated combustible items are stored in the SNM vault in sealed steel drums. 
TABLE B.3. Nuclear Materials Allowed at Rockwell International Canoga Park Facility Under Special Nuclear Materials License SNM-21

\begin{tabular}{|c|c|}
\hline $\begin{array}{c}\text { By-Product, Source, } \\
\text { and/or Special Nuclear } \\
\text { Material } \\
\end{array}$ & $\begin{array}{l}\text { Chemical and/or } \\
\text { Physical Form }\end{array}$ \\
\hline $\begin{array}{l}\text { Uranium enriched in the } \\
235 \mathrm{u} \text { isotope }\end{array}$ & $\begin{array}{l}\text { Any enrichment or form } \\
\text { except UF }-6\end{array}$ \\
\hline $235 u$ & Any \\
\hline $\mathrm{Pu}$ (principally $230 \mathrm{Pu}$ ) & Any \\
\hline
\end{tabular}

Maximum Amount that Licensee

May Possess at any One Time Under this License

$1,500 \mathrm{~kg} 235 \mathrm{U}$

$5 \mathrm{~kg} 233 \mathrm{U}$

Maximum of $3.5 \mathrm{~kg}$ of total $\mathrm{Pu}$ 1. NFDL Site
a. Hot laboratory--up to $3.5 \mathrm{~kg}$ Pu in irradiated fuel
b. Pu facility--less than $1.0 \mathrm{~kg} \mathrm{Pu}$ in process

2. HQ Site
a. HQ vault--up to $3.5 \mathrm{~kg}$
Pu packaged in sealed authorized shipping containers
b. A maximum of $2 \mathrm{~g}$ total Pu for gamma spectros- copy and radiometric counting analyses
$\mathrm{Pu}$ (principally ${ }^{239} \mathrm{Pu}$ ) Sealed sources (as $1.0 \mathrm{~kg}$ total Pu at either or

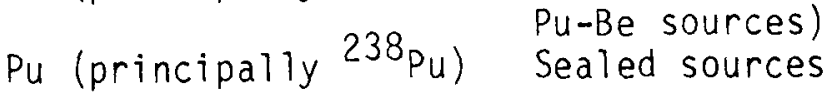 both sites
$0.5 \mathrm{~kg}$ total Pu at either or both sites

TABLE B.4. Mass Limits of $235 / \mathrm{J}$ at Fuel Fabrication Stations

\section{Location}

ATR manufacture vacuum arc furnace

Pulverizing and sieving glove box train

Accumulation of fines in blending, pressing, and compacting glove box train

Plate fabrication area

Annealing furnace
Mass Limit of $235 \mathrm{U}$

$350 \mathrm{~g}$

$350 \mathrm{~g}$

$350 \mathrm{~g}--13 \mathrm{~kg}$ working limit

$610 \mathrm{~g}$ in eight compacts

$916 \mathrm{~g}$ in twelve compacts

$50 \mathrm{~kg}$ 
Small amounts of solid sodium are handled in inert glove boxes at room temperature.

The UAlx crushed powder can be pyrophoric; hence, the powder is handled in an inert atmosphere and stored in sealed containers.

\section{B.3 REFERENCES}

General Atomic, Special Nuclear Material Application, Docket No. 70-734, U.S. Nuclear Reguiatory Commission, Washington, D.C., T965.

General Atomic, Amendment of Special Nuclear License SNM-0696, Docket

No.70-734, U.S. Nuclear Regulatory Commission, Washington, D.C., 1971.

General Atomic, Demonstration Volume SNM 696 Material License Renewal Part I, Docket No. 70-734, U.S. Nuclear Regulatory Commission, Washington, D.C., $1975 \mathrm{a}$.

General Atomic, Environmental Appraisal Report, GAA13033, General Atomic, San Diego, California, 1975b.

General Atomic, Environmental Information Report, Docket No. 70-734, U.S.

Nuclear Regulatory Commission, Washington, D.C., 1981a.

General Atomic, Radiological Contingency Plan, Docket No. 70-734, U.S. Nuclear Regulatory Commission, Washington, D.C., $1981 \mathrm{~b}$.

Rockwell International, Technical Information in Support of the Atomics

International Application for Broad Nuclear Materials License, Ai-76-46, Rockwell International, Atomics International Division, Canoga Park, California, 1977.

Rockwell International, Onsite Radiological Contingency Plan for Rockwell International Operations Licensed Under Special Nuclear Material License No. SNM-21, ESG-81-30, Rockwel1 International, Energy Systems Group, Canoga Park, California, 1981. 


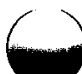

APPENDIX C

URANIUM HEXAFLUORIDE PRODUCTION 
APPENDIX C

URANIUM HEXAFLUORIDE PRODUCTION

C.1 ALLIED CHEMICAL CORPORATION, METROPOLIS, ILLINOIS

The Allied Chemical UF 6 plant at Metropolis, Illinois produces UF 6 by processing uranium ore concentrates. This appendix was developed using information in Allied Chemical Corporation reports $(1975,1980,1981)$.

\section{C.1.1 Process Description}

Operation

Fifty-five gallon drums of yellowcake with a concentration of $75 \%$ uranium are emptied into a hopper. The contents are blended, sampled, and packaged in drums. Sampling is done separately from the rest of the process to control dust levels. One hundred drums are received per day in two to three truckloads.

After sampling, yellowcake is calcined to $\mathrm{U}_{3} \mathrm{O}_{8}$. The $\mathrm{U}_{3} \mathrm{O}_{8}$ is crushed and blended to a uniform mixture. It is then remoistened, formed into pellets, dried, and crushed to $\mathrm{U}_{3} \mathrm{O}_{8}$ powder. The powder is converted to $\mathrm{UF}_{6}$ in a series of fluidized bed reactors. The first reactor uses $\mathrm{H}_{2}$ and $\mathrm{N}_{2}$ from dissociated ammonia as the fluidizing gas to convert $\mathrm{U}_{3} \mathrm{O}_{8}$ to $\mathrm{UO}_{2}{ }^{2}$ powder. The next two reactors operating in series use HF as the fluidizing gas, converting $\mathrm{UO}_{2}$ to $U_{4}$ powder. A fluid bed fluorinator then uses $F_{2}$ as a fluidizing gas, converting $\mathrm{UF}_{4}$ to $\mathrm{UF}_{6}$ gas.

Uranium hexafluoride is condensed in primary cold traps at $-20^{\circ} \mathrm{F}$. Secondary cold traps at lower temperatures remove residual UF 6 . The solid is liquified intermittently in the traps by heating, then transferred to distillation tanks. Low boiling impurities are stripped from the UF 6 in a low boiler distillation column, then high boiling impurities are stripped in a high boiler distillation column. The product, UF 6 :purified to less than $300 \mathrm{ppm}$ impurities, is condensed and packaged into 10- or 14-ton cylinders. Eight to nine hundred cylinders are stored on site and shipped at an average of 3 per day or 90 per month.

Waste Disposal

Liquid waste is sent to either sludge settling ponds or uranium spill control ponds before being discharged into the Ohio River. Lime is added to the liquid to: precipitate fluorides, which are separated out in settling basins and retained on site.

Off gases from the sampling to fluorination process steps are filtered and scrubbed with aqueous $\mathrm{KOH}$ to remove fluorine and residual uranium. Scrubbing liquors are sent to uranium recovery to extract uranium. 
Scrap Recovery

Uranium recovery from scrap is accomplished by leaching finely ground scrap with sodium carbonate solution. The leached material is filtered, dried, drummed, and disposed of in a radioactive waste facility. Uranium in the filtrate is precipitated with $\mathrm{NaOH}$ then pretreated with ammonium sulfate solution in a 4-stage counter-current decanter. Product uranium is sent to the calciner as feed.

\section{Other Operations}

Periodically, UF 6 product cylinders are washed with sodium carbonate solution and pressure tested. Uranium leached into the wash solution is recovered in the uranium recovery facility.

Besides manufacturing $U_{6}$, the plant also produces sulfur hexafluoride, iodine and antimony pentafluorides, and liquid fluorine.

\section{C.1.2 Facility Description}

Buildings

Essentially all of the UF 6 manufacturing processes are conducted in the feed materials building. This building and others that contain operations involving the handling or processing of significant amounts of source material are identified in the site plan, Figure C.1. The operations in those buildings and their estimated size are listed in. Table C.1.

\section{HVAC Systems}

Dust collectors and scrubbers are used to clean process gases. Air is circulated through the feed materials building by several fans and about 12 changes of air per hour are provided. The feed materials building has a roll-up door on the first floor, which may be open much of the time, and several windows leading to the outside.

The air system in the main control room is separate from that in the rest of the plant.

\section{Strength of Buildings}

Most buildings are constructed of concrete block, except the feed materials building which has sheet metal siding on a steel frame. All processing areas are concrete and steel construction. Most process buildings have at least one open pathway (door or window) to the outside. The feed materials building has 4 by $6 \mathrm{ft}$ Plexiglas ${ }^{\circledR}$ panels in many locations for windows.

(8) Plexiglas is a trademark of Rohn and Haas, Philadelphia, PA 19105 


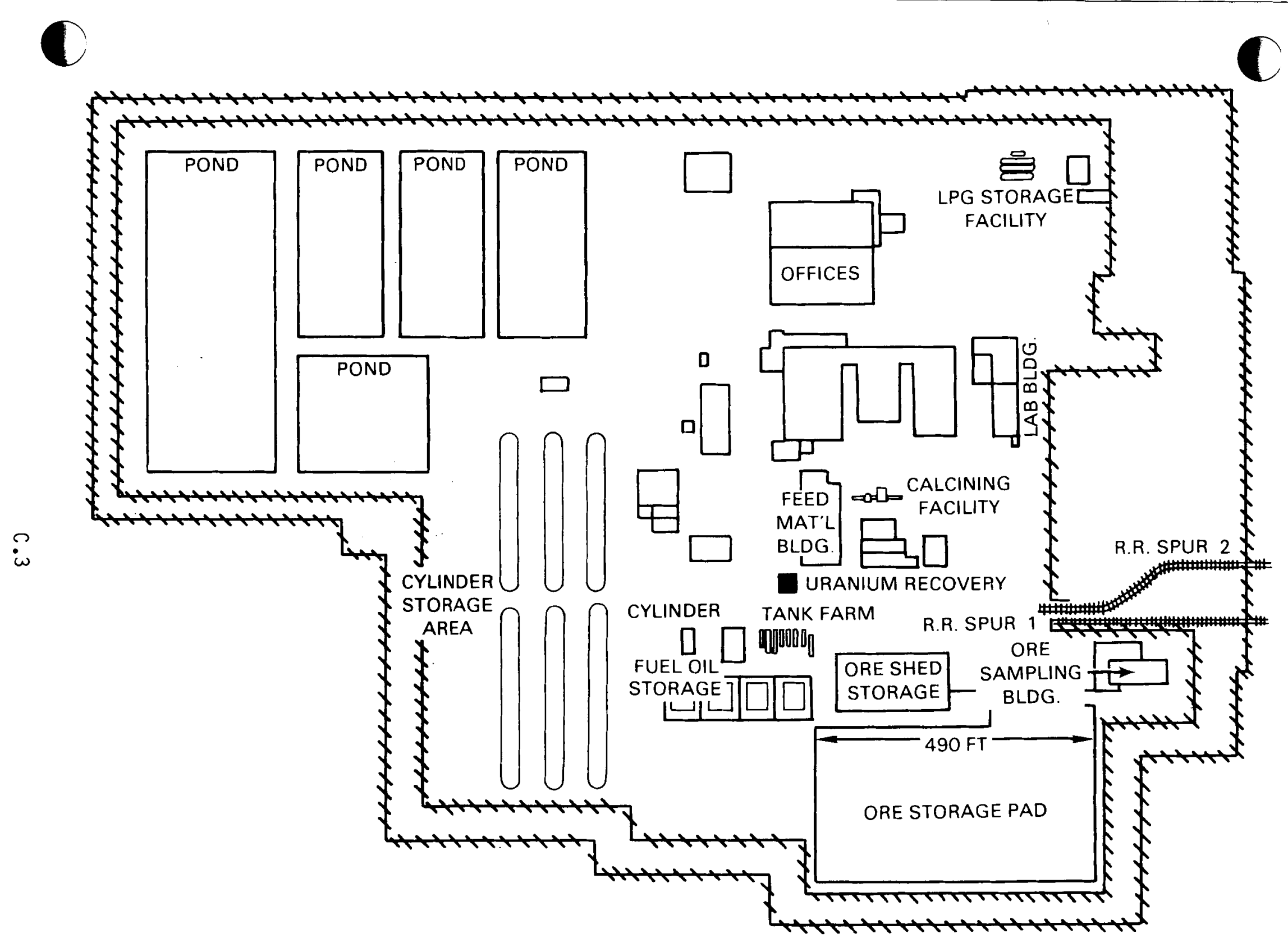

FIGURE C.1. Site Plan for Allied Chemical $U_{6}$ Plant, Metropolis, Illinois 
TABLE C.1. Areas Containing Amounts of Nuclear

Materials at Allied Chemical UF 6 Plant

\begin{tabular}{lll}
\multicolumn{1}{c}{ Area } & \multicolumn{1}{c}{ Operation } & \multicolumn{1}{c}{ Size, $f^{2}$} \\
\cline { 1 - 2 } Feed materials bldg. & $U_{6}$ manufacturing & $\begin{array}{l}11,900 \text { on each } \\
\text { floor, six stories } \\
\text { high }\end{array}$ \\
Ore sampling bldg. & Sampling ore concentrates & 4,600 \\
Na removal \& U recovery & $\begin{array}{l}\text { Ore purifying and U scrap } \\
\text { recovery }\end{array}$ & 7,000 \\
Calcining facility & $\begin{array}{l}\text { Incoming feed dried } \\
\text { Waste drier }\end{array}$ & 1,000 \\
Lab building & $\begin{array}{l}\text { U recovery wastes dried } \\
\text { prior to offsite disposal }\end{array}$ & 500 \\
Cylinder wash bldg. & $\begin{array}{l}\text { Process and product control } \\
\text { analyses }\end{array}$ & 9,900 \\
Ore storage shed & $\begin{array}{l}\text { tested } \\
\text { Feed ore stored inside }\end{array}$ & 900 \\
Ore storage pads & $\begin{array}{l}\text { Feed ore stored outside } \\
\text { Cylinder storage areas }\end{array}$ & $\begin{array}{l}\text { UF } 6 \text { product stored } \\
\text { outside }\end{array}$
\end{tabular}

Engineered Safety Systems

Fire protection is provided by manual fire extinguishers and a fire hose. Automatic sprinkler systems are provided in hazardous areas.

Besides alarms provided in the control room to alert personnel to malfunctions in process equipment, an alarm can be activated by personnel observing a release of $\mathrm{UF}_{6}$.

Surrounding Area

The plant is located in a rural area outside of a small town. It is bordered by the Ohio River, a coal blending plant, the highway, and privately owned land. 


\section{C.1.3 Inventory}

The facility is designed to produce about 14,000 short tons per year of uranium as UF 6 . The maximum license limit of uranium in all forms is 25,000 thans. Small-source inventories for which Allied is licensed are $100 \mathrm{~m}$ $\mathrm{C} i$ of ${ }^{13} \mathrm{Ce}$ as a sealed source, and $0.01 \mu \mathrm{Ci}$ each of $241_{\mathrm{Am}}$ and $232 \mathrm{Th}$ as plated sources. A typical plant inventory is given in Table C.2.

TABLE C.2. Typical Plant Radioactive Inventory at Allied Chemical UF 6 Plant

\begin{tabular}{ll}
\multicolumn{1}{c}{ Uranium Form } & \multicolumn{1}{c}{ Quantity, tons } \\
\hline Stored UF 6 & 11,000 \\
Ore concentrate & 7,000 \\
Waste material & 250 \\
In process & 100 to 125 \\
Primary cold traps & 11 to 11.5 \\
UF $_{6}$ Cylinders & 14 (each) \\
UF $_{6}$ Cylinders & 10 (each) \\
Green salt in storage hopper & 50 \\
Yellowcake in 55-gal drums & 600 to 800 1b (each)
\end{tabular}

Hazardous and Combustible Inventory

Hazardous and combustible materials used at Allied Chemical are compiled in Table C.3. In addition to those listed, antimony pentafluoride, fluorine, iodine pentafluoride, and sulfur hexafluoride are produced on the site.

C.2 KERR-MCGEE NUCLEAR CORPORATION, SEQUOYAH FACILITY, GORE, OKLAHOMA

Operations in the Kerr-McGee UF facility convert yellowcake from uranium mills into UF 6 for uranium fabrication plants. Information in this was developed using Kerr-McGee Corporation reports (1972a, 1972b, 1975, 1981).

\section{C.2.1 Process Description}

Operation

Yellowcake is received in 55-gal drums, which are emptied one at a time through a falling stream sampling unit. This system samples and weighs a portion of the stream. The drums are vacuum cleaned and reused. 
TABLE C.3. Chemicals, Hazardous, and Combustible Materials

Used at Allied Chemicals

Material

Ammonium sulfate

Diesel oil

Ethylene glycol

Fluorspar

Hydrofluoric acid

Lime

$L P G$

Natural gas

Potassium hydroxide

Sodium carbonate

Sodium hydroxide

Sulfuric acid
Description

Used in pretreatment of feed in sodium removal process

Stored underground, used for backup power

Used in cold traps condensing UF 6

Stored in ore storage building; used as bed material in fluidized bed reactors. Contaminated fluorspar stored in 55-gal drums for one year before recycling through uranium recovery

Fluidizing gas in hydrofluorinator

Used in liquid waste treatment

Stored in 60-ton quantities, dissociated to provide hydrogen-reducing gas to certain processes

Provided by city lines to supply electricity for calciners and distillation; lines run through main process building between all six floors

Used in scrubber system

Used to leach contaminated scrap and wash UF 6 cylinders

Precipitates uranium out of scrap recovery filtrate. Used to make ammonium sulfate, sulfur hexafluoride, and to treat waste

Stored yellowcake is fed to digestive tanks where it is dissolved in hot $\left(90\right.$ to $105^{\circ} \mathrm{C}$ ) $40 \%$ nitric acid solution. Recycled feed is added, and the solution is adjusted for acid and uranium content and then sent on to the countercurrent extraction decanters.

Solvent extraction takes place in several pumper-decanters. Thirty percent tributyl phosphate (TBP) in hexane is used to extract uranium from the nitric solution. The TBP-hexane solution is then washed with a 10 to $25 \%$ solution of ammonium sulfate followed by a wash with a 1 to $5 \%$ sodium hydroxide solution. After contact with solutions, the extractant is scrubbed to remove impurities and the uranium is re-extracted in a pulsed stripping column. The organic solvent is recycled while the aqueous stream now containing uranium is concentrated in a two-stage heating process.

The uranium-rich solution is dehydrated and denitrated in a stirred reactor to $\mathrm{UO}_{3}$, which is conveyed to a milling system and stored temporarily.

The $\mathrm{UO}_{3}$ powder is fed to a fluidized bed reactor countercurrent with reducing gases from dissociated ammonia that convert $\mathrm{UO}_{3}$ to $\mathrm{UO}_{2}$ powder. The $\mathrm{UO}_{2}$ is fed to hydrofluorinators and converted to $\mathrm{UF}_{4}$. The $\mathrm{UF}_{4}$ is then conveyed 
to a series of fluorination towers which burn $U_{4}$ in $F_{2}$ gas to make $U_{6}$ gas. Fluorine is provided by the electrolysis of a molten KF-HF electrolyte.

The gas is cooled and filtered twice with sintered metal particulate filters, then condensed to a solid in $30^{\circ} \mathrm{F}$ primary and $-75^{\circ} \mathrm{F}$ secondary cold traps. The solidified $U_{6}$ is melted with steam heat and drained into UF 6 shipping cylinders. The cylinders are stored before shipping.

\section{Waste Disposal}

Liquid wastes containing significant quantities of radioactive material are retained in basins and stored. Other liquid wastes containing traces of radioactivity are diluted and released to the lllinois River.

Combustible wastes may be incinerated in an open pit or an enclosed incinerator. Contaminated solids that are not burned are buried underground on site. The site is a licensed burial ground.

\section{C.2.2 Facility Description}

Buildings

The plant as shown in Figure $C .2$ consists of about $69,000 \mathrm{ft}^{2}$ of manufacturing, warehousing and office floor space in three separate buildings. Retention ponds for sludge and raffinate are also shown. Dimensions of the facility areas are listed in Table C.4.

All plant facilities are steel-framed structures except the shop and utility building. The lean-to on the north side of the process building has 12-in. masonry walls.

Four-hour fire walls separate the process area, cell room, shop, and utility rooms.

Storage tanks are located out-of-doors and are surrounded by 4-ft-high concrete walls. All parts of the solvent extraction system are 304 stainless steel. All equipment that contacts anhydrous HF or elemental fluorine is carbon steel.

HVAC Systems

The sampling area and other dust-generating areas are equipped with vacuum systems and dust collectors. Off gas from the reduction reactor is filtered through sintered metal filters and burned.

The digestor system operates at negative pressure. Process gases from the denitrator are scrubbed with $40 \% \mathrm{HNO}_{3}$ and piped to an absorption tower for absorption and concentration of nitrous oxides. Scrubber systems also clean process gases from the solvent extraction system and UF 6 collection system. 


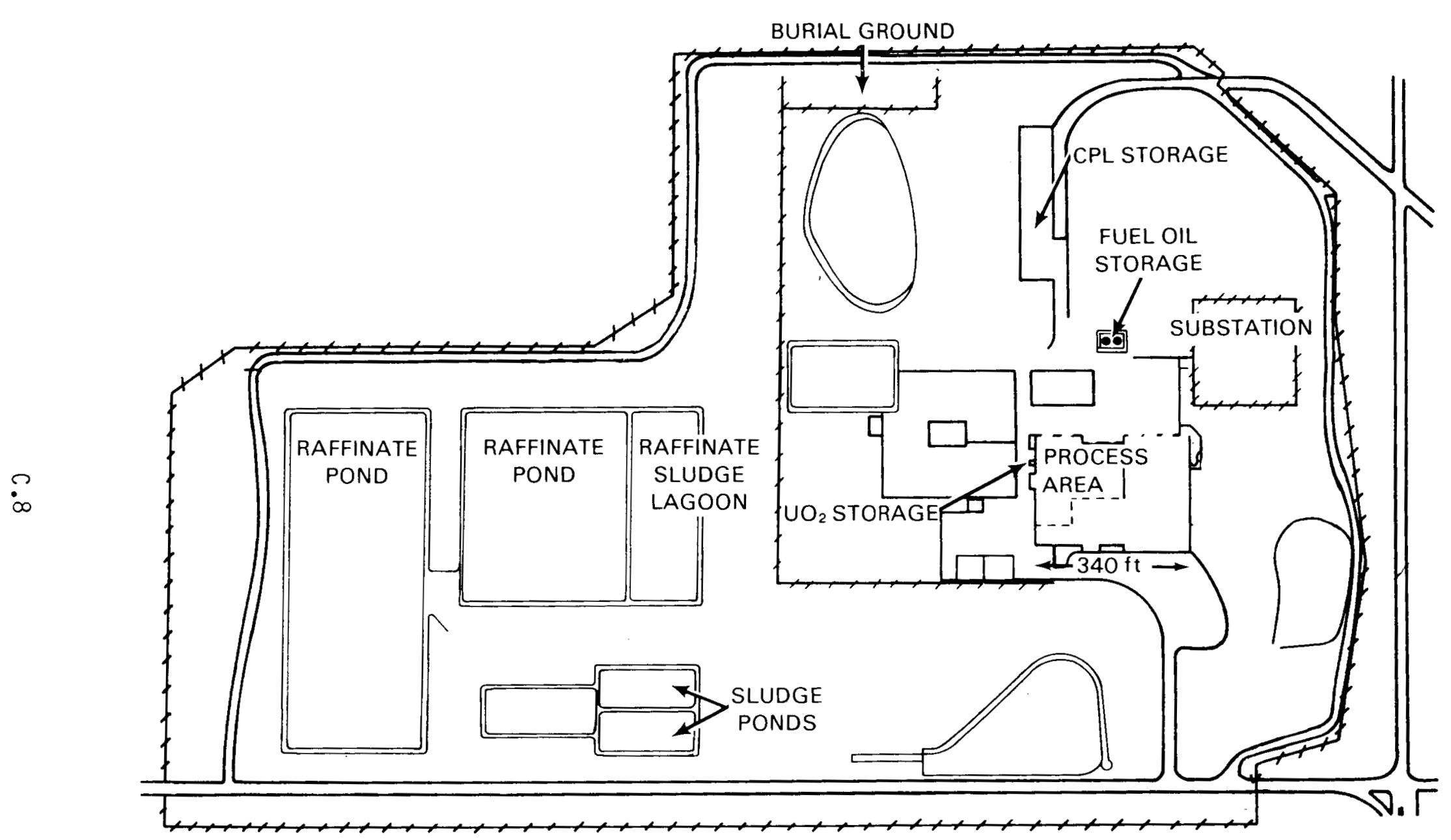

FIGURE C.2. Facility Diagram of Kerr-McGee Sequoyah UF 6 Plant 
TABLE C.4. Building Areas at the Sequoyah UF 6 Facility

\begin{tabular}{lr}
\multicolumn{1}{c}{ Area } & Size, ft ${ }^{2}$ \\
\hline Office and Laboratory & 10,600 \\
Fluorine Generation & 17,250 \\
Maintenance & 5,500 \\
Utility & 5,500 \\
Main Process Areas & 26,900 \\
Solvent Extraction Building & 4,000 \\
Cylinder Storage & 12,000
\end{tabular}

Off gas from the hydrofluorinator is condensed. Noncondensible gases are scrubbed with water before being released out the stack. Waste gases from the fluorinator are also water scrubbed before release.

Engineered Safety Systems

Movement of process material is completely enclosed.

Level alarms and automatic cutoffs are used to avoid overfilling the vessels, terminate feeds, and reduce operating temperature in the event of a boilover or excessive off-gas flow.

Curbs are placed around storage tanks to contain spilled materials. Lime inside the curbs will neutralize spills.

Pressure in the heating/cooling coils is maintained at above the solution pressure to minimize the leakage of process solutions into the coil if the coil fails.

There is an automatic water foam deluge system in the solvent extraction building.

Surrounding Area

The plant is located in a 75-acre fenced portion of a 2100-acre site. It is in a rural area surrounded by pasture and woodland. The site is bounded on the north by U.S. Highway 64, on the west by the Illinois and Arkansas rivers, and on the south by Interstate Highway 40 . 


\section{C.2.3 Inventory}

Radioactive Inventory

The plant can produce 10,000 tons of $U_{6} 6$ per year. The radioactive material storage capacity is shown in Table C.5.

TABLE C.5. Storage Capacity of Radioactive Materials at the Sequoyah Facility

Material and Containment

Ore concentrate as received in drums

Ore concentrate after sampling

$\mathrm{UO}_{2}\left(\mathrm{NO}_{3}\right) 2$ as 4 lb $\mathrm{U} / \mathrm{gal}$ solution

$\mathrm{UO}_{2}\left(\mathrm{NO}_{3}\right) 2$ as 10 ib $\mathrm{U} / \mathrm{gal}$ solution [sic]

Milled $\mathrm{UO}_{3}$

$\mathrm{UF}_{4}$ in storage bin

UF $_{4}$ in 10-day hopper

$U_{6}$ cylinder storage
Inventory

3,000 drums, $700 \mathrm{lb} / \mathrm{drum}$

$750 \mathrm{ft}^{3}$ (102 drums)

2,000 gal (4 tons IJ)

$75,0001 \mathrm{~b} U(38$ tons $U)$

$32,25016 \cup(16$ tons $U)$

$65,500 \mathrm{lb} \mathrm{U}(32$ tons $U)$

$322,0001 \mathrm{~b} \cup(161$ tons $U)$

100 cylinders, 10 tons $\mathrm{UF}_{6} /$ cylinder

Hazardous and Combustible Inventory

Chemicals and hazardous materials used in substantial amounts are listed in Table C.6. Ocher chemicals used are aluminum hydroxide, potassium hydrogen fluoride, sodium carbonate, and tributyl phosphate.

TABLE C.6. Chemicals, Hazardous, and Combustible Materials at the Sequoyah Facility

\begin{tabular}{lcc}
\multicolumn{1}{c}{ Chemical } & No. of Tanks & Nominal Capacity, gal \\
\cline { 3 - 3 } Ammonia & 1 & 15,000 \\
Anhydrous hydrofluoric acid & 2 & 30,000 \\
Aqueous hydrofluoric acid & 2 & 30,000 \\
Diesel oil & 1 & 2,000 \\
Fuel oil & 1 & 30,000 \\
Hexane & 1 & 19,000 \\
$40 \%$ nitric acid & 1 & 15,000 \\
$60 \%$ nitric acid & 1 & 15,000 \\
Sulfuric acid & 1 & 1,000
\end{tabular}

(a) Tanks usually $80 \%$ full. 


\section{C.3 REFERENCES}

Allied Chemical Corp., Supplemental Report, Docket No. 40-3392, U.S. Nuclear Regulatory Commission, Washington, D.C., 1975.

Allied Chemical Corp., Supplemental Report in Support of Application for Renewal of Source Material License SNM-526, Docket No. 40-3392, U.S. Nuclear Regulatory Commission, Washington, D.C., 1980.

Allied Chemical Corp., Onsite Radiological Contingency Plan, Docket

No. 40-3392, U.S. Nuc Tear Regulatory Commission, Washington, D.C., 1981.

Kerr-McGee Corporation, Applicant's Environmental Report, Docket No. 40-8027-9, U.S. Nuclear Regulatory Commission, Washington, D.C., 1972a.

Kerr-McGee Corporation, Sequoyah Uranium Hexafluoride Production Plant, Environmental Report Supplementary, U.S. Nuclear Regulatory Commission, Washington, D.C., 1972b.

Kerr-McGee Corporation, Final Environmental Statement Related to the Sequoyah Uranium Hexafluoride PTant, NUREG 75/007, Docket No. 40-8027, U.S. Nuclear Regulatory Commission, Washington, D.C., 1975.

Kerr-McGee Corporation, Radiological Contingency Plan for Sequoyah Conversion Facility, Kerr-McGee Corporation, Gore, Oklahoma, 1981. 
APPENDIX D

PLUTONIUM CONTAMINATED FACILITY 
APPENDIX D

PLUTONIUM CONTAMINATED FACILITY

D.1 BABCOCK AND WILCOX, PARKS TOWNSHIP, PENNSYLVANIA

The Babcock and Wilcox plutonium contaminated facility at the Parks Township site is currently being decommissioned. Inventories have been removed, and process and other equipment is being removed for disposal at a licensed burial site. Information in the appendix describing the facility was prepared using reports by Babcock and Wilcox (1975), U.S. Nuclear Regulatory Commission (1978), and Mishima, Schwendiman, and Ayer (1978).

\section{D.1.1 Process Description}

Operation

Operations during processing included conversion of plutonium nitrate to $\mathrm{PuO}_{2}$ by precipitation with the addition of peroxide or oxalate. The precipitate was filtered, dried, and calcined to $\mathrm{PuO}_{2}$. The $\mathrm{PuO}_{2}$ was then ball milled and blended to a uniform size.

Fuel rod fabrication also took. place in the plant. The $\mathrm{PuO}_{2}$ and $\mathrm{UO}_{2}$ powders were blended together along with recycle material. An organic binder was added to the mix, which was then compacted into slugs, granulated, and screened. The mixed oxide (MOX) was pressed into pellets, which were sintered in a reducing furnace. Pellets were ground to a specified diameter, and inspected before being loaded into fuel rods.

Scrap Recovery

Scrap recovery operations included an ion exchange system in which dirty scrap was dissolved in nitric acid, filtered, and passed through ion exchange columns. The product plutonium eluted from the column was concentrated in an evaporator.

Clean scrap was oxidized and reduced in a reactor before being recycled back to the blender.

\section{D.1.2 Facility Description}

Building

The plutonium plant occupies about $8,400 \mathrm{~m}^{2}\left(90,400 \mathrm{ft}^{2}\right)$. The latest addition is $12 \mathrm{~m}$ ( $39 \mathrm{ft}$ ) high. Other dimensions can be estimated using Figure D.1. Fabrication rooms range from $100 \mathrm{~m}^{2}\left(1,000 \mathrm{ft}^{2}\right)$ to $800 \mathrm{~m}^{2}\left(8,600 \mathrm{ft}^{2}\right)$ in size. The hot cell has about $100 \mathrm{ft}^{2}$ of area. Room dimensions are shown in Table D.1. Figure D.1 shows areas in the facility where radioactive materials were handled and that are thus potentially contaminated. Four 


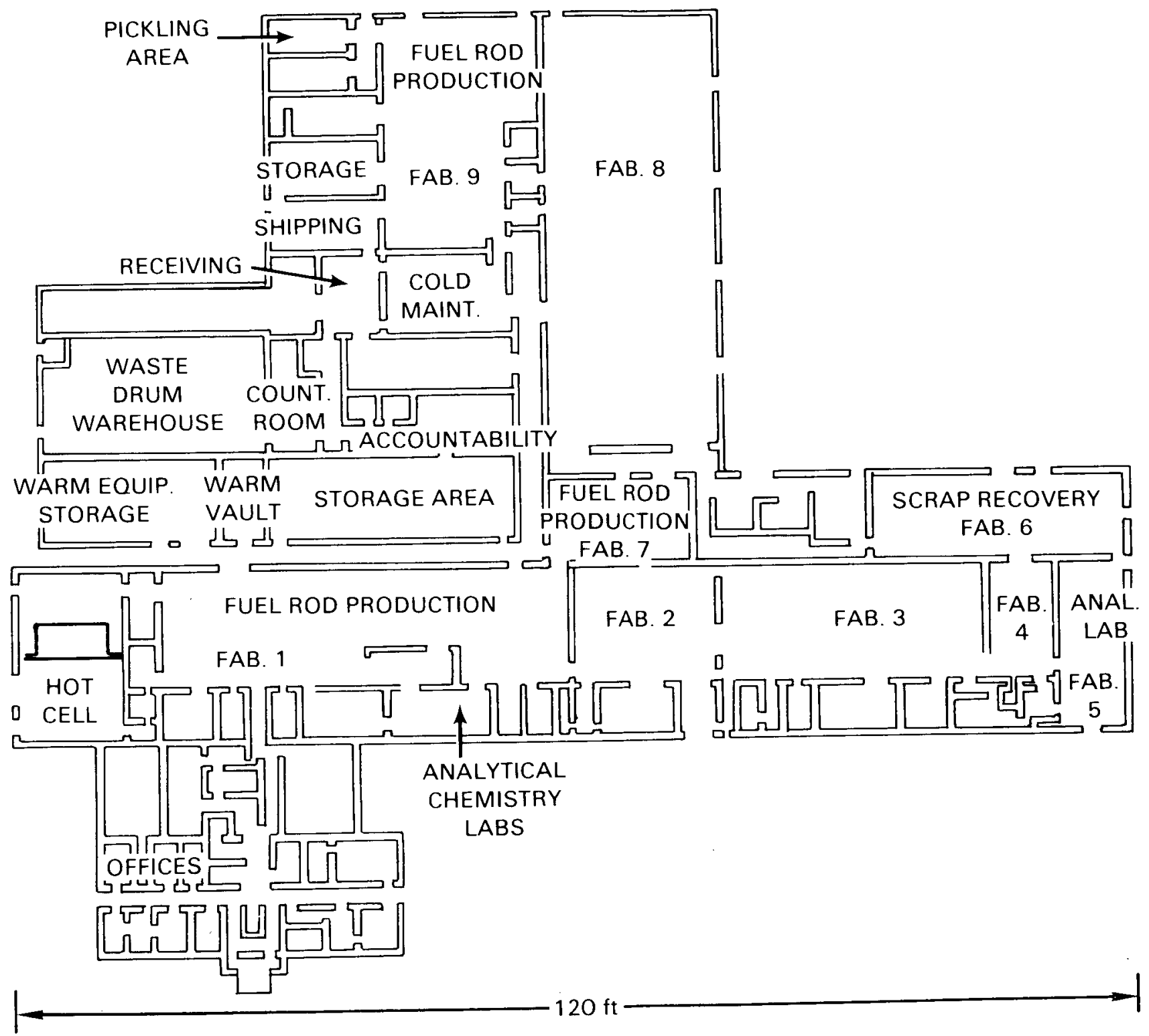

FIGURE D.1. Babcock and Wilcox Parks Township Site Plutonium Plant 
TABLE D.1. Floor Area of Potentially Contaminated Rooms

$\begin{array}{lc}\text { Room } & \text { Area, ft2 } \\ \text { Fabrication 1 } & 550 \\ \text { Fabrication } 5 & 150 \\ \text { Fabrication } 6 & 230 \\ \text { Fabrication } 7 & 150 \\ \text { Fabrication } 9 & 370 \\ \text { Hot cell } & 100\end{array}$

areas -- Fab-2, $-3,-4$, and -5 -- were used infrequently and held 1 imited quantities of fissile material. Seventy-five glove boxes are estimated to be in the facility.

The plutonium plant is made of concrete block, concrete block with brick facing, and insulated metal siding construction. The roof is made of precast concrete slabs on steel bar joists. The roof also has built-up tar and gravel on top of the slabs. Interior partitions are of concrete block or metal.

HVAC Systems

The Parks Township plutonium plant has six HVAC systems to clean air from areas handling radioactive materials. Each system has at least one stage of HEPA filters to filter contaminants from exhaust gases and may have as many as three stages. Airflow is towards areas of greater potential contamination and some air may be recirculated.

Engineered Safety Systems

Most construction materials are noncombustible. Automatic fire detectors are installed in most areas of the plant as well as in glove boxes. Automatic sprinklers are installed in the storage, shipping and receiving, and maintenance areas. Manual dry chemical fire extinguishers are located around the plant.

Surrounding Area

The facility is located on a 59-acre site. The building front is set back about $30 \mathrm{~m}$ from State Highway 66, which parallels the site's front boundary.

\section{D.1.3 Inventory}

\section{Radioactive Inventory}

While operating, the entire plant inventory was around $526 \mathrm{~kg}$ of plutonium and 2,000 to $3,000 \mathrm{~kg}$ of uranium. The licensed possession limits while the plant was under operation are shown in Table D.2. 
TABLE D.2. Licensed Limits of Special Nuclear Materials During Operations at Babcock and Wilcox Plutonium Plant

Facility Area

Pu plant

High-enriched uranium areas

$U_{6}$ cylinder areas

Metals and hafnium complex
Material

Pu (non-pyrophoric) fissile
$238 \mathrm{Pu}$ as sealed source
$238 \mathrm{Pu}$ as metal or oxide
$U \leqslant 5$ wt $235 \mathrm{U}$
$U \geqslant 5$ wt $235 \mathrm{U}$
$U$ natural or depleted

$U>5 w t \% 235 U$

$U \leqslant 5 w t \% 235$

$U$ natural or depleted

Sealed sources and other radioactive materials
Inventory, $\mathrm{kg}$

$$
1,000
$$

0.060

0.060

25,000

10,000

$<5$

200,000

100,000

$5 \mathrm{Ci}$

During operations, the amount of plutonium in process ranged from 0 to $8.6 \mathrm{~kg}$ per glove box. About 38 glove boxes were located in the main fabrication area and about 10 glove boxes were in the scrap recovery area. If the facility has been decontaminated to the point where only the glove boxes and ground-in contamination are left in the building, each glque box bas a small amount of contamination. A conservative value of $1 \times 10^{-4} \mathrm{~g} \mathrm{Pu} / \mathrm{m}^{2}$ of ground-in surface contamination has been used (Mishima and Ayer 1981).

\section{Hazardous and Combustible Inventory}

A natural-gas-fired furnace provides heat to areas in the plutonium plant. Construction materials of concern are plastic windows and rubber gloves in the glove boxes, some polyvinylchloride (PVC) ventilation ducts, and combustible frames on some HEPA filters. Plastic bags and tape, and solvent may be in the building for cleaning operations.

When the plant was under operation, hydrogen gas was piped in for processes requiring reducing atmospheres. Ion exchange resins were used in the scrap recovery processes.

The 75 glove boxes may contain an estimated 6,900 1b of polymethylmethacrylate (PMMA) as viewing windows. During the operating period, there could also be 900 . Ib of PVC as bagging plastic, 225 lb of cellulosic material as paper, rags, and wipes, 1,275 $1 \mathrm{~b}$ of elastomers, and $701 \mathrm{~b}$ of hydraulic fluid as lubricant for process equipment. 
The General Electric (GE) Vallecitos plutonium plant is currently being decontaminated and decommissioned. Information in this section was developed using a report by Mishima and Ayer (1980).

\section{D.2.1 Process Description}

Operations

Former operations in the plant included dry blending $\mathrm{PuO}_{2}$ and $\mathrm{UO}_{2}$ as well as coprecipitation of plutonium and uranium nitrate. Pellets were made and loaded into fuel elements. Product fuel ranged from 10 to $25 \%$ plutonium from coprecipitation processes with an average of $20 \%$ plutonium. Fuel was made on a small batch basis for experimental purposes, and was not run for production.

\section{Scrap Recovery}

Scrap recovery operations were provided during plant operation but the type of system was not identified. Laboratory operations were designed to specifically analyze plutonium solutions and compounds. Hot cells were provided to handle by-product materials.

\section{D.2.2 Facility Description}

Buildings

The total volume of the plutonium analytical laboratory (PAL) is $8,000 \mathrm{ft}^{3}$. Within the PAL, six enclosures have a total volume of $17 \mathrm{~m}^{3}$ $\left(600 \mathrm{ft}^{3}\right)$. In the advançed fuels laboratory (AFL), the scrap recovery glove box has a volume of $17 \mathrm{~m}^{3}$ and the nitrate conversion glove box has a volume of $18 \mathrm{~m}^{3}\left(640 \mathrm{ft}^{3}\right)$.

The sizes of some of the process areas are listed in Table 0.3. Figures $D .2$ and $D .3$ are diagrams of the facility showing areas of concern because of potentially high contamination levels.

TABLE D.3. Process Areas in General Electric Vallecitos Plant

\begin{tabular}{|c|c|c|}
\hline Area & Area, $\mathrm{ft}^{2}$ & Height, ft \\
\hline Advanced fuels laboratory & 3,500 & \\
\hline Plutonium analytical laboratory & 700 & $11-1 / 2$ \\
\hline Radiochemistry laboratory & 700 & \\
\hline 4 Hot cells & 1,000 & 18 to 20 \\
\hline
\end{tabular}




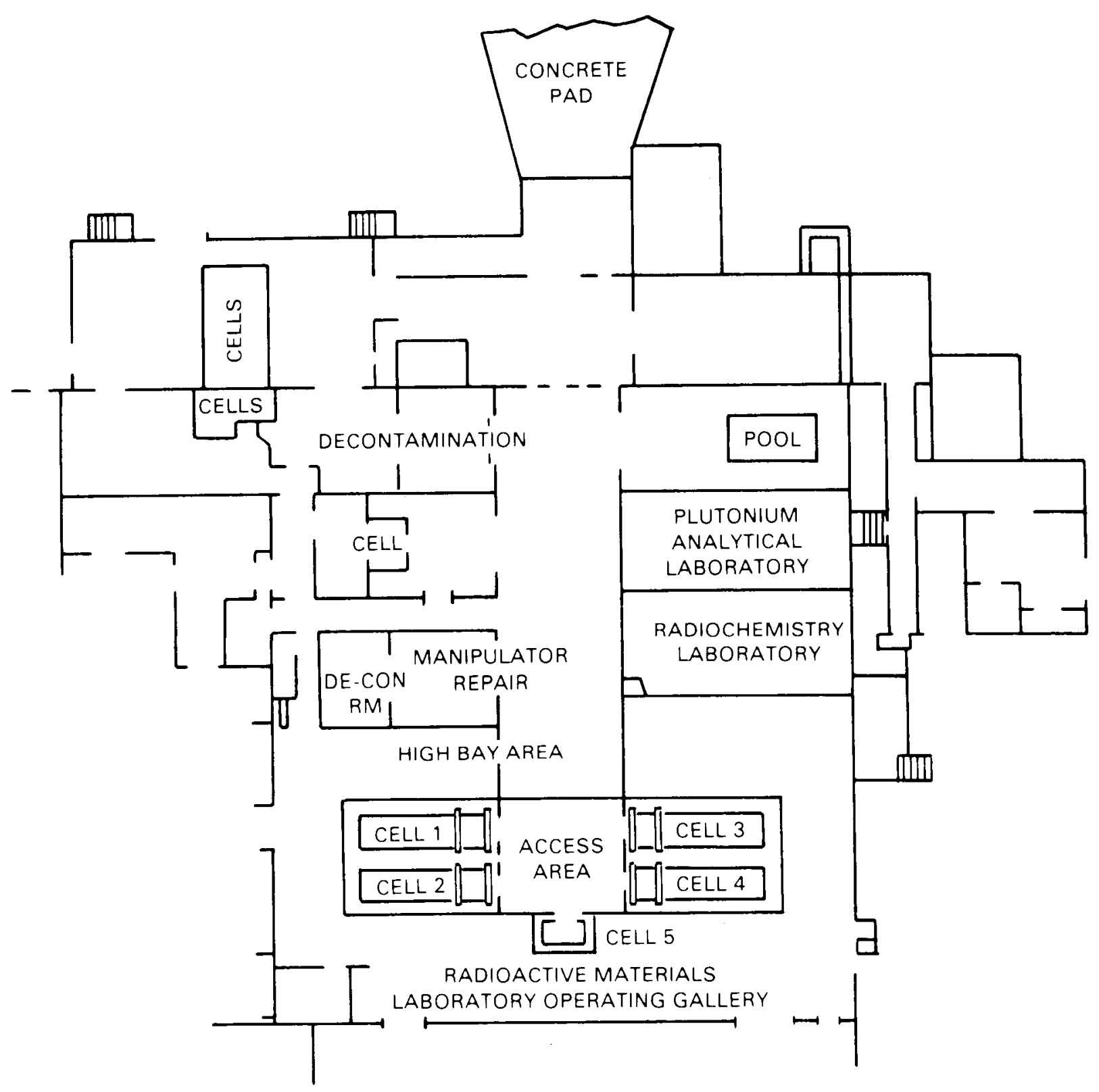

FIGURE D.2. Diagram of the Building 102 Main Floor, General Electric Nuclear Center 


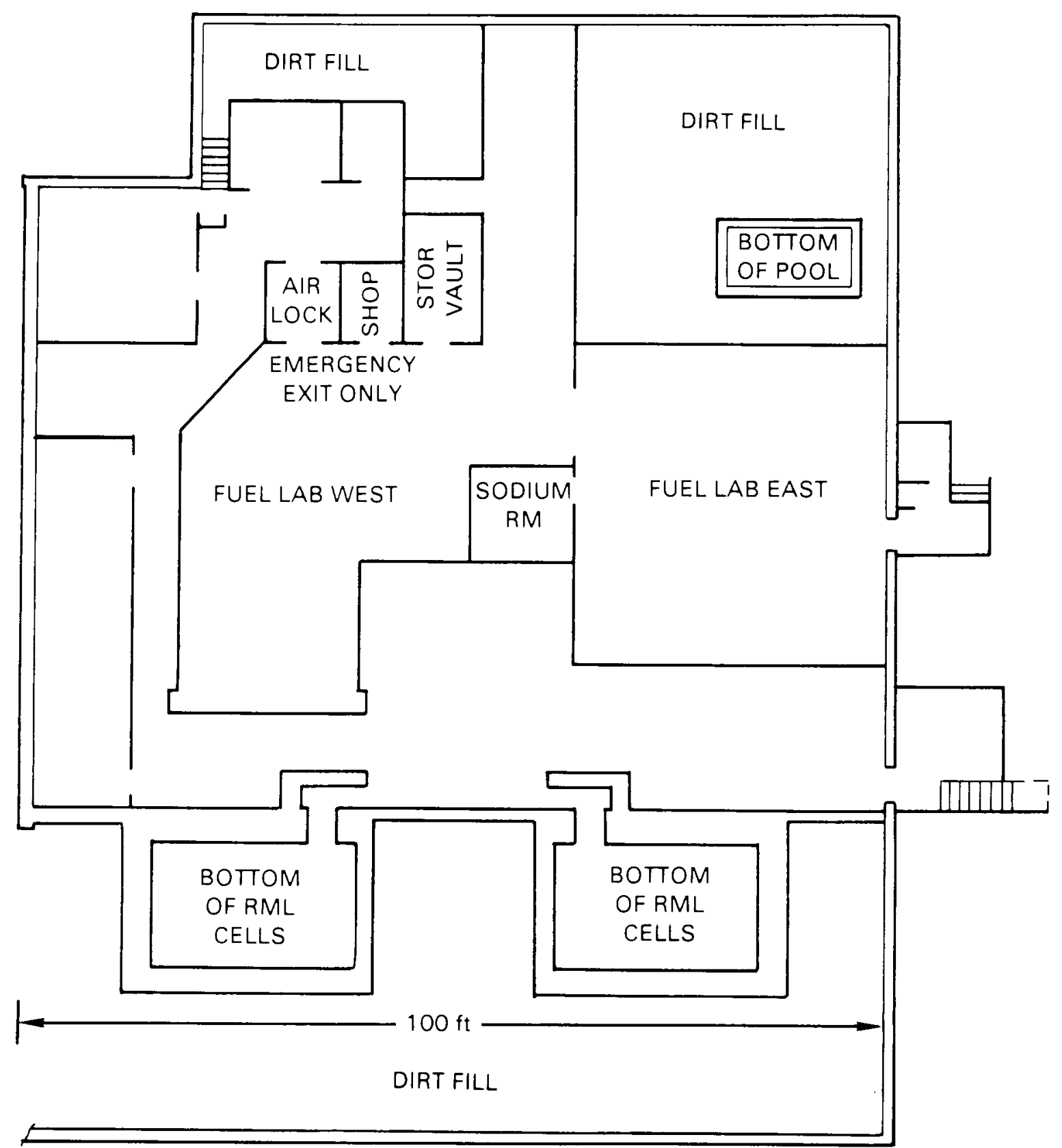

FIGURE D.3. Diagram of the Building 102 Basement, General Electric Nuclear Center

0.7 
The main building (102) is made of concrete and steel. The floor slabs are reinforced concrete. The roof has structural steel framing and a metal deck supported by structural steel columns. Walls on the ground floor are 8-in. reinforced concrete block, 4-in. reinforced concrete block, precast reinforced concrete, and wood studs with gypsum board. The floor slab over the basement is reinforced concrete as are the basement walls, columns, floor slabs and footings.

The four principal hot cells have 2- to 3-ft-thick walls of high-density concrete.

HVAC Systems

Room air is drawn in through HEPA filters. The room is at negative pressure with respect to the atmosphere and enclosures are at negative pressure with respect to the room. The sintering furnace is the only exception; it is kept at positive pressure. Exhaust ducts are primarily stainless steel.

Engineered Safety Systems

Thermal and smoke detectors are located in the advanced fuels laboratory in the basement of the 102 Building. An overhead sprinkler system as well as a dry extinguisher are also provided in this area.

Surrounding Area Center.

The facility is located within a fenced portion of the vallecitos Nuclear

\section{D.2.3 Inventory}

Radioactive Inventory

The advanced fuels laboratory in the basement of the 102 Building contained most of the dispensible, undiluted plutonium in three glove boxes. The blending glove box held up to $625 \mathrm{~g}$ of $\mathrm{PuO}_{2}$ powder. The scrap recovery glove box held $2 \mathrm{~kg}$ of plutonium as nitrate solution and had a total volume of $17 \mathrm{~m}^{3}$. The nitrate conversion gl guve box held $5 \mathrm{~kg}$ of plutonium as nitrate solution and had a volume of $18 \mathrm{~m}^{3}$.

Solutions in the plutonium analytical laboratory had a concentration of about $200 \mathrm{~g} \mathrm{Pu} / \mathrm{L}$.

The radiochemistry lab routinely handled $8 \mathrm{Ci}$ of ${ }^{99} \mathrm{Mo}, 0.4 \mathrm{Ci}$ of ${ }^{32} \mathrm{p}$, and $100 \mathrm{mg}$ of mixed oxide fuel in solution. This amount is minor compared to amounts handled in the advanced fuels and plutonium analytical laboratories.

Decontaminated glove boxes may be assumed to have $1 \times 10^{-4} \mathrm{~g} \mathrm{Pu} / \mathrm{m}^{2}$ surface contamination (Mishima and Ayer 1981). 
While under operation, the fire potential in the facility was limited. A few combustibles such as cellulosic waste in 55-gal drums were present. Two hydraulic fluid reservoirs were located in glove boxes within the facility. A small amount of isopropanol (50 to $200 \mathrm{~cm}^{3}$ ) was present as a die lubricant in one of the glove boxes.

Approximately 56 glove boxes in Building 102 may contain an estimated $5,150 \mathrm{lb}$ of PMMA as viewing windows. During the operating period there could also have been 6190 ib of PVC present along with 1,700 lb of cellulosic material, $950 \mathrm{lb}$ of elastomer, $150 \mathrm{lb}$ of polystyrene, and $16 \mathrm{lb}$ of hydraulic fluid.

\section{D.3 KERR-MCGEE, CIMMARRON, OKLAHOMA}

The Kerr-McGee plutonium contaminated facility is currently being decontaminated and decommissioned. Kerr-McGee reports (1971a, 1971b) were used as a source for information in this section.

\section{D.3.1 Process Description}

Operations

Former operations involved blending plutonium and uranium nitrate solutions, precipitating the plutonium-uranium mixture in a column with the addition of ammonia, filtering the slurry, and drying and calcining the precipitate into mixed oxide. The mixed oxide was milled to a uniform size, pressed into pellets, sintered, ground in a centerless grinder to a uniform shape, and loaded into tubes. Tubes were assembled into lots, cleaned, inspected, and packaged for shipment.

\section{Scrap Recovery}

A scrap recovery area in a separate section of the building held solvent extraction and operations purifying plutonium and uranium. Some waste was incinerated. Low-level wastes with uneconomically recoverable plutonium were drummed and shipped to licensed disposal sites. Liquid wastes were treated chemically and retained onsite in ponds before discharging.

\section{D.3.2 Facility Description}

Buildings

About 19,000 $\mathrm{ft}^{2}$ of space were used for manufacturing, maintenance, office, and laboratory operations in one building. Floor areas of potentially contaminated rooms at the Kerr-McGee plant are listed in Table D.4. These areas are among those designated in Figure 0.4 , which shows plans for the basement and first floor of the facility. 
TABLE D.4. Floor Area of Potentially Contaminated Rooms at Kerr-McGee Plutonium Contaminated Facility

\begin{tabular}{|c|c|}
\hline Room & $\begin{array}{r}31 z e, \\
\mathrm{ft} \\
\end{array}$ \\
\hline Inspection and assembly & 1,200 \\
\hline Fabrication & 1,200 \\
\hline Pellet processing & 1,200 \\
\hline Vault & 800 \\
\hline Scrap recovery & 700 \\
\hline Solvent extraction & 200 \\
\hline Wet processing & 1,100 \\
\hline
\end{tabular}

The plant building is made of precast concrete strengthened with reinforced steel to withstand $120 \mathrm{mph}$ winds. The vault within the main building is substantially stronger and can withstand up to $300 \mathrm{mph}$ winds. Glove boxes inside the building provide double containment for process materials and are built of $3 / 8-i n$. stainless steel.

HVAC Systems

Airflow is toward areas of greater potential contamination. Air is filtered as it enters the plant and conditioned to provide heating or cooling. This air is distributed throughout the plant, withdrawn through floorlevel vents, and exhausted through HEPA filters to a final filtration system. Backup ventilation is provided.

\section{Engineered Safety Systems}

Each exhaust system has a firescreen to prevent spread of fire in glove boxes. Final filters have steam dampeners to protect them from fire. Backup ventilation systems are provided.

Solvent extraction hoods have an automatic Halon ${ }^{\circledR}$ fire extinguishing system as well as a nitrogen purge.

Surrounding Area

The Cimmarron plant is located in a rural area. The site itself occupies 1,100 acres, 60 of which are used for Kerr-McGee operations. Farming and grazing are the primary activities surrounding the site.

(B) Halon is a trademark of the Allied Chemical Corp., Morristown, NJ 07960 


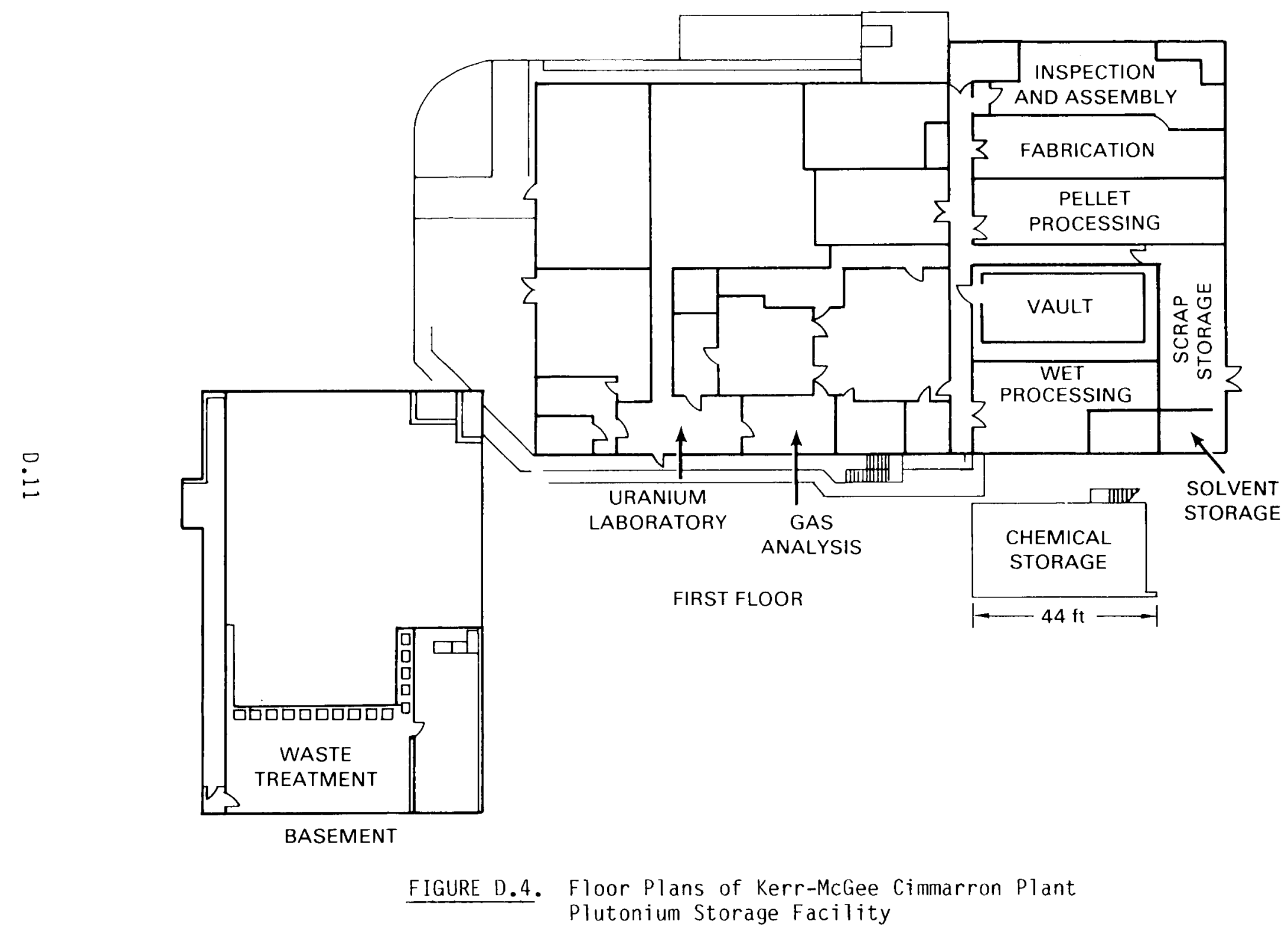


Gas and oil are produced in the vicinity of the plant also. Within a 5 mile radius there are several gas and $0 i 1$ wells.

\section{D.3.3 Inventory}

Radioactive Inventory

During operations, the inventory ranged from $1.1 \mathrm{~kg}$ of plutonium attached to process equipment to $201.1 \mathrm{~kg}$ of plutonium. Inventory may have reached 250 to $300 \mathrm{~kg}$ of plutonium during the processing of FFTF fuel. The plant was licensed to handle $360 \mathrm{~kg}$ of plutonium as oxide or other compounds, $2 \mathrm{~g}$ of plutonium as a sealed source, $1050 \mathrm{~g}$ of uranium enriched in $235 \mathrm{U}$ and $700 \mathrm{~kg}$ of natural or depleted uranium.

A conservative value of $1 \times 10^{-4} \mathrm{~g} \mathrm{Pu} / \mathrm{m}^{2}$ can be used to estimate residual contamination on surfaces of glove boxes and other decontaminated equipment (Mishima and Ayer 1981).

Hazardous and Combustible Inventory

During operations, the process used nitric acid, ammonia, a reducing gas composed of $8 \%$ by volume hydrogen in nitrogen, sodium carbonate, tributyl phosphate, and liquid hexane. Natural gas fueled the steam-producing boilers.

\section{D.4 WESTINGHOUSE ELECTRIC CORPORATION, CHESWICK, PENNSYLVANIA}

The Westinghouse Plutonium Fuels Development Laboratory (PFDL) is presently being decontaminated and decommissioned. In this process equipment is disassembled, surface contamination is fixed to become less dispersible, and the material is packaged for burial in a licensed waste facility.

In Building 8 , the gross decontamination of the lab is finished. Some glove boxes and hoods remain to be dismantled. Building 7 has been totally decontaminated except for a few systems such as liquid waste collection and ventilation. The building is used to store waste shipping containers for decontamination and decommissioning.

Information in this section was prepared using reports by Westinghouse Nuclear Fuels Division $(1975,1981)$ and Mishima et al. (1979).

\section{D.4.1 Process Description}

Operation

Former operations in the two buildings included the fabrication of uranium-plutonium blend pellets. Both oxide and carbide fuels were made in the plant as well as some thorium fuel blends. 0xide pellet fabrication involved mixing $\mathrm{PuO}_{2}$ and $\mathrm{UO}_{2}$ powders and slugging the mixture, followed by granulation and pressing of the granules into pellets. Pellets were sintered, ground to specified diameter, and loaded into tubes. Mixed carbide blends were made in a 
similar manner except the initial blending was done with carbon in a reducing atmosphere at high temperatures.

Waste Disposal

Plutonium-contaminated waste was sealed in PVC bags and transferred to a 55-gal drum. After the plutonium content was confirmed, the drum was shipped to an offsite disposal facility. Liquid wastes were transferred to tanks, analyzed, and accumulated. Process liquids in 30-gal drums were adsorbed on diatomaceous earth; that drum was sealed in an outer 55-gal drum, which was sealed and shipped to a disposal site.

Solid waste generated during decontamination and decommissioning is residually contaminated. This waste is sealed in polyvinyl bags, packaged in drums, and stored awaiting shipment to an offsite disposal facility. Potentially contaminated liquid wastes are collected in 1,000-gal tanks. The tank contents are pump-mixed, analyzed and discharged.

\section{D.4.2 Facility Description}

Buildings 7 and 8 can have potentially contaminated areas. Figure 0.5 shows Building 8 , the PFDL with critical areas with potential surface contamination identified. Table D.5 lists the sizes of both buildings holding contaminated materials as well as individual rooms that are potentially contaminated in the buildings. Building 8, the main building of the PFDL, is a single-story, open-bay structure.

Building 8 is a steel form structure. The floor is concrete slab and exterior walls are corrugated steel siding on steel girts. Interior walls have steel studs with cement plaster interior faces. Ceilings are cement plaster. The roof is steel decking with 2- to 4-in. cast-in-place concrete slab.

Building 7 is a one-story concrete building with concrete block walls and steel doors.

\section{HVAC Systems}

Room air is recycled and handled separately from glove box air. Each system goes through two stages of HEPA filters. Glove boxes are kept at negative pressures of -0.025 to $-0.1 \mathrm{in}$. of water with respect to the room. Airflow is towards areas of greater potential contamination. Doors are kept closed to maintain air balance and equipped with alarms indicating when they are opened. Glove box air is drawn from the room through an absolute filter.

\section{Engineered Safety Systems}

A dry pipe sprinkler system is installed in parts of Building 8 . Fire detectors and water spray systems provide fire protection for the filters. Each glove box is equipped with a fire detector and manual dry chemical fire extinguishers. 


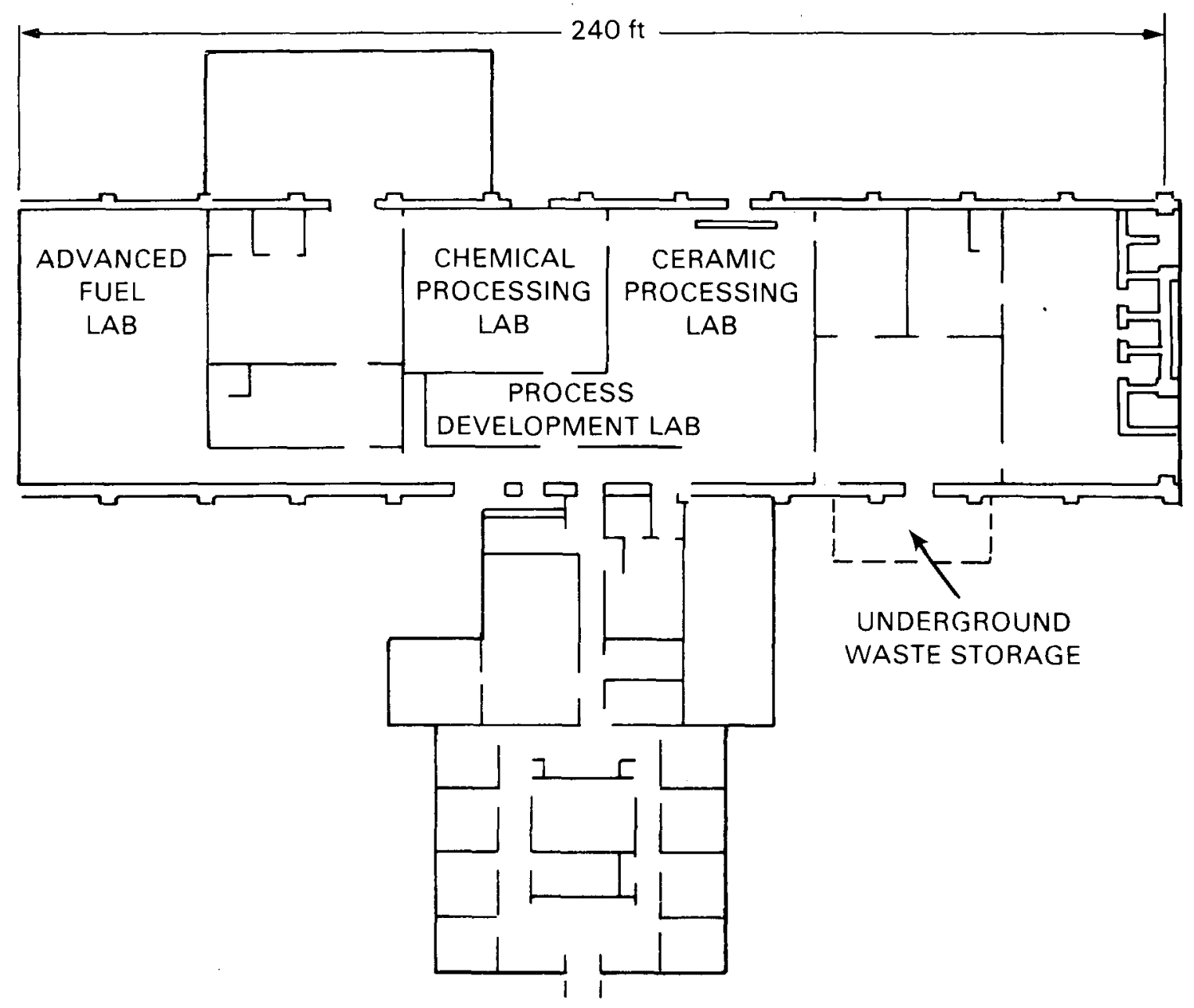

FIGURE D.5. Westinghouse Plutonium Fuel Development Facility General Plan

TABLE D.5. Arèas Holding Contaminated Materials at Westinghouse, Plutonium Fuel

Development Laboratory

Building 8

Chemical Processing Lab

Ceramic Processing Lab

Process Development Lab

ARD Fast Breeder Reactor Facility

Building 7

Contaminated Areas (includes Pu lab)

Pu Lab (largest lab)

$$
\begin{array}{r}
\text { Size, } f t^{2} \\
\hline 14,400 \\
1,000 \\
2,200 \\
500 \\
2,500 \\
11,000 \\
5,000 \\
1,500
\end{array}
$$


engine.

Backup power is supplied by a natural-gas- or manufactured-gas-fired

Alarm panels are located throughout the plant for detecting local accidental releases. Two central alarm panels are also provided.

Surrounding Area

The Cheswick site is located in a hilly rural area. Other buildings onsite are involved in the fabrication of nuclear pumps, mechanisms, and valves for the Navy.

Eight gasoline filling stations are located within a 1 -mi radius of the plant. A substation and an underground natural gas pipeline are also within $1 \mathrm{mi}$ of the site. An 18-in. underground pipe carrying either No. 2 diesel fuel oil, gasoline, or aviation kerosene runs $0.9 \mathrm{mi}$ north of the site.

\section{D.4.3 Inventory}

\section{Radioactive Inventory}

About 62 glove boxes contained radioactive materials in the manufacturing building. While in operation, inventory of these glove boxes ranged from $2 \mathrm{~g}$ to $100 \mathrm{~kg}$ of material. The possession limits (excluding sealed sources) for Buildings 7 and 8 during the operating period are listed in Table 0.6 .

Although many glove boxes have been removed (in Building 7 all glove boxes have been taken out), most of the contaminated glove boxes in Building 8 remain. As a common reference point for the source term, all the glove boxes will be assumed to be present.

Megsurement of residual contagmination in a fuel cycle facility was $5 \times 10^{-9} \mathrm{~g} \mathrm{Pu} / \mathrm{m}^{2}$ and $1 \times 10^{-8} \mathrm{~g}^{235} \mathrm{U} / \mathrm{cm}^{2}$ (Mishima and Ayer, 1981). A conservative value of $1 \times 10^{-4} \mathrm{~g} \mathrm{Pu} / \mathrm{m}^{2}$ for glove boxes formerly handing mixed oxide of $\mathrm{PuO}_{2}$ may be used (Mishima and Ayer, 1981).

Hazardous and Combustible Inventory

Natural gas used for heating and supply to the emergency generator is supplied through an underground main system. Other gases were used during operations. A reducing gas with a nominal $94 \% \mathrm{~N}_{2}$ and $6 \% \mathrm{H}_{2}$ mixture was used and hydrogen/nitrogen storage tanks were located outside.

Chemicals used during plant operations are listed in Table D.7. Ion exchange resins were used for scrap recovery. Cleaning operations could use solvents, plastic bags, rubber gloves, and combustible paper wipes.

A total of 53 glove boxes could contain 4,800 lb of PMMA. During the operating period, they could also hold 650 lb PVC, 1,600 lb cellulosic material, 900 lb elastomers, 500 lb polystyrene, and 16 lb hydraulic fluid. 
TABLE D.6. Possession Limits for Westinghouse PFDL

\begin{tabular}{|c|c|c|}
\hline \multirow{2}{*}{$\frac{\frac{\text { Material }}{\text { Building } 8}}{\mathrm{Pu}}$} & Description & Limit, $\mathrm{kg}$ \\
\hline & $\begin{array}{l}\text { Maximum } 238 \mathrm{PuO} \text { of } 2 \mathrm{wt} \% \\
\text { Minimum } 244 \mathrm{Pu} \text { of } 5 \mathrm{wt} \%\end{array}$ & 1.5 \\
\hline $\mathrm{Pu}$ & Calibration Samples & 0.020 \\
\hline $235 U$ & $\begin{array}{l}\text { Contained in enriched uranium } \\
\text { at level }>0.72 \text { wt } \%\end{array}$ & 0.334 \\
\hline u & Normal or depleted & 1,000 \\
\hline Th & Dry chemical or physical form & 25 \\
\hline $\mathrm{Pu}$ & $\begin{array}{l}\text { Maximum }{ }^{238} \mathrm{pu} \text { of } 2 \mathrm{wt} \% \\
\text { Minimum } 240 \mathrm{pu}_{\mathrm{u}} \text { of } 5 \mathrm{wt} \% \text {, as } \\
\text { residual contamination in waste } \\
\text { in containers awaiting shipment } \\
\text { to burial }\end{array}$ & 3 \\
\hline u & $\begin{array}{l}235 \mathrm{U} \text { in enriched uranium at } 20 \\
\text { wt\% or greater as residual con- } \\
\text { tamination dispersed in waste, } \\
\text { contained, awaiting shipments }\end{array}$ & 2 \\
\hline
\end{tabular}

Building 7

U

Normal or depleted

5000

Th

Any form

200 
TABLE D.7. Chemicals Used at the Cheswick Site

\begin{tabular}{|c|c|c|}
\hline Material & Container & Size \\
\hline Acetone & Steel drums & 55 gal \\
\hline $\begin{array}{l}\text { Caustic dry } \\
\text { powder }\end{array}$ & $\begin{array}{l}\text { Cardboard box lined with } \\
\text { polyethylene }\end{array}$ & \\
\hline Caustic flares & Steel drums & $201 b$ \\
\hline Hydrochloric acid & $\begin{array}{l}\text { Polyethylene carboys } \\
\text { Glass bottles }\end{array}$ & $\begin{array}{l}20 \mathrm{gal} \\
1 \mathrm{pt}\end{array}$ \\
\hline Nitric acid & Stainless steel drums & 55 gal \\
\hline Oxalic acid & Glass bottles & $1 \mathrm{pt}$ \\
\hline Perchloric acid & Glass bottles & $1 \mathrm{pt}$ \\
\hline Phosphoric acid & Glass bottles & \\
\hline Sulfamic acid & Brown bottles & \\
\hline Sulfuric acid & Glass bottles & $1 \mathrm{pt}$ \\
\hline
\end{tabular}

\section{D.5 REFERENCES}

Babcock and Wilcox, Environmental Data for the Apollo Site Materials Plant of the Nuclear Materials Division of the Babcock and Wilcox Corporation, Docket No. 70-135, U.S. Nuclear Regulatory Commission, Washington, D.C., 1975.

Kerr-McGee Corporation, Applicants Environmental Report, Docket No. 70-1193-3, U.S. Nuclear Regulatory Commission, Washington, D.C., 1971 a.

Kerr-MCGee Corporation, Cimmarron Plutonium Production Plant, License SNM-1174, Section E, Appendix D, Statement, Revised, Docket No. 70-1193-2, U.S. Nuclear Regulatory Commission, Washington, D.C., $1971 \mathrm{~b}$.

Mishima, J., L. C. Schwendiman, and J. E. Ayer, Increment of Analysis: An Estimate of Severe Airborne Release of Plutoni um from Babcock and Wilcox Plant as a Result of Wind Hazard and Earthquake, PNL-2812, Pacific Northwest Laboratory, Richland, Washington, 1978.

Mishima, J., R. B. McPherson, L. C. Schwendiman, E. C. Watson, and J. E. Ayer, Source Term and Radiation Dose Estimates for Postulated Damage to the 102 Building at the General Electric Vallecitos Nuclear Center, PNL-2844, Pacific Northwest Laboratory, Richland, Washington, 1979.

Mishima, J., and J. E. Ayer, Estimated Airborne Release of Plutonium from the 102 Building at the General Electric Vallecitos Nuclear Center, Villecitos, California, as a Result of Severe Wind and Earthquake Hazard, PNL-3601, Pacific Northwest Laboratory, Richland, Washington, 1980. 
Mishima, J., and J. E. Ayer, Estimated Airborne Release of Plutonium from Atomics International's Nuc Tear Materials Development Facility in the Santa Susana Site, California, as a Result of Severe Wind and Earthquake Hazard, PNL-3935, Pacific Northwest Laboratory, Richland, Washington, 1981.

U.S. Nuclear Regulatory Commission (USNRC), Environmental Impact Appraisal, Babcock and Wilcox Company, Nuclear Materials Division, Leechburg, Parks Township, Pennsylvania, U.S. Nuclear Regulatory Commission, Washington, D.C., 1978.

Westinghouse Nuclear Fuel Division, Westinghouse Cheswick Site Fuel Development Laboratories Environmental Report, Westinghouse Electric Company, Cheswick, Pennsyivania, 1975.

Westinghouse Nuclear Fuel Division, Plutonium Fuels Development Laboratory, Radiological Contingency Plan, Westinghouse Electric Company, Cheswick, Pennsylvania, 1981. 
$\theta$

APPENDIX E

RADIOPHARMACEUTICAL MANUFACTURING 


\section{APPENDIX E}

RADIOPHARMACEUTICAL MANUFACTURING

\section{E.1 ABBOTT LABORATORIES, NORTH CHICAGO, ILLINOIS}

The radiopharmaceutical division of Abbott Laboratories manufactyfes in vitro diagnostic products and diagnostic instruments iodinated with ${ }^{125}$ I. Operations are described in a report by Abbott Laboratories (1981) and the site was visited.

\section{E.1.1 Process Description}

Operation

Radiopharmaceuticals are manufactured in building AP-8, one of many facilities in the 110-acre Abbott Park site shown in Figure E.1. The primary process is iodinating organic substances using sodium iodide in the presence of chloramine-T. Purification using a sephadex column, dilution, filtration, filling and labeling are all conducted in AP-8. Iodine-125 is received in shipments of about $4 \mathrm{Ci}$ two to four times a month. These packages are smeartested for contamination and then transferred to a small lab area where microcurie-millicurie amounts are dispensed for production processes. Fume hoods are the primary confinement system. There are several small labs for labeling. A typical lab contains a single hood, bench, and cart as shown in Figure E.2. Additional lab space is provided for purification, dilution, etc.

Shipments of ${ }^{125}$ I are received in a central loading dock/warehouse area, which also provides temporary storage for approximately twelve 55-gal steel drums of compacted waste. The warehouse area in AP-8 also contains a materials storage area for paper, glassware, and compressed air. Several inactive hot cells in AP-8 are currently used for the decay of waste products from previous operations. Process chemicals and products awaiting shipment are stored in cabinets and refrigerators in several locations in AP-8.

Final diagnostic kit preparation and shipping are conducted in a separate building not included in the license.' A research and development area containing offices and small chemistry labs is located in AP-8.

Waste Disposal

Solid waste is collected regularly from all lab areas, compacted and drummed in 55-gal steel drums. It is transferred weekly to AP-15A, the radioactive waste storage area, which is part of building AP-15. Thirty-and 55-gal steel drums are stacked on pallets. 


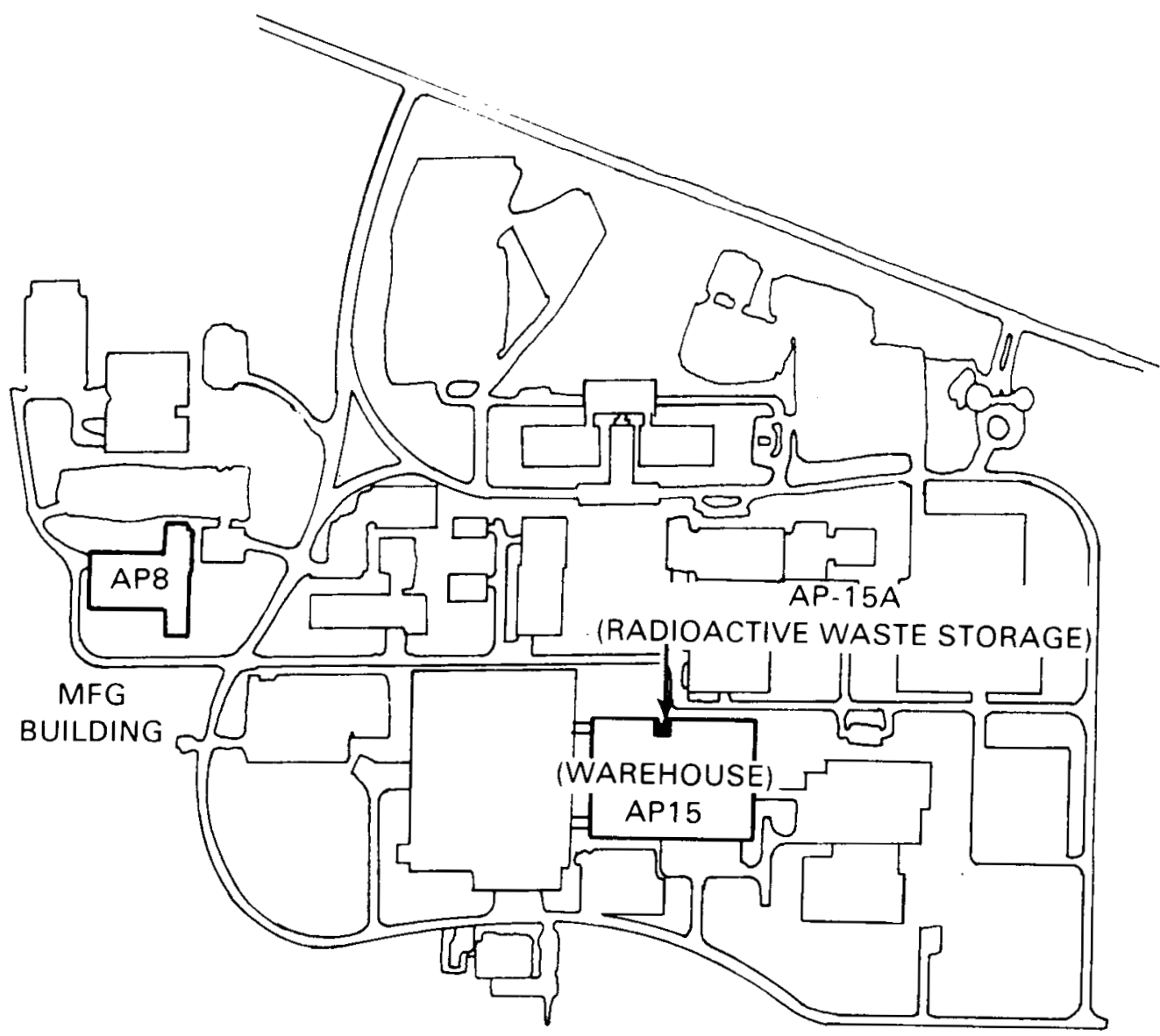

FIGURE E.1. Abbott Park Site Plan

\section{E.1.2 Facility Information}

\section{Buildings}

The AP-8 building is fabricated of concrete, steel, and brick and is specifically designed for handling radioactive production processes. Asphalt tiles cover a concrete slab floor, and walls are concrete block.

The AP-15 building is a $200,000-\mathrm{ft}^{2}$ warehouse with a $6400-\mathrm{ft}^{2}$ portion $(A P-15 A)$ set aside for radioactive waste storage. It is a concrete and brick building with metal walls separating the radioactive waste storage area from the rest of the building. An electric forklift is used for moving drums.

\section{HVAC Systems}

There are HVAC, HEPA, and charcoal filter systems located on the second floor of the AP-8 building. Fume hood exhaust air is not recirculated but passes through the filtration system before discharge to the atmosphere. All hood exhausts have dust, HEPA, and activated charcoal filters.

\section{E.2}




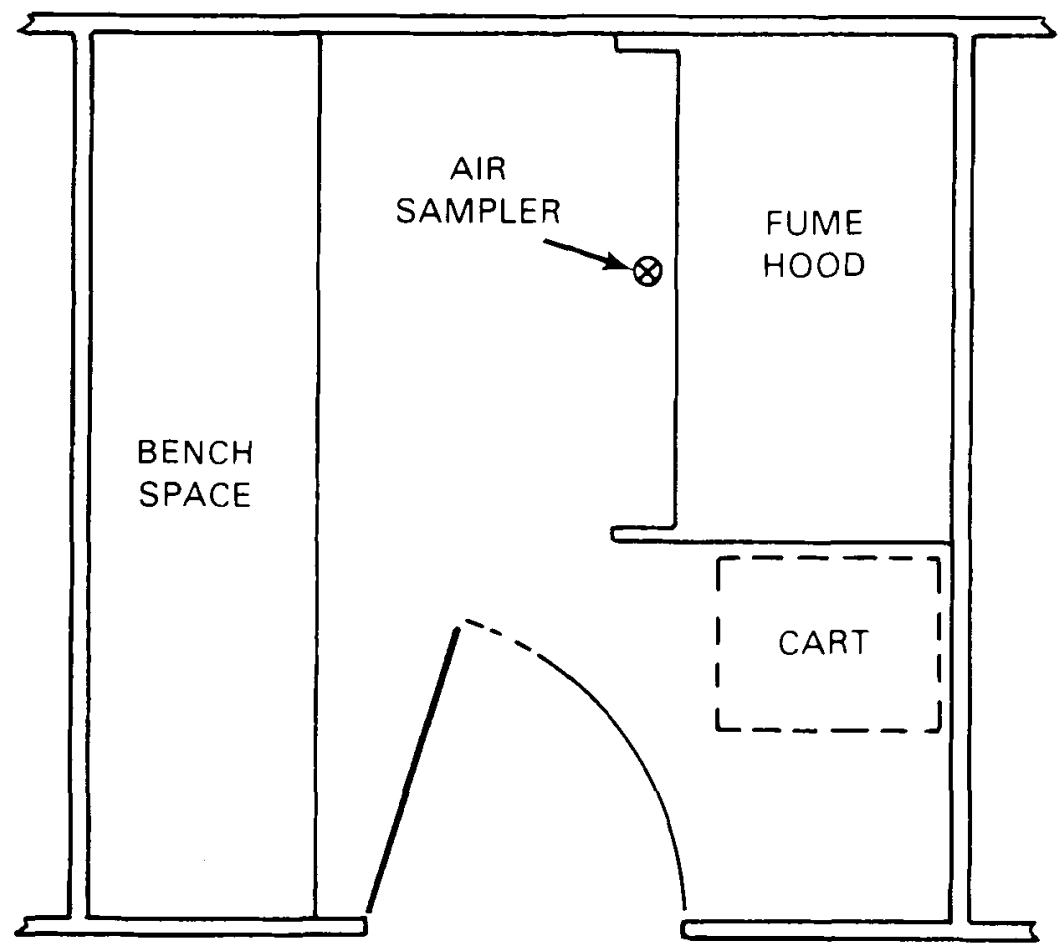

FIGURE E.2. A Typical Iodination Laboratory at Abbott Laboratories

Heat is provided by a central boiler facility serving the entire complex. No gas lines are located in the buildings. In AP-15, heat is provided by ceiling-mounted electric space heaters.

\section{Engineered Safety Systems}

Only areas with high combustible loading are sprinklered in AP-8. These are the warehouse, loading dock, and solvent storage areas. Offices and labs have fire walls and doors. Each fume hood is monitored for accidental discharge of radioactively contaminated air and loss of circulation. Solvent storage rooms are isolated from radioactive work area and have explosion relief panels.

\section{Surrounding Area}

The AP-8 and AP-i5 buildings are located within Abbott Park as shown in Figure E.1. The park is surrounded by gently rolling countryside. These two buildings have been deliberately separated from other facilities in the park to prevent the potential spread of contamination.

$$
\text { E.3 }
$$


E.1.3 Inventory

Radioactive Inventory

Abbott Laboratories' license allows a possession limit of $75 \mathrm{Ci}$ of $125 \mathrm{I}$ and less than $25 \mathrm{Ci}$ of by-product material (including $131_{\mathrm{I}}$ ) with atomic numbers 1 through 83. Iodine-125 is the only isotope currently handled in appreciable amounts. A typical inventory for all of the AP-8 is in the 23 to $26 \mathrm{Ci}$ range. The greatest concentration of material in the most limited space will occur on days when ${ }^{125}$ I shipments are received and $4 \mathrm{Ci}$ can be in the loading dock/ warehouse area, and in the $1 \mathrm{ab}$ where the ${ }^{125} \mathrm{I}$ pigs are opened and the material dispensed for production processes. Approximately $20 \mathrm{Ci}$ can be associated with waste.

Hazardous and Combustible Inventory

Combustible material is kept to a minimum in AP-8, and is virtually nonexistent in AP-15 except for arummed dry paper and liquid organic waste. Within AP-8, solvents and organics constitute the primary combustible materials. The building itself is constructed to be fire resistant (e.g., concrete, steel, brick, with fire walls). The research and development laboratory uses solvents and other combustibles such as ethyl alcohol. Hoods and lab furniture are stainless steel and metal construction. Some cardboard and plastic materials may be stored temporarily in AP-8 halls.

\section{E.2 NEW ENGLAND NUCLEAR, BOSTON, MASSACHUSETTS}

New England Nuclear (NEN) is the world's largest producer of radionuclidelabeled compounds used for medical diagnostic and tracer purposes. Located in metropolitan Boston, the facility consists of eight buildings, three of which handle the bulk of radioactive materials (development, production, storage, and shipping). Other buildings house the corporate headquarters, offices, and services. Locations of the buildings are shown in Figure E.3. Information was developed from a site visit and a New England Nuclear report (1981a).

\section{E.2.1 Process Description}

Operation

Four radioactive elements are primarily used for labeling organic compounds. In order of decreasing activity inyentory they are: tritium $\left({ }^{3} \mathrm{H}\right)$, carbon $\left({ }^{14} \mathrm{C}\right)$, phosphorous $\left({ }^{32} \mathrm{P}\right)$, and sulfur $\left({ }^{32} \mathrm{~S}\right)$. Gaseous tritium constitutes most of the activity handled by NEN. Two thousand curies are received each week in truck shipments of two 1,000-Ci pressurized cylinders. Ninety-five percent of the tritium processed becomes waste. Tritium is produced in a $1 a b$ on the fifth floor of the 575 Albany building shown in Figure E.4. Tritiated compounds, usually water, are produced in gas transfer systems using vacuum line chemistry operations enclosed in a Plexiglas ${ }^{\circledR}$ glove box.' These compounds 
E. BROOKLINE STREET

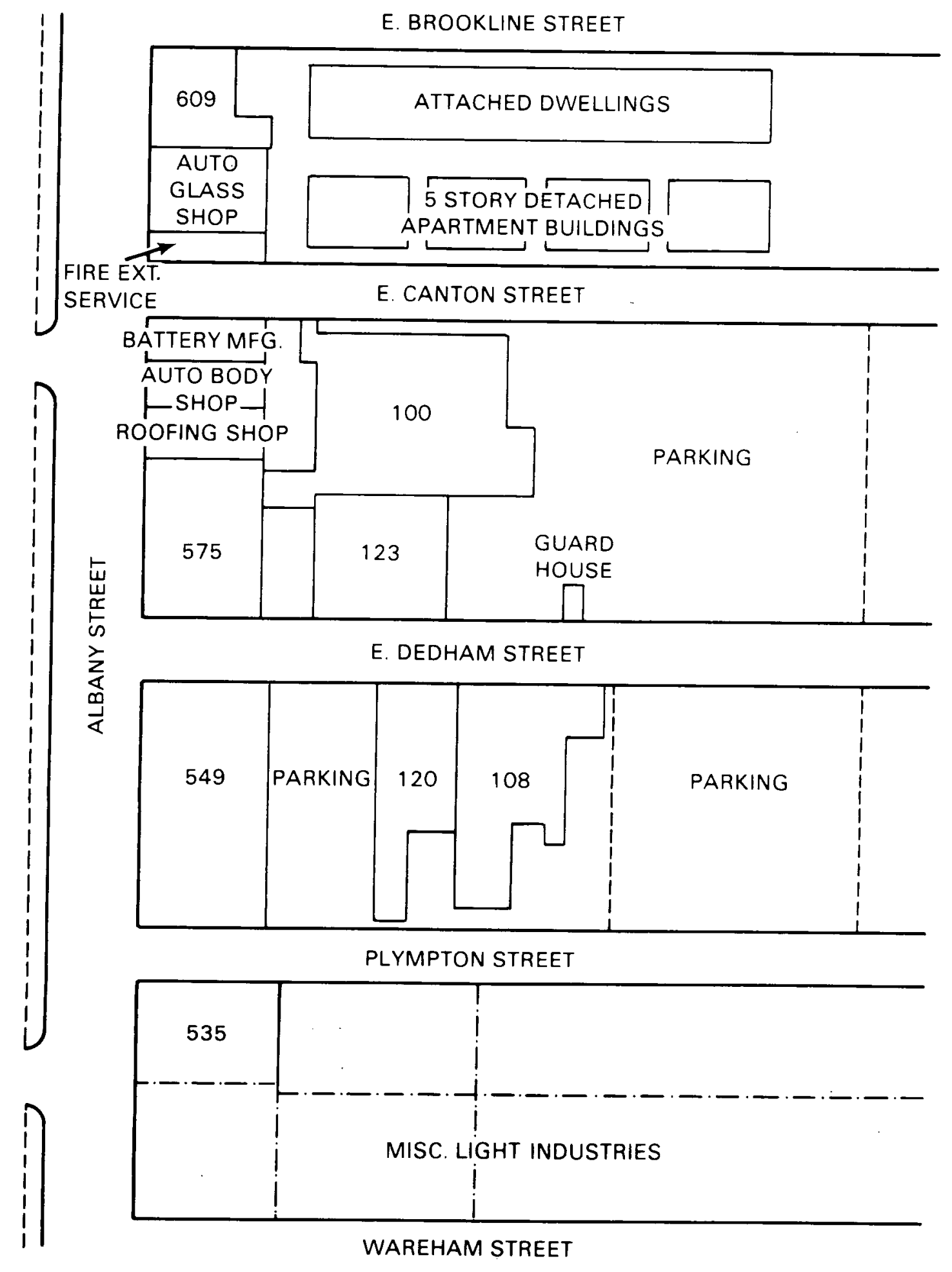

FIGURE E.3. New England Nuclear Buildings

$$
\text { E. } 5
$$




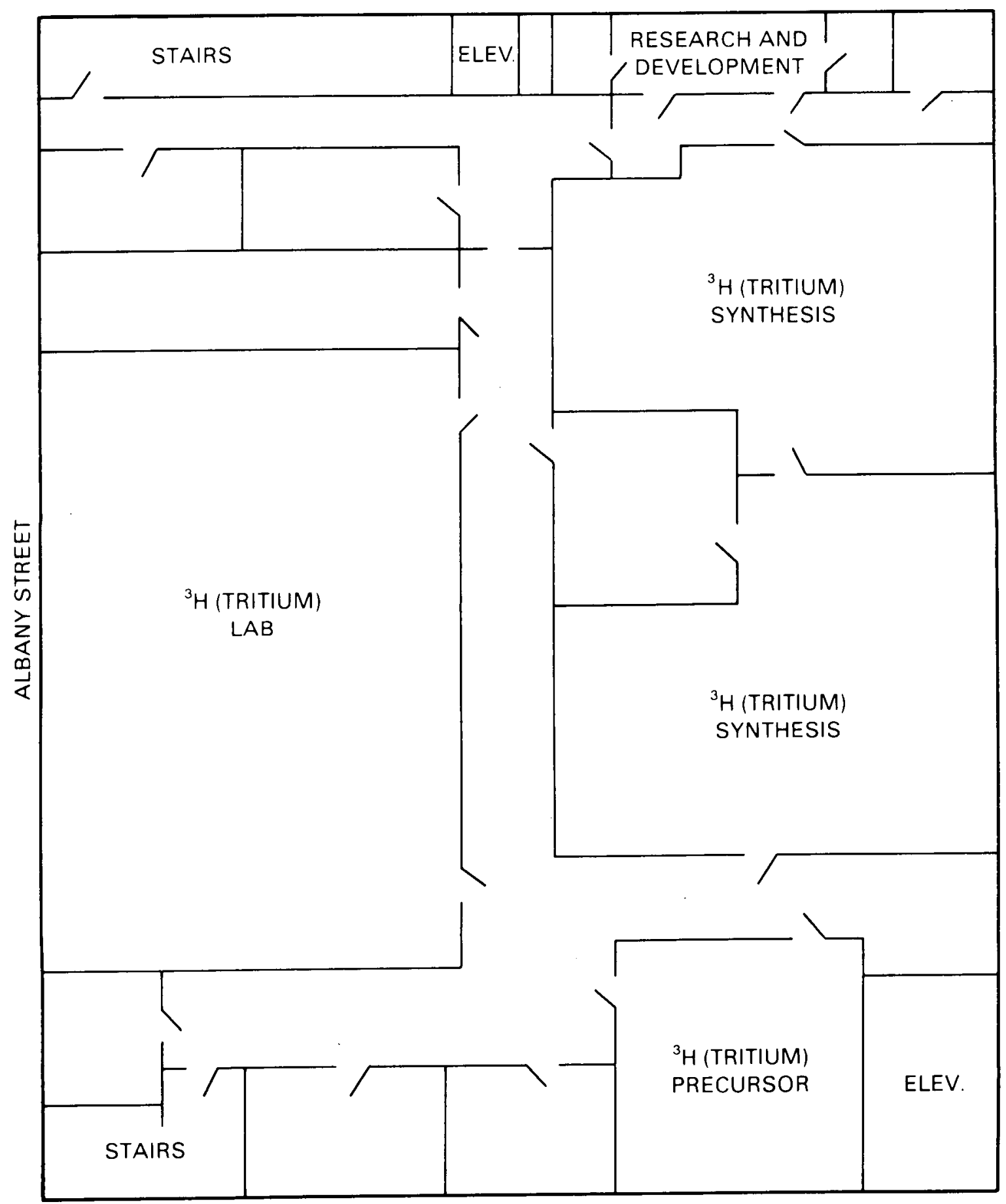

FIGURE E.4. Plan of Fifth Floor at New England Nuclear Building

$$
\text { E.6 }
$$


are passed to the $3 \mathrm{H}$ precursor lab, also on the fifth floor, where precursors sed for labeling organic compounds (usually $\mathrm{CH}_{3} \mathrm{I}$ ) are produced. The production lab handles 100 to $400 \mathrm{Ci}$ per operation in one glove box, while the precursor lab handles $500 \mathrm{Ci}$ during each process. The production lab has 5 to 10 glove boxes in use at one time, while the precursor lab usually has only one operation going at a time.

The ${ }^{3} H$ synthesis $l a b$, also on the fifth floor, receives the tritium compounds and is the area where many of the labeling operations actually take place. Most work is done in fume hoods, where 5 to $20 \mathrm{Ci}$ of tritium are handled per operation.

Other floors of the 575 Albany building contain additional lab space for compound labeling and research and development.

Adjacent to and connected with the 575 Albany building is the $100 \mathrm{E}$. Canton building where ${ }^{14} \mathrm{C},{ }^{35} \mathrm{~S}$, and ${ }_{\mathrm{H}}$ compound production and labeling occurs. On the third floor is a large ggganics lab where wet chemistry is performed, usually in fume hoods. The ${ }^{35} \mathrm{~S}$ labeling is conducted in a smaller laboratory adjacent to the main lab area. Protein and carbohydrate compounds represent the majority of substances processed in the facility.

Bulk storage, dispensing, packaging, quality assurance, product storage, packaging and shipping are conducted in the 120 E. Dedham building.

\section{Waste Disposal}

Most of the radioactive waste is produced by the labs in the 575 Albany and $100 \mathrm{E}$. Canton buildings. This material is sent to a room on the second floor of the 575 Albany building where it is sorted, compacted and drummed for shipment to NEN's Billerica facility for storage. Approximately one to two dozen 55-gal steel drums of waste can be found in this area. These wastes are primarily glassware and lab refuse contaminated with ${ }_{H}$.

\section{E.2.2 Facility Description}

\section{Buildings}

The 575 Albany building is a converted warehouse built about 1890. It uses wooden beams and cross members for support. Wall studs are both wood and steel installed since NEN took possession. Rooms are $12 \mathrm{ft}$ high with drop ceilings concealing HVAC ductwork (placed as space permits), steam lines, oxygen and natural gas lines, electrical conduits, and sprinkler lines as space permits. Floors are usually asphalt tile on wood. Standard windows, that is, wooden frames with single pane glass, are found in all areas, and they are usually sealed shut.

The $100 \mathrm{E}$. Canton building is a new facility specifically designed for housing organic labs. It is a concrete and steel structure with brick facing. All utilities and ventilation lines are housed in a central 4- by $40-f t$ shaft. 
The $120 \mathrm{E}$. Dedham building is of moderate age, and concrete, steel, and brick construction. Utilities and service lines are concealed by drop ceilings.

\section{HVAC System}

Heat is supplied by a central boiler with a fuel oil storage tank buried under the $100 \mathrm{E}$. Canton building parking lot. There are, HVAC, HEPA filters, scrubbers, and associated ductwork located in all lab areas.

\section{Engineered Safety Systems}

A11 areas are sprinklered, and portable fire extinguishers are provided. Exhaust airflow from hoods and boxes is monitored for line pressure and sampled for contamination. If these checks indicate abnormal levels, alarm systems will activate.

\section{Surrounding Area}

The NEN complex is located in the south end of Boston in the heart of a commercial district, where vehicle traffic can be heavy. City utility and service lines are located underground.

\section{E.2.3 Inventory}

\section{Radioactive Inventory}

The radioactive inventory at NEN is listed in Table E.1. Both the license limit and amount on hand in specific buildings are listed. Tritium is primarily located on the fifth floor of the 575 Albany building. Spęcifically tritium activities are $1.5 \times 10^{4} \mathrm{Ci}$ in the production area, $2.0 \times 10^{3} \mathrm{Ci}$ in the precursor $1 \mathrm{ab}$, and $5.04 \times 10^{2} \mathrm{Ci}$ in synthesis $1 \mathrm{ab}$. Waste on the second floor could contain $1.0 \times 10^{4} \mathrm{Ci}$.

Hazardous and Combustible Inventory

Because of the type of wet chemistry process used at the facility, numerous combustibles and other hazardous materials can be found in all lab areas. Some materials that might be found in the 575 Albany building are listed in Table E.2.

Combustible materials similar to those in the 575 Albany building can be found in $100 \mathrm{E}$. Canton building lab areas. Plexiglas ${ }^{\circledR}$ "coffins," glove boxes, and PVC piping are found in the ${ }^{35} S$ work area.

In the $120 \mathrm{E}$. Dedham building, the bulk of the combustible material is cardboard containers for packaging products for shipping. These containers are stored on the first floor. Dispensing labs and quality control areas are 
TABLE E.1. Radioactive Inventory at NEN Boston

\begin{tabular}{|c|c|c|c|c|}
\hline Element & Isotope & Building & $\begin{array}{c}\text { License } \\
\text { Limit, } \\
\text { Ci }\end{array}$ & $\begin{array}{c}\text { Approximate } \\
\text { Inventory, } \\
\text { Ci } \\
\end{array}$ \\
\hline $\begin{array}{l}\text { Calcium } \\
\text { Carbon }\end{array}$ & $\begin{array}{l}{ }^{45} \mathrm{Ca} \\
{ }^{4} \mathrm{C}\end{array}$ & $\begin{array}{l}609 \\
575 \\
123 \\
120 \\
100\end{array}$ & $5.0 \times 10^{2}$ & $\begin{array}{l}10^{-3} \\
59 \\
5 \\
360 \\
\frac{17}{445}\end{array}$ \\
\hline Chromium & ${ }^{51} \mathrm{Cr}$ & 609 & & $1 \times 10^{-3}$ \\
\hline Hydrogen & $3_{\mathrm{H}}$ & $\begin{array}{l}575 \\
123 \\
120 \\
100\end{array}$ & $1 \times 10^{5}$ & $\begin{array}{l}2.9 \times 10^{4} \\
200 \\
390 \\
\frac{160}{3.0} \times 10^{4}\end{array}$ \\
\hline Iodine & $125_{I}$ & 100 & & $2 \times 10^{-3}$ \\
\hline Phosphorus & $32 p$ & $\begin{array}{l}575 \\
100\end{array}$ & $5.0 \times 10^{1}$ & $\begin{array}{r}1 \\
20 \\
21\end{array}$ \\
\hline Sulfur & ${ }^{35} \mathrm{~s}$ & $\begin{array}{l}575 \\
100\end{array}$ & $1.0 \times 10^{2}$ & $\begin{array}{l}10 \\
28 \\
38\end{array}$ \\
\hline
\end{tabular}

located on the upper floors, with bulk storage areas for organic compounds. Natural gas and oxygen lines are present for flame-sealing operations in hoods. Miscellaneous combustibles include paper trash, cardboard containers and some wooden furniture.

\section{E.3 NEW ENGLAND NUCLEAR, NORTH BILLERICA, MASSACHUSETTS}

The New England Nuclear facility in North Billerica produces both radiopharmaceuticals and sealed sources. The medical and diagnostics product

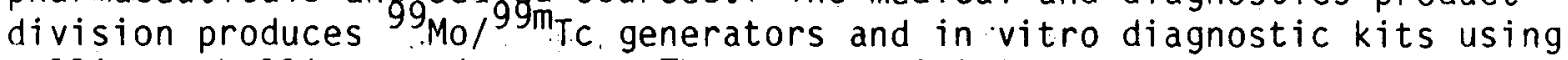
gallium, thallium, and xenon. The source division produces a variety of isotopes for sealed sources and for radiolabeling organic compounds. The description was developed using information gathered in a site visit and in a New England Nuclear report (1981b). 
TABLE E.2. Hazardous and Combustible Materials in NEN 575 Buildings

Operational Area

${ }^{3} \mathrm{H}$ Production

$3_{H}$ Percusor (a)

Waste compaction
Material

Oxygen and natural
gas

Hydrogen Plexiglas ${ }^{\circledR}$, Lucite ${ }^{\circledR}$ Solvents

PVC

Paper

Plastic

0xygen, natural gas

Organics such as

enzymes and amino acids

Solvents

Flammables

Spray paint

Paper
Notes

Gas supplied by city utilities, found at each glove box. Lines above drop ceilings of acoustic tile

Gas 1 ine

Glove box

Stored in quartz bottles

Piping on scrubber

Trash, lab clothing

Gloves, shoe covers

Gas 1 ines

Stored

Stored

In storage cabinet

Open storage

Trash

(a) Some reactions may run overnight.

\section{E.3.1 Process Description}

Operation

The primary gperations of the medical diagnostic djvision include productign of the ${ }^{99} \mathrm{MO}^{99 \mathrm{~m}_{\mathrm{TC}}}$ generators, thallus chloride $\left({ }^{201} \mathrm{Tl}\right)$, gallium citrate $\left({ }^{6} \mathrm{Ga}\right)$, and xenon gas $\left({ }^{13} \mathrm{Xe}_{\mathrm{e}}\right)$. All of these operations are conducted in the pharmaceutical building. The generators are produced on two shielded lines, with the ${ }^{99}$ Mo loaded into the generators in remote hot cells. Approximately 950 generators are produced weekly. Each generator contains 0.2 to $2.8 \mathrm{Ci}$ $99 \mathrm{Mo} /{ }^{99 \mathrm{~m}} \mathrm{TC}$ per generator at the time of shipment. About 1400 to $1500 \mathrm{Ci}$ per week (about a half to one liter by volume) are used. Six $500-\mathrm{cm}^{3}$ canisters of 99 Mo (totaling about $800 \mathrm{ci}$ ) each are received each week. Quality control, final packaging, and shipping are performed in separate areas.

The gallium, thallium, and xenon production areas are located adjacent to the generator production area. Gallium and thallium solutions are handled in

(3) Plexiglas is a trademark of Rohn and Haas, Philadelphia, PA 19105.

(8) Lucite is a trademark of DuPont de Nemours, E.I. \& Co., Wilmington, DE 19898. 
remote cells, where the solution is dispensed to vials. Xenon gas dispensing is conducted in Plexiglas ${ }^{\circledR}$ hoods. The gas is stored in cylinders of $350 \mathrm{Ci}$ each (positive pressure) and dispensed in 10 to $100 \mathrm{mCi}$ increments to vials. Six thousand vials per week are produced.

Both the packaging and shipping areas are warehouse-type rooms. The shipping area contains a high bay area for truck shipments.

The source division building houses 4 cyclotrons where bulk isotope raw material is prepared. Approximately 100 nuclides are produced here, 25 of them routinely. Over a third of all activity at Billerica is contained in this building. Target preparation areas, iodination labs, nickel plating operations, and offices are also located in this building.

Waste Disposal

The Billerica facility contains a warehouse where radioactive waste from all NEN plant sites is stored. Billerica operations themselves produce a wide variety of wastes, including lab materials, waste paper, rejected sources and generators, and liquid waste which has been solidified in an absorbent material.

The bulk of the waste stored in 55-gal steel drums in the warehouse consists of ${ }_{H}$ from the Boston site. Three shipments arrive per week from Boston. Liquid waste is stored in 30 -gal plastic drums.

\section{E.3.2 Facility Description}

Buildings

The North Billerica facility has several buildings located as shown in Figure E.5.

The pharmaceutical building is a one-story brick, concrete, and steel structure of $70,000 \mathrm{ft}^{2}$. The nuclides and source division building is also one story, of similar construction, and has about $100,000 \mathrm{ft}^{2}$. The waste warehouse is built of concrete blocks with a metal roof and has an area of 10,000 $\mathrm{ft}^{2}$. All of these buildings are of recent construction and are specifically designed for housing radioactive materials. Thick concrete and lead walls shield the four cyclotrons.

\section{HVAC Systems}

Each building housing radioactive operations is equipped with standard airflow filtration systems consisting of HEPA and charcoal filters. All hoods have roughing and HEPA filters except in the iodine processing areas where they are fitted with charcoal filters. Glove boxes with potential for airborne activity have their own HEPA filters. Exhaust air from hoods, boxes, and hot cells passes through these control systems before discharge to the atmosphere.

\section{E.11}




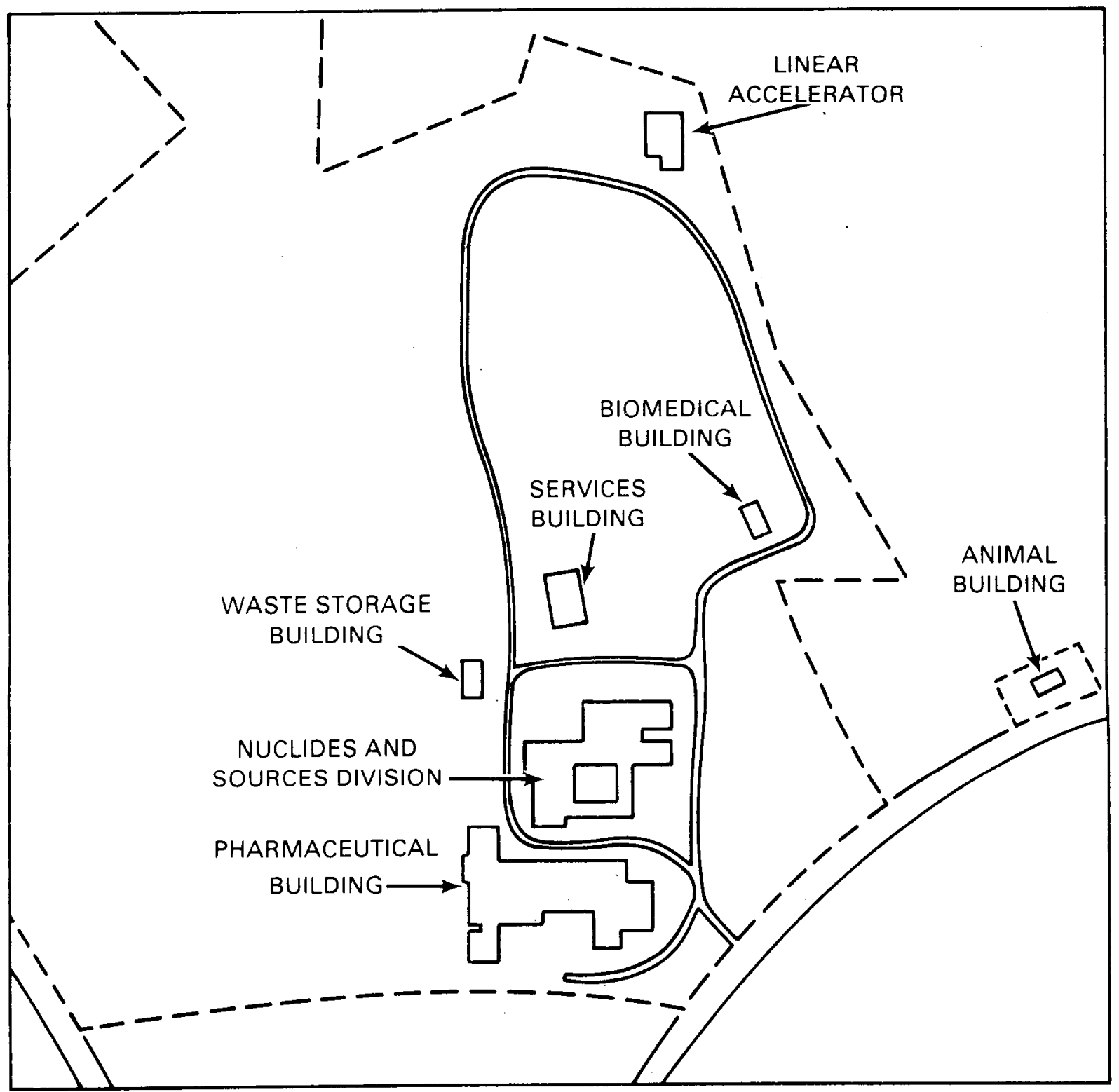

FIGURE E.5. New England Nuclear North Billerica Site Diagram 
Engineered Safety Systems

All operations are equipped with radiation detectors, exhaust airflow monitors, and fire alarms. All areas except the animal building are sprinklered. The buildings are specifically designed and operations are situated to prevent the accidental spread of contamination.

\section{Surrounding Area}

The Billerica facility is situated on a 215 -acre site; 30 areas are actually in use. Single family homes are adjacent to the site, and a county prison is located just north of the plant boundary.

\section{E.3.3 Inventory}

\section{Radioactive Inventory}

The license inventory is shown in Tables E.3 and E.4. However, the actual inventory on hand can vary between 65 to $85 \%$ of the licensed amounts. The inventory on hand varies according to requirements for filling orders. Since most isotopes have fairly short half-lives, they are frequently transported within 30 hours after receiving the raw materials. Table E.5 lists the major activity on hand during a specific time period, and Table E. 6 shows isotope movement during a typical week at North Billerica. The inventory associated with radioactive waste is listed in Table E.7.

Hazardous and Combustible Inventory

In the pharmaceutical building, combustible material includes supplies of laboratory plastics and paper; cardboard containers and packaging materials are in the shipping areas; solvents and flammable chemicals are kept in storage cabinets. Similar materials may be found in the nuclide and sources building. Both buildings have drop ceilings with acoustic tiles concealing utility and service lines that include natural gas, oxygen, and steam. Many hoods and glove boxes are constructed of plastic and PVC piping is used extensively in the buildings.

The waste warehouse contains natural-gas-fueled space heaters, plywood boxes containing used HEPA filters, and plastic 30-gal drums containing liquid waste. An LPG-fueled forklift is used to transfer drums.

A small area where vehicles can be fueled is located near the waste warehouse. It contains both gas and diesel fuel tanks. 
TABLE E.3. License Quantities for the North Billerica Nuclides and Sources Division Building

\begin{tabular}{|c|c|c|}
\hline Element & Isotope & $\mathrm{Ci}$ \\
\hline $\begin{array}{l}\text { By-product Atomic } \\
\text { number }(a) \text { to } 83\end{array}$ & & $\begin{array}{l}\text { No single nuclide to } \\
\text { exceed } 10 \mathrm{Ci} \text {, Total } 500\end{array}$ \\
\hline $\begin{array}{l}\text { By-product, atomic } \\
\text { number }(a) \text { greater } \\
\text { than } 83 \\
\text { Calcium }\end{array}$ & $241_{A m}(b)$ & 350 \\
\hline Carbon & ${ }^{14} \mathrm{C}$ & 500 \\
\hline Cerium & ${ }^{141} \mathrm{Ce}$ & 50 \\
\hline Cesium & ${ }^{134} \mathrm{Cs}$ & 25 \\
\hline & ${ }^{137} \mathrm{Cs}$ & 500 \\
\hline Chromium & ${ }^{51} \mathrm{Cr}$ & 100 \\
\hline Gold & ${ }^{198} \mathrm{Au}$ & 200 \\
\hline Iodine & $125_{I}$ & 100 \\
\hline & ${ }^{131} 1_{I}$ & 25 \\
\hline Iron & ${ }^{55} \mathrm{Fe}$ & 200 \\
\hline Krypton & ${ }^{85} \mathrm{Kr}$ & $1.0 \times 10^{4}$ \\
\hline Nickel & ${ }^{63} \mathrm{Ni}$ & $1.0 \times 10^{3}$ \\
\hline Phosphorus & $32 p$ & 500 \\
\hline Rubidium & ${ }^{86} \mathrm{Rb}$ & 50 \\
\hline Ruthenium & ${ }^{103} \mathrm{Ru}$ & 25 \\
\hline Selenium & & 100 \\
\hline Strontium & ${ }^{90} \mathrm{Sr}$ & 500 \\
\hline Sulfur & ${ }^{35} \mathrm{~S}$ & $1 \times 10^{3}$ \\
\hline Thulium & ${ }^{170_{\mathrm{Tm}}}$ & 25 \\
\hline Tin & $113_{\mathrm{Sn}}$ & 100 \\
\hline Ytterbium & ${ }^{169}{ }_{Y b}$ & 50 \\
\hline
\end{tabular}

(a) Except those individually identified

(b) Sealed sources 
TABLE E.4. License Quantities for the North Billerica Medical Diagnostic Division Building

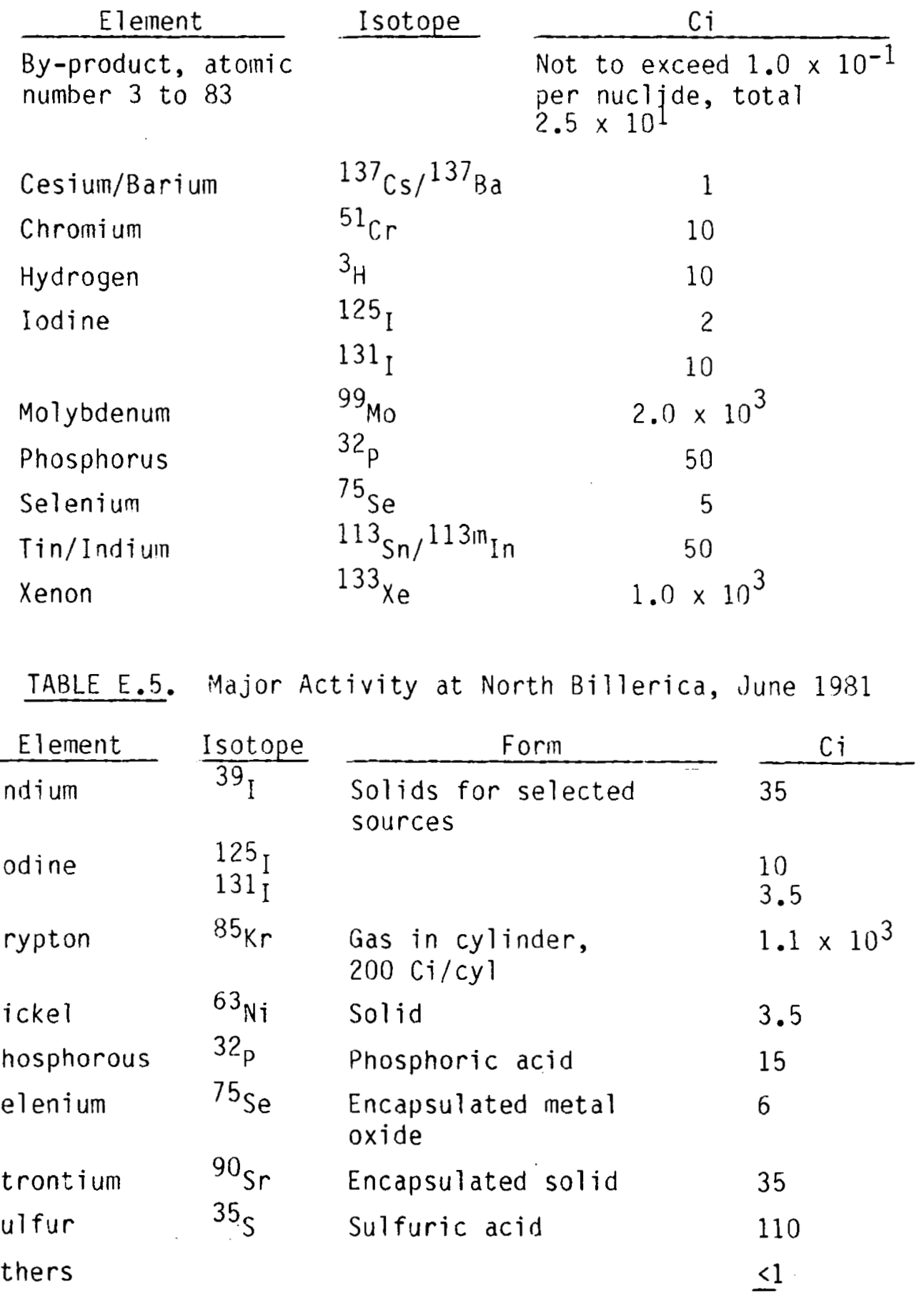


TABLE E.6. Isotope Movement During a Typical Week at North Billerica

\begin{tabular}{|c|c|c|c|c|c|}
\hline $\begin{array}{l}\text { Mate } \\
\text { Rece }\end{array}$ & $\begin{array}{l}\text { erial } \\
\text { eived }\end{array}$ & Isotope & Quantity, $\mathrm{Ci}$ & $\begin{array}{r}\text { Rear } \\
\mathrm{SH} \\
\end{array}$ & $\begin{array}{l}\text { iy to } \\
\text { iip }\end{array}$ \\
\hline Mon & 0700 & ${ }^{67} \mathrm{Ga}$ & 3.4 & Mon & 1330 \\
\hline & 0500 & ${ }^{201} \mathrm{Tl}$ & 4.5 & & 1230 \\
\hline Tue & 1400 & ${ }^{133} \times \mathrm{e}$ & 450 & Wed & 1700 \\
\hline & 1500 & ${ }^{99} 9_{\text {Mo }}$ & 20 & & 1100 \\
\hline Wed & 0500 & ${ }^{201}{ }_{T 1}$ & 3.2 & Wed & 1230 \\
\hline Th & 1500 & ${ }^{99}$ Mo & 600 & Fri & 1100 \\
\hline Fri & 0500 & ${ }^{99} \mathrm{Mo}$ & 1,500 & Sat & 1100 \\
\hline
\end{tabular}

TABLE E.7. Radioactive Waste Inventory at North Billerica in June 1981

\begin{tabular}{|c|c|c|c|}
\hline Element & Isotope & Form & $\mathrm{Ci}$ \\
\hline Americium & $241_{A m}$ & $\begin{array}{l}\text { Packaged capsules } \\
\text { Capsules in drums } \\
\text { Lab trash }\end{array}$ & $\begin{array}{r}77 \\
4 \\
1\end{array}$ \\
\hline Carbon & ${ }^{14} \mathrm{C}$ & Lab trash & 50 \\
\hline Cesium & ${ }^{137} \mathrm{Cs}$ & $\begin{array}{l}\text { Lab trash } \\
\text { Production equipment }\end{array}$ & $\begin{array}{l}20 \\
20\end{array}$ \\
\hline Gallium & ${ }^{67} \mathrm{Ga}$ & Liquid in drummed vials & 0.5 \\
\hline Hydrogen. & $3_{H}$ & $\begin{array}{l}\text { Drumined gas cylinders } \\
\text { Lab trash }\end{array}$ & $\begin{array}{l}2 \times 10^{4} \\
2 \times 10^{3}\end{array}$ \\
\hline Iodine & ${ }^{125} 5_{I}$ & Lab trash & 2 \\
\hline Phosphorus & $32 p$ & $\begin{array}{l}\text { Lab trash, equipment } \\
\text { in drums }\end{array}$ & 5 \\
\hline Thallium & ${ }^{201}$ & Liquid in vials & 0.25 \\
\hline Xenon & ${ }^{133} \mathrm{Xe}$ & $\begin{array}{l}\text { Gas in vials in shipping } \\
\text { shields }\end{array}$ & 0.25 \\
\hline Zinc & ${ }^{65} \mathrm{Zn}$ & $\begin{array}{l}\text { Cyclotron targets as } \\
\text { drummed pigs } \\
\text { Liquid on clay }\end{array}$ & $\begin{array}{l}2 \\
2\end{array}$ \\
\hline
\end{tabular}


E.4 E. R. SQUIBB AND SONS, NEW BRUNSWICK, NEW JERSEY

The Squibb facility in New Brunswick, New Jersey, produces ${ }^{99}{ }_{M 0}{ }^{99 m} \mathrm{TC}$ generators and iodinated ( $\left.13 \mathrm{I}_{\mathrm{I}}\right)$ solution and capsules. A site visit and a report by E. R. Squibb and Sons, Inc. (1981) were used as a basis for this description.

\section{E.4.1 Process Description}

Operation

All handling of radioisotopes for the production of radiopharmaceuticals is confined to the 124 building. Processes are the production of $99_{\text {Mo/ }}{ }^{9} 9_{\mathrm{mTC}} \mathrm{T}$ generators and iodination of pharmaceuticals using $131_{\text {I. Both isotopes are }}$ received in liquid form at a central geceiving dock. Iodine-131 is received in lots of $25 \mathrm{Ci}$ once a week; $200 \mathrm{Ci}$ of $99 \mathrm{I}$ are received three times a week. All materials are received in Department of Transportation-approved packages. These casks are transferred to specially constructed caves in the 124 building, opened by remote manipulators, and bulk lots are dispensed for production runs. A maximum of $45 \mathrm{Ci}$ may be in one cave at one time. A maximum of $2.5 \mathrm{Ci}$ may be transferred to a production lab.

There are several iodination labs within the building which are similar in layout and construction. Hoods and glove boxes are steel. Glove boxes are used for dispensing the ${ }^{13 l_{I}}$. A single run may consist of up to $50 \mathrm{mC} i$ of liquid pharmaceuticals, and up to $1.5 \mathrm{Ci}$ for the production of encapsulated dry iodinated pharmaceuticals.

The ${ }^{99} \mathrm{Mo}^{99 \mathrm{~m}_{\mathrm{TC}}}$ production area is in two rooms: one where the empty generator packages are prepared and one containing a remotg slave cave. The packages enter via a conveyor and are filled with liquid ${ }^{99}$ Mo. Packages are then returned to the packaging area for figal preparation before shipment. Generators contain 200 to $2,200 \mathrm{mCi}{ }^{99} \mathrm{Mo} /{ }^{99 \mathrm{~m}} \mathrm{Tc}$.

Quality control and final packaging of the pharmaceuticals are conducted in separate areas. Bulk amounts of radionuclides are stored in hot cell caves until they are needed.

\section{Waste Disposal}

Dry waste consists of lab glassware, miscellaneous, trash, and rejected generators. Millicurie to curie $(<2 \mathrm{C} i)$ quantities of $131^{2}$ are removed each week in the form of rejected vials of liquid pharmaceuticals. Two or three 55-gal steel drums of waste are accumulated each week and removed for disposal. Amounts of waste contains less than $2 \mathrm{mC} i$ are stored in a small, specially constructed concrete building. Liquid waste is held in four 10,000-gal tanks buried outside the central receiving area. 


\section{E.4.2 Facility Description}

Buildings

The 124 building shown in Figure E.6 is part of a sizable industrial park. It is specially constructed of concrete, steel, and brick for housing radiopharmaceuticals. Heat is provided by a central boiler for the entire plant site. Most of the labs are small, about 20 by $30 \mathrm{ft}$, but the filling and packaging areas for the 131 I products are quite large, about $60 \mathrm{ft}$ by $60 \mathrm{ft}$. Caves for isotope storage are constructed of concrete, steel, and lead, and have walls $3 \mathrm{ft}$ thick. Waste is stored in the 122 building adjacent to the 124 building.

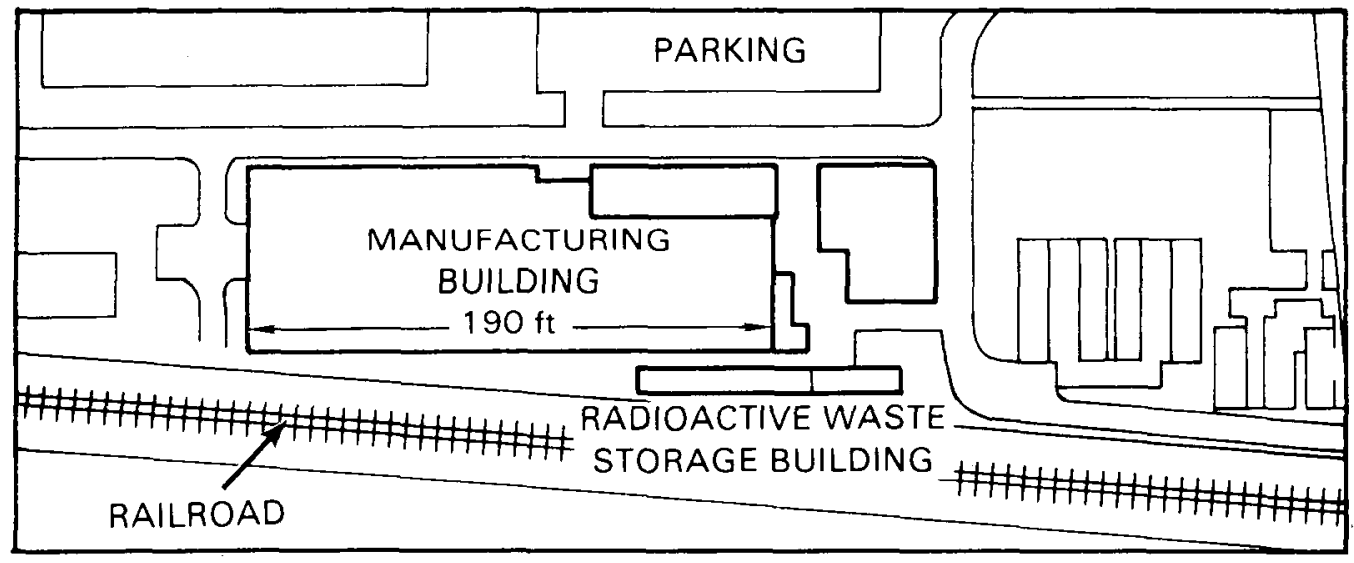

FIGURE E.6. Plan of the E. R. Squibb and Sons Site

\section{E.4.3 Inventory}

\section{Radioactive Inventory}

Although their license permits the possession of curie amounts of several isotopes, production changes have resulted in the handling of only ${ }^{13}$ I and 99 Mo as described above. Actual amounts on hand are approximately half the license limits as shown in Table E.8.

The greatest concentration of radioactive materials will occur in the receiving area when shipments of bulk material arrive. Following that, the material is stored in caves for dispensing throughout the laboratory. 
TABLE E.8. Inventory at E. R. Squibb and Sons

\begin{tabular}{|c|c|c|c|}
\hline Element & Isotope & Inventory, $\mathrm{Ci}$ & $\begin{array}{r}\text { License } \\
\text { Limit, Ci } \\
\end{array}$ \\
\hline Iodine & $131_{I}$ & 75 & 150 \\
\hline $\begin{array}{l}\text { Mo lybdenum/ } \\
\text { Technetium }\end{array}$ & ${ }^{99} \mathrm{Mo} /^{99} \mathrm{~m}_{\mathrm{T}}$ & $1 \times 10^{3}$ & $2 \times 10^{3}$ \\
\hline
\end{tabular}

Hazardous and Combustible Inventory

A minimal amount of combustible material is located in the 124 and 122 buildings. Paper and similar materials are almost nonexistent in the laboratories, and no combustible gases are used in the processes. Furniture is constructed of sheet metal or steel. An emergency generator is located in the 124 building, with fuel oil stored in a 100 to 200-gal buried tank. Near the loading dock area is a chemical storage area containing process chemicals and solvents. These could include acetic acid and hydrochioric acid. Near the caves is a wood-paneled, walk-in refrigerator containing radiopharmaceuticals with a total activity of 600 to $800 \mathrm{mci}$. Another chemical dispensing room contains a fire/explosion-proof cabinet where combustible materials such as ether and acetone are stored. Liquid process chemicals, solvents, etc. are stored in glass bottles, one gallon or less in size.

\section{E.5 REFERENCES}

Abbott Laboratories, Radiological Contingency Plan, License No. 12-00621-03, North Chicago, Illinois, 1981.

New England Nuclear, Radiological Contingency Plans, License No. 20-00320-98, Boston, Massachusetts, 1981a.

New England Nuclear, Radiological Contingency Plans, License No. 20-00320-13 and 20-11868-01, North Billerica, Massachusetts, 1981b.

Squibb, E.'R. and Sons, Inc., Radiological Contingency Plan, License No. 29-00139-02, New Brunswick, New Jersey, 1981. 
$\Theta$

APPENDIX F

RAD IOPHARMACY 
RADIOPHARMACY

\section{F.1 OHIO STATE UNIVERSITY NUCLEAR PHARMACY, COLUMBUS, OHIO}

The following description of the Ohio State University nuclear pharmacy is based on a report by Ohio State University (1981).

\section{F.1.1 Process Description}

Operation

The nuclear pharmacy at Ohio State University orders and stores radiopharmaceuticals, kits, and materials; prepares pharmaceuticals, cold kits, and in-house preparations; and prepares and dispenses doses. Radiopharmaceuticals are used in patient diagnosis and/or therapy. Radioactive materials are located in a fume hood, glove box, concrete or lead storage area, or a refrigerator.

Waste Disposal

Contaminated waste materials are stored in an area surrounded by concrete blocks. Radioactive waste is removed each week or on request and sent elsewhere for disposal.

\section{F.1.2 Facility Description}

Building

The nuclear pharmacy is in the north wing of the university hospital, which is located in the southeastern section of the campus. A diagram of the nuclear pharmacy area in the hospital building is shown in Figure $F .1$, which also shows nearby offices. It is approximately $25 \mathrm{ft}$ from an exit to

12th Avenue. Radioactive materials are handled in the hood or glove box.

HVAC System

Hood airflow volume is calculated at $600 \mathrm{ft}^{3} / \mathrm{min}$. Airflow velocity is $100 \mathrm{ft} / \mathrm{min}$ through a $6-\mathrm{ft}^{2}$ opening. Air is exhausted at the roof of the hospital.

\section{Engineered Safety Systems}

Air is monitored by an alarmed system.

Surrounding Area

The nuclear pharmacy is surrounded by the Ohio State University campus. 


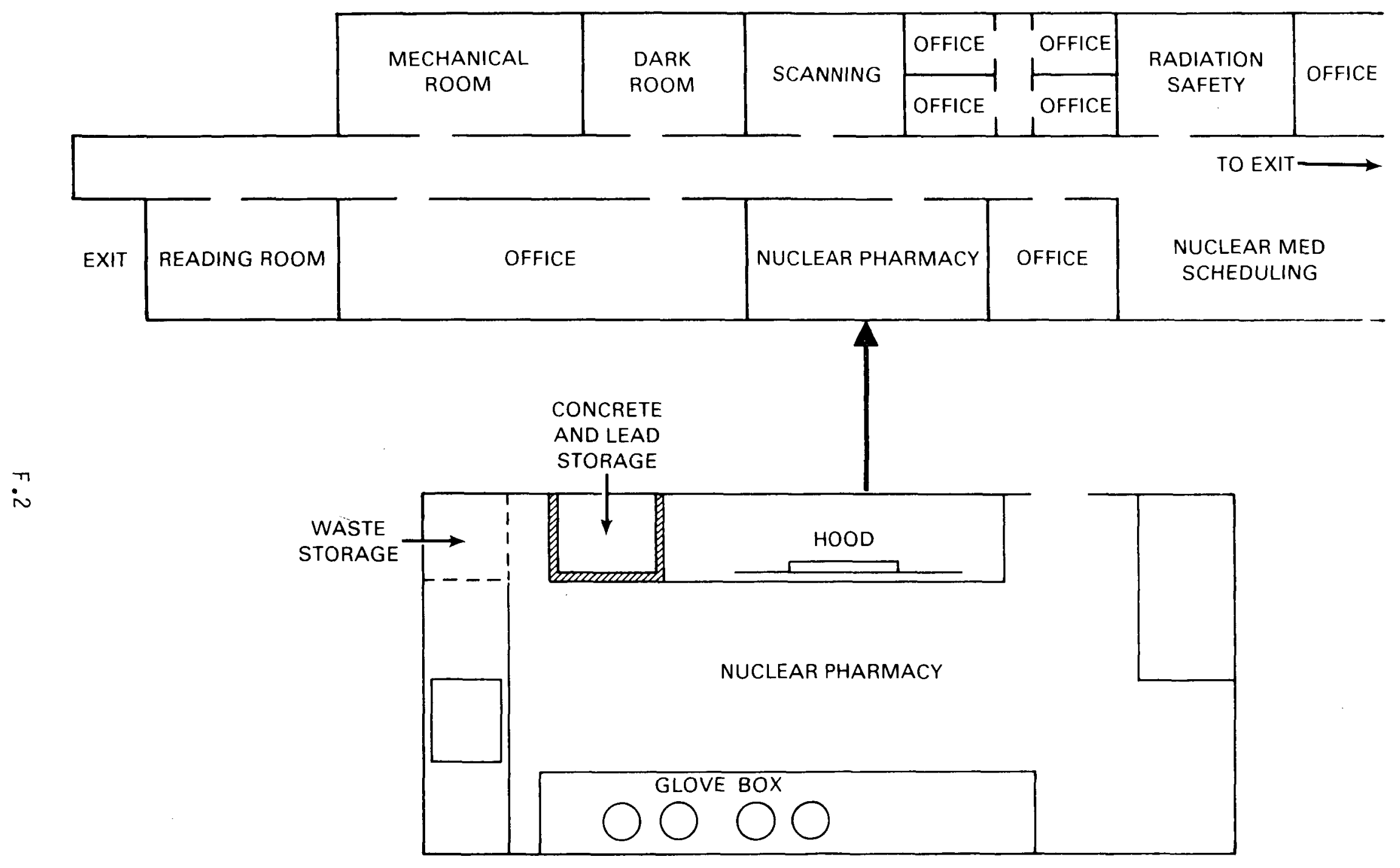

FIGURE F.1. Facility Diagram of Nuclear Pharmacy at Ohio State University 


\section{F.1.3 Inventory}

Radioactive Inventory

Typical radioactive materials and activities ordered by the nuclear pharmacy during the year are shown in Table F.1.

TABLE F.1. Material and Activities Ordered by Ohio State University Pharmacy During One Year

\begin{tabular}{|c|c|c|c|c|}
\hline Element & Isotope & $\begin{array}{l}\text { Compound } \\
\text { or Form }\end{array}$ & Act & $\begin{array}{l}\text { ivity, } \\
\text { Ci }\end{array}$ \\
\hline Chromium & ${ }^{5}{ } \mathrm{Cr}$ & Sodium Chromate & 1.3 & $\times 10^{-2}$ \\
\hline Cobalt & $\begin{array}{l}57 \mathrm{Co} \\
{ }^{58} \mathrm{Co}\end{array}$ & Cyanocobalim & 1.4 & $\times 10^{-4}$ \\
\hline Gallium & ${ }^{67} \mathrm{Ga}$ & Gallium & 1.22 & $\times 10^{0}$ \\
\hline Indium & $111_{\text {In }}$ & Indium & 4.86 & $\times 10^{-1}$ \\
\hline \multirow[t]{3}{*}{ Iodine } & $123_{I}$ & Sodium iodide & 1.87 & $\times 10^{-1}$ \\
\hline & ${ }^{124} \mathrm{I}$ & Fibrinogen & 2.5 & $\times 10^{-4}$ \\
\hline & $131_{I}$ & $\begin{array}{l}\text { Iodomethylchloresterol } \\
\text { Sodium iodide solution } \\
\text { HSA (human serum albumin) } \\
\text { Sodium iodide }\end{array}$ & $\begin{array}{l}6.0 \\
4.5 \\
3.3 \\
1.87\end{array}$ & $\begin{array}{l}\times 10^{-3} \\
\times 10^{1} \\
\times 10^{-2} \\
\times 10^{-1}\end{array}$ \\
\hline Iron & ${ }^{59} \mathrm{Fe}$ & Ferrous Citrate & 1.25 & $\times 10^{-3}$ \\
\hline $\begin{array}{l}\text { Mo lybdenum/ } \\
\text { Technetium }\end{array}$ & $\begin{array}{l}99 \mathrm{Mo} / \\
99 \mathrm{~m}_{\mathrm{TC}}\end{array}$ & Generator & 4.26 & $\times 10^{2}$ \\
\hline Phosphorous & $32 p$ & Phosphorous & 3.5 & $\times 10^{-1}$ \\
\hline Selenium & ${ }^{75} \mathrm{Se}$ & Selenium & 1.28 & $\times 10^{-3}$ \\
\hline Thallium & $201_{T 1}$ & Thallium & 2.1 & $\times 10^{0}$ \\
\hline Xenon & ${ }^{133} \mathrm{xe}$ & Gas & 7.5 & $\times 10^{1}$ \\
\hline
\end{tabular}

\section{F.2 REFERENCE}

Ohio State University, Radiological Contingency Plan, License No. 34-00293-02, Columbus, Ohio, 1981. 
APPENDIX G

SEALED SOURCE MANUFACTUR ING

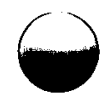


SEALED SOURCE MANUFACTURING

\section{G.1 AMERSHAM CORPORATION, ARLINGTON HEIGHTS, ILLINOIS}

The Amersham facility performs a variety of functions: distribution of in vitro test kits; distribution of in vivo radiopharmaceuticals; distribution of radioactive sealed sources; standardized solutions of radioactive materials as reference sources; assembly of smoke detectors; manufacture of fibrinogen; and research and development. Amersham Corporation reports (1969-1980) provided information for this appendix.

\section{G.1.1 Process Description}

Operation

Plutonium and uranium are acquired and distributed as calibration stan-

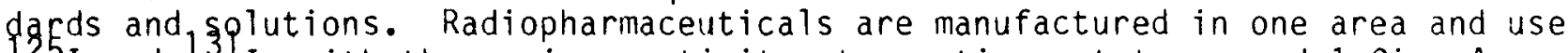
$125 \mathrm{I}$ and ${ }^{13} \mathrm{I}_{\mathrm{I}}$, with the maximum activity at one time not to exceed $1 \mathrm{Ci}$. A small manufacturing area is used for producing sealed sources and liquid scintillation standards (maximum activity at one time not to exceed $50 \mathrm{mC} i$ ). Sealed sources for smoke detectors are assembled in an area that allows $5 \mu \mathrm{Ci}$ per source, not exceeding $1 \mathrm{Ci}$ total activity. Research and development is conducted in a lab where no isotope is present at $>50 \mathrm{mCi}$ total activity except tritium, which may be present up to $2 \mathrm{Ci}$.

High-level gamma sources are stored in a special room protected by additional concrete blocks.

Waste Disposal

Waste is stored in two lead receptacles in a small storage area. A high bay area also contains two waste storage areas (high- and low-activity waste). These areas are protected by additional shielding.

\section{G.1.2 Facility Description}

Building

Radioactive material is handled in the main building, which has 10-in.thick concrete exterior walls. The building is divided into several areas, and some inner. walls include an additional 8 in. of concrete blocks. Floors are poured concrete. A warehouse area is used for receiving shipments of bulk isotopes and repackaging these materials for distribution. 


\section{G.1.3 Inventory}

Radioactive Inventory

Possession limits of radioisotopes are listed in Table G.1. Approximately $1800 \mathrm{Ci}$ of activity are permitted under the license; however, daily inventories may range between 350 and $500 \mathrm{Ci}$. An additional $200 \mathrm{Ci}$ may be present as waste. Most of the activity on hand is ${ }^{3} \mathrm{H},{ }^{14} \mathrm{C},{ }^{125} \mathrm{I}$, and ${ }^{32} \mathrm{p}$ as 1 abeled radiopharmaceuticals or radiochemical compounds.

\section{G.2 AUTOMATION INDUSTRIES, INC., PHOENIXVILLE, PENNSYLVANIA}

Automation Industries, Inc., manufactures a line of gamma radiography equipment through its instrument division. These radiatjon detection instruments use by-product sealed sources consisting of ${ }^{192} \mathrm{Ir}$ and ${ }^{60} \mathrm{Co}$. The sealed sources are produced on site. Information in this appendix was developed using Automation Industries, Inc. reports (1966-1980).

\section{G.2.1 Process Description}

Operation

Iridium is received in bulk quantities as encapsulated metallic pellets. Iridium-192 is doubly encapsulated and sealed using heliarc welding or brazing. Bulk shipments of ${ }^{6}$ Co are received either as sealed sources and placed directly into instruments, or as unencapsulated metallic pellets in approved containers. The coptainers are simply redistributed to customers with no further processing. All ${ }^{6}$ Co is stored in the hot cell.

\section{Waste Disposal}

All waste is packaged and stored in a locked area before shipment to a disposal facility. Liquid waste with high contamination levels is solidified before packaging and disposal.

\section{G.2.2 Facility Description}

Buildings

All radioisotopes are handled in a separate masonry building at the facility. Building dimensions are $54 \mathrm{ft}$ long, $38 \mathrm{ft}$ wide, and $18 \mathrm{ft}$ high. The interior is partitioned into areas for the hot cell, waste storage, utility and boiler room, shipping and receiving area, offices, laboratory change room, and decontamination area. The hot cell has wall's of 42-in.-thick concrete and a 30-in.-thick roof. It contains a 72-by 60-in. stainless steel work pan. The floor is at least 42 in. thick. Entrance is through a 7-in.-thick lead and steel door. Operations are performed using master-slave manipulators and are viewed through a $42-$ in.-thick window. 
TABLE G.1. Radioisotope Possession Limits at Amersham Facility

\begin{tabular}{|c|c|c|}
\hline Element & Isotope & License Limit, Ci \\
\hline $\begin{array}{l}\text { Any by-product } \\
\text { material, atomic } \\
\text { number } 1 \text { to } 83\end{array}$ & & $3.0 \times 10^{1}$ \\
\hline Actinium & ${ }^{227} A C$ & $1.0 \times 10^{-2}$ \\
\hline Americium & $241_{A m}$ & $5.0 \times 10^{2}$ \\
\hline Californium & ${ }^{242} \mathrm{Cf}$ & $5.36 \times 10^{-1}$ \\
\hline Carbon & ${ }^{14} \mathrm{C}$ & $5.0 \times 10^{1}$ \\
\hline Cesium & ${ }^{137} \mathrm{Cs}$ & $1.5 \times 10^{2}$ \\
\hline Curium & $\begin{array}{l}{ }^{242} \mathrm{Cm} \\
{ }^{244} \mathrm{Cm}\end{array}$ & $\begin{array}{l}2.0 \times 10^{-2} \\
1.0 \times 10^{1}\end{array}$ \\
\hline Hydrogen & $3_{H}$ & $1.0 \times 10^{3}$ \\
\hline Krypton & $85_{k r}$ & $5 \times 10^{1}$ \\
\hline Neptunium & $237 \mathrm{~Np}$ & $2.0 \times 10^{-2}$ \\
\hline Polonium & $\begin{array}{l}208 \mathrm{Po}_{\mathrm{P}} \\
209_{\mathrm{Po}} \\
210_{\mathrm{Po}}\end{array}$ & $\begin{array}{l}1 \times 10^{-2} \\
5 \times 10^{-3} \\
5\end{array}$ \\
\hline & & Limit, $g$ \\
\hline Plutonium & $\begin{array}{l}{ }^{238} \mathrm{Pu} \\
239 \mathrm{Pu}\end{array}$ & $\begin{array}{l}5 \\
1\end{array}$ \\
\hline & $240 \mathrm{Pu}$ & $2 \times 10^{-1}$ \\
\hline & $\begin{array}{l}241_{p u} . \\
242 p u\end{array}$ & $\begin{array}{l}1 \times 10^{-1} \\
1 \times 10^{-1}\end{array}$ \\
\hline Uranium & $233_{U}$ & $1 \times 10^{-1}$ \\
\hline
\end{tabular}

G.3 
Waste is stored in an area with dimensions about 11 by 9 by $8 \mathrm{ft}$ and has 14-in.-thick concrete walls.

HVAC Systems

A separate ventilation system with two HEPA filters in series is provided for the cell. An electric hoist and several $115 \mathrm{~V}$ and $220 \mathrm{~V}$ outlets are located inside the cell.

\section{G.2.3 Inventory}

Radioactive Inventory

Possession limits are: ${ }^{192} \mathrm{Ir}, 27,000 \mathrm{Ci}$ as metallic pellets, wafers, or sealed sources; ${ }^{6} \mathrm{Co}, 5,000 \mathrm{Ci}$ as sealed sources (maximum 3,000 $\mathrm{Ci}$ per source) and $15,000 \mathrm{Ci}$ as metallic pellets or wafers.

\section{G.3 MICRO DISPLAY SYSTEMS, INC., BEVERLY, MASSACHUSETTS}

Micro Display Systems distributes LCD watches containing sealed gaseous tritium $\left({ }^{3} \mathrm{H}\right)$ light sources. Possession limits stipulate that no watch is to contain more than $200 \mathrm{mci}$ of tritium. The firm also repairs such watches. Repairs may be done in chemical fume hoods if the repairs require replacement of the tritium glass vial light source. Micro Display Systems reports (19801981) were used to develop this information. No further information was available.

\section{G.4 MINNESOTA MINING AND MANUFACTURING, NEW BRIGHTON, MINNESOTA}

Minnesota Mining and Manufacturing (3M) operates a sealed-source production facility on the 2,370-acre site of the Twin Cities Army Ammunition Plant (TCAAP) north of Minneapolis and St. Paul, Minnesota. The facility consists of four primary buildings (573, 575, 590, and 675) and an emergency power facility. The range of products produced is extensive, but consists primarily $6 \mathrm{f}^{f}$ encapsulated sealed sources and radiophapmaceutical products using ${ }^{85} \mathrm{Kr},{ }^{60} \mathrm{Co}$, $90 \mathrm{Sr}$, $139_{\mathrm{Cs}}$, $149_{\mathrm{Pm}}$, $210_{\mathrm{Po},} 169_{\mathrm{Yb}}$, and $125_{\mathrm{I}}$. Bulk raw isotopes are purchased from vendors, brought to the $3 M$ site, and repackaged as sealed sources directly. They can be first converted to another form such as microspheres and then be packaged and distributed. The facility is under the auspices of 3M's Static Control Systems Department. Information on the 3M sealed-source plant was developed using a report by Minnesota Mining and Manufacturing (1981).

\section{G.4.1 Process Description}

Operation

575 Building. This building is shown in Figure G.1. Isotopes handled regularly include $85 \mathrm{kr},{ }^{60} \mathrm{Co}, 90 \mathrm{Sr}, 137 \mathrm{Cs}, 210 \mathrm{Po}$, and $147 \mathrm{Pm}$. Krypton gas is received from an outside vendor and used in the north wing to produce sealed sources. Cobalt, strontium, and cesium are processed into microspheres and 


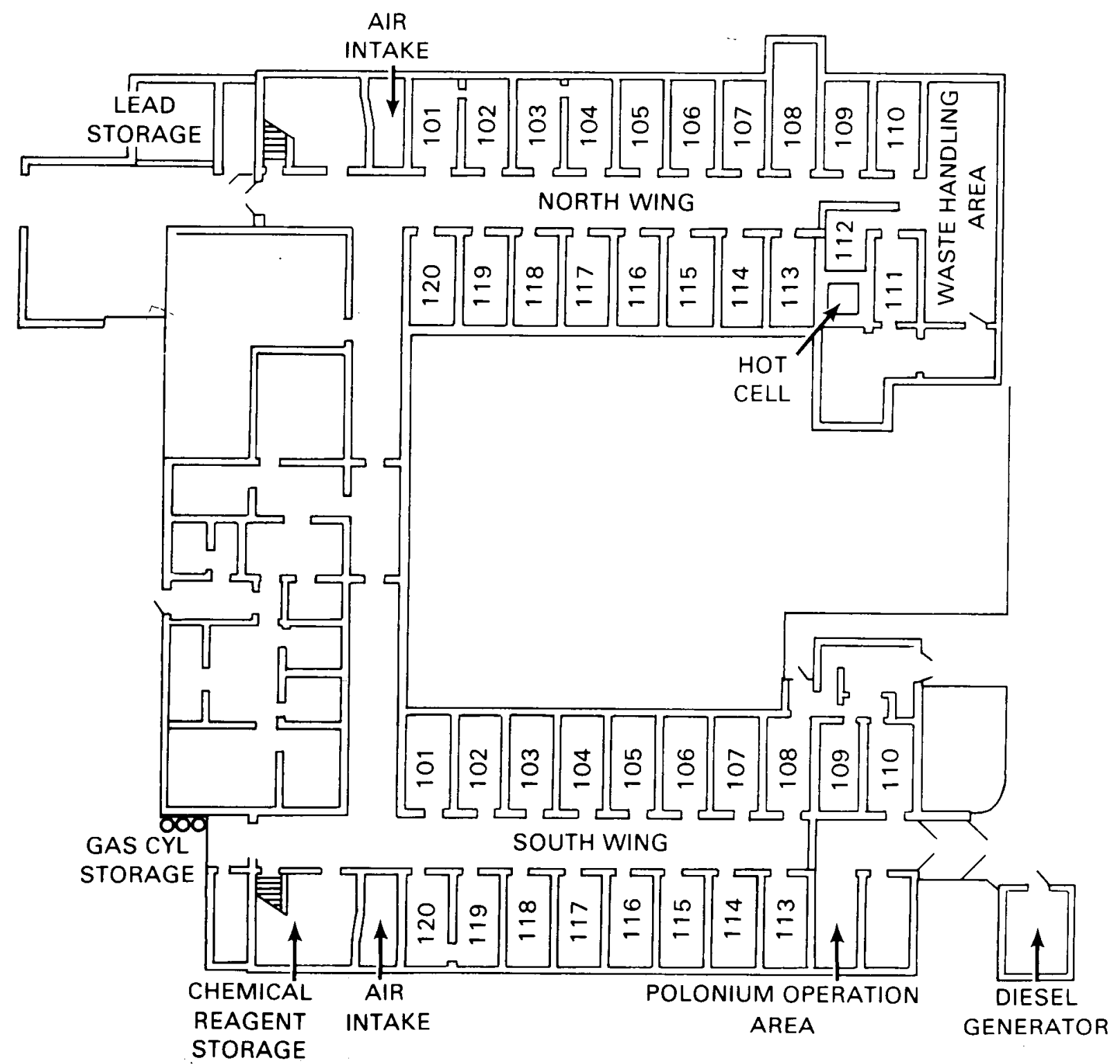

FIGURE G.1. 575 Building at the 3M Site

incorporated into a variety of sources in modules in the north wing. Polonium is pyrochemically extracted from neutron-activated bismuth slugs and later electroplated onto platinum gauzes and converted to microsphere form. Promethium is received at the building and converted to microspheres, then transferred to the 675 building for incorporation into sources. Operations using these latter isotopes are conducted in the south wing of 575 .

Krypton-85 source production requires several steps conducted in individual modules in this building. In module $116,100 \mathrm{Ci}$ of gaseous ${ }^{85} \mathrm{Kr}$ enters the production process and is transferred to individual sources using a nitrogen cold trap and associated vacuum pump system. Each source contains a $1.5 \mathrm{Ci}$ 
maximum. The individual metallic tube sources are sealed with an LPG torch. Three cylinders of LPG gas may be present in the production module. All work is conducted in metal and Plexiglas ${ }^{\circledR}$ fume hoods. The finished sources are transferred to other modules for quality control checks and storage before packaging and shipping. Mgdule 102 is used for storage of the ${ }^{85 \mathrm{Kr}}$ sources, as well as storage of ${ }^{\mathrm{CO}}{ }^{9} \mathrm{Sr}$, and ${ }^{137} \mathrm{Cs}$ sources. Up to $100 \mathrm{Ci}$ of each isotope may be present, except ${ }^{137} \mathrm{Cs}$ which may have a total activity of $500 \mathrm{Ci}$. All sources are stored in a steel and lead safe. Quality control is performed on the sealed sources in a remote-slaved concrete fort.

For ${ }^{90} \mathrm{Sr}$ sealed source production, the bulk isotope (double encapsulated) is received from vendors and transferred to a hot cell, module 112. It is opened there, placed in solution, then incorporated into ceramic microspheres. The microspheres are placed in brass cylinders and transferred to module 110 for temporary storage in steel safes. $\mathrm{BB}_{\mathrm{B}}$ to $1,000 \mathrm{Ci}$ are processed in this manner. Up to $500 \mathrm{Ci}$ of liquid and solid ${ }^{\mathrm{Sr}}$ waste may be held in the hot cell before removal and disposal.

Periodically, 1-Ci samples of finished product are transferred to module 111 for assay in a Plexiglas ${ }^{\circledR}$ fume hood. The microspheres are transferred to module 105 for loading to inner capsules, sealing with a tungsten welder, and brazing with a propane torch. Then they are moved to module 106 for final sealed source encapsulation and brazing with an acetylene-oxygen torch. Shielded remote-slaved enclosures are used for all production steps during this stage. Additional final source production is conducted in module 114.

Similar production steps for the manufacture of different varieties of ${ }^{137} \mathrm{Cs}$ and ${ }^{6} \mathrm{Co}$ sources are conducted in north wing modules $109,113,103,104$, 115, 117, and 118. Final products are stored in module 101. Al1 the sources are handled in either slaved forts or Plexiglas ${ }^{\circledR}$ and steel fume hoods.

Promethium-147 sealed source production occurs in south wing module $1147_{\mathrm{Pm}}$
capsule containing the bulk isotopes is opened in a glove box and the The capsule containing the bulk isotopes is opened in a glove box and the ${ }^{14} \mathrm{P}$
is dissolved and incorporated into ceramic microspheres. The microspheres are packaged in Department of Transportation (DOT)-approved containers and transferred to Building 675 for further processing. Periodically, 1-Ci samples are taken to module 113 for dilution and assay.

Polonium-210 is also processed into microsphere form before source fabrication. All handling of the isotope occurs in the Alpha Module Complex, which consists of modules $109,110,111$, and 112 in the south wing. These areas are segregated from the rest of the building process areas. Polonium-210 is extracted from neutron-activated bismuth slugs in module 112 . This process involves cleaning the irradiated capsules containing the 210 Po using solvent, then removing and electrically melting the metal isotope in contact with $210 \mathrm{Po}_{0}$
sodium hydroxide solution. The sodium hydroxide solution containing the is neutralized with nitric acid and the polonium is carrier-precipitated from solution using potassium manganate and manganous nitrate. The precipitate is

(8) Plexiglas is a trademark of Rohn and Haas, Philadelphia, PA 19105 
dissolved in a nitric acid and hydrogen peroxide solution and the $210 p_{0}$ is subsequently electroplated onto platinum gauzes. Operations are conducted in a series of shielded steel and Plexiglas enclosures. The gauzes are transferred to module 109 where a hydrochloric acid and ammonium hydroxide solution is used to produce microspheres, which are subsequently heat treated and nickel plated using a plating solution of nitric acid, stannous chloride, and palladiam chloride. The finished microspheres are packaged in approved shipping containers and transferred to the 675 building for incorporation into products. The above steps are conducted in a sequence of Plexiglas ${ }^{\circledR}$, steel, and plywood glove boxes and fume hoods.

590 Building. Radionuclides are delivered at the 590 building receiving dock and transferred to a microsphere production area to produce carbonized mircospheres. These microspheres are placed in glass vials and checked for quality control before being packaged in shielded containers and shipped to customers. All materials are handled in fume hoods or shielded containment areas. Various isotopes are handled in this manner and are listed in the section on radioactive inventory.

675 Building. This building contains a warehouse, shipping and receiving area, offices, and production areas for 210 po static elimination devices, radioluminous products, and nuclear medical sources. A nonradioactive process also takes place here: plastic cylinders are dipped in a solution of $147 \mathrm{pm}$ processing area. Fume hoods are used to exhaust vapors from three 55-gal steel drums that comprise the holding tanks.

Polonium-210 microspheres are transferred by truck from the 575 building to the 675 building. These microspheres are incorporated into static elimination devices. All work is conducted in steel and Plexiglas ${ }^{\circledR}$ glove boxes and the final product is dried electrically in a fume hood with a plywood base. The material in which the 210 po microspheres are imbedded is proprietary. Other microspheres are silk-screened onto aluminum strips and fixed with epoxy resin before incorporation into static elimination devices.

Ytterbium-169 is processed in two areas. Ytterbium chelate in liquid form is dispensed to vials in fume hoods in the chelate loading room. The vials are autoclaved and packaged into lead pigs for shipment. The chelate itself is produced in the chelate production room in a lead-shielded fort inside a fume hood. The ${ }^{169} \mathrm{Yb}$ is purchased in liquid form from a vendor, arrives at the 590 building and is transferred to 675 building after quality control checks.

Promethium-147 microspheres manufactured in the 575 building are transferred in DOT-approved packages to the 675 building by truck. The microspheres are mixed with phosphorous and binding agents to produce a radioluminous pigment, which is applied to a number of products. These include watch dials, compass faces, glass tubes, etc. The glass tubes are sealed with a miniature acetylene-oxygen torch. Acetone, isopropyl alcohol, trichloroethylene, and lacquer thinner are stored in this area in safety cans. 
Iodine-125 in liquid form is absorbed onto ion exchange resins, the resin beads loaded into titanium cans and the cans tungsten-welded. All operations are conducted in steel glove boxes. After inspection and leak testing, the cans are autoclaved, leak tested again, packaged and shipped.

\section{Waste Disposal}

Solid waste collection, compaction, preparation, and storage before offsite disposal is conducted in 573 building. Radioactive waste is collected from a variety of process steps within the $3 M$ site. The building is divided into concrete-walled modules for storage. All waste is stored in DOT-approved shipping containers. This waste generally includes discarded microspheres, glassware, filters, plastic containers, and solidified liquid waste. Waste from the individual processes is packaged at the work site and then transferred to the 573 building.

\section{G.4.2 Facility Description}

\section{Buildings}

The 573 building is designed with a number of modules, which are separated by reinforced concrete walls. One end of the building has plywood walls with a wood-tar roof. The other end has wood-framed walls with steel siding and a roof with fiberglass skylights. The floor is a concrete pad. The building contains a waste compactor, fork lift, and other materials for handling radioactive waste.

Prinary production operations occur in the 575 building. Other facilities include offices, shipping and receiving, quality control, and employee facilities. Production areas are divided into modules constructed of reinforced concrete on a concrete pad. Each module is approximately 7 by $14 \mathrm{ft}$ with a wood-framed outside wall and wood-tar roof. Modules in the north wing of the building handle beta- and gamma-emitting radionuclides; modules in the south wing handle beta- and alpha-emitting isotopes. Each wing contains 20 modules.

The 590 building houses offices, locker areas, warehousing operations, manufacturing of nonradioactive property, and production and quality control of nuclear medical products. The building is wood frame construction with a tar roof.

The 675 building houses offices, warehouse space, shipping and receiving areas, and production areas for static control devices, nuclear medical products and nonradioactive pharinaceuticals. The building is constructed of reinforced concrete pillars supporting a concrete roof over a concrete slab. Outside and interior walls are of dry-wall construction.

\section{HVAC Systems}

In 573 building, only the compactor module is heated, with an LPG space heater. No water or sewer service is provided. 
Other buildings $(575,590$, and 675) are steam heated from the facility central boiler. High-pressure steam $\left(190 \mathrm{lb} / \mathrm{in} .^{2}\right)$ is reduced to $15 \mathrm{lb} / \mathrm{in} .^{2}$ at stations in each wing before circulation to the building.

An emergency diesel generator and 265-gal diesel fuel storage tank are located next to the south wing of 575 building shown in Figure G.1. The generator is used to provide electricity in event of power failure.

All areas where radioactive isotopes are handled have systems that include a circulation fan, filter units, and ductwork. Air intakes are provided at two points in the 575 building with exhaust air exiting through fume hoods or exhaust ducts and discharged via roof stacks. Areas where sealed sources are handled generally do not have filter systems. Where filters are used, they are usually banks of Ultra-Aire ${ }^{\circledR}$ which are $99.97 \%$ effective for $0.3-\mu m$-diameter particles. In the 590 building, all containment systems (glove boxes) are provided with filters (type not identified). Standard ductwork carries gxhaust air to a roof stack. In the 675 building, containments for processing ${ }^{125}$ I are filtered using a series of activated charcoal filters. Ing ${ }^{14} \mathrm{Pm}$ areas are filtered by a series of Ultra-Aire filters, as are the ${ }^{{ }^{\circledR}}{ }^{\mathrm{Yb}}$ and ${ }^{210} \mathrm{Po}_{\mathrm{O}}$ production areas. Air intake to the building is provided by two inflow points while exhaust air is removed via ductwork and a roof-mounted exhaust stack. In the 573 building, the waste compactor room is the only one provided with filtration ( $99.97 \%$ effective for $3-\mu \mathrm{m}$ particles) and ventilation.

Engineered Safety Systems

Ventilation alarms, temperature control alarms, fire alarms, lightning protection, sprinkler systems, and fire extinguishers are provided throughout the 3M facility. Isotope handling modules are separated by reinforced concrete walls. An onsite fire department is maintained for the entire army facility site.

Surrounding Area

The entire TCAAP site is a restricted area of 2,370 acres with its own road system and railway spur line, which is only used occasionally. Medical and fire fighting facilities are provided, and a common sewer service and central heating are provided for the entire site. The area outside the TCAAP site is primarily residential with some light industry.

Potentially hazardous operations found at facilities other than $3 M$ within the TCAAP site include small arms ammunition and gun powder, and explosive detonator storage. These operations are segregated from the 3M sealed-source operation.

(B) Ultra-Aire is a trademark of the Mine Safety Appliances Co., Pittsburgh, Pennsylvania 


\section{G.4.3 Inventory}

\section{Radioactive Inventory}

License limits of isotopes at $3 M$ are listed in Table G.2. Inventories in the various buildings are listed in Table $G .3$ for the 575 building; Table G.4 for the 590 building and Table G.5 for the 675 building. A list of the maximum inventory of isotopes in DOT-approved containers awaiting shipment in the waste storage building, 575, is given in Table G.6.

Hazardous and Combustible Inventory

Table G.7 lists the hazardous and combustible materials at 3M. In addition to the listed materials, several fuel storage tanks are present on the $3 M$ site. These include:

- 500-gal propane tank adjacent to 573 building (waste storage)

- 600-gal aboveground gasoline tank located $100 \mathrm{ft}$ from 573 building

- 265-gal diesel fuel storage in the emergency power building

- 500-gal propane storage $150 \mathrm{ft}$ from 590 building (static division).

G.5 MONSANTO RESEARCH CORPORATION, DAYTON, OHIO

Monsanto Research Corporation (MRC) operates a sealed-source production facility in Dayton, Ohio, under the control of its Engineered Products Department (EPD). This facility manufactures, tests, and distributes neutron, beta, and gamma sources using a variety of isotopes. It also fabricates DOTapproved isotope shipping containers. The Dayton lab occupies a 20 -acre site

TABLE G.2. License Limits of Isotopes at 3M

\begin{tabular}{|c|c|c|}
\hline Element & Isotope & Inventory, $\mathrm{Ci}$ \\
\hline Americium & ${ }^{241} \mathrm{Am}$ & 0.1 (any form), 5 (sealed source) \\
\hline Bismuth & $210_{B i}$ & 200 \\
\hline Cesium & ${ }^{137} \mathrm{Cs}$ & 8,000 \\
\hline Cobalt & ${ }^{60} \mathrm{C}$ & 200 \\
\hline Hydrogen & $3_{H}$ & 1000 \\
\hline Iodine & ${ }^{125} \mathrm{I}$ & 100 \\
\hline Krypton & ${ }^{85} \mathrm{Kr}$ & 1500 \\
\hline Polonium & $210_{\mathrm{Po}}$ & 4000 \\
\hline Promethium & ${ }^{147} \mathrm{Pm}$ & 3500 \\
\hline Strontium & $90 \mathrm{Sr}$ & 3000 \\
\hline Ytterbium & ${ }^{169}{ } \mathrm{~b}$ & 100 \\
\hline $\begin{array}{l}\text { By-product } \\
\text { isotopes atomic } \\
\text { number } 3 \text { to } 83\end{array}$ & & 10 each, 100 total \\
\hline
\end{tabular}


TABLE G.3. Typical Radioactive Inventory in 575 Building Modules

\begin{tabular}{|c|c|c|c|c|}
\hline Element & Isotope & Form & Location & $\begin{array}{c}\text { Inventory, } \\
\mathrm{Ci}\end{array}$ \\
\hline \multirow[t]{20}{*}{ Cesium } & \multirow[t]{20}{*}{$\overline{137 \mathrm{Cs}}$} & Sealed Capsules & 112 , hot cell & 3000 \\
\hline & & Microspheres & & 20 \\
\hline & & Liquid & & 2000 \\
\hline & & Microspheres or liquid & 111, assay & 1 \\
\hline & & Microspheres & 110 , storage & 100 \\
\hline & & Microspheres & 105 , source production & 1000 \\
\hline & & Inner source & & 50 \\
\hline & & Sealed source & 106, source production & 50 \\
\hline & & Sealed source & 114 , source production & 50 \\
\hline & & Microspheres & 109, source production & 10 \\
\hline & & Inner source & & 10 \\
\hline & & Sealed source & 113 , source production & 10 \\
\hline & & Microspheres & 103, source production & 10 \\
\hline & & Inner sources & & 5 \\
\hline & & Sealed source & 104 , source production & 5 \\
\hline & & Microspheres & 117, source production & 75 \\
\hline & & Inner sources & & 10 \\
\hline & & Sealed sources & 118, source production & 10 \\
\hline & & Sealed sources & 101 , storage & 20 \\
\hline & & Sealed sources & Quality control & 200 \\
\hline \multirow[t]{13}{*}{ Cobalt } & \multirow[t]{12}{*}{${ }^{60} \mathrm{Co}$} & Sealed capsules & 112, not cell & 50 \\
\hline & & Microspheres & & 20 \\
\hline & & Liquid & & 50 \\
\hline & & Liquid or microspheres & 111 , assay & 1 \\
\hline & & Microspheres & 110 , storage & 100 \\
\hline & & inicrospheres & 105, source production & 50 \\
\hline & & Inner sources & & 10 \\
\hline & & Sealed sources & 106, source production & 10 \\
\hline & & Sealed sources & 114 , source production & 10 \\
\hline & & ilicrospheres & 109, source production & 2 \\
\hline & & inner sources & & 2 \\
\hline & & Seded sources & 113 , source production & 2 \\
\hline & 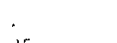 & Sealed sources & Quality Control & 200 \\
\hline \multirow[t]{3}{*}{ Krpton } & \multirow[t]{3}{*}{$355_{K r}$} & Gas/sealed sources & 116 , production & 100 \\
\hline & & Sealed sources & 102 , storage & 100 \\
\hline & & Sealed sources & Quality Control & 200 \\
\hline \multirow[t]{4}{*}{ Prometnium } & \multirow[t]{4}{*}{$1+7_{D_{m}}$} & Sealed capsule & $\begin{array}{l}114, \text { microsphere } \\
\text { production }\end{array}$ & 2000 \\
\hline & & inicrosphere & & 200 \\
\hline & & Liquid $\left(100 \mathrm{~cm}^{3}\right)$ & & 800 \\
\hline & & Liquid or microsphere & 113, assay. & 1 \\
\hline \multirow[t]{4}{*}{ Polonim } & \multirow[t]{4}{*}{$210_{\mathrm{Po}}$} & Sealed sources & 112, extraction & 1500 \\
\hline & & Liquid (GuL) & & 2300 \\
\hline & & Liquid & Microsphere production & 200 \\
\hline & & Microspheres & Microsphere production & 200 \\
\hline \multirow[t]{8}{*}{ Strontium } & \multirow[t]{8}{*}{$\left.{ }^{9}\right)_{S r}$} & Sealed capsules & 112, not cell & 1000 \\
\hline & & idicrospheres & & 200 \\
\hline & & Liquid. $\left(100 \mathrm{~cm}^{3}\right)$ & & 1000 \\
\hline & & Liquid or microsphere & 111 , assay & 1 \\
\hline & & Microspheres & 110 , storage & 1000 \\
\hline & & $\begin{array}{l}\text { Wicrospheres or } \\
\text { sedled source }\end{array}$ & 107, source production & 100 \\
\hline & & Sealed source & 106 , source testing & 10 \\
\hline & & Sealed source & lul, source testing & 10 \\
\hline
\end{tabular}

\section{G.11}


TABLE G.4. Maximum Amounts of Nuclear Medical Isotopes

Present in 590 Building at 3M

\begin{tabular}{|c|c|c|c|c|}
\hline Element & Isotope & Form & Location & $\begin{array}{c}\text { Inventory, } \\
\mathrm{Ci}\end{array}$ \\
\hline Cerium & & Microspheres & NW Corner & 0.4 \\
\hline Chromium & ${ }^{5} 1_{C r}$ & Microspheres & NW Corner & 0.4 \\
\hline Cobalt & ${ }^{60} \mathrm{Co}$ & Sealed sources & Shipping/receiving & 10 \\
\hline Cesium & ${ }^{137} \mathrm{Cs}$ & Sealed sources & Shipping/receiving & 40 \\
\hline \multirow[t]{2}{*}{ Iodine } & ${ }^{125}$ I & Sealed source & Shipping/receiving & 1 \\
\hline & & Microspheres & NW Corner & 0.2 \\
\hline Krypton & & Sealed source & Shipping/receiving & 10 \\
\hline Niobium & & Microspheres & NW Corner & 0.1 \\
\hline Polonium & & Sealed sources & Shipping/receiving & 15 \\
\hline Promethium & & Sealed Sources & Shipping/receiving & 10 \\
\hline Scandium & & Microspheres & NW Corner & 0.3 \\
\hline \multirow[t]{2}{*}{ Strontium } & & Microspheres & NW Corner & 0.3 \\
\hline & & Sealed sources & Shipping/receiving & 1 \\
\hline Ytterbium & & Microsphere & NW Corner & 0.05 \\
\hline
\end{tabular}

TABLE G.5. Maximum Amounts of Isotopes Present in Processes in Building 675 at 3M

\begin{tabular}{|c|c|c|c|c|}
\hline Element & Isotope & Form & Location & $\begin{array}{c}\text { Inventory, } \\
\mathrm{Ci}\end{array}$ \\
\hline Iodine & & $\begin{array}{l}\mathrm{KOH} \text { solution } \\
\text { Ion exchange resins } \\
\text { Sealed source }\end{array}$ & $\begin{array}{l}\text { Production room } \\
\text { Production room } \\
\text { Production room }\end{array}$ & $\begin{array}{l}5 \\
5 \\
5\end{array}$ \\
\hline Polonium & $210_{\mathrm{Po}}$ & $\begin{array}{l}\text { Microspheres } \\
\text { Finished products }\end{array}$ & $\begin{array}{l}\text { Static elimination room } \\
\text { Static elimination room }\end{array}$ & $\begin{array}{l}160 \\
160\end{array}$ \\
\hline Promethium & ${ }^{147} \mathrm{Pm}$ & $\begin{array}{l}\text { Microspheres } \\
\text { Products }\end{array}$ & $\begin{array}{l}\text { Radioluminous production } \\
\text { area } \\
\text { Radioluminous production } \\
\text { area }\end{array}$ & $\begin{array}{r}500 \\
10\end{array}$ \\
\hline Ytterbium & ${ }^{169}{ }^{Y b}$ & $\begin{array}{l}\text { Liquid } \\
\text { Liquid }\end{array}$ & $\begin{array}{l}\text { Chelate production room } \\
\text { Chelate loading room }\end{array}$ & $\begin{array}{l}5 \\
5\end{array}$ \\
\hline
\end{tabular}


TABLE G.6. Maximum Inventory of Waste in Storage in 573 Building

\begin{tabular}{|c|c|c|}
\hline Element & Isotope & Inventory, $\mathrm{Ci}$ \\
\hline Cesium & ${ }^{137} \mathrm{Cs}$ & 2,000 \\
\hline Cerium & ${ }^{14} 1_{\mathrm{Ce}}$ & $<2$ \\
\hline Chromium & ${ }^{51} \mathrm{Cr}$ & $<2$ \\
\hline Cobalt & ${ }^{60} \mathrm{Co}$ & 50 \\
\hline Iodine & $125_{I}$ & 15 \\
\hline Krypton & ${ }^{85} \mathrm{Kr}$ & 50 \\
\hline Niobium & ${ }^{95} \mathrm{Nb}$ & $<2$ \\
\hline Polonium & $210_{p_{0}}$ & 2,500 \\
\hline Promethium & ${ }^{147} \mathrm{Pm}$ & 50 \\
\hline Scandium & ${ }^{46} \mathrm{SC}$ & $<2$ \\
\hline \multirow[t]{2}{*}{ Strontium } & ${ }^{85} \mathrm{Sr}$ & $<2$ \\
\hline & ${ }^{90} \mathrm{Sr}$ & 500 \\
\hline
\end{tabular}

within the Dayton city limits. The site consists of 10 buildings, two of which are used for handling radioactive materials. Figure G.2 is a site plan with the EPD controlled-access area indicated. A report by Monsanto Research Corporation (1981) was the basis for this description.

\section{G.5.1 Process Description}

Operation

Monsanto produces a variety of sealed sources. Generally, the isotopes are handled in enclosed boxes or remote cells and are doubly encapsulated. Three rooms in Building 2 contain glove boxes constructed of sheet metal and glass. The remote cells are placed in a single room and are also constructed of sheet metal and glass.

60 Solid isotopes in powder, wire, and pellet form include ${ }^{238} \mathrm{Pu},{ }^{137} \mathrm{Cs}$, ${ }^{60} \mathrm{Co}$, and ${ }^{252} \mathrm{Cf}$. Amounts required for processing are removed from bulk storage and inserted into the process stream. One process produces neutron sources from plutonium and beryllium by first cleaning the source capsule with acetone, crushing the plutonium metal, and measuring the required amount. In a glove box, the metal chips are placed in a beryllium cup, which in turn is placed in the inner capsule, welded with a tungsten inert gas (TIG) welder and leak tested. The source is activated by heating the tantalum capsule to 1300 to $1500^{\circ} \mathrm{C}$ in an inert atmosphere using an induction coil. The activated source is then sealed in the second capsule and again leak tested. Polonium/beryllium sources are produced in a similar manner. Polonium-210 as received is electroplated on platinum gauzes; a similar procedure is used with americium. 
TABLE G.7. Hazardous and Combustible Materials at 3M

\begin{tabular}{|c|c|c|c|}
\hline Building & ModuTe & Material & Notes \\
\hline 575 & 103 & $\begin{array}{l}\text { Plasma needles arc welder, } \\
\text { glycerin }\end{array}$ & $\begin{array}{l}\text { Sealing }{ }^{137} \text { Cs source } \\
\text { cleaning }\end{array}$ \\
\hline & 104 & Nickel chloride & Plating ${ }^{137}$ Cs source \\
\hline . & 105 & $\begin{array}{l}\text { TIG }(a) \text { welder, propane, tri- } \\
\text { sodium phosphate }\end{array}$ & $\begin{array}{l}\text { Sealing source, } \\
\text { cleaning }\end{array}$ \\
\hline & 106 & $\begin{array}{l}\text { TIG welder, acetylene/oxygen } \\
\text { torch, glycerin, toluene }\end{array}$ & $\begin{array}{l}\text { Sealing sources, } \\
\text { cleaning }\end{array}$ \\
\hline & 107 & $\begin{array}{l}\text { TIG welder, glycerin, } \\
\text { toluene }\end{array}$ & $\begin{array}{l}\text { Sealing sources, } \\
\text { cleaning }\end{array}$ \\
\hline & 109 & $\begin{array}{l}\text { Propane, nitric acid, stannous } \\
\text { chloride, palladium chloride }\end{array}$ & $\begin{array}{l}\text { Source brazing, } \\
\text { extraction }\end{array}$ \\
\hline & 112 & $\begin{array}{l}\text { Nitric acid, ammonium hydroxide } \\
\text { hydrochloric acid, nitric acid, } \\
\text { solution peroxide }\end{array}$ & For solutions \\
\hline & 113 & TIG welder & Source sealing \\
\hline & 114 & TIG welder & Source sealing \\
\hline & $\begin{array}{l}116 \\
117\end{array}$ & $\begin{array}{l}\text { LPG } \\
\text { Plasma arc welder }\end{array}$ & $\begin{array}{l}3 \text { cylinders } \\
\text { source sealing }\end{array}$ \\
\hline 675 & ${ }_{\text {roduction }}^{125}$ & TIG welder & $\begin{array}{l}\text { Sealing resin beads } \\
\text { in cans in glove box }\end{array}$ \\
\hline $\begin{array}{l}\text { Radiolun } \\
\text { product }\end{array}$ & $\begin{array}{l}\text { Iminous } \\
\text { ion area }\end{array}$ & $\begin{array}{l}\text { Acetone, isopropyl alcohol, } \\
\text { trichlorethylene, lacquer } \\
\text { thinner, oxyacetylene } \\
\text { torch }\end{array}$ & In storage \\
\hline
\end{tabular}

(a) Tungsten Inert Gas (TIG) 


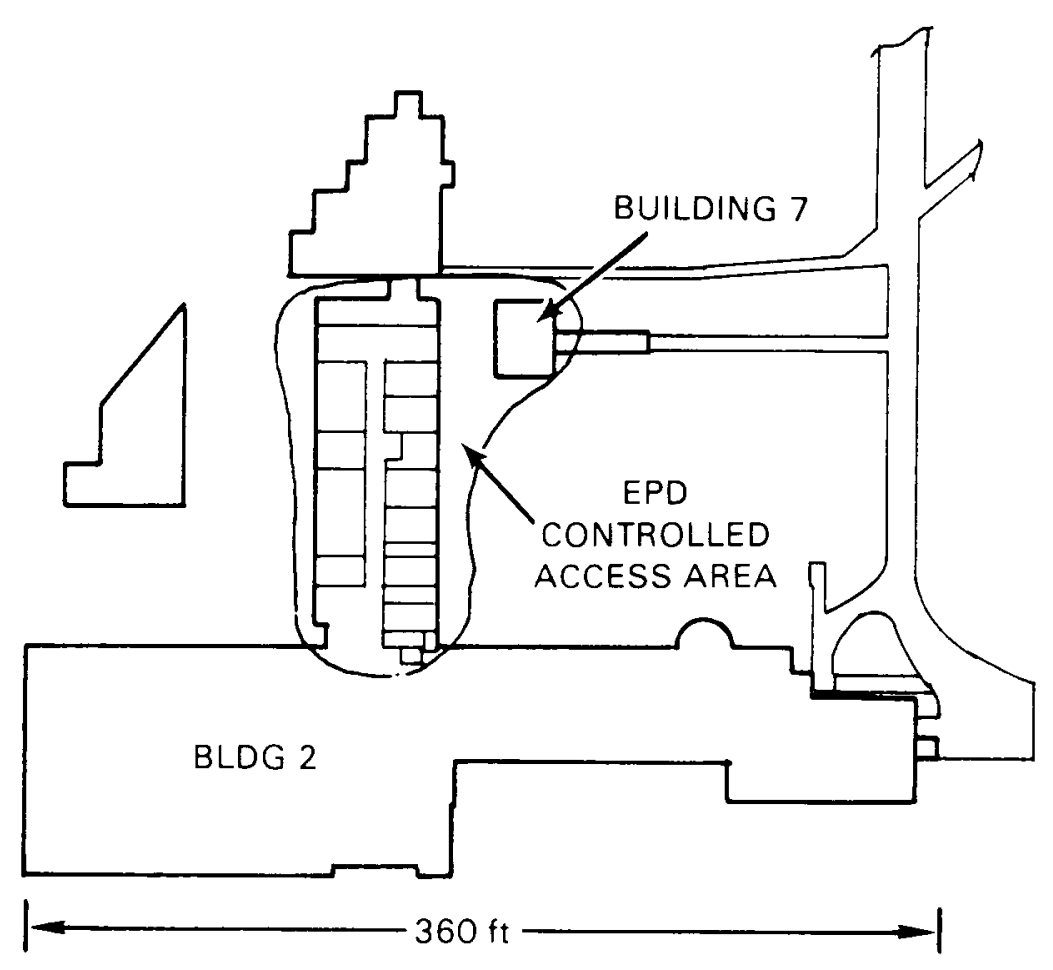

FIGURE G.2. Monsanto Site Plan

liquid source production follows similar steps, with additional processes for dissolving solid isotopes and checking for purity of the solution.

Waste Disposal

Radioactive waste produced during production is packaged within the containment where it is generated, then removed for drumming and storage in Building 7. Solid waste is separated into burnable and nonburnable categories; liquid waste is first solidified before final packaging and disposal. The final separation of waste is based on whether material is of low or high specific activity, or whether it is transuranic waste with specific activity greater than $10 \mathrm{mC} / \mathrm{g}$ waste. Approximately thirty 55-gal drums of waste are generated each year. Any combustible materials stored in Building 7 with the radioactive waste must be sealed in inetal or approved fire-resistant

containers.

\section{G.5.2 Facility Description}

Buildings

Isotope processing occupies rooms 3 through 14 in a wing of Building 2 . Building 7 is a below-grade storage bunker for housing drummed radioactive waste.

\section{G.15}


Building 2 was built in 1929 and modified in 1962 to allow handling of radioactive materials. It is divided into two areas: one designated a support area for handling sources and package preparation, the other designated a hot area where liquid and powder isotopes are handled in glove boxes or cells and the sources actually produced. The support area consists of 6 rooms built of 1-ft-thick poured concrete walls faced with tile on a 5-in.-thick concrete floor. Windows have been sealed with concrete blocks and the roof is constructed of concrete beams and deck covered with asphalt. The hot area consists of 5 rooms built from steel wall panels over masonite interior panels on dry wall with steel framing. The floor is a poured concrete slab, and the roof is either steel roof panels with wood sheeting, or steel and wood frame with tar paper cover and dry-wall interiors.

The waste bunker, Building 7 , is built below grade from poured reinforced concrete. It was specifically designed to protect drummed waste from tornado damage.

HVAC Systems

Airflow in the isotope handling rooms is from the room to the containment such as hoods, glove boxes, or remote cells. Air is exhausted through HEPA filters, usually two in series with one at the containment and the other at the exhaust stack. Ductwork is standard sheet metal piping. The ventilation system is designed such that airflow is from areas of low contamination to areas where higher contamination might exist. Glove box and remote cell airflow is exhausted through two absolute filters in series, each $99.9 \%$ efficient for $0.3-\mu m$ particles.

Engineered Safety Systems

Building 2 is fully sprinklered and contains monitors and alarms for fire, air contamination, and exhaust fan operation. Manual fire extinguishers are located inside each glove box. Fire extinguishers are automatically operated in the remote cell. The remote cell system is manually deactivated when lithium is present in the cell.

Surrounding Area

Monsanto is located in an industrialized area of Dayton. Neighbors include a junk yard, a steel plant, an automotive parts plant, and a coalburning power plant. Two gasoline service stations are located about half a mile from the facility.

\section{G.5.3 Inventory}

Radioactive Inventory

Possession limits of isotopes at Monsanto are listed in Table G.8. The inventories on hand are assumed to approach possession limits. Most of the material, appropriately contained, is held in storage in below-ground "wells" in Building 2. Only 80 to $100 \mathrm{Ci}$ of a single material is in process at one time in the glove boxes or cells. Stored sources are doubly encapsulated. 
TABLE G.8. Possession Limits of Isotopes at Monsanto Research Corporation

\begin{tabular}{|c|c|c|}
\hline Element & Isotope & $\begin{array}{l}\text { Possession } \\
\text { Limit, Ci } \\
\end{array}$ \\
\hline Americium & ${ }^{241_{A m}}$ & 6,000 \\
\hline Antimony & ${ }^{204} \mathrm{Sb}$ & 50 \\
\hline Bismuth & $210_{B i}$ & 50 \\
\hline Californium & ${ }^{252} \mathrm{Cf}$ & $10 \mathrm{mg}$ \\
\hline Cesium & ${ }^{137} \mathrm{Cs}$ & 200 \\
\hline Cobalt & ${ }^{60} \mathrm{Co}$ & 50 \\
\hline \multirow[t]{3}{*}{ Curium } & ${ }^{242} \mathrm{Cm}$ & 600 \\
\hline & ${ }^{243} \mathrm{Cm}$ & 10 \\
\hline & ${ }^{244} \mathrm{Cm}$ & 600 \\
\hline Neptunium & ${ }^{237} \mathrm{~Np}$ & 0.1 \\
\hline Prutonium & $\begin{array}{l}236,239,244,241 \\
242 \mathrm{pu}\end{array}$ & $199 \mathrm{~g}$ \\
\hline Promethium & ${ }^{147} \mathrm{Pm}$ & 70 \\
\hline Polonium & ${ }^{210} \mathrm{Po}_{0}$ & 3,000 \\
\hline Strontium & ${ }^{90} \mathrm{Sr}$ & 50 \\
\hline Thallium & ${ }^{204} \mathrm{TI}$ & 50 \\
\hline Thulium & ${ }^{170} \mathrm{Tm}$ & 10 \\
\hline $\begin{array}{l}\text { By-product with } \\
\text { atomic number } \\
3 \text { through } 83\end{array}$ & & 2 \\
\hline
\end{tabular}

Although Monsanto handles solid and liquid isotopes, the license does not distinguish between bulk isotopes in solution and dry solid isotopes.

Hazardous and Combustible Inventory

Volatile or flammable liquids and gases are handled only in glove boxes in room 9, and only $5 \mathrm{Ci}$ of any isotope are allowed in boxes containing materials such as benzene. This type of operation usually occurs only 2 weeks during the year. Some of the shielding used on the containment systems is plastics or acrylics.

\section{G.6 PAN AMERICAN WORLD AIRWAYS, KENNEDY SPACE CENTER, FLORIDA}

Pan American World Airways (Pan Am) is under contractual agreement with NASA and the U.S. Air Force to provide service to organizations that require

\section{G.17}


the handling of radioactive materials. These services include the packing, storage, and disposal of waste, and health physics operations. The latter require the use of instrumentation containing sealed sources. Pan American World Airways reports (1977-1979) were used to develop this appendix.

\section{G.6.1 Process Description}

Operation

Sealed sources used by Pan Am's health physics operations include sources, required for dosimetry studies, field instrumentation calibration, and laboratory instrument calibration.

Waste Disposal

Waste handled by Pan Am includes any by-product material with atomic number 1 through 83 and not to exceed $100 \mathrm{Ci} /$ nuclide or ${ }^{125} \mathrm{Ci}$ total. All waste is stored in 55-gal metal drums.

\section{G.6.2 Facility Description}

Pan Am's main building at Kennedy Space Center, which houses the sources is constructed of cement block with concrete floors and a reinforced concrete and steel roof. Waste is stored in a small building built of metal siding and roofing.

\section{G.6.3 Inventory}

Radioactive Inventory

Possession limits for the facility are listed in Table G.9.

\section{G.7 SAFETY LIGHT CORPORATION, SOUTH CENTRE, PENNSYLVANIA}

Safety Light Corporation (SLC), formerly U.S. Radium and now a division of VSR Industries, 3 produces and distributes a variety of sealed-source products using tritium, $H$. The majority of these products are divided among the following types: self-luminous safety devices used in commercial and military aircraft; tritium foils used for industrial research and development; titanium tritide-coated rods and pins used in electron tubes; and tritium targets for neutron-generating devices. Information was developed using a report by Safety Light Corporation (1981).

\section{G.7.1 Process Description}

\section{Operation}

The main processing building indicated in the site plan, Figure G.3, contains two tritium handling areas: tritium paint preparation using tritiated 
TABLE G.9. Possession Limits for Pan American World Airways

\begin{tabular}{|c|c|c|c|c|}
\hline \multirow{3}{*}{$\frac{\text { Element }}{\text { Americium }}$} & \multirow{3}{*}{$\frac{\text { I sotope }}{241_{\mathrm{Am}}}$} & \multirow[b]{2}{*}{ Form } & \multicolumn{2}{|c|}{ Inventory, $\mathrm{C} i$} \\
\hline & & & per Source & Total \\
\hline & & $\begin{array}{l}\text { Sealed source, } \\
\text { plated source, } \\
\text { foil }\end{array}$ & $5 \times 10^{-4}$ & 5 \\
\hline Californium & ${ }^{252} \mathrm{Cf}$ & Sealed source & 11 & 11 \\
\hline Curium & ${ }^{244} \mathrm{Cm}$ & $\begin{array}{l}\text { Sealed source, } \\
\text { plated source, } \\
\text { foil }\end{array}$ & $1 \times 10^{-4}$ & $1 \times 10^{-3}$ \\
\hline Polonium & $210_{\mathrm{Po}}$ & Sealed source & 0.025 & 5 \\
\hline Thorium & $\begin{array}{l}228 \mathrm{Th} \\
230 \mathrm{Th} \\
{ }^{232} \mathrm{Th}\end{array}$ & & $5 \times 10^{-4}$ & 1 \\
\hline Uranium & $238 v$ & $\begin{array}{l}\text { Sealed source, } \\
\text { plated source, } \\
\text { foil }\end{array}$ & $1 \times 10^{-4}$ & 0.001 \\
\hline & $238 \mathrm{U}$ & Depleted uranit & & $15,000 \mathrm{~kg}$ \\
\hline
\end{tabular}

phosphor, and tritium processing using gaseous tritium. Tritiated paint is prepared by mixing the phosphor with various adhesives within fume hoods. Luminous paint is then applied to a variety of products, which are packaged and shipped.

In the tritium processing area three separate processes occur: 1) production of gaseous tritium light sources, 2) impregnation of foil with tritium, and 3) a spark gap filling system. Light source production consists of filling phosphor-coated glass ampules with $94 \%$ pure tritium gas. The gas arrives in cylinders from 0ak Ridge in shipments of $20,000 \mathrm{Ci}$. The gas is transferred to a depleted uranium bed reservoir system for storage and dispensing. Gas is driven off the beds by heating thein with an electric heater, and is then discharged to glass ampules. The ampules are sealed using infrared heat lamps.

Tritium foil impregnation consists of heating titanium and scandium foils in quartz reaction vessels under vacuum and then introducing ${ }^{3}$ gas, which impregnates the foils. The $\mathrm{H}$ is stored as above in depleted uranium reservoirs. These reservoirs are heated to above $250^{\circ} \mathrm{C}$ to drive gas out of the beds. The impregnated foils are packaged in hoods and sent on for storage and shipment. 


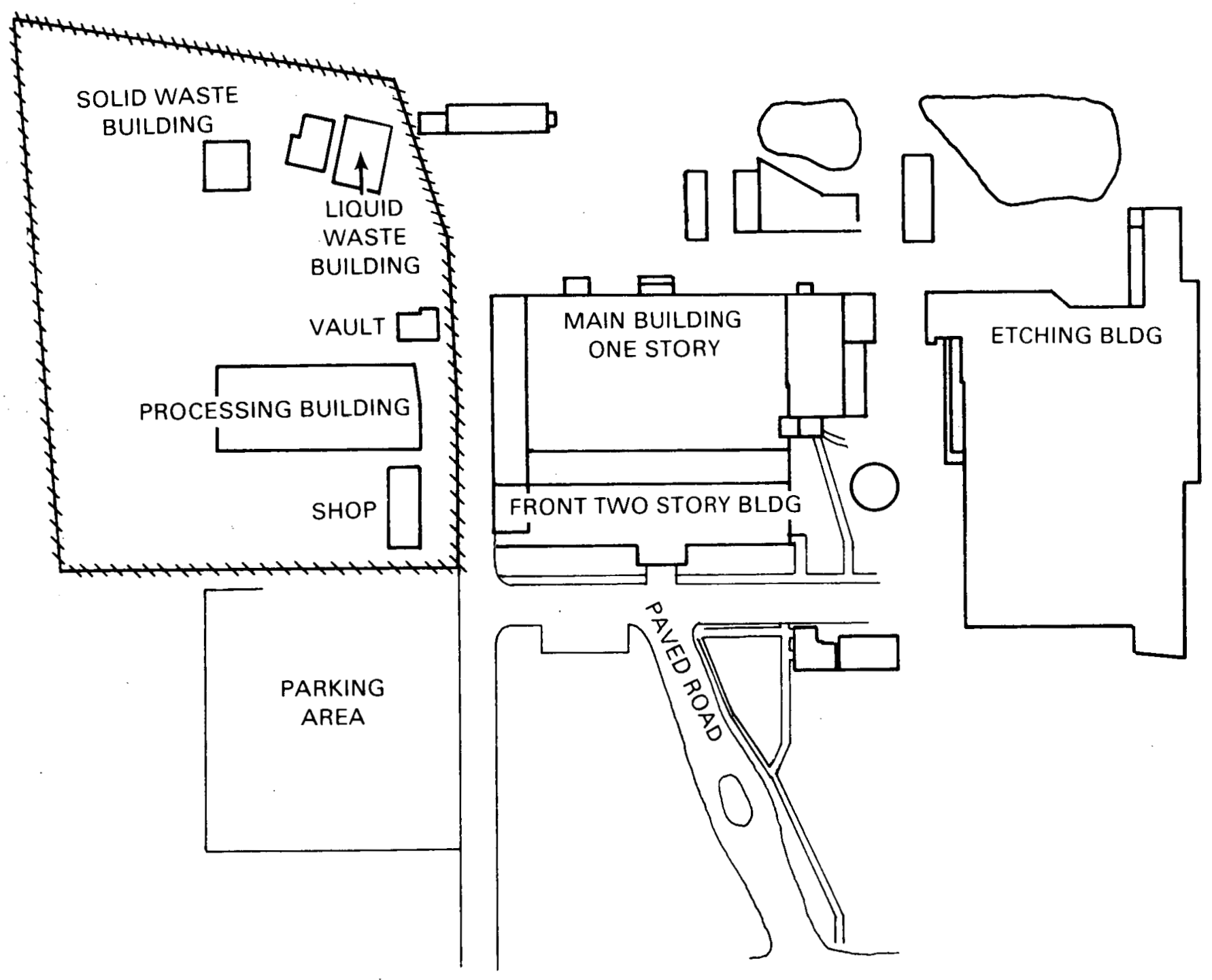

FIGURE G.3. Safety Light Site Plan 
The spark gap tube filling system consjsts of filling ceramic and copper vessels with hydrogen diluted with gaseous ${ }^{3} \mathrm{H}$. The tubes are sealed, packaged, and shipped after quality control checks. All work on the tubes is performed in fume hoods.

Waste Disposal

Gaseous tritium and oxide effluents are discharged to the atmosphere after filtration. Liquid waste effluents from processing areas and sinks are discharged to holding tanks for decay before discharge to a nearby river. Some low-level liquid waste is drummed and disposed of at approved sites. Solid waste is composed of foil scraps, paint residues, scrubber columns, and miscellaneous paper and clothing. This material is drummed and disposed of periodically.

Used tritium products such as self-luminous safety devices, spent tritium foils, and watch dials are returned by customers for disposal. These are accumulated and disposed of at approved disposal sites.

\section{G.7.2 Facility Description}

Buildings

The facility is located on the 2-acre site shown in Figure G.3, in South Centre, Pennsylvania. Another VSR subsidiary located on the site is VSR Metals, which does not handle radioactive materials. VSR Metals produces dials, name plates, and other products used by industry and the military. The SLC buildings consist of main processing, liquid waste storage, and three storage buildings, and a machine shop.

The main processing building is a steel-framed structure puilt on a concrete slab. Building dimensions are 50 by $120 \mathrm{ft}, 6,000 \mathrm{ft}^{2}$. Inner walls use steel studs covered by dry wall. The building contains service lines for gas, oxygen, compressed air, and electricity.

The liquid waste building is a steel-framed structure containing the holding tanks. This building is also used as the receiving area for the gaseous ${ }^{3} H$ from 0ak Ridge. The gas is subsequently transferred to the processing building in its original containers.

Of the three storage buildings, one is a two-story wood-framed structure, while the other two are of concrete block construction. The wood-framed building houses both contaminated and uncontaminated production equipment. One of the concrete block buildings also houses contaminated equipment, while the other is used for storage of uncontaminated equipment and supplies.

HVAC Systems

In the main processing building, intake and exhaust air are filtered as needed to maintain quality control. Air conditioning and heat are provided by 
two separate electrical heat pump systems, one providing recirculated air to nonradioactive work areas and the second providing air to the radioactive areas. Air from the radioactive areas is not recirculated but is discharged through a roof-mounted exhaust stack.

Engineered Safety Systems

The main processing building is sprinklered with water provided by an onsite supply system. Fire extinguishers are strategically placed throughout the facility. When tritium is handled, air is continuously monitored for contamination. Stainless steel is used as much as possible for containing the gaseous ${ }^{3} \mathrm{H}$. Alarm systems are located throughout the main processing building. Fume hoods and glove boxes are used as needed in the tritium handling areas.

The water supply and controls for the sprinkler system are located in a pump house in the northeast corner of the plant site. A gas-fired heater is connected to the holding tank. This building is of concrete block construction.

\section{Surrounding Area}

The Safety Light facility is located in rural Pennsylvania immediately adjacent to the Susquehanna River. Grass-covered ridges and agricultural land form the boundary of the site. Some residential housing is located nearby. Within 1 mile of the plant site are several light industrial firms and a high school.

The river has flooded the SLC facility waste storage buildings in the past, after Hurricane Agnes in 1972.

\section{G.7.3 Inventory}

Radioactive Inventory

Safety Light's license permits the use of $1 \mathrm{mC} i$ any by-product material in sealed-source form as a reference standard. The principal sources of radioactivity at the Safety Light facility are shown in Table G.10. Gaseous tritium is received in shipments of $20,000 \mathrm{Ci}$ or less and then divided into $5,000 \mathrm{Ci}$ batches. These batches are distributed to the self-luminous device process system or the tritium foil impregnation system. All of this activity is in the processing building. No estimates are available of inventories of radioactive waste.

Hazardous and Combustible Inventory

Limited quantities of solvents can be found in several locations in the main processing building. 
TABLE G.10. Possession Limits of Principal Isotopes
at Safety Light Corporation

\begin{tabular}{|c|c|c|c|}
\hline Element & I sotope & Form & $\begin{array}{l}\text { Possession } \\
\text { Limit, Ci }\end{array}$ \\
\hline Carbon & ${ }^{14} \mathrm{C}$ & Sealed source gas, & 2.05 \\
\hline Hydrogen & $3_{H}$ & $\begin{array}{l}\text { Gas, tritiated paint, } \\
\text { sealed sources }\end{array}$ & $1 \times 10^{5}$ \\
\hline Krypton & $85 k$ & Sealed source & 5 \\
\hline
\end{tabular}

G.8 STOCKER AND YALE, INC., BEVERLY, MASSACHUSETTS

The Stocker and Yale facility produces self-luminous devices, primarily hand-he] 8 compasses, for use by military personnel. The only isotopes used are

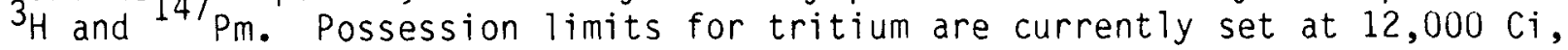
and are in the form of phosphor paint and sealed sources. Tritium is segregated in two areas in the facility that may hold up to $6,000 \mathrm{Ci}$ on each side of a 4-in.-thick maple wall. The 4 total floor area of the plant is $50,000 \mathrm{ft}^{2}$. The possession limit for the ${ }^{14} \mathrm{Pm}$ is $10 \mathrm{Ci}$ and is in the form of luminous paint. Stofkar and Yale currently produce up to 20,000 compasses per year with $0.4 \mathrm{mC} i$ of ${ }^{2} \mathrm{Pm}$ in each compass. The entire facility is sprinklered (Stocker and Yale 1975-1981).

G.9 TECHNICAL OPERATIONS, BURLINGTON, MASSACHUSETTS

Technical Operations (Tech/Ops) functions as a sealed-source manufacturer producing sources from a number of isotopes. Technical Operations reports (1957-1981) provided background information used for this appendix.

\section{G.9.1 Process Description}

Sources are unloaded in a hot cell and encapsualted in another cell. The material handled will be in the form of pellets or wafers, which are placed in an inner capsule. This capsule is welded and placed in an outer capsule, which is also welded.

\section{G.9.2 Facility Description}

The radioisotope laboratory at Tech/0ps is located underground in one end of their main building. It consists of two $x$-ray areas for exposing radiation sources; a general storage area for holding shielded containers of radioisotopes; a source cutting area for remotely removing sealed sources from their container ang transferring the source to another storage container; a storage area for ${ }^{6}{ }_{82}$ sealed sources; storage area for waste in 30- to 55-gal steel drums; and a ${ }^{19}$ Ir work area for unloading and encapsulating it into sealed sources. 


\section{G.9.3 Radioactive Inventory}

Possessign liqits for Tegb/Ops are listed in Table G.11. Sources containing ${ }^{13} \mathrm{Cs}$, $170 \mathrm{Tm}$, or ${ }^{169}{ }_{\mathrm{Yb}}$ are permitted as up to $1 \mathrm{Ci}$ of by-product material in unsealed solid metallic form and yp to $1200 \mathrm{C}$ as sealed sourges. operating procedures permit up to $1,000 \mathrm{Ci}{ }^{192} \mathrm{Ir}, 100 \mathrm{Ci}{ }^{137} \mathrm{Cs}$, or $1 \mathrm{Ci} 6 \mathrm{CO}_{\mathrm{Cn}}$ the loading cell at one time.

TABLE G.11. Possession Limits at Tech/0ps

\begin{tabular}{|c|c|c|c|}
\hline Element & Isotope & Form & $\begin{array}{l}\text { Inventory, } \\
\text { Limit, Ci }\end{array}$ \\
\hline Cesium & ${ }^{137} \mathrm{Cs}$ & Sealed source & $1 \times 10^{4}$ \\
\hline Cobalt & ${ }^{60} \mathrm{Co}$ & $\begin{array}{l}\text { Solid metallic, } \\
\text { sealed sources }\end{array}$ & $1.5 \times 10^{4}$ \\
\hline Hydrogen & $3_{H}$ & Sealed source & $5 \times 10^{3}$ \\
\hline Iridium & ${ }^{192}$ Ir & $\begin{array}{l}\text { Solid metallic, } \\
\text { carbide, sealed } \\
\text { source }\end{array}$ & $5 \times 10^{4(a)}$ \\
\hline Strontium & $90_{S}$ & Sealed source & 19 \\
\hline \multirow[t]{2}{*}{ Tantalum } & ${ }^{182} \mathrm{Ta}$ & $\begin{array}{l}\text { Solid metallic } \\
\text { carbide, sealed } \\
\text { source }\end{array}$ & 200 \\
\hline & ${ }^{183} \mathrm{Ta}$ & $\begin{array}{l}\text { Solid metallic, } \\
\text { carbide, sealed } \\
\text { source }\end{array}$ & $2 \times 10^{3}$ \\
\hline Thulium & ${ }^{170} \mathrm{Tm}$ & Sealed source & $5 \times 10^{3}$ \\
\hline
\end{tabular}

(a) Application for amendment to change possession limit from $25,000 \mathrm{Ci}$ to $50,000 \mathrm{Ci}$

\section{G.10 REFERENCES}

Amersham Corporation, Letters from Amersham Corp. to U.S. Nuclear Regulatory Commission, Docket No. 30-4261, U.S. Nuclear Regulatory Commission, Washington, D.C., 1969-1980.

Automation Industries, Inc., Letters from Automation Industries to U.S. Nuclear Regulatory Commission, Docket No. 30-5998, U.S. Nuclear Regulatory Commission, Washington, D.C., 1966-1980. 
Micro Display Systems, Inc., License Application Information - Docket No. 30-17293, U.S. Nuclear Regulatory Commission, Washington, D.C., 1980-1981.

Minnesota Mining and Manufacturing, Radiological Contingency Plan, Docket No. 30-4951, U.S. Nuclear Regulatory Commission, Washington, D.C., 1981.

Monsanto Research Corporation, Radiological Contingency Plan, Docket No. 70-572, U.S. Nuclear Regulatory Commission, Washington, D.C., 1981.

Pan American World Airways, License Application Information, Docket No. 30-03974, U.S. Nuclear Regulatory Commission, Washington, D.C., 1977-1979.

Safety Light Corporation, Radiological Contingency Plan, U.S. Nuclear Regulatory Commission, Washington, D.C., 1981.

Stocker and Yale, Inc., License Application Information, Docket No. 30-11189, U.S. Nuclear Regulatory Commission, Washington, D.C., 1975-1981.

Technical Operations, License Application Information, Docket No. 30-4579, U.S. Nuclear Regulatory Commission, Washington, D.C., 1957-1981. 


\section{APPENDIX H}

RESEARCH AND DEVELOPMENT OF NUCLEAR FUELS 


\section{H.1 ISOTOPIC ANALYSIS, INC., TULSA, OKLAHOMA}

Isotopic Analysis, Inf., ghovides mass spectrographic analysis of nuclear materials, particularly $233_{U}, 235 \mathrm{U}$, and plutonium. The basis for the facility description presented here is a report by Istopic Analysis (1976).

\section{H.1.1 Process Description}

\section{Operation}

Process steps include chemical separation of impurities from the nuclear material using ion exchange techniques, loading small samples of the uranium or plutonium onto wire filaments for the spectrographic analysis, analyzing the sample, and returning unused materials to the customer.

Nuclear material is received in either solid form as an oxide, alloy, or pure metal, or in liquid form as a nitrate or sulfate. Plutonium may also be recieved in a chloride solution. The material is packaged in plastic containers which are packed inside a metal container with vermiculite separating individual packages. The metal container is in turn packed in a metal, cardboard, or wooden outer container. Nuclear material is unpacked and dispensed in smaller quąhtities in a glove box or hood. Uranium-235 is handled in fume hoods while $23{ }_{U}$ and plutonium are handled in glove boxes. Unused materials are placed in a special storage safe.

\section{Waste Disposal}

All low-level liquid waste is collected inside the glove boxes or fume hoods and placed in polyethylene bottles. These bottles are assayed when full for recoverable material. If any is present they are returned to the customer; if not they are solidified and disposed of at a burial site. Solid waste (glassware, paper, etc:) is sealed in plastic bags or metal containers for shipment to a burial site.

\section{H.1.2 Facility Description}

Buildings

The facility where nuclear materials are handled is divided into offices, a cold area, an instrument room, and a hot area. The building has concrete outer walls with no windows, sheet rock interior walls, a metal-paieled roof with asphalt coating and an acoustical tiled drop ceiling concealing sheet metal ductwork and conduits for services. 
HVAC Systems

Ventilation is provided by a central heating and air conditioning unit with exhaust air discharging through the hoods and glove boxes in the hot area. There are HEPA filters installed in the hot area exhaust system.

\section{H.1.3 Inventory}

Radioactive Inventory

Maximum amounts of nuclear materials in process at any one time are:

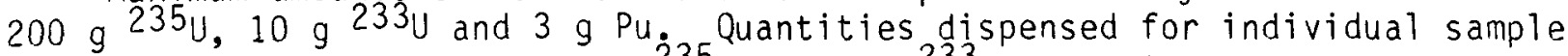
preparation are: 0.05 to $0.5 \mathrm{~g} 235 \mathrm{U}, 0.01 \mathrm{~g} 233 \mathrm{U}$, and $20 \mathrm{mg} \mathrm{Pu}$.

Unused materials are accumulated in the dispensing glove box/hood up to a level of $50 \mathrm{~g}$ of enriched uranium; then returned to the customer.

Hazardous and Combustible Inventory

Flammable organic solvents are stored in a single metal storage cabinet. H.2 BABCOCK AND WILCOX LYNCHBURG RESEARCH CENTER, LYNCHBURG, VIRGINIA

Research and development using source, byproduct, and special nuclear material is performed at the Lynchburg Research Center. The facility description is based on Babcock and Wilcox reports (1978, 1981).

\section{H.2.1 Process Description}

\section{Operation}

In Building $A$, which houses two research reactors, experiments are conducted on metals that are placed near the reactor core and exposed to radiation. In Building $B$ hot cells, destructive and nondestructive testing of irradiated materials takes place. Materials are received in the cask handing area in shielded containers, placed in the transfer canal and storage pool, and the containers are opened. The material is then transferred to the hot cells and examined.

Building $B$ also has radiochemistry and counting laboratories that analyze small quantities of radioactive materials to support hot cell activities.

Building $C$ is equipped with glove boxes, and fume hoods to test methods of nuclear fuel preparation. Research and development of fuel manufacturing processes takes place intermittently in this building. Process steps may include receiving oxide powders, blending, pellet pressing, sintering, grinding, and packaging of the fuel. 
Experimental apparatus from irradiating metal samples in Building $A$ are disposed of as solid waste. Liquid waste from this facility is drained to a holding tank and pumped to the liquid waste treatment facility at Babcock and Wilcox's Naval Nuclear Fuel Division.

Solid waste from the hot cells in Building B is containerized and held for offsite shipment. Liquid wastes are evaporated or solidified and handled as solid waste. Following examination in the hot cells, nuclear material is returned to the sponsor after packaging, or handled as solid waste. Water in the transfer canal and storage pool is recirculated through ion exchange columns. When exhausted, the ion exchange resins are dried and disposed of as solid waste.

Solid wastes from Building $C$ are collected and stored for shipment to a licensed waste disposal facility. Low-level liquid wastes from this area are transferred to the liquid waste disposal facility for storage, mixing, and sampling, then discharged to the liquid waste treatment facility at the Naval Nuclear Fuel Division.

\section{H.2.2 Facility Description}

Buildings

Building $A$ has an area of $20,000 \mathrm{ft}^{2}$ on two levels as shown in Figure H.1. The building can withstand $100 \mathrm{mph}$ winds overall and $60 \mathrm{mph}$ [sic] winds on the northwest wall. Interior walls are cinder block.

Building $B$, shown in Figure $H .2$, has $35,000 \mathrm{ft}^{2}$ of floor area on two floors. The hot cells occupy $6,000 \mathrm{ft}^{2}$ and have walls of 11 - to 13-in.-thick lead sheet. One hot cell has 42-in.-thick concrete walls. The storage pool is concrete and has dimensions of 10 by 10 by $22.5 \mathrm{ft}$ deep. The transfer canal is a concrete pool 6 by 24 by $24 \mathrm{ft}$ deep. This building can withstand $100 \mathrm{mph}$ winds overall and $60 \mathrm{mph}$ (sic) winds on the east end wall.

Building $C$, shown in Figure H.3, has $20,000 \mathrm{ft}^{2}$ of floor area and is a steel-framed, cinder block building with metal ceilings. Glove boxes in the nuclear fuel research and development area are stainless steel with fire retardant Plexiglas ${ }^{\circledR}$. Two storage vaults with 12-in.-thick concrete walls are also located in the facility.

Buildings should only sustain minor damage from an earthquake of up to VII on the modified Mercalli scale. Extensive damage to all buildings could occur from a major tornado loading.

هPlexiglas is a trademark of Rohn and Haas, Philadelphia, PA 19105. 


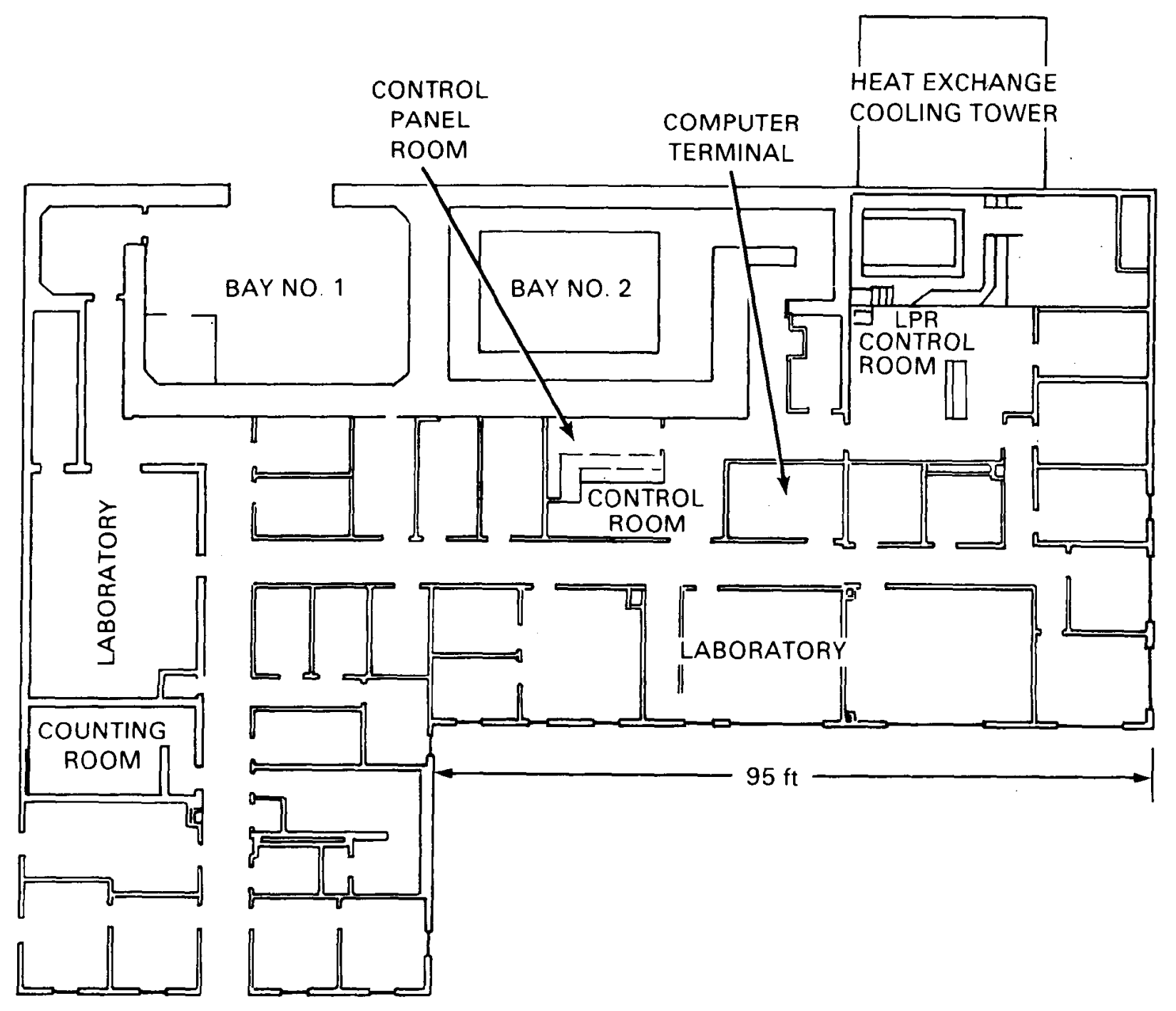

FIGURE H.1. Building A of the Lynchburg Research Center

HVAC Systems

Hot cells, glove boxes, hoods, and other forms of containment are kept under negative pressure. Airflow is towards areas of greater potential contamination.

Building $A$ has a single exhaust ventilation system, which passes air through a prefilter and a HEPA filter before release.

In Building $B$, hot cells and hoods have separate ventilation systems from the main ventilation system. Air from contaminated areas is screened through at least two filters (a prefilter and an absolute filter) before combining with the main ventilation system and exhausting out of the stack. 


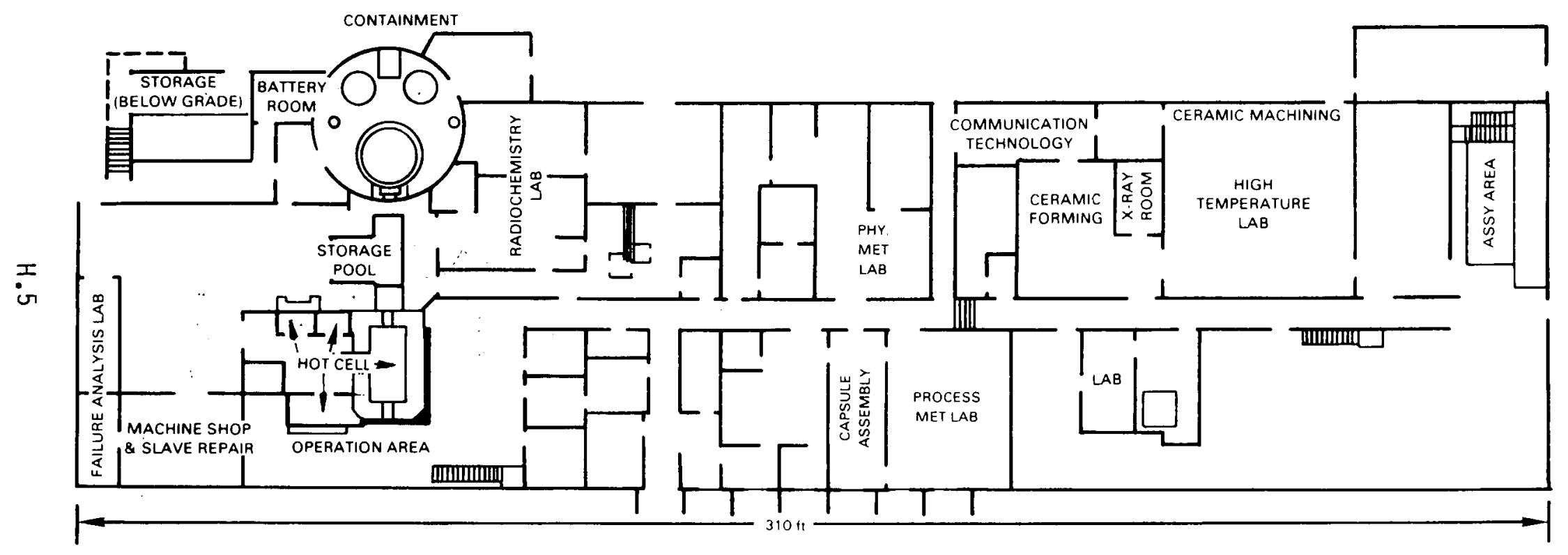

FIGURE H.2. Building B of the Lynchburg Research Center 


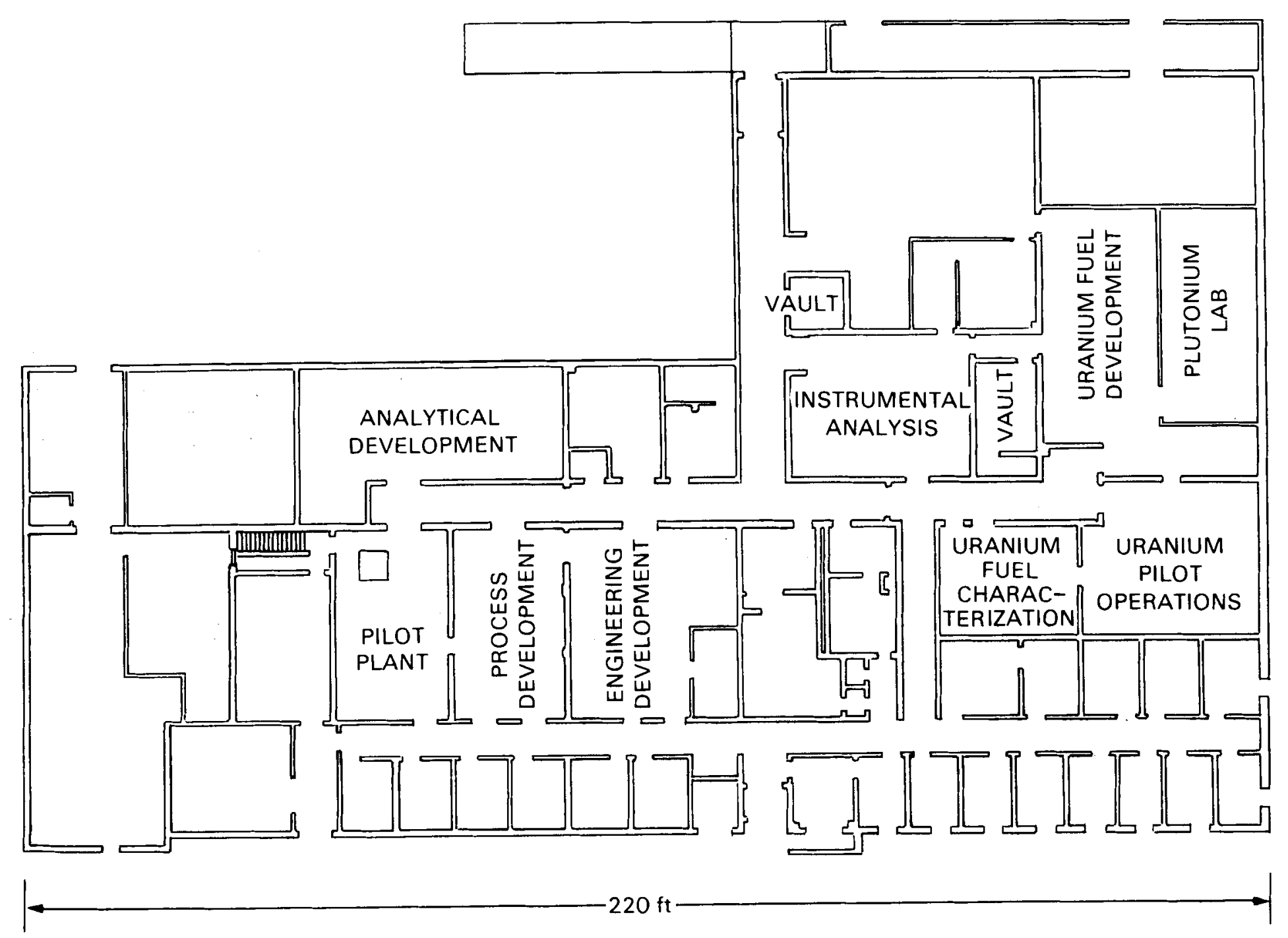

FIGURE H.3. Building $C$ of the Lynchburg Research Center 
Building $C$ has two exhaust systems. Glove boxes and fume hoods are exhausted to two HEPA filters before release to a $50 \mathrm{-m}$ stack. Room exhaust is filtered through one stage of HEPA filters before release.

Ducting is mostly PVC with some carbon steel.

\section{Engineered Safety Systems}

Building $A$ has smoke detectors, criticality alarms, and automatic shutdown systems for the two test reactors.

The hot cells in Building B have an automatic fire suppression system. The cask-handling area has smoke detectors, an air monitor, and criticality and radiation monitors.

Building $C$ has constant air monitors and criticality monitors.

Filters are fire resistant.

Surrounding Area

The Lynchburg Research Center occupies about 4 acres of a 525-acre site about 4 miles east of Lynchburg, Virginia. The site is next to the James River in a rural area. Two fuel fabrication facilities, the Babcock and Wilcox Commercial Nuclear Fuel Plant and Naval Nuclear Fuel Division Plant, are also located on the site. A criticality accident at either of these two plants would activate the criticality monitoring system for the research center and sound the evacuation alarms.

\section{H.2.3 Inventory}

Radioactive Inventory

License limits for the Lynchburg Research Center are shown in Table H.I.

The quantity of nuclear material that may be transferred to different areas of the plant depends on the concentration of plutonium or $235 \mathrm{U}$. Mass limits for different concentrations are given in Table H.2. Hot cells may handle one unit' as given in the table.

Glove boxes in Building $C$ are limited to $2.4 \mathrm{~kg}$ of fissile material in each where dry, organic-free operations take place.

Hazardous and Combustible Inventory

Plastic is used for bagging material to transfer special nuclear material into and out of containment. 
TABLE H.1. License Limits at Lynchburg Research Center

Material

U enriched to $\geq 20 \%$ in any form
$U$ enriched to $\leq 20 \%$ in any form
$233_{\mathrm{IJ}}$
$\mathrm{Pu}$
Source Material
By-product, special nuclear material,
and source material
By-product, special nuclear material,
and source material
Fission products and transuranium
elements
Fission products and transuranium
elements
Any by-product material (neutron
irradiated)

Any by-product material with atomic numbers 3-83

Transuranium elements

${ }^{252} \mathrm{Cf}$ (sealed sources)

$241_{\text {Am }}$ (sealed sources)

$3_{H}$ (sealed sources)

$3_{H}$ (Ni alloy plated SC tritide foil)

$3_{H}$ (oxide)
License Limit

$4.9 \mathrm{~kg} \mathrm{235U}$

$900 \mathrm{~kg} \mathrm{235} \mathrm{U}$

$1 \mathrm{~kg} 233 \mathrm{U}$

$1.9 \mathrm{~kg}$

$6,000 \mathrm{~kg}$

40 irradiated Lynchburg Pool Reactor fuel elements

Irradiation of $250 \mathrm{~kg}$ source material

3 irradiated commercial fuel assemblies

$5,000,000 \mathrm{Ci}$

$50,000 \mathrm{Ci}$

$3,000 \mathrm{Ci}$ each not to exceed

$1,000,000 \mathrm{Ci}$

$20 \mathrm{mc} ;$ each

$4 \mathrm{mg}$

$30 \mathrm{Ci}$

$100 \mathrm{Ci}$

$3 \mathrm{Ci}$

$3 \mathrm{Ci}$

Flammable liquid storage cabinets are located in all buildings for safe storage of bulk quantities. Liter quantities or less are permitted out of storage for laboratory use. Larger quantities are permitted out of storage in safety cases.

Sodium-potassium alloys in irradiated fuel capsules are flammable and can be found in the hot cell when this type of fuel is examined.

Zircaloy is ground up in the hot cells and up to $16 \mathrm{~g}$ may be accumulated. Ground Zircaloy is normally kept in a fire extinguishing medium in a pan. 
TABLE H.2. Mass Limits for Nuclear Materials at Lynchburg Research. Center

\begin{tabular}{|c|c|}
\hline wt\% Pu or $235 \mathrm{U}$ & $\begin{array}{c}\text { Mass Limit, } \\
9 \\
\end{array}$ \\
\hline 0 & 350 \\
\hline 1 to 20 & 313 \\
\hline 20 to 40 & 283 \\
\hline 40 to 60 & 258 \\
\hline 60 to 80 & 237 \\
\hline 80 to 100 & 220 \\
\hline Mixture of $233 \mathrm{U}$ and $235 \mathrm{U}$ & 220 \\
\hline Mixture of ${ }^{233} U$ and ${ }^{235} U$ & 250 \\
\hline Uranium enriched to $4 \%$ in $235 \mathrm{U}$ & 850 \\
\hline
\end{tabular}

H.3 ROCKWELL NUCLEAR DEVELOPMENT FUEL LABORATORY, SANTA SUSANA, CALIFORNIA

Research and development of nuclear fuels and examination of irradiated fuels take place at the Rockwe1l Nuclear Development Fuel Laboratory (NDFL). Information on this facility is obtained from Rockwell International reports (1976 and 1981) and from a report by Mishima and Ayer (1981).

\section{H.3.1 Process Description}

\section{Operation}

Two buildings operate under the same nuclear material license. Building 020 contains hot cells in which reactor fuel is declad and examined with remote equipment. A shipping canister containing up to three rods $(600$ to $805 \mathrm{~g}$ of plutonium total) transports the fuel rods from a fuel storage facility to the 020 building and into one of the hot cells. The end of the fuel rod is cut and fuel pellets are removed. Approximately 55 fuel pellets are in each rod. These are placed in a transfer can and sealed. The cans are checked for contamination, weighed, and shipped to a storage facility. Other internal pieces of the fuel rod, cladding scrap, and waste generated in the process are put in appropriate containers and shipped off site. Hot cells may be supplied with nitrogen so that processes take place in an inert atmosphere.

Building 055 is used for research and development work developing solid reactor fuel materials, radioisotope heat sources, or radiation sources in a variety of forms and compositions. Plutonium, uranium or other highly radioactive fuels are brought in as oxides, nitrides, sulfides, or other forms depending on the process under investigation. Two glove box lines, one for fuel fabrication and the other for analytical services are provided in the 
plant to contain research and development processes. These processes vary from weighing, blending, crushing and sintering, to inspecting and surveying. Materials are transferred from one glove box to another through transfer tunnels.

\section{H.3.2 Facility Description}

\section{Buildings}

Building 020 , shown in Figure $\mathrm{H.4}$, has $17,800 \mathrm{ft}^{2}$ of floor space. Hot cells in the building are constructed of 42-in.-thick concrete. Building 055, shown in Figure H.5, has 12,900 $\mathrm{ft}^{2}$ of floor space and is constructed of steel and reinforced concrete. Glove boxes in this building are steel with Plexiglas ${ }^{\circledR}$ on each of two faces. Both buildings are built to withstand a maximum ground acceleration of $0.28 \mathrm{~g}$.

HVAC Systems

Both buildings filter exhaust air through HEPA filters. Flow of air goes from areas of low potential contamination to higher potential contamination.

The exaust system for Building 020 has a nominal discharge ratse of $23,000 \mathrm{ft} / \mathrm{min}$ for exhaust from the general facility plus $13,000 \mathrm{ft}^{3} / \mathrm{min}^{\mathrm{f}}$ from the cell high-volume exhaust. The hot cells are equipped with nitrogen purge systems.

Building 055 has a high-volume exhaust for working areas and a separate low-volume exhaust to maintain negative pressure in the glove boxes. Both systems total 23,000 $\mathrm{ft}^{3} / \mathrm{min}$ of exhaust. The glove box room undergoes about 10 air changes per hour.

\section{Engineered Safety Systems}

Building 055 is equipped with an automatic wet pipe sprinkler system in all areas except the glove box room and the vault, which can be flooded with argon to suppress a fire. Smoke detectors and heat detectors are provided throughout the building as well as a manual fire alarm system. Portable fire extinguishers are also located throughout the facility.

Hot cells and decontamination rooms have heat detectors, which alarm in the event of a fire and activate a nitrogen purge system.

\section{Surrounding Area}

The Rockwell NDFL is located on a plateau about 29 miles northwest of downtown Los Angeles. It is relatively isolated from surrounding communities and over one mile from the closest dwelling. 


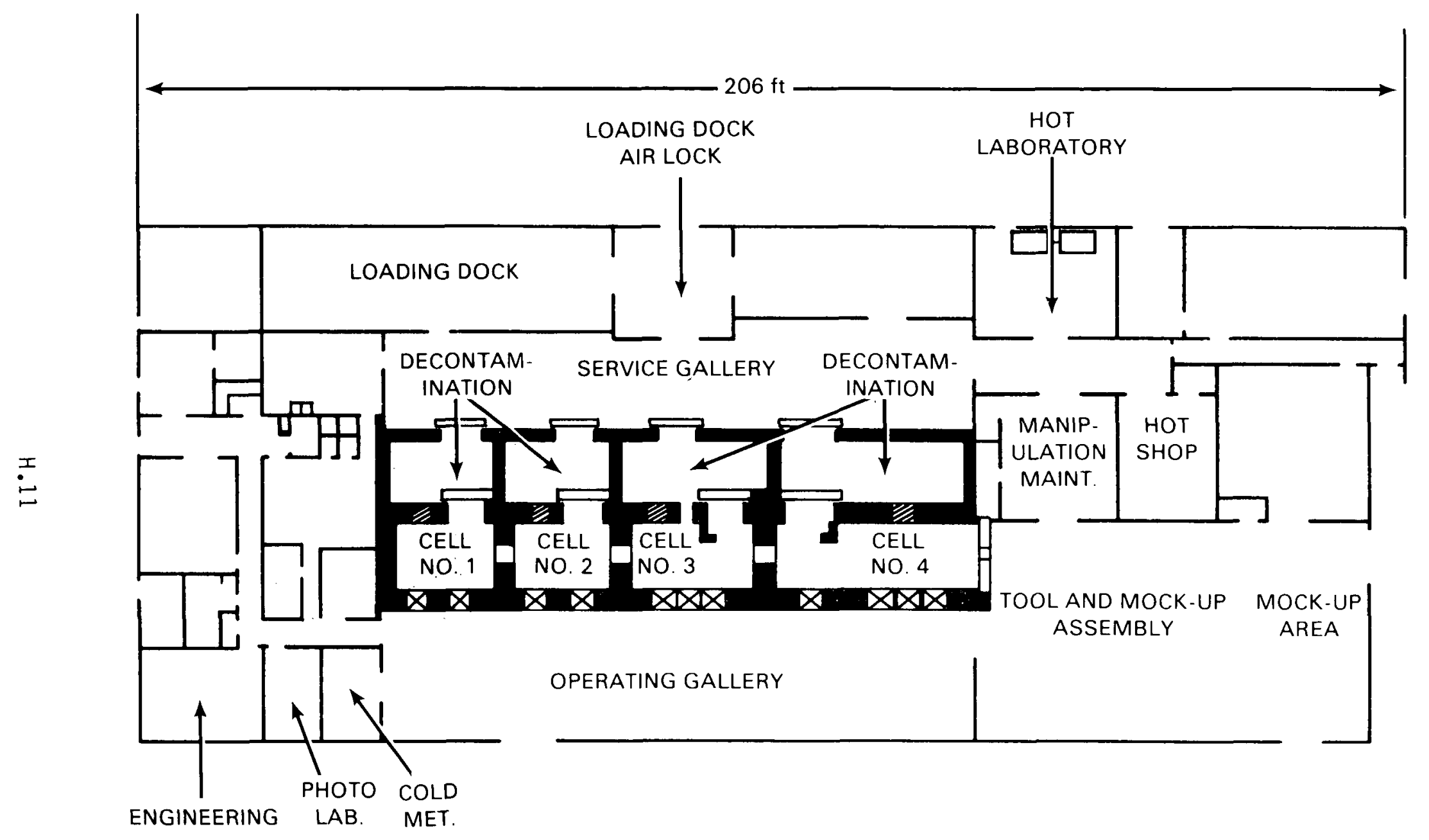

FIGURE H.4. Building 020 Floor Plan, Rockwell NDFL 


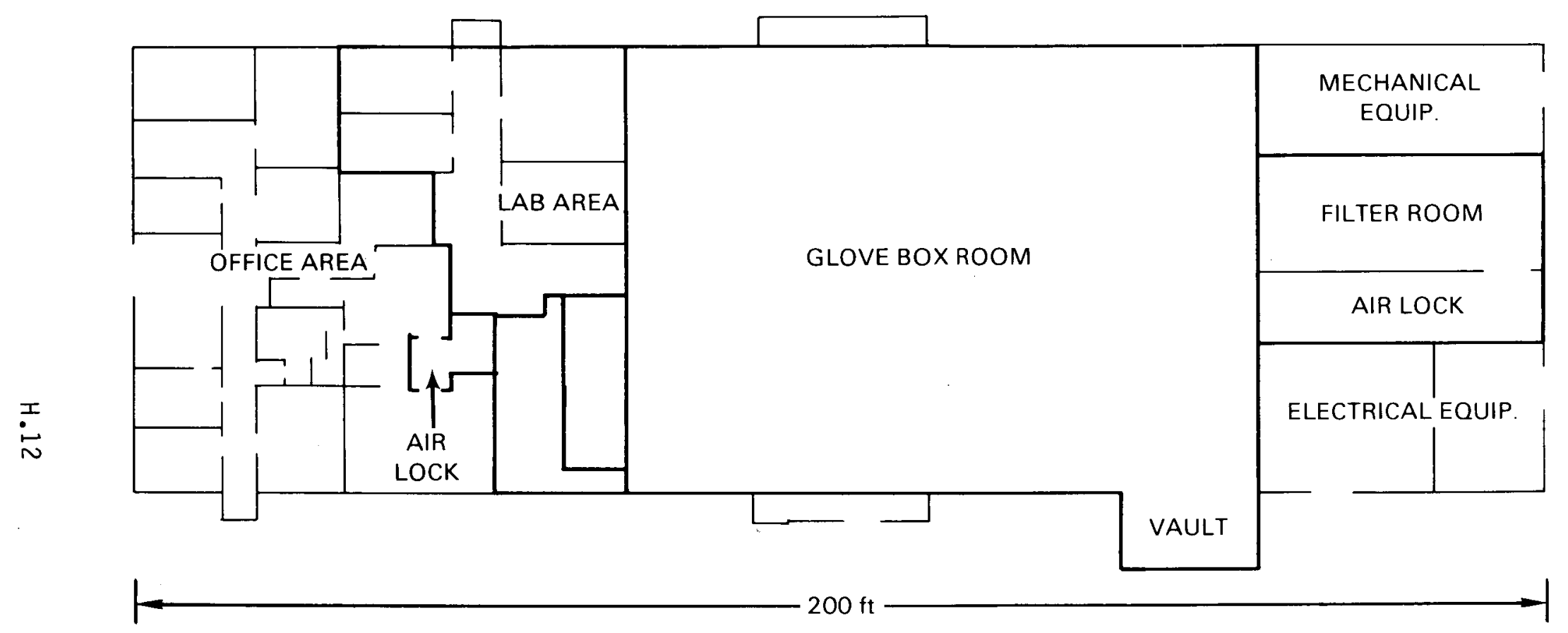

FIGURE H.5. Building 055 Floor Plan, Rockwell NDFL 


\section{H.3.3 Inventory}

Radioactive Inventory

In the 020 building only three fuel rods containing 600 to $805 \mathrm{~g}$ of plutonium are in process at one time. The material is in the form of fuel pellets, 55 pellets per rod, 18 to $25 \% \mathrm{Pu}$ in $\mathrm{PuO}_{2}-\mathrm{UO}_{2}$. Unencapsulated fuel is processed only within the four hot cells.

In the 055 Building radioactive material is mass limited to 0.23 to $2.51 \mathrm{~kg} 235 \mathrm{pu} / \mathrm{station}$ depending upon moderation and container geometry. This material may be in any form from powders to pellets. Table H.3 gives an inventory at risk for the glove box room.

TABLE H.3. Inventory-at-Risk in Glove Box Room

Amount of

Radionuclide

Glovebox Normal Processing

\begin{tabular}{|c|c|c|c|c|}
\hline $\begin{array}{l}\text { Glovebox } \\
\text { Process Operations } \\
\end{array}$ & $\mathrm{Pu}, \mathrm{g}$ & ${ }^{235} \mathrm{U}, \mathrm{g}$ & Physical Form & Chemical Compounds (a) \\
\hline Batching, Slugging & 225 & 540 & Powder & $A, B$ \\
\hline Carbothermic & 0 to 120 & 0 to 350 & Slugs & $A, B, C$ \\
\hline Size reduction & 0 to 120 & 0 to 350 & Powder & $\mathrm{C}$ \\
\hline Sintering & 0 to 120 & 0 to 350 & Pellets & C \\
\hline $\begin{array}{l}\text { Pressing and } \\
\text { inspection }\end{array}$ & 0 to 120 & 0 to 350 & $\begin{array}{l}\text { Powder and } \\
\text { pellets }\end{array}$ & C \\
\hline Coulometry & 10 & 40 & $\begin{array}{l}\text { Dissolved in } \\
\text { solutions }\end{array}$ & $A, B, C$ \\
\hline $\begin{array}{l}\text { Emission } \\
\text { Spectroscopy }\end{array}$ & 1 & 1 & $\begin{array}{l}\text { Crushed } \\
\text { pellets }\end{array}$ & $A, B, C$ \\
\hline Carbon analysis & 20 & 80 & Powder & $A, B, C$ \\
\hline Metallography & 2 & 8 & Pellets & $\mathrm{C}$ \\
\hline Metallography & 20 & 80 & Pellets & C \\
\hline Oxygen analysis & 2 & 5 & $U-P u-P t$ & $C$ \\
\hline Thermogravimetric & 100 & 400 & $\begin{array}{l}\text { Solidified } \\
\text { waste }\end{array}$ & $\begin{array}{l}\text { Analytical solutions } \\
\text { solidified in ben- } \\
\text { tonite clay--stored } \\
\text { until disposed of }\end{array}$ \\
\hline Storage of Fuel & 0 to 360 & 0 to 1050 & Pellets & $\mathrm{C}$ \\
\hline
\end{tabular}

Pellets

(a) $A=P u 0_{2}, B=U 0_{2}, C=\operatorname{Mixed}\left(P u \frac{U}{1} U\right)$ Carbide 
License limits restrict plutonium inventory to $3.5 \mathrm{~kg} / \mathrm{fH}$ in the 820 building, and $13 \mathrm{~kg} \mathrm{Pu}$ in the 055, Buliding. Fifteen hundred $\mathrm{kg} 235 \mathrm{U}, 5 \mathrm{~kg} 233 \mathrm{U}$; and $1 \mathrm{~kg}{ }^{239} \mathrm{Pu}$, and $0.5 \mathrm{~kg}{ }^{238} \mathrm{Pu}$ as sealed sources are allowed in the license.

Hazardous and Combustible Inventory

In the 020 building, waste such as plastic, paper towels, and gloves is generated in the decladding ${ }_{3}$ process. Alcohol and other cleaning liquids are limited to less than $500 \mathrm{~cm}^{3}$ in a hot cell at one time.

Diesel fuel is stored in an underground tank and an aboveground 50-gal tank, both outside the 055 Building. Flammable liquids such as benzene, methanol and vacuum pump oils are stored in a metal cabinet outside the west wall of the building and brought into the building in quantities less than 5 gal. Glove boxes have Plexiglas ${ }^{\circledR}$ windows and may contain plastic bagging material, neoprene gloves and pump oil. Waste material is stored in 55-gal drums. An inventory of combustible materials found in the glove box room is shown in Table H.4. Natural gas is used for space heating in both facilities.

TABLE H.4. Amounts of Combustible Materials in Glove Box Room

\begin{tabular}{|c|c|c|}
\hline Material & Norma 1 Amount & Maximum Amount \\
\hline Methanol & $500 \mathrm{~cm}^{3}$ & $1000 \mathrm{~cm}^{3}$ \\
\hline Vacuum oil & 20 gal & $20 \mathrm{gal}$ \\
\hline Lapping oil & $500 \mathrm{~cm}^{3}$ & $1000 \mathrm{~cm}^{3}$ \\
\hline Epoxy & $1 \mathrm{qt}$ & $2 \mathrm{qt}$ \\
\hline Paper towels & $101 \mathrm{~b}$ & $151 \mathrm{~b}$ \\
\hline PVC sheet & $1001 \mathrm{~b}$ & $2241 \mathrm{~b}$ \\
\hline PVC bags & $301 \mathrm{~b}$ & $401 \mathrm{~b}$ \\
\hline Spray paint & $30 \mathrm{oz}$ & $40 \mathrm{oz}$ \\
\hline $\mathrm{Film}$ & $0.51 \mathrm{~b}$ & $1.01 \mathrm{~b}$ \\
\hline Sodium & $50 \mathrm{~g}$ & $200 \mathrm{~g}$ \\
\hline
\end{tabular}

\section{H.4 WESTINGHOUSE ELECTRIC CORPORATION, WALTZ MILL, PENNSYLVANIA}

The Westinghouse Waltz Mill facility provides a wide variety of research, development, and analysis of nuclear materials. Information on the Waltz Mill site is obtained from a Westinghouse Electric Corporation report (1980) and from other docket information. 
Operation

Nuclear material is received and stored in the transfer building (Figure H.6), which contains a large pool for underwater shielding. Small samples of material are then transferred to other laboratories on site for analyses.

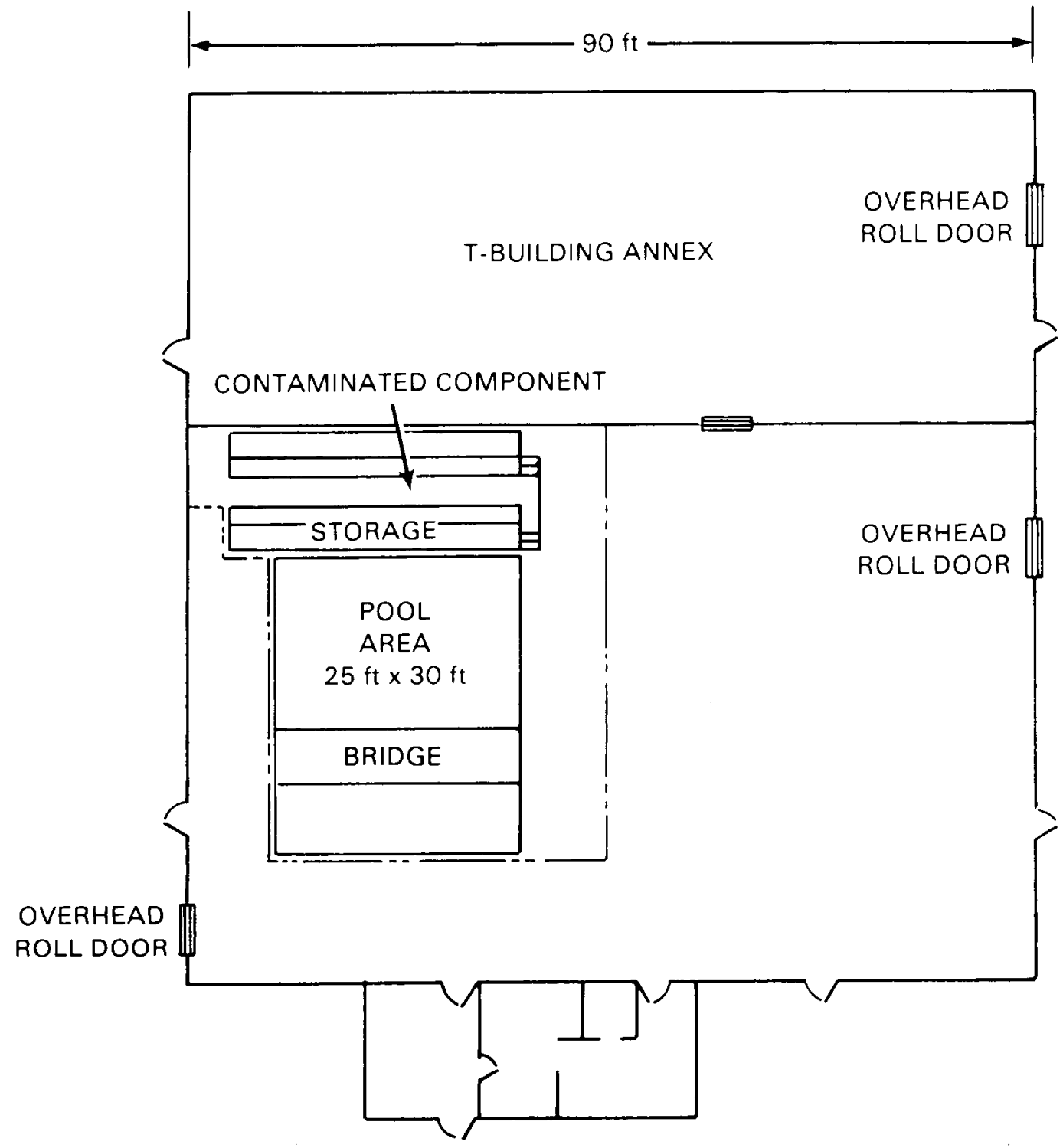

FIGURE H.6. Waltz Mill Transfer Building Floor Plan 
Analytical laboratories contain glove boxes, fume hoods, storage vaults and a variety of analytical instruments. Analyses performed include gamma spectrometry, mass spectrometry, and analysis of alkali metals. In the sodium technology laboratories, various experiments investigating the performance of selected materials and behavior of fission products in a liquid sodium environment are performed.

Waste Disposal

Radioactive liquid waste is stored in two 120,000-gal retention basins and processed once a year through activated charcoal, ion exchange resins, or a chemical treatment decontamination system. pad.

Solid waste is packaged in DOT-approved containers and stored on a waste

\section{H.4.2 Facility Description}

Buildings

Four buildings handle radioactive materials. These are the transfer building, reactor service building, analytical laboratories, and sodium technology laboratories. Diagrams of these facilities are shown in Figures H.6 through H.9.

The reactor service building is of brick and concrete construction. Radioactive material in the building is in the form of residual contamination of field service equipment in the building's decontamination and repair area.

The analytical laboratories are housed in a brick and cement block building. A shielded vault is located in the building for storage of radioactive materials.

The sodium technology laboratories are in a concrete and steel building. Millicurie quantities of selected isotopes are handled in the laboratories. A shielded vault is provided to store radioactive materials.

\section{HVAC Systems}

Hoods may have separate ventilation systems. Prefilters and HEPA filters are used to remove particles. Glove boxes and hoods are kept at negative pressure except those handling sodium with microcurie to millicurie amounts of radioactivity. These are under inert atmosphere at slightly positive pressure. Air exhaust systems are constructed of non-combustible material. The HEPA filters are either flame retardant or noncombustible and are designed to withstand a minimum of $3.4 \mathrm{lb} / \mathrm{in}^{2}$ overpressure and $350^{\circ} \mathrm{F}$. 
Figineered Safety Systems

Several fire hoses, 1-1/2 in. in diameter, are available within the buildings and sprinklers are provided at strategic locations. Fire extinguishers including $\mathrm{CO}_{2}$, water, and dry chemical are located at appropriate locations throughout the facility.

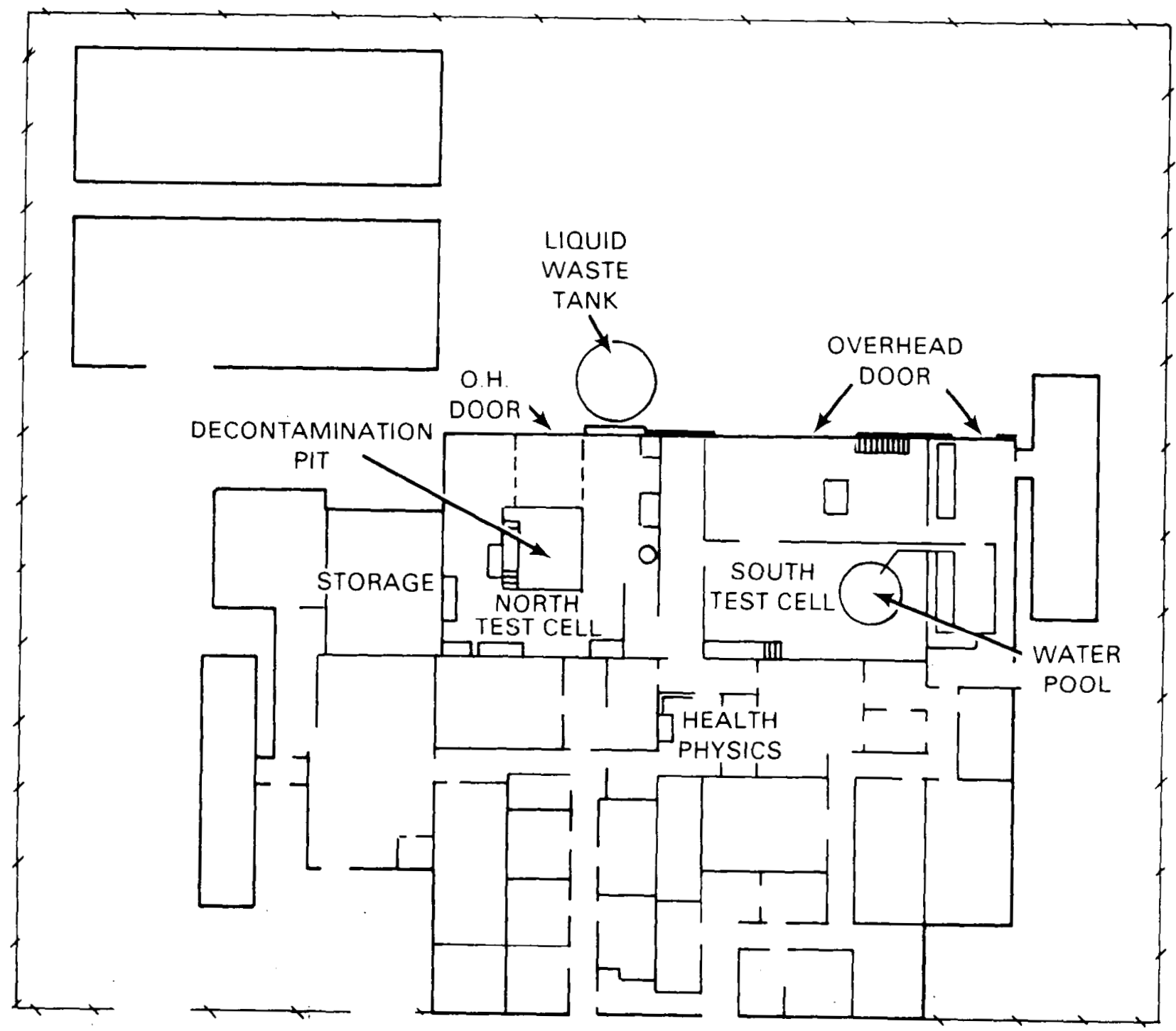

FIGURE H.7. Reaçtor Service Waltz Mill Building Floor Plan 


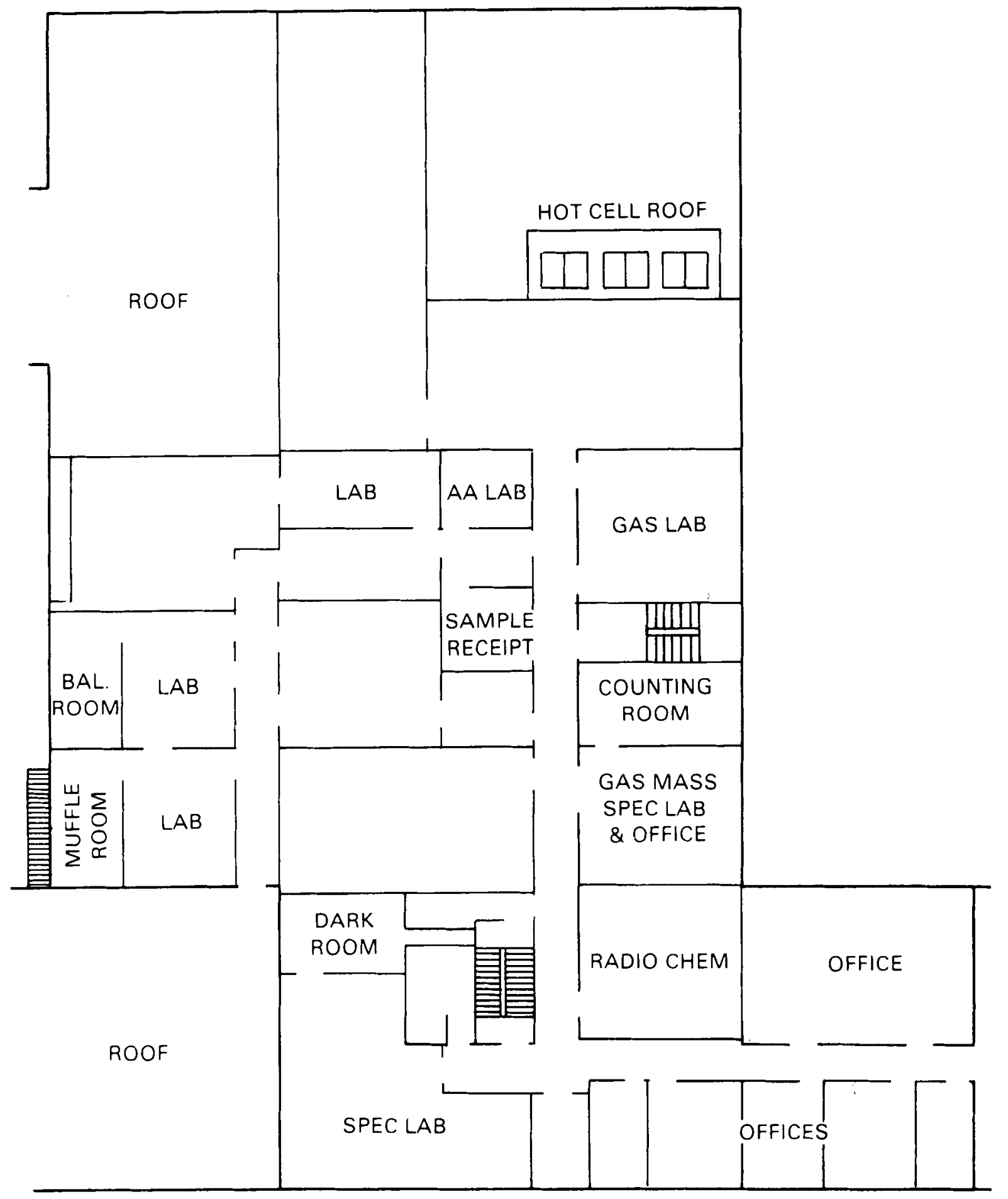

FIgURE H.8. Waltz Mill Analytical Laboratories Second Floor G Building 


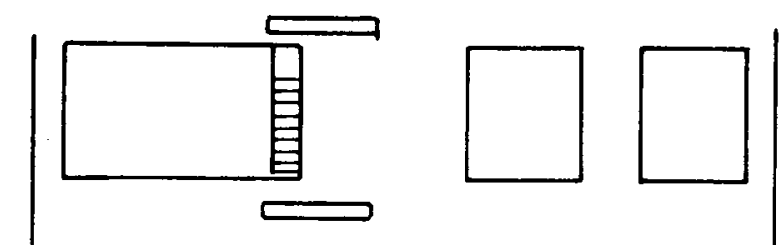

C BUILDING

SODIUM TECHNOLOGY

LOOP AREA

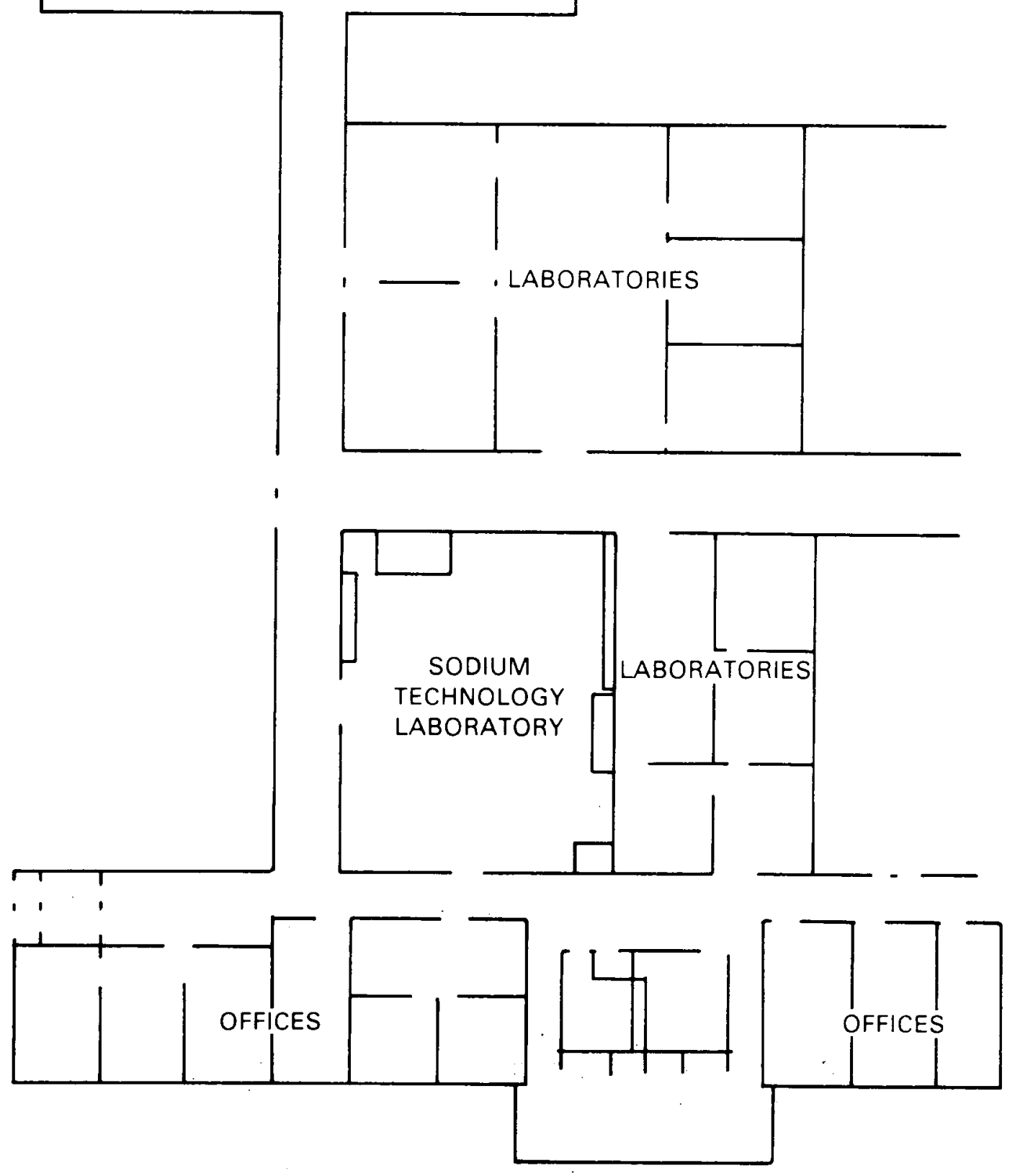

FIGURE H.9. Waltz Mill Sodium Technology Laboratories and C Building 
Gamma alarms are located in various areas of the facility as well as continuous air monitors.

Fire alarms are located throughout the facility.

Surrounding Area

The Waltz Mill facility is located on 850 acres in a sparsely settled area about 20 miles SE of the Pittsburgh suburbs.

\section{H.4.3 Inventory}

Radioactive Inventory

The reactor service building has only residual contamination on field service equipment. Control limits for radioactive materials in the analytical and sodium technology laboratories are given in Table H.5.

\section{H.5 REFERENCES}

Babcock and Wilcox, Demonstration and Conditions for License SNM-778, Docket No. 70-824, U.S. Nuclear Regulatory Commission, washington, D.C., 1978.

Babcock and Wilcox, Apollo Site Radiological Contingency Plan, SNM-145, Docket No. 70-135, U.S. Nuclear Regulatory Commission, Washington, D.C., 1981.

Isotopic Analysis, Inc., Letter from Isotopic Analysis, Inc. to U.S. Nuclear Regulatory Commission, Docket No.70-854, U.S. Nuclear Regulatory Commission, Washington, D.C., 1976.

Mishima, J. and J. E. Ayer, Esimated Airborne Release of Plutonium from Atomics International's Nuclear Materials Development Facility in the Santa Susana Site, California, as a Result of Severe Wind and Earthquake Hazard, PNL-3935, Pacific Northwest Laboratory, Richland, Washington, 1981.

Rockwel1 International, Environmental Impact Assessment of Operations at Atomics International Under Special Nuclear Material License No. SNM-21, AI-76-21, Rockwell International, Atomics International Division, Canoga Park, California, 1976.

Rockwell International, Onsite Radiological Contingency Plan for Rockwell International Operations Licensed Under Special Nuclear Material License No. SNM-21, ESG-81-30, Rockwell International, Energy Systems Group, Canoga Park, California, 1981.

Westinghouse Electric Corporation, Application for Renewal of SNM-770, Docket No. 70-696, U.S. Nuclear Regulatory Commission, Washington, D.C., 1980. 
TABLE H.5. Limits on Amounts of Radioactive Materials at the Waltz Mill Laboratories

\begin{tabular}{|c|c|c|c|c|}
\hline Location & Element & Isotope & Amount, $\mathrm{C} i$ & $\mathrm{~g}$ \\
\hline \multirow[t]{10}{*}{$\begin{array}{l}\text { Analytical } \\
\text { Laboratories }\end{array}$} & Uraniuin & $235 \mathrm{U}$ & $\begin{array}{l}0.5 \\
7.2 \times 10^{-4}\end{array}$ & 344 \\
\hline & Plutonium & irradiated & 0.5 & \\
\hline & & $239 \mathrm{Pu}$ & 0.3 & 5 \\
\hline & Strontium & ${ }^{90} \mathrm{Sr}$ & 0.1 & \\
\hline & Iodine & 131 & 0.1 & \\
\hline & Cobalt & ${ }^{60} \mathrm{Co}$ & 0.1 & \\
\hline & Cesium & ${ }^{137} \mathrm{Cs}$ & 0.1 & \\
\hline & & ${ }^{134} \mathrm{Cs}$ & 0.1 & \\
\hline & Neptunium & ${ }^{237} \mathrm{~Np}$ & 0.1 & \\
\hline & Others & & $\begin{array}{l}0.1 \text { each not to exceed } \\
5 \mathrm{Ci} \text { of all nuclides }\end{array}$ & \\
\hline \multirow[t]{13}{*}{$\begin{array}{l}\text { Sodium Technology } \\
\text { Laboratories }\end{array}$} & $\begin{array}{l}\text { Strontium } \\
\text { Cobalt }\end{array}$ & ${ }^{90} \mathrm{Sr}$ & $\begin{array}{l}0.1 \\
0.1\end{array}$ & \\
\hline & Cobalt & ${ }^{58} \mathrm{Co}$ & 0.1 & \\
\hline & Iodine & $131_{I}$ & 0.1 & \\
\hline & Cesium & ${ }^{137} \mathrm{Cs}$ & 0.1 & \\
\hline & & ${ }^{134} \mathrm{Cs}$ & 0.1 & \\
\hline & Manganese & $54 \mathrm{Mn}$ & 0.1 & \\
\hline & Barium & $133 \mathrm{Ba}$ & 0.1 & \\
\hline & Sodium & ${ }^{22} \mathrm{Na}$ & 0.1 & \\
\hline & Krypton & $85 \mathrm{Kr}$ & 0.1 & \\
\hline & Xenon & $135 \times e$ & 0.1 & \\
\hline & Others & & $\begin{array}{l}0.1 \text { each not to exceed } \\
5 \mathrm{Ci} \text { of all nuclides }\end{array}$ & \\
\hline & Uranium & $\begin{array}{l}235_{U} \\
233_{U}\end{array}$ & & $\begin{array}{r}344 \\
1\end{array}$ \\
\hline & Plutonium & ${ }^{239} \mathrm{Pu}$ & & 5 \\
\hline
\end{tabular}


$\Theta$

APPENDIX I

WASTE WAREHOUSING

$\vartheta$ 
WASTE WAREHOUSING

I.1 ATOMIC DISPOSAL, INC., TINLEY PARK, ILLINOIS

The Atomic Disposal facility in Tinley Park, Illinois, receives and stores radioactive waste for a short period of time until it is shipped to a licensed burial ground. Information on this facility was obtained from an Atomic Disposal report (1980).

\section{I.1.1 Process Description}

Operation

Radioactive waste in 55-, 30-, and 5-gal barrels is picked up at the customer's facility and transported to a warehouse in Tinley Park. The waste in the drums if primarily liquid scintillation vials containing toluene and benzene with ${ }^{14} \mathrm{C}$ and ${ }^{3} \mathrm{H}$ contaminants. Absorbed liquids, animal carcasses, dry wastes, and some bulk liquids are also stored.

Drums may be opened and repackaged at the warehouse to ensure integrity of barrels before shipment off site.

\section{I.1.2 Facility Description}

\section{Buildings}

The storage warehouse shown in Figure $I .1$ is 50.5 by $40.5 \mathrm{ft}$ with a ceiling over $9 \mathrm{ft}$ tall. An overhead door and an emergency exit provide openings to the outside. An office is located inside the warehouse which has an opening to the storage area and to the outside. A drum handling area (15 by 15 by $9 \mathrm{ft}$ high) is proposed to be built in one corner of the warehouse.

The walls of the warehouse are 6-in. cinderblock. The drum-handling room is designed to have two walls and the ceiling of 1/8-in.-thick clear cast acrylic sheet. The other two walls are warehouse walls.

\section{HVAC Systems}

The opening and repackaging area to be built (drum-handling room) includes four fume absorbers drawing $234 \mathrm{ft}^{3} / \mathrm{min}$ from the room or about seven air changes per hour. The system draws the air through $98 \%$ efficient charcoal filters.

\section{Engineered Safety Systems}

An automatic sprinkler system and fire extinguishers are present in the warehouse. Monitoring systems are also available, primarily for the drumhandling room. 
WALL (TO CEILING)

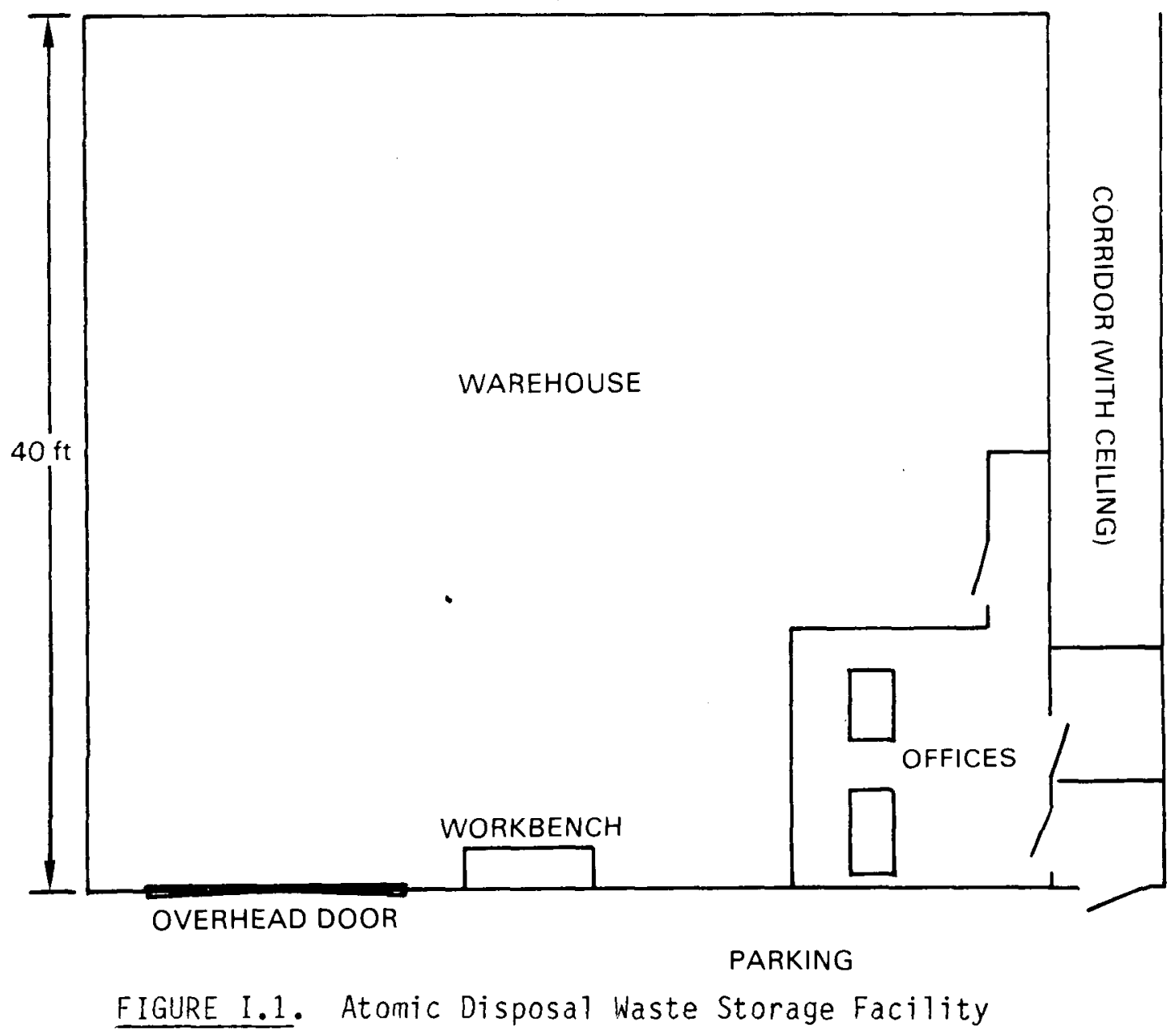

Surrounding Area

The storage warehouse is located in an industrial center. Activities within the industrial center are not specified. No estimate can be made on the possible impact of neighboring facilities on the warehouse.

\subsubsection{Inventory}

Atomic Disposal is amending its license limit to read:

- $25 \cdot \mathrm{Ci}$ by-product material

- $100 \mathrm{~kg}$ source material

- $1,900 \mathrm{~kg}$ source material at temporary job sites in the United States

- 75 g total of $235 \mathrm{U}$ and $233_{\mathrm{U}}$. 
A typical inventory in the warehouse is shown in Table I.1.

\section{TABLE I.1. Typical Inventory at Atomic Disposal}

Number of Barrels (a)

\begin{tabular}{|c|c|c|}
\hline Avg. & Range & \\
\hline & 1,200 to 1,500 & $\begin{array}{l}\text { Liquid } \\
\text { (tolue }\end{array}$ \\
\hline $\begin{array}{l}200 \\
200\end{array}$ & & $\begin{array}{l}\text { Absorb } \\
\text { Animal }\end{array}$ \\
\hline 50 & 400 to 800 & $\begin{array}{l}\text { Dry wa } \\
\text { Bulk }\end{array}$ \\
\hline 2300 & 2,000 to 2,700 & Total \\
\hline & $\begin{array}{l}\text { of barrels are } \\
\% \text { are } 30 \text { gal } \\
\text { ew are } 5 \text { gal }\end{array}$ & $55 \mathrm{ga}$ \\
\hline
\end{tabular}

The primary isotopes present in the drums and total activity present in storage are given in Table I.2.

TABLE 1.2. Drummed Inventory at Atomic Disposal

Ci Present

$\frac{\text { Element }}{\text { Carbon }} \frac{\text { Isotope }}{{ }^{14} \mathrm{C}} \frac{\text { (in 2,200 drums) }}{0.85}$

Chromium

${ }^{51} \mathrm{Cr}$

0.63

Hydrogen

$3 \mathrm{H}$

Iodine

125

15

Iodine

$131_{1}$

3.0

Molybdenum

${ }^{99} \mathrm{Mo}$

Mixed

Mixed

${ }^{99 m_{T C}}$ and $131_{\text {I }}$ Radionuclides

Phosphorous $\quad 32$

0.21

Sulfur

${ }^{35} \mathrm{~S}$

0.91

Technetium

${ }^{99} \mathrm{TC}$

1.55

0.80

Xenon

$133 \mathrm{xe}$

1.20

0.085 
Hazardous and Combustible Inventory

Protective clothing (which is combustible) is required when working in the repackaging area. The waste in the drums contains solvents, cellulosics, and other combustibles.

\section{I.2 INTEREX CORPORATION, NATICK, MASSACHUSETTS}

The Interex facility in Natick, Massachusetts, is used to store low-level radioactive waste temporarily until it is shipped to a licensed burial ground. Information on this facility was obtained from docket material (Interex Corporation 1971-1977).

\section{I.2.1 Process Description}

Operation

Radioactive waste packaged by the customer in 5-, 30-, or 55-gal drums is transported by Interex to the storage site in trucks. The waste is stored for a maximum of 6 months before being moved by a licensed carrier to a licensed burial ground.

Interex is not authorized to open waste containers at any time. Smear tests are taken and inspections made to ensure the level of radioactivity does not exceed that posted by the customer.

\section{I.2.2 Facility Description}

Buildings

Waste is stored in a trailer shown in Figure I.2 to the rear of the main building. Dimensions are 15 by $40 \mathrm{ft}$. No additional information on materials of construction and capacity of the trailer is available from the docket.

Two other buildings had previously been used for storage. The original storage area was in two-story cinderblock and stucco building. The storage area occupied $624 \mathrm{ft}^{2}$ of the first floor, and had a loading door and four windows protected by heavy steel mesh. Ceilings were $10 \mathrm{ft}$ high.

The second storage building was an annex to the original and had a poured cement foundation with corrugated metal walls and roof. The walls were $12 \mathrm{ft}$ high and the ceiling peaked at $17 \mathrm{ft}$. The two windows were protected by heavy steel mesh wire. The storage area occupied about $850 \mathrm{ft}^{2}$ of the total building.

\section{HVAC Systems}

The only indication of a HVAC system given in the docket material is a reference to the procedure to follow in the event of an accident. The procedure indicates that all ventilation including fans, ducts, and windows should be shut off. 


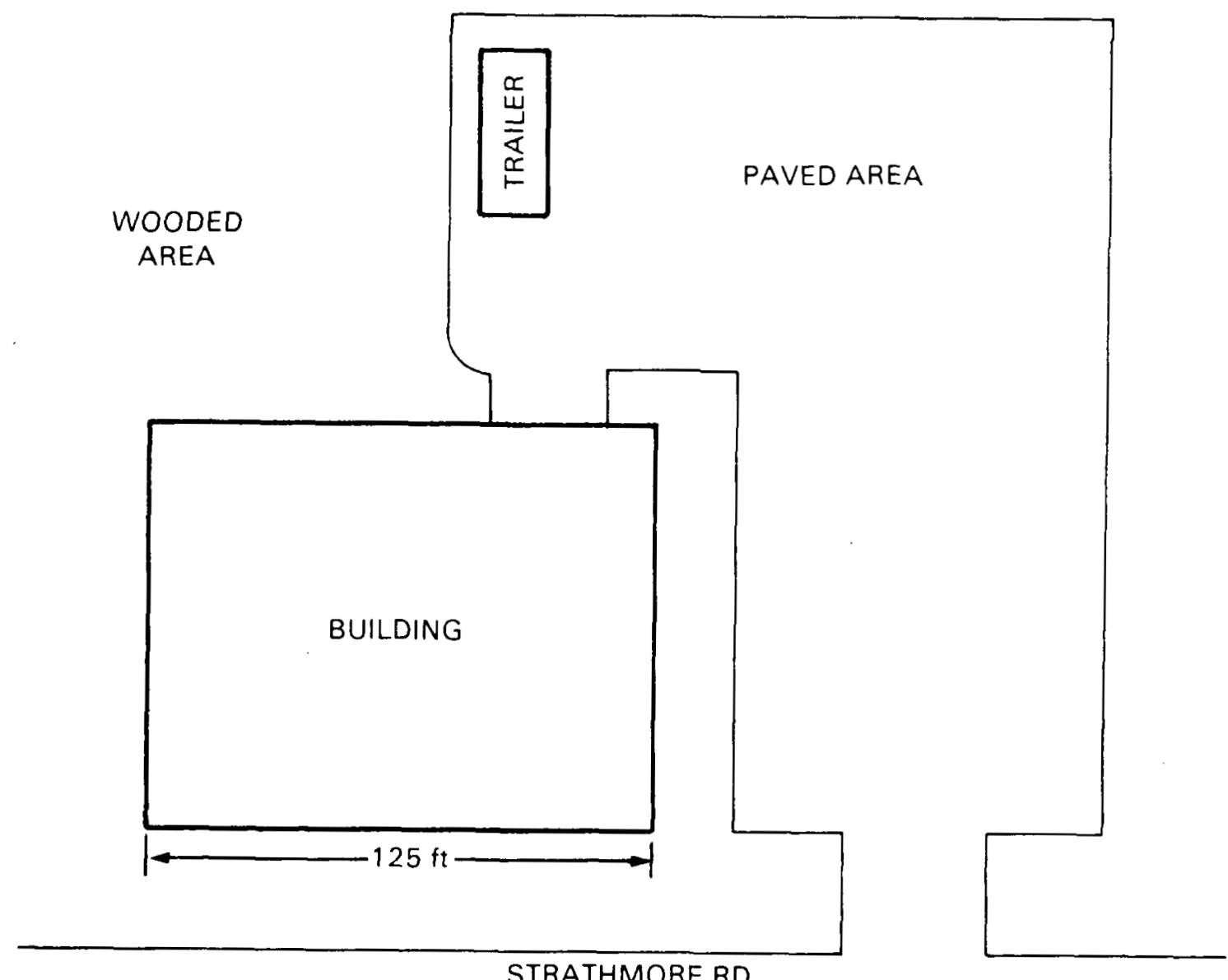

FIGURE I.2. Interex Waste Storage Building

\section{Engineered Safety Systems}

The original storage area was equipped with a sprinkler system. Information was not available on whether the current storage trailer contains any engineered safety systems. Radiation surveys of the facilities are done at intervals. Personnel are monitored weekly.

Surrounding Areas

The storage area is next to the main building, which is assumed to contain offices and labs. A wooded area surrounds the storage trailer. 


\section{I.2.3 Inventory}

Radioactive Inventory

Possession limits are listed in Table I.3. The external radiation level of most drums does not exceed $2 \mathrm{mrem} / \mathrm{hr}$.

TABLE 1.3. Possession Limits at Interex Corporation

$\begin{array}{lr}\text { Material } & \frac{\text { Amount }}{2000 \mathrm{Ci}} \\ { }^{3} \mathrm{H} & 2000 \mathrm{Ci} \\ \text { other than } \mathrm{H}^{3} & 500 \mathrm{lb} \\ \text { Source material } & 100 \mathrm{~g}\end{array}$

Only radioactive solids are accepted. No liquids, gases, or pyrophoric or explosive material are received, except for the following:

1) Liquids in scintillation vials are accepted in 55-gal drums if the drum contains at least twice the absorbent needed to absorb the liquid. The drum is marked. For example, a 30-gal drum holds $2,00020 \mathrm{~cm}$ vials with $10 \mathrm{~cm}^{3}$ fluid each and with $75 \mathrm{lb}$ of absorbent material.

2) Animal carcasses in preservative in plastic bags are considered solid. They must be in 55-gal marked drums.

3) Small amounts of liquids may be converted to a solid by adding absorbent. No liquid must be released when absorbent is compressed.

Hazardous and Combustible Inventory

Little information was given for this facility except that no pyrophoric or explosive material is accepted in the drums.

Most waste is from hospitals and clinical labs. Radioactive wastes expected from these facilities are contaminated rubber gloves, cellulosic materials, glassware, plastic, animal carcasses, and some liquid wastes packed in absorbent.

\section{I.3 TELEDYNE ISOTOPES, INC., WESTWOOD, NEW JERSEY}

The purpose of the Teledyne Isotopes facility in Westwood, New Jersey, is to receive and store radioactive waste temporarily for a maximum of 6 months until it is shipped to a licensed burial ground. Information on this facility was taken from docket material (Teledyne Isotopes, Inc. 1968-1981). 


\section{I.3.1 Process Description}

Operation

Radioactive waste is received at the customer's facility. A swipe test is made and containers are monitored. Containers reading in excess of $200 \mathrm{mR} / \mathrm{hr}$ at the surface and $10 \mathrm{mR} / \mathrm{hr}$ at $1 \mathrm{~m}$ must be repackaged before acceptance. The container is marked as to its contents and radiation level, sealed, and transported to the waste storage site. Drums are monitored during storage and transported to a licensed radioactive waste burial ground within 6 months.

Three sizes of containers are used: 5, 30, and 55 gal. Radioactive waste may be in the form of animal carcasses preserved in formalin in plastic bags, scintillation vials packed in an absorbent, and other contaminated laboratory equipment. The storage area is separated according to containers holding animal carcasses, containers with a dose greater than $10 \mathrm{mR} / \mathrm{hr}$, and all other containers.

Teledyne is not authorized to open waste containers.

\section{I.3.2 Facility Description}

\section{Buildings}

The storage building at 103 woodland Avenue is 24.5 by $38.5 \mathrm{ft}$ with a total area of $950 \mathrm{ft}^{2}$ and a ceiling height of $12 \mathrm{ft}$. Seven windows and two doors are located along the walls of the building. One door is a rollup door and the windows are 4 by $4 \mathrm{ft}$.

The storage building is constructed of concrete block with a ceiling covered in 5/8-in.-thick fire-retardant sheet rock panels.

Former storage operations took place in a warehouse in Avon, Ohio. This building was also concrete block with steel mesh windows and surrounded by a 6-ft-high cyclone fence.

\section{HVAC Systems}

The ventilation system for the 103 Woodland storage building is not described. However, Teledyne was planning to use part of the 50 van Buren Avenue building as a storage location. The proposed area contained a selfsustained air system segregated from the remainder of the building.

\section{Engineered Safety Systems}

The 103 Woodland Storage building has an automatic fire alarm and extinguishing device using $\mathrm{CO}_{2}$. 
Surrounding Area

The waste storage building is located next to a radiochemistry building operated by Teledyne Isotopes and on the corner of two streets. Other buildings and operations in the area are not identified in the docket information.

\section{I.3.3 Inventory}

Radioactive Inventory

Possession limits are listed in Table I.4.

Radioactive waste may be in the form of contaminated animal carcasses preserved in formalin, put in plastic bags, and drummed, or scintillation vials filled with $12.5 \mathrm{~L}$ of liquid and packed in adsorbent, or other lab wastes such as contaminated gloves, wipes, glass and plastic lab equipment, and clothing. Hazardous and Combustible Inventory

Combustibles in the form of contaminated gloves, rags, cellulosic materials, and plastic bags may be part of the waste in the drums.

TABLE I.4. Possession Limits at Teledyne Isotopes, Inc.

$\begin{array}{lr}\frac{1}{\text { Material }} & \frac{\text { Limit }}{750 \mathrm{Ci}} \\ \text { By-product material } & 5,000 \mathrm{Ci} \\ 3_{\mathrm{H}} & 12,500 \mathrm{lb} \\ \text { Source material } & 200 \mathrm{~g}\end{array}$

\section{I.4 REFERENCES}

Atomic Disposal Co., Appendix A, Emergency Plan for Atomic Disposal Co. Tinley Park, Illinois, Atomic Disposal Co., Tinley Park, Illinois, 1980.

Interex Corporation, License Application Information, Docket No. 30-7725, U.S. Nuclear Regulatory Commission, Washington, D.C., 1971-1977.

Teledyne Isotopes, Inc., License Application Information, Docket No. 30-8681, Nuclear Regulatory Commission, Washington, D.C., 1968-1981. 
APPENDIX J

UNIVERSITY RESEARCH AND DEVELOPMENT 
J.1 HARVARD UNIVERSITY, CAMBRIDGE, MASSACHUSETTS

Harvard University uses radioactive isotopes for research and development in hospitals, medical and dental schools, and animal research centers. Information on this facility was taken from docket material (Harvard University 1965-1981).

\section{J.1.1 Process Description}

Operation

Isotopes are assumed received at a central point and distributed to users. Isotopes are used to perform iodinations and inject animals. Iodinations are performed in glove boxes attached to hoods equipped with a charcoal filter for outlet air.

Animal injections are performed on trays lined with absorbent paper. Animals are then kept in labeled cages while under study.

Some radioisotopes are handled in special labs equipped with cave boxes. The boxes have remote tongs, $1-1 / 2$ in. of lead shielding, lead glass viewing windows, and absolute filters for the exhaust.

Waste Disposal

The Environmental Health and Safety group regulates the distribution and disposal of wastes at Harvard. Liquid wastes are either discharged into the sewer if activity is under the required level, or neutralized to a $\mathrm{pH}$ of 6 to 8 and stored in nonbreakable bottles, such as polyethylene, before being disposed of by a commercial waste company.

Solid wastes with low activity, such as animal carcasses and combustibles, are incinerated in the power house incinerator. Some animal carcasses are bagged and stored in a freezer, then. sent to the primate center for burial.

About $90 \%$ of the radioactive waste generated is packed in 30-gal metal barrels and stored in a storeroom in the Harvard Medical School before removal by a commercial disposal firm.

\section{J.1.2 Facility Description}

$\underline{\text { Buildings }}$

Some radioisotope labs have cave boxes with 1-1/2-in.-thick lead shielding, arid lead viewing windows. 


\section{HVAC Systems}

Charcoal filters are used for iodination processes. Areas handling volatile materials are equipped with extra ventilation equipment, such as hoods, to prevent build-up of radioactive materials.

\section{Engineered Safety Systems}

Fire extinguishers are located close to metal waste baskets in the labs and at various locations in the facilities. The recommended method of handling fires in glove boxes or hoods is to cut off air supply to the unit by shutting off ventilation and closing openings.

\section{j.1.3 Inventory}

\section{Radioactive Inventory}

Iodinations involve up to $10 \mathrm{mC}$ i of ${ }^{125}$ I at one time. License limits for radioactive material at Harvard University are shown in Table J.1.

Hazardous and Combustible Inventory

Gloves, plastic bags, absorbent material, animal carcasses, and animal excreta are some of the combustible materials that may be contaminated and may be found in the labs or waste storage.

\section{J.2 MICHIGAN STATE UNIVERSITY, EAST LANSING, MICHIGAN}

Michigan State University (MSU) uses radioisotopes for research and development studies on plants and animals. Some diagnosis and therapy is performed. Information on this facility was obtained from docket material (Michigan State University 1963-1981).

\section{J.2.1 Process Description}

\section{Operations}

Radioactive materials are received and stored at a central location before distribution to users at 350 different labs on the MSU campus. Some of the ${ }_{32}$ and ${ }^{35} \mathrm{~S}$ in the form of amino acids and metabolites, which are used for entomology studies. Some of the processes are described below.

Carbon-14 is applied to marsh plants by acidifying 10 to $100 \mathrm{mC} i$ of $\mathrm{NaH}^{14} \mathrm{CO}_{3}$ in a closed chamber. The plant retains $5 \%$ of the activity. The study is done in situ.

Sulfur-35 is applied to codling moth eggs $(0.08 \mu \mathrm{Ci}$ total in 300 eggs). The eggs are placed in small apple trees. Later the larvae and apples are collected and studied. 
TABLE J.1. License Limits for Radioactive Materials at Harvard University

Element

Atamic No. $3-38$
Americium
Americium (sealed sourc
Californium (sealed sourc
Carbon
Cesium (sealed sources)
Cobalt (sealed sources)
Curium
Curium (sealed sources)
Hydrogen
Iodine

krypton

Phosphorous

Polonium

Strontium

Strontium (sealed sources)

Sulfur

Thorium

Xenon
I sotope $241_{A m}$

$241_{\text {Am }}$

${ }^{252} \mathrm{Cf}$

${ }^{14} \mathrm{C}$

${ }^{137} \mathrm{Cs}$

${ }^{60} \mathrm{Co}$

${ }^{244} \mathrm{Cm}$

${ }^{244} \mathrm{Cm}$

$3_{\mathrm{H}}$

125 I

$129 \mathrm{I}$

131

$85_{\mathrm{Kr}}$

$32 \mathrm{p}$

$210_{p_{0}}$

${ }^{90} \mathrm{Sr}$

$90 \mathrm{Sr}$

${ }^{35} \mathrm{~S}$

${ }^{238} \mathrm{Th}$

$133 \mathrm{xe}$
$\mathrm{Ci}$

1 each

$5 \times 10^{-3}$

0.5

$5.6 \times 10^{-3}$

10

10

20

$1 \times 10^{-3}$

$5 \times 10^{-2}$

300

2

$1 \times 10^{-3}$

3

10

3

$2 \times 10^{-2}$

$5 \times 10^{-2}$

1

5

$1.5 \times 10^{-2}$

10

A bone mineral analyzer containing $400 \mathrm{mc}$ i of sealed ${ }^{125}$ I source is used for studies on humans and animals. The analyzer may be transported in the trunk of a car to areas within the state. The machine operates in a scanning inode.

A ${ }^{99} \mathrm{Mo}^{99 \mathrm{~m}_{\mathrm{TC}}}$ generator is stored in a special unit. The eluate ${ }^{99 \mathrm{~m}_{\mathrm{TC}}}$ is extracted and stored in a vial in a lead pig before use.

A ${ }^{90}$ Sr eye applicator is used on humans and animals. 


\section{Waste Disposal}

Liquid wastes are stored in disposable metal cans, polyethylene jugs, or glass carboys, which must be set in a large pan to contain spills. Solid wastes are stored within plastic liners in waste containers. Wastes are disposed of by a licensed firm. Short-lived materials are stored for decay at the MSU radioactive waste building before disposal with regular waste. Exhausted Mo/TC generators are decayed in storage for 15 half-lives or more before disposal.

\section{J.2.2 Facility Description}

Buildings

The radioisotope shipment storage area is approximately $6 \mathrm{ft}$ by $6 \mathrm{ft}$ and is located on the first floor of the Department of Public Safety building.

The storage room for the Mo/TC generator and other radioactive materials is in the MSU Clinical Center (shown in Figure J.1). Dimensions are about $14 \mathrm{ft}$ by $10 \mathrm{ft}$. A safe for the storage of radioactive materials has a volume of $1 \mathrm{ft}^{3}$ and has 2-in.-thick lead shielding. The nuclear medicine room containing a gamma camera is nearby. This room is about $17 \mathrm{ft}$ by $26 \mathrm{ft}$.

The lead shielding housing the Mo/Tc generator is also 2 in. thick. HVAC Systems

Radioactive materials are handled in hoods equipped to give a minimum of 100 linear feet per minute air flow.

\section{J.2.3 Inventory}

Radioactive Inventory

Table 0.2 lists the quantity of radioactive materials that Michigan State is licensed for.

\section{J.3 OHIO STATE UNIVERSITY, COLUMBUS, OHIO}

Ohio State University uses radioactive isotopes for research and development primarily in the area of nuclear medicine. Information on this facility was obtained from docket material (Ohio State University 1979).

\section{J.3.1 Process Description}

Operation

Ohio State has a radiopharmacy that dispenses radioactive materials for use in treatment and therapy of patients as well as medical research. This description emphasizes areas exclusive of the radiopharmacy since radiopharmacies are covered in another category. 


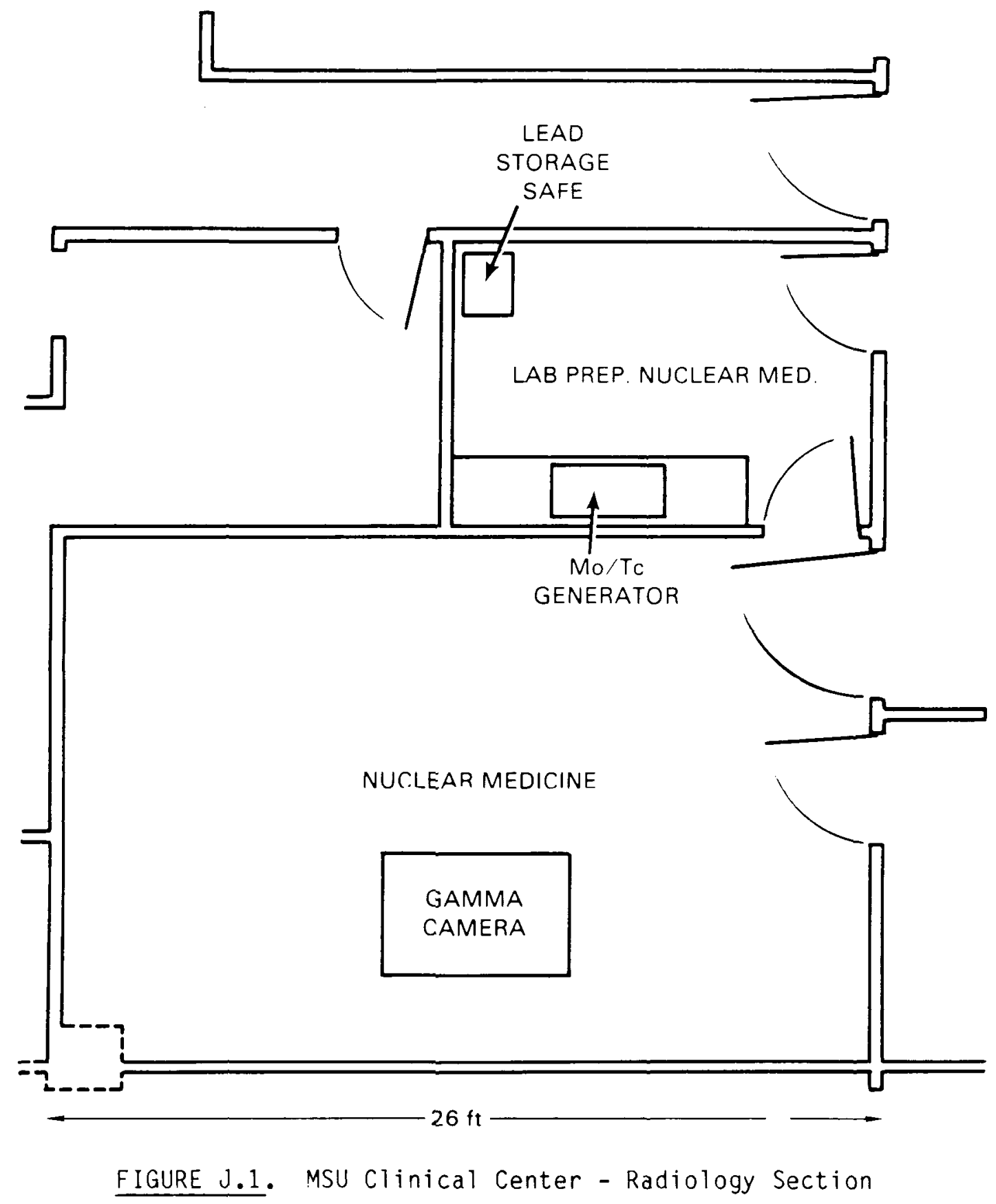

In the hospital, ${ }^{60} \mathrm{Co},{ }^{137} \mathrm{Cs},{ }^{198} \mathrm{Au}$, and ${ }^{192}$ Ir implantation in patients fakes place. Patients are kept hospifalized until the implant is removed. The

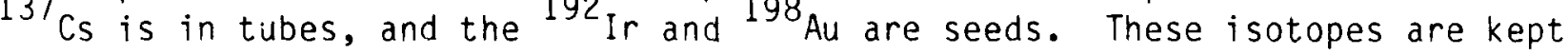
in a lead-lined safe until required. Then they are transported on carts lined with steel. Strontium-90 is also used for therapy. Strontium disks are stored in wooden boxes and used at the storage location. 
TABLE J.2. Radioactive Materials at Michigan State University

\begin{tabular}{|c|c|c|}
\hline Element & Isotope & $\mathrm{Ci}$ \\
\hline $\begin{array}{l}\text { By-product material with } \\
\text { atomic No. } 3-84\end{array}$ & & 10 total \\
\hline $\begin{array}{l}\text { By-product material with } \\
\text { atomic No. } 85-103\end{array}$ & & 0.25 \\
\hline Carbon $(a)$ & ${ }^{14} \mathrm{C}$ & $5 \times 10^{-3}$ \\
\hline Cesium (sealed sources) & & 0.1 max each source \\
\hline Hydrogen & $3_{H}$ & 300 \\
\hline Hydrogen (a) & $3_{H}$ & $1 \times 10^{-2}$ \\
\hline Iodine (sealed source) & $125 \mathrm{I}$ & 0.4 \\
\hline Molybdenum/Technetium & ${ }^{99} \mathrm{Mo} /{ }^{99 \mathrm{~m}} \mathrm{TC}$ & 1 generator \\
\hline Phosphorous & $32 p$ & $2 \times 10^{-3}$ \\
\hline Strontium & & 0.1 \\
\hline Sulfur $(a)$ & ${ }^{35} \mathrm{~s}$ & $2 \times 10^{-3}$ \\
\hline
\end{tabular}
(a) Isotopes used in entomology studies in the form of amino
acids and metabolites.

Iodine-131 and ${ }^{32} \mathrm{p}$ are injected as iodide and soluble phosphate respectively for treatment of diseases. The iodine is given in $30 \mathrm{mci}$ doses or less while the phosphorous is given in 0.5 to $5.0 \mathrm{mC} i$ doses.

Xenon-133 is given to patients in either a gaseous or saline form for blood flow studies. Doses of 10 to $30 \mathrm{mC} i$ are applied. Xenon is also used in a lab for respiratory studies. The gas is injected into apparatus in a hood in $28 \mathrm{mC} i$ quantities. The lungs of a dog are used in the experiment and then are disposed of by packaging in radioactive waste containers.

Waste Disposal

A commercial waste disposal service removes liquid waste, ${ }^{99} \mathrm{Mo}^{99 \mathrm{~m}_{\mathrm{Tc}}}$ generators, and other solid waste. Some solid waste is held for decay and disposed of as ordinary waste. Liquid waste below a specified radioactive limit is disposed of in a sewer.

\section{J.3.2 Facility Description}

Buildings

Room dimensions are listed in Table J.3. 
TABLE J.3. Room Dimensions of Labs at Ohio State University

\begin{tabular}{|c|c|c|}
\hline Room & Dimensions, $\mathrm{ft}$ & Volume, $\mathrm{ft}^{3}$ \\
\hline Nuclear pharmacy & 20 by 16 by 8 & 2560 \\
\hline In vitro room & 12 by 16 by 8 & 1500 \\
\hline Injection room & 5 by 16 by 8 & 640 \\
\hline$N-165$ & & 2000 \\
\hline$N-149$ & & 2400 \\
\hline
\end{tabular}

HVAC Systerns

Room ventilation for lab rooms in the nuclear medicine area was measured at:

17 to 30 linear $\mathrm{ft} / \mathrm{min}$ under open doors

80 to 300 linear $\mathrm{ft} / \mathrm{min}$ under closed doors

180 to 145 linear $\mathrm{ft} / \mathrm{min}$ from supply air

90 to 300 linear $\mathrm{ft} / \mathrm{min}$ from vents

Hood flow rates provide $600 \mathrm{ft}^{3} / \mathrm{min}$. About 9 air changes per hour are provided in the wing.

\section{J.3.3 Inventory}

Radioactive Inventory

Table J.4 gives the license limits of radioactive material at Ohio State as of December 1979.

Individual doses given to patients are $3 \times 10^{-2} \mathrm{Ci} 131 \mathrm{I}$ injected, $5 \times 10^{-4}$ to $5 \times 10^{-3} \mathrm{C}^{i}{ }^{32} \mathrm{P}$ injected, and $1 \times 10^{-2}$ to $3 \times 10^{-2} \mathrm{Ci} 133 \times$ Xe injected. Doses of $2.8 \times 10^{-2} \mathrm{Ci}{ }^{133} \dot{x}_{\mathrm{e}}$ are used for one set of experiments.

Chemicals and Hazardous Materials

Combustibles such as lab coats, gloves, wipes, and plastic bags can be found in the labs and hospital. Strontium sources in disks are kept in wooden boxes.

J.4 ORAL ROBERTS UNIVERSITY, TULSA, OKLAHOMA.

Oral Roberts University uses radioactive isotopes in research and development studies involving animals and biological tissue. Information on this facility was obtained from docket material (Oral Roberts University 1979-1981). 
TABLE J.4. License Limits at Onio State University

\begin{tabular}{|c|c|c|c|}
\hline Element & Isotope & Form/Use & $\mathrm{Ci}$ \\
\hline $\begin{array}{l}\text { By-product material } \\
\text { atomic No. } 3-83\end{array}$ & & $\begin{array}{l}\text { Medical research, diagnosis and } \\
\text { therapy }\end{array}$ & 10 any \\
\hline Americium & ${ }^{241} \mathrm{Am}$ & & 5 \\
\hline Californium & ${ }^{252} \mathrm{Cf}$ & Sealed sources & $1 \times 10^{-6} \mathrm{~g}$ \\
\hline \multirow[t]{2}{*}{ Cesium } & ${ }^{137} \mathrm{Cs}$ & Sealed source/R\&D & 1 \\
\hline & ${ }^{137} \mathrm{Cs}$ & Sealed source/storage & 44 \\
\hline \multirow[t]{2}{*}{ Cobalt } & $\begin{array}{l}60 \\
{ }^{60} \mathrm{Co}\end{array}$ & Sealed sources/training source & $3 \times 10^{-2}$ each \\
\hline & ${ }_{3}^{0} \mathrm{CO}$ & Sealed source/storage & 5 \\
\hline \multirow[t]{4}{*}{ Hydrogen } & ${ }^{{ }^{H}} \mathrm{H}$ & $\begin{array}{l}\text { Medical research, diagnosis } \\
\text { and therapy }\end{array}$ & 100 \\
\hline & ${ }^{3} \mathrm{H}$ & Sealed sources & 90 \\
\hline & $3_{H}$ & Gas & 500 \\
\hline & $3_{H}$ & $\begin{array}{l}\text { Tritiated compounds incorporated } \\
\text { into cells }\end{array}$ & 2000 \\
\hline Iodine & ${ }^{131} I$ & Iodide/medical treatment & 0.7 \\
\hline Krypton & ${ }^{85} \mathrm{Kr}$ & Sealed source & 1.5 \\
\hline Neptunium & ${ }^{237} \mathrm{~Np}$ & & 0.1 \\
\hline Nickel & ${ }^{63} \mathrm{Ni}$ & Sealed source & 1 \\
\hline Phosphorous & $32 p$ & $\begin{array}{l}\text { Soluble phosphate/medical } \\
\text { treatment }\end{array}$ & 0.1 \\
\hline Polonium & $210 p_{0}$ & & 100 \\
\hline Polonium & $210 p_{0}$ & Sealed source & 25 \\
\hline Strontium & ${ }^{90} \mathrm{Sr}$ & & 500 \\
\hline Xenon & ${ }_{133}^{13} \times e^{2}$ & Gas or saline/blood flow studies & 2000 \\
\hline Ytterbium & ${ }^{169} Y_{\mathrm{b}}$ & & 100 \\
\hline
\end{tabular}

\section{J.4.1 Process Description}

Operation

Several departments use radioisotopes in research studies. Isotopes are received and distributed from a central office. Some of the processes and studies are described below. 
Labeling of organic compounds such as cellular proteins, enzymes, and other biological materials takes place in labs. Iodinations may be performed in isolated hot labs.

Isotopes are injected into animals and animal tissue to study various biological processes. The animals are kept isolated in labeled cages during studies.

Americium-241 sources are used to eliminate static electricity in weighing cells during some studies.

Waste Disposal

Animal carcasses are stored in freezers until activity has decayed sufficiently to allow incinerations or disposal to a licensed burial site. Liquid waste is neutralized and stored in polyethylene bottles before disposal in 30-gal steel barrels. Solid wastes are packed in 5-, 30-, or 55-gal steel barrels, then shipped to a licensed disposal site.

\section{J.4.2 Facility Description}

Most of the labs are in one building, the Graduate Center. Room sizes are about 12 by $20 \mathrm{ft}$ to 10 by $12 \mathrm{ft}$.

The animal facilities containing rooms for surgery, necropsy, lockers, cage wash, and incinerator has an area of $46,000 \mathrm{ft}^{2}$. Animals containing radioactive material are kept in isolated rooms.

Labs are equipped with linoleum tile floors, vinyl-coated sheetrock walls, epoxy resin bench tops and metal casework.

HVAC Systems

Labs have hoods with absolute filters and flow rate capacities of $1300 \mathrm{ft} / \mathrm{min}$. The rooms have one or two air conditioning ducts as well as an outlet to the return air duct in the ceilings.

\section{J.4.3 Inventory}

Radioactive Inventory

Table 0.5 gives the license limits for radioactive material at Oral Roberts University. Organics are in the form of amino acids, carbohydrates, nucleosides, nucleotides, purines, pyrimidines, proteins, vitamins, and fatty acids. Inorganics are in water and hydride salts or appropriate acids.

Hazardous and Combustible Inventory

Rubber gloves, protective clothing, absorbent paper, and other combustible items can be found in the labs. 
TABLE J.5. License Limits at Oral Roberts University

\begin{tabular}{|c|c|c|c|}
\hline Element & \multirow{2}{*}{$\frac{\text { Isotope }}{241_{\text {Am }}}$} & Form/Use & $\mathrm{Ci}$ \\
\hline Americium & & & $1 \times 10^{-3}$ \\
\hline Cadmium & ${ }^{109} \mathrm{Cd}$ & & $2 \times 10^{-2}$ \\
\hline Calcium & ${ }^{45} \mathrm{Ca}$ & Inorganic & 0.1 \\
\hline Carbon & ${ }^{14} \mathrm{C}$ & Organic & 10 \\
\hline Cerium & ${ }^{141} \mathrm{Ce}$ & & $2 \times 10^{-2}$ \\
\hline Cesium & ${ }^{137} \mathrm{Cs}$ & Sealed source & $2 \times 10^{-2}$ \\
\hline Chlorine & ${ }^{36} \mathrm{Cl}$ & & $1 \times 10^{-2}$ \\
\hline Chromium & ${ }^{51} \mathrm{Cr}$ & Inorganic & 1 \\
\hline \multirow{2}{*}{ Hydrogen } & $3_{\mathrm{H}}$ & Organic & 15 \\
\hline & $3_{H}$ & Inorganic & 4 \\
\hline \multirow[t]{4}{*}{ Iodine } & ${ }^{125} \mathrm{I}$ & Inorganic & 4 \\
\hline & ${ }^{125} \mathrm{I}$ & Protein & 4 \\
\hline & $131_{I}$ & Inorganic & 0.2 \\
\hline & ${ }^{131_{I}}$ & Protein & 0.2 \\
\hline Iron & ${ }^{59} \mathrm{Fe}$ & Inorganic & 0.1 \\
\hline Nickel & ${ }^{63} \mathrm{Ni}$ & & $8 \times 10^{-3}$ \\
\hline \multirow[t]{4}{*}{ Phosphorous } & $32 p$ & Organic & 2 \\
\hline & $32 p$ & Inorganic & 2 \\
\hline & $33 p$ & Organic & 1.5 \\
\hline & $33 p$ & Inorganic & 1 \\
\hline Platinum & $195 m_{P t}$ & & 0.1 \\
\hline Potassium & $42_{k}$ & & $1 \times 10^{-2}$ \\
\hline Rubidium & $86_{\mathrm{Rb}}$ & & $1 \times 10^{-2}$ \\
\hline Scandium & ${ }^{46} \mathrm{Sc}$ & Foil & $2 \times 10^{-3}$ \\
\hline Strontium & ${ }^{85} \mathrm{Sr}$ & & $2 \times 10^{-3}$ \\
\hline \multirow[t]{2}{*}{ Sulfur } & ${ }^{35} s$ & Organic & 0.2 \\
\hline & ${ }^{35} \mathrm{~S}$ & Inorganic & 0.2 \\
\hline Technetium & ${ }^{99 m} \mathrm{Tc}$ & & $5 \times 10^{-2}$ \\
\hline Tin & ${ }^{113} \mathrm{Sn}$ & & $2 \times 10^{-2}$ \\
\hline Zinc & ${ }^{65} \mathrm{Zn}$ & & 0.2 \\
\hline
\end{tabular}


Organics are used in labeling processes in the labs and are in the forms mentioned under radioactive inventory.

J.5 UNIVERSITY OF ILLINOIS, URBANA, ILLINOIS

The University of Illinois uses radioisotopes for various research and development operations. Animal studies, diagnosis and therapy of veterinary diseases, soil sciences and plant studies are performed. Information on this facility was obtained from docket material (University of Illinois 1957-1981).

\section{J.5.1 Process Description}

Operation

Over 320 laboratories in 40 different buildings conduct studies using radioactive materials. The isotopes are ordered and received by a central health and safety group, which also collects and disposes of waste materials. Some of the research and development operations at the university are described below.

Iodinations involving 2 to $4 \mathrm{mC}$ i of ${ }^{125}$ I per reaction are performed in hoods on absorbent-lined metal trays. Disposable plastic lab equipment may be used for this operation.

Animals may be injected with various isotopes and studied. The cages are labeled and animal carcasses and excreta are monitored before disposal.

Americium-241 and ${ }^{137} \mathrm{Cs}$ are used off-campus as moisture and density gages and well-logging devices.

The ${ }^{60} \mathrm{Co}_{\mathrm{O}}$ and $1 \mathrm{mCi}{ }^{137} \mathrm{Cs}$ sources are used for training courses throughout the state.

Phosphorous-32 is used in soil science and plant and animal studies on experimental farm plots.

\section{Waste Disposal}

Combustible liquid waste is metered in with fuel oil and incinerated at a local power plant. This waste comes from liquid scintillation vials and contains 60 to $70 \%$ toluene, 30 to $40 \%$ xylene, 4 to $5 \%$ dioxane, and 1 to $10 \%$ water and miscellaneous compounds. About 1200 to $1500 \mathrm{gal} / \mathrm{yr}$ are generated.

Animal carcasses may be incinerated, shipped to a licensed burial site, or disposed of with sewage after grinding or chemical digestion.

Solid waste is disposed of through a commercial waste disposal firm. Liquid waste that is not incinerated may be disposed of in a sewer if activity is below a certain level. Otherwise it may be solidified in cement or plaster of Paris, or pH-adjusted to 6.8 to 8.0 and stored in 1- to 5-gal breakresistant containers before disposal by a commercial firm. 


\section{J.5.2 Facility Description}

Buildings

The storage room for well-logging sources has brick masonry walls and $35 \mathrm{ft}^{2}$ of floor space.

HVAC Systems

Iodination hoods have flow rates of $1000 \mathrm{ft}^{3} / \mathrm{min}$.

J.5.3 Inventory

Radioactive Inventory

Table 0.6 gives the license limits of radioazctive material at the University of Illinois. Iodinations use $2 \times 10^{-3}$ to $4 \times 10^{-3} \mathrm{Ci}$ amounts of iodine isotopes.

Hazardous and Combustible Inventory

Gloves, absorbent paper, plastic test tubes, and plastic bags are some combustible materials that may be found in the laboratories.

Liquid waste has some volatile, flammable, and toxic components as discussed above. Although no information was given on the contamination level of the liquid, it is assumed less than that given in Table J.7 to be able to incinerate the liquid at the power plant.

J.6 UNIVERSITY OF WISCONSIN, MADISON, WISCONSIN

The University of Wisconsin uses radioactive isotopes for research and development in the following areas: medical research, diagnosis and therapy to human beings, and tracer studies in laboratory animals. Information on this facility was obtained from docket material (University of Wisconsin 1956-1981).

\section{J.6.1 Process Description}

\section{Operation}

Radioactive isotopes are delivered in from radiopharmaceutical manufacturing facilities, the University of Wisconsin reactor, and the University of Wisconsin accelerator. Materials are received by a central ordering, receiving, and distribution group. This group does not do any aliquoting of materials but surveys the packages and ships them to the laboratories and hospital facilities where they are used.

The Veterans Administration Hospital in Madison administers ${ }^{137} \mathrm{Cs}$ and ${ }^{192}$ Ir implants to humans. Other treatments and therapy performed is 
TABLE 0.6. License Limits at University of Illinois

\section{(C) Element}

By-product material atomic No. $3-83$

Americium

Californium

Cesium

Cobalt

Hydrogen

Iodine

Neptunium

Phosphorous

Polonium

Protactinium

Thorium
Isotope

$241_{A m}$

$241_{A m}$ Sealed sources

$241_{A m}$ Sealed sources/moisture gage

${ }^{252} \mathrm{Cf} \quad$ Sealed sources

${ }^{137} \mathrm{Cs}$ Sealed sources/density gage

${ }^{137}$ Cs Sealed sources/thickness measurement

${ }^{137} \mathrm{Cs} \quad$ Sealed sources/training course

${ }^{137} \mathrm{Cs}$ Well logging sources (2)

${ }^{60} \mathrm{Co}$ Sealed sources/training course

$3_{\mathrm{H}}$

125 I Iodinations

$131_{\text {I Iodinations }}$

$237 \mathrm{~Np}$

$32 p$

$210_{\mathrm{Po}}$

$210_{\mathrm{Po}}$

$210_{p_{0}}$

$233 \mathrm{~Pa}$

$231 . \mathrm{Pa}$

${ }^{239}{ }_{\text {Th }}$

Form/Use

vacuum system
$\mathrm{Ci}$

25 each, 500 total

$5 \times 10^{-4}$

1 per source

5 total

$1 \times 10^{-2}$

per source

$9 \times 10^{-3}$

$3.5 \times 10^{-3}$

per source

$5 \times 10^{-3}$

per source

$1 \times 10^{-3}$

0.125

$1 \times 10^{-2}$

per source

$3 \times 10^{-2}$

total

2000

$5 \times 10^{-4}$

Soil, plant, and animal studies

$5 \times 10^{-2}$

30

2

0.1

$5 \times 10^{-4}$

$1 \times 10^{-3}$

per source 
TABLE J.7. Maximum Concentration of Radioactive Isotopes

Allowed in Liquid Waste Incinerated at the

University of Illinois Power Plant

\begin{tabular}{|c|c|c|}
\hline Compound & Isotope & $\mathrm{Ci} / \mathrm{gal}$ \\
\hline \multirow[t]{2}{*}{ Calcium } & ${ }^{45} \mathrm{Ca}$ & $4.9 \times 10^{-4}$ \\
\hline & ${ }^{47} \mathrm{Ca}$ & $3.0 \times 10^{-3}$ \\
\hline Carbon & ${ }^{14} \mathrm{C}$ & $5 \times 10^{-2}$ \\
\hline Chromi um & ${ }^{57} \mathrm{Cr}$ & $4 \times 10^{-2}$ \\
\hline Hydrogen & $3_{H}$ & $9.9 \times 10^{-2}$ \\
\hline \multirow[t]{2}{*}{ Iodine } & $125 \mathrm{I}$ & $4.0 \times 10^{-5}$ \\
\hline & ${ }^{131} I_{I}$ & $5.0 \times 10^{-5}$ \\
\hline Phosphorous & $32 \mathrm{p}$ & $9.9 \times 10^{-4}$ \\
\hline \multirow[t]{2}{*}{ Strontium } & ${ }^{85} \mathrm{Sr}$ & $2 \times 10^{-3}$ \\
\hline & ${ }^{90} \mathrm{Sr}$ & $1 \times 10^{-5}$ \\
\hline Sulfur & ${ }^{35} \mathrm{~S}$ & $4.5 \times 10^{-3}$ \\
\hline
\end{tabular}

administration of ${ }^{60}$ Co implants, ${ }^{131} \mathrm{I}$, and ${ }^{199} \mathrm{Au}$ treatment. Implant patients stay at the hospital until the implant is removed. Therapy patients treated with iodine or gold are hospitalized until the residual activity is $30 \mathrm{mCi}$ or less.

Laboratory animals are treated with radioactive material for research studies. Other unspecified research and development experiments take place in the labs.

The University of Wisconsin is licensed to perform research experiments involving $1-\mathrm{mCi}$ amounts of ${ }^{3} \mathrm{H},{ }^{14} \mathrm{C},{ }^{32} \mathrm{P}$, and ${ }^{35_{S}}$ at several lakes and streams away from of the University campus.

Waste Disposal

Liquid waste containing ${ }^{14} \mathrm{C}$ and ${ }^{3} \mathrm{H}$ concentrations of $3 \mathrm{mCi}$ per $5 \mathrm{gal}$ or less are kept in 5-gal jugs partially filled with fuel oil. This liquid is then fed to an incinerator. Less than $50 \mathrm{mCi}$ per day can be incinerated.

By-product materials in animal carcasses and animal waste are also incinerated. The ash from the incinerations is monitored and disposed of with ordinary waste if it gives less than $300 \mathrm{cpm}$ or $0.5 \mathrm{mR} / \mathrm{hr}$ at $1 \mathrm{~m}$ from the waste package. Radioactive ash is put in barrels for disposal at a licensed site.

Solid waste such as syringe needles, broken glass, gloves, aprons and cellulosic wastes are packaged in bags, boxes, and drums prior to pick up by a radioactive waste disposal service. 


\section{J.6.2 Inventory}

Radioactive Inventory

Table 3.8 gives the license limits of radioactive material for the University of Wisconsin. Fifteen hundred $\mathrm{Ci}$ of the tritium are used for research and development. The other $1500 \mathrm{Ci}$ are stored in the waste storage area in the original shipping containers or as concentrated waste ( $>10 \mathrm{Ci}$ per 55-gal drum where the ${ }_{H}$ is absorbed on a molecular sieve and immobilized in concrete). Cesium-137 is stored in a radium bank within a shielded storage area.

\section{TABLE J.8. License Limits for University of Wisconsin}

\begin{tabular}{|c|c|c|c|}
\hline Element & Isotope & Form/Use & $\mathrm{Ci}$ \\
\hline $\begin{array}{l}\text { By-product material } \\
\text { atomic No. } 3-83\end{array}$ & & & $\begin{array}{l}3 \text { each, } \\
30 \text { total }\end{array}$ \\
\hline Americium & $241_{A m}$ & & 2 \\
\hline Carbon & ${ }^{14} \mathrm{C}$ & & 5 \\
\hline Cesium & ${ }^{137} \mathrm{Cs}$ & & 15 \\
\hline Cobalt & ${ }^{60} \mathrm{Co}$ & & 5 \\
\hline Curium & ${ }^{244} \mathrm{Cm}$ & & $1 \times 10^{-5}$ \\
\hline Gadolinium & $153 \mathrm{Gd}$ & Sealed Sources & 12 \\
\hline Hydrogen & $3_{H}$ & & 3000 \\
\hline $\begin{array}{l}\text { Molybdenum/ } \\
\text { Technetium }\end{array}$ & $\begin{array}{l}99 \mathrm{Mo} / \\
99 \mathrm{~m}_{\mathrm{TC}}\end{array}$ & & 10 \\
\hline Phosphorous & $32 p$ & & 5 \\
\hline Uranium & depleted & $\begin{array}{l}\text { Plated metal/collimater in } \\
X \text {-ray unit }\end{array}$ & $500 \mathrm{~kg}$ \\
\hline
\end{tabular}

Millicurie amounts of ${ }^{3} \mathrm{H},{ }^{14} \mathrm{C},{ }^{32} \mathrm{P}$, and ${ }^{35} \mathrm{~S}$ are allowed at various locations off of the university campus for research efforts.

Hazardous and Combustible Inventory

Combustibles such as gloves, aprons, lab coats, plastic bags, wipes, and cellulosic wastes may be found in the labs where radioactive material is handled and in waste storage areas. The ${ }^{14} \mathrm{C}$ and ${ }^{3} \mathrm{H}$ are mixed with a flammable liquid (fuel oil) in 5-gal drums before being incinerated. 


\section{J.7 UNIVERSITY OF WYOMING, LARAMIE, WYOMING}

The University of Wyoming uses radioactive isotopes for field experiments and laboratory research and development of plants and animals. Information on this facility was obtained from docket material (University of Wyoming 1966-1979).

\section{J.7.1 Process Description}

\section{Operation}

Radioactive materials are received and distributed through the Radiation Safety Office. The laboratories normally handle less than $1 \mathrm{mCi}$ of radionuclides with five shielded storage areas available for storage of radioactive material. About 50 laboratories on campus handle the isotopes as well as areas off campus where studies are performed on plants and animals. Some of these studies are described below.

Millicurie amounts of ${ }^{75}$ Sc were fed to plants in greenhouses on campus.

Millicurie amounts of ${ }^{3} \mathrm{H}$ and ${ }^{14} \mathrm{C}$ were administered to pronghorn antelope and big horn sheep at a game research unit. The apimals were kept in a corral for the study. Total quantities used were $0.3 \mathrm{Ci}{ }^{3}$ and $0.3 \mathrm{Ci}{ }^{14} \mathrm{C}$.

Antimony-124 in $10 \mu \mathrm{Ci}$ implants was embedded in brown trout in a creek. The stream was fenced off and implants removed after the experiment. Twentyfive to $50 \mathrm{fish}$ were studied.

Waste Disposal

Most radioactive waste is collected in drums in a central storage area until enough accumulates for burial at the university radioactive waste burial grounds. The university is authorized for 27 burials per year or one apout exery 2 weeks. The most common isotopes found in waste are ${ }^{14} \mathrm{C},{ }_{\mathrm{H}},{ }^{125} \mathrm{I}$, and ${ }^{32 \mathrm{P} ;}{ }^{75} \mathrm{Se}$ is limited to $10 \mu \mathrm{Ci}$ per burial.

Liquid radioactive waste is absorbed into dry sawdust in 55-gal drums lined with plastic before burial. About $1 \mathrm{Ci} / \mathrm{yr}$ can be buried. Therefore, up to $36 \mathrm{mCi}$ inight be stored in each burial load.

\section{J.7.2 Facility Description}

\section{Buildings}

About 50 laboratories handle radioactive material. The labs are equipped with fume hoods, sinks, nonporous table tops, refrigerators, and areas specially designed for storage of by-product material. Five shielded rooms are available for storage of radioactive material. Storage bins for radioactive materials have lead-lined covers. Doors to the labs may be lead lined. 
Radioactive waste is stored in a separate building that has protected windows and a separate heating system. Waste is accumulated here until enough for one burial has been stored. Lead bricks and sheets may also be stored. HVAC Systems

Laboratories are equipped with fume hoods with a capacity to draw $200 \mathrm{ft} / \mathrm{min}$ velocity.

\section{J.7.3 Inventory}

\section{Radioactive Inventory}

Table J.9 gives an inventory of the major isotopes used at the University of Wyoming for the first 6 months of 1978.

Radioactive waste is contaminated mainly with ${ }^{14} \mathrm{C}, 125 \mathrm{I},{ }^{32} \mathrm{P},{ }^{75} \mathrm{Se}$, and ${ }^{3} \mathrm{H}$ with the major activity (greater than 90\%) coming from ${ }^{125} \mathrm{I}$.

License limits for the University are shown in Table J.10.

TABLE 3.9. Inventory of Major Isotopes at University of Wyoming

\begin{tabular}{|c|c|c|c|}
\hline Element & Isotope & Number of Items & $\mathrm{Ci}$ \\
\hline Carbon & ${ }^{14} \mathrm{C}$ & 21 & $2.2 \times 10^{-3}$ \\
\hline Hydrogen & $3_{H}$ & 13 & 0.1236 \\
\hline Iodine & $125 \mathrm{I}$ & 8 & $3.9 \times 10^{-2}$ \\
\hline Phosphorous & $32 p$ & 14 & $6.95 \times 10^{-2}$ \\
\hline Selenium & ${ }^{75} \mathrm{Se}$ & & $1.3 \times 10^{-3}$ \\
\hline Other & & & $1.4 \times 10^{-3}$ \\
\hline
\end{tabular}

Hazardous and Combustible Inventory

Protective clothing is worn in controlled areas. Rubber or plastic gloves, paper towels, and disposable handkerchiefs may be found in laboratories and radioactive waste storage. These materials are combustible. 
TABLE J.10. License Limits at the University of Wyoming

\begin{tabular}{|c|c|c|c|}
\hline Element & Isotope & Form/Use & $\mathrm{Ci}$ \\
\hline By-product material & & Any form/on-campus & $\begin{array}{l}1 \text { each, } \\
10 \text { total }\end{array}$ \\
\hline Atomic No. $3-83$ & & Sealed sources/on-campus & $\begin{array}{l}2 \text { each, } \\
20 \text { total }\end{array}$ \\
\hline \multirow[t]{2}{*}{ Anericium } & $241_{A m}$ & On-campus & 0.5 \\
\hline & $241_{A m}$ & Sealed source/on-campus & 5 \\
\hline Californium & ${ }^{252} \mathrm{Cf}$ & Sealed sources/on-campus & $\begin{array}{l}1.5 \times 10^{-3} \\
\text { each, } 0.1 \\
\text { total }\end{array}$ \\
\hline \multirow[t]{2}{*}{ Carbon } & ${ }^{14} \mathrm{C}$ & National forest and park & $2 \times 10^{-3}$ \\
\hline & ${ }^{14} \mathrm{C}$ & Sybille game research unit & 0.30 \\
\hline Cesium & ${ }^{137} \mathrm{Cs}$ & Sealed sources/state of Wyoming & $1 \times 10^{-3}$ \\
\hline Chromium & ${ }^{51} \mathrm{Cr}$ & Off-campus & $5 \times 10^{-3}$ \\
\hline Cobalt & ${ }^{60} \mathrm{Co}$ & Sealed sources/state of Wyoming & $3 \times 10^{-2}$ \\
\hline \multirow[t]{3}{*}{ Hydrogen } & $3_{H}$ & On-campus & 5 \\
\hline & $3_{H}$ & University farm and ag. substation & 4 \\
\hline & $3_{\mathrm{H}}$ & off-campus & 0.3 \\
\hline Mercury & $203 \mathrm{Hg}$ & Medicine box & $1 \times 10^{-2}$ \\
\hline Polonium & $210_{\mathrm{Po}}$ & Sealed sources/on-campus & $\begin{array}{l}1 \times 10^{-2} \text { each } \\
0.1 \text { total }\end{array}$ \\
\hline Tantalum & $182 \mathrm{Ta}$ & Jackson Hole & $1 \times 10^{-2}$ \\
\hline
\end{tabular}

\section{J.8 REFERENCES}

Harvard University, License Application Information - Docket No. 30-753, License No. 20-00297-53, U.S. Nuclear Regulatory Commission, Washington, D.C., 1965-1981.

Michigan State University, License Application Information - Docket No. 30-806, License No. 21-00021-29, U.S. Nuclear Regulatory Commission, Washington, D.C., 1963-1981.

Ohio State University, Materials License, License No. 34-00293-02, U.S. Nuclear Regulatory Commission, Washington, D.C., 1979.

Oral Roberts University, License Application Information - Docket No. 30-14781, License No. 35-18282-01, U.S. Nuclear Regulatory Commission, Washington, D.C., 1979-1981. 
University of Illinois, License Application Information - Docket No. 30-652, License No. 12-00330-050, U.S. Nuclear Regulatory Commission, Washington, D.C., 1957-1981.

University of Wisconsin, License Application Information - Docket No. 30-3405, License No. 48-09843-18, U.S. Nuclear Regulatory Commission, Washington, D.C., $1956-1981$.

University of Wyoming, License Application Information - Docket No. 30-1176, License No. 49-09955-10, U.S. Nuclear Regulatory Commission, Washington, D.C., 1966-1979. 
APPENDIX K

GLOSSARY

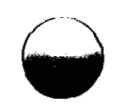




\section{APPENDIX K}

\section{GLOSSARY}

By-product material - Any radioactive material (except special nuclear material) yielded in or made radioactive by exposure to the radiation incident to the process of producing or utilizing special nuclear material.

Carboy - A large bottle for holding corrosive liquids. $\frac{\text { "Cracked" Ammonia - Ammonia that has been thermally dissociated to provide } \mathrm{H}_{2}}{\text { as a process gas. }}$

Criticality - A self-sustaining nuclear chain reaction.

Cyanocobalamin - Vitamin B-12.

Cyclotron - An accelerator in which charged particles are successively accelerated by a constant-frequency alternating electrical field that is synchronized with movement of the particles on spiral paths in a constant magnetic field.

Cylinder Heel - Residual content of an emptied UF 6 cylinder.

Dead Load - A static or nonvarying load; the basal pressure exerted by the weight of a mass at rest.

Excursion - An accidental increase in neutron multiplication.

Fibrinogen - A plasma protein essential to blood clotting.

Fission - The splitting of the nucleus of an atom into nuclei of lighter atoms, accompanied by the release of energy.

F-scale - Fujita scale for classifying the magnitude of tornadoes.

Green Salt - Uranium tetrafluoride, corrosive green crystals used in the manufacture of uranium metal.

Half-Life - The average time interval required for one-half of any quantity of identical radioactive atoms to undergo radioactive decay.

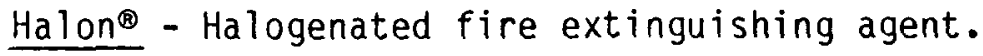

(3) Halon is a trademark of the Allied Chemical Corp., Morristown, NJ 07960

$$
\text { K.1 }
$$


High-Efficiency Particulate Air Filter - A filter having a minimum particle removal efficiency of no less than $99.97 \%$ for $0.3-\mu m$ particles; a maximum resistance, when clean, of 1.0-in. water gauge when operated at rated airflow capacity; a rigid casing extending the full depth of the medium.

Live Load - A moving load of variable force acting upon a structure in addition to its own weight.

Mercalli Scale - Scale for classifying the magnitude of an earthquake.

Purex - Process using solvent extraction and ion exchange for separating plutonium and uranium from irradiated fuel.

Raffinate - In solvent refining, that portion of the solute that is not extracted by the selective solvent.

"Red 0il" Explosion - An explosion that may occur as a result of solvent degradation in the Purex process.

Sealed Source - Any byproduct that is encased in a capsule designed to prevent leakage, or escape of the byproduct material.

Special Form - A physical form of licensed material of any transport group as defined in 10 CFR 71.

Special Nuclear Material - Plutonium; uranium enriched in the isotope 233 or 235, and any other material as defined in 10 CFR 70 by the NRC.

TNT Equivalent - A measure of the energy produced by an explosive event expressed in terms of the weight of TNT that would release the same amount of energy when exploded.

Tritium - The hydrogen isotope having mass number $3,{ }^{3} \mathrm{H}$.

Type B Container - Shipping packagings that must meet stringent requirements.

Yellowcake - The final precipitate formed during milling of uranium ores.

Zircaloy - Zirconium alloyed with tin and iron. 


\section{DISTRIBUTION}

No. of

Copies

OFFSITE

U.S. Nuclear Regulatory Commission

Division of Technical

Information and Document Control

7920 Norfolk Avenue

Bethesda, MD 20014

Stephen McGuire

U.S. Nuclear Regulatory

Commission

5450 Nicholson Lane

Rockville, MD 20852

David Bennett

Sandia National Laboratories

P.0. Box 5800

Albuquerque, NM 87185

5 Dr. Justin Long

Uranium Fuel Licensing Branch

Fuel Cycle and Material Safety

U.S. Nuclear Regulatory Commission

Washington, DC 20555
No. of

Copies

ONSITE

50 Pacific Northwest Laboratory

M. Y. Ballinger (5)

D. W. Dragnich

T. H. Essig

J. D. Jamison (10)

R. K. Had lock

P. C. Hays

N. S. Laulainen

C. G. Lindsey

J. Mishima (5)

J. V. Ramsdell

S. L. Sutter (15)

E. C. Watson

Publishing Coordination (2)

Technical Information (5) 


\begin{tabular}{|c|c|}
\hline $\begin{array}{l}\text { U.S. NUCLEAR REGULATORY COMMISSION } \\
\text { BIBLIOGRAPHIC DATA SHEET }\end{array}$ & $\begin{array}{l}\text { 1. REPORT NUMEER (ASsIGneO OY DOC) } \\
\text { NUREG/CR-3796 } \\
\text { PNL-5081 }\end{array}$ \\
\hline TITLE AND SUBTITLE (AdA VOlume No, if a.porooriate) & 2. (Leave o $(\sin x)$ \\
\hline $\begin{array}{l}\text { Emergency Preparedness Source Term Development for } \\
\text { the Office of Nuclear Materials Safety and Safeguards } \\
\text { Licensed Facilities }\end{array}$ & \\
\hline $\begin{array}{l}\text { 7. AUTHOR(S) S.L. Sutter, J. Mishima, M. Y. Ballinger } \\
\text { C.G. Lindsey }\end{array}$ & 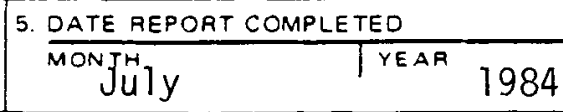 \\
\hline 9. PERFORMING ORGANIZATION NAME AND MAILING ADDRESS (InCIUde Zio COde) & DATE REPORT ISSUED \\
\hline \multirow{3}{*}{$\begin{array}{l}\text { Pacific Northwest Laboratory } \\
\text { P0 Box } 999 \\
\text { Richland, Washington } 99352\end{array}$} & \begin{tabular}{l|l} 
MONTH \\
August & YrEAR \\
\end{tabular} \\
\hline & 6. (Leave $\mathrm{O} / \mathrm{ank})$ \\
\hline & a. (Leave blank) \\
\hline \multirow{2}{*}{$\begin{array}{l}\text { 12. SPONSORING ORGANIZATION NAME ANO MAILING AOORESS "Include Zio Code/ } \\
\text { Uranium Fuel Licensing Branch } \\
\text { Fuel Cycle and Material Safety } \\
\text { U.S. Nuclear Regulatory Commission } \\
\text { Washington, DC } 20555\end{array}$} & 10. PROJECTITASK!WORK UNITNO. \\
\hline & $\begin{array}{l}\text { 11. FIN NO. } \\
\text { B-2218 }\end{array}$ \\
\hline
\end{tabular}

13. TYPE OF REPORT

PERIOD COVERED (Inclusire dares)

15. SUPPLEMENTARY NOTES

14. (Leave olank)

16. ABSTRACT 200 words or less/

To establish requirements for emergency preparedness plans at facilities licensed by the Office of Nuclear Materials Safety and Safeguards, the Nuclear Regulatory

Commission (NRCO needs to develop source terms (the amount of material made airborne) for accidents. They are used to estimate potential public doses from the events, which will be used to judge whether emergency preparedness plans are needed. Pacific Northwest Laboratory is providing the NRC with source terms by developing accident scenarios for fuel cycle and by-product operations. Several scenarios are developed for each operation, leading to the identification of the maximum release considered for emergency preparedness planning (MREPP) scenario. Fire was the MREPP at oxide fuel fabrication, $U_{6}$ production, radiopharmaceutical manufacturing, radiopharmacy, sealed source manufacturing, waste warehousing, and university research and development facilities. Tornadoes were MREPP events for uranium mills and plutonium contaminated facilities, and criticalities were significant at nonoxide fuel fabrication and nuclear research and development facilities. Techniques for adjusting the MREPP release to different facilities are also described.

17. KEY WORDS ANO DOCUMENT ANALYSIS TI. OESCRIPTORS

source term

176. IDENTIFIE AS OPEN.ENDED TERMS

8. AVAILABILITY STATEMENT

Unl imited

\begin{tabular}{|c|c|}
\hline $\begin{array}{l}\text { 19. SE CURITY CLASS ITh, reoOrt } \\
\text { unClaSS ified }\end{array}$ & 21 NO. OFPAGES \\
\hline $\begin{array}{l}\text { 20 SECUAITY CLASS IThis Dagei } \\
\text { UnClass ified }\end{array}$ & $\begin{array}{l}\text { 22. PAICE } \\
\text { S }\end{array}$ \\
\hline
\end{tabular}

NRC FORM 335 |11.811 